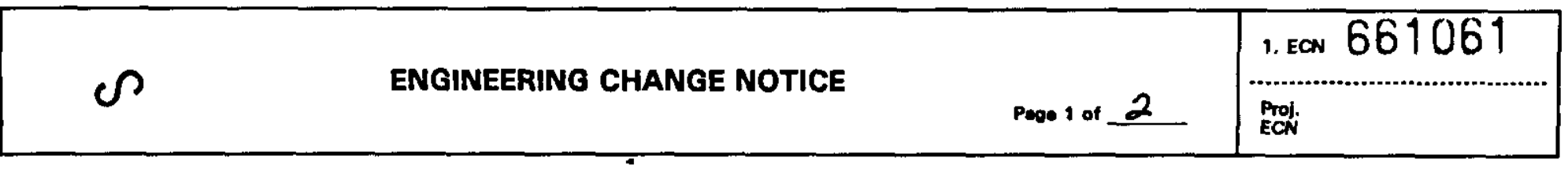

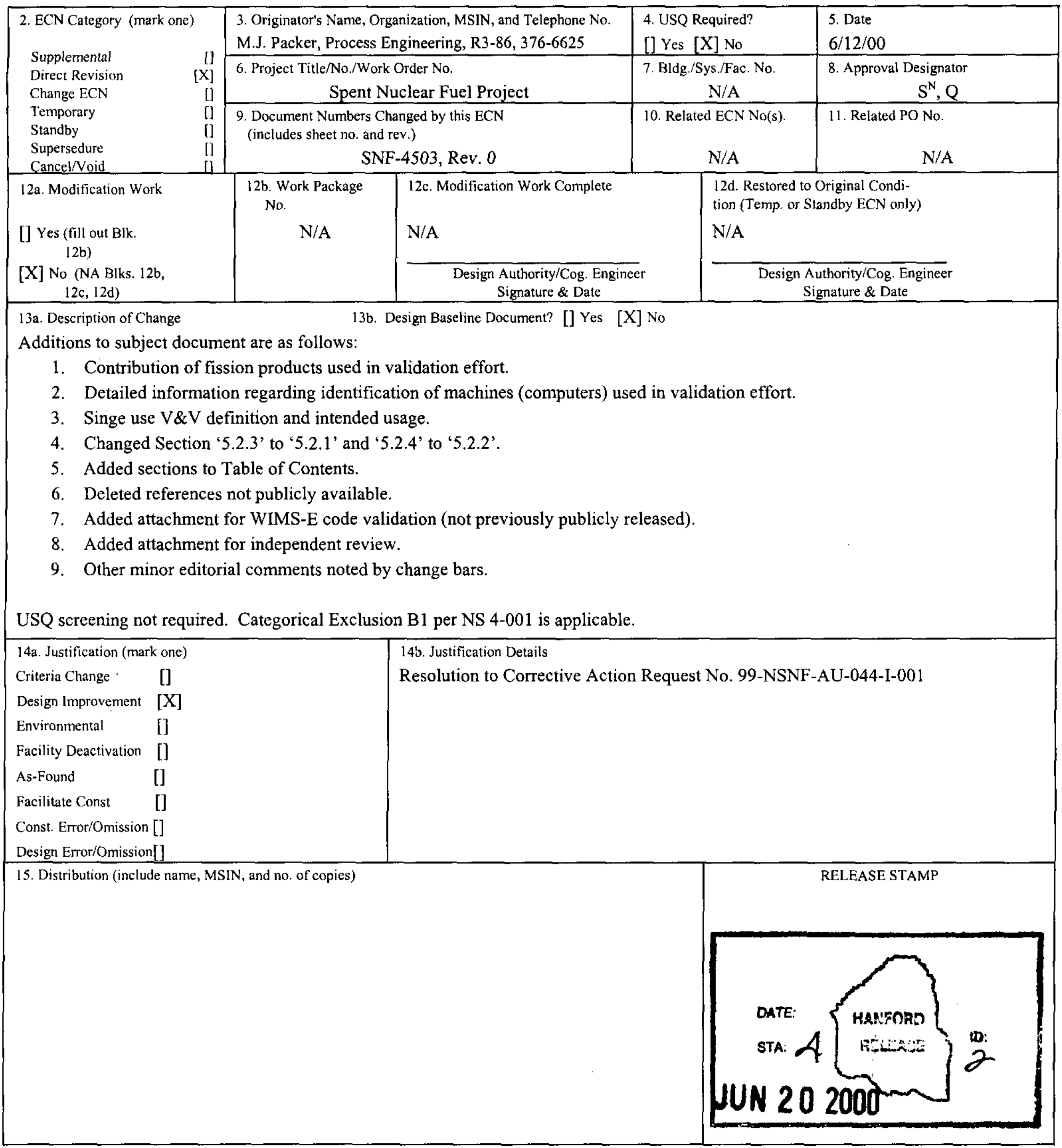




\begin{tabular}{|c|c|c|c|c|c|c|}
\hline \multicolumn{4}{|c|}{ ENGINEERING CHANGE NOTICE } & \multirow[t]{2}{*}{ Page 2 of 2} & \multicolumn{2}{|c|}{$\begin{array}{l}\text { 1. ECN (use no. from pg. 1) } \\
661061\end{array}$} \\
\hline 16. Design & \multicolumn{3}{|c|}{ 17. Cost Impact } & & \multirow{2}{*}{\multicolumn{2}{|c|}{ 18. Schedule Impact (days) }} \\
\hline Verification & & INEERING & & NSTRUCTION & & \\
\hline $\begin{array}{l}\text { Required } \\
\text { [] Yes }\end{array}$ & Additional & [N/A] $\$$ & Additional & {$[N / A] \quad \$$} & $\begin{array}{l}\text { Improve } \\
\text { ment }\end{array}$ & [N/A] \\
\hline$[X]$ No & Savings & {$[\mathrm{N} / \mathrm{A}] \quad \$$} & Savings & {$[N / A] \$$} & Delay & [N/A] \\
\hline
\end{tabular}

19. Change Impact Review: Indicate the related documents (other than the engineering documents identified on Side 1) that will be affected by the change described in Block 13. Enter the affected document number in Block 20. SDD/DD

Functional Design Criteria

Operating Specification

Criticality Specification

Conceptual Design Report

Equipment Spec.

Const. Spec.

Procurement Spec

Vendor Information

OM Manual

FSAR/SAR

Safety Equipment List

Radiation Work Permit

Environmental Impact Statement

Environmental Report

Environmental Permit

$\begin{array}{lll}{[]} & \text { Scismic/Stress Analysis } & {[]} \\ {[]} & \text { Stress/Design Report } & {[]} \\ {[]} & \text { Interface Control Drawing } & {[]} \\ {[]} & \text { Calibration Procedure } & {[]} \\ {[]} & \text { Installation Procedure } & {[]} \\ {[]} & \text { Maintenance Procedure } & {[]} \\ {[]} & \text { Enginecring Procedure } & {[]} \\ {[]} & \text { Operating Instruction } & {[]} \\ {[]} & \text { Operating Procedure } & {[]} \\ {[]} & \text { Operational Safety Requirement } & {[]} \\ {[]} & \text { 1EFD Drawing } & {[]} \\ {[]} & \text { Cell Arrangement Drawing } & {[]} \\ {[]} & \text { Essentiaj Material Specification } & {[]} \\ {[]} & \text { Fac. Proc. Samp. Schedule } & {[]} \\ {[]} & \text { Inspection Plan } & {[]} \\ {[]} & \text { Inventory Adjustment Request } & {[]}\end{array}$

\section{N/A}

Tank Calibration Manual

Health Physics Procedure

Spares Mułtiple Unit Listing

Test Procedures/Specification

Component lndex

ASME Coded liem

Human Factor Consideration

Camputer Software

Electric Circuit Schedule

ICRS Procedure

Process Control Manual/Plan

Process Flow Chart

Purchase Requisition

Tickler File

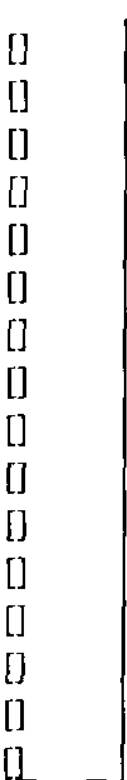

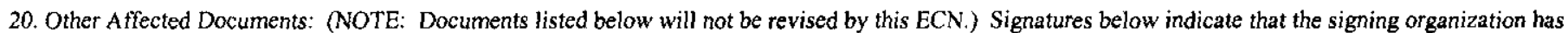
been notified of other affected documents listed below.

N/A

21. Approvals

Signature

Design Authority Cog. Mgr. J. R. Frederickson

QA D.W. Smith $P W$ Som ith.

Safety L. J. Garvin

Environ.

Other
Date

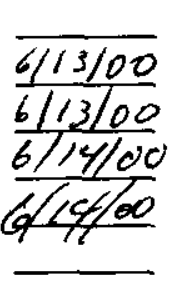

Signature

Date

Design Agent

PE

QA

Safety

Design

Environ.

Other

\section{DEPARTMENT OF ENERGY}

Signature or a Control Number that tracks the Approval Signature

AODITIONAL 


\section{DISTRIBUTION SHEET}

\begin{tabular}{|c|c|c|c|c|c|}
\hline \multirow{2}{*}{$\begin{array}{l}\text { To } \\
\text { Distribution }\end{array}$} & \multirow{2}{*}{\multicolumn{3}{|c|}{$\begin{array}{l}\text { From } \\
\text { Process Engineering }\end{array}$}} & \multicolumn{2}{|l|}{ Page 1 of 1} \\
\hline & & & & \multicolumn{2}{|l|}{ Date $6 / 12 / 00$} \\
\hline \multicolumn{4}{|c|}{ Project Title/Work Order } & \multicolumn{2}{|l|}{ EDT No. N/A } \\
\hline \multicolumn{4}{|c|}{$\begin{array}{l}\text { Single Use Letter Report for the Verification and Validation of the Radnuc-2A and ORIGEN2 } \\
\text { S. } 2 \text { Computer Modes }\end{array}$} & \multicolumn{2}{|c|}{ ECN No. 661061} \\
\hline & MSIN & $\begin{array}{c}\text { Text } \\
\text { With All } \\
\text { Attach. }\end{array}$ & Text Only & $\begin{array}{l}\text { Attach./ } \\
\text { Appendix } \\
\text { Only }\end{array}$ & $\begin{array}{c}\text { EDT/ECN } \\
\text { Only }\end{array}$ \\
\hline
\end{tabular}

Spent Nuclear Fuel Project

R. D. Crowe

R3-26 X

D. R. Duncan

R3-86 $\quad \mathrm{X}$

J. R. Frederickson

R3-86

M. J. Packer

R3-86

A. L. Pajunen

R3-86

CVD Project Files

SNF Project Files

R3-86

R3-11

$\mathrm{X}$

$\mathrm{X}$

$\mathrm{X}$

$\mathrm{X}$

Other

K. N. Schwinkendorf - Fluor Federal Services

B4-44

$\mathrm{X}$ 


\section{Single Use Letter Report for the Verification and Validation of the RADNUC- 2A and ORIGEN2 S.2 Computer Codes}

Prepared for the U.S. Department of Energy

Assistant Secretary for Environmental Management

Project Hanford Management Contractor for the

U.S. Department of Energy under Contract DE-AC06-96RL13200

Fluor Hanford

P.O. Box 1000

Richland, Washington 
SNF-4503

Revision 1

ECN 661061

\title{
Single Use Letter Report for the Verification and Validation of the RADNUC-2A and ORIGEN2 S.2 Computer Codes
}

\author{
M. J. Packer
}

Fiuor Hanford

Date Published

June 2000

Prepared for the U.S. Department of Energy

Assistant Secretary for Environmental Management

Project Hanford Management Contractor for the

U.S. Department of Energy under Contract DE-AC06-96RL13200

Fluor Hanford

P.O. Box 1000

Richland, Washington
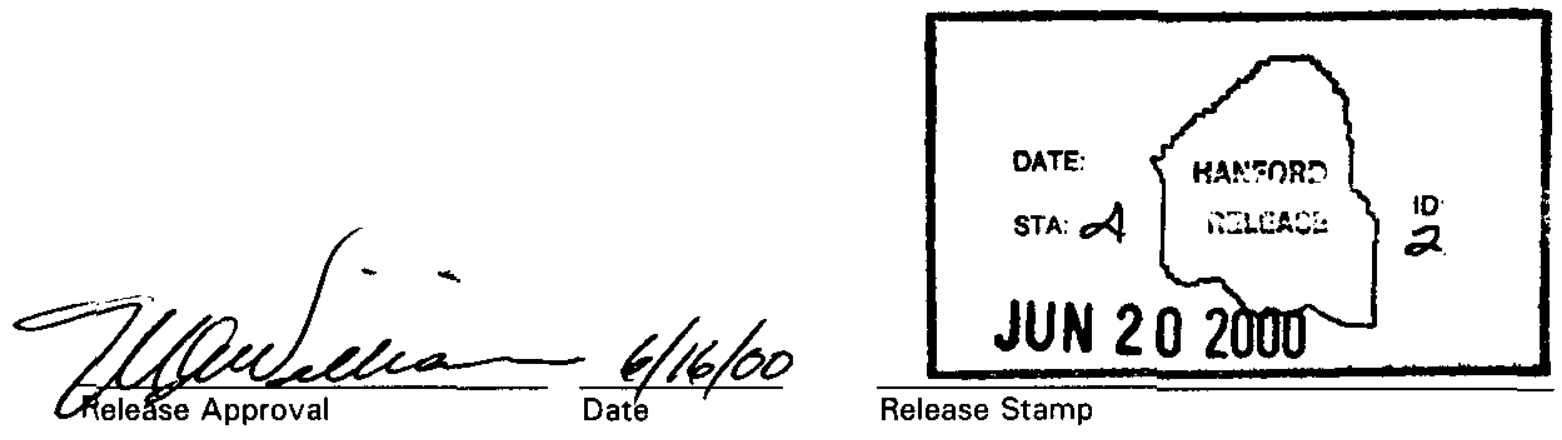

Release Stamp 


\section{TRADEMARK DISCLAIMER}

Reference herein to any specific commercial product, process, or service by trade name, trademark, manufacturer, or otherwise, does not necessarily constitute or imply its endorsement, recommendation, or favoring by the United States Government or any agency thereof or its contractors or subcontractors.

This report has been reproduced from the best available copy. Available in paper copy and microfiche.

Available electronically at http://mww.doe.gov/bridge. Available for a processing fee to the U.S. Department of Energy and its contractors, in paper, from:

U.S. Department of Energy

Office of Scientific and Technical Information

P.O. Box 62

Oak Ridge, TN 37831-0062

phone: $865-576-8401$

fax: $865-576-5728$

email: reports@adonis.osti.gov(423) 576-8401

Available for sale to the public, in paper, from:

U.S. Department of Commerce

National Technical Information Service

5285 Port Royal Road

Springfield, VA 22161

phone: $800-553-6847$

fax: 703-605-6900

email: orders@ ntis.fedworld.gov

online ordering: http://www.ntis.gov/ordering.htm

Printed in the United States of America

Total Pages: 245

Unix is a registered trademark of UNIX System Laboratories, Inc. Windows NT is a registered trademark of Microsoft Corporation Intel is a registered trademark of Intel Corporation Pentium is a registered trademark of Intel Corporation Pentium II is a registered trademark of Intel Corporation Cray is a registered trademark of Cray Research, Inc.

$$
\text { SNF- } 4503, \text { sed }
$$




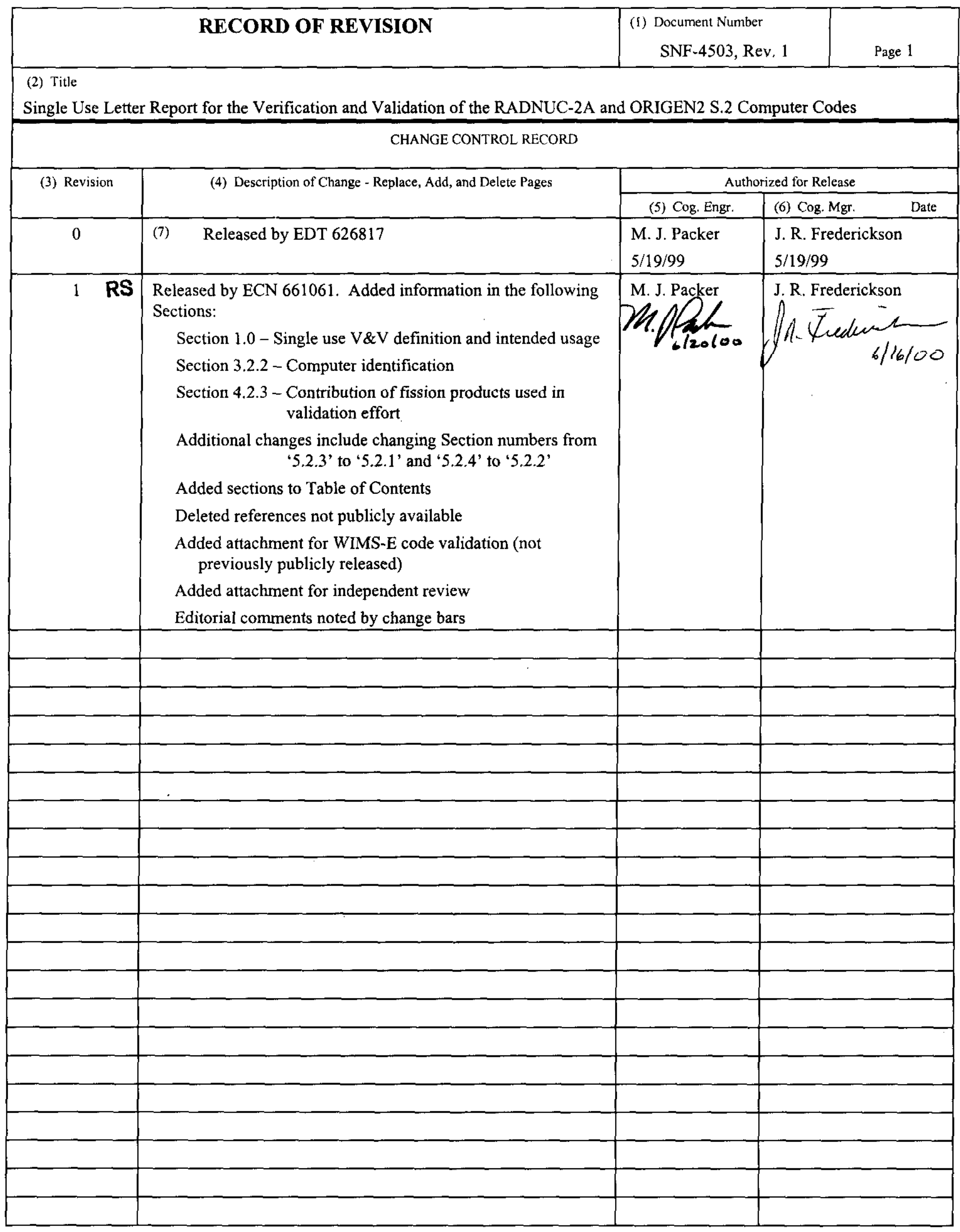




\section{SINGLE USE LETTER REPORT FOR THE VERIFICATION AND VALIDATION OF THE RADNUC-2A AND ORIGEN2 S.2 COMPUTER CODES}

Prepared by

FLUOR DANIEL NORTHWEST, INC.

APRIL 1999

Prepared for

DE\&S HANFORD, INC.

Task Order 99-006B, Rev. 2

Prepared by: _(original signed by)

K. N. Schwinkendorf, Engineer

Date

Criticality and Shielding

Prepared by: _(original signed by)

S. P. Roblyer, Engineer

Date

Criticality and Shielding

Reviewed by: _(original signed by)

D. W. Wootan, Engineer

Date

Environmental and Nuclear Initiatives

Approved by: _(orignal signed by)

$\vec{R}$. J. Puigh II, Manager

Date

Environmental and Nuclear Initiatives 


\section{Contents}

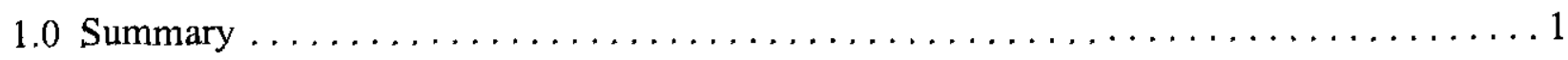

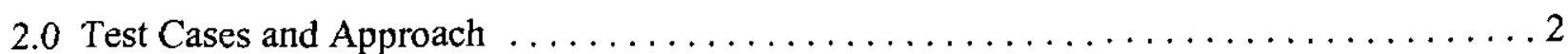

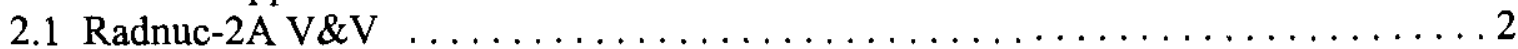

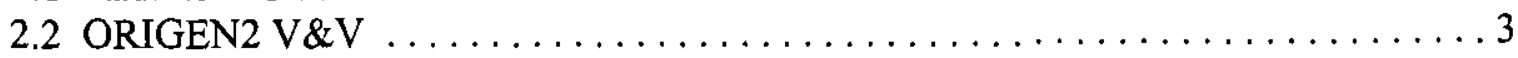

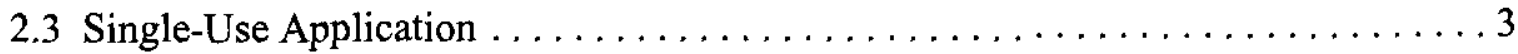

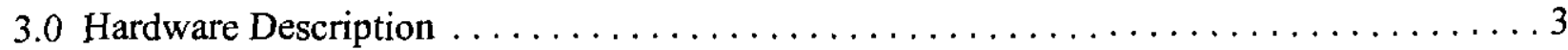

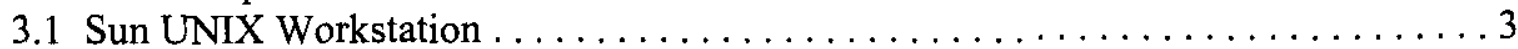

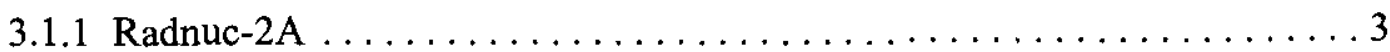

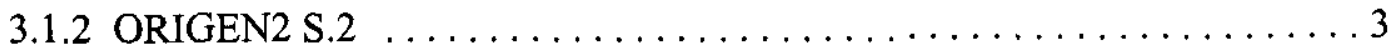

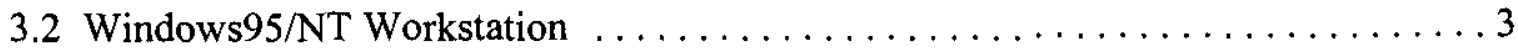

3.2 .1 Radnuc-2A . . . . . . . . . . . . . . . . . . . . . 4

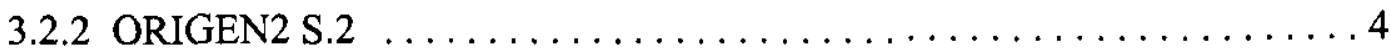

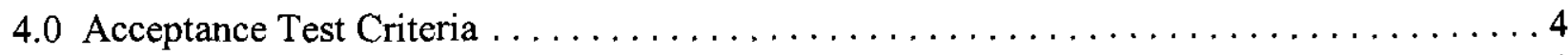

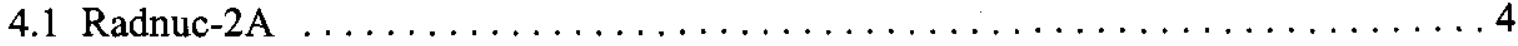

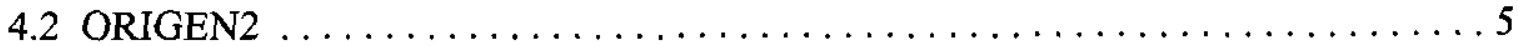

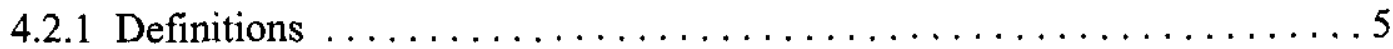

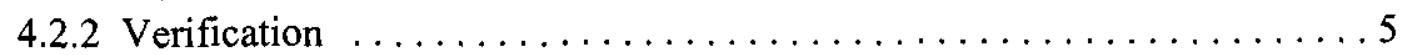

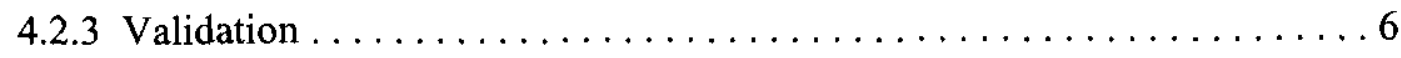

5.0 Results for Single-Use Test Problems $\ldots \ldots \ldots \ldots \ldots \ldots \ldots \ldots \ldots \ldots \ldots \ldots$

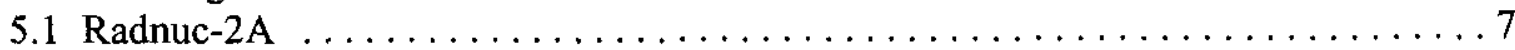

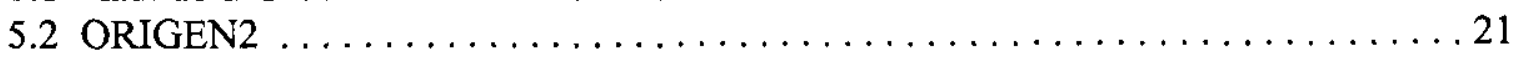

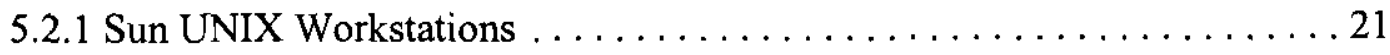

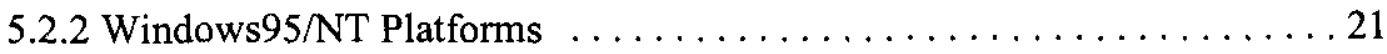

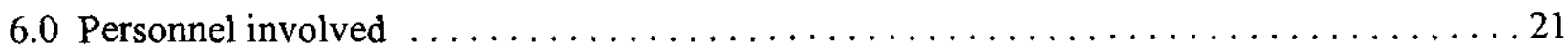

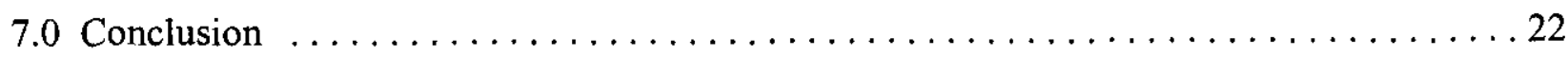

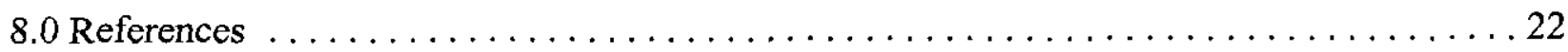

APPENDIX A
VERIFICATION AND VALIDATION OF RADNUC- 2 A $\ldots \ldots \ldots \ldots \ldots \ldots$ A-1

1.0 VERIFICATION $\ldots \ldots \ldots \ldots \ldots \ldots \ldots \ldots \ldots \ldots \ldots \ldots \ldots \ldots \ldots \ldots \ldots \ldots \ldots$

2.0 VALIDATION $\ldots \ldots \ldots \ldots \ldots \ldots \ldots \ldots \ldots \ldots \ldots \ldots \ldots \ldots \ldots \ldots \ldots \ldots$

3.0 CONCLUSION $\ldots \ldots \ldots \ldots \ldots \ldots \ldots \ldots \ldots \ldots \ldots \ldots \ldots \ldots \ldots \ldots \ldots$

APPENDIX B

RADNUC-2A SOURCE CODE LISTING $\ldots \ldots \ldots \ldots \ldots \ldots \ldots \ldots \ldots \ldots \ldots$ 
APPENDIX C

VERIFICATION OF ORIGEN2 $\mathrm{S} .2 \ldots \ldots \ldots \ldots \ldots \ldots \ldots \ldots \ldots \ldots \ldots \ldots \ldots$

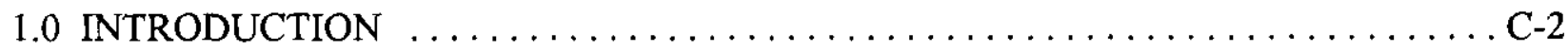

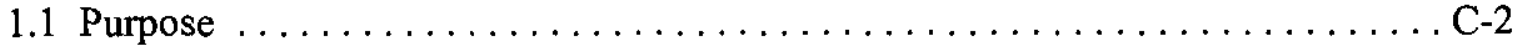

1.2 Scope $\ldots \ldots \ldots \ldots \ldots \ldots \ldots \ldots \ldots \ldots \ldots \ldots \ldots \ldots \ldots \ldots \ldots \ldots \ldots \ldots, 2$

1.3 Definitions $\ldots \ldots \ldots \ldots \ldots \ldots \ldots \ldots \ldots \ldots \ldots \ldots \ldots \ldots \ldots \ldots \ldots \ldots \ldots \ldots \ldots, 2$

2.0 TEST VERIFICATION APPROACH $\ldots \ldots \ldots \ldots \ldots \ldots \ldots \ldots \ldots \ldots \ldots \ldots \ldots$, C-3

2.1 Background of ORIGEN2 $\ldots \ldots \ldots \ldots \ldots \ldots \ldots \ldots \ldots \ldots \ldots \ldots \ldots \ldots \ldots \ldots \ldots \ldots$

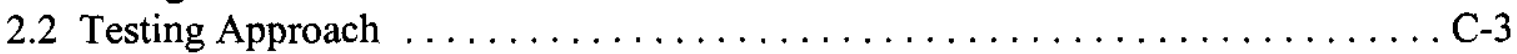

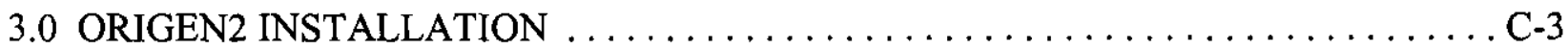

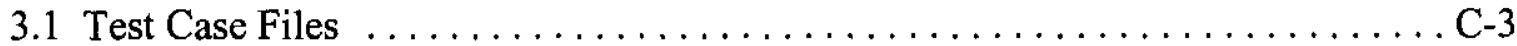

3.1 .1 Executable $\ldots \ldots \ldots \ldots \ldots \ldots \ldots \ldots \ldots \ldots \ldots \ldots \ldots \ldots \ldots \ldots, 3$

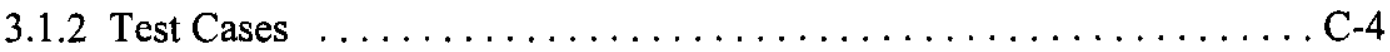

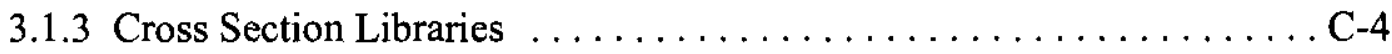

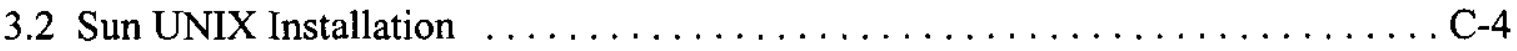

3.2 .1 ORIGEN2 Files $\ldots \ldots \ldots \ldots \ldots \ldots \ldots \ldots \ldots \ldots \ldots \ldots \ldots \ldots \ldots \ldots \ldots \ldots, 4$

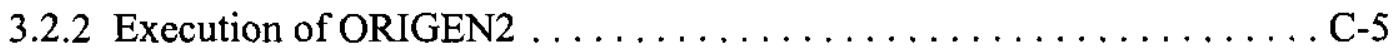

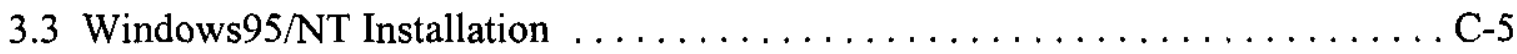

3.3 .1 ORIGEN2 Files $\ldots \ldots \ldots \ldots \ldots \ldots \ldots \ldots \ldots \ldots \ldots \ldots, \mathrm{C}-5$

3.3.2 Execution of ORIGEN2 $\ldots \ldots \ldots \ldots \ldots \ldots \ldots \ldots \ldots \ldots \ldots \ldots$

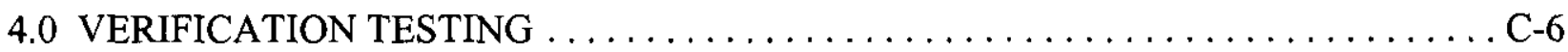

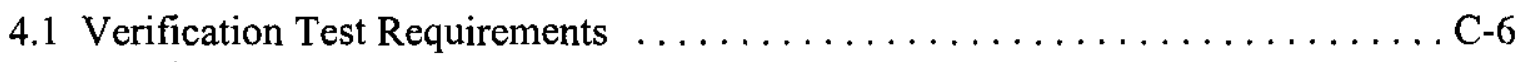

4.2 Verification Test Results ........................... 6

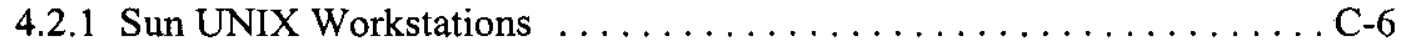

4.2.2 Windows $95 / \mathrm{NT}$ Platforms $\ldots \ldots \ldots \ldots \ldots \ldots \ldots \ldots \ldots \ldots \ldots \ldots \ldots \ldots$

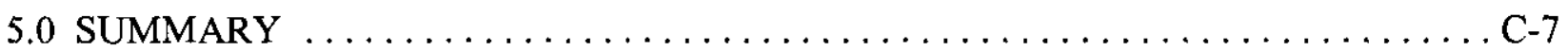

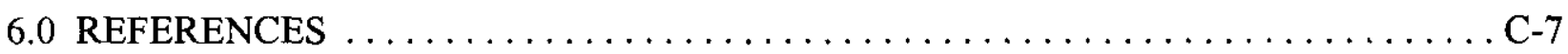

ATTACHMENT A. Modifications Made To ORIGEN2 And Its Data Libraries

By Hanford Contractors . . . . . . . . C-8

ATTACHMENT B. ORIGEN2 Program And Data Files Supplied From RSICC . . . . . . C-10

ATTACHMENT C. ORIGEN2 Input Files For ORNL Sample Problem And N Reactor Mark IV And Mark IA Fuels Cases . . C-12

APPENDIX D

VALIDATION OF ORIGEN2 S.2 $\ldots \ldots \ldots \ldots \ldots \ldots \ldots \ldots \ldots \ldots \ldots \ldots \ldots \ldots \ldots \ldots \ldots$ 
SNF-4503 Rev. 1

APPENDIX E

SOURCE CODE LISTINGS OF PROGRAMS 1YR.FOR AND COMPARE.C . . . . E E-1

APPENDIX F

ORIGEN2 SOURCE CODE LISTING $\ldots \ldots \ldots \ldots \ldots \ldots \ldots \ldots \ldots \ldots \ldots \ldots$ F-1

APPENDIX G

PEER REVIEW CHECKLIST $\ldots \ldots \ldots \ldots \ldots \ldots \ldots \ldots \ldots \ldots \ldots \ldots \ldots$ G-1

ATTACHMENT 1

SOFTWARE CERTIFICATION PACKAGE FOR THE WIMS-E CODE $\ldots \ldots \ldots 1-1$

ATTACHMENT 2

INDEPENDENT REVIEW PACKAGE FOR SNF-4503, REV. $1 \ldots \ldots \ldots \ldots \ldots 2-1$ 


\section{RADNUC-2A AND ORIGEN2 S.2 SINGLE-USE V\&V REPORT}

\subsection{Summary}

This report documents the verification and validation $(V \& V)$ activities undertaken to support the use of the RADNUC2-A and ORIGEN2 S.2 computer codes for the specific application of calculating isotopic inventories and decay heat loadings for Spent Nuclear Fuel Project (SNFP) activities as described herein. Two recent applications include the reports HNF-SD-SNF-TI-009, 105-K Basin Material Design Basis Feed Description for Spent Nuclear Fuel Project Facilities, Volume 1, Fuel (Praga, 1998), and HNF-3035, Rev. 0B, MCO Gas Composition for Low Reactive Surface Areas (Packer, 1998). Representative calculations documented in these two reports were repeated using RADNUC2-A, and the results were identical to the documented results. This serves as verification that version $2 \mathrm{~A}$ of Radnuc was used for the applications noted above; the same version was tested herein, and perfect agreement was shown. Comprehensive $\mathrm{V} \& \mathrm{~V}$ is demonstrated for RADNUC2-A in Appendix A.

This single use V\&V report was performed according to HNF-PRO-309, "Computer Software Quality Assurance Requirements, Rev. 0." This version of HNF-PRO-309 was effective from 9/2/98 to 4/10/00; this V\&V effort was performed and completed during fiscal year 1999 . The applicable section of HNF-PRO-309 is Section 2.5.4:

Single-use software for a specific application (e.g., preparation of an analysis report) may be documented exclusively in that report. The minimum required information shall include a copy of the source listing and the test documentation.

The single-use V\&V was intended for applications where there is no need or intention of subsequent use of the software by the organization preparing the report. Consistent with the requirements of HNF-PRO-309, the source listings for ORIGEN2 and RADNUC-2A are included in this report as well as test documentation.

Because RADNUC2-A has embedded data tables created from ORIGEN2 S.2 calculations, this single-use V\&V report also contains the results of the most recent V\&V activities performed for this code. Appendix $\mathrm{C}$ and $\mathrm{D}$ are a self-contained report covering the most recent V\&V results for ORIGEN2 S.2. Source code listings for both RADNUC2-A and ORIGEN2 S.2 may be found in Appendices B and F, respectively.

The ORIGEN2 code was acquired originally from the RSICC (Radiation Safety Information Computational Center) as a versatile point depletion and isotope decay computer code for use in simulating nuclear fuel irradiation or material activation.

The ORIGEN2 code, which has cross section libraries for many reactor types, has been adapted for application to $\mathrm{N}$ Reactor with cross section libraries. ORIGEN2 was first implemented on the Hanford Cray and then converted to the Sun UNIX System as Version S.1. Version S.2 of ORIGEN2 incorporates code corrections for spontaneous fission calculations when multiple cross section libraries are used. In addition, improved $\mathrm{N}$ Reactor cross section libraries generated by the WIMS-E computer code and code modifications enabling the code to operate on both the Sun UNIX and Microsoft Windows95/NT Intel architectures have been implemented. 
This report describes the identification of the S.2 version of ORIGEN2, the correct N Reactor data libraries, and the test results.

\subsection{Test Cases and Approach}

The computer modeling or simulation of physical systems or processes can be a challenging endeavor. Unlike the creation of operating systems, mathematical function libraries, or financial software (which have specific verification and validation criteria to certify acceptance), the modeling of physical systems is different. These systems are relatively straightforward to verify (that the models have been correctly implemented). However, their validation is based on how well they reproduce physical measureables (i.e., measured data).

As modeling sophistication improves, the degree of agreement with these measureables should also improve. Older versions of Radnuc were based on older versions of ORIGEN2, which used older nuclear cross section data libraries. It was shown (Appendix D) that WIMS-E reproduced measured data extremely well, and so WIMS-E was used to generate new and improved cross section libraries for ORIGEN2, so that ORIGEN2 would better match WIMS-E. These new ORIGEN2 libraries were used to create the data tables contained within the RADNUC2-A program. However, even though agreement was significantly improved (between ORIGEN2 S.2 and WIMS-E), some discrepancies still remain, and are probably attributable to the fact that the $(\mathrm{n}, 2 \mathrm{n})$ cross sections from WIMS-E are still not, as of yet, incorporated into the ORIGEN2 S.2 cross section libraries. Therefore, the current version of Radnuc (version 2A) does represent the best-available method for the prediction of activities and decay heat loadings that are attainable within the framework of the Radnuc code. This process may be summarized as follows:

1. The comparison of WIMS-E to measured data showed that WIMS-E reproduced measured transuranic buildup in N Reactor Mark IV fuel extremely well.

However, an older version of ORIGEN2 performed not as well, and for ${ }^{244} \mathrm{Cm}$, the comparison was terrible (high by an order of magnitude, or factor of 10 ).

2. WIMS-E was used to generate new cross sections for ORIGEN2, which allows ORIGEN2 version S.2 to come much closer to WIMS-E predictions than before.

3. The comparison of ORIGEN2 S.2 values to WIMS-E values (see Table D.1 in Appendix D) shows much improved agreement between ORIGEN2 S.2 and WIMS-E (and therefore with measured data).

\subsection{RADNUC2-A V\&V}

RADNUC2-A incorporates new activity data tables, produced using the latest ORIGEN2 S.2 results, and the cross section libraries created using WIMS-E. Appendix A documents the verification that both the logarithmic interpolation and decay chain calculations were both derived and implemented in Fortran coding correctly. Validation is demonstrated against ORIGEN2 S. 2 results, which constitute the baseline (i.e., ORIGEN2 S. 2 is assumed to provide the "correct" results). The maximum deviation of RADNUC2-A from ORIGEN2 S.2 for a 10year decay from the exposure basepoints is approximately $2 \%$. For the same 10 -year decay from 
interpolated exposure points, the maximum deviation is approximately $10 \%$. These deviations match the degree of agreement shown in previous Radnuc certification reports, are within the expected accuracy of the algorithms used, and are acceptable for the application of calculating decay heat loadings for SNFP.

\subsection{ORIGEN2 V\&V}

The ORIGEN2 Version S.2 code incorporated the new N Reactor cross sections, the spontaneous fission calculation fix, and for the Windows95/NT platform, the code changes needed to migrate the code from the Sun UNIX platform. For code verification, the code was tested to 1) determine if all changes had been implemented and 2) the base test case results for ORIGEN2 were reproducible on each target platform. The validation of ORIGEN2 Version S.2 consisted of verifying that the cross section libraries had been implemented and the $\mathrm{N}$ Reactor test cases using these cross sections produce results that were consistent with results produced by WIMS-E 6a as published in the document, Modification to ORIGEN2 for Generating N Reactor Source Terms (Schwarz, 1997). At the time these WIMS-E results were generated and used, WIMS-E was certified and under configuration control as an approved code (Attachment 1). The "diff" function, which does a byte-by-byte comparison of computer files, was utilized to compare resulting output for each test case.

\subsection{Single-Use Application}

A selected subset of RADNUC2-A results previously documented (Praga, 1998 and Packer, 1998) were reproduced, which establishes that the calculations performed for these specific applications are supported by the V\&V activities documented in Appendix A.

\subsection{Hardware Description}

\subsection{Sun UNIX Workstation}

\subsubsection{RADNUC2-A}

RADNUC2-A has not been installed on the UNIX computers.

\subsubsection{ORIGEN2 S.2}

The ORIGEN2 Version S.2 code has been installed to operate on a Sun UNIX SPARC 10 workstation with 32 megabytes of memory and 9 gigabytes of disk space. ORIGEN2 Version S.2 requires 2.0 megabytes of memory to accommodate the code and its required cross sections. The disk space requirements vary, but average 4.0 megabytes to provide storage of the executable file, cross section libraries, and the output file. For multiple calculations, the user should set aside between 50-100 megabytes of disk space to operate this code.

\subsection{Windows95/NT Workstation}

\subsubsection{RADNUC2-A}


RADNUC2-A has been installed on a Windows95/NT 4.0 Intel based workstation with 256 megabytes of memory and 9 gigabytes of disk space; this is the configuration where all test cases were performed. However, RADNUC2-A has also been executed on an 80386 PC with only 4 megabytes of memory, and still ran correctly (RADNUC2-A should therefore run on virtually any Intel-based personal computer).

\subsubsection{ORIGEN2 S.2}

The ORIGEN2 Version S.2 code has been installed to operate on a Windows95/NT 4.0 Intel based workstation with a minimum of 64 megabytes of memory and 4 gigabytes of disk space. The same memory and disk storage requirements as apply to the Sun UNIX workstation (See Section 3.1.2) apply to the Windows95/NT 4.0 Intel based workstation.

\subsubsection{System Hardware Identification}

The two systems used in the Single-Use V\&V of ORIGEN2 and RADNUC 2A are:

$\begin{array}{ll}\text { SUN Unix System: } & \text { SUN SPARCstation 10 "frs5" } \\ \text { Operating System: } & \text { Sun Solaris 2.6 } \\ \text { Property Number: } & \text { WC42360 } \\ \text { Serial Number: } & 312 \text { F1902 } \\ & \\ \text { INTEL Pentium System: } & \text { Intergraph TDZ 2000 (450 MHz) } \\ \text { Operating System: } & \text { MS Windows 95/NT 4.0 } \\ \text { Property Number: } & 30032280 \\ \text { Serial Number: } & \text { H28AFF }\end{array}$

\subsection{Acceptance Test Criteria}

\subsection{RADNUC2-A}

For the V\&V activities documented in Appendix A, the mathematical expression for logarithmic interpolation was independently derived. It was verified by direct inspection of the RADNUC2-A source code that this expression was incorporated correctly. Next, the differential equations for the three decay chain models built into RADNUC2-A were solved analytically, with the proper initial conditions, and again, it was verified by direct inspection of the RADNUC2-A source code that these expressions were properly incorporated. Finally, hand calculations were performed for a subset of isotopes (selected to test each of the decay functions in RADNUC2-A).

Because no iterative (and convergence logic) methods are involved, agreement between these selected hand calculations and RADNUC2-A must agree exactly (to within the numerical precision of the RADNUC2-A output). Otherwise, something must not be implemented as intended. 
For the validation section of Appendix A, it must be shown that current agreement between RADNUC2-A and ORIGEN2 S.2 is comparable to previous documented agreement.

Previous documented agreement between Radnuc and ORIGEN2 results was approximately $2 \%$ for a 10-year decay from activities on the exposure basepoints $\left(6,9,12\right.$, and $16 \mathrm{wt} \%{ }^{240} \mathrm{Pu}$ ), and approximately $10 \%$ for the same 10 -year decay, but from starting points that are logarithmically interpolated between the exposure basepoints (i.e., 7.5 and $14 \mathrm{wt} \%{ }^{240} \mathrm{Pu}$ ).

The acceptance test criterion for the single-use application is to show perfect agreement (to within the numerical precision output by RADNUC2-A) between several representative example problems previously documented, and when using the verified and validated copy of RADNUC2-A.

\subsection{ORIGEN2}

\subsubsection{Definitions}

Verification (Acceptance Testing) - Testing many of the features and capabilities of the ORIGEN2 S.2 software using a set of 3 input files to ensure that a new installation of the software will function properly. The purpose is to prove that a known input will produce the same expected results on a new computer platform as at ORNL.

Validation - A testing process which uses a set of input data to produce results which are compared to results obtained from measured results or results from accepted calculations established in the open literature.

\subsubsection{Verification}

The verification test on each computer platform will consist of the three sample problems. These sample problems consisted of the sample problem supplied with the original users manual (Croff, 1980) supplied by Oak Ridge National Laboratory (ORNL), and two N Reactor fuel problems representing Mark IV and Mark IA fuel at exposures close to $12 \%{ }^{240} \mathrm{Pu}$. The sample problem in the original users manual (Croff, 1980) tested for consistency with the problem run on the ORNL computer and other computers such as the Hanford Cray. The two $\mathrm{N}$ Reactor problems for $12 \mathrm{wt} \%$ ${ }^{240} \mathrm{Pu}$ in Mark IV and Mark IA fuels tested for consistency of the modified cross section data libraries and ORIGEN2 modifications developed for $N$ Reactor fuels. The $N$ Reactor fuel problems were tested for consistency with the original cases that were run for the Radnuc code support (Schwartz, 1997).

The output of ORIGEN2 is generally given in four significant figures. A variation in the last of the four digits is acceptable for the applications of ORIGEN2 calculations. An acceptance criteria of $0.05 \%$ agreement between individual output data of similar test problems is required. This variation is expected when comparing between the Sun UNIX and Windows95/NT computer platforms due to the difference in floating point accuracy. 


\subsubsection{Validation}

The acceptance test criteria for ORIGEN2 S.2 shall apply to fuel exposures out to the range of $4000 \mathrm{MWd} / \mathrm{MTU}$ for measured data of $\mathrm{N}$ Reactor Mark IV fuel. The isotopes ${ }^{234} \mathrm{U},{ }^{235} \mathrm{U},{ }^{236} \mathrm{U},{ }^{237} \mathrm{U}$, ${ }^{238} \mathrm{U},{ }^{239} \mathrm{~Np},{ }^{239} \mathrm{Pu},{ }^{240} \mathrm{Pu},{ }^{241} \mathrm{Pu},{ }^{242} \mathrm{Pu},{ }^{241} \mathrm{Am},{ }^{243} \mathrm{Am}$, and ${ }^{244} \mathrm{Cm}$, shall demonstrate at least $10 \%$ agreement. The isotopes ${ }^{230} \mathrm{Th},{ }^{232} \mathrm{Th},{ }^{243} \mathrm{Cm}$, and ${ }^{245} \mathrm{Cm}$, shall have at least $20 \%$ agreement. The isotopes ${ }^{231} \mathrm{~Pa},{ }^{233} \mathrm{U},{ }^{237} \mathrm{~Np},{ }^{238} \mathrm{~Np},{ }^{238} \mathrm{Pu},{ }^{242 \mathrm{~m}} \mathrm{Am},{ }^{242} \mathrm{Am}$, and ${ }^{242} \mathrm{Cm}$ shall demonstrate at least $60 \%$ agreement. While several of these isotopes were not included in the creation of new cross sections using WIMS-E (e.g., ${ }^{231} \mathrm{~Pa},{ }^{242} \mathrm{Cm},{ }^{245} \mathrm{Cm}$ ), none of the $(\mathrm{n}, 2 \mathrm{n})$ cross sections were incorporated into the new libraries, and so some work remains to be done. The output files for all of these cases (as reported in Sections 4.2.2 and 4.2.3) are archived on a CD-R disc, which is in the possession of the ORIGEN2 S.2 and RADNUC2-A code custodian.

Fission products contributing to the majority (over $85 \%$ as shown below) of the total decay heat load have been included in the "single use only" validation effort. For example, checking the ORIGEN2 database (Schwarz 1997) for both MK1A and MKIV fuel at $16 \%{ }^{240} \mathrm{Pu}$, results are as follows:

MK1A $16 \%{ }^{240} \mathrm{Pu}$

Total fission products heat load used in validation effort: 128.9 Watts/MTU

Total heat load from fission products, activation products, and actinides: $146.4 \mathrm{Watts} / \mathrm{MTU}$

Therefore \% heat load from fission products used in validation effort: $128.9 / 146.4 \times 100 \%=87.9 \%$

MKIV $16 \%{ }^{240} \mathrm{Pu}$

Total fission products heat load used in validation effort: 106.1 Watts/MTU

Total heat lead from fission products, activation products, and actinides: $122.7 \mathrm{Watts} / \mathrm{MTU}$

Therefore \% heat load from fission products used in validation effort: $106.1 / 122.7 \times 100 \%=86.5 \%$

RADNUC-2A was validated by making a detailed comparison between RADNUC-2A and ORIGEN2 for fuel with a 10-year decay after discharge. The ORIGEN2 library is a database which includes calculated amounts of radionuclides (including primary fission products) at specified dates after discharge from the reactor. RADNUC-2A interpolates between these specified dates in ORIGEN2. Also used for validation was the WIMS-E lattice transport code to generate the same TRU isotopics as ORIGEN2 for comparison to measured data; however, the WIMS-E code is used only for transuranics comparisons since fission products and activation products are not predicted by this code.

As noted in Appendix A the RADNUC-2A prediction for ${ }^{60} \mathrm{Co}$ is approximately $20 \%$ higher than the ORIGEN2 prediction. This is because of the Cobalt Factor (COFAC) adjustment built into RADNUC-2A, which increases the ${ }^{60} \mathrm{Co}$ activity by $19 \%$ to improve agreement with measured data. The COFAC adjustment accounts for the higher level of ${ }^{60} \mathrm{Co}$ in the fuel as an activation product (not a fission product) in the nickel impurity in the charged fuel. The ORIGEN2 predictions of ${ }^{60} \mathrm{Co}$, sensitive to the assumed nickel impurity of charged fuel, were based on the fabrication specification for impurities. Actual $\mathrm{N}$ Reactor fuel ${ }^{60} \mathrm{Co}$ values from waste tank and PUREX samples resulted in the COFAC adjustment (Willis 1995).

\subsection{Results for Single-Use Test Problems}


The objective of this section is to demonstrate that previously reported results, using RADNUC2-A for the Spent Nuclear Fuel Project, are reproducible using the version of the program transmitted to the Fluor Daniel Northwest Criticality and Shielding group for verification and validation. Section 5.1 below contains these results. Section 5.2 on ORIGEN2 is included for completeness.

\subsection{RADNUC2-A}

\section{HNF-SD-SNF-TI-009}

The RADNUC2-A input file for the combined KE/KW Basin found in Praga (1998) was scanned and read into a text file using optical character recognition (OCR) software. When RADNUC2-A was executed with this input file, perfect agreement was shown for both total curies and decay heat loading. According to the reference document, the total activity for this case is $5.50 \times 10^{7} \mathrm{Ci}$ and the decay heat loading is $5.49 \times 10^{5} \mathrm{Btu} / \mathrm{hr}$. When this problem was executed using the verified and validated copy of RADNUC2-A, these totals were reproduced exactly. The input file for this case is listed below:

$\begin{array}{lccccccc}\text { "105-K Basins charge data" } & & & & \\ & 7 & & & & \\ \text { "Key" } & \text { "Grade" "Fuel " "Pieces" } & \text { " Pu-240" } & \text { "Uranium" } & \text { "Mo" } & \text { "Yr" } \\ 09621 & 1 & 4 & 000 & 5.94 & 0.006673 & 12 & 99 \\ 09621 & 1 & 4 & 000 & 5.94 & 0.076694 & 12 & 99 \\ 09621 & 1 & 4 & 000 & 6.01 & 0.023972 & 12 & 99 \\ 09621 & 1 & 4 & 000 & 5.94 & 0.0099 & 12 & 99 \\ 09621 & 1 & 4 & 000 & 5.94 & 0.002374 & 12 & 99 \\ 09621 & 1 & 4 & 000 & 5.94 & 0.072655 & 12 & 99 \\ 09621 & 1 & 4 & 000 & 5.94 & 0.149847 & 12 & 99 \\ 09621 & 1 & 4 & 000 & 5.94 & 0.009728 & 12 & 99 \\ 09621 & 1 & 4 & 000 & 5.94 & 0.050475 & 12 & 99 \\ 10001 & 3 & 4 & 000 & 12.4 & 0.04212 & 12 & 99 \\ 10001 & 3 & 4 & 000 & 12.4 & 0.014903 & 12 & 99 \\ 10001 & 3 & 4 & 000 & 12.4 & 0.006639 & 12 & 99 \\ 10001 & 3 & 4 & 000 & 12.4 & 0.00991 & 12 & 99 \\ 10001 & 3 & 4 & 000 & 12.4 & 0.029932 & 12 & 99 \\ 10001 & 3 & 4 & 000 & 12.4 & 0.035065 & 12 & 99 \\ 10201 & 2 & 4 & 000 & 9.09 & 1.075459 & 12 & 99 \\ 10201 & 2 & 4 & 000 & 9.09 & 0.366031 & 12 & 99 \\ 10201 & 2 & 4 & 000 & 9.09 & 0.343918 & 12 & 99 \\ 10201 & 2 & 4 & 000 & 9.09 & 0.537029 & 12 & 99 \\ 10201 & 2 & 4 & 000 & 9.09 & 0.172074 & 12 & 99 \\ 10201 & 2 & 4 & 000 & 9.09 & 0.161819 & 12 & 99 \\ 10259 & 3 & 4 & 000 & 10.41 & 0.050612 & 12 & 99 \\ 10259 & 3 & 4 & 000 & 10.41 & 1.476838 & 12 & 99 \\ 10259 & 3 & 4 & 000 & 10.41 & 12.34494 & 12 & 99 \\ 10259 & 3 & 4 & 000 & 10.41 & 0.031588 & 12 & 99 \\ 10259 & 3 & 4 & 000 & 10.41 & 0.718433 & 12 & 99 \\ 10259 & 3 & 4 & 000 & 10.41 & 5.758699 & 12 & 99 \\ 10294 & 2 & 4 & 000 & 8.94 & 0.032608 & 12 & 99 \\ 10294 & 3 & 4 & 000 & 10.4 & 0.012648 & 12 & 99 \\ 10294 & 3 & 4 & 000 & 10.4 & 0.812226 & 12 & 99 \\ 10294 & 3 & 4 & 000 & 10.4 & 24.15077 & 12 & 99 \\ 10294 & 3 & 4 & 000 & 10.4 & 0.762301 & 12 & 99 \\ 10294 & 2 & 4 & 000 & 8.94 & 0.027153 & 12 & 99 \\ 10294 & 3 & 4 & 000 & 10.4 & 0.006317 & 12 & 99\end{array}$


SNF-4503 Rev. 1

\begin{tabular}{|c|c|c|c|c|c|c|c|}
\hline 10294 & 3 & 4 & 000 & 10.4 & 0.381403 & 12 & 99 \\
\hline 10294 & 3 & 4 & 000 & 10.4 & 11.35286 & 12 & 99 \\
\hline 10294 & 3 & 4 & 000 & 10.4 & 0.344639 & 12 & 99 \\
\hline 10350 & 2 & 4 & 000 & 9.28 & 0.031646 & 12 & 99 \\
\hline 10350 & 2 & 4 & 000 & 9.28 & 0.238728 & 12 & 99 \\
\hline 10350 & 2 & 4 & 000 & 9.28 & 0.089727 & 32 & 99 \\
\hline 10350 & 2 & 4 & 000 & 9.28 & 0.014861 & 12 & 99 \\
\hline 10350 & 2 & 4 & 000 & 9.28 & 0.112204 & 12 & 99 \\
\hline 10350 & 2 & 4 & 000 & 9.28 & 0.042207 & 12 & 99 \\
\hline 10385 & 3 & 4 & 000 & 10.21 & 0.130384 & 12 & 99 \\
\hline 10385 & 3 & 4 & 000 & 11.21 & 0.141018 & 12 & 99 \\
\hline 10385 & 3 & 4 & 000 & 11.21 & 23.81023 & 12 & 99 \\
\hline 10385 & 3 & 4 & 000 & 11.21 & 0.298905 & 12 & 99 \\
\hline 10385 & 3 & 4 & 000 & 10.21 & 0.075994 & 12 & 99 \\
\hline 10385 & 3 & 4 & 000 & 11.21 & 0.059715 & 12 & 99 \\
\hline 10385 & 3 & 4 & 000 & 11.21 & 11.17924 & 12 & 99 \\
\hline 10385 & 3 & 4 & 000 & 11.21 & 0.154738 & 12 & 99 \\
\hline 10456 & 3 & 4 & 000 & 11.24 & 0.009548 & 12 & 99 \\
\hline 10456 & 3 & 4 & 000 & 11.24 & 0.031918 & 12 & 99 \\
\hline 10456 & 3 & 4 & 000 & 11.24 & 0.414766 & 12 & 99 \\
\hline 10456 & 3 & 4 & 000 & 11.24 & 1.348222 & 12 & 99 \\
\hline 10456 & 3 & 4 & 000 & 11.24 & 21.44289 & 12 & 99 \\
\hline 10456 & 3 & 4 & 000 & 11.24 & 3.186772 & 12 & 99 \\
\hline 10576 & 3 & 4 & 000 & 11.09 & 3.881855 & 12 & 99 \\
\hline 10576 & 3 & 4 & 000 & 11.09 & 0.043956 & 12 & 99 \\
\hline 10602 & 4 & 4 & 000 & 13.75 & 0.081456 & 12 & 99 \\
\hline 10602 & 3 & 4 & 000 & 11.09 & 0.031925 & 12 & 99 \\
\hline 10602 & 4 & 4 & 000 & 13.75 & 0.55955 & 12 & 99 \\
\hline 10602 & 3 & 4 & 000 & 11.09 & 0.030958 & 12 & 99 \\
\hline 10602 & 4 & 4 & 000 & 13.75 & 24.79309 & 12 & 99 \\
\hline 10602 & 4 & 4 & 000 & 13.75 & 1.22853 & 12 & 99 \\
\hline 10679 & 4 & 4 & 000 & 14.09 & 0.309509 & 12 & 99 \\
\hline 10679 & 3 & 4 & 000 & 11.09 & 0.014136 & 12 & 99 \\
\hline 10679 & 4 & 4 & 000 & 14.09 & 0.124291 & 12 & 99 \\
\hline 10679 & 3 & 4 & 000 & 11.09 & 1.255033 & 12 & 99 \\
\hline 10679 & 4 & 4 & 000 & 14.09 & 22.96605 & 12 & 99 \\
\hline 10679 & 4 & 4 & 000 & 14.09 & 1.296428 & 12 & 99 \\
\hline 10742 & 4 & 4 & 000 & 14.25 & 1.170103 & 12 & 99 \\
\hline 10742 & 4 & 4 & 000 & 14.25 & 12.36114 & 12 & 99 \\
\hline 10742 & 4 & 4 & 000 & 14.25 & 0.462965 & 12 & 99 \\
\hline 10742 & 3 & 4 & 000 & 10.8 & 0.549476 & 12 & 99 \\
\hline 10742 & 4 & 4 & 000 & 14.25 & 5.806125 & 12 & 99 \\
\hline 10742 & 3 & 4 & 000 & 10.8 & 0.22488 & 12 & 99 \\
\hline 10770 & 3 & 4 & 000 & 11.66 & 0.681667 & 12 & 99 \\
\hline 10770 & 4 & 4 & 000 & 13.91 & 14.11261 & 12 & 99 \\
\hline 10770 & 4 & 4 & 000 & 13.91 & 4.436449 & 12 & 99 \\
\hline 10832 & 4 & 4 & 000 & 13.65 & 0.260688 & 12 & 99 \\
\hline 10832 & 4 & 4 & 000 & 13.65 & 0.041425 & 22 & 99 \\
\hline 10832 & 4 & 4 & 000 & 13.65 & 2.044619 & 12 & 99 \\
\hline 10832 & 4 & 4 & 000 & 23.65 & 47.31945 & 12 & 99 \\
\hline 10832 & 4 & 4 & 000 & 13.65 & 3.138458 & 12 & 99 \\
\hline 10982 & 4 & 4 & 000 & 14.97 & 0.173868 & 12 & 99 \\
\hline 10982 & 4 & 4 & 000 & 14.97 & 0.126892 & 12 & 99 \\
\hline 10982 & 3 & 4 & 000 & 11.7 & 0.706201 & 12 & 99 \\
\hline 10982 & 4 & 4 & 000 & 14.97 & 15.20181 & 12 & 99 \\
\hline 10982 & 4 & 4 & 000 & 14.97 & 0.94076 & 12 & 99 \\
\hline 10982 & 4 & 4 & 000 & 14.97 & 0.08688 & 12 & 99 \\
\hline 10982 & 3 & 4 & 000 & 11.7 & 0.059721 & 12 & 99 \\
\hline 10982 & 3 & 4 & 000 & 11.7 & 0.331757 & 12 & 99 \\
\hline 10982 & 4 & 4 & 000 & 14.97 & 7.090482 & 12 & 99 \\
\hline 10982 & 3 & 4 & 000 & 11.7 & 0.498938 & 12 & 99 \\
\hline 11036 & 4 & 4 & 000 & 14.37 & 0.006372 & 12 & 99 \\
\hline 11036 & 4 & 4 & 000 & 13.31 & 0.326927 & 12 & 99 \\
\hline 11036 & 4 & 4 & 000 & 14.37 & 7.817157 & 12 & 99 \\
\hline
\end{tabular}


SNF-4503 Rev. 1

\begin{tabular}{|c|c|c|c|c|c|c|}
\hline 11036 & 4 & 4 & 000 & 14.37 & 0.686572 & 12 \\
\hline 11036 & 4 & 4 & 000 & 13.31 & 0.003176 & 12 \\
\hline 11036 & 4 & 4 & 000 & 14.37 & 0.013257 & 12 \\
\hline 11036 & 4 & 4 & 000 & 13.31 & 0.123844 & 12 \\
\hline 11036 & 4 & 4 & 000 & 14.37 & 3.698878 & 12 \\
\hline 11036 & 4 & 4 & 000 & 14.37 & 0.330283 & 12 \\
\hline 11109 & 4 & 4 & 000 & 14.62 & 0.16921 & 12 \\
\hline 11109 & 4 & 4 & 000 & 14.62 & 0.674804 & 12 \\
\hline 11109 & 4 & 4 & 000 & 14.62 & 15.10859 & 12 \\
\hline 11109 & 4 & 4 & 000 & 14.62 & 1.238823 & 12 \\
\hline 11109 & 3 & 4 & 000 & 20.32 & 0.079566 & 12 \\
\hline 11109 & 3 & 4 & 000 & 10.32 & 0.331711 & 12 \\
\hline 11109 & 4 & 4 & 000 & 14.62 & 7.091013 & 12 \\
\hline 11109 & 4 & 4 & 000 & 14.62 & 0.576213 & 12 \\
\hline 11183 & 4 & 4 & 000 & 14.49 & 0.184538 & 12 \\
\hline 11183 & 4 & 4 & 000 & 14.49 & 0.140773 & 12 \\
\hline 11183 & 4 & 4 & 000 & 14.49 & 0.189703 & 12 \\
\hline 11183 & 4 & 4 & 000 & 14.49 & 32.90384 & 12 \\
\hline 11183 & 4 & 4 & 000 & 14.49 & 1.014554 & 12 \\
\hline 11183 & 4 & 4 & 000 & 14.49 & 0.031018 & 12 \\
\hline 11183 & 4 & 4 & 000 & 14.49 & 0.210257 & 12 \\
\hline 11183 & 4 & 4 & 000 & 14.49 & 0.043892 & 12 \\
\hline 11183 & 4 & 4 & 000 & 14.49 & 0.097674 & 12 \\
\hline 11183 & 4 & 4 & 000 & 14.49 & 0.066214 & 12 \\
\hline 11183 & 3 & 4 & 000 & 11.02 & 0.089084 & 12 \\
\hline 11183 & 4 & 4 & 000 & 14.49 & 15.43086 & 12 \\
\hline 11183 & 4 & 4 & 000 & 14.49 & 0.491747 & 12 \\
\hline 11372 & 4 & 4 & 000 & 25.17 & 0.130374 & 12 \\
\hline 11372 & 4 & 4 & 000 & 15.17 & 0.042237 & 12 \\
\hline 11372 & 4 & 4 & 000 & 15.17 & 0.421612 & 12 \\
\hline 11372 & 4 & 4 & 000 & 15.17 & 19.91088 & 12 \\
\hline 11372 & 4 & 4 & 000 & 15.17 & 0.686564 & 12 \\
\hline 11372 & 4 & 4 & 000 & 15.17 & 0.059719 & 12 \\
\hline 11372 & 3 & 4 & 000 & 12.05 & 0.019892 & 12 \\
\hline 11372 & 3 & 4 & 000 & 12.05 & 0.178219 & 12 \\
\hline 11372 & 3 & 4 & 000 & 12.05 & 9.414279 & 12 \\
\hline 11372 & 4 & 4 & 000 & 15.17 & 0.309187 & 12 \\
\hline 11449 & 4 & 4 & 000 & 14.37 & 0.197256 & 12 \\
\hline 11449 & 4 & 4 & 000 & 14.37 & 0.094853 & 12 \\
\hline 11449 & 4 & 4 & 000 & 14.37 & 16.26954 & 12 \\
\hline 11449 & 4 & 4 & 000 & 14.37 & 3.361394 & 12 \\
\hline 11449 & 4 & 4 & 000 & 14.37 & 0.0861 .93 & 12 \\
\hline 11449 & 3 & 4 & 000 & 11.03 & 0.039598 & 12 \\
\hline 11449 & 4 & 4 & 000 & 14.37 & 7.629647 & 12 \\
\hline 11449 & 3 & 4 & 000 & 11.03 & 1.616732 & 12 \\
\hline 11540 & 3 & 4 & 000 & 11.66 & 0.152125 & 12 \\
\hline 11540 & 3 & 4 & 000 & 11.3 & 0.141035 & 12 \\
\hline 11540 & 3 & 4 & 000 & 11.3 & 0.042167 & 12 \\
\hline 11540 & 3 & 4 & 000 & 11.3 & 7.603293 & 12 \\
\hline 11540 & 3 & 4 & 000 & 11.3 & 0.59779 & 12 \\
\hline 11540 & 3 & 4 & 000 & 11.3 & 0.982763 & 12 \\
\hline 11540 & 3 & 4 & 000 & 11.66 & 0.076006 & 12 \\
\hline 11540 & 3 & 4 & 000 & 11.3 & 0.072978 & 12 \\
\hline 11540 & 3 & 4 & 000 & 11.3 & 0.024759 & 12 \\
\hline 11540 & 3 & 4 & 000 & 11.3 & 3.567068 & 12 \\
\hline 11540 & 3 & 4 & 000 & 11.3 & 0.274249 & 12 \\
\hline 11733 & 3 & 4 & 000 & 12.82 & 0.349841 & 12 \\
\hline 11733 & 3 & 4 & 000 & 12.82 & 0.089642 & 12 \\
\hline 11733 & 3 & 4 & 000 & 10.36 & 0.156979 & 12 \\
\hline 11733 & 3 & 4 & 000 & 10.36 & 0.049213 & 12 \\
\hline 11806 & 4 & 4 & 000 & 15.03 & 0.162968 & 12 \\
\hline 11806 & 3 & 4 & 000 & 11.94 & 0.084643 & 12 \\
\hline 11806 & 3 & 4 & 000 & 11.94 & 0.021097 & 12 \\
\hline 11806 & 4 & 4 & 000 & 25.03 & 18.25962 & 12 \\
\hline
\end{tabular}


SNF-4503 Rev. 1

\begin{tabular}{|c|c|c|c|c|c|c|c|}
\hline 11806 & 4 & 4 & 000 & 15.03 & 0.268532 & 12 & 99 \\
\hline 11806 & 3 & 4 & 000 & 11.94 & 0.327677 & 12 & 99 \\
\hline 11806 & 4 & 4 & 000 & 15.03 & 0.070582 & 12 & 99 \\
\hline 11806 & 3 & 4 & 000 & 11.94 & 0.033183 & 12 & 99 \\
\hline 11806 & 3 & 4 & 000 & 11.94 & 0.00991 & 12 & 99 \\
\hline 11806 & 3 & 4 & 000 & 11.94 & 8.607779 & 12 & 99 \\
\hline 11806 & 4 & 4 & 000 & 15.03 & 0.126466 & 12 & 99 \\
\hline 11897 & 3 & 4 & 000 & 11.69 & 3.046193 & 12 & 99 \\
\hline 11897 & 4 & 4 & 000 & 15.47 & 20.37553 & 12 & 99 \\
\hline 11897 & 4 & 4 & 000 & 15.47 & 1.61182 & 12 & 99 \\
\hline 11897 & 4 & 4 & 000 & 15.47 & 0.00663 & 12 & 99 \\
\hline 11897 & 3 & 4 & 000 & 11.69 & 1.431082 & 12 & 99 \\
\hline 11897 & 4 & 4 & 000 & 15.47 & 9.584959 & 12 & 99 \\
\hline 11897 & 4 & 4 & 000 & 15.47 & 0.751884 & 12 & 99 \\
\hline 11979 & 4 & 4 & 000 & 15.34 & 0.081493 & 12 & 99 \\
\hline 11979 & 4 & 4 & 000 & 15.34 & 1.854741 & 12 & 99 \\
\hline 11979 & 4 & 4 & 000 & 15.34 & 14.26082 & 12 & 99 \\
\hline 11979 & 4 & 4 & 000 & 15.34 & 1.926291 & 12 & 99 \\
\hline 11979 & 4 & 4 & 000 & 15.34 & 0.371669 & 12 & 99 \\
\hline 11979 & 4 & 4 & 000 & 15.34 & 9.622194 & 12 & 99 \\
\hline 11979 & 4 & 4 & 000 & 15.34 & 0.461079 & 12 & 99 \\
\hline 11979 & 3 & 4 & 000 & 11.7 & 0.89586 & 12 & 99 \\
\hline 11979 & 4 & 4 & 000 & 15.34 & 6.693747 & 12 & 99 \\
\hline 11979 & 3 & 4 & 000 & 11.7 & 0.892379 & 12 & 99 \\
\hline 12127 & 4 & 4 & 000 & 14.73 & 0.146527 & 12 & 99 \\
\hline 12127 & 4 & 4 & 000 & 14.73 & 0.497313 & 12 & 99 \\
\hline 12127 & 4 & 4 & 000 & 14.73 & 0.340679 & 12 & 99 \\
\hline 12127 & 4 & 4 & 000 & 14.73 & 26.23191 & 12 & 99 \\
\hline 12127 & 4 & 4 & 000 & 14.73 & 3.336408 & 12 & 99 \\
\hline 12201 & 4 & 4 & 000 & 13.98 & 0.13036 & 12 & 99 \\
\hline 12201 & 3 & 4 & 000 & 11.38 & 0.01059 & 12 & 99 \\
\hline 12201 & 3 & 4 & 000 & 11.38 & 0.449298 & 12 & 99 \\
\hline 12201 & 4 & 4 & 000 & 13.98 & 15.9358 & 12 & 99 \\
\hline 12201 & 4 & 4 & 000 & 13.98 & 5.664989 & 12 & 99 \\
\hline 12201 & 3 & 4 & 000 & 11.38 & 0.007507 & 12 & 99 \\
\hline 12240 & 4 & 4 & 000 & 14.51 & 0.063584 & 12 & 99 \\
\hline 12240 & 3 & 4 & 000 & 11.22 & 0.029896 & 12 & 99 \\
\hline 12285 & 4 & 4 & 000 & 14.45 & 0.014083 & 12 & 99 \\
\hline 12285 & 4 & 4 & 000 & 24.45 & 0.031772 & 12 & 99 \\
\hline 12285 & 3 & 4 & 000 & 12.1 & 0.759011 & 12 & 99 \\
\hline 12285 & 4 & 4 & 000 & 14.45 & 57,7036 & 12 & 99 \\
\hline 12285 & 4 & 4 & 000 & 14.45 & 6.101811 & 12 & 99 \\
\hline 12285 & 3 & 4 & 000 & 12.1 & 0.004972 & 12 & 99 \\
\hline 12480 & 4 & 4 & 000 & 14.29 & 0.580019 & 12 & 99 \\
\hline 12480 & 3 & 4 & 000 & 12.38 & 0.24784 & 12 & 99 \\
\hline 12480 & 4 & 4 & 000 & 14.29 & 49.62144 & 12 & 99 \\
\hline 12480 & 4 & 4 & 000 & 14.29 & 3.732459 & 12 & 99 \\
\hline 12565 & 4 & 4 & 000 & 14.15 & 0.290153 & 12 & 99 \\
\hline 12565 & 4 & 4 & 000 & 14.15 & 0.139326 & 12 & 99 \\
\hline 12565 & 4 & 4 & 000 & 14.15 & 34.78675 & 12 & 99 \\
\hline 12565 & 4 & 4 & 000 & 14.15 & 3.646776 & 12 & 99 \\
\hline 12639 & 4 & 4 & 000 & 13.84 & 0.02309 & 12 & 99 \\
\hline 12639 & 4 & 4 & 000 & 13.84 & 40.3312 & 12 & 99 \\
\hline 12639 & 4 & 4 & 000 & 13.84 & 5.400192 & 12 & 99 \\
\hline 12852 & 3 & 4 & 000 & 11.43 & 2.525342 & 12 & 99 \\
\hline 13015 & 4 & 4 & 000 & 13.29 & 0.216604 & 12 & 99 \\
\hline 13015 & 4 & 4 & 000 & 13.19 & 0.654274 & 12 & 99 \\
\hline 13016 & 1 & 4 & 000 & 5.63 & 0.02194 & 12 & 99 \\
\hline 13371 & 1 & 4 & 000 & 6.58 & 0.021128 & 12 & 99 \\
\hline 13649 & 3 & 4 & 000 & 11.4 & 0.374685 & 12 & 99 \\
\hline 13649 & 4 & 4 & 000 & 13.25 & 0.588463 & 12 & 99 \\
\hline 13649 & 4 & 4 & 000 & 13.25 & 3.972961 & 12 & 99 \\
\hline 13685 & 4 & 4 & 000 & 13.34 & 2.617419 & 12 & 99 \\
\hline 14065 & 1 & 4 & 000 & 5.62 & 0.023287 & 12 & 99 \\
\hline
\end{tabular}


SNF-4503 Rev. 1

\begin{tabular}{|c|c|c|c|c|c|c|c|}
\hline 14355 & 4 & 4 & 000 & 15.74 & 0.094818 & 12 & 99 \\
\hline 24355 & 3 & 4 & 000 & 12 & 6.202162 & 12 & 99 \\
\hline 14355 & 4 & 4 & 000 & 15.74 & 0.313212 & 12 & 99 \\
\hline 14355 & 4 & 4 & 000 & 15.74 & 0.04455 & 12 & 99 \\
\hline 14355 & 3 & 4 & 000 & 12 & 2.916202 & 12 & 99 \\
\hline 14355 & 4 & 4 & 000 & 15.74 & 0.147505 & 12 & 99 \\
\hline 14356 & 3 & 4 & 000 & 11.28 & 0.180698 & 12 & 99 \\
\hline 14356 & 3 & 4 & 000 & 11.28 & 3.207757 & 12 & 99 \\
\hline 24356 & 3 & 4 & 000 & 11.28 & 0.022035 & 12 & 99 \\
\hline 14356 & 3 & 4 & 000 & 11.28 & 8.161901 & 12 & 99 \\
\hline 14356 & 3 & 4 & 000 & 11.28 & 1.352138 & 12 & 99 \\
\hline 14356 & 3 & 4 & 000 & 11.28 & 0.372588 & 12 & 99 \\
\hline 14356 & 3 & 4 & 000 & 11,28 & 0.085034 & 12 & 99 \\
\hline 14356 & 3 & 4 & 000 & 11.28 & 0.103665 & 12 & 99 \\
\hline 14722 & 1 & 4 & 000 & 5.05 & 0.068843 & 12 & 99 \\
\hline 15204 & 1 & 4 & 000 & 6.01 & 0.015919 & 12 & 99 \\
\hline 15204 & 1 & 4 & 000 & 5.53 & 0.351245 & 12 & 99 \\
\hline 15204 & 1 & 4 & 000 & 6.01 & 14.30584 & 12 & 99 \\
\hline 15204 & $I$ & 4 & 000 & 6.01 & 3.164697 & 12 & 99 \\
\hline 15204 & 1 & 4 & 000 & 6.01 & 59.48539 & 12 & 99 \\
\hline 15204 & 1 & 4 & 000 & 6.01 & 20.10897 & 12 & 99 \\
\hline 25204 & 1 & 4 & 000 & 6.01 & 0.007492 & 12 & 99 \\
\hline 15240 & 1 & 4 & 000 & 5.6 & 0.015919 & 12 & 99 \\
\hline 15240 & 1 & 4 & 000 & 5.71 & 0.374804 & 12 & 99 \\
\hline 15240 & 1 & 4 & 000 & 5.6 & 0.088008 & 12 & 99 \\
\hline 15240 & 1 & 4 & 000 & 5.6 & 0.006644 & 12 & 99 \\
\hline 15240 & 1 & 4 & 000 & 5.6 & 0.007041 & 12 & 99 \\
\hline 15316 & 1 & 4 & 000 & 6.1 & 10.04697 & 12 & 99 \\
\hline 15316 & 1 & 4 & 000 & 6.1 & 0.186043 & 12 & 99 \\
\hline 15316 & 1 & 4 & 000 & 6.1 & 4.962912 & 12 & 99 \\
\hline 15316 & 1 & 4 & 000 & 6.1 & 4.334796 & 12 & 99 \\
\hline 15316 & 1 & 4 & 000 & 6.1 & 0.007492 & 12 & 99 \\
\hline 25444 & 1 & 4 & 000 & 4.7 & 0.103706 & 12 & 99 \\
\hline 15111 & 1 & 4 & 000 & 4.7 & 0.116956 & 12 & 99 \\
\hline 15444 & 1 & 4 & 000 & 4.7 & 0.087941 & 12 & 99 \\
\hline 15451 & 1 & 4 & 000 & 4.97 & 1.497135 & 12 & 99 \\
\hline 15451 & 1 & 4 & 000 & 6.79 & 6.799597 & 12 & 99 \\
\hline 15451 & 1 & 4 & 000 & 6.79 & 0.092684 & 12 & 99 \\
\hline 15451 & 1 & 4 & 000 & 6.79 & 0.044007 & 12 & 99 \\
\hline 15455 & 1 & 4 & 000 & 4.94 & 0.373161 & 12 & 99 \\
\hline 15455 & 1 & 4 & 000 & 4.94 & 0.748424 & 12 & 99 \\
\hline 15455 & 1 & 4 & 000 & 4.94 & 0.373987 & 12 & 99 \\
\hline 15457 & 1 & 4 & 000 & 1.69 & 0.046801 & 12 & 99 \\
\hline 15457 & 1 & 4 & 000 & 4.35 & 0.290374 & 12 & 99 \\
\hline 15458 & 1 & 4 & 000 & 3.44 & 0.374335 & 12 & 99 \\
\hline 15458 & 1 & 4 & 000 & 4.26 & 21.2791 & 12 & 99 \\
\hline 15458 & 1 & 4 & 000 & 4.26 & 2.597811 & 12 & 99 \\
\hline 15458 & 1 & 4 & 000 & 4.26 & 67.36977 & 12 & 99 \\
\hline 15458 & 1 & 4 & 000 & 4.26 & 0.373516 & 12 & 99 \\
\hline 15458 & 1 & 4 & 000 & 4.26 & 40.36723 & 12 & 99 \\
\hline 15460 & 1 & 4 & 000 & 2.83 & 2.948269 & 12 & 99 \\
\hline 15460 & 1 & 4 & 000 & 4.29 & 14.93406 & 12 & 99 \\
\hline 15461 & 1 & 4 & 000 & 1.55 & 12.73 & 12 & 99 \\
\hline 14356 & 3 & 4 & 000 & 11.28 & 0.014051 & 12 & 99 \\
\hline 14356 & 3 & 4 & 000 & 11.28 & 0.010471 & 12 & 99 \\
\hline 09621 & 1 & 1 & 000 & 6.04 & 0.105599 & 12 & 99 \\
\hline 09964 & 1 & 1 & 000 & 6.18 & 0.01714 & 12 & 99 \\
\hline 09964 & 1 & 1 & 000 & 6.18 & 0.279918 & 12 & 99 \\
\hline 09964 & 1 & 4 & 000 & 6.26 & 0.041696 & 12 & 99 \\
\hline 09964 & 1 & 1 & 000 & 6.18 & 0.013785 & 12 & 99 \\
\hline 09964 & 1 & 1 & 000 & 6.18 & 0.003883 & 12 & 99 \\
\hline 09964 & 1 & 1 & 000 & 6.18 & 0.005486 & 12 & 99 \\
\hline 09964 & 1 & 4 & 000 & 6.26 & 0.033371 & 12 & 99 \\
\hline 09993 & 3 & 1 & 000 & 10.29 & 0.246594 & 12 & 99 \\
\hline
\end{tabular}


SNF-4503 Rev. 1

\begin{tabular}{|c|c|c|c|c|c|c|c|}
\hline 09993 & 3 & 1 & 000 & 10.29 & 4.643864 & 12 & 99 \\
\hline 09993 & 3 & 1 & 000 & 10.29 & 3.572316 & 12 & 99 \\
\hline 10001 & 4 & 4 & 000 & 13.59 & 0.031624 & 12 & 99 \\
\hline 10001 & 4 & 4 & 000 & 13.59 & 0.031755 & 12 & 99 \\
\hline 10001 & 1 & 4 & 000 & 5.61 & 0.013364 & 12 & 99 \\
\hline 10001 & 4 & 4 & 000 & 13.59 & 0.029833 & 12 & 99 \\
\hline 10001 & 4 & 4 & 000 & 13.59 & 0.723905 & 12 & 99 \\
\hline 10001 & 1 & 4 & 000 & 5.61 & 0.019654 & 12 & 99 \\
\hline 10001 & 1 & 4 & 000 & 5.61 & 0.02194 & 12 & 99 \\
\hline 10001 & 4 & 4 & 000 & 13.59 & 0.007474 & 12 & 99 \\
\hline 10001 & 1 & 4 & 000 & 5.61 & 0.006289 & 12 & 99 \\
\hline 10001 & 4 & 4 & 000 & 13.59 & 0.014039 & 12 & 99 \\
\hline 10201 & 2 & 1 & 000 & 9.22 & 0.249793 & 12 & 99 \\
\hline 10201 & 2 & 1 & 000 & 9.22 & 0.490728 & 12 & 99 \\
\hline 10201 & 2 & 1 & 000 & 9.22 & 12.14053 & 12 & 99 \\
\hline 10201 & 2 & 1 & 000 & 9.22 & 1.236388 & 12 & 99 \\
\hline 10259 & 3 & 1 & 000 & 10.35 & 0.736071 & 12 & 99 \\
\hline 10259 & 3 & 1 & 000 & 10.35 & 2.228769 & 12 & 99 \\
\hline 10294 & 2 & $I$ & 000 & 9.8 & 19.0871 & 12 & 99 \\
\hline 10294 & 2 & 1 & 000 & 9.8 & 0.061858 & 12 & 99 \\
\hline 10350 & 3 & 1 & 000 & 10.65 & 0.011009 & 12 & 99 \\
\hline 10350 & 3 & 1 & 000 & 10.65 & 1.30869 & 12 & 99 \\
\hline 10350 & 3 & 1 & 000 & 10.65 & 13.58606 & 12 & 99 \\
\hline 10350 & 3 & 1 & 000 & 10.65 & 0.896723 & 12 & 99 \\
\hline 10350 & 3 & 1 & 000 & 10.65 & 0.005503 & 12 & 99 \\
\hline 10385 & 3 & 1 & 000 & 10.42 & 0.011227 & 12 & 99 \\
\hline 10385 & 3 & 1 & 000 & 10.42 & 7.494582 & 12 & 99 \\
\hline 10456 & 3 & 1 & 000 & 11.37 & 15.61247 & 12 & 99 \\
\hline 10456 & 3 & 1 & 000 & 11.37 & 0.958057 & 12 & 99 \\
\hline 10602 & 3 & 1 & 000 & 11.11 & 0.011238 & 12 & 99 \\
\hline 10602 & 3 & 1 & 000 & 11.11 & 13.86589 & 12 & 99 \\
\hline 10602 & 3 & 1 & 000 & 11.11 & 0.649808 & 12 & 99 \\
\hline 10679 & 3 & 1 & 000 & 11.76 & 0.163905 & 12 & 99 \\
\hline 10679 & 3 & 1 & 000 & 11.76 & 7.764973 & 12 & 99 \\
\hline 10679 & 3 & 1 & 000 & 11.76 & 3.558569 & 22 & 99 \\
\hline 10742 & 3 & 1 & 000 & 12.77 & 0.007962 & 12 & 99 \\
\hline 10742 & 3 & 1 & 000 & 12.77 & 0.210765 & 12 & 99 \\
\hline 10742 & 3 & 1 & 000 & 12.77 & 3.650096 & 12 & 99 \\
\hline 10742 & 3 & 1 & 000 & 12.77 & 2.783527 & 12 & 99 \\
\hline 10742 & 3 & 1 & 000 & 12.77 & 0.005285 & 12 & 99 \\
\hline 10770 & 4 & 1 & 000 & 13.16 & 0.010359 & 12 & 99 \\
\hline 10770 & 4 & 1 & 000 & 13.16 & 6.159879 & 12 & 99 \\
\hline 10770 & 4 & 1 & 000 & 13.16 & 2.009749 & 12 & 99 \\
\hline 10770 & 4 & 1 & 000 & 13.16 & 0.005106 & 12 & 99 \\
\hline 10832 & 3 & 1 & 000 & 12.92 & 13.07947 & 12 & 99 \\
\hline 10832 & 3 & 1 & 000 & 12.92 & 3.696517 & 12 & 99 \\
\hline 10982 & 4 & 1 & 000 & 13.73 & 0.020983 & 12 & 99 \\
\hline 10982 & 4 & 1 & 000 & 23.73 & 0.023391 & 12 & 99 \\
\hline 10982 & 4 & 1 & 000 & 13.73 & 16.49613 & 12 & 99 \\
\hline 10982 & 4 & 1 & 000 & 13.73 & 0.694274 & 12 & 99 \\
\hline 10982 & 4 & 1 & 000 & 13.73 & 0.010547 & 12 & 99 \\
\hline 11036 & 4 & 1 & 000 & 13.6 & 7.613446 & 12 & 99 \\
\hline 11109 & 4 & 1 & 000 & 13.7 & 0.468068 & 12 & 99 \\
\hline 11109 & 4 & 1 & 000 & 13.7 & 14.63286 & 12 & 99 \\
\hline 11109 & 4 & 1 & 000 & 13.7 & 0.005275 & 12 & 99 \\
\hline 11183 & 4 & 1 & 000 & 13.31 & 0.022094 & 12 & 99 \\
\hline 11183 & 4 & 1 & 000 & 13.31 & 0.678594 & 12 & 99 \\
\hline 11183 & 4 & 1 & 000 & 13.31 & 9.361327 & 12 & 99 \\
\hline 11183 & 4 & 1 & 000 & 13.31 & 0.24688 & 12 & 99 \\
\hline 11183 & 4 & 1 & 000 & 13.31 & 0.010881 & 12 & 99 \\
\hline 11372 & 4 & 1 & 000 & 13.77 & 0.690168 & 12 & 99 \\
\hline 11372 & 4 & 1 & 000 & 13.77 & 18.57126 & 12 & 99 \\
\hline 11372 & 4 & 1 & 000 & 13.77 & 0.709699 & 12 & 99 \\
\hline 11449 & 4 & 1 & 000 & 13.45 & 0.105257 & 12 & 99 \\
\hline
\end{tabular}


SNF-4503 Rev. 1

\begin{tabular}{|c|c|c|c|c|c|c|c|}
\hline 11449 & 4 & 1 & 000 & 13.45 & 18.58285 & 12 & 99 \\
\hline 11449 & 4 & 1 & 000 & 13.45 & 1.298701 & 12 & 99 \\
\hline 11540 & 4 & 1 & 000 & 13.26 & 12.48741 & 12 & 99 \\
\hline 11806 & 4 & 1 & 000 & 13.86 & 0.210315 & 12 & 99 \\
\hline 11806 & 4 & 1 & 000 & 13.86 & 19.23798 & 12 & 99 \\
\hline 11806 & 4 & 1 & 000 & 13.86 & 0.54114 & 12 & 99 \\
\hline 11897 & 4 & 1 & 000 & 14.4 & 0.023484 & 12 & 99 \\
\hline 11897 & 4 & 1 & 000 & 14.4 & 1.986457 & 12 & 99 \\
\hline 11897 & 4 & 1 & 000 & 14.4 & 17.69781 & 12 & 99 \\
\hline 11897 & 4 & 1 & 000 & 14.4 & 0.003856 & 12 & 99 \\
\hline 11979 & 4 & 1 & 000 & 14.27 & 0.007981 & 12 & 99 \\
\hline 11979 & 4 & 1 & 000 & 14.27 & 0.011234 & 12 & 99 \\
\hline 11979 & 4 & 1 & 000 & 14.27 & 0.010507 & 12 & 99 \\
\hline 11979 & 4 & 1 & 000 & 14.27 & 1.952108 & 12 & 99 \\
\hline 11979 & 4 & 1 & 000 & 14.27 & 14.49357 & 12 & 99 \\
\hline 11979 & 4 & 1 & 000 & 14.27 & 8.884854 & 12 & 99 \\
\hline 11979 & 4 & 1 & 000 & 14.27 & 0.010731 & 12 & 99 \\
\hline 12127 & 4 & 1 & 000 & 14.22 & 0.982493 & 12 & 99 \\
\hline 12127 & 4 & 1 & 000 & 14.22 & 13.32088 & 12 & 99 \\
\hline 12127 & 4 & 1 & 000 & 14.22 & 1.483142 & 12 & 99 \\
\hline 12201 & 4 & 1 & 000 & 13.24 & 0.748323 & 12 & 99 \\
\hline 12201 & 4 & 1 & 000 & 13.24 & 24.37494 & 12 & 99 \\
\hline 12285 & 4 & 1 & 000 & 13.17 & 0.246182 & 12 & 99 \\
\hline 12285 & 4 & 1 & 000 & 13.17 & 19.5675 & 12 & 99 \\
\hline 12480 & 4 & 1 & 000 & 13.78 & 0.022173 & 12 & 99 \\
\hline 12480 & 4 & 1 & 000 & 13.78 & 19.43003 & 12 & 99 \\
\hline 12565 & 4 & 1 & 000 & 13.7 & 0.011092 & 12 & 99 \\
\hline 12565 & 4 & 1 & 000 & 13.7 & 25.24008 & 12 & 99 \\
\hline 12639 & 4 & 1 & 000 & 13.06 & 0.011095 & 12 & 99 \\
\hline 12639 & 4 & 1 & 000 & 13.06 & 23.608 & 12 & 99 \\
\hline 12639 & 4 & 1 & 000 & 13.06 & 0.005465 & 12 & 99 \\
\hline 12823 & 4 & 1 & 000 & 13.17 & 7.213609 & 12 & 99 \\
\hline 12823 & 4 & 1 & 000 & 13.17 & 0.63684 & 12 & 99 \\
\hline 12852 & 4 & 1 & 000 & 13.01 & 10.86065 & 12 & 99 \\
\hline 12852 & 4 & 1 & 000 & 13.01 & 2.874132 & 12 & 99 \\
\hline 12852 & 4 & 4 & 000 & 13.42 & 0.047668 & 12 & 99 \\
\hline 12852 & 4 & 4 & 000 & 13.42 & 66.60527 & 12 & 99 \\
\hline 12852 & 4 & 4 & 000 & 13.42 & 0.373472 & 12 & 99 \\
\hline 12852 & 4 & 4 & 000 & 13.42 & 0.022424 & 12 & 99 \\
\hline 12942 & 4 & 1 & 000 & 13.03 & 0.740693 & 12 & 99 \\
\hline 12942 & 4 & 1 & 000 & 13.03 & 17.44634 & 12 & 99 \\
\hline 12942 & 4 & 1 & 000 & 13.03 & 2.250894 & 12 & 99 \\
\hline 12942 & 3 & 4 & 000 & 12.1 & 0.374625 & 12 & 99 \\
\hline 12942 & 3 & 4 & 000 & 12.82 & 0.370306 & 12 & 99 \\
\hline 12942 & 3 & 4 & 000 & 12.82 & 0.557199 & 12 & 99 \\
\hline 12942 & 3 & 4 & 000 & 12.82 & 50.14236 & 12 & 99 \\
\hline 12942 & 3 & 4 & 000 & 12.82 & 1.471475 & 12 & 99 \\
\hline 13015 & 4 & 4 & 000 & 13.19 & 0.010524 & 12 & 99 \\
\hline 13015 & 3 & 4 & 000 & 12.13 & 0.374619 & 12 & 99 \\
\hline 13015 & 4 & 4 & 000 & 13.19 & 4.595128 & 12 & 99 \\
\hline 13015 & 4 & 4 & 000 & 13.19 & 36.66284 & 12 & 99 \\
\hline 13015 & 4 & 4 & 000 & 13.19 & 2.61431 & 12 & 99 \\
\hline 13015 & 4 & 4 & 000 & 13.19 & 0.004952 & 12 & 99 \\
\hline 13016 & 4 & 1 & 000 & 13.18 & 0.764476 & 12 & 99 \\
\hline 13016 & 4 & 1 & 000 & 13.18 & 19.61489 & 12 & 99 \\
\hline 13016 & 4 & 1 & 000 & 13.18 & 0.248292 & 12 & 99 \\
\hline 13016 & 4 & 1 & 000 & 13.18 & 0.005246 & 12 & 99 \\
\hline 13016 & 4 & 1 & 000 & 13.18 & 0.015362 & 12 & 99 \\
\hline 13017 & 3 & 4 & 000 & 11.39 & 1.131855 & 12 & 99 \\
\hline 13017 & 3 & 4 & 000 & 11.39 & 25.42655 & 12 & 99 \\
\hline 13017 & 3 & 4 & 000 & 12.39 & 0.374331 & 12 & 99 \\
\hline 13371 & 3 & 1 & 000 & 12.95 & 0.015909 & 12 & 99 \\
\hline 13371 & 3 & 1 & 000 & 12.95 & 0.245652 & 12 & 99 \\
\hline 13371 & 3 & 1 & 000 & 12.95 & 4.723547 & 12 & 99 \\
\hline
\end{tabular}


SNF-4503 Rev. 1

\begin{tabular}{|c|c|c|c|c|c|c|c|}
\hline 13371 & 3 & 1 & 000 & 12.95 & 0.010241 & 12 & 99 \\
\hline 13372 & 4 & 4 & 000 & 13.02 & 0.01496 & 12 & 99 \\
\hline 13372 & 4 & 4 & 000 & 13.02 & 3.176879 & 12 & 99 \\
\hline 13372 & 4 & 4 & 000 & 13.02 & 11.79194 & 12 & 99 \\
\hline 13372 & 4 & 4 & 000 & 13.02 & 4.333318 & 12 & 99 \\
\hline 13372 & 4 & 4 & 000 & 13.02 & 0.004961 & 12 & 99 \\
\hline 13524 & 4 & 4 & 000 & 13.13 & 4.10635 & 12 & 99 \\
\hline 13524 & 4 & 4 & 000 & 13.13 & 2.929691 & 12 & 99 \\
\hline 13524 & 4 & 4 & 000 & 13.13 & 25.97653 & 12 & 99 \\
\hline 13524 & 4 & 4 & 000 & 13.13 & 4.639363 & 12 & 99 \\
\hline 13525 & 4 & 1 & 000 & 13.52 & 1.219785 & 12 & 99 \\
\hline 13525 & 4 & 1 & 000 & 13.52 & 16.37086 & 12 & 99 \\
\hline 13648 & 3 & 1 & 000 & 11.67 & 0.032575 & 12 & 99 \\
\hline 13650 & 4 & 1 & 000 & 13.41 & 1.438302 & 12 & 99 \\
\hline 13650 & 4 & 1 & 000 & 13.41 & 12.42106 & 12 & 99 \\
\hline 13650 & 4 & 1 & 000 & 13.41 & 2.724184 & 12 & 99 \\
\hline 13686 & 3 & 1 & 000 & 12.41 & 0.023387 & 12 & 99 \\
\hline 13686 & 3 & 1 & 000 & 12,41 & 17.62132 & 12 & 99 \\
\hline 13686 & 3 & 1 & 000 & 12.41 & 0.247753 & 12 & 99 \\
\hline 13724 & 1 & 1 & 000 & 5.99 & 0.015523 & 12 & 99 \\
\hline 13858 & 3 & 4 & 000 & 12.01 & 0.374632 & 12 & 99 \\
\hline 13858 & 3 & 4 & 000 & 12.04 & 3.127837 & 12 & 99 \\
\hline 13858 & 3 & 4 & 000 & 12.04 & 48.353 & 12 & 99 \\
\hline 13858 & 3 & 4 & 000 & 12.04 & 1.011267 & 12 & 99 \\
\hline 13858 & 3 & 4 & 000 & 12.04 & 0.004955 & 12 & 99 \\
\hline 13859 & 3 & 1 & 000 & 12.28 & 0.007927 & 12 & 99 \\
\hline 13859 & 3 & 1 & 000 & 12.28 & 0.011657 & 12 & 99 \\
\hline 13859 & 3 & 1 & 000 & 12.28 & 25.87721 & 12 & 99 \\
\hline 13859 & 3 & 1 & 000 & 12.28 & 3.751426 & 12 & 99 \\
\hline 13859 & 3 & 1 & 000 & 12.28 & 0.005246 & 12 & 99 \\
\hline 14055 & 1 & 4 & 000 & 2.39 & 0.327945 & 12 & 99 \\
\hline 14065 & 1 & 4 & 000 & 5.67 & 0.015902 & 12 & 99 \\
\hline 14065 & 1 & 4 & 000 & 5.67 & 0.071951 & 12 & 99 \\
\hline 14065 & 1 & 4 & 000 & 5.67 & 0.00446 & 12 & 99 \\
\hline 14065 & 1 & 4 & 000 & 5.67 & 0.024244 & 12 & 99 \\
\hline 14065 & 1 & 4 & 000 & 5.67 & 0.007021 & 12 & 99 \\
\hline 14448 & 1 & 4 & 000 & 5.99 & 0.012272 & 12 & 99 \\
\hline 14883 & 1 & 4 & 000 & 5.66 & 0.022262 & 12 & 99 \\
\hline 15204 & 1 & 4 & 000 & 5.92 & 0.015919 & 12 & 99 \\
\hline 15244 & 1 & 1 & 000 & 5.44 & 0.007949 & 12 & 99 \\
\hline 15244 & 1 & 1 & 000 & 5.44 & 0.01126 & 12 & 99 \\
\hline 15244 & 1 & 1 & 000 & 5.44 & 0.042169 & 12 & 99 \\
\hline 15244 & 1 & 1 & 000 & 5.44 & 0.02338 & 12 & 99 \\
\hline 15244 & 1 & 1 & 000 & 5.44 & 0.132474 & 12 & 99 \\
\hline 15244 & 1 & 1 & 000 & 5.44 & 0.124027 & 12 & 99 \\
\hline 15244 & 1 & 1 & 000 & 5.44 & 0.007481 & 12 & 99 \\
\hline 15244 & 1 & 1 & 000 & 5.44 & 0.004961 & 12 & 99 \\
\hline 15244 & 4 & 4 & 000 & 13.58 & 0.007019 & 12 & 99 \\
\hline 15347 & 1 & 1 & 000 & 6.16 & 0.007949 & 12 & 99 \\
\hline 15347 & 1 & 1 & 000 & 6.16 & 0.01169 & 12 & 99 \\
\hline 15347 & 1 & 1 & 000 & 6.16 & 0.083168 & 12 & 99 \\
\hline 15347 & 1 & 1 & 000 & 6.16 & 0.031137 & 12 & 99 \\
\hline 15347 & 1 & 1 & 000 & 6.16 & 0.010645 & 12 & 99 \\
\hline 15445 & 1 & 1 & 000 & 5.23 & 1.297919 & 12 & 99 \\
\hline 15445 & 1 & 1 & 000 & 5.23 & 0.669493 & 12 & 99 \\
\hline 15448 & 1 & 1 & 000 & 4.54 & 0.008002 & 12 & 99 \\
\hline 15448 & 1 & 1 & 000 & 4.54 & 0.015812 & 12 & 99 \\
\hline 15448 & 1 & 1 & 000 & 4.54 & 0.003766 & 12 & 99 \\
\hline 15448 & 1 & 1 & 000 & 4.54 & 0.005327 & 12 & 99 \\
\hline 15451 & 1 & 1 & 000 & 5.31 & 0.46584 & 12 & 99 \\
\hline 15457 & 1 & 1 & 000 & 2.85 & 0.033293 & 12 & 99 \\
\hline 15459 & 1 & 1 & 000 & 4.06 & 25.28046 & 12 & 99 \\
\hline 15459 & $I$ & 1 & 000 & 4.06 & 8.661046 & 12 & 99 \\
\hline 15460 & 1 & 1 & 000 & 3.32 & 2.097296 & 12 & 99 \\
\hline
\end{tabular}


SNF-4503 Rev. 1

$\begin{array}{llllllll}15555 & 1 & 1 & 000 & 4 & 0.008002 & 12 & 99 \\ 15555 & 1 & 1 & 000 & 4 & 0.01132 & 12 & 99 \\ 11540 & 4 & 4 & 000 & 16.49 & 0.031623 & 12 & 99 \\ 11540 & 4 & 4 & 000 & 16.49 & 6.873061 & 12 & 99 \\ 11540 & 4 & 4 & 000 & 16.49 & 0.984106 & 12 & 99 \\ 11540 & 4 & 4 & 000 & 13.73 & 0.009902 & 12 & 99 \\ 11540 & 4 & 4 & 000 & 16.49 & 3.241216 & 12 & 99 \\ 11540 & 4 & 4 & 000 & 16.49 & 0.456485 & 12 & 99 \\ 12565 & 4 & 4 & 000 & 16.72 & 6.674973 & 12 & 99 \\ 12565 & 4 & 4 & 000 & 16.72 & 0.175589 & 12 & 99 \\ 12852 & 4 & 4 & 000 & 16.62 & 4.201198 & 12 & 99\end{array}$

The output file is included below:

\begin{tabular}{|c|c|c|}
\hline (1) & 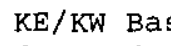 & \\
\hline Results & decayec & $05 / 31 /$ \\
\hline Total 1 & & 2099.1 \\
\hline Total & uries & $5.50 D+07$ \\
\hline Total & $\Gamma U$ & $5.49 D+05$ \\
\hline I sotop & Curies & BTUs \\
\hline $\mathrm{H}-3$ & $3.59 D+04$ & $4.12 \mathrm{D}+00$ \\
\hline$C-14$ & $2.35 D-02$ & $2.34 \mathrm{D}-05$ \\
\hline $\mathrm{Se}-79$ & $8.62 D+01$ & $9.07 D-02$ \\
\hline $\mathrm{Kr}-85$ & $5.90 D+05$ & $3.02 D+03$ \\
\hline $5 x-89$ & $0.00 D+00$ & $0.00 D+00$ \\
\hline $5 r-90$ & $1.01 D+07$ & $4.01 D+04$ \\
\hline$Y-90$ & $1.01 D+07$ & $1.91 D+05$ \\
\hline$Y-91$ & $2.23 D-14$ & $2.73 D-16$ \\
\hline Zr-93 & $3.87 D+02$ & $1.52 D-01$ \\
\hline $\mathrm{Nb}-93 \mathrm{~m}$ & $2.39 D+02$ & $1.46 D-01$ \\
\hline Zr-95 & $1.67 D-12$ & $2.87 D-14$ \\
\hline $\mathrm{Nb}-95$ & $3.70 D-12$ & $6.06 \mathrm{D}-14$ \\
\hline $\mathrm{Nb}-95 \mathrm{~m}$ & $1.24 D-14$ & $5.57 D-17$ \\
\hline TC-99 & $2.88 D+03$ & $4.93 D+00$ \\
\hline $2 u-103$ & $0.00 D+00$ & $0.00 D+00$ \\
\hline $\mathrm{Rh}-103 \mathrm{~m}$ & $0.00 D+00$ & $0.00 \mathrm{D}+00$ \\
\hline Ru- 106 & $1.82 D+03$ & $3.70 D-01$ \\
\hline Rh- 106 & $1.82 \mathrm{D}+03$ & $5.94 \mathrm{D}+01$ \\
\hline$P d-107$ & $1.63 D+01$ & $3.05 D-03$ \\
\hline $\mathrm{Ag}-110$ & $2.84 D-04$ & $7.27 D-09$ \\
\hline $\mathrm{Ag}-110 \mathrm{~m}$ & $2.14 D-02$ & $1.21 D-0.3$ \\
\hline $\mathrm{Cd}-113 \mathrm{~m}$ & $3.55 D+03$ & $1.33 \mathrm{D}+01$ \\
\hline Cd-115m & $0.00 D+00$ & $0.00 D+00$ \\
\hline $3 n-119 m$ & $2.76 \mathrm{D}-02$ & $4.85 D-05$ \\
\hline $\mathrm{Sn}-121 \mathrm{~m}$ & $2.69 D+01$ & $9.64 \mathrm{D}-02$ \\
\hline$S n-123$ & $1.74 \mathrm{D}-05$ & $1.85 D-07$ \\
\hline $\mathrm{Te}-123 \mathrm{~m}$ & $2.76 \mathrm{D}-11$ & $1.36 \mathrm{D}-13$ \\
\hline$S b-124$ & $3.03 D-18$ & $1.37 D-19$ \\
\hline$S b-125$ & $3.23 \mathrm{D}+04$ & $3.47 D+02$ \\
\hline $\mathrm{Te}-125 \mathrm{~m}$ & $7.89 D+03$ & $2.27 D+01$ \\
\hline $\mathrm{Sn}-126$ & $1.56 \mathrm{D}+02$ & $1.63 \mathrm{D}-01$ \\
\hline$S b-126$ & $2.18 D+01$ & $1.35 D+00$ \\
\hline$S b-126 m$ & $1.56 \mathrm{D}+02$ & $6.81 D+00$ \\
\hline $\mathrm{Te}-127$ & $9.49 D-07$ & $4.37 D-09$ \\
\hline $\mathrm{Te}-127 \mathrm{~m}$ & $9.68 \mathrm{D}-07$ & $1.64 \mathrm{D}-09$ \\
\hline $\mathrm{Te}-129$ & $0.000+00$ & $0.000+00$ \\
\hline $\mathrm{Te}-129 \mathrm{~m}$ & $0.00 D+00$ & $0.000+00$ \\
\hline I - 129 & $6.37 \mathrm{D}+00$ & $1.02 D-02$ \\
\hline $\mathrm{Cs}-134$ & $1.59 D+04$ & $5.54 D+02$ \\
\hline $\mathrm{Cs}-135$ & $7.75 D+01$ & $8.84 D-02$ \\
\hline $\mathrm{Cs}-137$ & $1.32 \mathrm{D}+07$ & $4.55 D+04$ \\
\hline $\mathrm{Ba}-137 \mathrm{~m}$ & $1.25 D+07$ & $1.67 D+05$ \\
\hline
\end{tabular}


SNF-4503 Rev. 1

\begin{tabular}{|c|c|c|}
\hline $\mathrm{Ce}-141$ & $0.00 D+00$ & $0.00 D+00$ \\
\hline Pr- 143 & $0.00 D+00$ & $0.00 D+00$ \\
\hline $\mathrm{Ce}-144$ & $9.14 D+02$ & $2.060+00$ \\
\hline Pr- 144 & $9.03 D+02$ & $2.26 \mathrm{D}+01$ \\
\hline $\operatorname{Pr}-144 \mathrm{~m}$ & $1.10 D+01$ & 1. 26D-02 \\
\hline $\mathrm{Pm}-147$ & $4.62 D+05$ & $5.79 D+02$ \\
\hline Pm- 148 & $0.00 D+00$ & $0.00 \mathrm{D}+00$ \\
\hline $\mathrm{Pm}-148 \mathrm{~m}$ & $0.00 D+00$ & $0.00 D+00$ \\
\hline $\mathrm{Sm}-151$ & $1.76 \mathrm{D}+05$ & $7.02 D+01$ \\
\hline$E u-152$ & $9.45 \mathrm{D}+02$ & $1.46 \mathrm{D}+01$ \\
\hline Gd-153 & $1.28 D-04$ & $3.94 \mathrm{D}-07$ \\
\hline $\mathrm{Eu}-154$ & $1.07 D+05$ & $3.29 D+03$ \\
\hline Eu- 155 & $2.21 D+04$ & $5.45 D+01$ \\
\hline $\mathrm{Tb}-160$ & $2.77 D-15$ & $7.55 \mathrm{D}-17$ \\
\hline $\mathrm{H}-3$ & $7.24 \mathrm{D}+02$ & $8.31 D-02$ \\
\hline$C-14$ & $6.93 D+02$ & $6.91 D-01$ \\
\hline $\mathrm{Fe}-55$ & $1.84 \mathrm{D}+03$ & $2.09 D-01$ \\
\hline $\mathrm{Ni}-59$ & $4.10 D+01$ & $5.55 \mathrm{D}-03$ \\
\hline $\mathrm{Co}-60$ & $3.96 \mathrm{D}+03$ & $2.0 \mathrm{BD}+02$ \\
\hline $\mathrm{Ni}-63$ & $4.49 D+03$ & $1.55 \mathrm{D}+00$ \\
\hline $2 r-93$ & $1.32 \mathrm{D}+01$ & $5.20 D-03$ \\
\hline $\mathrm{Nb}-93 \mathrm{~m}$ & $8.18 D+00$ & $5.00 D-03$ \\
\hline $\operatorname{Zr}-95$ & $1.63 D-14$ & $2.81 D-16$ \\
\hline $\mathrm{Nb}-95$ & $3.63 \mathrm{D}-14$ & $5.94 D-16$ \\
\hline $\mathrm{Nb}-95 \mathrm{~m}$ & $1.21 D-16$ & $5.47 D-19$ \\
\hline In-113m & $2.14 \mathrm{D}-07$ & $1.69 D-09$ \\
\hline$S n-113$ & $2.14 D-07$ & $1.21 D-10$ \\
\hline $\mathrm{Sn}-119 \mathrm{~m}$ & $2.69 D-01$ & $4.73 D-04$ \\
\hline$S n-121 m$ & $5.27 D+01$ & $1.890-01$ \\
\hline$S b-125$ & $1.19 D+03$ & $1.27 D+01$ \\
\hline $\mathrm{Te}-125 \mathrm{~m}$ & $2.89 D+02$ & $8.32 D-01$ \\
\hline $\mathrm{U}-234$ & $8.74 \mathrm{D}+02$ & $8.44 D+01$ \\
\hline$U-235$ & $3.37 D+01$ & $3.12 \mathrm{D}+00$ \\
\hline$U-236$ & $1.27 D+02$ & $1.16 \mathrm{D}+01$ \\
\hline $\mathrm{U}-238$ & $6.96 \mathrm{D}+02$ & $5.92 \mathrm{D}+01$ \\
\hline$N p-237$ & $5.72 \mathrm{D}+01$ & $5.63 \mathrm{D}+00$ \\
\hline $\mathrm{Pu}-238$ & $1.11 D+05$ & $1.24 D+04$ \\
\hline $\mathrm{Pu}-239$ & $2.51 D+05$ & $2.62 \mathrm{D}+04$ \\
\hline $\mathrm{Pu}-240$ & $1.44 \mathrm{D}+05$ & $1.51 D+04$ \\
\hline$P u-241$ & $6.68 \mathrm{D}+06$ & $7.07 D+02$ \\
\hline $\mathrm{Pu}-242$ & $5.49 D+01$ & $5.45 \mathrm{D}+00$ \\
\hline$A m-241$ & $3.75 D+05$ & $4.19 D+04$ \\
\hline$A m-242 m$ & $1.96 \mathrm{D}+02$ & $1.02 \mathrm{D}+00$ \\
\hline$A m-242$ & $1.95 D+02$ & $5.53 \mathrm{D}+00$ \\
\hline$A m-243$ & $1.20 D+02$ & $1.30 D+01$ \\
\hline $\mathrm{Cm}-242$ & $1.62 \mathrm{D}+02$ & $2.00 D+01$ \\
\hline $\mathrm{Cm}-244$ & $1.44 \mathrm{D}+03$ & $1.69 D+02$ \\
\hline
\end{tabular}

This calculation includes both Mark IV and Mark IA fuel types, exposures up to $16 \mathrm{wt} \%{ }^{240} \mathrm{Pu}$, and (because various discharge dates are decayed to one common final date) decay times of between 10 30 years. The output matches the previously reported results extremely well, which satisfies the acceptance criterion. Out of $89 \times 2=178$ numerical values output, there were four numbers that did not match exactly, but only differed by " 1 " in the second decimal place. This is considered to be extremely good agreement (and might be due to roundoff error arising from compiler differences). 


\section{2. $\mathrm{HNF}-3035$}

Two of the 11 cases reported in Appendix C of Packer (1998) were executed using RADNUC2-A, for keys 13016 (Mark IA fuel) and 13372 (Mark IV fuel). For both of these keys, perfect agreement was shown, for both total curies and decay heat loading. No anomalies were found. For key 13016, the reported activity level is $6.41 \times 10^{5} \mathrm{Ci}$ and the decay heat loading was equal to $6.40 \times 10^{3} \mathrm{Btu} / \mathrm{hr}$. The input file for this key is shown below:

\begin{tabular}{|c|c|c|c|c|c|c|c|}
\hline "Key" & "Grade" & "Fuel" & "Pieces" & $" 8 \mathrm{Pu}-240 "$ & "Uranium" & "Mo" & "Yr" \\
\hline 13016 & 4 & 1 & 000 & 13.180 & 0.764476 & 12 & 99 \\
\hline 13016 & 4 & 1 & 000 & 13.180 & 19.61489 & 12 & 99 \\
\hline 13016 & 4 & 1 & 000 & 13.180 & 0.248292 & 12 & 99 \\
\hline 13016 & 4 & 1 & 000 & 13.180 & 0.005246 & 12 & 99 \\
\hline 13016 & 4 & 1 & 000 & 13.180 & 0.015362 & 12 & 99 \\
\hline
\end{tabular}

When the verified and validated copy of RADNUC2-A was executed on this problem, the following output file was produced:

\begin{tabular}{|c|c|c|}
\hline \multicolumn{3}{|c|}{$\begin{array}{l}\text { Resting } \ldots \\
\text { Results de }\end{array}$} \\
\hline \multicolumn{3}{|c|}{ Total MTU } \\
\hline \multicolumn{2}{|c|}{ Total Curies } & $6.41 D+05$ \\
\hline \multicolumn{2}{|c|}{ Total BTU } & $6.40 D+03$ \\
\hline ope & Curies & BTUS \\
\hline $\mathrm{H}-3$ & $4.08 D+02$ & $4.68 \mathrm{D}-02$ \\
\hline$C-14$ & $2.78 D-04$ & $2.77 D \sim 07$ \\
\hline Se-79 & $1.02 \mathrm{D}+00$ & $1.07 D-03$ \\
\hline $\mathrm{Kr}-85$ & $6.88 \mathrm{D}+03$ & $3.52 \mathrm{D}+01$ \\
\hline Sr-89 & $0.00 D+00$ & $0.00 D+00$ \\
\hline$S r-90$ & $1.22 D+05$ & $4.83 D+02$ \\
\hline$Y-90$ & $1.22 D+05$ & $2.30 D+03$ \\
\hline$Y-91$ & $0.00 D+00$ & $0.000+00$ \\
\hline Zr-93 & $4.65 D+00$ & $1.82 \mathrm{D}-03$ \\
\hline$N b-93 m$ & $2.90 D+00$ & $1.770-03$ \\
\hline$z x-95$ & $0.00 D+00$ & $0.00 D+00$ \\
\hline $\mathrm{Nb}-95$ & $0.00 D+00$ & $0.00 D+00$ \\
\hline $\mathrm{Nb}-95 \mathrm{~m}$ & $0.00 D+00$ & $0.00 D+00$ \\
\hline Tc-99 & $3.41 \mathrm{D}+01$ & $5.84 D-02$ \\
\hline Ru-103 & $0.00 D+00$ & $0.00 D+00$ \\
\hline $\mathrm{Rh}-103 \mathrm{~m}$ & $0.00 D+00$ & $0.00 D+00$ \\
\hline$R u-106$ & $9.78 D-01$ & $1.99 D-04$ \\
\hline Rh- 106 & $9.78 D-01$ & $3.19 D-02$ \\
\hline Pd- 107 & $1.77 D-01$ & $3.32 D-05$ \\
\hline $\mathrm{Ag}-110$ & $2.74 D-08$ & $7.01 \mathrm{D}-13$ \\
\hline $\mathrm{Ag}-110 \mathrm{~m}$ & $2.06 \mathrm{D}-06$ & $1.17 D-07$ \\
\hline $\mathrm{cd}-113 \mathrm{~m}$ & $3.82 \mathrm{D}+01$ & 1. $43 \mathrm{D}-01$ \\
\hline$c d-115 m$ & $0.00 D+00$ & $0.00 D+00$ \\
\hline$S n-119 m$ & $5.15 \mathrm{D}=07$ & $9.06 \mathrm{D}-10$ \\
\hline $\mathrm{Sn}-121 \mathrm{~m}$ & $3.03 D-01$ & $1.08 D-03$ \\
\hline$S n-123$ & $6.48 \mathrm{D}-14$ & $6.90 D-16$ \\
\hline $\mathrm{Te}-123 \mathrm{~m}$ & $2.43 D-19$ & $1.200-21$ \\
\hline $\mathrm{Sb}-124$ & $0.00 D+00$ & $0.000+00$ \\
\hline$S b-125$ & $2.34 D+02$ & $2.51 D+00$ \\
\hline $\mathrm{Te}-125 \mathrm{~m}$ & $5.72 D+01$ & $1.64 \mathrm{D}-01$ \\
\hline $5 n-126$ & $1.75 D+00$ & $1.83 D-03$ \\
\hline$S b-126$ & $2.44 \mathrm{D}-01$ & $1.51 \mathrm{D}-02$ \\
\hline
\end{tabular}


SNF-4503 Rev. 1

\begin{tabular}{|c|c|c|}
\hline $\mathrm{Sb}-126 \mathrm{~m}$ & $1.75 D+00$ & $7.63 D-02$ \\
\hline Te-127 & $1.40 \mathrm{D}-16$ & $6.45 \mathrm{D}-19$ \\
\hline $\mathrm{Te}-127 \mathrm{~m}$ & $1.43 \mathrm{D}-16$ & $2.41 D-19$ \\
\hline $\mathrm{Te}-129$ & $0.00 D+00$ & $0.00 D+00$ \\
\hline $\mathrm{Te}-129 \mathrm{~m}$ & $0.000+00$ & $0.00 D+00$ \\
\hline$I-129$ & $7.35 \mathrm{D}-02$ & $1.17 \mathrm{D}-04$ \\
\hline $\mathrm{Cs}-134$ & $1.13 D+02$ & $3.94 D+00$ \\
\hline $\mathrm{Cs}-135$ & $8.90 D-01$ & $1.02 \mathrm{D}-03$ \\
\hline $\mathrm{Cs}-137$ & $1.55 \mathrm{D}+05$ & $5.36 D+02$ \\
\hline $8 a-137 m$ & $1.47 D+05$ & $1.97 \mathrm{D}+03$ \\
\hline $\mathrm{Ce}-141$ & $0.00 D+00$ & $0.00 D+00$ \\
\hline $\operatorname{Pr}-143$ & $0.00 D+00$ & $0.00 \mathrm{D}+00$ \\
\hline $\mathrm{Ce}-144$ & $6.01 D-02$ & $1.35 \mathrm{D}-04$ \\
\hline $\operatorname{Pr}-144$ & $5.94 D-02$ & $1.49 \mathrm{D}-03$ \\
\hline Pr $-144 \mathrm{~m}$ & $7.21 \mathrm{D}-04$ & $8.27 D-07$ \\
\hline Pm- 147 & $3.08 D+03$ & $3.86 \mathrm{D}+00$ \\
\hline$P m-148$ & $0.00 D+00$ & $0.00 \mathrm{D}+00$ \\
\hline Pm-148m & $0.00 D+00$ & $0.00 \mathrm{D}+00$ \\
\hline$S m-151$ & $1.99 D+03$ & $7.96 D-01$ \\
\hline Eu-152 & $1.07 \mathrm{D}+01$ & $1.65 \mathrm{D}-01$ \\
\hline Gd-253 & $1.88 D-08$ & $5.77 \mathrm{D}-11$ \\
\hline Eu-154 & $1.17 D+03$ & $3.58 \mathrm{D}+01$ \\
\hline Eu- 155 & $2.04 D+02$ & $5.03 \mathrm{D}-01$ \\
\hline $\mathrm{Tb}-160$ & $0.00 D+00$ & $0.00 D+00$ \\
\hline $\mathrm{H}-3$ & $7.39 D+00$ & $8.48 D-04$ \\
\hline$C-14$ & $7.59 D+00$ & $7.56 \mathrm{D}-03$ \\
\hline $\mathrm{Fe}-55$ & $1.21 D+01$ & $1.38 D-03$ \\
\hline $\mathrm{Ni}-59$ & $4.63 D-01$ & $6.28 D-05$ \\
\hline Co- 60 & $4.28 D+01$ & $2.25 D+00$ \\
\hline $\mathrm{Ni}-63$ & $5.06 \mathrm{D}+01$ & $1.75 \mathrm{D}-02$ \\
\hline Zr-93 & $1.61 \mathrm{D}-01$ & $6.32 \mathrm{D}-05$ \\
\hline $\mathrm{Nb}-93 \mathrm{~m}$ & $1.00 D-01$ & $6.14 D-05$ \\
\hline $2 r-95$ & $0.00 D+00$ & $0.00 \mathrm{D}+00$ \\
\hline $\mathrm{Nb}-95$ & $0.00 D+00$ & $0.00 \mathrm{D}+00$ \\
\hline $\mathrm{Nb}-95 \mathrm{~m}$ & $0.00 D+00$ & $0.00 \mathrm{D}+00$ \\
\hline In-113m & 8. $71 D-17$ & $6.87 D-19$ \\
\hline$S n-113$ & $8.71 D-17$ & $4.93 D-20$ \\
\hline Sn-119m & $5.05 \mathrm{D}-06$ & $8.87 D-09$ \\
\hline $\mathrm{Sn}-121 \mathrm{~m}$ & $6.26 D-01$ & $2.24 D-03$ \\
\hline$S b-125$ & $8.95 D+00$ & $9.59 D-02$ \\
\hline $\mathrm{Te}-125 \mathrm{~m}$ & $2.18 D+00$ & $6.28 D-03$ \\
\hline$U-234$ & $9.08 \mathrm{D}+00$ & $8.77 D-01$ \\
\hline$U-235$ & $3.61 \mathrm{D}-01$ & $3.34 \mathrm{D}-02$ \\
\hline$U-236$ & $1.40 D+00$ & $1.28 \mathrm{D}-01$ \\
\hline$U-238$ & $6.83 D+00$ & $5.81 D-01$ \\
\hline$N p-237$ & $6.13 D-01$ & $6.03 D-02$ \\
\hline Pu -238 & $1.14 \mathrm{D}+03$ & 1. $27 \mathrm{D}+02$ \\
\hline Pu-239 & $2.67 D+03$ & $2.78 D+02$ \\
\hline $\mathrm{Eu}-240$ & $1.55 \mathrm{D}+03$ & $1.61 D+02$ \\
\hline $\mathrm{Pu}-241$ & $7.09 D+04$ & $7.50 \mathrm{D}+00$ \\
\hline $\mathrm{Pu}-242$ & $5.41 \mathrm{D}-01$ & $5.37 D-02$ \\
\hline Am- 241 & $3.98 D+03$ & $4.46 \mathrm{D}+02$ \\
\hline $\mathrm{Am}-242 \mathrm{~m}$ & $1.72 D+00$ & $8.99 D-03$ \\
\hline$A m-242$ & $1.71 D+00$ & $4.86 \mathrm{D}-02$ \\
\hline Am- 243 & $1.01 \mathrm{D}+00$ & $1.09 \mathrm{D}-01$ \\
\hline $\mathrm{Cm}-242$ & $1.42 \mathrm{D}+00$ & $1.76 \mathrm{D}-01$ \\
\hline$n-244$ & $1.01 D+01$ & $1.19 D+00$ \\
\hline
\end{tabular}


For key 13372 , the reported activity level is $5.38 \times 10^{5} \mathrm{Ci}$ and the decay heat loading was equal to $5.35 \times 10^{3} \mathrm{Btu} / \mathrm{hr}$. The input file for this key is shown below:

"105-K Basins charge data"

$\begin{array}{lccccccc}\text { "Key" } & \text { "Grade" } & \text { "Fuel" } & \text { "Pieces" } & \text { "Pu-240" } & \text { "Uranium" } & \text { "Mo" } & \text { "Yr" } \\ 13372 & 4 & 4 & 000 & 13.020 & 0.01496 & 12 & 99 \\ 13372 & 4 & 4 & 000 & 13.020 & 3.176879 & 12 & 99 \\ 13372 & 4 & 4 & 000 & 13.020 & 11.79194 & 12 & 99 \\ 13372 & 4 & 4 & 000 & 13.020 & 4.333318 & 12 & 99 \\ 13372 & 4 & 4 & 000 & 13.020 & 0.004961 & 12 & 99\end{array}$

When the verified and validated copy of RADNUC2-A was executed on this problem, the following output file was produced:

$\begin{array}{lll}\text { Testing } & \ldots & \\ \text { Results } & \text { decayed } & \\ \text { Total } & \text { MTU } & 11 / 30 / 2000 \\ \text { Total } & \text { Curies } & 5.38 D+05 \\ \text { Total } & \text { BTU } & 5.35 D+03 \\ & & \\ \text { Isotope } & \text { Curies } & \text { BTUs } \\ \text { H-3 } & 3.59 D+02 & 4.11 D-02 \\ \text { C-14 } & 2.26 D-04 & 2.25 D-07 \\ \text { Se-79 } & 8.30 D-01 & 8.72 D-04 \\ \text { Kr-85 } & 5.79 D+03 & 2.96 D+01 \\ \text { Sr-89 } & 0.00 D+00 & 0.00 D+00 \\ \text { Sr-90 } & 9.80 D+04 & 3.88 D+02 \\ \text { Y-90 } & 9.80 D+04 & 1.85 D+03 \\ \text { Y-91 } & 0.00 D+00 & 0.00 D+00 \\ \text { Zr-93 } & 3.70 D+00 & 1.45 D-03 \\ \text { Nb-93m } & 2.25 D+00 & 1.38 D-03 \\ \text { Zr-95 } & 0.00 D+00 & 0.00 D+00 \\ \text { Nb-95 } & 0.00 D+00 & 0.00 D+00 \\ \text { Nb-95m } & 0.00 D+00 & 0.00 D+00 \\ \text { TC-99 } & 2.77 D+01 & 4.74 D-02 \\ \text { Ru-103 } & 0.00 D+00 & 0.00 D+00 \\ \text { Rh-103m } & 0.00 D+00 & 0.00 D+00 \\ \text { Ru-106 } & 1.70 D+00 & 3.46 D-04 \\ \text { Rh-106 } & 1.70 D+00 & 5.55 D-02 \\ \text { Pd-107 } & 1.61 D-01 & 3.02 D-05 \\ \text { Ag-110 } & 6.79 D-08 & 1.74 D-12 \\ \text { Ag-110m } & 5.11 D-06 & 2.89 D-07 \\ \text { Cd-113m } & 3.63 D+01 & 1.36 D-01 \\ \text { Cd-115m } & 0.00 D+00 & 0.00 D+00 \\ \text { Sn-119m } & 1.25 D-06 & 2.20 D-09 \\ \text { Sn-121m } & 2.67 D-01 & 9.55 D-04 \\ \text { Sn-123 } & 3.77 D-13 & 4.01 D-15 \\ \text { Te-123m } & 1.81 D-18 & 8.94 D-21 \\ \text { Sb-124 } & 0.00 D+00 & 0.00 D+00 \\ \text { Sb-125 } & 2.66 D+02 & 2.85 D+00 \\ \text { Te-125m } & 6.49 D+01 & 1.87 D-01 \\ \text { Sn-126 } & 1.53 D+00 & 1.61 D-03 \\ \text { Sb-126 } & 2.14 D-01 & 1.33 D-02 \\ \text { Sb-126m } & 1.53 D+00 & 6.69 D-02 \\ \text { Te-127 } & 1.14 D-15 & 5.26 D-18 \\ \text { Te-127m } & 1.16 D-15 & 1.97 D-18 \\ \text { Te-129 } & 0.00 D+00 & 0.00 D+00 \\ \text { Te-129m } & 0.00 D+00 & 0.00 D+00 \\ \text { I-129 } & 6.19 D-02 & 9.89 D-05 \\ \text { Cs-134 } & 1.28 D+02 & 4.44 D+00 \\ & & \end{array}$


SNF-4503 Rev, 1

\begin{tabular}{|c|c|c|}
\hline $\mathrm{Cs}-135$ & $7.55 \mathrm{D}-01$ & \\
\hline $\mathrm{Cs}-137$ & $1.29 D+05$ & $4.45 \mathrm{D}+02$ \\
\hline $\mathrm{Ba}-137 \mathrm{~m}$ & $1.22 \mathrm{D}+05$ & $1.63 D+03$ \\
\hline$C e-141$ & $0.00 D+00$ & $0.00 D+00$ \\
\hline $\operatorname{Pr}-143$ & $0.00 D+00$ & $0.00 D+00$ \\
\hline $\mathrm{Ce}-144$ & $1.13 \mathrm{D}-01$ & $2.54 \mathrm{D}-04$ \\
\hline $\operatorname{Pr}-144$ & $1.11 \mathrm{D}-01$ & $2.79 D-03$ \\
\hline $\mathrm{Pr}-144 \mathrm{~m}$ & $1.35 D-03$ & $1.55 D-06$ \\
\hline $\mathrm{Pm}-147$ & $3.22 D+03$ & $4.04 D+00$ \\
\hline$P m-148$ & $0.00 D+00$ & $0.00 D+00$ \\
\hline $\mathrm{Pm}-148 \mathrm{~m}$ & $0.00 D+00$ & $0.00 \mathrm{D}+00$ \\
\hline$S m-151$ & $1.71 D+03$ & $6.84 \mathrm{D}-01$ \\
\hline$E u-152$ & $9.76 \mathrm{D}+00$ & $1.51 D-01$ \\
\hline Gd- 153 & $4.60 D-08$ & $1.42 \mathrm{D}-10$ \\
\hline EL- 154 & $1.07 D+03$ & $3.29 D+01$ \\
\hline Eu- 155 & $2.05 D+02$ & $5.05 D-01$ \\
\hline $\mathrm{Tb}-160$ & $0.00 D+00$ & $0.00 D+00$ \\
\hline $\mathrm{H}-3$ & $7.49 D+00$ & $8.59 D-04$ \\
\hline$C-14$ & $6.89 D+00$ & $6.87 D-03$ \\
\hline $\mathrm{Fe}-55$ & $1.39 \mathrm{D}+01$ & $1.58 \mathrm{D}-03$ \\
\hline $\mathrm{Ni}-59$ & $4.02 \mathrm{D}-01$ & $5.44 \mathrm{D}-05$ \\
\hline $\mathrm{Co}-60$ & $3.74 \mathrm{D}+01$ & $1.97 \mathrm{D}+00$ \\
\hline $\mathrm{Ni}-63$ & $4.43 D+01$ & $1.53 \mathrm{D}-02$ \\
\hline $2 x-93$ & $1.25 \mathrm{D}-01$ & $4.92 D-05$ \\
\hline $\mathrm{Nb}-93 \mathrm{~m}$ & $7.61 \mathrm{D}-02$ & $4.65 D-05$ \\
\hline$z x-95$ & $0.00 D+00$ & $0.00 D+00$ \\
\hline $\mathrm{Nb}-95$ & $0.00 D+00$ & $0.00 D+00$ \\
\hline $\mathrm{Nb}-95 \mathrm{~m}$ & $0.00 D+00$ & $0.00 D+00$ \\
\hline $\operatorname{In}-113 \mathrm{~m}$ & $5.78 D-16$ & $4.56 D-18$ \\
\hline $\operatorname{sn}-113$ & $5.77 D-16$ & $3.27 D-19$ \\
\hline $\operatorname{Sn}-119 m$ & $1.100-05$ & $1.93 D-08$ \\
\hline $\mathrm{Sn}-121 \mathrm{~m}$ & $5.09 D-01$ & $1.83 D-03$ \\
\hline$S b-125$ & $9.16 \mathrm{D}+00$ & $9.82 \mathrm{D}-02$ \\
\hline $\mathrm{Te}-125 \mathrm{~m}$ & $2.24 D+00$ & $6.42 \mathrm{D}-03$ \\
\hline $\mathrm{U}-234$ & $7.73 \mathrm{D}+00$ & $7.47 \mathrm{D}-01$ \\
\hline $\mathrm{U}-235$ & $2.81 D-01$ & $2.60 \mathrm{D}-02$ \\
\hline $\mathrm{U}-236$ & $1.19 \mathrm{D}+00$ & $1.08 \mathrm{D}-01$ \\
\hline $\mathrm{U}-238$ & $6.41 D+00$ & $5.45 D-01$ \\
\hline$N p-237$ & $5.75 D-01$ & $5.65 \mathrm{D}-02$ \\
\hline Pu-238 & $1.10 D+03$ & $1.23 \mathrm{D}+02$ \\
\hline$P u-239$ & $2.54 D+03$ & $2.64 D+02$ \\
\hline $\mathrm{Pu}-240$ & $1.45 D+03$ & $1.51 D+02$ \\
\hline $\mathrm{Pu}-241$ & $6.96 \mathrm{D}+04$ & $7.36 \mathrm{D}+00$ \\
\hline$P u-242$ & $5.02 D-01$ & $4.98 D-02$ \\
\hline $\mathrm{Am}-241$ & $3.63 \mathrm{D}+03$ & $4.07 D+02$ \\
\hline $\mathrm{Am}-242 \mathrm{~m}$ & $1.75 \mathrm{D}+00$ & $9.14 \mathrm{D}-03$ \\
\hline $\mathrm{Am}-242$ & $1.74 D+00$ & $4.94 \mathrm{D}-02$ \\
\hline$A m-243$ & $9.75 D-01$ & $1.05 \mathrm{D}-01$ \\
\hline $\mathrm{Cm}-242$ & 1. $44 \mathrm{D}+00$ & $1.78 \mathrm{D}-01$ \\
\hline $\mathrm{Cm}-244$ & $1.06 \mathrm{D}+01$ & $1.24 \mathrm{D}+00$ \\
\hline
\end{tabular}

These results meet the acceptance test criterion.

These test cases were executed on an Intergraph Pentium II Xeon personal computer running the Microsoft Windows NT 4.0 operating system. This system is part of the Fluor Daniel Northwest Advanced Computing Center (ACC), which is a part of the Fluor Daniel Network (FLAN). 


\subsection{ORIGEN2}

The first objective of the verification test is to demonstrate that the test problem received from RSICC meets the test requirements when compared to the results of the calculations performed on the ORNL computer and the Hanford Cray computer. The second objective of the verification test is to demonstrate that the N Reactor Mark IV and Mark IA fuel test problems meet the test requirements when compared to the results of the calculations performed on the sun 3 and Windows95/NT platforms. The following are the results of the above comparisons.

\subsubsection{Sun UNIX Workstations}

The test case using the input file listed in Appendix C, Attachment $\mathrm{C}$ and pwru.lib libraries supplied by ORNL (Croff, 1980) met the acceptance criteria of Section 4.2 when the output file was compared to the output file supplied by ORNL (Croff, 1980).

The N Reactor Mark IV test case using the input file listed in Appendix C, Attachment C and data libraries for Mark IV fuel listed in Table 1 met the acceptance criteria of Section 4.2 when the output file was compared to the output file listed in Schwartz (1997).

The N Reactor Mark IA test case using the input file listed in Appendix C, Attachment C and data libraries for Mark IA fuel listed in Table 1 met the acceptance criteria of Section 4.2 when the output file was compared to the output file listed in Schwartz (1997).

\subsubsection{Windows95/NT Platforms}

The test case using the input file listed in Appendix C, Attachment $\mathrm{C}$ and pwru.lib libraries supplied by ORNL (Croff, 1980) met the acceptance criteria of Section 4.2 when the output file was compared to the output file supplied by ORNL (Croff, 1980).

The N Reactor Mark IV test case using the input file listed in Appendix C, Attachment C and data libraries for Mark IV fuel listed in Table 1 met the acceptance criteria of Section 4.2 when the output file was compared to the output file listed in Schwartz (1997).

The $\mathrm{N}$ Reactor Mark IA test case using the input file listed in Appendix C, Attachment $\mathrm{C}$ and data libraries for Mark IA fuel listed in Table 1 met the acceptance criteria of Section 4.2 when the output file was compared to the output file listed in the Schwartz (1997).

\subsection{Personnel involved}

The individual who performed the RADNUC2-A tests was Kevin N. Schwinkendorf of Criticality and Shielding, Fluor Daniel Northwest. The individuals who performed the ORIGEN2 S.2 tests were Steven P. Roblyer of Criticality and Shielding, and Donald J. Hammervold of Environmental and Nuclear Initiatives, both of whom work for Fluor Daniel Northwest. The independent technical peer review was provided by David W. Wootan of Environmental and Nuclear Initiatives, Fluor Daniel Northwest. 


\subsection{Conclusion}

The RADNUC2-A computer code is approved for use for the calculation of activities and decay heat loadings for $\mathrm{N}$ Reactor tube-in-tube fuel assemblies.

\subsection{References}

Bell, M. J., May 1973, ORIGEN - The ORNL Isotope Generation and Depletion Code., ORNL4628, Oak Ridge National Laboratory, Oak Ridge TN.

Croff, A. C., R. L. Haese, and N. B. Gove, 1979, Updated Decay and Photon Libraries for the ORIGEN Code, ORNL/TM-6055, Chemical Technology Division, Oak Ridge National Laboratory, Oak Ridge TN.

Croff, A. C., 1980, A User's Manual for the ORIGEN2 Computer Code, ORNL/TM-7175, Chemical Technology Division, Oak Ridge National Laboratory, Oak Ridge TN.

Packer, M. J.,1998, MCO Gas Composition for Low Reactive Surface Areas, HNF-3035, Rev. 0B, Duke Engineering \& Services Hanford, Inc., Richland, Washington.

Praga, A. N., 1998, 105-K Basin Material Design Basis Feed Description for Spent Nuclear Fuel Project Facilities, Volume 1, Fuel, HNF-SD-SNF-TI-009, Rev. 2, Duke Engineering \& Services Hanford, Inc., Richland, Washington.

Schmittroth, F. A., 1993, Conversion Of ORIGEN2 Code To Sun Workstations. WHC-SD-SWD006, Rev 0-A, Westinghouse Hanford Company, Richland WA.

Schwinkendorf, K. N., S. P. Roblyer, and S. A. Parra, 1996, Use of the WIMS-E Lattice Code for Prediction of the Transuranic Source Term for Spent Fuel Dose Estimation, Spectrum 96, International Topical Meeting on Nuclear and Hazardous Waste Management, August 1823, 1996 (Seattle, Washington), American Nuclear Society, La Grange Park, Illinois, pp. 709713.

Schwarz, R. A., 1997, Modification to ORIGEN2 for Generating N Reactor Source Terms, PNNL11555 UC-610, Pacific Northwest National Laboratory, Richland, Washington

Willis, W. L., 1995, 105-K Basin Material Design Basis Feed Description for Spent Nuclear Fuel Project Facilities, WHC-SD-SNF-TI-009, Rev. 0A, Westinghouse Hanford Company, Richland, Washington.

Wittekind, W. D., 1994, Software Certification Package for the ORIGEN2 Code, WHC-SD-NRSWD-006, Rev. 0, Westinghouse Hanford Company, Richland WA. 
SNF-4503 Rev. 1

\section{APPENDIX A}

VERIFICATION AND VALIDATION OF RADNUC2-A

A-1 


\subsection{VERIFICATION}

The interpolation functions built into Radnuc are based on the assumption that the natural logarithms of the activity data will be linear with respect to exposure, based on the $w t \%{ }^{240} \mathrm{Pu}$ in total plutonium. These two-point interpolation formulae were rederived and verified to be correct. The logarithmic interpolation formula is:

$$
A(t)=\exp \left[\left(\frac{\ln A_{2}-\ln A_{1}}{E_{2}-E_{1}}\right)\left(E-E_{1}\right)+\ln A_{1}\right]
$$

where $A(t)$ is the activity of the radioisotope of interest at exposure $E$ (as related to $w t \%{ }^{240} \mathrm{Pu}$ ). The subscripts 1 and 2 refer to the two points between which the interpolation is made. This expression has been verified to be correctly implemented in function CPT.

The decay expressions built into RADNUC2-A are based on three explicitly-defined forms of decay chains. These forms are:

1) $I_{1} \rightarrow I_{2}$ (stable): The expression for the activity of isotope $I_{/}$present at time $t$ is:

$$
A_{1}(t)=N_{1}\left(t_{0}\right) \lambda_{1} e^{-\lambda_{1}\left(t-t_{0}\right)}
$$

In this expression, $N$ is the number density of atoms present, $\lambda$ is the decay constant (defined as the natural logarithm of 2 divided by the half-life), and $t_{o}$ is a reference time (and $t>t_{o}$ ).

2) $I_{1}-I_{2}-I_{3}$ (stable): The expression for the activity of isotope $I_{2}$ present at time $t$ is:

$$
A_{2}(t)=\frac{N_{1}\left(t_{o}\right) \lambda_{1} \lambda_{2}}{\lambda_{2}-\lambda_{1}}\left(e^{-\lambda_{1}\left(t-t_{0}\right)}-e^{-\lambda_{2}\left(t-t_{0}\right)}\right)
$$

This expression assumes that $N_{2}\left(t_{d}\right)=0$.

3) $I_{1} \rightarrow I_{2} \rightarrow I_{3} \rightarrow I_{4}$ (stable): The expression for the activity of isotope $I_{3}$ present at time $t$ is:

$$
\begin{aligned}
A_{3}(t)= & \frac{N_{2}\left(t_{0}\right) \lambda_{2} \lambda_{3}}{\lambda_{3}-\lambda_{2}}\left(e^{-\lambda_{2}\left(t-t_{0}\right)}-e^{-\lambda_{3}\left(t-t_{0}\right)}\right) \\
& +N_{1}\left(t_{0}\right) \lambda_{1} \lambda_{2} \lambda_{3}\left[\frac{e^{-\lambda_{1}\left(t-t_{0}\right)}}{\left(\lambda_{2}-\lambda_{1}\right)\left(\lambda_{3}-\lambda_{1}\right)}+\frac{e^{-\lambda_{2}\left(t-t_{0}\right)}}{\left(\lambda_{1}-\lambda_{2}\right)\left(\lambda_{3}-\lambda_{2}\right)}+\frac{e^{-\lambda_{3}\left(t-t_{0}\right)}}{\left(\lambda_{1}-\lambda_{3}\right)\left(\lambda_{2}-\lambda_{3}\right)}\right]
\end{aligned}
$$

This expression assumes that $N_{3}\left(t_{d}\right)=0$.

Decay chains 1 through 3 above correspond to functions DK, DK2, and DK3 in RADNUC2-A. These above expressions were rederived and verified to be correct. For decay chain 1 , the 
SNF-4503 Rev. 1

differential equation governing the number of radioactive atoms present is:

$$
\frac{d N_{1}}{d t}=-\lambda_{1} N_{1}
$$

If this equation is divided by $N_{I}$ and integrated over time from some reference time, $t_{o}$, to some later time, $t$, the result is:

$$
\begin{aligned}
\int_{t_{0}}^{t} \frac{d N_{1}}{N_{1}} & =-\int_{t_{0}}^{t} \lambda_{1} d t \\
\ln \left(\frac{N_{1}(t)}{N_{1}\left(t_{0}\right)}\right) & =-\lambda_{1}\left(t-t_{0}\right) \\
N_{1}(t) & =N_{1}\left(t_{0}\right) e^{-\lambda_{1}\left(t-t_{0}\right)}
\end{aligned}
$$

The activity of some quantity of radioactive material is the number of atoms of that material multiplied by its decay constant, with the result being equation (2).

For decay chain 2 , the governing differential equations are:

$$
\begin{aligned}
& \frac{d N_{1}}{d t}=-\lambda_{1} N_{1} \\
& \frac{d N_{2}}{d t}=\lambda_{1} N_{1}-\lambda_{2} N_{2}
\end{aligned}
$$

The solution to the first equation is simply equation (2). For the second equation, one first adds $\lambda_{2} N_{2}$ to both sides, then multiplies both sides by an integrating factor, $e^{-\lambda_{2} t}$, and thus obtains

$$
\frac{d}{d t}\left(e^{\lambda_{2} t} N_{2}\right)=e^{\lambda_{2} t} \lambda_{1} N_{1}=e^{\lambda_{2} t} \lambda_{1} N_{1}\left(t_{0}\right) e^{-\lambda_{1}\left(t-t_{0}\right)}
$$

One again integrates over time from $t_{o}$ to $t$ :

$$
\begin{aligned}
\int_{t_{0}}^{t} \frac{d}{d t}\left(e^{\lambda_{2} t} N_{2}\right) d t & =\lambda_{1} N_{1}\left(t_{0}\right) e^{\lambda_{1} t_{0}} \int_{t_{0}}^{t} e^{-\lambda_{1} t} e^{\lambda_{2} t} d t \\
& =\frac{\lambda_{1} N_{1}\left(t_{0}\right) e^{\lambda_{1} t_{0}}}{\left(\lambda_{2}-\lambda_{1}\right)}\left[e^{\left(\lambda_{2}-\lambda_{1}\right) t}-e^{\left(\lambda_{2}-\lambda_{1}\right) t_{0}}\right]
\end{aligned}
$$

After some algebra, the result is: 


$$
N_{2}(t)=N_{2}\left(t_{0}\right) e^{-\lambda_{2}\left(t-t_{0}\right)}+\frac{\lambda_{1} N_{1}\left(t_{0}\right)}{\left(\lambda_{2}-\lambda_{1}\right)}\left[e^{-\lambda_{1}\left(t-t_{0}\right)}-e^{-\lambda_{2}\left(t-t_{0}\right)}\right]
$$

Again, the activity of some quantity of radioactive material is the number of atoms of that material multiplied by its decay constant. When equation (10) is multiplied by $\lambda_{2}$, the result will be equation (3), except that in this more general case, $N_{2}(t)$ is not equal to zero.

For decay chain 3 , the governing system of differential equations is:

$$
\begin{aligned}
& \frac{d N_{1}}{d t}=-\lambda_{1} N_{1} \\
& \frac{d N_{2}}{d t}=\lambda_{1} N_{1}-\lambda_{2} N_{2} \\
& \frac{d N_{3}}{d t}=\lambda_{2} N_{2}-\lambda_{3} N_{3}
\end{aligned}
$$

We now just have to solve for the third equation. As before, one first adds $\lambda_{3} N_{3}$ to both sides, then multiply both sides by the integrating factor $e^{-\lambda_{3} t}$, and obtain

$$
\begin{aligned}
\frac{d}{d t}\left(e^{\lambda_{3} t} N_{3}\right) & =e^{\lambda_{3} t} \lambda_{2} N_{2} \\
& =e^{\lambda_{3} t} \lambda_{2}\left[N_{2}\left(t_{0}\right) e^{-\lambda_{2}\left(t-t_{0}\right)}+\frac{\lambda_{1} N_{1}\left(t_{0}\right)}{\left(\lambda_{2}-\lambda_{1}\right)}\left[e^{-\lambda_{2}\left(t-t_{0}\right)}-e^{-\lambda_{2}\left(t-t_{0}\right)}\right]\right]
\end{aligned}
$$

One again integrates over time from $t_{o}$ to $t$ :

$$
\begin{aligned}
\int_{t_{0}}^{t} \frac{d}{d t}\left(e^{\lambda_{3} t} N_{3}(t)\right) d t & =\lambda_{2} \int_{t_{0}}^{t} e^{\lambda_{3} t} N_{2}(t) d t \\
& =\lambda_{2} \int_{t_{0}}^{t} e^{\lambda_{3}}\left[N_{2}\left(t_{0}\right) e^{-\lambda_{2}\left(t-t_{0}\right)}+\frac{\lambda_{1} N_{1}\left(t_{o}\right)}{\left(\lambda_{2}-\lambda_{1}\right)}\left[e^{-\lambda_{1}\left(t-t_{0}\right)}-e^{-\lambda_{2}\left(t-t_{0}\right)}\right]\right] d t \\
& =\lambda_{2}\left[\frac { N _ { 2 } ( t _ { 0 } ) e ^ { \lambda _ { 2 } t _ { 0 } } } { \lambda _ { 3 } - \lambda _ { 2 } } \left(e^{\left(\lambda_{3}-\lambda_{2}\right) t_{-}}-e^{\left.\left(\lambda_{3}-\lambda_{2}\right) t_{0}\right)}+\frac{\lambda_{1} N_{1}\left(t_{o}\right) e^{\lambda_{2} t_{0}}}{\left(\lambda_{2}-\lambda_{1}\right)\left(\lambda_{3}-\lambda_{1}\right)}\left(e^{\left.\left(\lambda_{3}-\lambda_{1}\right) t_{-}\left(\lambda_{3}-\lambda_{1}\right) t_{0}\right)}\right)\right.\right. \\
& \frac{\lambda_{1} N_{1}\left(t_{0}\right) e^{\lambda_{2} t_{0}}}{\left(\lambda_{2}-\lambda_{1}\right)\left(\lambda_{3}-\lambda_{2}\right)}\left(e^{\left(\lambda_{3}-\lambda_{2}\right) t_{-}} e^{\left.\left(\lambda_{3}-\lambda_{2}\right) t_{0}\right)}\right]
\end{aligned}
$$

After more algebra, the result can be shown to be: 


$$
\begin{aligned}
N_{3}(t)= & N_{3}\left(t_{0}\right) e^{-\lambda_{3}\left(t-t_{0}\right)}+\frac{\lambda_{2} N_{2}\left(t_{o}\right)}{\left(\lambda_{3}-\lambda_{2}\right)}\left[e^{-\lambda_{2}\left(t-t_{0}\right)}-e^{-\lambda_{3}\left(t-t_{0}\right)}\right]+ \\
& \lambda_{1} \lambda_{2} N_{1}\left(t_{o}\right)\left[\frac{e^{-\lambda_{1}\left(t-t_{0}\right)}}{\left(\lambda_{2}-\lambda_{1}\right)\left(\lambda_{3}-\lambda_{1}\right)}+\frac{e^{-\lambda_{2}\left(t-t_{0}\right)}}{\left(\lambda_{1}-\lambda_{2}\right)\left(\lambda_{3}-\lambda_{2}\right)}+\frac{e^{-\lambda_{3}\left(t-t_{0}\right)}}{\left(\lambda_{2}-\lambda_{3}\right)\left(\lambda_{1}-\lambda_{3}\right)}\right]
\end{aligned}
$$

Again, when equation (14) is multiplied by $\lambda_{3}$, the result (activity) will be equation (4), except that in this more general case, $N_{3}\left(t_{d}\right)$ is not equal to zero.

As another check, these terms were compared against the generalized form of the Bateman series, and the above expressions were again verified to be correct. In both cases 2 and 3, it is clear that there is no initial activity arising from the first-order decay of that particular isotope. The term arising from some non-zero amount of $I_{2}$ present at $\mathrm{t}=0$ is missing in case 2 , and the corresponding term arising from some non-zero amount of $I_{3}$ present at $t=0$ is also missing in case 3. In both cases, this term is of the same form as in case 1. However, these terms are ultimately included as RADNUC2-A executes. Functions DK2 and DK3 add in the higher-order Bateman terms, as required on an isotope-by-isotope basis, after RADNUC2-A first calculates the case 1 , first-order decay terms for all 89 isotopes.

The RADNUC2-A Fortran function DK, as implemented, will return the value of the fraction remaining of the activity of isotope $I_{l}$, (only the exponential in case 1 is evaluated). It was also verified that this is how RADNUC2-A uses this Fortran function. Functions DK2 and DK3 were written to return the ratios of the activities for either case 2 or case 3 , respectively, ratioed to the activity $A_{l}$. If the expressions as implemented in DK2 and DK3 are multiplied by the expression for $A_{l}$, the results can be shown to be identical with the above expressions.

These decay functions form the basis for how RADNUC2-A performs its decay calculations. For all 89 isotopes, RADNUC2-A first calculates the first-order decay as described by case 1 . Then, for each isotope, the higher-order decay terms described by cases 2 and 3 are added in. There are 25 ELSEIF blocks within the isotope decay DO-loop that add in these higher-order terms for specific decay chains, treating branching ratios as required. Of these 25 blocks, there are only four calls to function DK3. Not every one of these special cases were verified. As a spot-check, however, two isotope decay models, one using DK2 and the other using DK3, were verified. As a check on proper useage of DK2, ${ }^{90} \mathrm{Y}$ was chosen, and was found to be correctly implemented. As a check on DK3, ${ }^{242} \mathrm{Cm}$ was chosen, and (assuming the branching ratios documented in the comment statements are correct) a minor error was discovered (and is discussed later).

Hand calculations were performed for isotopes ${ }^{90} \mathrm{Y}$ and ${ }^{242} \mathrm{Cm}$, for 6,8 , and $9 \mathrm{wt} \%{ }^{240} \mathrm{Pu}$, and compared to RADNUC2-A output for these isotopes, for Mark IA fuel. Agreement was exact, to within the numerical precision output by RADNUC2-A (i.e., 3 significant digits). Table A.1 summarizes this comparison. For 6 and $9 \mathrm{wt} \%{ }^{240} \mathrm{Pu}$, the activity tables in RADNUC2-A were used along with the decay expressions above to hand-calculate the activities after a 9-year decay (from the 1-year-decay tables contained in RADNUC2-A). The hand-calculation results are shown below the RADNUC2-A results, in parentheses. For the $8 \mathrm{wt} \%{ }^{240} \mathrm{Pu}$ case, logarithmic 
interpolation was used in addition to the decay models to check against the RADNUC2-A results. Hand-calculated values in Table A.2 were obtained using equations (10) and (16).

As an example, the $8 \mathrm{wt} \%{ }^{240} \mathrm{Pu}$ value for ${ }^{242} \mathrm{Cm}$ activity will now be calculated. The decay chain leading to ${ }^{242} \mathrm{Cm}$ is: ${ }^{242 \mathrm{~m}} \mathrm{Am} \rightarrow{ }^{242} \mathrm{Am} \rightarrow{ }^{242} \mathrm{Cm}$. According to comment statements contained within the RADNUC2-A source code, $99.5 \%$ of the ${ }^{242 \mathrm{~m}} \mathrm{Am}$ decay reactions go to ${ }^{242} \mathrm{Am}$. This value $(99.5 \%)$ is known as the "branching ratio" for this radioactive decay channel. (When some radioactive decay reactions proceed, the result may be to more than one possible set of reaction products. However, it is usually well-known what percentage of the time a given decay will proceed to each possible set of daughter products. The fraction of the time which a given decay will proceed to a given set of daughter products is known as the "branching ratio" for that set of daughter products.) When ${ }^{242} \mathrm{Am}$ decays, $82.7 \%$ proceed to ${ }^{242} \mathrm{Cm}$. These branching ratios must therefore be factored into equation (14) for application to this particular decay reaction. The modified set of governing differential equations is:

$$
\begin{aligned}
& \frac{d N_{1}}{d t}=-\lambda_{1} N_{1} \\
& \frac{d N_{2}}{d t}=r_{1} \lambda_{1} N_{1}-\lambda_{2} N_{2} \\
& \frac{d N_{3}}{d t}=r_{2} \lambda_{2} N_{2}-\lambda_{3} N_{3}
\end{aligned}
$$

where $r_{1}=0.995$ and $r_{2}=0.827$. Solving this system in the same manner as before, the result is:

$$
\begin{aligned}
N_{3}(t)= & N_{3}\left(t_{0}\right) e^{-\lambda_{3}\left(t-t_{0}\right)}+\frac{r_{2} \lambda_{2} N_{2}\left(t_{0}\right)}{\left(\lambda_{3}-\lambda_{2}\right)}\left[e^{-\lambda_{2}\left(t-t_{0}\right)}-e^{-\lambda_{3}\left(t-t_{0}\right)}\right]+ \\
& r_{1} r_{2} \lambda_{1} \lambda_{2} N_{1}\left(t_{0}\right)\left[\frac{e^{-\lambda_{1}\left(t-t_{0}\right)}}{\left(\lambda_{2}-\lambda_{1}\right)\left(\lambda_{3}-\lambda_{1}\right)}+\frac{e^{-\lambda_{2}\left(t-t_{0}\right)}}{\left(\lambda_{1}-\lambda_{2}\right)\left(\lambda_{3}-\lambda_{2}\right)}+\frac{e^{-\lambda_{3}\left(t-t_{0}\right)}}{\left(\lambda_{2}-\lambda_{3}\right)\left(\lambda_{1}-\lambda_{3}\right)}\right]
\end{aligned}
$$

As implemented in RADNUC2-A, function DK3 returns the higher-order decay terms, consistent with equation (4). As explained in the comment statements, the two branching ratios are multiplied together to obtain $0.995 \times 0.827=0.823$, and this value $(0.823)$ multiplies the value returned by DK3. Unfortunately, this means that the product, $r_{1} r_{2}$, incorrectly multiplies both terms in equation (4). As shown in equation (16), the second term (involving $N_{2}$ ) should only be multiplied by $r_{2}$. In practice, this bug introduces only a very small error. Because of the relative magnitudes of the decay constants and activities for ${ }^{242} \mathrm{Am},{ }^{242 \mathrm{~m}} \mathrm{Am}$, and ${ }^{242} \mathrm{Cm}$, the term in equation (16) which contains $N_{2}$ is five orders of magnitude smaller than the smaller of the other two terms. The $0.5 \%$ error in this term is therefore insignificant, and is several orders of magnitude smaller than the numerical precision output by RADNUC2-A.

However, RADNUC2-A calls function DK3 four times. This bug does not affect the ${ }^{126} \mathrm{Sn}$ decay chain calculation because $r_{1}=1$. However, ${ }^{95} \mathrm{Nb}$ is handled twice (once as a fission product and once as an activation product). In this decay chain, ${ }^{95} \mathrm{Zr}$ decays 0.993 of the time directly to ${ }^{95} \mathrm{Nb}$, 
but 0.007 of the time through the ${ }^{95 \mathrm{~m}} \mathrm{Nb}$ metastable state. Following the channel through the metastable state, $r_{1}=0.007$ and $r_{2}=1$. RADNUC2-A multiplies the DK3 contribution by 0.007 , when only the third term in equation (16) (involving $N_{1}$ ) should be multiplied by 0.007 . Again, the term involving $N_{2}$ is several orders of magnitude smaller than the other two terms, and the RADNUC2-A error incorrectly multiplies an insignificant term by 0.007 , making it even smaller than it should be. However, this error does not affect the sum to within the numerical precision output by RADNUC2-A.

Using the 1-year-decay activity data in the RADNUC2-A tables, the basepoints for logarithmic interpolation are shown in Table A.2. The " $8 \mathrm{wt} \%{ }^{240} \mathrm{Pu}$ " column contains the results from using equation (1) to interpolate between the " $6 \mathrm{wt} \%{ }^{240} \mathrm{Pu}$ " and the " $9 \mathrm{wt} \%{ }^{240} \mathrm{Pu}$ " columns (note: one must remember to use $E_{2}=9.0431$ and $E_{l}=6.1224$, from Table A.12).

Table A.1. Comparison of RADNUC2-A with Hand-Calculation Results.

\begin{tabular}{|c|c|c|c|}
\hline Exposure & $6 w t \%{ }^{240} \mathrm{Pu}$ & $8 w t \%{ }^{240} \mathrm{Pu}$ & $9 w t \%{ }^{240} \mathrm{Pu}$ \\
\hline${ }^{90} \mathrm{Y}$ & $\begin{array}{c}2.91 \mathrm{E} 3 \mathrm{Ci} \\
(2910.6 \mathrm{Ci})\end{array}$ & $\begin{array}{c}3.95 \mathrm{E} 3 \mathrm{Ci} \\
(3945.7 \mathrm{Ci})\end{array}$ & $\begin{array}{c}4.67 \mathrm{E} 3 \mathrm{Ci} \\
(4672.4 \mathrm{Ci})\end{array}$ \\
\hline${ }^{242} \mathrm{Cm}$ & $\begin{array}{c}1.19 \mathrm{E}-3 \mathrm{Ci} \\
(1.188 \mathrm{E}-3 \mathrm{Ci})\end{array}$ & $\begin{array}{c}4.65 \mathrm{E}-3 \mathrm{Ci} \\
(4.649 \mathrm{E}-3 \mathrm{Ci})\end{array}$ & $\begin{array}{c}9.92 \mathrm{E}-3 \mathrm{Ci} \\
(9.919 \mathrm{E}-3 \mathrm{Ci})\end{array}$ \\
\hline
\end{tabular}

When values are substituted into equation (16), using $t-t_{o}=9$, , the result is $A_{3}(t)=\lambda_{3} N_{3}(t)=$ $4.648 \times 10^{-3} \mathrm{Ci}$. If one assumes (as RADNUC2-A does) that the product of these two branching ratios is 0.823 , which is only correct to three significant figures, then the result is $4.649 \times 10^{-3} \mathrm{Ci}$, and this is the value shown in Table A. 2 below.

Table A.2. Data for Sample Hand-Calculation of ${ }^{242} \mathrm{Cm}$ Remaining after 9-Year Decay.

\begin{tabular}{|c|c|c|c|c|c|}
\hline Nuclide & Subscript & $\lambda\left(\mathrm{yr}{ }^{-1}\right)$ & $\begin{array}{c}\text { Activity (Ci) } \\
\left(6 \mathrm{wt} \%{ }^{240} \mathrm{Pu}\right)\end{array}$ & $\begin{array}{c}\text { Activity (Ci) } \\
\left(9 \mathrm{wt} \%{ }^{240} \mathrm{Pu}\right)\end{array}$ & $\begin{array}{c}\text { Activity (Ci) } \\
\left(8 \mathrm{wt} \%{ }^{240} \mathrm{Pu}\right)\end{array}$ \\
\hline${ }^{242 \mathrm{~m}} \mathrm{Am}$ & 1 & 0.00456 & $1.499 \times 10^{-3}$ & $1.251 \times 10^{-2}$ & $5.864 \times 10^{-3}$ \\
\hline${ }^{242} \mathrm{Am}$ & 2 & 379.312 & $1.491 \times 10^{-3}$ & $1.245 \times 10^{-2}$ & $5.834 \times 10^{-3}$ \\
\hline${ }^{242} \mathrm{Cm}$ & 3 & 1.55133 & $9.548 \times 10^{-1}$ & $9.300 \times 10^{0}$ & $4.125 \times 10^{0}$ \\
\hline
\end{tabular}




\section{SNF-4503; Rev. 1}

\section{ENGINEERING DATA TRANSMITTAL}

2. To: (Receiving Organization)

Engineering Configuration

ATTN: Jackie Perkins

5. Proj/Prog/Dept/Div:

8. Originator Remarks:

11. Receiver Remarks:
22520

Being distributed for approval and final sign-off

Comments from previous reviews by QA have been incorporated.

3. From: (Originating Organization)

Thermal Reactor Physics

6. Cog/Proj Engr: K.N. Schwinkendorf

K.N. Schwinkendorf

1. EDT 109170

4. Related EDT No:

$N / A$

7. Purchase Order No:

$N / A$

9. Equip/Component No:

$\mathrm{N} / \mathrm{A}$

10. System/8/dg/Facility:

N/A

12. Major Assm Dwg No:

$N / A$

13. Permit/Permit Application No $\mathrm{N} / \mathrm{A}$

14. Required Response Date:

N/A

15

DATA TRANSMITTED

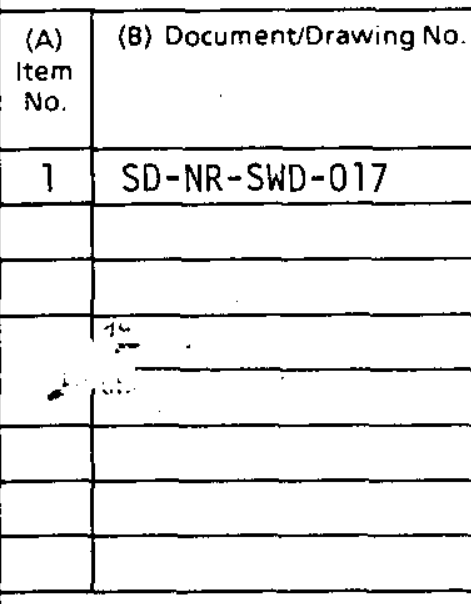

16.

\begin{tabular}{l}
$\begin{array}{c}\text { (C) Sheet } \\
\text { No. }\end{array}$ \\
\hline \\
\hline
\end{tabular}

(D) Rev
No.

(E) Title or Description of Data Transmitted

0

Software Certification Package for the WIMS-E Code.

\begin{tabular}{|c|c|c|}
\hline (G) & $(\mathrm{H})$ & $(\mathrm{I})$ \\
\hline $\begin{array}{c}\text { Reason } \\
\text { for } \\
\text { Trans- } \\
\text { mittal }\end{array}$ & $\begin{array}{c}\text { Origi- } \\
\text { nator } \\
\text { Dispo- } \\
\text { sition }\end{array}$ & $\begin{array}{c}\text { Receiv- } \\
\text { er } \\
\text { Dispo- } \\
\text { sition }\end{array}$ \\
\hline 1 & & \\
\hline & & \\
\hline & & \\
\hline & & \\
\hline
\end{tabular}

KEY

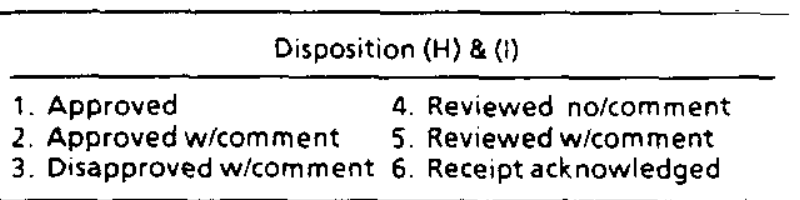

ist (Receipt Acknow. Required)

(G)

(H) I(See impact Level for required signatures)

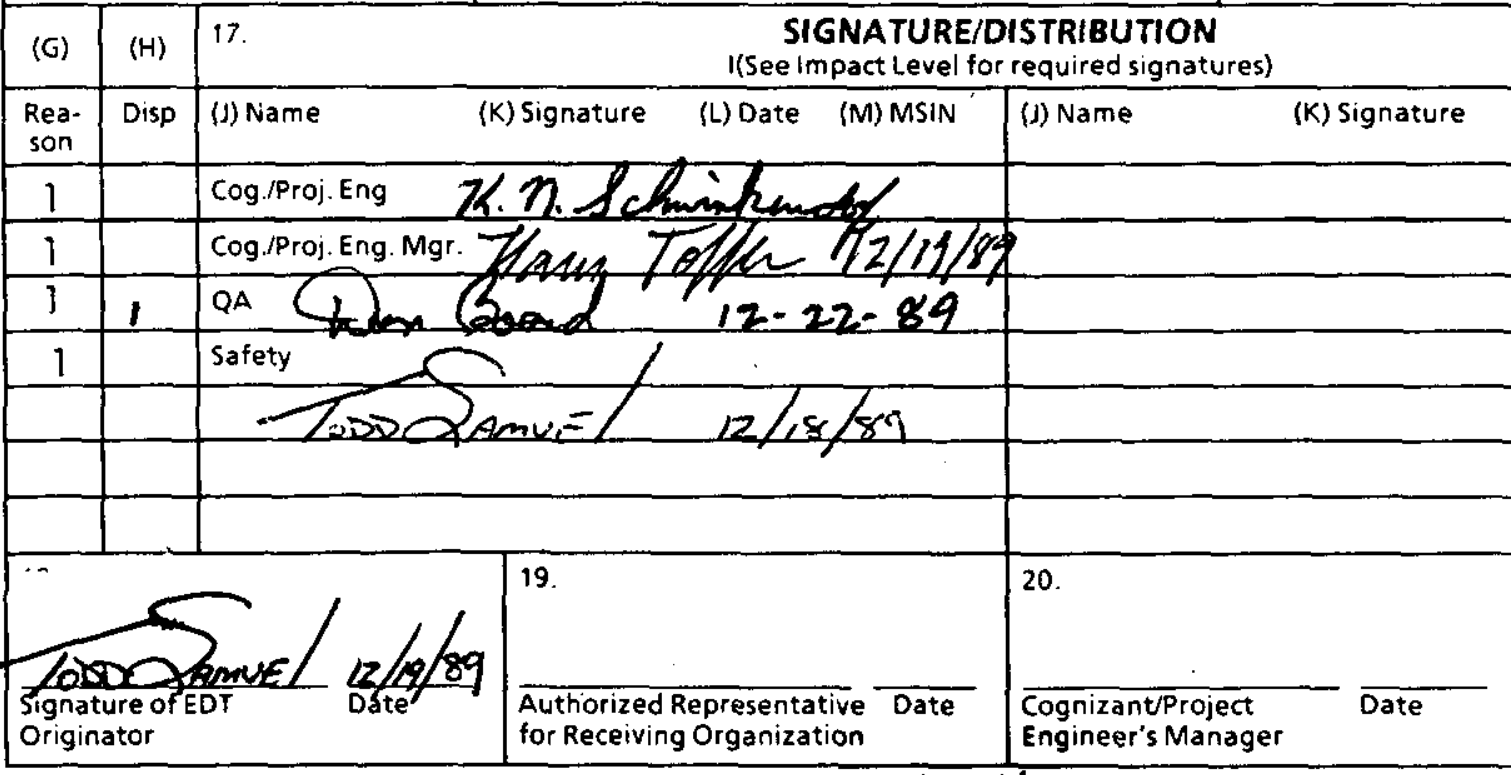

Attachment 1

(L) Date (M) MSIN

Rea- Disp

21. DOE APPROVAL (if required) Ltr No.

$\square$ Approved
$\square$ Approved w/comments
$\square$ Disapproved w/comments BD-7400-172 (2/89: 
SNF-4503, Rev. 1

SUPPORTING DOCUMENT

1 Page 1 of

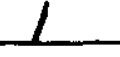

\begin{tabular}{|c|c|}
\hline $\begin{array}{l}\text { Software Certification Package } \\
\text { for the WIMS-E Code. }\end{array}$ & WHC-SD-NR - SWD-017 \\
\hline $\begin{array}{l}5 \text { key woras } \\
\text { WIMS -E }\end{array}$ & $\begin{array}{l}6 \text { Autnor } \\
\text { Kevin N. Schwinkendorf } \\
\text { Namedroe or Pring } \\
\text { SLnature } \\
\text { Thermal Reactor Physics (22520) } \\
\text { Organization }\end{array}$ \\
\hline
\end{tabular}

7 Abstract

The Winfrith Improved Multi-group Scheme, Version E (WIMS-E), is a completely reorganized, extended outgrowth of the earlier WIMS-D lattice physics computer code. Whereas WIMS-D is a self contained computer code, WIMS-E is a highly modul.arized computer code system. The seperate modules perform seperate functions, and the user controls how the various modules interact with each other over various "interfaces" (sets of five input/ output files each), through the user input file. WIMS-E can be used to perfiorm a wide range of lattice physics calculations, including reactivity perturbations, isotopic production, and few group cross section generation for later use in multi-dimensional diffusion theory reactor physics codes.

This package documents that the version of WIMS-E used at the Hanford Site meets all Westinghouse Hanford Company code quality assurance requirments.

8 PURPOSE AND USE OF DOCUMENT - This document was prepared for use within Westingnouse Hantord Company and is to be used only to perform, direct. or integrate work under U.S. Department of Energy contracts. DISTRIBUTION EXTERNAL TO WHC REQUIRES THE APPROPRIATE DOCUMENT CLEARANCE.

$-$

PATENT STATUS - This document copy, since it is transmireo in advance of patent clearance. is made avallable in confidence solely for use in performance of work under contracts with the U.S. Department of Energy. This document is not to be published nor its contents otherwise disseminated or used for purposes other than specified above Defore patent approval for such release or use has been secured. upon request. from the U.S. Department of Energy. Patent Attorney. Richland Operations Office, Richland. WA
ENGINEERING RELEASE STAMP

(Does not authorize public dissemination)

10 impact Level 


\title{
Software Certification Package for the WIMS-E Code
}

\author{
K. N. Schwinkendorf
}

Date Published

December 1989

\section{Westinghouse P.O. Box 1970 \\ Hanford Company Richland, Washington 99352}

Hanford Operations and Engineering Contractor for the U.S. Department of Energy under Contract DE-AC06-87RL10930

Appiled Technology Any further distribution by any holder of this docurnent or ot the deta therein to third parties representin Applied Technology Any luther distritoution by any hoider of this document or do the deta therein to third parlies representing oproved by the U.S. Department of Energy. Aseccialo Deputy Assistant Secretary lor Roactor Systerna Dovelopment and a 10, and'or may be subjoct to Section 127 of the Alomic Energy Ad.

Purpose and Use of Document This document was prepared for use within Westinghouse Hantord Company and is to be used only to perlorm, direct, or integrale work under U.S. Department of Energy contracts. This document if not approved for public nilease until reviewer.

Patent Status This document copy, since it is transmilted in advanoe of patenl clearance, to made available in conlidence solely lor use in performance of work undor $\infty$ nliacts with the U.S. Department of Energy. This document is nod to be published nor its contents atherwise dlaseminal od or used lor purpos es other than specilied abova before patent approval for such release or use has been secured, upon request, trom the U.S. Department of Energy. Palent Attorney, Fichland Operations OHice, Flichland, WA.

Attachment 1 
SNF-4503, Rev. 1

WHC-SD-NR-SWD-017

\section{Software Certification Package for the WIMS-E Code}

Prepared by: $\frac{\text { Th.n. Schinkendy }}{\text { K. N. Schwinkendorf, Advanced Engineer }}$ Thermal Reactor Physics

Approved by:
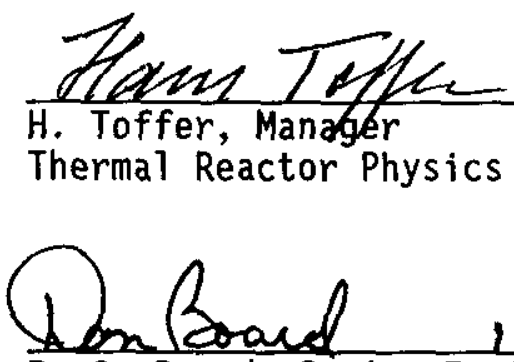

12.22 .89

D. C. Board, Senior Engineer

Environmental Quality Assurance

E. J. Krejci, Manager

Facility Safety 
SNF-4503, Rev. 1

WHC-SD-NR-SWD-017

\section{Software Certification Package for the WIMS-E Code \\ Table of Contents}

\section{Page}

1.0 Scope 3

2.0 Program Description Summary 3

3.0 Origen of Code 5

4.0 Description of Validation Process 5

5.0 Description of Verification Process 5

6.0 Procedure to Follow in Case an Error is Discovered 6 in the Code, or in Associated Cross Section Sets and/or Libraries

7.0 Computer Code Configuration Control Plan 6

8.0 Hardware Requirements 9

9.0 Operating System Requirements 9

$\begin{array}{lll}10.0 & \text { References } & 10\end{array}$

Appendix A. WIMS-E User's Notes A-1

Appendix B. WIMS-E Test Problems B-1

Appendix C. WIMS-E Validation and Benchmarking Document C-I 
SNF-4503, Rev. 1

WHC-SD-NR-SWD-017

\subsection{SCOPE}

The Winfrith Improved Multi-group Scheme, Version E (WIMS-E), is a completely reorganized, extended outgrowth of the earlier WIMS-D lattice physics computer code. Whereas WIMS-D is a self-contained computer code, WIMS-E is a highly modularized computer code system. The separate modules perform separate functions, and the user controls how the various modules interact with each other over various "interfaces" (sets of five input/output files each), through the user input file. WIMS-E has been used in the past to perform a wide range of lattice physics calculations, including reactivity perturbations, isotopic production, and few group cross section generation for later use in multi-dimensional diffusion theory reactor physics codes.

Many of the modules in the WIMS-E system were originally in the older WIMS-D code, and the historical development of WIMS-D is given in the QA documentation for that code. Some modules, however, have been added, including the W-CACTUS module which was originally a self-contained two-dimensional transport theory code but was then integrated into the overall WIMS-E system. There are other computer codes in the nuclear industry which perform the same sort of calculations (some using different numerical methods), such as the Westinghouse Commercial Nuclear Fuel Division (CNFD) code, PHOENIX-P.

This package documents that the version of WIMS-E used at the Hanford Site meets all Westinghouse Hanford Company code quality assurance requirements.

\subsection{PROGRAM DESCRIPTION SUMMARY}

\subsection{USER'S MANUAL}

There is no single user's manual for WIMS-E, but rather a collection of user manuals for the various modules which make up the overall system. There are some documents which serve as summary publications, which tie the other module user manuals together. These documents are listed in Section 11.0, References.

\subsection{CODE DESCRIPTION}

The user must first perform integral transport theory calculations (in 69 groups) for each of the pin-types to be used in a possible W-CACTUS calculation. Several options are available for this, including integral transport theory according to Carlvik's method (module W-FLU), integral transport theory (for cylindrical geometry) according to Bonalumi's method, or (for slab geometry) Newmarch's method (module W-THES), or integral transport theory for grains in annular geometry (module W-PROC). Also available is W-PIJ, which performs integral transport theory calculations for rod cluster geometry. Once the collision probabilities are calculated, multi-group fluxes are calculated by the W-PIP module. Burnup is calculated by the W-BRNUP module. In addition to these modules, there are separate modules for performing a variety of tasks, including collapsing cross sections in space and energy, merging interfaces, reading input data, as well as for many other options. User input is usually in the form of a "keyword, "followed by numeric data, in free-form format. There are exceptions to this, particularly in W-CACTUS input. All keywords must currently be in upper case. 
W-CACTUS solves the two-dimensional neutron transport equations by means of a "track method," where the one-dimensional equations are solved for a network of tracks, or angles, over the two-dimensional problem space.

The cross section data library which the Hanford version of WIMS-E (version 1.4) uses is "The '1986' WIMS Nuclear Data Library" (Halsall and Taubman 1986). This Tibrary was generated by combining an older WIMS library (Halsall and Taubman 1983 and Halsall 1982), certain data files from the Joint European File (JEF-1), and a number of integral adjustments. The library contains cross sections and resonance parameters in 69 energy groups (14 fast, 13 resonance, and 42 thermal groups), for each of 129 nuclides. Materials include fissile and fissionable nuclides, fission products, moderator, and structural materials. Resonance parameters for the principal absorbers U-238, $\mathrm{U}-235$, and $\mathrm{Pu}-239$ were generated using the multi-level, multi-channel formulation contained in the GENEX code (Brissenden and Durston 1968). According to Halsall and Taubman (1986) both s- and p-wave neutron wave contributions are included, with a statistical treatment for resonances in the unresolved region. A total of 120,000 energy points are included. Other resonance absorbers are treated using an Intermediate Resonance approximation, which uses the Goldstein-Lambda parameter to interpolate between the Narrow Resonance (NR) and Narrow Resonance Infinite Mass (NRIM) treatments. For thermal scattering, special treatments are given for certain moderators, including the Nelkin model for hydrogen. The generalized method for generating the $42 \times 42$ scattering matrix has been to input the S(alpha, beta) Scattering Law into the PIXSE code (MacDougall 1963) which supplies the $42 \times 42$ scattering matrix for a specified temperature. WIMS-E uses linear interpolation to obtain the elements of the scattering matrix for any desired temperature. For other nuclides, the scattering $l a w$ is derived from a free-gas model.

In addition, 35 fission product nuclides are modeled explicitly (with the remainder being lumped into a "pseudo-fission product," 4902) and generalized burnup chains are allowed.

There is additional "documentation" which exists and is a good summary of the most often used input options for Hanford Site applications. This documentation is in the form of class notes (handouts) given in a training session for Hanford Site personnel, and was taught by the Hanford Site Code custodian. These class notes were never issued, except to the people who attended the class.

Additional (academic) material discussing the theory behind these methods in reactor and lattice design may be found in Stammler and Abbate (1983). This text is an excellent reference on the practical applications of nuclear design methodology and discusses the WIMS code and its methods explicitly.

\subsection{CODE APPLICATION}

The current cross section library was created by collapsing finer group data down to the 69-group set by assuming a thermal neutron spectrum characteristic of a light-water reactor system. It would therefore be inappropriate to use this library to perform lattice calculations for either a graphite or heavy water moderated system. The resonance integral tabulations 
were generated with fuel of commercial applications in mind, and thus the minimum "sigma-p" is equal to approximately $500 \mathrm{~b}$. This results in extrapolations in the resonance integral tables when the enrichment exceeds about $5 \% \mathrm{U}-235$ for $\mathrm{UO}_{2}$ oxide fuel.

\subsection{CODE CUSTODIAN}

Refer to the Thermal Reactor Physics Code Notebook

\subsection{CODE IMPACT LEVEL}

The WIMS-E code has been assigned and Impact Level of 2 per EP-1.7 of WHC-CM-6-1.

\subsection{ORIGEN OF CODE}

The WIMS-E computer code system at Hanford, version 1.4, was obtained directly from the British Atomic Energy Establishment (AEE), Winfrith Laboratory, and exists at Hanford under license agreement with the British. WIMS-E Version 1.4 currently operates on the Hanford Site CRAY XMP-18, under UNICOS 4.0.

\subsection{DESCRIPTION OF VALIDATION PROCESS}

A document which illustrates reactivity prediction comparisons of WIMS-E to results generated by both WIMS-D and the LEOPARD code is attached as Appendix C. A sample problem was selected from a CNFD LWR fuel design and these three codes were used to predict pincell reactivity as a function of exposure. Acceptable agreement was attained.

\subsection{DESCRIPTION OF VERIFICATION PROCESS}

WIMS-E is a computer code which the Hanford Site acquired from the British AEE, Winfrith, and no comprehensive verification effort was made by Hanford Site personnel regarding the correctness of the FORTRAN coding of these industry accepted methods for lattice calculations in reactor design. However, there were a number of benchmark test cases supplied to the Hanford Site when this code was imported from AEE, Winfrith. After conversion of WIMS-E to the Hanford LSSS, these test cases were executed and acceptable agreement was achieved. Two test cases supplied by AEE, Winfrith are listed in Appendix B and can be used to ensure that the code is functioning correctly on the CRAY XMP-18. 


\subsection{PROCEDURE TO FOLLON IN CASE AN ERROR IS DISCOVERED IN THE CODE, OR IN ASSOCIATED CROSS SECTION SETS AND/OR LIBRARIES}

If a user in the course of this code execution determines that an error exists, contact the code custodian (see section 2.4). An investigation of the error will be pursued and, if necessary, a documented alteration to the code will be implemented. All users of the code shall be promptly notified of any errors and/or changes to the code or associated cross sections sets and/or libraries.

\subsection{COMPUTER CODE CONFIGURATION CONTROL PLAN}

\subsection{PURPOSE}

The purpose of this section is to document the plan used to establish requirements for control of the WIMS-E code that is used by the Thermal Reactor Physics group of Westinghouse Hanford Company. This documentation represents an implementation of EP-2.1 and other Engineering practices applicable to physics and applied physics activities.

\subsection{SCOPE}

This $p l a n$ describes the responsibilities, requirements, and controls needed to maintain the WIMS-E program and its data libraries in such a way as to ensure its quality and integrity on the Hanford CRAY XMP-18.

\subsection{DEFINITIONS}

Computer Code - A sequence of instructions suitable for processing by a computer. This may include the use of an assembler, a compiler, and interpreter, or a translator to prepare the program for execution as well as to execute it.

Data Libraries - Data files or tables on the computer that the code uses for decision making or in its calculations.

Cognizant Manager - The manager in charge of overseeing the analysis activity.

Computer Code Developer(s) - The person(s) in charge of making the actual modifications to the computer code or data libraries.

Computer Code Custodian - The person in charge of making sure that the code and its data libraries are approved for use. This person may also be the code developer.

Computer Code User - The person who uses the code to compute results for the task at hand.

Source Code - The program statements that are readable by a person and are changed when the code is modified. 
Executable Code - The code that is ready to execute after it has been compiled and linked, assembled, or interpreted into a machine readable format.

Verification/Acceptance Testing - A set of input data used to test the various options of the code and its algorithms.

Validation - A set of input data and results which are compared to experiment or some other method of calculation (either other computer code or hand calculations) to check the applicability of the code to the task at hand.

\subsection{RESPONSIBILITIES}

\subsubsection{Cognizant Manager}

Responsible for:

7.4.1.1 Assuring that this configuration control plan is followed.

7.4.1.2 Assuring that all necessary verification and validation is completed and documented.

7.4.1.3 Determining that the code is appropriate for the analysis.

7.4.1.4 Assuring that all computer code users are capable of performing the required analysis.

7.4.1.5 Assigning appropriate Impact Level for computer code.

\subsubsection{Computer Code Developer(s)}

Responsible for:

7.4.2.1 Making any modifications to the code or data libraries in accordance with plan described herein.

7.4.2.2 Making sure that any modifications are made to the code or its libraries are correct.

7.4.2.3 Updating version identification in the code or its data libraries when changes are made.

\subsubsection{Computer Code Custodian}

Responsible for:

7.4.3.1 Maintaining the approved archived version of the code and its data libraries.

7.4.3.2 Controlling access to the code and notifying users when modifications are made to the code or its data libraries.

7.4.3.3 Ensuring that all who use the code understand the responsibility of proper use of the code and have the appropriate documentation. 
7.4.3.4 Verifying that any changes made to the code were properiy identified with comment cards.

7.4.3.5 Prepare and maintain a complete set of all documentation pertaining to the control, verification, modification, archiving, etc., for the code and its data libraries.

7.4.3.6 Prepare and document a set of test problems to be used to verify the correct operation of the code.

7.4.3.7 Analyze and correct, if necessary, any errors discovered in the operation of the code. Document fully all changes to the code and notifying all users of code modifications.

7.4.3.8 Prepare and maintain an updated listing of all authorized users of the code. The listing shall be located in the code custodian notebook.

\subsubsection{Computer Code Users}

Responsible for:

7.4.4.1 Assuring that the version of code is approved for use.

7.4.4.2 Validating the code for the range of applications.

7.4.4.3 Requesting changes or modifications to be made to the code.

7.4.4.4 Reporting any problems encountered while using the code and what may have caused the problem.

7.4.4.5 Informing the code custodian that they need to retain access to a certain version of the code until the analysis is complete.

7.4.4.6 Assuring that every computer calculation is properly identified as to the code and cross section versions, the computer and compiler used, and the date of processing.

\subsection{REQUIREMENTS}

7.5.1 The code and its data libraries shall be controlled by the code custodian.

7.5.1.1 The code custodian and a backup will be the only users with write access to the directories containing the approved version of the source code, executable, and data libraries.

7.5.1.2 Modifications made to the code or its data libraries will be verified by the use of the established set of problems and documented.

7.5.1.3 Modifications to the code will require a new unique version identifier for the source and executable. 


\subsubsection{Modifications to the data libraries will require a new unique version identifier for those data libraries that were modified.}

7.5.2 There shall be a documented, established set of problems for verification/acceptance testing of the code.

7.5.3 The code custodian shall have a documented procedure on how modifications to the code are implemented, how it is compiled and linked, how it is tested for acceptance, where the approved version will be available, and where it will be archived.

7.5.4 If the computer operating system is modified or updated during the duration of an analysis, the code shall be recompiled if necessary and the set of test problems for verification/acceptance testing shall again be executed to test the code for any changes, and the results shall be documented. A case from the current analysis shall be rerun, the results shall be compared to the same case executed before the operating system changed. Results of the comparison case shall be documented in the custodian notebook and appropriate action shall be taken.

7.5.5 If an error is encountered in the code, its consequences on the analysis shall be determined and appropriate corrective action shall be taken, if necessary, and documented.

7.5.6 An updated 1isting of all authorized users of the code shall be available from the code custodian at all times, and shall be contained in the code custodians notebook.

\subsection{References}

WHC-CM-6-1, EP-2.1, EP-5.8, "Computer Software Configuration Management," March 31, 1989.

WHC-CM-6-16, Section 2.5, Section 2.6, "FFTF Core Conversion Group Work Control," October $31,1989$.

\subsection{HARDWARE REQUIREMENTS}

The memory requirements of WIMS-E is highly dependent upon the size of the problem being solved. However, the size of the WIMS-E executable is equal to 532 CRAY blocks (equivalent to approximately 2130 kbytes). The WIMS-E data library (in the binary form required by WIMS-E) is 482 CRAY blocks in length (equivalent to approximately 1928 kbytes).

\subsection{OPERATING SYSTEM REQUIREMENTS}

WIMS-E currently executes under the UNICOS 4.0 operating system on the Hanford LSSS CRAY XMP-18. 
SNF-4503, Rev. 1

WHC-SD-NR-SWD-017

\subsection{REFERENCES}

Anderson, D. W., "The WIMS-E Module W-PIJ," AEEW-R862, General Reactor Physics Division, Atomic Energy Establishment, Winfrith, England, September 1973.

Askew, J. R., and M. J. Roth, "WIMS-E, A Scheme for Neutronics Calculations," AEEW-R1315, Energy Systems Analysis Division, Atomic Energy Establishment, Winfrith, England, June 1982.

Brissenden R. J., and C. Durston, "A User's Guide to GENEX, SRD and Related Computer Codes," AEEW-R622, 1968.

Gubbins, M. E., and J. Sherwin, "The WIMS-E Module W-BRNUP," AEEW-R902, General Reactor Physics Division, Atomic Energy Establishment, Winfrith, England, November 1973.

Gubbins, M. E., and M. J. Roth, "The WIMS-E Module W-COND," AEEW-R1772, Energy Systems Analysis Division, Atomic Energy Establishment, Winfrith, England, July 1980.

Gubbins, M. E., M. J. Roth, and C. J. Taubman, "A General Introduction to the Use of the WIMS-E Modular Program," AEEW-R1329, Reactor Systems Analys is Division, Atomic Energy Estabiishment, Winfrith, England, July 1982.

Halsal1, M. J., "Recent Adjustments to the WIMS Nuclear Data Library," AEEW-R1492, Reactor Systems Analysis Division, Atomic Energy Establishment, Winfrith, England, May 1982.

Halsa11, M. J., and C. J. Taubman, "The '1981' WIMS Nuclear Data Library," AEEW-R1442, Reactor Physics Division, Atomic Energy Establishment, Winfrith, England, September 1983.

Halsa11, M. J., and C. J. Taubman, "The '1986' WIMS Nuclear Data Library," AEEW-R2133, Reactor Physics Division, Atomic Energy Establishment, Winfrith, England, September 1986.

Lander, P. A., "The WIMS-E Module W-PONE," AEEW-R1907, Reactor Physics Division, Atomic Energy Establishment, Winfrith, England, March 1985.

MacDouga11, J. D., "PIXSE," AEEW-M318, 1963

Roth, M. J., "The WIMS-E Module W-SMEAR," AEEW-R966, SGHW Development Division, Atomic Energy Establishment, Winfrith, England, 1974.

Roth, M. J., "The WIMS-E Module W-HEAD," AEEW-R1322, Energy Systems Analys is Division, Atomic Energy Establishment, Winfrith, England, April 1980.

Roth, M. J., "The WIMS-E Module W-INTER," AEEW-R1476, Energy Systems Analysis Division, Atomic Energy Establishment, Winfrith, England, June 1982.

Roth, M. J., "The WIMS-E Module W-MIX," AEEW-R1326, Energy Systems Analysis Division, Atomic Energy Establishment, Winfrith, England, July 1982. 


\section{WHC-SD-NR-SWD-017}

Roth, M. J., "The WIMS-E Module W-FORTE," AEEW-R1688, Reactor Physics Division, Atomic Energy Establishment, Winfrith, England, September 1983.

Roth, M. J., "The WIMS-E Modules W-PRES and W-RES," AEEW-R1707, Reactor Physics Division, Atomic Energy Establishment, Winfrith, England, October 1983.

Roth, M. J., AEEW-R1920, "The Collision Probability Modules of WIMS-E," Reactor Physics Division, Atomic Energy Establishment, Winfrith, England, April 1985.

Roth, M. J., and M. J. Halsal1, "A User's Guide to the WIMS-E Module W-CACTUS," AEEW-R1710, Reactor Physics Division, Atomic Energy Establishment, Winfrith, England, November 1983.

Roth, M. J., and D. W. G. Harris, "The WIMS-E Module W-PROC," AEEW-R1365, Energy Systems Analysis Division, Atomic Energy Establishment, Winfrith, Engl and, June 1982.

Stammler, R. J. J., and M. J. Abbate, "Methods of Steady-State Reactor Physics in Nuclear Design," Academic Press, San Diego, California, 1983. 
SNF-4503, Rev. 1

WHC-SD-NR-SWD-017

Appendix A

WIMS-E User's Notes

This appendix contains lecture notes summarizing the various WIMS-E computational modules as given by the Hanford Site WIMS-E code custodian. WIMS-E sample input and listings of the nuclide identifier codes used to access the WIMS-E cross section library are also included in tabular form. 


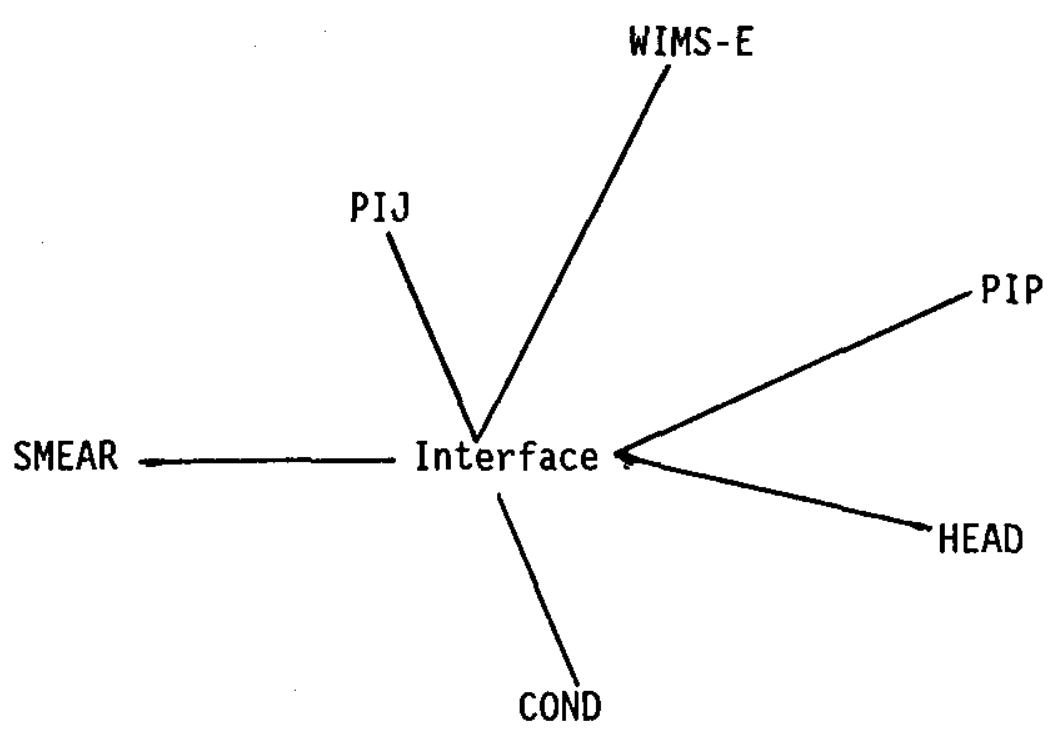

Each interface consists of five files:

1. Interface information

2. Microscopic cross sections

3. Number densities and macroscopic cross sections

4. Geometry

5. Flux

\section{STARTING MODULES}

W-HEAD: The starting point of most WIMS-E calculations, H-HEAD reads geometry and material specifications, gets microscopic cross sections from a nuclear data library, and corrects them for the effects of resonant absorption.

W-FORTE: Reads output files from WIMSD4 or LWRWIMS and writes the same information in the format of a WIMS-E interface.

W-INTER: Writes a new interface from codeword input, or copies, prints, or punches an interface.

\section{SERVICE MODULES}

W-MIX: Calculates macroscopic cross sections so that a partially written interface may be completed. The purpose of W-MIX is, in general, to allow modules that write a new interface to write only microscopic cross sections leaving to $W$-MIX the job of calculating macroscopic ones.

W-COND: Produces a new interface with the cross sections, etc., condensed over energy.

W-SMEAR: Produces a new interface with the cross sections, etc., averaged over space. These cross sections may be corrected for the effects of neutron streaming or they may be renormalized to preserve absorber worth by means of an inverse finite difference operation. 


\section{WHC-SD-NR-SWD-017}

W-MERGE: Merges several interfaces to produce a single interface. Includes a multicell calculation.

W-CRITIC: Modifies a given spatial flux solution by means of a fundamental mode critical spectrum calculation according to input buckling terms, producing a new interface.

W-INTER in its copying mode could also be regarded as a service module.

\section{COLLISION PROBABILITY MODULES}

W-FLU: Calculates collision probabilities in annular geometry using Carlvik's method.

W-THES: Calculates collision probabilities in slab geometry using Newmarch's method or in annular geometry using Bonalumi's method.

W-PROC: Calculates collision probabilities for grains in annular geometry.

W-PIJ: Calculates collision probabilities in rod cluster geometry.

W-PIP: Calculates fluxes from given collision probability and scatter cross section matrices.

W-MERGE in its multicell mode could also be regarded as a Collision Probability Module.

\section{EDIT MODULES}

W-WIRE: Prints reaction rates by mesh and material over specified energy ranges.

W-WED: Prints a neutron balance edit.

W-INTER in its printing mode could also be regarded as an Edit Module.

BURNUP MODULE

W-BURNUP: Estimates the effect of irradiation on fuel materials by solving the number density depletion equations within the material regions of a lattice cell.

SUBGROUP MODULES

W-PRES: Prepares subgroup cross sections for a collision probability calculation prior to W-RES.

W-RES: Calculates group averaged resonance cross sections by the subgroup method.

W-CACTUS: Calculates multi-group fluxes by solving the 20 Boltzmann transport equation using a "track method." May be used to evaluate pin power distributions within a PWR fuel assembly where rectangular boundary distributions are required. Generalized geometry input is supported. 


\section{DATA FORMAT CONVENTIONS}

1. Generally free format

2. Col 1.- 72

3. Input stream consists of a sequence of codewords which may or may not be followed by items of numeric or literal data.

4. Codeword consists of a string of alphabetic characters of any length terminated by any non-alphabetic character or by co1. 73. Only first four characters of a codeword are used for identification.

Examples:

$\begin{array}{lll}\text { PARTITIONS } & - & \\ \text { PARTS } & - & \\ \text { PART } & - & \text { Legal } \\ \text { PAR } & - & \text { not legal }\end{array}$

5. Numeric item - a string of digits with or without a sign, a decimal point, and an exponent. The exponent has the form En where $n$ is a positive or negative number. No embedded blanks. Numeric items are terminated by any alphabetic or special character not allowed in the number or col. 73 .

Examples:

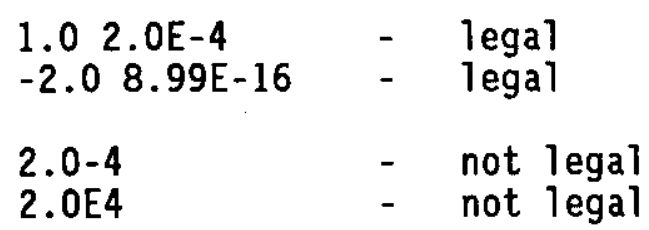

6. Comment can be included anywhere on the 1 ine by preceding it with *. Any character between * and col. 73 is treated as a comment.

7. Continuation sign $\$$ is not needed. Will be ignored. *

W-HEAD - Used as a starting point. Reads geometry and material specifications, gets microscopic cross sections from the library and corrects them for resonance absorption effects.

WHEAD $\mathrm{m}$ or WHEAD $1 \mathrm{~m}$ $m=$ interface number to write to

1 = interface number to read from (usually from BRNUP module)

NREG $j \quad-$ number of annuli

NMAT $k$ - number of materials

NMESH $n$ - number of mesh intervals. If omitted, assume $n=j$.

BURN [KB][KC]

ENDP 


\section{MAIN DATA}

\section{General}

Apart from CENT and MILL, the Main Data Codewards may be in any order provided BEGIN is last. One of CENT or MILL must be included in W-HEAD and whichever it is must precede any codeword specifying length, i.e., SLAB, ANNU, or POLY.

MILL - Lengths are in millimeters (approved SI units).

CENT - Lengths are in centimeters.

PRINT LP - A general method of controlling printed output has been devised to cover all modules in the Integrated WIMS-E Program (2). Every print statement is allocated to one of ten print levels, numbered 0-9. Prints at level 0 always appear. Such prints generally include the input data and error diagnostics. The prints at other levels are controlled by the input data as follows:

PRIN LP - Specifies that only levels 0 to LP inclusive are to be printed.

PRIN 0 List - specifies that all levels in the list are to be printed. The two forms may be combined; thus:

PRIN 26 - causes levels $0,1,2$, and 6 to be printed. The default specification is $L P=2$.

The print control may be set either in the Main Data of $W-H E A D$, where it operates only within W-HEAD, or in the control Routine Data where it operates on all the modules. If used in both, that used in W-HEAD will apply throughout the execution of $W-H E A D$, but on return to the control routine, that previously specified to it will be remembered.

The print control options for $W-H E A D$ are given in Table 2 .

TEST - this has the same effect as PRIN 6 (i.e., all prints are produced).

BEGIN - this terminates the Main Data for $W$-HEAD. It must be the last codeword presented to W-HEAD.

Material Compositions

MATERIAL $m, d, T, i,\left(N I(n), F_{n}, N=1, M X\right)$ - This is used to describe the composition of each material.

$$
\begin{aligned}
& m=\text { material number } \\
& T=\text { temperature in } k \\
& i=\text { resonance region number (no " }-1 \text { " allowed) }
\end{aligned}
$$

The resonance calculation is carried out in a simplified geometry in which all the materials of Resonance Region 1 are in the center, surrounded by Regions 2, 3, etc., in order. Average values of cross sections are used in 
Table 2. Print Levels in W-HEAD

Level

0

al1

1

5

Output

Error diagnostics, warning messages, short heading, unused storage, input data, library name, number of nuclides, and energy groups on the library, message on completion.

Full heading, summary of recent changes to the coding, general information messages, temperatures, number of nuclides and their identifiers, number of materials, number of slabs or annuli and their contents and volumes.

Microscopic cross sections for each resonance group.

Temperatures, number densities, can correction factor beta, the probability $R$ of crossing the moderator, $Q=1-R$, resonance escape probability $p$, correction factor $f$ to the scatter out cross section, flux depression factor $x$, extent of the pseudo-homogeneous region.

6 Absorption cross sections before interaction correction and after interaction but before flux depression correction. 
each region. It is essential to put all material containing resonant absorbers into Resonance Region 1. The resonances will be calculated on a homogeneous basis if only Resonance Region 1 is used.

The pairs of numbers $\left(N I(n), F_{n}\right)$ - there may be any number of pairs indicate how the material is made up of nuclides with identifiers $N I(n)$. The definition of $F_{n}$ depends on the value of $d$.

(i) $d=-1 . \quad F_{n}=$ number density in atoms per barn $\mathrm{cm}$.

(ii) $d=$ density (specific gravity). $F_{n}=$ proportion of the mass of the material that is nuclide $N I(n)$. These need not sum to unity as W-HEAD will renormalize them. W-HEAD will use these values to convert to number densities using the formula

$N_{n}=\frac{A d F_{n}}{w S_{q} F_{q}} \quad \cdots \times 10^{-24}$

$A=$ Avogadro's Number $=0.602306 \times 10^{24} \mathrm{molecules} / \mathrm{mol}$

$W$ is the atomic weight, which $W-H E A D$ reads from it suclear data 1 ibrary. Both $A$ and $W$ are in the $C 12$ scale. The factor $10^{-24}$ converts from atoms/cc to atoms/barn $\mathrm{cm}$.

Voids need not be specified; they may be referred to as Material 0 . Any material used in two resonance regions requires two MATE codewords.

TRACE (NI $(K), K=1, N D)$ - This may be used to insert traces of the nuclides identified by (NI $(K), K=1, N D$ ) into every material so that they become available to a reaction rate edit. Traces have a number density of $10^{-20}$ atoms per barn $\mathrm{cm}$ and do not include transport or scatter cross sections.

DETECTOR NQ NI $m$ - This means that detector NQ is to consist of a trace of the nuclide with identifier NI in material $m$ only, in order to retain the hyperfine structure. NQ will be used as the nuclide identifier and therefore must be different from any other nuclide identifier used. W-HEAD checks that it is different from any library nuclide identifier. Thus, if $N I$ is 3238 , then it would be appropriate to use 4238 for NQ. In this case:

REAC 4238 would be used in W-WIRE.

It is quite reasonable to have another detector with different values of $N Q$ and $m$ and the same value of $N I$.

IEMP $(T(m), m=1, M)$ - This resets all material temperatures to $T(m)$ in $K$ (not delta-T's).

ALTER NI $\left(m(K), N_{n}(K), K=1, M A\right)$ - This resets the number densities for the nuclide with identifier $N I$ to $N_{n}(K)$ in atoms per barn $\mathrm{cm}$ in material $\mathrm{m}(K)$. For example: 
SNF-4503, Rev. 1

WHC-SD-NR-SWD-017

\section{ALTER $\quad 1012 \quad 1 \quad 9.88 \mathrm{E}-2 \quad 2 \quad 6.79 \mathrm{E}-2$}

resets the number density for nuclide 1012 to $9.88 \mathrm{E}-2$ atoms per barn $\mathrm{cm}$ in Material 1 and 6.79E-2 atoms per barn $\mathrm{cm}$ in Material 1 .

Geometry Specification

SLAB $\mathrm{j} r \mathrm{~m}$ - This codeword should be used when the lattice cell is divided into slabs. W-HEAD assumes that a cell in slab geometry is symmetrical about its center and consequently that data are supplied for only half a cell, from the center to the outer boundary. A reflective boundary condition is aiways assumed for both boundaries.

$j=$ slab number counting outward from the center

$r=$ distance from the center to the outer edge of this slab

$m=$ material number

ANNULUS $\mathrm{j} r \mathrm{~m}$ - This codeword should be used when the lattice cell is divided into annuli.

$j=$ annulus number, counting outward from the center

$r=$ outer radius

$\mathrm{m}=$ material number

Thus, the definitions of the SLAB and ANNU codewords are identical, and indeed they may be used interchangeably for slab, annular, or spherical geometry. It is the Prelude Data codeword MPLA that tells W-HEAD which geometry to use.

POLYGON $j \mathrm{~s} m r$ - This is another alternative to ANNU in which $j$ and $m$ have the same definition. $s$ is the number of sides of a regular polygon and $r$ the radius of the inscribed circle. The effect is that $W$-HEAD interprets this as

$$
\text { ANNU } j, r \sqrt{\frac{\tan (\pi / s)}{\pi / s}}, m
$$

\section{i.e., preserving volume. This is cylindricized.}

BEHRENS $V$ - This instructs $W$-HEAD to store $V$. until all the data have been read and then subtract it from the volume of the last slab or annulus, giving the radius of the last annulus as $\sqrt{r^{2}-V / \pi}$ or the distance from the center to the outer edge in slab geometry as $r-V$. For spherical geometry, $W-H E A D$ at present incorrectly uses the same formula as for slab geometry.

MESH $(M M(j), j=1, N A)$ - This gives for each slab or annulus the number of mesh intervals into which it should be divided. The volume of the slab or annulus is divided equally between the meshes in it. If this codeword is omitted, it is assumed that each slab or annulus is one mesh interval. 
SNF-4503, Rev. 1

WHC-SD-NR-SWD-017

Resonance Calculation

The resonance treatment in W-HEAD, as described in Section 3.0 calculates the microscopic cross sections of the resonant absorbers, allowing for selfshielding and the interaction effects of overlapping resonances. This treatment includes calculation of the Dancoff effect between adjacent pin cells and the effect of the absorption resonances on the scatter out cross section. The process is fully automatic and normally requires no special codeword input. It may, however, be modified by the following:

BELL a - Alter the Bell factor from its default value of 1.16 to a.

DANCOFF - Alter the Dancoff factor from the calculated value $(1-\beta R)$ to $\gamma$. $\gamma$ may be one number to apply to all resonance groups or there may be a different number for each resonance group, following one appearance of the codeword DANC.

RESX NI,NR, ( $\left(\sigma_{r}(I K)\right.$, IK $\left.\left.=1, I 2\right), r=1, N R\right)$ - Alter the cross section in the resonance groups $I K=1,12$ for the nuclide with identifier $N I$ from their calculated values to $\sigma_{r}$ (IK) barns. I2 is the number of resonance groups and NR signifies whether fission resonances are to be included. Thus, for NI = $3238, N R=1$ and only $\sigma_{a}$ is given; for $N I=235, N R=2$ and $N I=3238, N R=2$ and both $\sigma_{a}$ and $\sigma_{f}\left(\right.$ not $\left.v \sigma_{f}\right)$ are given.

NORESONSNCE - This deletes the resonance shielding calculation. W-HEAD then produces infinitely dilute resonance integrals per unit lethargy width instead of cross sections for resonant absorbers in the resonance energy range. The scatter out cross sections are not corrected for the effects of the absorption resonances, not even if the latter have been provided via the codeword RESX.

NOFP - This instructs W-HEAD not to correct the scatter out cross sections for the effects of the absorption resonances. However, this input is for test purposes only, and will not normally be required.

SAMPLE CASE \#1

WHEAD 1

BURN

NREGION 3

NMAT 3

NMEAH 11

ENDP

MESH 515

CENT

MATE $110.0942 .0122358 .82823879 .376016 \quad 11.806 \quad 1.0 E-4$

MATE $2 \quad-1 \quad 623.02291 \quad 3.963 \mathrm{E}-2$

$\begin{array}{llllllll}\text { MATE } 3 & 693 & 587.0 & 3 & 3001 & 11.2 & 6016 & 88.8\end{array}$

ANNU $10.277 \quad 1$

ANNU 20.3422

ANNU 30.67793

PRINT 2

BEGIN

STOP 


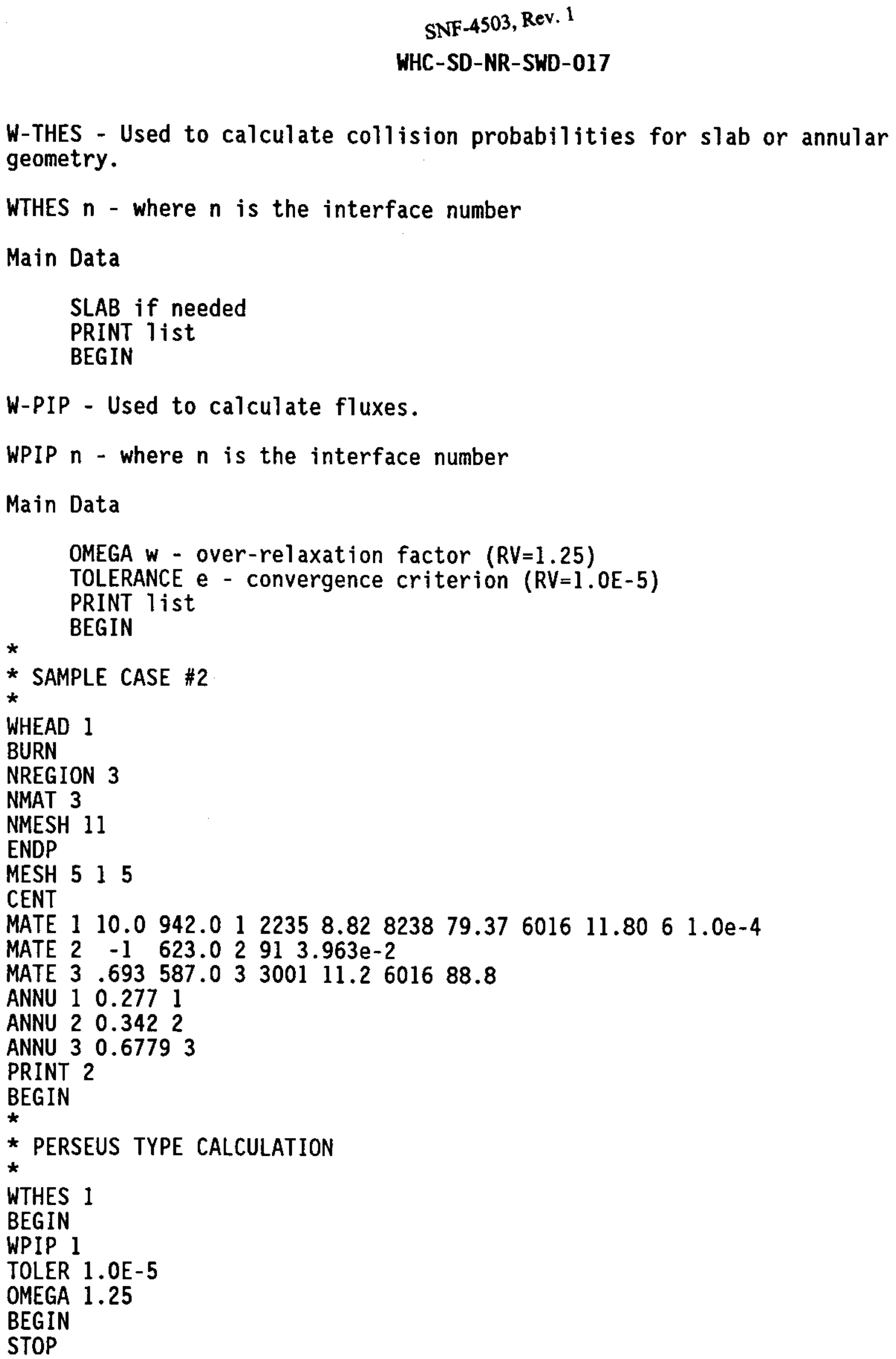


W-SMEAR - Used to perform spatial collapse of the cross section data and flux distributions.

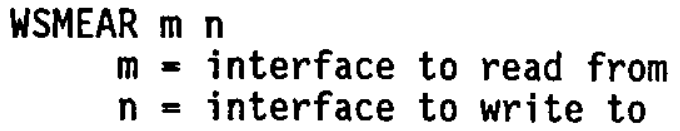

MATERIALS $\mathbf{i}$

$i=$ number of new materials

MESHES $\mathbf{j}$

$j=$ number of new meshes

ENDP

NEWMAT $x, K_{1}, K_{2}, \ldots ., K_{n}$ - form a new material $x$ by smearing the $N$ old meshes $K_{j}$.

MCODE list - new material code for each new mesh.

BEGIN

Examples

MATE 3

MESH 4

ENDP

NEWM 1112

MEWM $2 \begin{array}{llll}3 & 4 & 5 & 6\end{array}$

NEWM 37

MCODE 12233

BEGIN

W-COND - Used to perform energy collapse of cross section data and flux distributions.

WCOND $m n$

$$
\begin{aligned}
& m=\text { interface to read from } \\
& n=\text { interface to write to }
\end{aligned}
$$

GROUPS $\mathbf{i}=$ number of new energy groups

ENDP

PARTITIONS list $(=i)$

BEGIN 
WHC-SD-NR-SWD-017

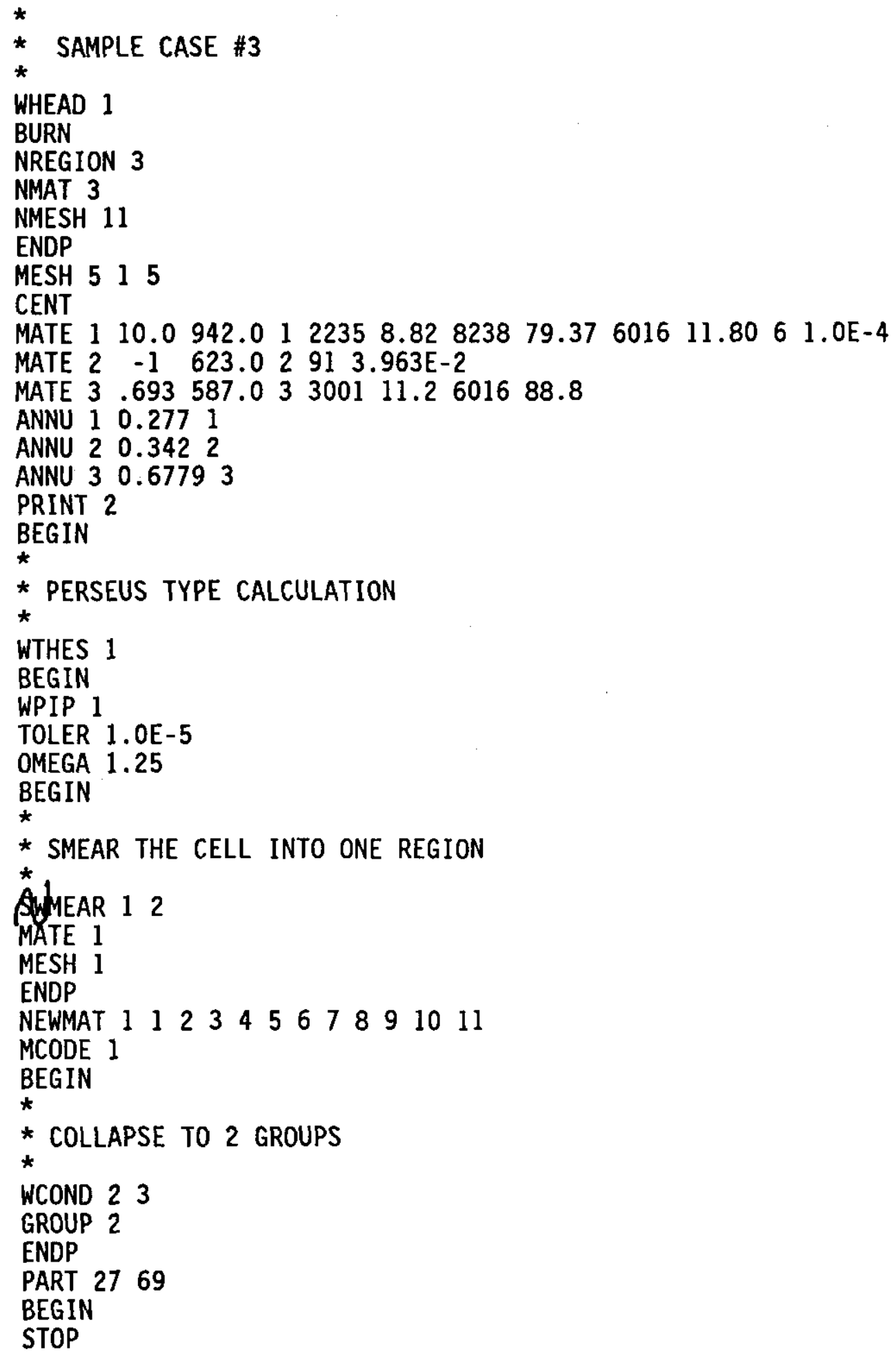


SNF-4503, Rev. 1

\section{WHC-SD-NR-SWD-017}

W-INTER - Used to write an interface from input information, to copy an interface, and to print or punch contests of an interface.

WINTER $m[n]$

$m=$ interface to read from

$\mathrm{n}=$ interface to write or copy to

COPY

PRINT

FILE list (1-5)

MATRIX - to print scatter matrix, instead of scatter spectrum (value from 0 to 1)

SNAP - to punch cross section data from file 3 to unit 7 in SNAP-SCRAMBLE format.

BEGIN 
*SAMPLE CASE \#4

*

WHEAD 1

BURN

NREGION 3

NMAT 3

NMESH 11

ENDP

MESH 515

CENT

MATE $1 \quad 10.0 \quad 942.0122358 .82823879 .37 \quad 6016 \quad 11.80 \quad 6 \quad 1.0 \mathrm{E}-4$

MATE 2 - $11023.02291 \quad 3.963 E-2$

MATE $3 \quad 693 \quad 587.033001 \quad 11.2601688 .8$

ANNU $10.227 \quad 1$

ANNU 20.3422

ANNU 30.67793

PRINT 2

BEGIN

*

* PeRSEUS type calculation

*

WTHES 1

BEGIN

WPIP 1

TOLER 1.0E-5

OMEGA 1.25

BEGIN

*

* SMEAR the CELL INTO ONE REgION

WSMEAR 12

MATE 1

MESH 1

ENDP

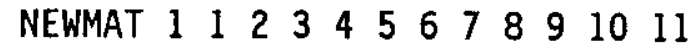

MCODE 1

BEGIN

$\star$

* COLLAPSE TO 2 GROUPS

*

WCOND 23

GROUP 2

ENDP

PART 2769

BEGIN

*

* PRINT THE 2 gROUP CROSS SECTIONS AND SAVE IT ON UNIT 7 (FROM SNAP)

WINTER 3

PRINT

FILE 3

MATRIX

SNAP

BEGIN 
SNF-4503, Rev. 1

WHC-SD-NR-SWD-017

SNAP OUTPUT FROM UNIT 7 -- 2 GROUP DATA

I $1 \mathrm{D}$

$1.8029 \mathrm{E}+00$

$3.0638 \mathrm{E}-02$

$2.2565 \mathrm{E}-03$

4.3296E-01

$2.8396 \mathrm{E}-02$

$5.3452 \mathrm{E}-01$

4. $4798 \mathrm{E}-02$

$4.7565 \mathrm{E}-05$

$2.8062 \mathrm{E}-02$

W 1

8.9549E-04 1.8428E-02

$\mathrm{SP}$

$1.0000 E+00 \quad 0.0000 E+00$

W-BRNUP - Used to perform burnup calculations

WBRNUP $\mathrm{m} n$

$m=$ interface to read from

$n=$ interface to write to

RATING iq, rq, ig

iq $=$ power specification trigger

$=1$ - rating in MW/MT heavy elements (A.W.> 231)

$=2$ - in fissions $/ \mathrm{ml} / \mathrm{sec}$ averaged over cell

$=3$ - in fissions $/ \mathrm{ml} / \mathrm{sec}$ averaged over the burnable region

$=4$ - as total flux averaged over specified materials of cell $\left(\mathrm{n} / \mathrm{cm}^{2}\right.$ sec). Use with TRIGGER card.

$=5$ - as flux in group ig is averaged over specified materials. Use with TRIGGER card.

$r q=$ rating

$\mathrm{ig}=$ group indicator required if $\mathrm{iq}=5$

STEPS ib, rtau

$i b=$ number of substeps within this burnup time step.

rtau = length in days of each substep

BEGIN

NOTE: In WIMS-D, xenon and samarium are assumed to reach equilibrium

concentrations immediately. Not so in WIMS-E. To get data for BOL with xenon, use :

STEPS 21.0

for the first burnup step. 
SNF-4503, Rev. 1

WHC-SD-NR-SWD-017

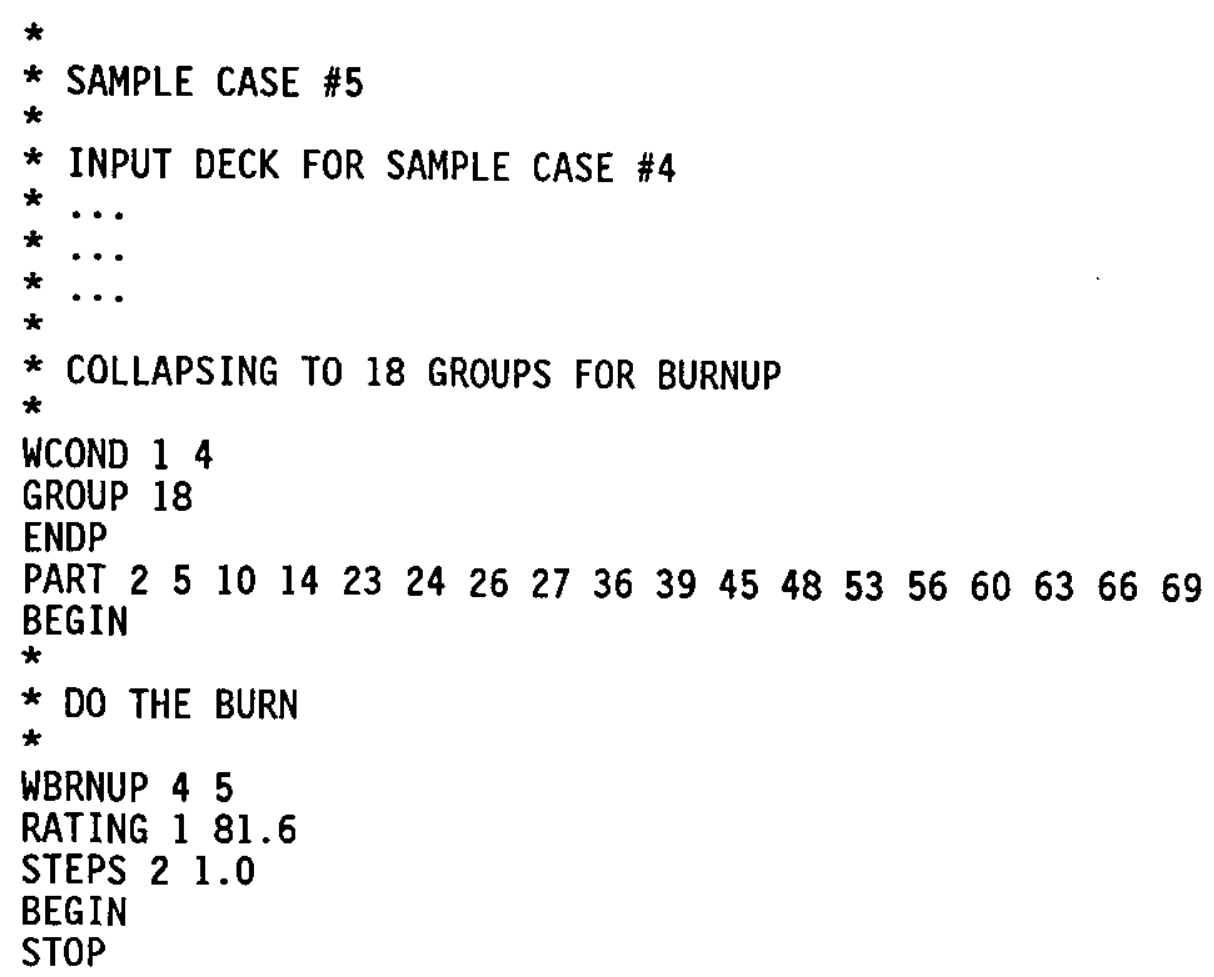


WHC-SD-NR-SWD-017

\section{CYCLIC CALCULATIONS}

NCYCLE $m n$

FINISH

$$
\text { similar to }
$$

To change data from cycle to cycle:

QUAL $n$ list - means that $n$ card images immediately following apply only to cycles in the list.

Example

QUAL $2 \quad 3 \quad 6 \quad 9$

WWED 4

BEGIN

MISS $n$ list - same as QUAL except it causes the specified card images to be missed for the cycles listed.

QUAL $52 \begin{array}{llllll} & 3 & 4 & 5 & 6 & \text { can be written as }\end{array}$

QUAL $5 \quad 2-6$

To avoid counting cards, use:

GOTO $n$ list

PRINT $n$

which causes all data up to the POINT $n$ card to be skipped for all cycles in the list.

Example

GOTO 101024578

WWED 4

BEGIN

POINT 10

\section{Restrictions}

1. The codeword (NCYCLE, QUAL, etc.) and its associated data must occupy a single separate card image.

2. Must be used between NCYCLE and FINISH.

3. GOTO-POINT jump must be forward. 
SNF-4503, Rev. 1

WHC-SD-NR-SWD-017

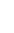

* SAMPLE CASE \#6

t

NCYCLE 13

QQUAL 11

WHEAD 1

MISS 11

WHEAD 51

BURN 1

NREGION 3

NMAT 3

NMESH 11

ENDP

...

$\cdots$

$\ddot{*}$

* DO THE BURN

*

WBRNUP 45

RATING 181.6

QUAL 11

STEPS 21.0

MISS 11

STEPS 130.0

BEGIN

FINISH

STOP 
SNF-4503, Rev. 1

WHC-SD-NR-SWD-017

W-WED and W-WIRE

W-WED - gives region and cell edits

WWED $m$

OPTION $x$ where $x=0,1,2,3$, or 4 edit option

REGION ij

BEGIN

W-WIRE - gives reaction rate edits

WWIRE $\mathrm{m}$

REACTION i, NIPC, list

$\mathbf{i}=$ nuclide identification number

NIPC $=4$ digit integer to control output

non-zero value of $N=$ suppress print of cross section

non-zero value of $I$ = suppress print of reaction rates by mesh

non-zero value of $P=$ suppress print of reaction rates by material

non-zero value of $C=$ suppress print of reactions by material

list = specifies combination of energy groups in the edit

BEGIN

Example

WWIRE 2

REAC $2235 \quad 0 \quad 14 \quad 27 \quad 69$

REAC $8238 \quad 1110142769$

BEGIN

PIJ - Used to calculate collision probabilities, mainly for rod cluster geometry.

WPIJ (interface \#)

CELLD NR, NAN, NS, MNCS, MNSS, NCSYM

$N R=$ number of regions in the system

NAN $=$ number of annuli

NS $=$ number of surfaces

MNCS = maximum number of sections

MNSS $=$ number of surface sectors

NCSYM = cell and surface symmetry number

RODDIM NRODS, NTYPES, MRAN, MNREC

NRODS = total number of rods

NTYPES = number of rod types

MNRAN = maximum number of annuli per rod

MNRSEC = maximum number of different angles per rod 
CONTROL NSYM, NLINES, NANGLES, NCLUST, NREST, NBOPT

$$
\begin{aligned}
\text { NSYM } & =\text { symmetry number for angular integration mesh } \\
\text { NLINES } & =\text { total number of lines. Used with LINE card. } \\
\text { NANGLES } & =\text { number of discrete angles. Should be an odd number } \\
\text { NCLUST } & =0 \text { for unrodded system } \\
& 1 \text { for rodded system } \\
\text { NREST } & =\text { restart number (= } 0 \text { for no restart) } \\
\text { NBOPT } & =\text { boundary condition option } \\
& =1 \text { block (free) boundary } \\
& =2 \text { "matrix" boundary condition } \\
& =3 \text { "vector" boundary condition }
\end{aligned}
$$

MILL - length in millimeters - 1 is required

CENT - length in centimeters - 1 is required

ADEG - angles in degrees - 1 is required

ARAD - angles in radians - 1 is required

ANNULUS $J R M_{1} \theta_{1} M_{2} \theta_{2} \ldots M_{n} \theta_{n}$

$J=$ annulus number

$\mathrm{R}=$ outer radius

$M_{n}=$ material code of sector $n$

$\theta_{n}=$ leading angle of sector $n$

SURFACE
one surface ${ }^{\theta_{1}}=$ SURFACE ${ }^{\theta_{n}}$.

ARRAY . . . .

RODSUB . . .

LINES $\mathrm{N}_{1} \mathrm{~N}_{2}$. . . N NAN

BMAT . . if NBOPT $=2$

BVECT NG $\alpha_{1} \alpha_{2}$. . $\alpha_{N S}$ if NBOPT $=3$

same $\alpha$ for all group $\Rightarrow$ BVECT 01.0

BEGIN

ARRAY - Rod centers are positioned by means of ARRAY cards, each type of rod being described by one card or set of cards. These take the form:

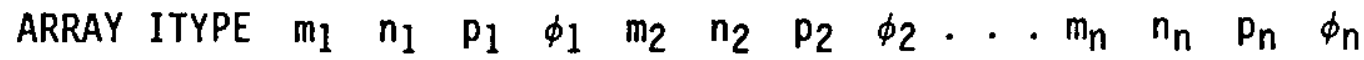

Up to twelve sets of $(m \cap p \phi)$ data are allowed. The first number of each set, $m$, specifies the option on the coordinates chosen to describe the array. All angles are measured from the fixed reference direction. All rings, squares, and hexagons of rods are based on the cell center. The options are: 
$m=1$ A ring, radius $p$, of $n$ equally spaced rods one of which has angular coordinate $\phi . \phi$ should be the smallest coordinate in the range $0 \leq \phi<2 \pi$.

$m=3$ A ring of $n$ equally spaced rods with separation $p$, the first of which has angular coordinate $\phi$. (As $m=1$ except $p$ is separation instead of radius.)

$m=4 \quad$ A hollow square of $n$ equally spaced rods with separation $p . \phi$ is the angular coordinate of the first corner rod in the range $0 \leq \phi$ $<2{ }^{*} \pi$.

Rods may be specified singly by using $m=1$ and $n=1$. Note that rods are allocated the same region numbers if:

a. they are the same type and

b. their outer annuli at the point furthest from the cell center lies in the same cell annulus.

If $m=1$ or 3 , then all rods specified by one set of four numbers will automatically be at the same distance from the cell center and hence have the same set of region numbers. With Options 4 and 6 , this is not true and care must be taken to ensure the correct assignments.

RODSUB - The subdivision of each type of rod is specified by RODSUB cards. These cards are similar in format to the ANNULUS cards apart from the first number which specifies the type number of the rod. The angles are measured in an anticlockwise sense in the range $0 \leq \theta<2 \pi$ relative to the outward going line from cell center through the rod center. Thus:

$$
\text { ROBDUB ITYPE } J \quad \begin{array}{llllllllll}
R & M_{1} & \theta_{1} & M_{2} & \theta_{2} & \ldots & M_{N} & \theta_{N}
\end{array}
$$

where

$$
\begin{aligned}
\text { ITYPE } & =\text { rod type number } \\
J & =\text { annulus number within the rod } \\
R & =\text { outer radius of the annulus } \\
M_{N} & =\text { material code in sector } N \\
\Theta_{N} & =\text { leading angle of sector } N
\end{aligned}
$$

Example

Rods of Type 1 have two annuli with outer radii 1.0 and $2.0 \mathrm{cms}$. The first annulus is not divided into sectors and is void but the second is divided into two with the division along the line joining cell center to rod center. The first half contains Material 1 and the second half material 2. Thus we would have:

CENT

ADEG

RODSUB 1111.00

RODSUB 1222.01020180 


\section{WHC-SD-NR-SWD-017}

Note that if a rod annulus is not divided into sectors, a card of the form below suffices.

RODSUB ITYPE J R M

and Material M fills the whole of Annulus $\mathrm{J}$.

\section{MULTICELL CALCULATIONS}

1. Flux substitution in WCOND
FFACE $N$
WCOND $\mathbf{i} \mathrm{j}$
GROUPS ...
ENDP
SUBF
PART
BEGIN

2. WMERGE - Used to merge more than one interfaces into one interface (referenced only in AEEW-R1920, "The Collision Probability Modules of WIMS-E.")

$$
\text { WMERGE } 1223
$$

NOIF 2

ENDP

BEGIN

3. Burnup consequences

In WHEAD, BURN $K B \quad K C \Rightarrow$ get the number densities for cell type KC. Must read File 1 of the interface written by WMERGE. Done by using MFACE card appearing before the WHEAD card.

Example

\section{MFACE 5}

WHEAD 6 l 1

BURN 11

-

WHEAD 62

BURN 12

WMERGE 125

WPIJ 5

WBRNUP 56 
SNF-4503, Rev. 1

WHC-SD-NR-SWD-017

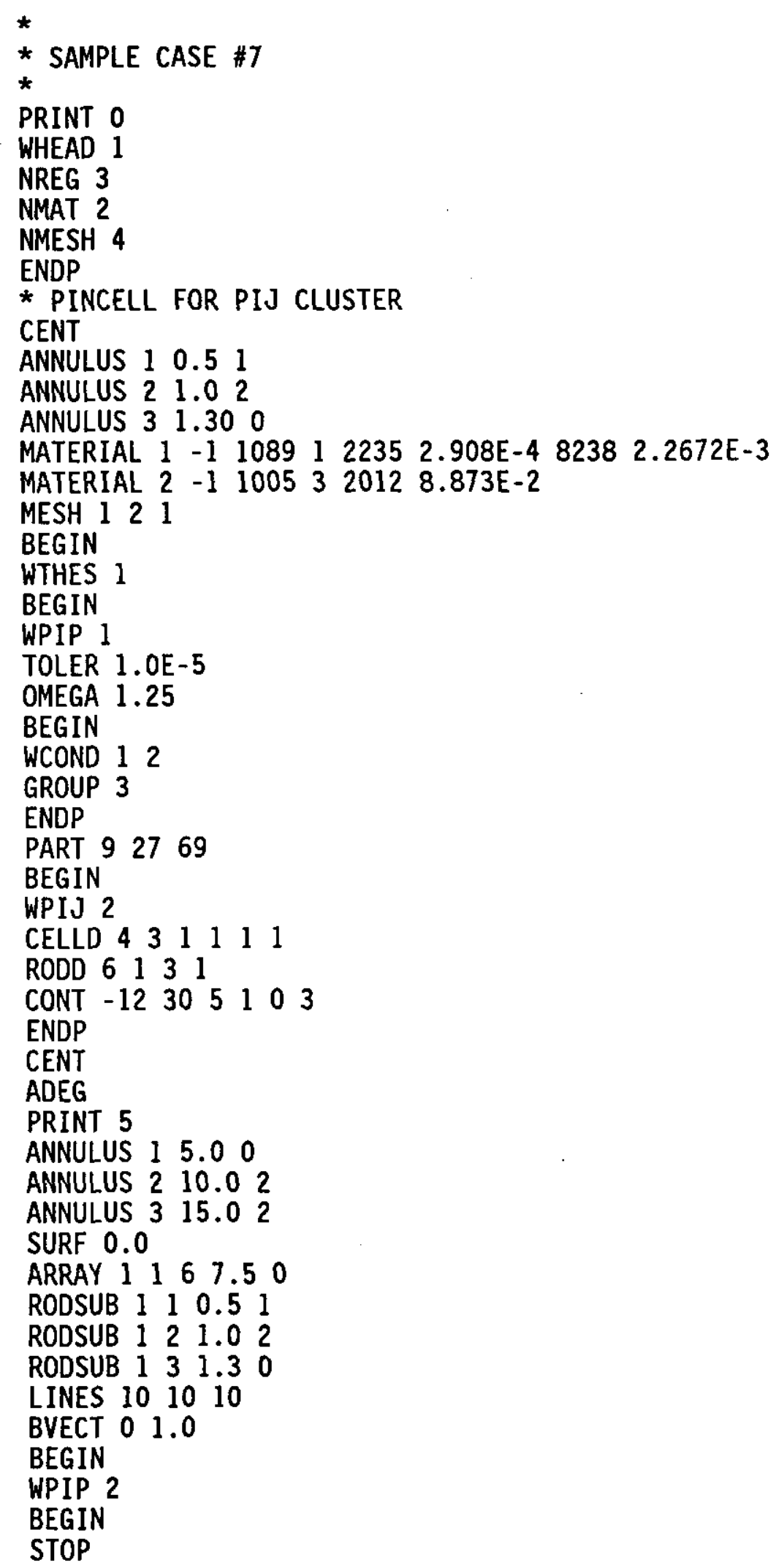


SNF-4503, Rev. 1

WHC-SD-NR-SWD-017

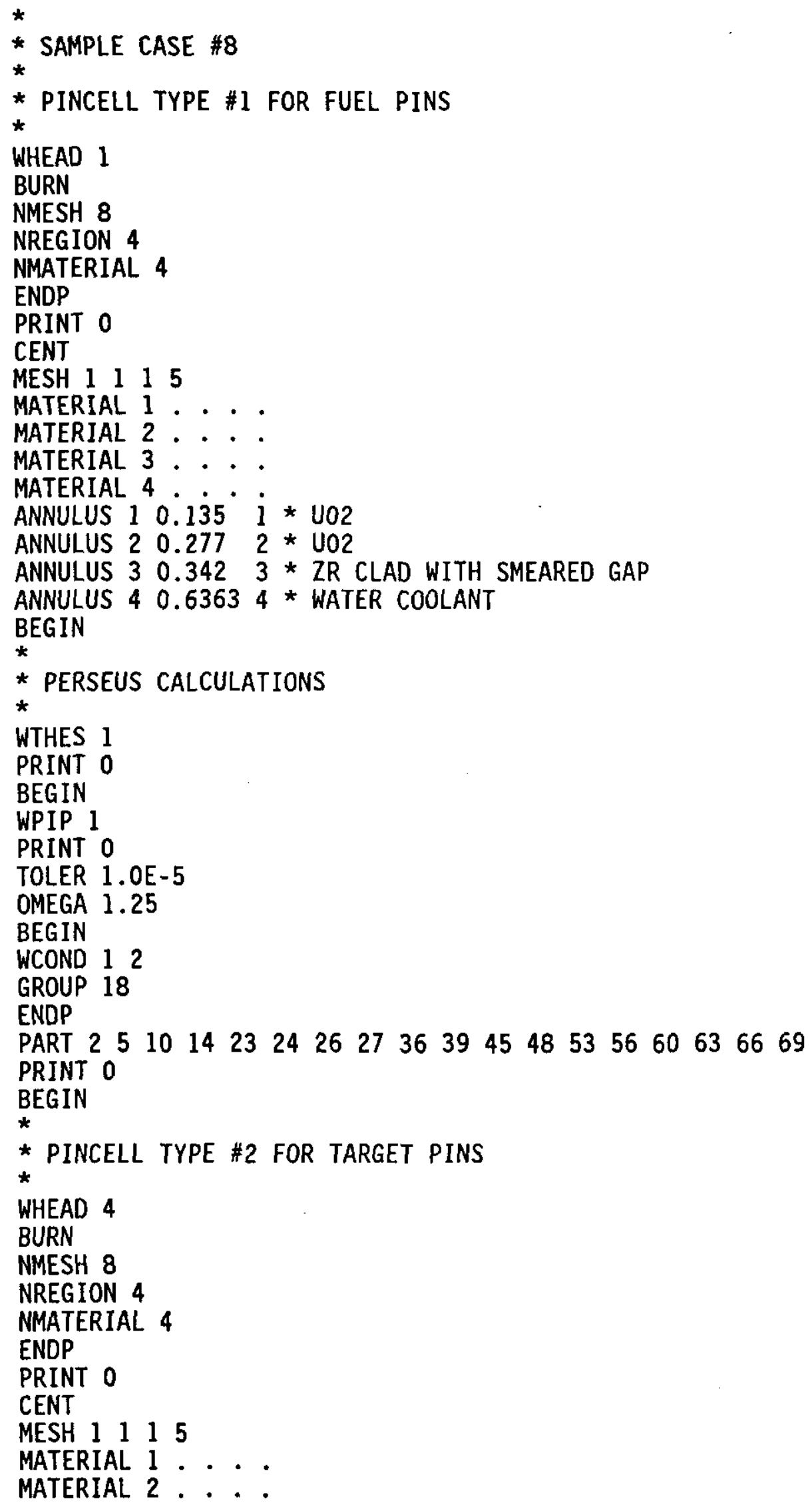


WHC-SD-NR-SWD-017

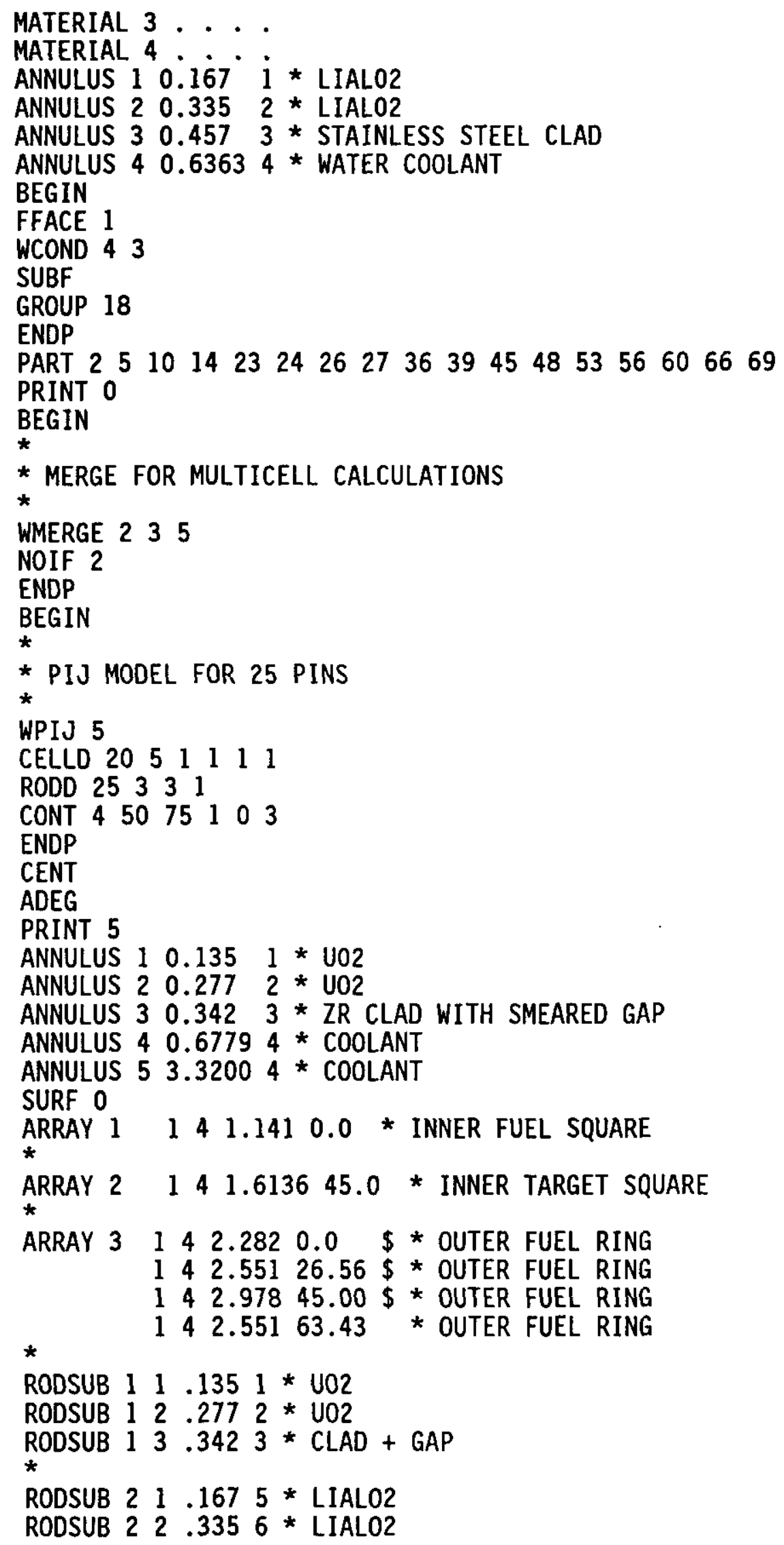


SNF-4503, Rev. 1

WHC-SD-NR-SWD-017

RODSUB 23.4577 * CLAD

*

RODSUB 31.1351 * U02

RODSUB 32.2772 * U02

RODWUB $3 \quad 3.3423 \bullet$ CLAD + GAP

*

$\begin{array}{llllll}\text { LINES } & 10 & 10 & 10 & 10 & 10\end{array}$

BVECT 01.0

BEGIN

WPIP 5

BEGIN

STOP 
SNF-4503, Rev. 1

WHC-SD-NR-SWD-017

W-CACTUS - Solves two-dimensional transport equations with the aid of lines or tracks as used in collision probability calculations.

- general geometry features

- limited to geometries with rectangular outer boundary with reflecting or periodic boundary conditions.

Geometry

User defines the problem in terms of "nodes," edges," "elements," and

1. Node = any point on an $x-y$ map of the problem

2. Edge = connection of two nodes by either a straight line or a circular $\operatorname{arc}$

3. Element = discrete zone defined by edges

4. Insert = special provision to simplify the definition of cylindrical fuel pins

No "islands" are permitted in the problem except for those defined by "inserts."

Input

WCACTUS $m$

PRELUDE MNODE, MEDGE, MELEM, MIN, MJ, MK, NNN5, MSIDE, MGRP, MMAT

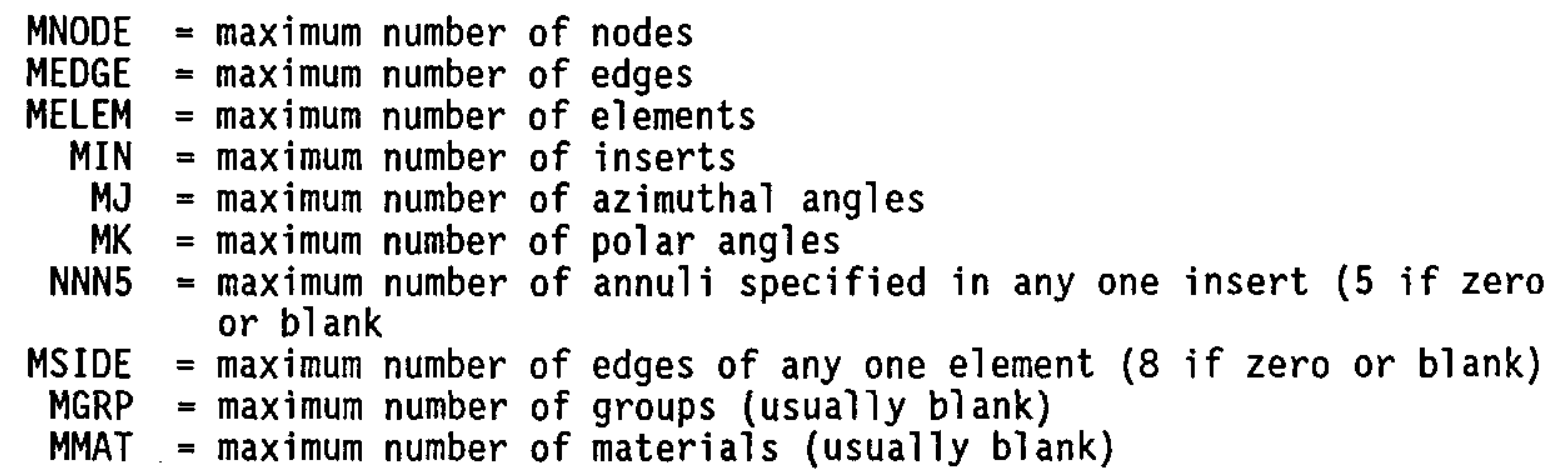

\section{GEOMETRY}

DIMENSION XMAX, YMAX

NODES

$V_{1} V_{2} V_{3} V_{4}$ - general form. By default, $v_{1}$ and $v_{2}$ are the $x$ - and $y$ coordinates relative to an origen at the bottom left hand corner of the problem. For this case, $V_{3}$ and $V_{4}$ are omitted. See Roth and Halsall (1983) for details for RTHETA coordinates.

EDGE - One line for each edge. For a straight line, 2 data items are required. - the node numbers at the ends of the edge. For an arc, 4 numbers are needed 2 node numbers and the $x$ - and $y$-coordinates of the center of curvature of the arc.

\section{A-27}


SNF-4503, Rev. 1

WHC-SD-NR-SWD-017

Node numbers are given in counter-clockwise direction.

ELEMENTS - One line for each element containing a list of edge numbers defining the element. Normally listed in counter-clockwise order.

For a simple $x-y$ mesh, with or without inserts, the DIMENSION, NODES, EDGES, and ELEMENTS data can be replaced by the much simpler XYCOORDINATES or XYINTERVALS.

See reference for details on BOX option.

\section{INSERTS}

$I N, X C, Y C,(\operatorname{RAD}(L), L=1, N)$

IN $=$ element number to be inserted

$X C, Y C=X$ - and $y$-coordinates of the insert center

$R A D(L)=1$ ist of radi $i$ of $N$ concentric insert annuli

MATERIAL - material identification numbers of each region in turn; that is, first for each element and then for each annulus of each insert in the order they were specified.

\section{ENDGEOMETRY}

PICTURE - Produces a graphics file which will draw a picture on a TEK graphics terminal of the CATCUS geometry.

The user must supply information which tells the code how to "draw" its tracks for solving the problem. Two keywords must be used:

AZIMUTHAL NJ, SEPMAX, KH, KV, ISYM, PROP, IAZM

where $\mathrm{NJ}$ is the number of azimuthal angles (i.e. in the $x-y$ plane) $(7,5,3,2$ respectively may be sufficient for the 4 values of ISYM given below)

SEPMAX is the maximum separation between tracks (this should be of the same order of magnitude as the geometric detail)

$\mathrm{KH}=1$ or 2 indicates translation or reflection at the horizontal boundaries $\left(y=0, y=y_{\max }\right)$ of the problem.

$K V=1$ or 2 indicates translation or reflection at the vertical boundaries $\left(x=0, x=x_{\max }\right)$ of the problem 
ISYM denotes an angle $2 \pi$ /ISYM which may be divided between the $\mathrm{NJ}$ tracks. Values may be

1 for cases with all translational boundaries and ny symmetry

2 for cases with translational boundaries at $x=0, x=x_{\max }$, i.e. with $\mathrm{KH}=2$ and $\mathrm{KV}=1$

4 for general cases with reflecting boundaries

8 for reflecting boundary cases with symmetry about the $x=y$ diagonal. In the limit of many angles and close lines there may be a detectable lack of symmetry in the flux solution when the angles are restricted to $45^{\circ}$. The eigenvalue will be correct in such a situation and a best estimate of fluxes could be obtained by smearing symmetrically placed regions.

PROP is normally zero or blank. This parameter is used in the definition of a track starting point, and default values are 0.249 if the vertical boundaries are reflecting $(K V=2)$ and 0.499 if these are translational $(K V=1)$. These default values will be supplied if PROP and IAZM are blank.

IAZM is normally zero or blank. If a value 2 is input, the AZIMUTHAL card must be followed by $\mathrm{NJ}$ further cards each with a value of angle (in degrees), SEPMAX, and PROP. (No default values.)

For continuation cases, it is necessary only to specify values on this line up to the last one that is required to be changed.

POLAR NK POW

where NK is the number of polar angles ( 3 may be sufficient)

POW may have values of 0 or 1 and is the power of $\cos \phi$ in the polar angle subdivision algorithm. The recommended value is zero, or blank.

The following data apart from the terminating keywords are optional and can be input in any order.

If CACTUS is run normally in a sequence of WIMS-E modules, the nuclear data will be read from the interface indicated in the control data used to call CACTUS. If the user wishes to run CACTUS as an independent program that does not interact with any WIMS-E interface, he can specify MGRP and MMAT in the PRELUDE data and CACTUS will then expect to read cross sections from lines of data following the keyword:

\section{NUCLEAR}

The lines of data that follow are:

a Number of energy groups, number of materials (unformatted)

b Fission spectrum (unformatted with $\$$ to indicate continuation to the next line if necessary)

c For each material:

i a title line (unformatted)

ii for each energy group $\mathrm{J}$, (in standard DSN format) 


\section{WHC-SD-NR-SWD-017}

$$
\begin{aligned}
& M, N, \sum_{t}, \nu \sum_{f}, \sum_{f} \quad(2 I 6,3 E 12.4) \\
& \sum_{a}, \sum_{s}(L=L L, L L L) \quad(6 E 12.4) \\
& \text { where } L L= J-M+2 \text { (M is the position on the second line of } \\
& \text { the self scatter cross section) } \\
& L L L= J-M+N \text { (N is the number of items on the second } \\
& \text { and subsequent lines if necessary) } \\
& \sum_{t}= \text { transport corrected total cross section } \\
& \nu \sum_{f}= \text { fission yield cross section } \\
& \sum_{f}= \text { fission cross section } \\
& \sum_{a}= \text { absorption cross section (including fission) } \\
& \sum_{s}= \text { scattering cross section from group } J \text { to other } \\
& \text { groups } L
\end{aligned}
$$

CACTUS normally writes WIMS-E File 4 (geometry) and File 5 (fluxes) to the interface from which the cross section data were read. If these data were not read from a WIMS-E interface, but under control of the keyword NUCLEAR, then the geometry and fluxes will not be written to a WIMS-E interface. It is also possible to suppress the writing of Files 4 and 5 by inserting the line:

LINK L

where a negative value of $L$ will suppress the output and a zero or positive value will cause it to be written. This option is most likely to be useful if several CACTUS cases are run consecutively within a sequence of WIMS-E modules, and output is required only from the last.

A few optional keywords are available to control convergence criteria and amount of printout:

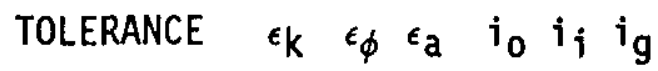

where $\epsilon_{\mathbf{K}}$ is the required convergence accuracy of $k_{\infty}$ (default $10^{-5}$ )

$\epsilon_{\phi} \quad$ is the required convergence accuracy of scaler flux (default $10^{-4}$ )

$\epsilon_{\mathrm{a}}$ is the required convergence accuracy of boundary angular flux (default $10^{-4}$ )

$i_{0} \quad$ is an upper limit to the number of outer iterations (default 50)

$i_{i} \quad$ is an upper limit to the number of inner iterations (default $\infty$ )

$i_{g}$ is an upper limit to the number of inner iterations per energy group (default 2) 


\section{WHC-SD-NR-SWD-017}

$$
\text { EDITS } E_{i}, i=1 \text { to } 4
$$

where zero values give no edit output and values of unity produce output as follows (default values are $0,0,1,1$ )

$$
\begin{array}{ll}
\mathbf{i}=1 & \text { absorptions and fissions for every region in the problem } \\
\mathbf{i}=2 & \text { scatters for every region } \\
\mathbf{i}=3 & \begin{array}{l}
\text { a sum over the whole problem of absorptions, fissions, and } \\
\text { scatters }
\end{array} \\
\mathbf{i}=4 & \begin{array}{l}
\text { a print of the iteration count, fluxes and } k \infty \text { at every } E_{4} \text { th outer } \\
\text { iteration }
\end{array}
\end{array}
$$


SNF-4503, Rev. 1

WHC-SD-NR-SWD-0I7

$$
\text { W-CACTUS (cont.) }
$$

$$
\begin{gathered}
\bar{O} \equiv \omega \equiv \\
\{
\end{gathered}
$$

ENDC

Example

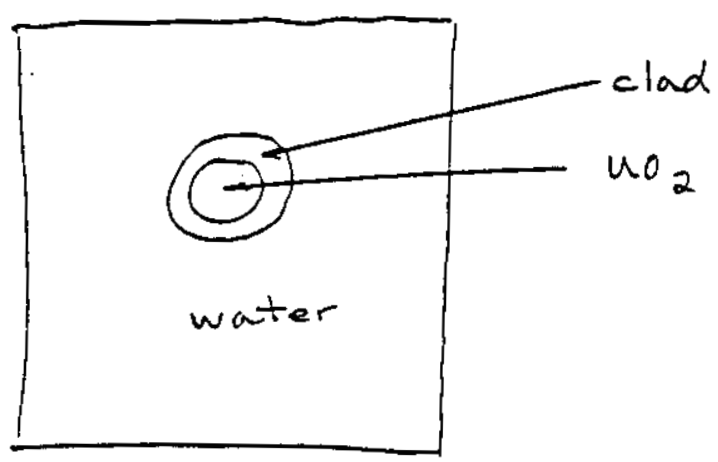


SNF-4503, Rev. 1

WHC-SD-NR-SWD-017

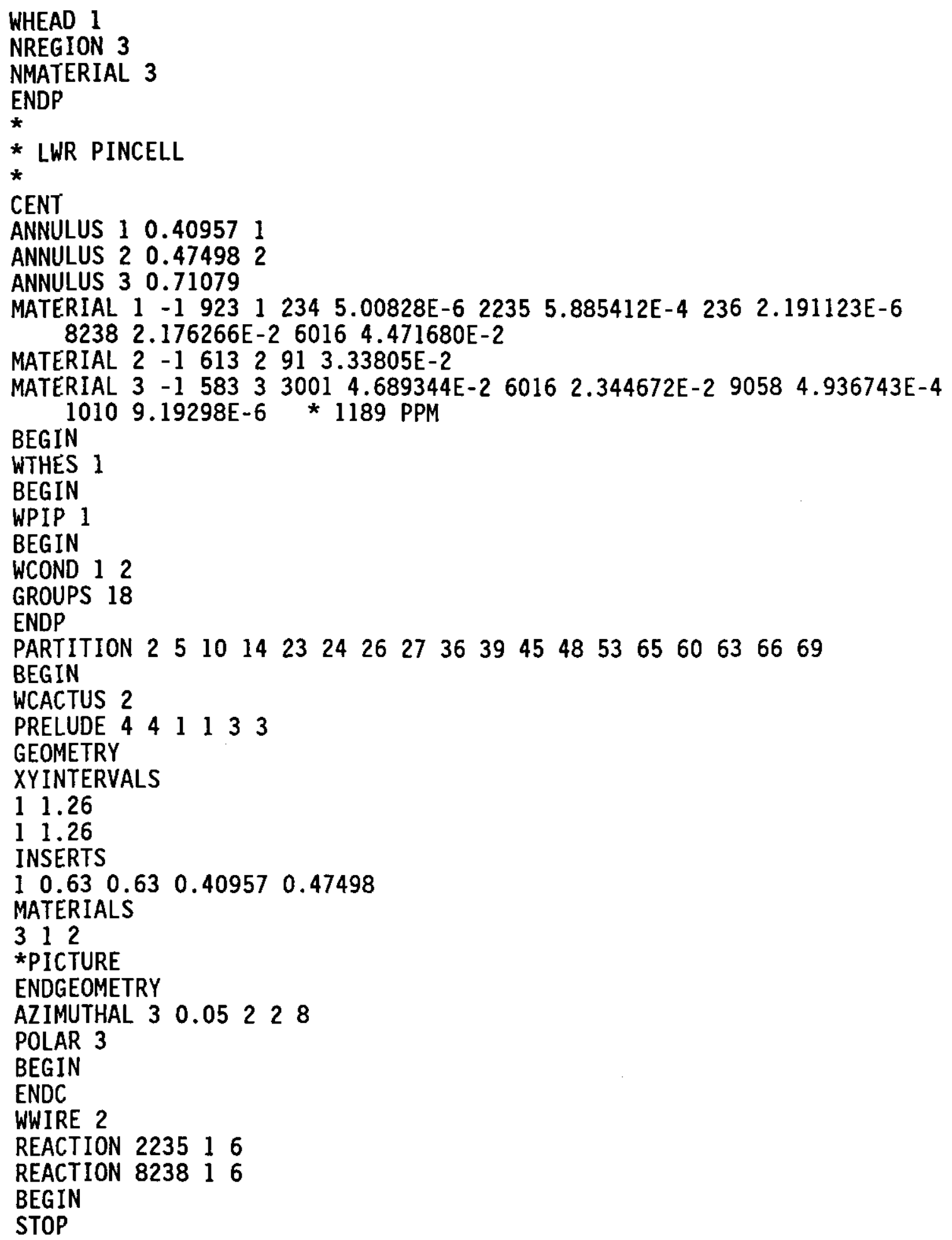


SNF-4503, Rev. 1

WHC-SD-NR-SWD-017

W-CACTUS (cont.)

1.

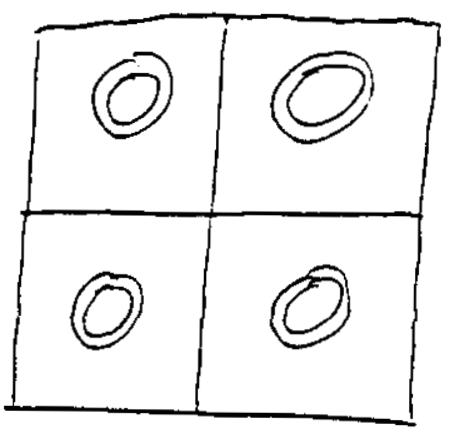

Did work.

2.

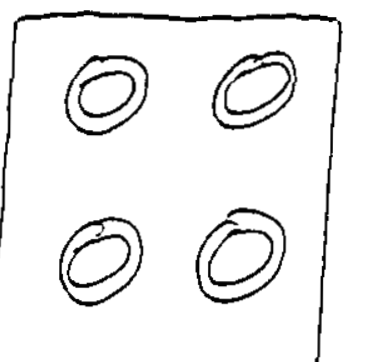

Did work!

3.

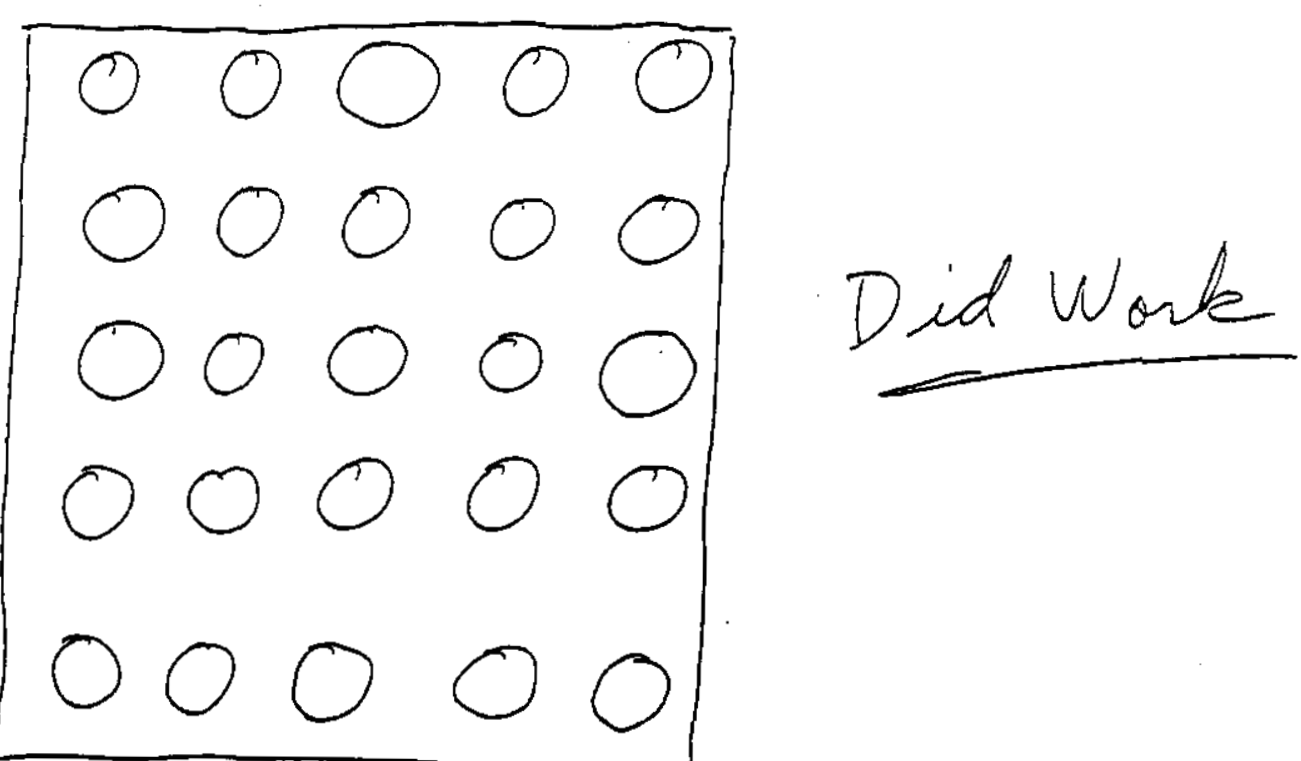

$5 \times 5$ burma (5 steps) - 3 min. CRAY $19 \times 19$ burnous $(5$ steps $)-30 \mathrm{~min}$ CRAY

A-34

Attachment 1 
SNF-4503, Rev. 1

WHC-SD-NR-SWD-017

WIMS-E 1986 CROSS SECTION LIBRARY

Nuclide ID

$\checkmark 3001$

3002

3

4

6

7

9

10

1010

1011

2012

2212

14

6016

19

23

24

27

29

48

51

$\times \quad 52$

1054

55

2056

9056

58

1058

3058

8058

9058

1059

$\checkmark 3063$

84

$\checkmark \quad 91$

1091

93

96

2103

3109

2113

2115

121

123

2154

2155

2156

2157

2158
Nuclide

hydrogen

deuterium

hel ium-3

hel ium-4

lithium-6 (burnable)

1ithium-7

beryllium-9

boron-10 (burnable)

boron-10 (unburnable)

natural boron (unburnable, purely $1 / \mathrm{v}<100 \mathrm{keV}$ )

carbon

graphite damage

nitrogen

oxygen

fluorine

sodium

magnes ium-24

aluminum

silicon

T:

vanadium $(n, \gamma)$ reaction

chromium

Fe-54 (n,p) Mn-54 reaction

manganese

iron

stainless steel

nickel

$\mathrm{Ni}-58(n, p) \quad \mathrm{Co}-58$

$\mathrm{Fe}-58(n, \gamma) \mathrm{Fe}-59$

Incone] 750

Inconel 718

Co-59 $(n, \gamma)$ Co-60

copper

krypton-84

zirconium

zircaloy damage

niobium ?

Mo yodear?

$\mathrm{Rh}-103\left(\mathrm{n}, \mathrm{n}^{1}\right) \mathrm{Rh}-103 \mathrm{~m}$

silver

natural cadmium

indium

ant imony-121

ant imony- 123

gadol in ium- 154

gadol in ium- 155

gadol inium-156

gadol in ium- 157

gadol in i um- 158 


\begin{tabular}{|c|c|}
\hline $\begin{array}{r}164 \\
167 \\
176 \\
2176 \\
2177 \\
2178 \\
2179 \\
2180 \\
178 \\
181 \\
197 \\
251 \\
252 \\
253 \\
254 \\
105 \\
135 \\
500 \\
4083 \\
4095 \\
4099 \\
4101 \\
5103 \\
4103 \\
4105 \\
5105 \\
4108 \\
4109 \\
4113 \\
4115 \\
4127 \\
4131 \\
4133 \\
4134 \\
6135 \\
4135 \\
5135 \\
4143 \\
4145 \\
4147 \\
5147 \\
6147 \\
4148 \\
5148 \\
5149 \\
4149 \\
4150\end{array}$ & 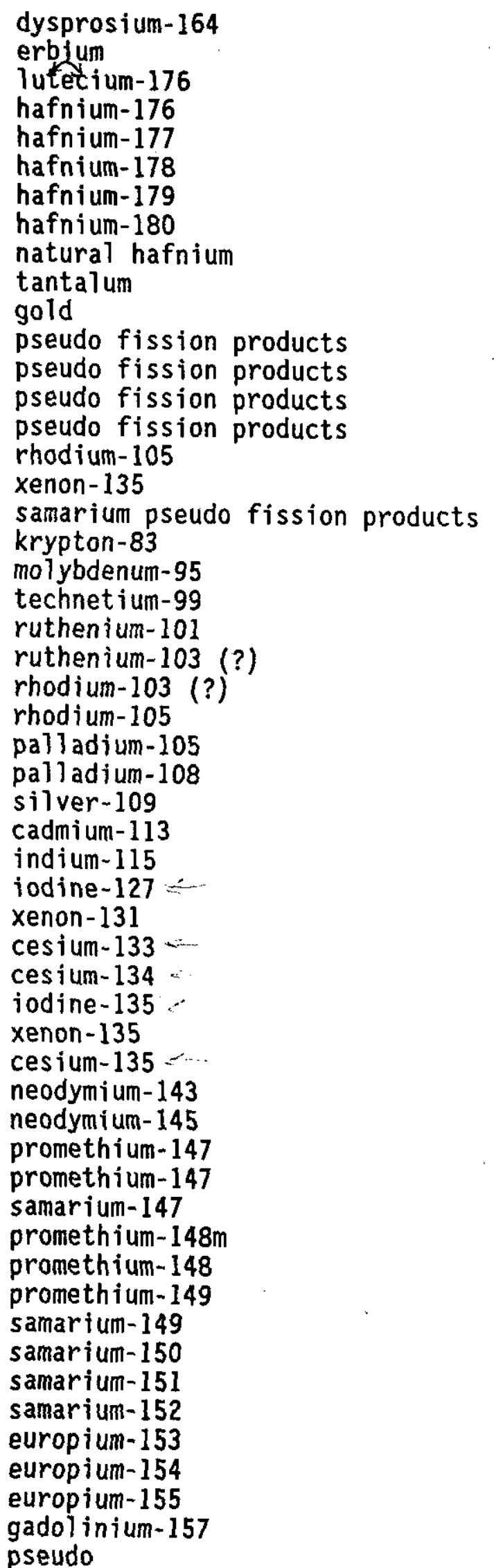 \\
\hline
\end{tabular}


SNF-4503, Rev. 1

WHC-SD-NR-SWD-017

207
2232
9233
1233
234
2235
236
927
8238
937
1939
948
6239
1240
1241
1242
951
952
953
1000
1003
1999
2000
3000
4000
3003

lead

thorium-232

uranium-233

protactinium-233

uranium-234

uranium-235

uranium-236

uranium-237

uranium-238

neptunium -237

neptun ium-239

plutonium-238

plutonium-239

plutonium- 240

plutonium-141

p Tutonium-242

americium-241

americium- 242

americium-243

$+1 / \mathrm{V}$ absorber

U-235 fission detector (from 2235 nuclide)

resonance part of $1 / \mathrm{V}$

- 1/v absorber

pure absorber

inverse lethargy intervals

tritium 
SNF-4503, Rev. 1

WHC-SD-NR-SWD-017

Appendix B

WIMS-E Test Problems

This appendix contains complete listings of the input and corresponding output for two WIMS-E Test Problems. The WIMS-E Test Case \#1 and \#3, supplied to the Hanford Site by AEE, Winfrith (code developer), were selected.

B-1

Attachment 1 
SNF-4503, Rev. 1

\section{WHC-SD-NR-SWD-017}
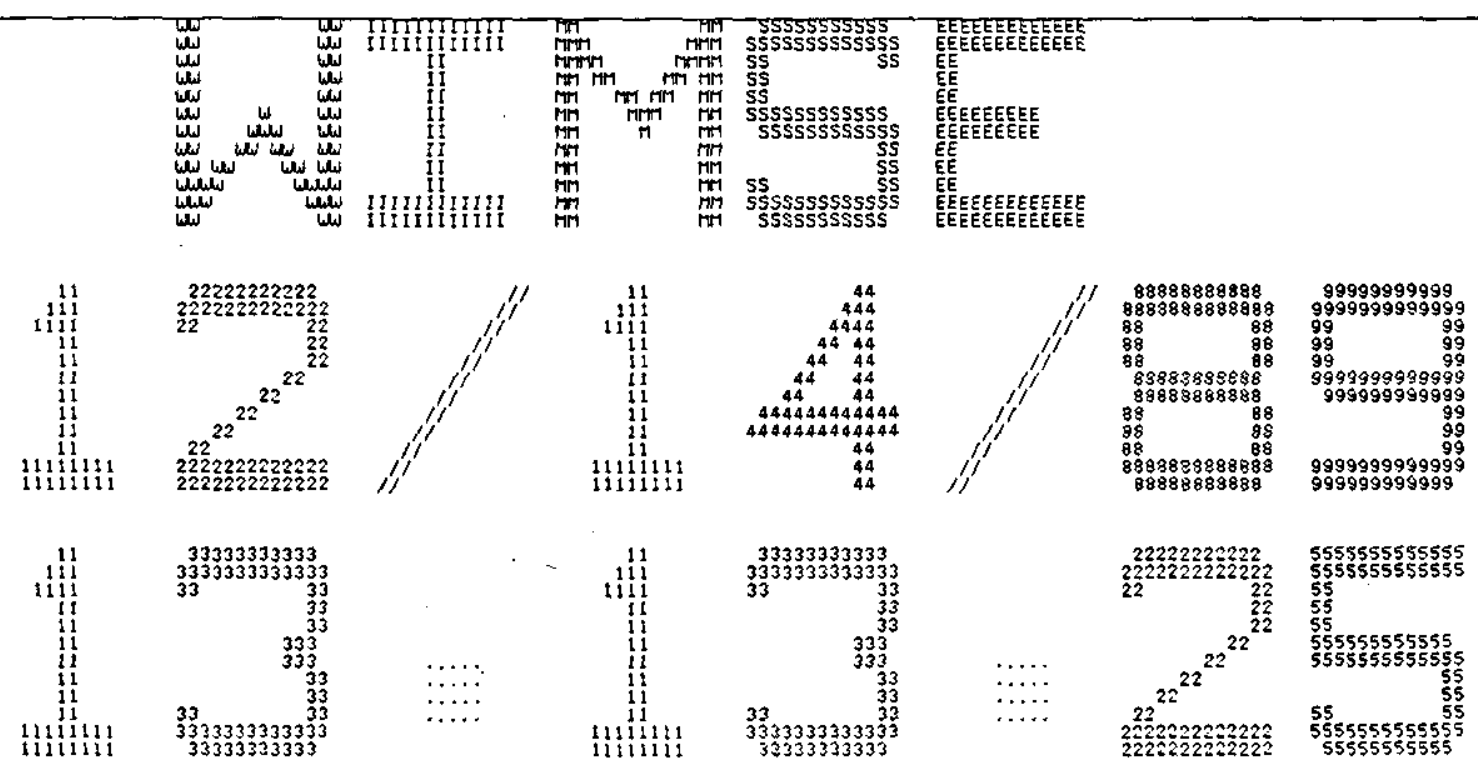
SNF-4503, Rev. 1

WHC-SD-NR-SWD-017

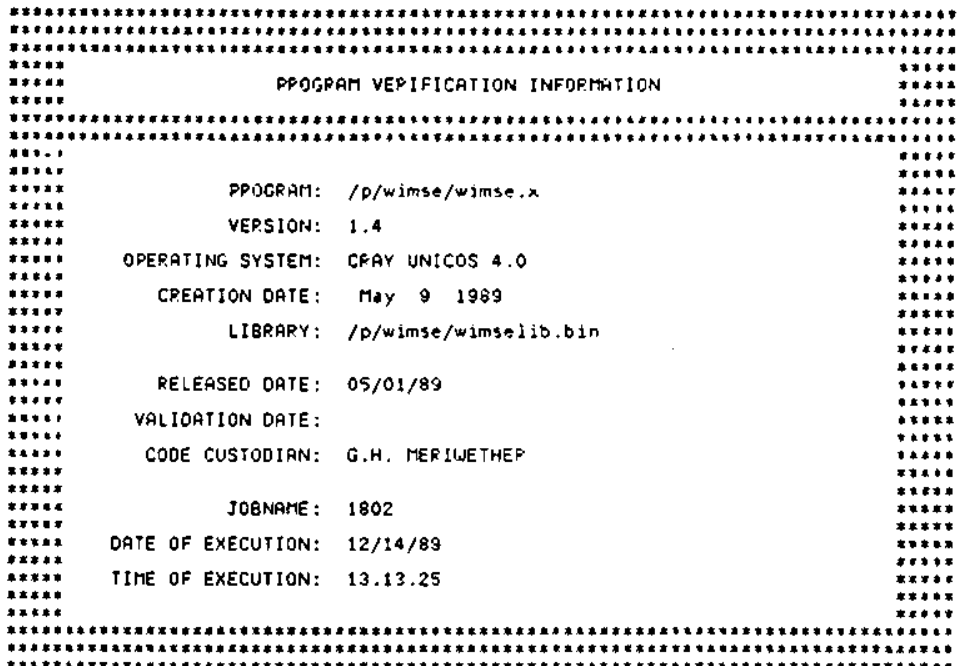

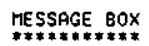

REPORTED PROBLEMS

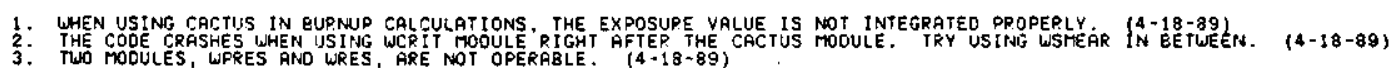


SNF-4503, Rev. 1

WHC-SD-NR-SWD-017

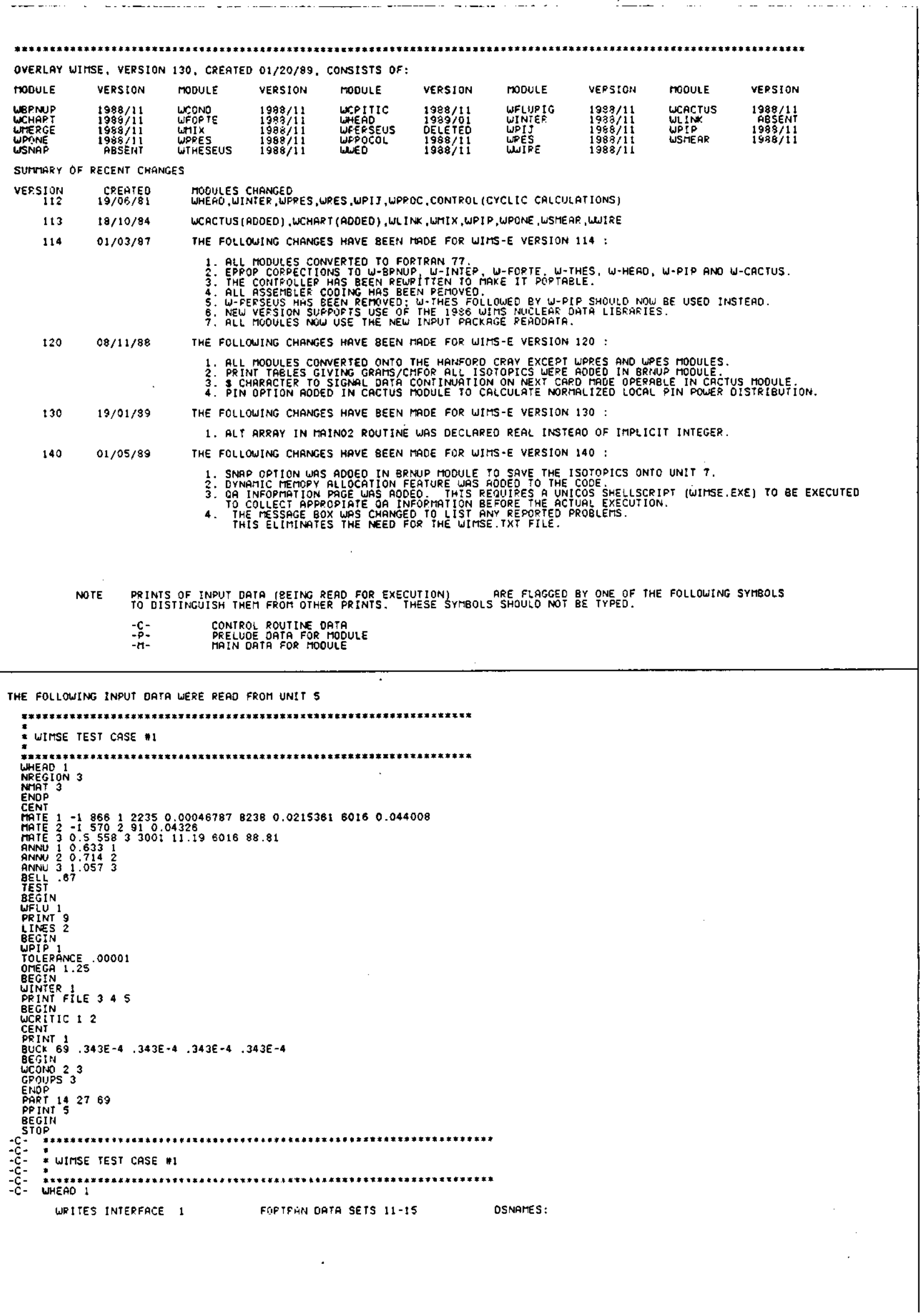




\section{SNF-4503, Rev. 1}

\section{WHC-SD-NR-SWD-017}

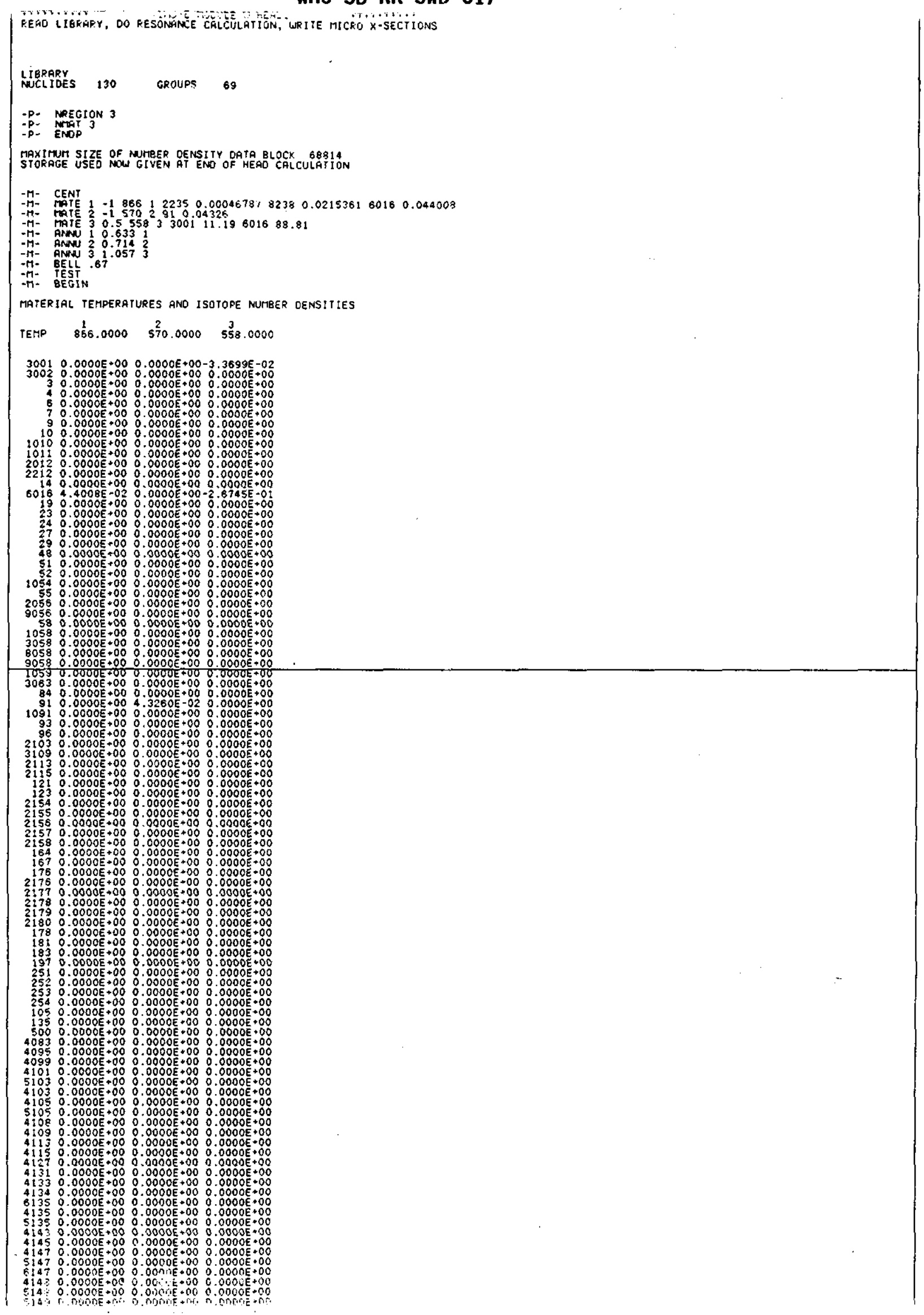

\section{B 5 ttachment 1}


SNF -4503 , Rev. 1

WHC-SD-NR-SWD-017

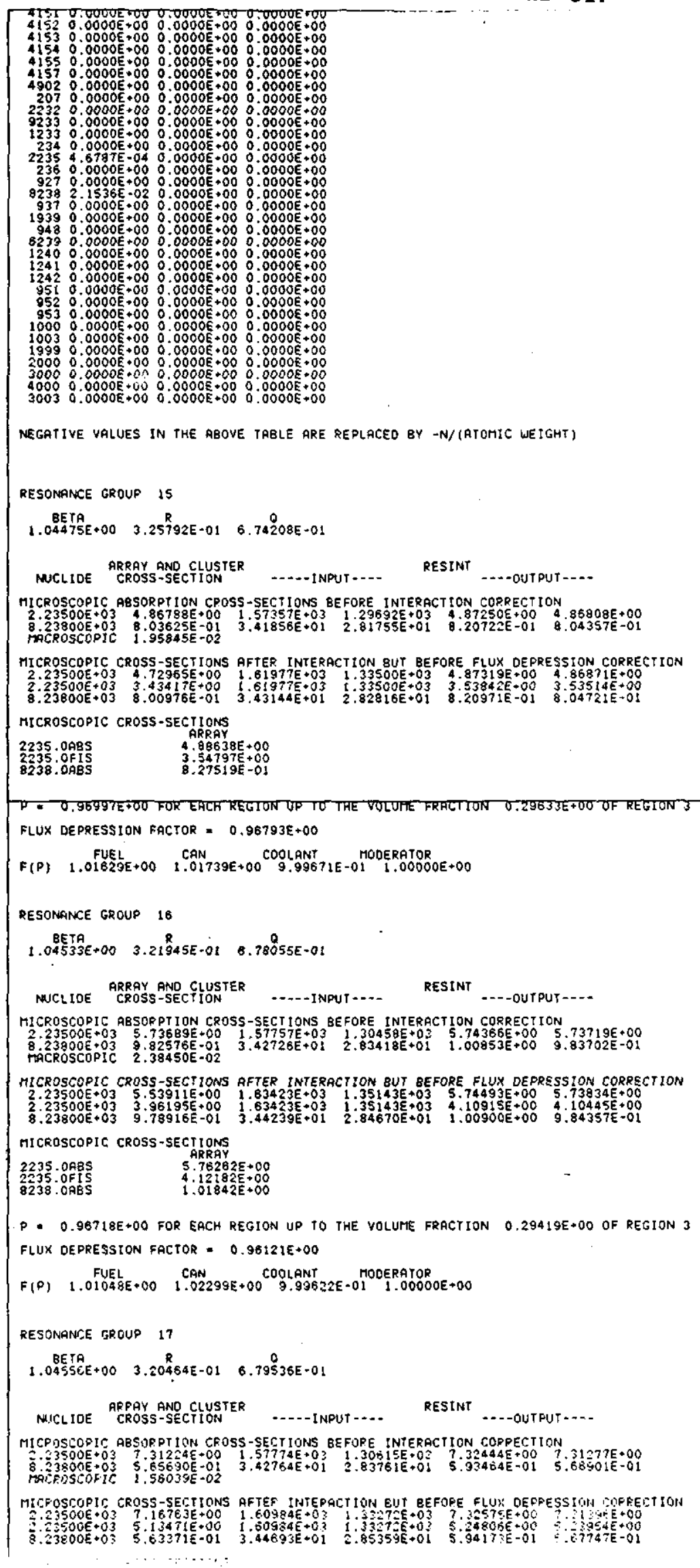

Attach 6 ment 1

1-57 
SNF-4503, Rev. 1

WHC-SD-NR-SWD-017

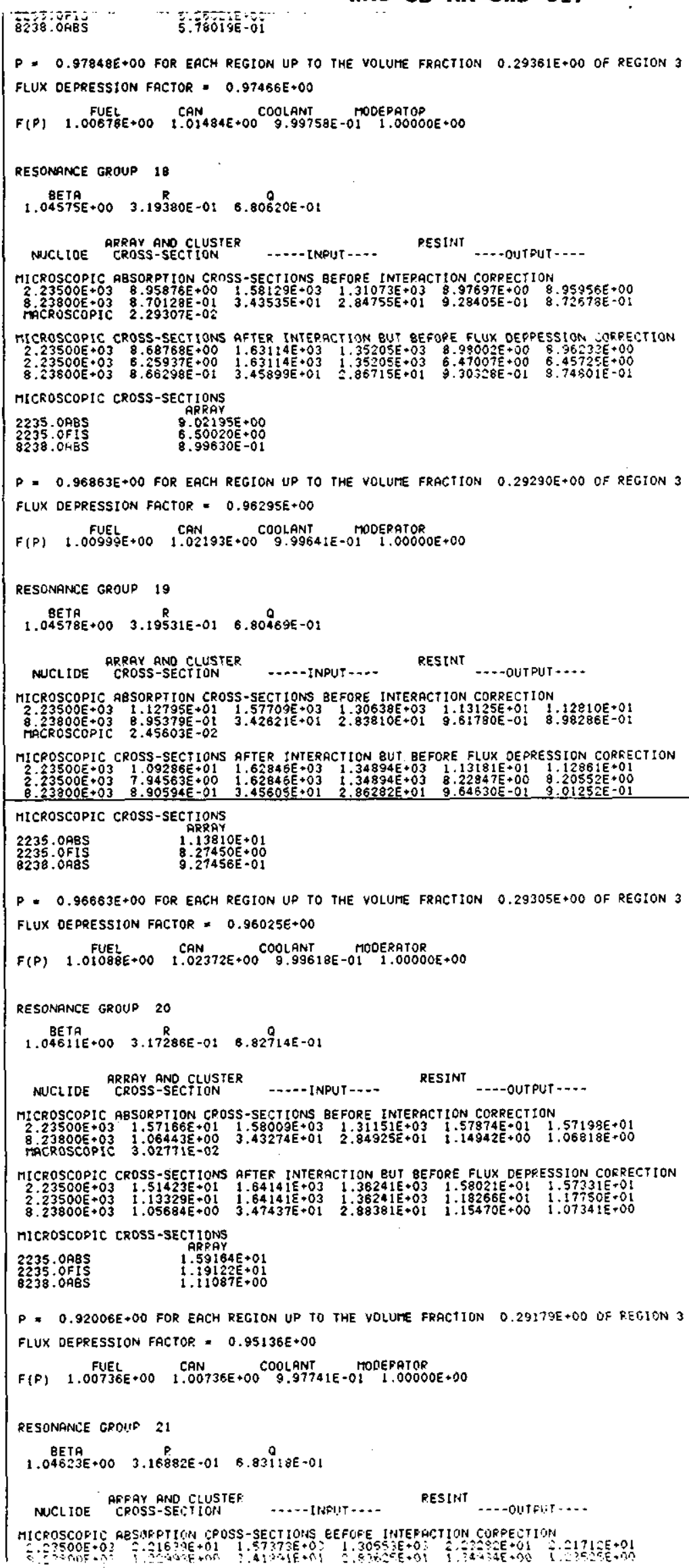




\section{SNF-4503, Rev. 1}

\section{WHC-SD-NR-SWD-017}

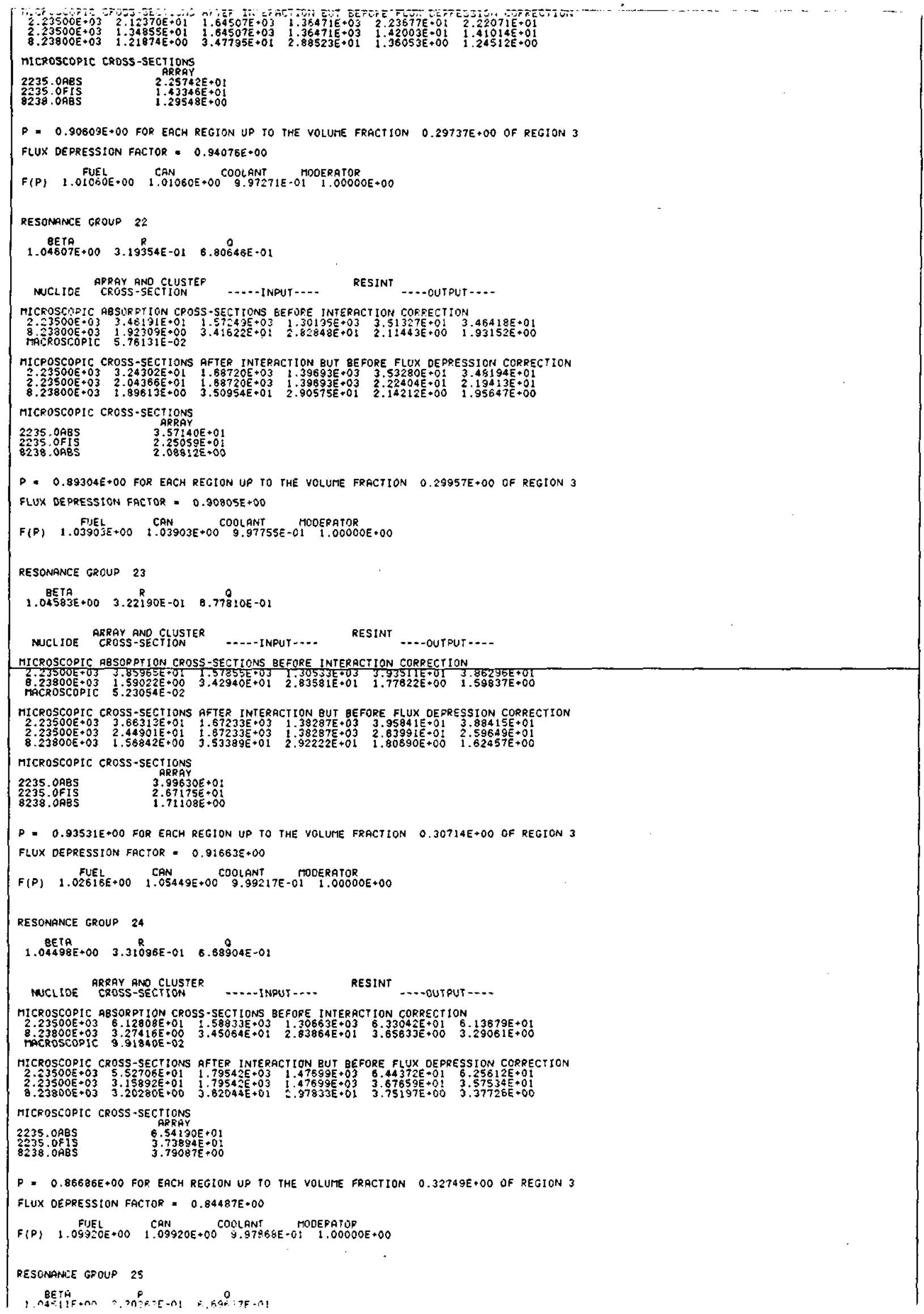




\section{WHC-SD-NR-SWD-017}

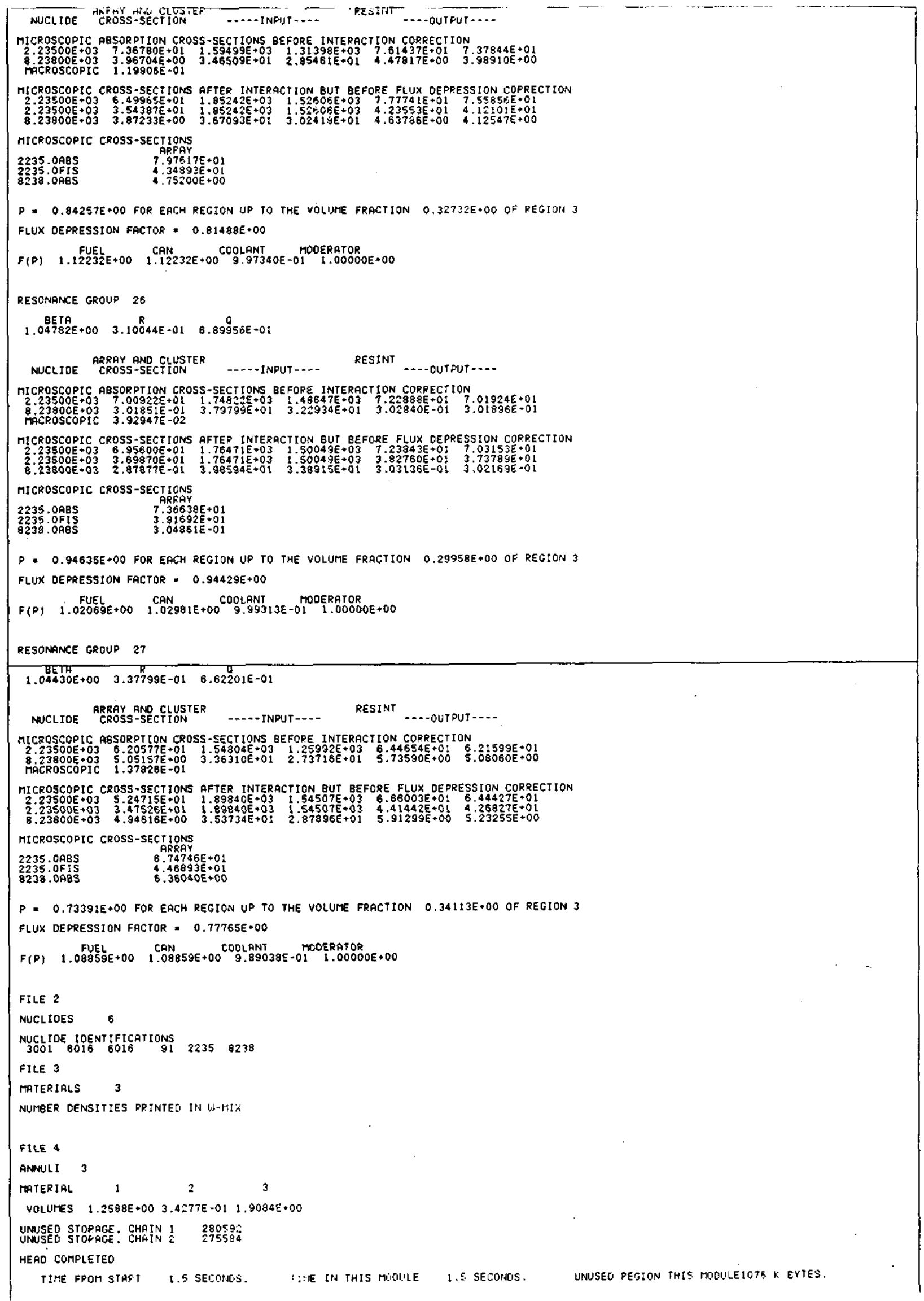


SNF-4503, Rev. 1

WHC-SD-NR-SWD-017

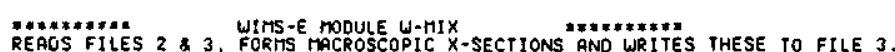

REAOS FILES $2 \% 3$ FORMS HACROSCOPIC $X$-SECTIONS AND WRITES THESE TO FILE

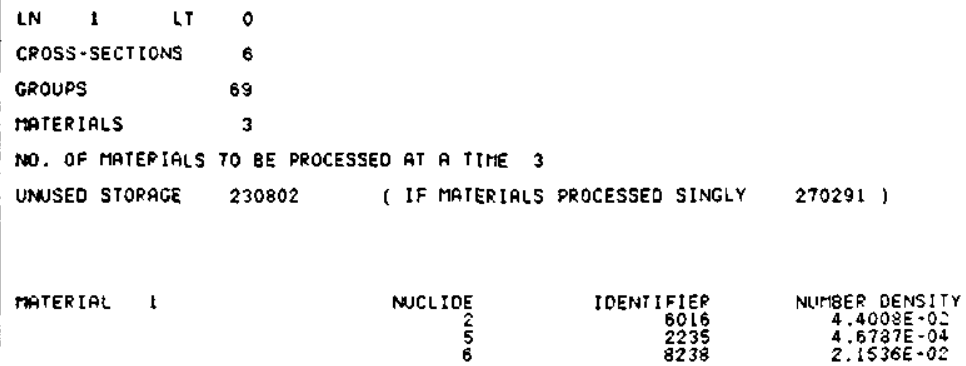




\section{SNF-4503, Rev. 1}

\section{WHC-SD-NR-SWD-017}

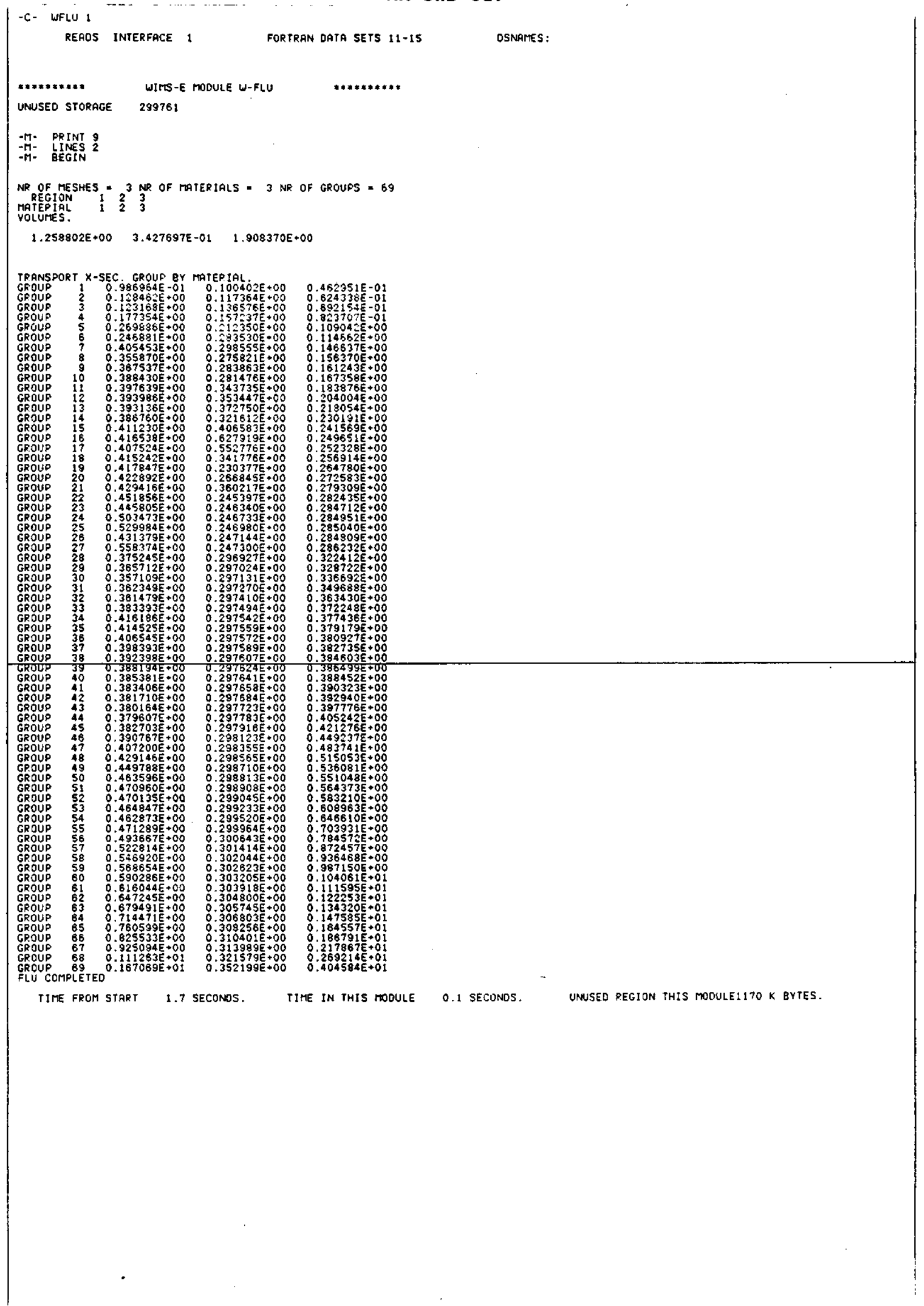

\section{B-11.ttachment 1


SNF-4503, Rev. 1

WHC-SD-NR-SWD-017

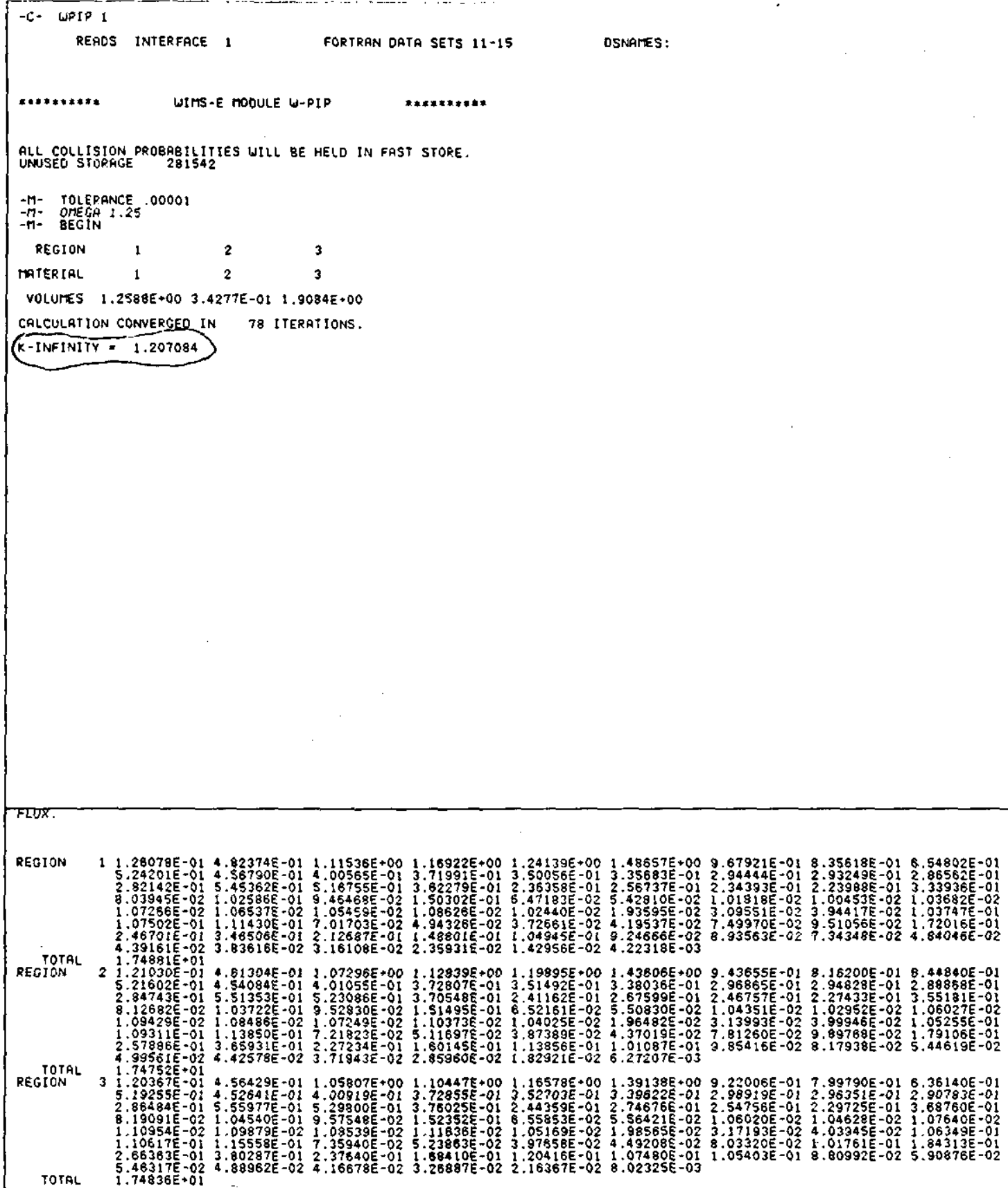

\section{B-12}

Attachment 1 


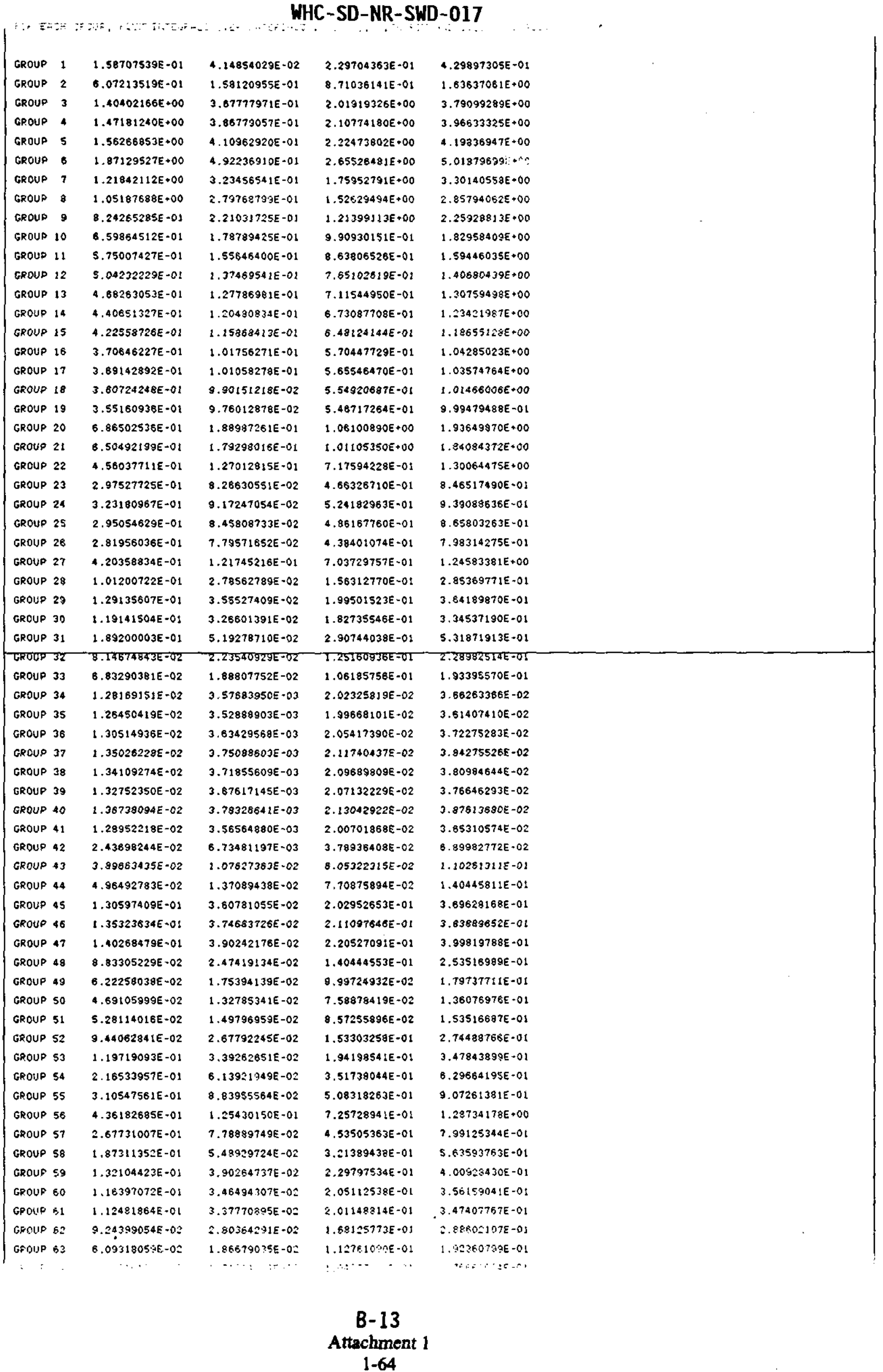


SNF-4503, Rev. 1

\section{WHC-SD-NR-SWD-017}

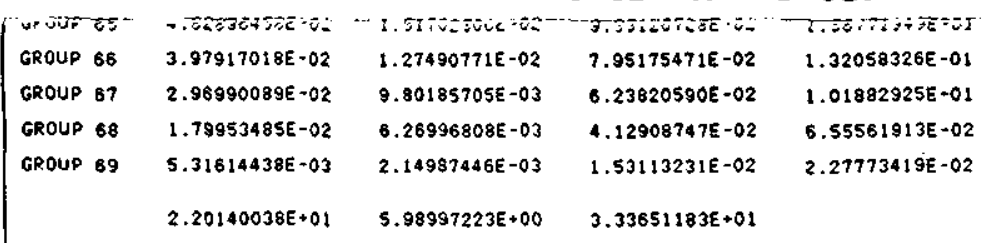
PIP COMPLETED

TITE FROM START 1.9 SECONOS. TIME IN THIS MOOULE 0.2 SECONOS. UNUSEO REGION THIS MOOULELOSS K BYTES.

$-C-$ WINTER 1

REAOS INTERFREE 1 FORTRAN ORTA SETS 11 -15 OSNATES:

**********) WITS-E HODULE W-INTER **********

-M- PRINT FILE 345
-H-

B-14

Attachment 1 
SNF-4503, Rev. 1

\section{WHC-SD-NR-SWD-017}

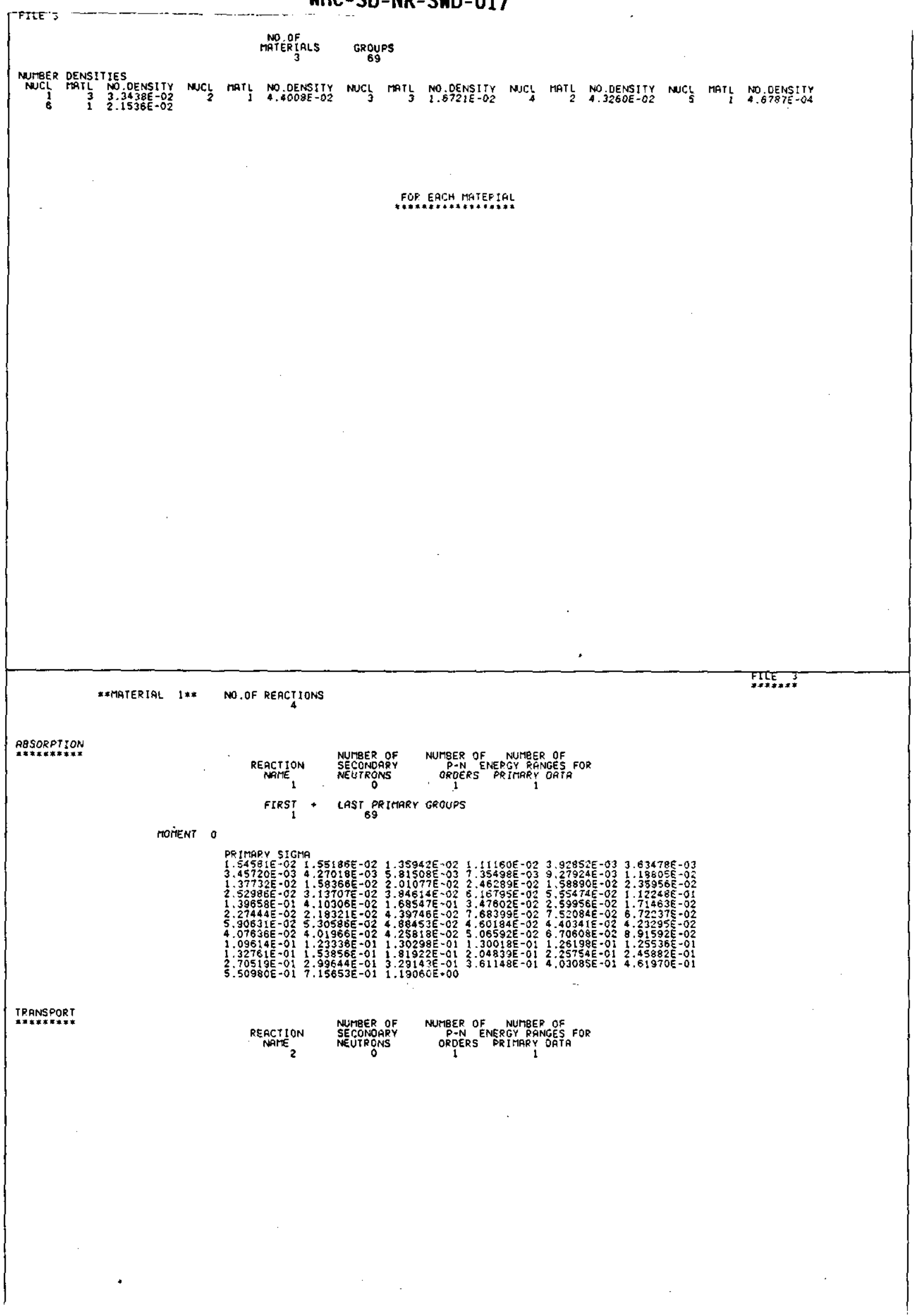

B-15

Attachment 1 
SNF-4503, Rev. 1

\section{WHC-SD-NR-SWD-017}

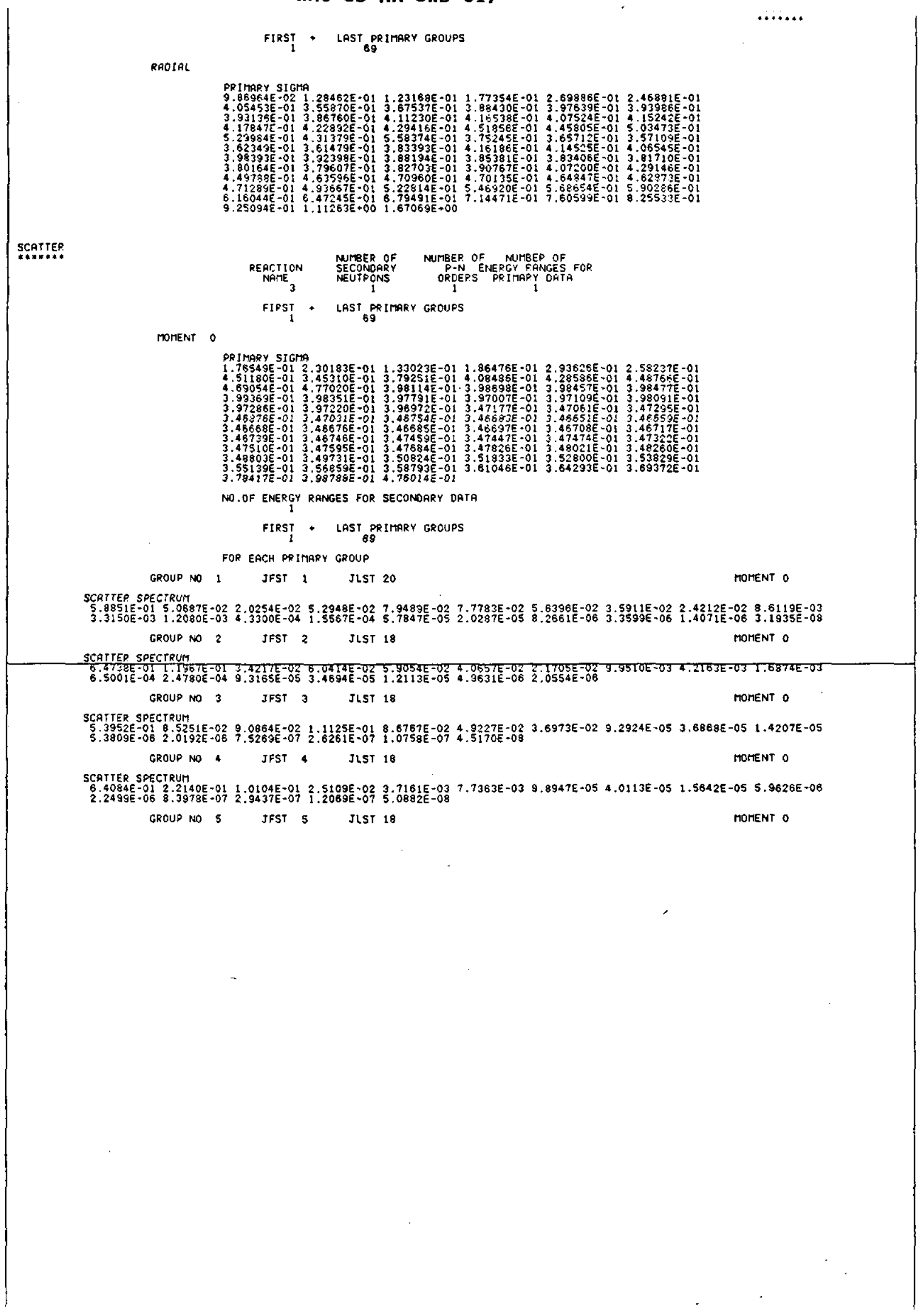

B-16

Attachment 1 


\section{WHC-SD-NR-SWD-017}

SCATTER SPECTRUM

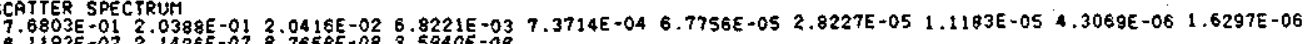
GROUP NO 6 JFST 6 JLST 1 MOMENT 0

SCAT TER SPECTRUM $\begin{array}{lll}8.5657 E-01 & 1.4286 E-01 & 2.5245 E-04 \\ 1.6520 E-07 & 6.7846 E-08 & 2.7645 E-08\end{array}$

GROUP NO 7 JFST 7 JLST 15 MUNENT 0

SCATTER SPECTRUM

MOMENT 0

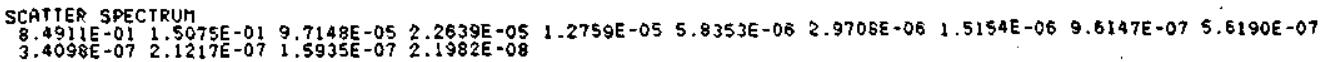

GROUD NO 9 JFST 9 JLST 16 MORENT O

SCATTER SPECTPUT GROUP NO 10 JFST 10 JLST 19 MOMENT $O$

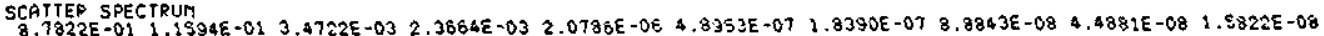
GROUP NO 11 JFST 11 JIST 19 MOMENT O

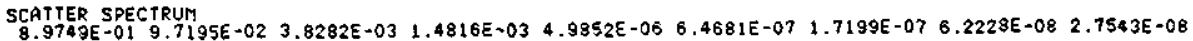

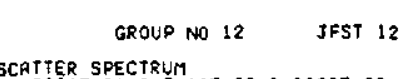

SCATFER SPECTRUMA

$$
\text { GROUP NO } 13 \text { JFST } 13
$$

SCATTER SPECTRUM

SCATYER SPECTRUT OSE-03 $3.7276 E-07$

GROUP NO 14 JFST 14

SCATTER SPECTR

S.0911E-0I $9.0897 E-02$ GROUP NO 15

SCATTER SPECTRUA
B.8928E-01 $1.1072 E-01$

GROUP NO 15

SCATTER SPECTRUM
B.783SE-01 1.2165E-01

GROUP NO 17

SCATTER SPECTRUM
$8.7874 \mathrm{E}-01$ 1.2126E-OI

GROUD NO JB

SCATTER SPECTRUM
$8.7838 E-01$ 1.2164E-OI

GROUP ND 19
JFST is

JFST 16

JFST 17

JFST 18

JFST 19
JLST 14

JLST 15

JLST 15

JLST 16

JLST 17

JLST 18

JLST 19

JLST 20
FIE: 3

MONENT O

MOMENT O

MORENT O

MONENT O

MOMENT O

MOMENT O

MOMENT O

MOHENT O 
SNF-4503, Rev. 1

WHC-SD-NR-SWD-017

SCATTER SPECTRUM
$8.7848 E-011.2153 E-01$

GROUP NO 20

JF5T 20 JLST 21

MOMENT 0

SCATTER SPECTRUM
$9.3932 E-016.0681 E-02$

GROUP NO 21

JFST 21 JLST 22

MOMENT O

SCATTER SPECTRUM
$9.3905 E-01$
$6.0944 E-02$

GROUP NO 22

JFST 22 JLST 23

MOTENT: O

SC,ATIEA SPECTRUA
9.1631 S-OI 8.3688 -02 GROUP NO 23

JFST 23 JLST 24

MOMENT O

\begin{tabular}{l} 
SCATTER SPECTRUM \\
$8.7802 E-01$ \\
\hline t.2338E-02
\end{tabular} GROUP NO 24

JFST 24 JLST 25

MOMENT O

SCATTER SPECTRUIA
$8.9129 E-01$ 1.087IE -01 Group No 25

JFST 25 JLST 26

MOMENT O

SCATTER SPECTRYM GROUP NO 26

JFSI 26

SLST 27

MOMENT O

SCATTEP SPECTRUM
$B, 8403 E-01$ I. $1597 E-01$ 
SNF-4503, Rev. 1

\section{WHC-SD-NR-SWD-017}

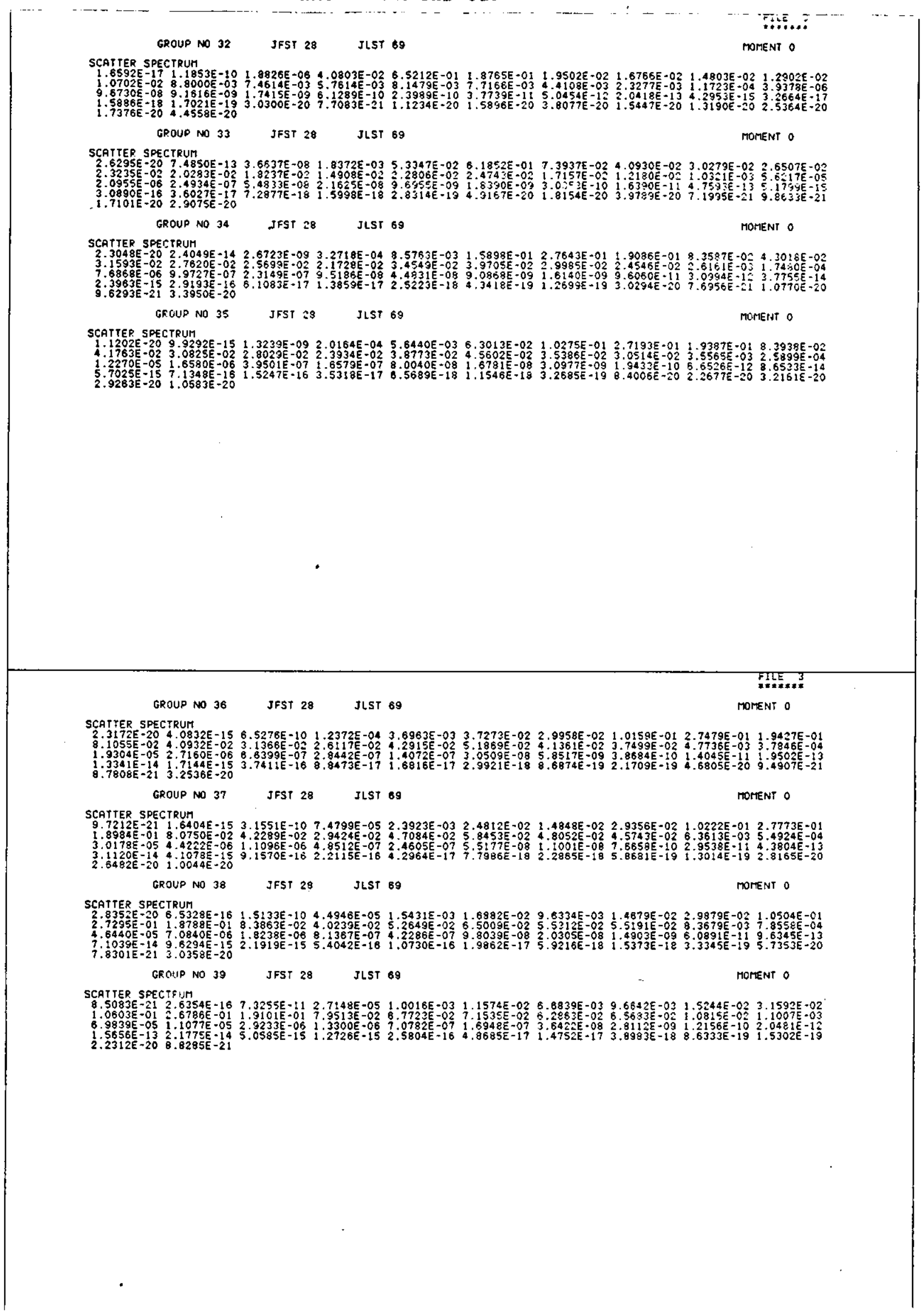

\section{B-19}

Attachment 1 
SNF-4503, Rev. 1

WHC-SD-NR-SWD-017

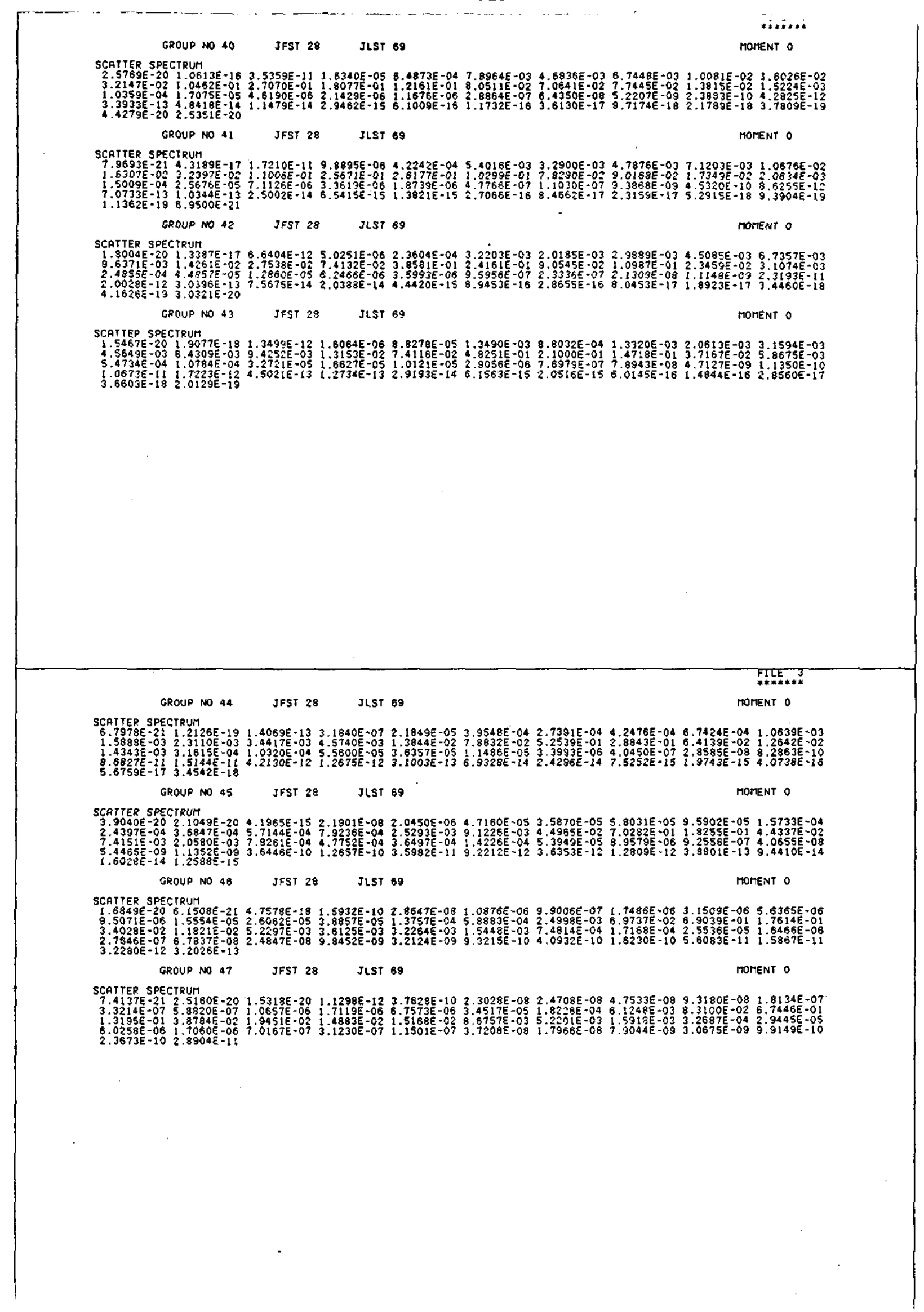


SNF-4503, Rev. 1

\section{WHC-SD-NR-SWD-017}

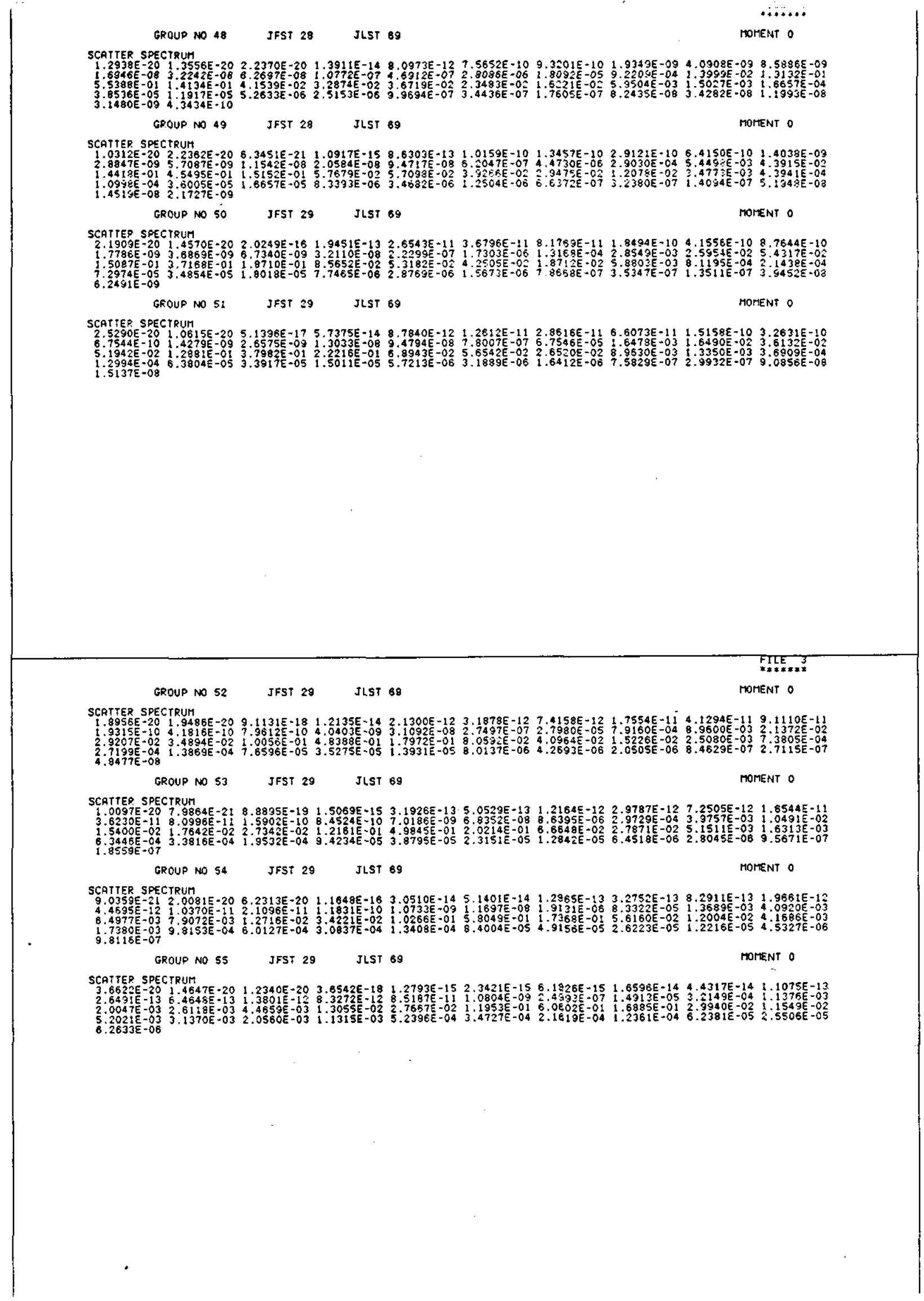

\section{B-21}

Attachment 1 
SNF-4503, Rev. 1

WHC-SD-NR-SWD-017

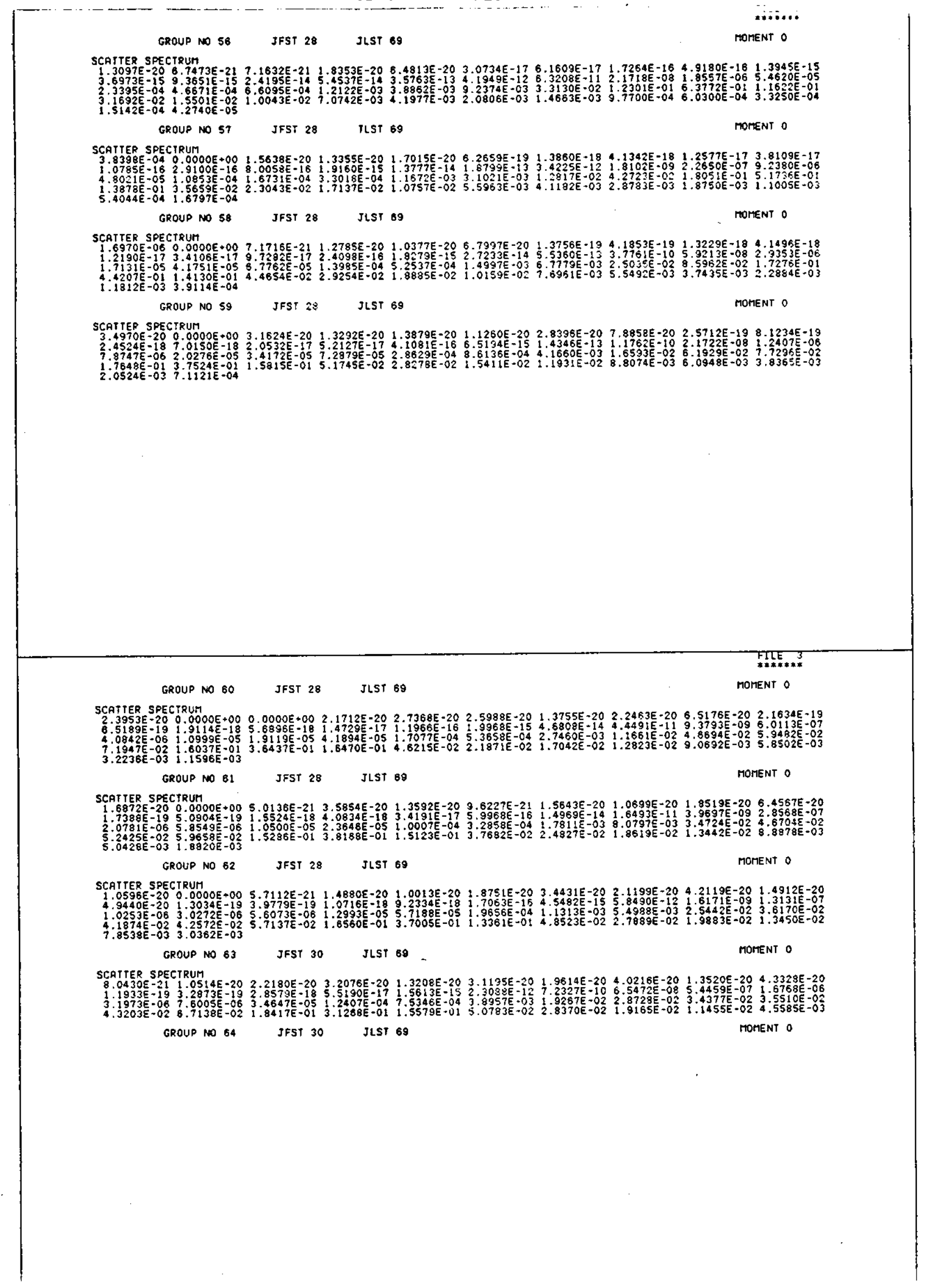

\section{B-22}

Attachment 1 
SNF-4503, Rev. 1

WHC-SD-NR-SWD-017

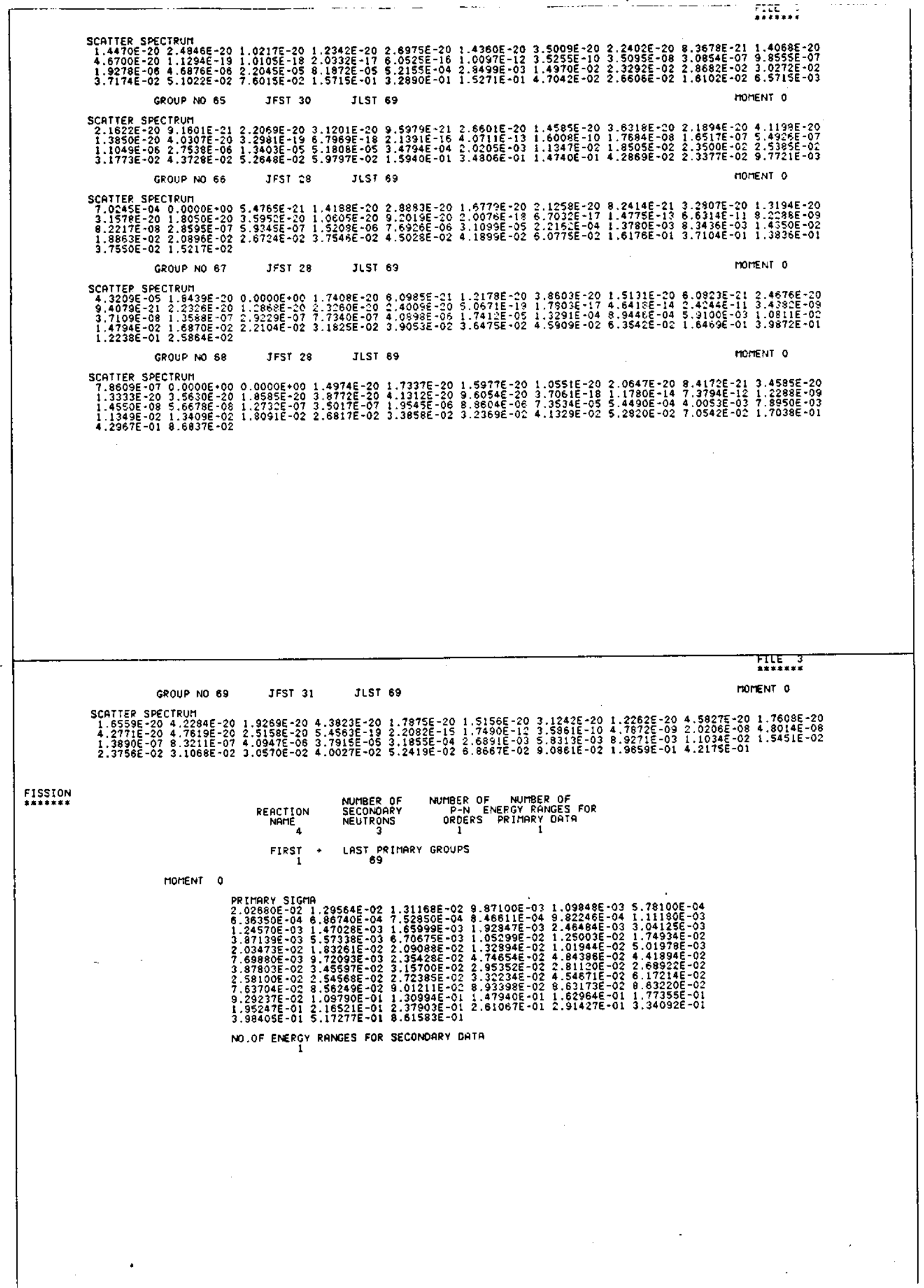

B-23

Attachment 1 
SNF-4503, Rev. 1

\section{WHC-SD-NR-SWD-017}

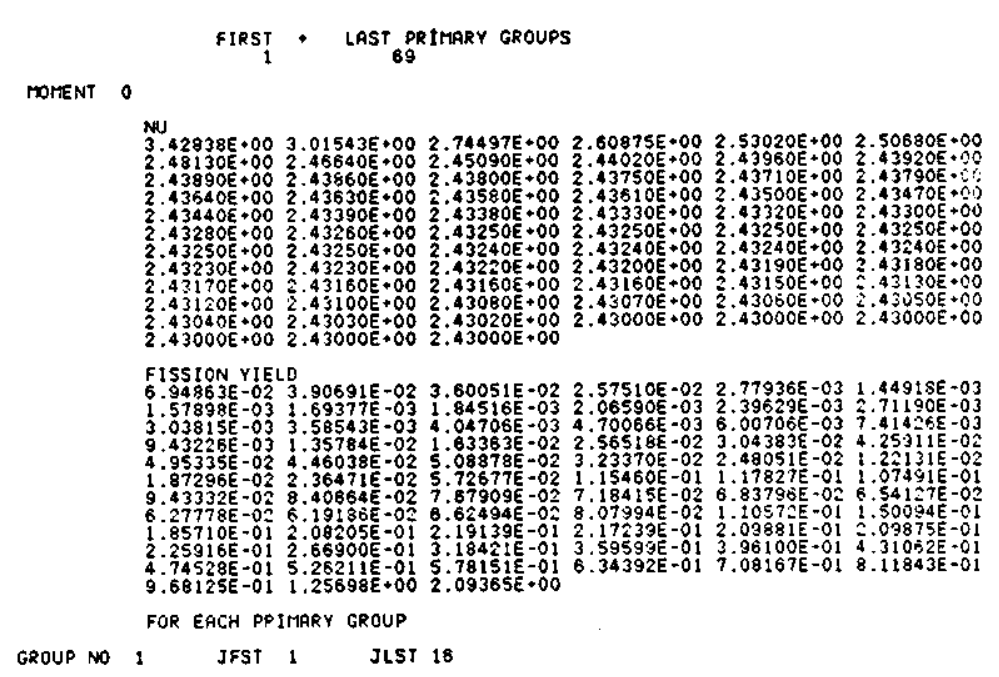

MOMENT 0

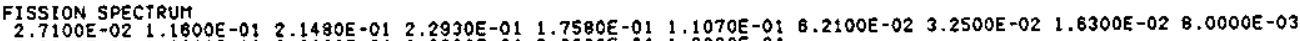

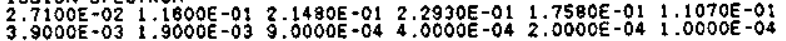

$\begin{array}{llll}\text { GROUP NO } 2 & 2 & \text { JFST } 1 & \text { JLST } 16\end{array}$

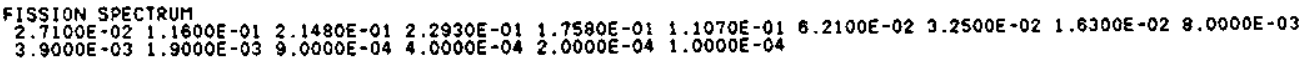

$\begin{array}{lllll}\text { GROUP NO } 3 & \text { JFST } 1 & \text { JLST } 16 & \text { MOTENT } 0\end{array}$

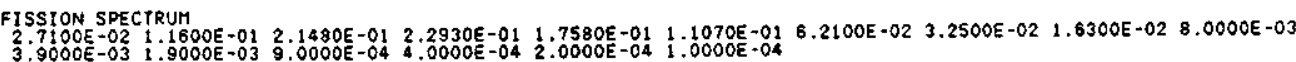

GROUP NO 4 JFST 1 JLST $\$ 6$

MOMENT O

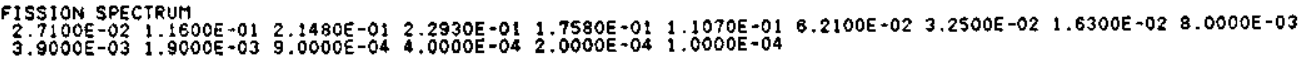

GROUP NO 5 JFST 1 JLST 16

MOMENT 0

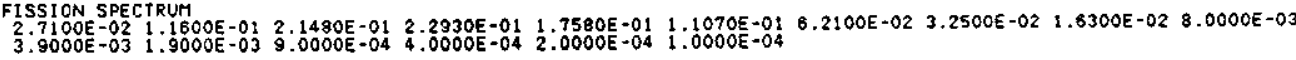

GROUP NO 6 JFST 1 JLST 18

MOMENT O

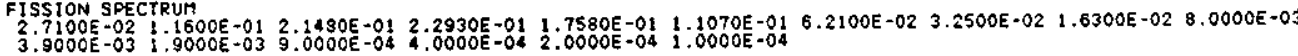

GROUP NO 7 JFST 1 JLST 16

MOMENT 0

\section{B-24}

Attachment 1

1.75 
SNF-4503, Rev. 1

WHC-SD-NR-SWD-017

FISSION SPECTRLMT

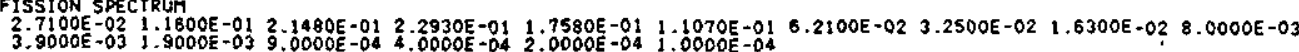

GROUP NO 8 JFST 1 JLST $16 \quad$ MOMENT O

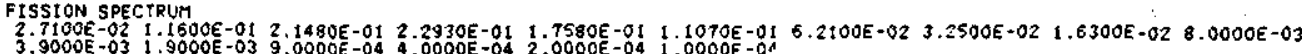

GROUP NO 9 JFST 1 JLST 16

MOMENT O

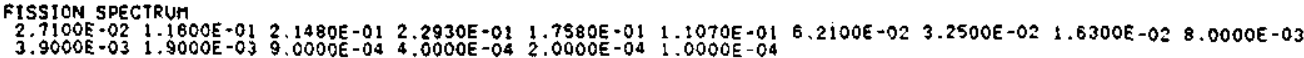
GROUP NO 10 JFST 1 JLST 16

MOMENT O

FISSION SPECTRUM

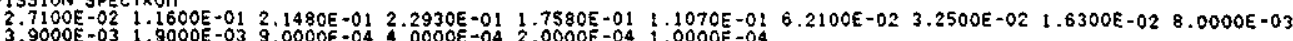
GROUP NO 11 JFST 1 JLST 16

MOMENT 0

FISSION SPECTRUM

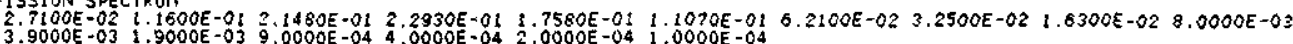
GROUP NO 12 JFST 1 JLST 16

MOMENT O

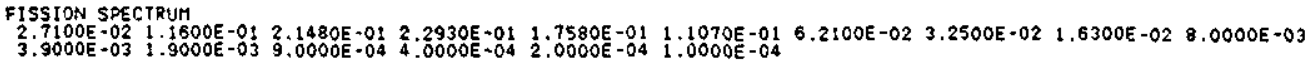
GROUP NO:3 JFST 1 JLST 18

MORENT O

TIRE

FISSION SPECTRUM

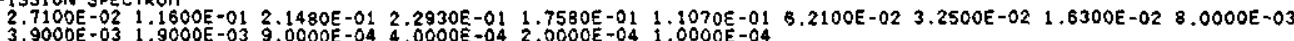

GROUP NO 14 JFST 1 JLST 16

MOMENT O

FISSTON SPECTRUM

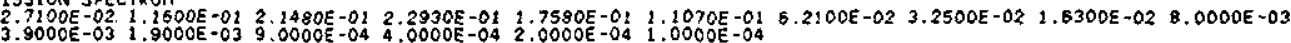

GROUP NO 15 JFST 1 JLST 18

MOMENT 0

FISSION SPECTRUM

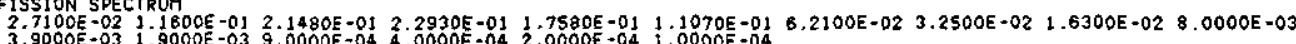

GROUP NO 16 JFST \& JIST 16 HOMENT O

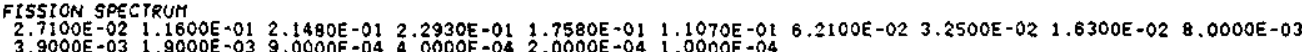

GROUP NO 17 JFST 1 JLST 16

MOMENT O

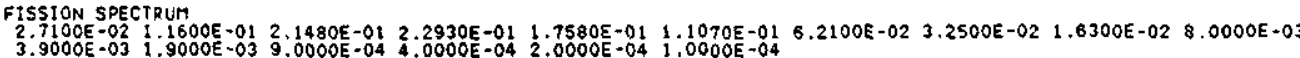

GROUP NO 18 JFST 1 JLST 18 -

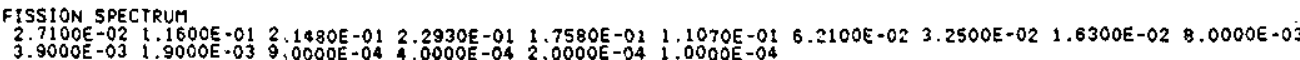
GROUP NO 19 JFST 1 JLST 18

MOMENT 0

\section{B-25}

Attachment 1 
SNF-4503, Rev. 1

\section{WHC-SD-NR-SWD-017}

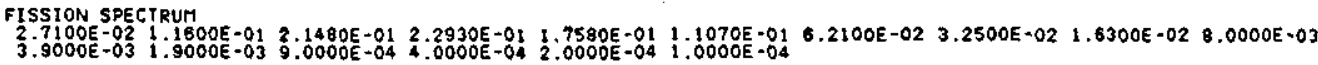
GROUP NO 20 JFST

MOTENT O

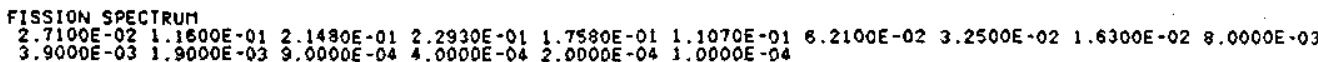
GROUP NO 21 JFST 1 JLST 16

MOMENT $O$

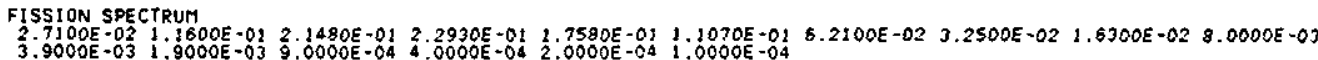
GROUP NO 22 JFST 1 JLST 16

MOMENT O

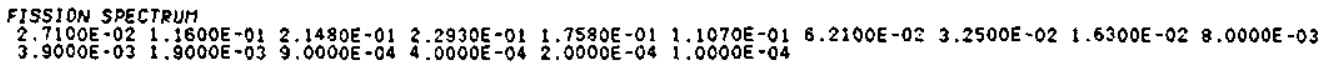
GROUP NO 23 JFST 1 JLST 16

MOMENT 0

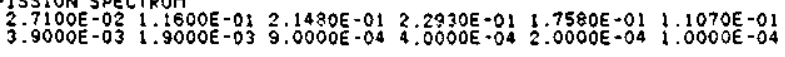
GRQUP NO $24 \quad J F S T 1$ JLST 16

FISSION SPECTRUM

$\begin{array}{cccccc}2.7100 E-02 & 1.1600 E-01 & 2.1480 E-01 & 2.2930 E-01 & 1.7580 E-01 & 1.1070 E-01 \\ 3.9000 E-03 & 1.9000 E-03 & 9.0000 E-04 & 4.0000 E-04 & 2.0000 E-04 & 1.0000 E-04\end{array}$

GRDUP NO 25 JFST 1 JLST 18

MOMENT O

ThEm

FISSION SPECTRUM

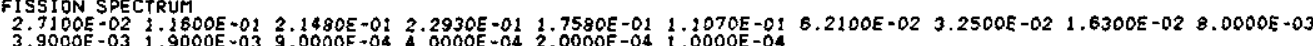
GROUP NO 26 JFST 1 JLST 16

MOMENT 0

FISSION SPECTRUM

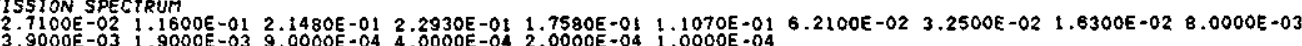
GROUP NO 27 JFST 1 JLST 16

MOMENT 0

FISSION SPECTRUM

$\begin{array}{llllll}2.7100 E-02 & 1.1800 E-01 & 2.1480 E-01 & 2.2930 E-0.2 & 1.7580 E-01 & 1.1070 E-01 \\ 3.9000 E-03 & 1.9000 E-03 & 9.0000 E-04 & 4.0000 E=04 & 2.0000 E-04 & 1.0000 E-04\end{array}$

GROUP NO 28 JFST 1 JLST 16

MOMENT O

FISSION SPECTRUM

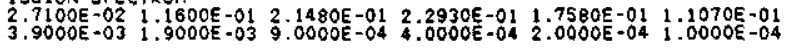

GROUP NO 29 JFST 1 JLST 16

MOMENT O

FISSION SPECTRUM

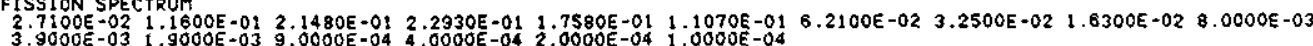
GROUP N 30 JFST 1 JLST 16

MOMENT 0

F!SSION SPECTRUM

$2.7: 00 E-02$
3 GROUP NO 31 JFST 1 JLST $1 B$

MOMENT O 
SNF-4503, Rev. 1

WHC-SD-NR-SWD-017

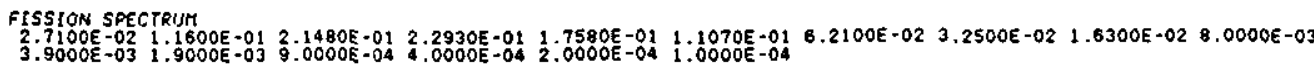

GROUP NO 32 JFST 1 JLST 16

MOMENT 0

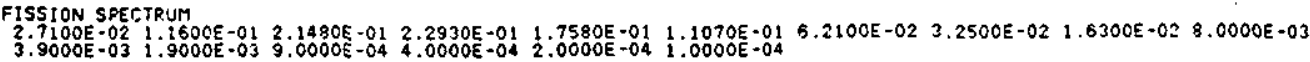

GROUP NO 33 JFST 1 JLST 16

MMENT 0

FISS ION SPECTRUM

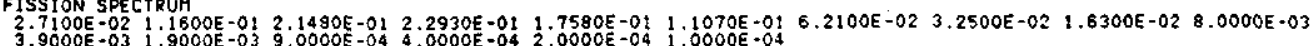

MOTERS O

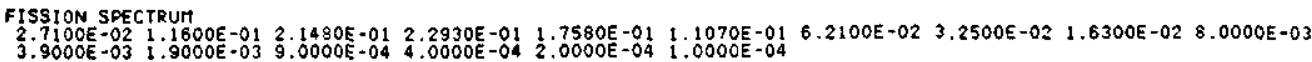
GROUP NO 35 JFST 1 JLST 16

MOMENT 0

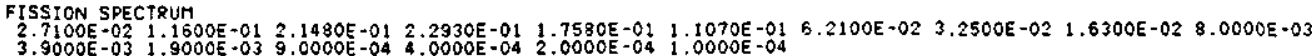

GFOUP NO $36 \quad$ JFST 1 JLST 16

MOTENT O

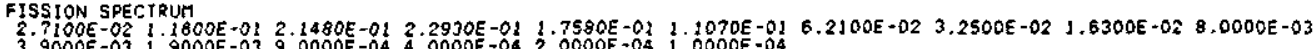

JLST 16

MOMENT 0

FILE $* * * * * 3$

$\begin{array}{llllllllllll}\text { FIS\$ION SPECTRUM } & \\ 2 & .7100 E-02 & 1.1600 E-01 & 2.1480 E-01 & 2.2930 E-01 & 1.7580 E-01 & 1.1070 E-01 & 6.2100 E-02 & 3.2500 E-02 & 1.6300 E-02 & 8.0000 E-03\end{array}$ GRDUP NO 38 JFST 1 JLST 16

MOMENT 0

FISSION SPECTRUM

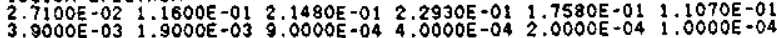

GROUP NO 39 JFST 1 JLST 1 B

MOMENT $O$

FISSION SPECTRUM

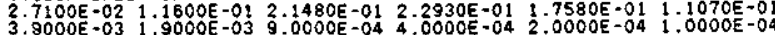

GROUP NO 40 JFST 1 SLST 18

MOMENT 0

FISSION SPECTRUM

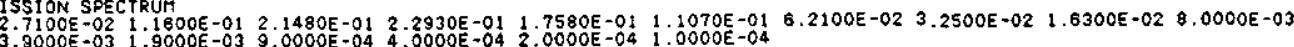
GROUP NO 41 JFST 1 JLST 16

MOMENT $O$

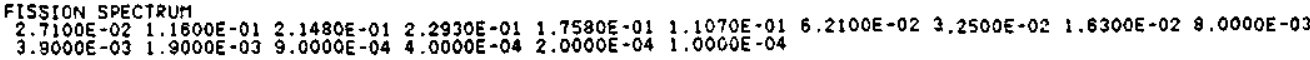

GROUP NO 42 JFST 1 JLST 16

MOMENT O

FISSI ON SPECTRUI:

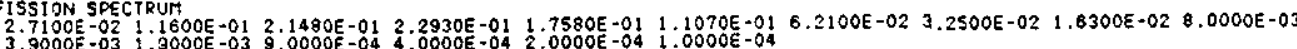
GROUP NO 43

JFST 1

JLST 16

MOMENT O 
SNF-4503, Rev. 1

WHC-SD-NR-SWD-017

FISSION SPECTRUH

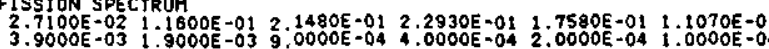

GROUP NO \&4 JFST 1 JIST 16

GROUP
FISSION SPECTRUM

$\begin{array}{llllll}2.7100 E-02 & 1.1600 E-01 & 2.1480 E-01 & 2.2930 E-01 & 1.7580 E-01 & 1.1070 E-01 \\ 3.9000 E-03 & 1.9000 E-03 & 9.0000 E-04 & 4.0000 E-04 & 2.0000 E-04 & 1.0000 E-04\end{array}$

GROUP NO 45 JFST 1 JIST 16

MOMENT O

FISSION SPECTRUM

$\begin{array}{llllllllll}2.7100 E-02 & 1.1600 E-01 & 2.1490 E-01 & 2.2930 E-01 & 1.7580 E-01 & 1.1070 E-0 t & 6.2100 E-02 & 3.2500 E-02 & 1.6300 E-02 & 8.0000 E-03\end{array}$

GROUP NO 4

JFST 1

JLSt 16

MOMENT $O$

FISSION SPECTRUM

$\begin{array}{llllllllll}2.7100 E-02 & 1.1600 E-01 & 2.1480 E-01 & 2.2930 E-01 & 1.7580 E-01 & 1.10700 E-01 & 6.2100 E-02 & 3.2500 E-02 & 1.0300 E-02 & 8.0000 E-03\end{array}$ GROUP NO 47 JFST 1 JIST 16

MOMENT 0

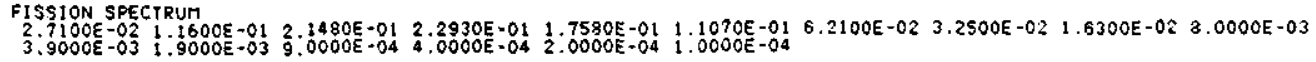

GROUP NO 48 JFST 1 JLST 16

MOMENT 0

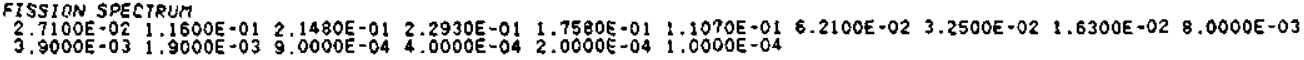

GROUP NO 49 JFST 1 JIST 16

MOMENT $O$

FISSION SPECTRUM

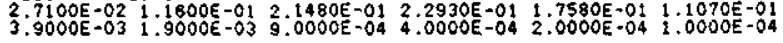

GROUP NO SO JFST 1 JLST to

MOMENT 0

FISSION SPECTRUM

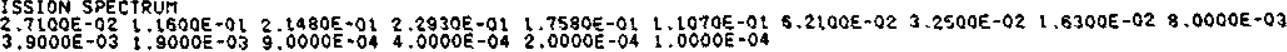

GROUP NDSI JFST 1 JLST 16

MOMENT O

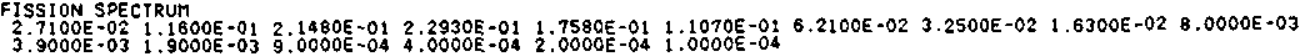
GROUP NO 52
JFST 1
JLST 16
MOMENT O

FISSION SPECTRUT

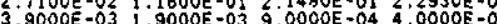
GROUP NO 5
JFST 1
JLST 16
MOMENT O

FISSION SPECTRUM

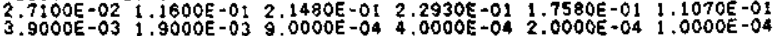
GROUP NO 54
JFST 1
JLST 16
MOMENT O

FISSION SPECTRUM

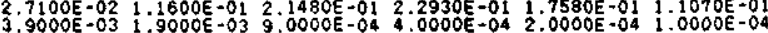

$$
\text { GROUP NO } 55 \text { JFST } 1 \text { JLST } 16
$$

MOMENT 0

\section{B-28}

Attachment 1 
SNF-4503, Rev. 1

\section{WHC-SD-NR-SWD-017}

FISSION SPECTRUM

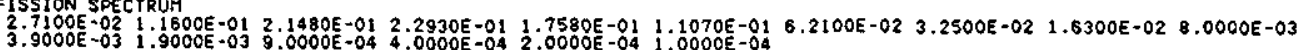
GROUP NO 58 JFST 1 JLST 18

MOMENT 0

FISSION SPECTRUI

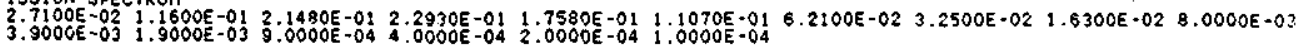
GROUP NO 57 JFST 1 JLST 16

MOMEN: $Q$

FISSION SPECTRUM

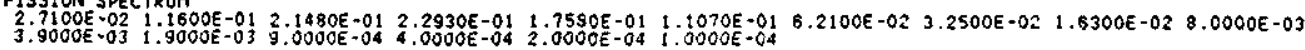
GROUP NO 58 JFST 1 JLST 16

MOMENT O

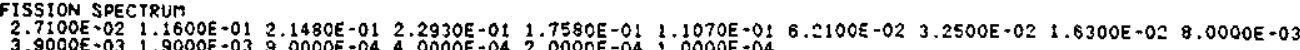

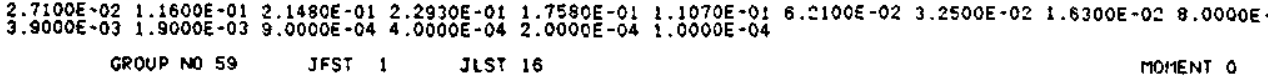

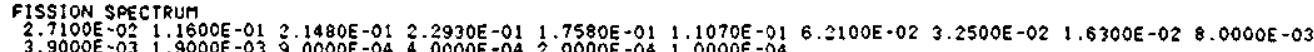
GROUP ND 60 JFST 1 JLST 16

MOMENT O

$\begin{array}{lllllllllll}\text { FISSTON SPECTRUM } & \\ 2.7100 E-02 & 1.1600 E-01 & 2.1480 E-01 & 2.2930 E-01 & 1.7580 E-01 & 1.1070 E-01 & 6.2100 E-02 & 3.2500 E-02 & 1.6300 E-02 & 8.0000 E-03\end{array}$ GROUP NO 61 JFST $\$$ JLST 16

MOMENT $O$

FISSTON SPECTRUH

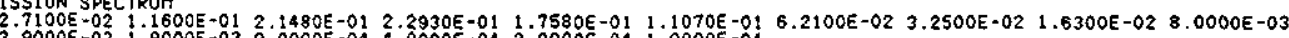
GROUP NO 62 JFST 1 JLST 16

MOMENT 0

FISSION SPECIRUI

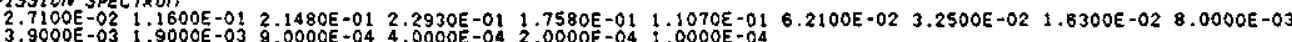
GROUP NO B3 JFST 1 JLST 18

MOMENT O

FISSION SPECTRUM

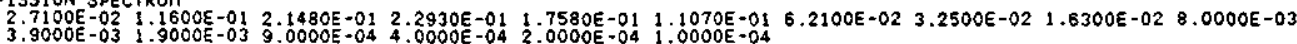
GROUP NO B4 JFST 1 JLST 16

MOMENT O

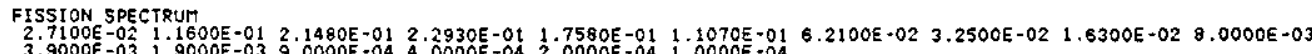

$$
\text { GROUP NO } 65 \text { JFST : JLST } 16
$$

MOMENT O

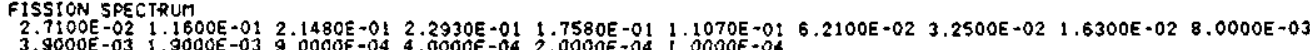

$$
\text { GROUP NO } 66 \text { JFST } 1 \text { JLST } 18
$$

MOMENT O

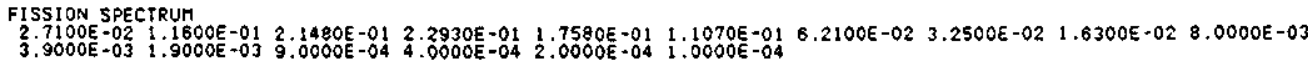


SNF-4503, Rev. 1

\section{WHC-SD-NR-SWD-017}

FISSION SPECTRUM

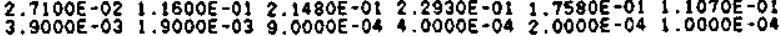

GROUP NO 68 JFST 1 JLST 16

MOMENT 0

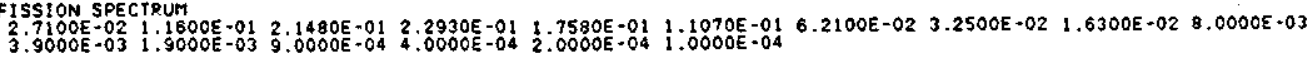

GROUP NO 69 JFST 1 JLST 18

MOMENT 0

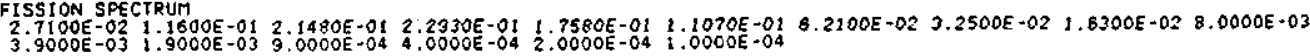

**Material 2** NO.OF REACTIONS

PBSORPTION

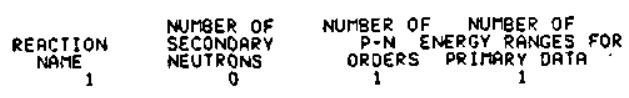

FIRST + LAST ${ }_{69}^{\text {PRIMARY GROUPS }}$

MOMENT 0

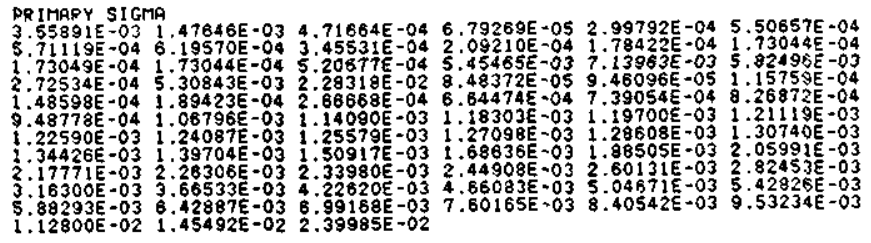

YRANSPORT
$* * * * * * * * *$

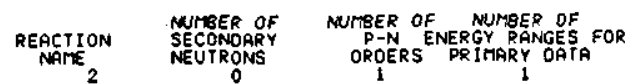


SNF-4503, Rev. 1

\section{WHC-SD-NR-SWD-017}

FIRST + LAST PRIMARY GROUPS

RAOIAL

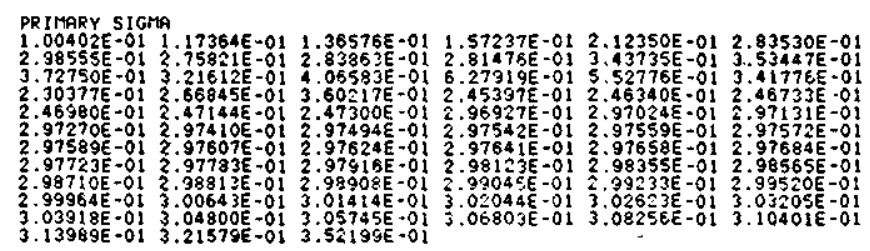

SCATTER

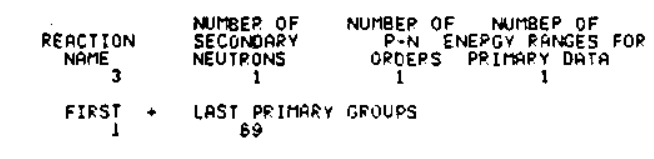

MOTENT O

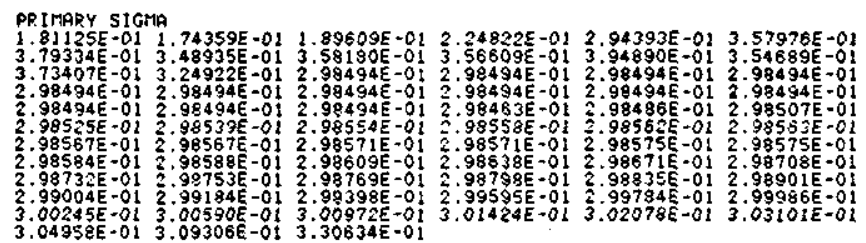

NO. OF ENERGY RANGES FOR SECONDARY OATR

FIRST + LAST PRIMARY GROUPS

FOR EACH PRIMARY GROUP

GROUP NO 1 JFST $:$ JLST 17 MOMENT 0

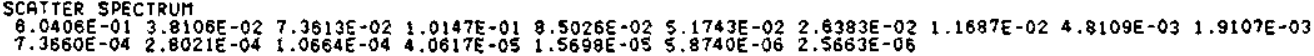

$\begin{array}{lllll}\text { GROUP NO } 2 & 2 & \text { JFST } 2 & \text { JLST } 17 & \end{array}$

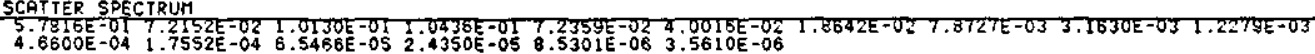

GROUP NO 3 JFST 3 JLST 17

MOMENT O

SCATTER SPECTRUM

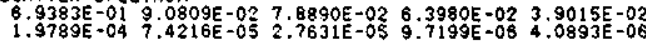

GROUP NO 4 JFST 4 JLST 15

MOMENT O

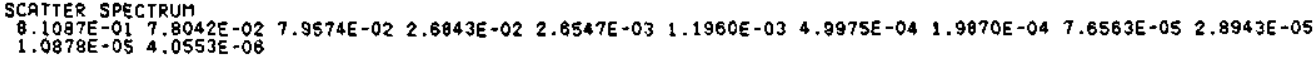

GROUP NO 5 JFST $S$ JLST 13

MOMENT 0

\section{B-31}

Attachment 1 
SNF-4503, Rev. 1

WHC-SD-NR-SWD-017

SCATTER SPECTRUM

9.1441E-01 $4.5943 E-02 \quad 1.7376 E-02 \quad 1.4481 E-02 \quad 8.8474 E-03 \quad 8.6118 E-04 \quad 6.7047 E-05 \quad 1.1535 E-05 \quad 1.8238 E-06$

$$
\text { GROUP NO } 6 \text { JFST } 6 \text { JLST } ?
$$

SCAITER SPECTRUM

GROUP NO 7

JFST 7 JLST 8

Just 8

SCATTER SDECTRUM

S.5768E-OI $4.2321 E-02$
SCATTER SPECTRUM

GROUP NO 8

JFST 8 JLST 9

SCATTER SPECTRUM
$9.5907 E-01$
$4.0933 E-02$ GROUP NO 9

JFST 9 JLST 10

SCATTER SPECTRUH
G.6643E $-013.3574 E-02$

GROUP NO 10

JFST 10 JLST 11

SCATTER SPECTRUM
$9.6592 E-01$ 3.4081E-02

GROUP NO 11

JFST 11 JLST 12

SCATTER SPECTRUM
$9.5074 E-014.926: E-02$

GROUP NO 12

JFST 12 ILST 13

SCATTER SPECTRUM
$9.5385 E-01$
$4.6254 E-02$

MOMENT $O$

ROMENT 0

MOMENT O

MOMENT O

MOMENT O

MOMENT O

MOMENT O

\begin{tabular}{|c|c|c|}
\hline GROUP NO 13 & JFST 13 & JLST 14 \\
\hline \multicolumn{3}{|l|}{$\begin{array}{l}\text { SCATTER SPECTRUM } \\
9.7172 E=01 \quad 2.8279 E-02\end{array}$} \\
\hline GROUP NO 14 & JFST 14 & JLST 15 \\
\hline \multicolumn{3}{|l|}{$\begin{array}{l}\text { SCATTER SPECTRUM } \\
9.5840 E=01 \quad 4.3601 E-02\end{array}$} \\
\hline GROUP NO 15 & JFST 15 & JLST 16 \\
\hline \multicolumn{3}{|l|}{$\begin{array}{l}\text { SCAT TER SPECTRUM } \\
9.5 \$ 34 E-014.4663 E-02\end{array}$} \\
\hline GROUP NO 16 & JFST 16 & JLST 17 \\
\hline \multicolumn{3}{|l|}{$\begin{array}{l}\text { SCATTER SPECTRUH } \\
9.5031 \mathrm{E}-014.9687 E-02\end{array}$} \\
\hline GROUP NO IT & JFST 17 & $J L S T$ IB \\
\hline \multicolumn{3}{|l|}{$\begin{array}{l}\text { SCATTER SPECTRUM } \\
9.5071 E-01 \quad 4.92 \$ 2 E-02\end{array}$} \\
\hline GROUP NO IB & JFST 18 & JLST 19 \\
\hline \multicolumn{3}{|l|}{$\begin{array}{l}\text { SCATTER SPECTRUM } \\
9.5037 E-01 \quad 4.9634 E-02\end{array}$} \\
\hline GROUP NO 19 & JFST 19 & JLSt 20 \\
\hline \multicolumn{3}{|l|}{$\begin{array}{l}\text { SCA:TER SPECTRUM } \\
9.502 B E-01 \quad 4.9734 E-02\end{array}$} \\
\hline GROUP NO 20 & JFST 20 & JLST 21 \\
\hline
\end{tabular}

FILE:

MOMENT 0

MOMENT O

MOMENT O

MOMENT O

MOMENT O

MOMENT D

MOMENT O

ROMENT O 
SNF-4503, Rev. 1

\section{WHC-SD-NR-SWD-017}

SCATTER SPECTRUM
9.7553E-01 2.446

GROUP NO 21

JFST 21

JLST 22

SCATTER SPECTRUM
$9.7545 E-01 \quad 2.4542 E-02$

GROUP NO 22

JFST 22

JLST 23

SCATTER SPECTRUM

Group ino 23

JFST 23 JLST 24

SCAT TEP SPECTRUM
$9.4877 E-01$
$5.1229 E-02$

GROUP NO 24

JFST 24 JLST 25

MOMENT O

SCATTER SPECTRUM
$9.5620 \mathrm{~V}-01$ 4.3805E-02

GROUP NO 25

JFST 25 JLST 28

SCATTER SPECTRUM
$9.5528 E-014.4728 E-02$

GROUP NO 26

JFST 26

JLST 27

SCATTER SPECTRUM
9.5294 E-01 $4.7061 E-02$

GROUP NO 27

3FST 27 JLST 29

\section{SCATTER SPECTRUM
$9.7356 E-01$
$2.6437 E-02 \quad 1.4889 E-13$}

MOMENT 0

MOMENT O

MOMENT 0

MOMENT O

MOTENT 0

MOMENT O

FitE: $\overrightarrow{\text { B. }}$

MOMENT O

MOMENT 0

MOTENT $O$

MOMENT $O$

MOMENT $O$

MOMENT 0

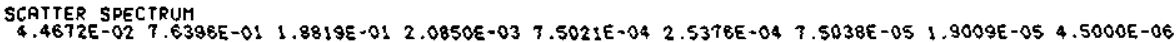

GROUP NO 33 JFST 31 JLST 43

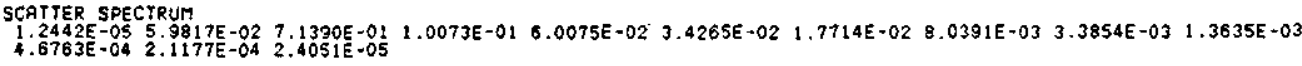

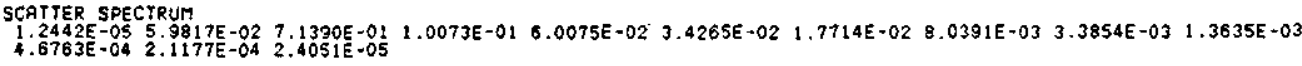
GROUP NO $34 \quad$ JFST 32 JLST 44

MOMENT 0

SCATTER SPECTRUM

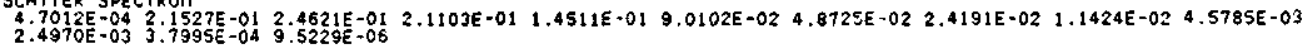

\section{B-33}

Attachment 1 
SNF-4503, Rev. 1

WHC-SD-NR-SWD-017

GROUP NO 35 JFST 32 JLST 44 MOMENT 0

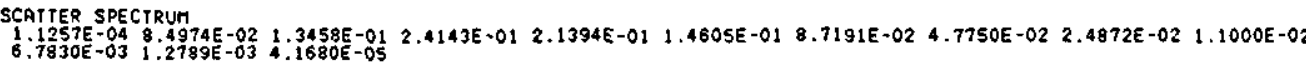

GROUP NO 36 JFST 32

JLST 45

ROMENT $O$

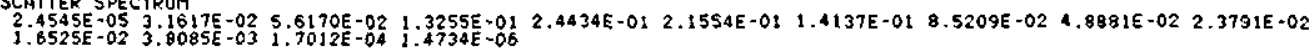

GROUP No 37 JFST 32 JLST 45

MOMENT $O$

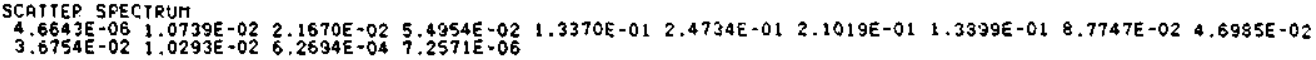
GROUP NO 38 JFST 33 JLST 45

MOMENT 0

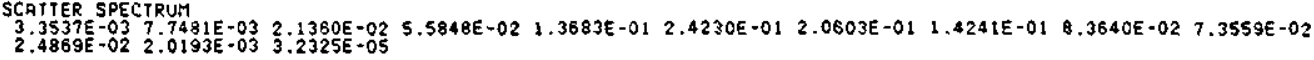

GROUP NO 39 JFST 33 JLST 45

MOMENT 0

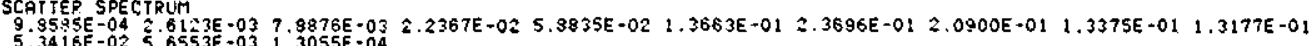

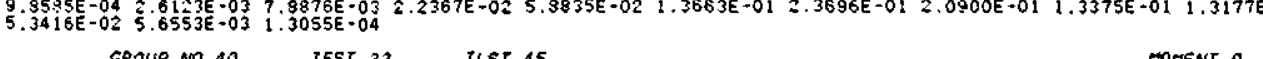
GROUP NO 40 JFST 33 JLST 45

MOMENT

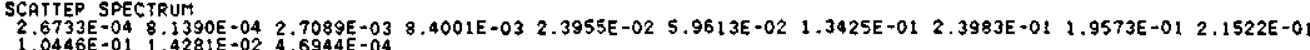

GROUP NO 41 JFST $33 \quad$ JLST 45

SCATTER SPECTRUM

$\begin{array}{ll}6.7753 E-05 & 2.3702 E-04 \\ 1.8387 E-01 & 8.7352 E-04 \\ 1.1968-02 & 1.442 E-03\end{array}$

GROUP NO 42

JFST 33

JLST 45

FILE

MOMENT $O$

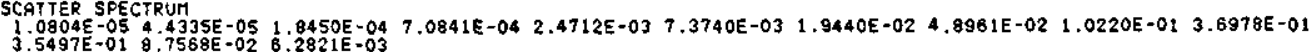

GROUP NO 43 JFST 34 JLST 46

MOMENT 0

SCATTER SPECTRUM

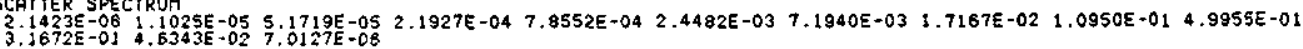

GROUP NO 44 JFST 37 JLST 48

MOMENT 0

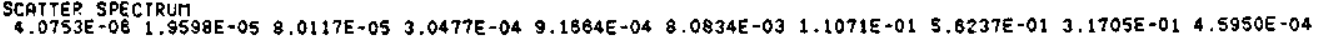
GROUP NO 45 JEST 41 JLST $4 T$

MOMENT $O$

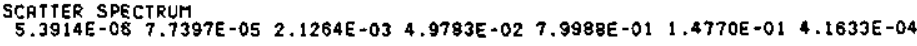

GROUP NO 46 JFST 44 JLST 49

MOMENT 0

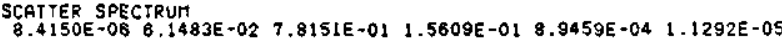

GROUP NO 47 JFST 45 JLST 52

ROMENT O

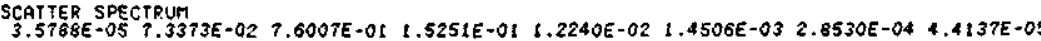


SNF-4503, Rev. 1

\section{WHC-SD-NR-SWD-017}

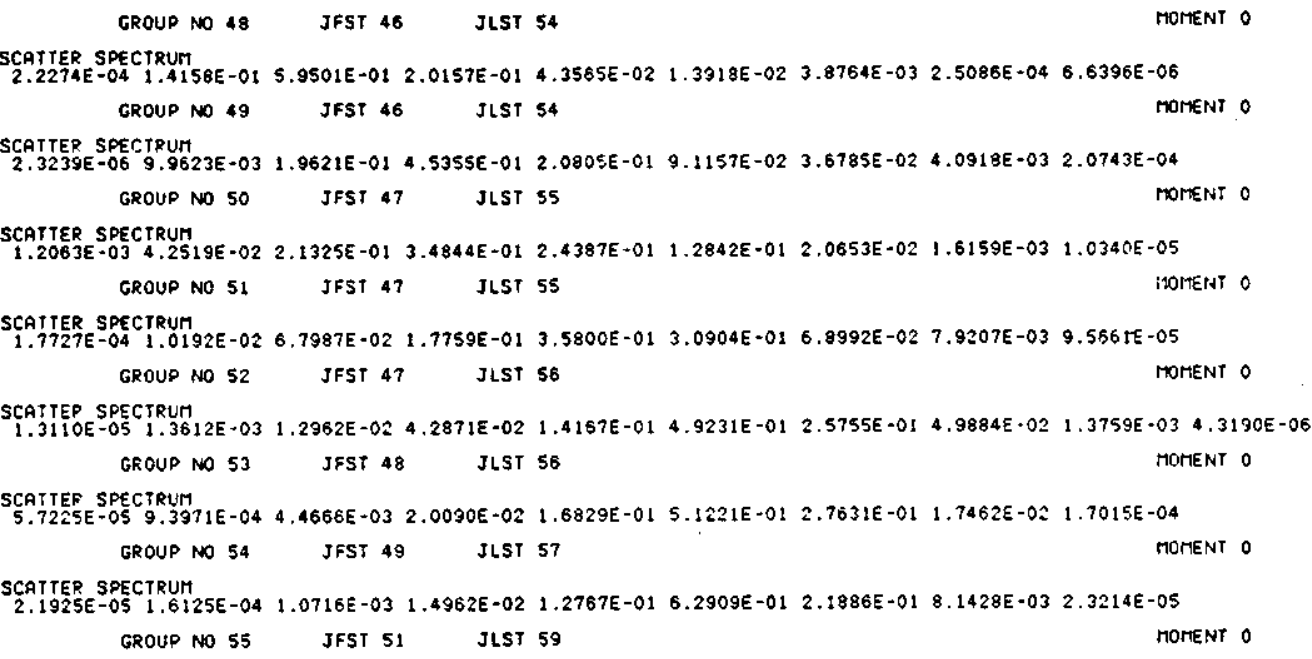

FILE $*$ F*

SCQATTER SPECTRUM

GROUP NO $56 \quad$ JFST $53 \quad$ JLST 62

MOMENT 0

$\begin{array}{llllllllll}\text { SCATTER SPECTRUMT } & \\ 2 \text { SO90E-05 } 2.6689 E-03 & 1.1017 E-02 & 7.0614 E-01 & 1.6002 E-01 & 1.7997 E-02 & 2.4401 E-03 & 4.5393 E-04 & 7.5565 E-05 & 7.9131 E-06\end{array}$ GROUP NO 57 JFST 54 JLST 65

MOMENT $O$

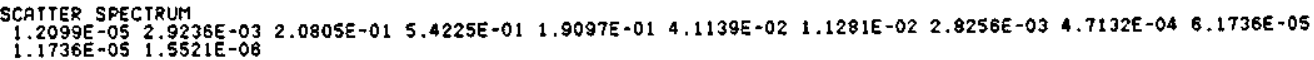
GROUP NO 58 JFST 55

JLST 66

MOMENT $O$

SCATTER SPECTRUM $1.4846 E-04$
$4.0986 E-05$
$4.86228 E-06$ GROUP NO 59

JFST 55

JLST $B 7$

MOMENT 0

SCATTER SPECTRUM

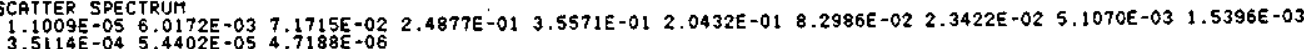

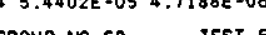

GROUP NO 60 JFST $56 \quad$ JLST 68

MOMENT 0

SCATTER SPECTRUH

$1.2331 E-032.1733 E-029.8050 E-02$

GPOUP NO 61

JFST 56

JLST 68

MOMENTO

SCATTER SPECTRUM

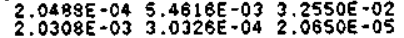

B-35

Attachment 1 
SNF-4503, Rev. 1

WHC-SD-NR-SWD-017

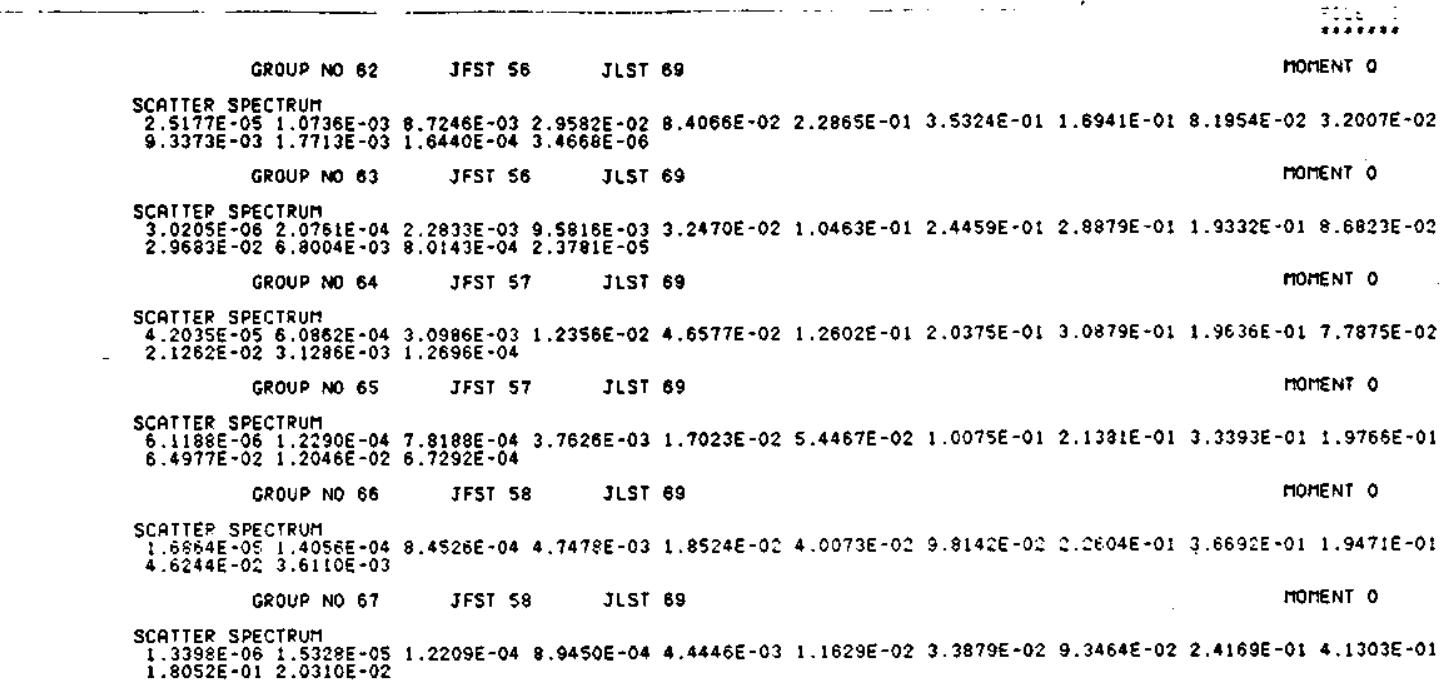

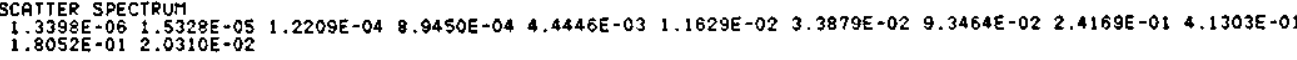
FILE ${ }^{3}$ GROUP NO 68 JFST 60 JLST $69 \quad$ MOMENT 0 $\begin{array}{llllllllll}\text { SCATTER SPECTRUM } & \\ 8.6444 E-06 & 9.0558 E-05 & 6.1454 E-04 & 2.0472 E-03 & 7.4558 E-03 & 2.5893 E-02 & 8.5377 E-02 & 2.6458 E-01 & 4.8389 E-01 & 1.3006 E-01\end{array}$ GROUP NO 69 JFST 61 JLST 69 MOIENT 0

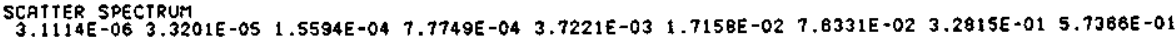


SNF-4503, Rev. 1

WHC-SD-NR-SWD-017

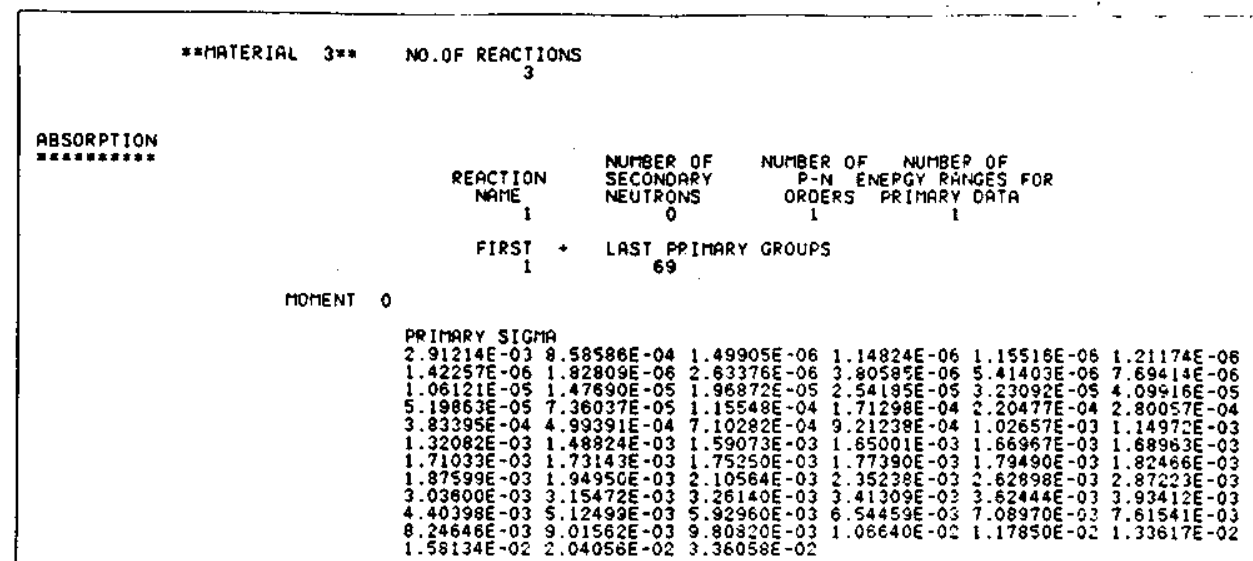

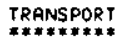

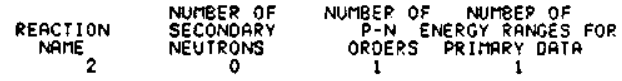

FILE***

FIRST - LAST PRIMARY GROUPS

RAOIAL

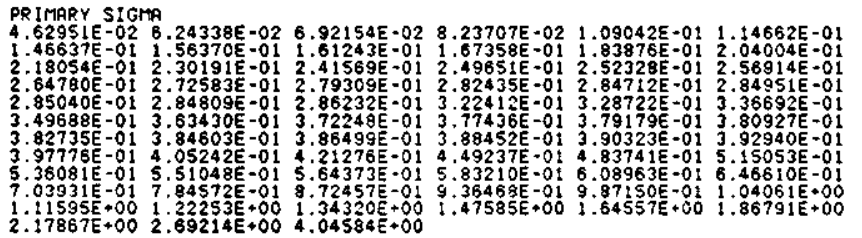

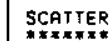

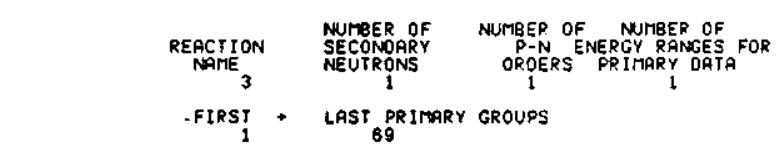

MOMENT 0

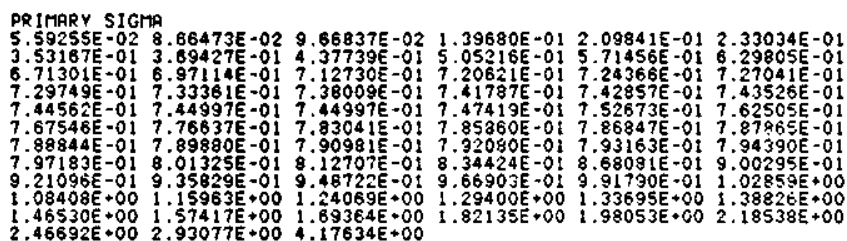

$1.46530 E+00$
$2.56692 \mathrm{E}+00$
$2.93077 \mathrm{E}+00$

NO. OF ENERGY RANGES FOR SECONOARY DHTA

FIRST + LAST PRITARY GROUPS

FOR EACH PRIMAPY GROUP

GROUP NO 1 JFST 1 JIST 22

MOMENT $O$

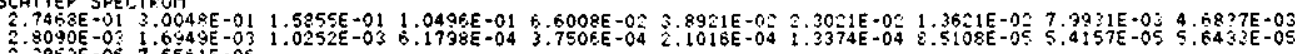

B-37

Attachment 1 
SNF-4503, Rev. 1

\section{WHC-SD-NR-SWD-017}

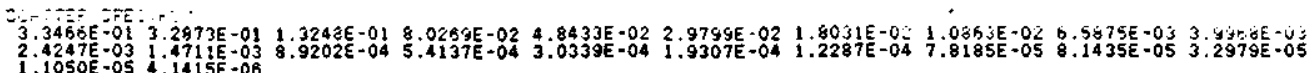
GROUP NO 3 JFST 3 JLST 25 MOMENT 0

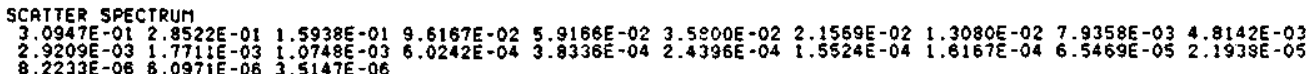
$2.9209 E-03$
$8.2233 E-06 \quad 8.0971 E-03$
8.09

GROUP NO 4 JFST 4 JLST 27

MOMENT $O$

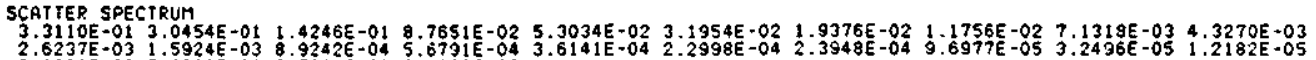
9.

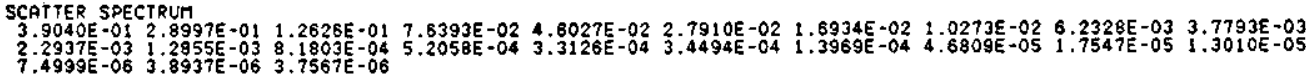

GROUP NO 6 JFST 6 JLST 27

MOMENT $O$

SCATTER SPECTRUM

$\begin{array}{llllllllll} & \\ 3.5194 E-01 & 2.8091 E-01 & 1.4505 E-01 & 8.7395 E-02 & 5.2994 E-02 & 3.2153 E-02 & 1.9505 E-02 & 1.1834 E-02 & 7.2759 E-03 & 4.3550 E-03 \\ 2.4409 E-03 & 1.5533 E-03 & 9.8950 E-04 & 6.2902 E-04 & 8.5488 E-04 & 2.5520 E-04 & 9.8872 E-05 & 3.3320 E-05 & 2.4702 E-05 & 1.4240 E-05\end{array}$

$7.3933 E-06$ 7.1321E-06

GROUP NO 7 JFST 7 JLST 31

MOMENT O

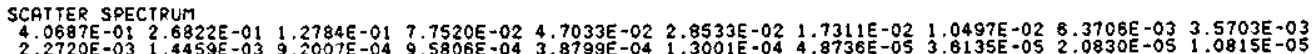
$1.0434 E-051.2429 E-06 \quad 1.2423 E-06 \quad 8.8775 E-07$ 1.0654E-06

$$
\text { GROUP NO } 8 \text { JFST, } 8 \text { JLST } 31
$$

MOMENT 0

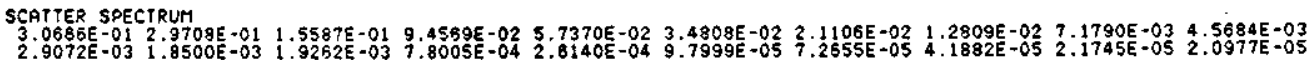
2.4992E-08 2.4992E-06 1.7852E-06 2.1421E-06 GROUP NO 9 JFST 9 JLST 45

MOMENT O

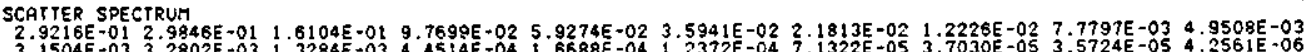

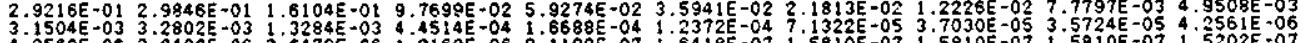

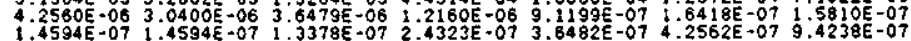

\section{B-38}

Attachment 1 
SNF-4503, Rev. 1

\section{WHC-SD-NR-SWD-017}

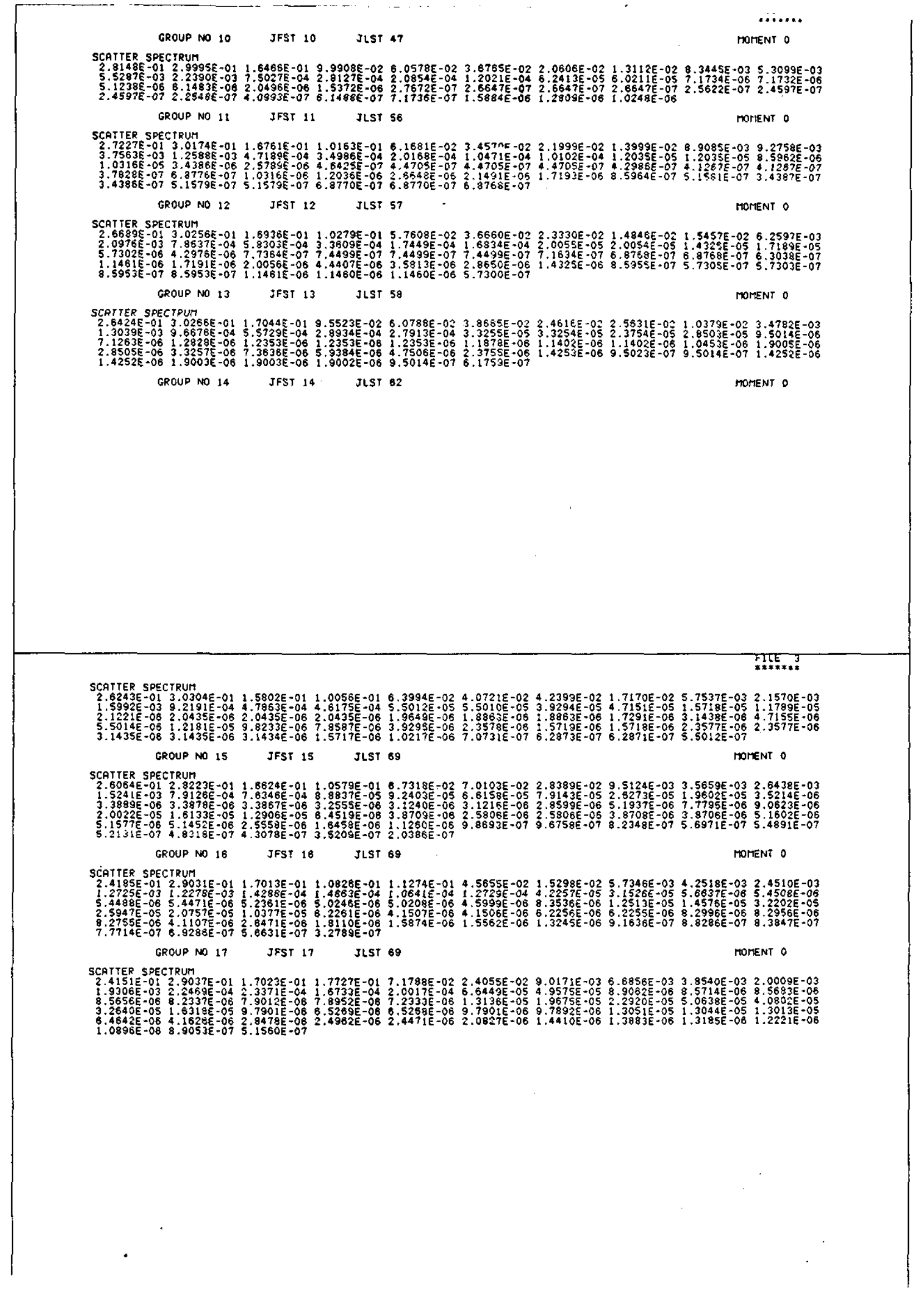


SNF-4503, Rev. 1

WHC-SD-NR-SWD-017

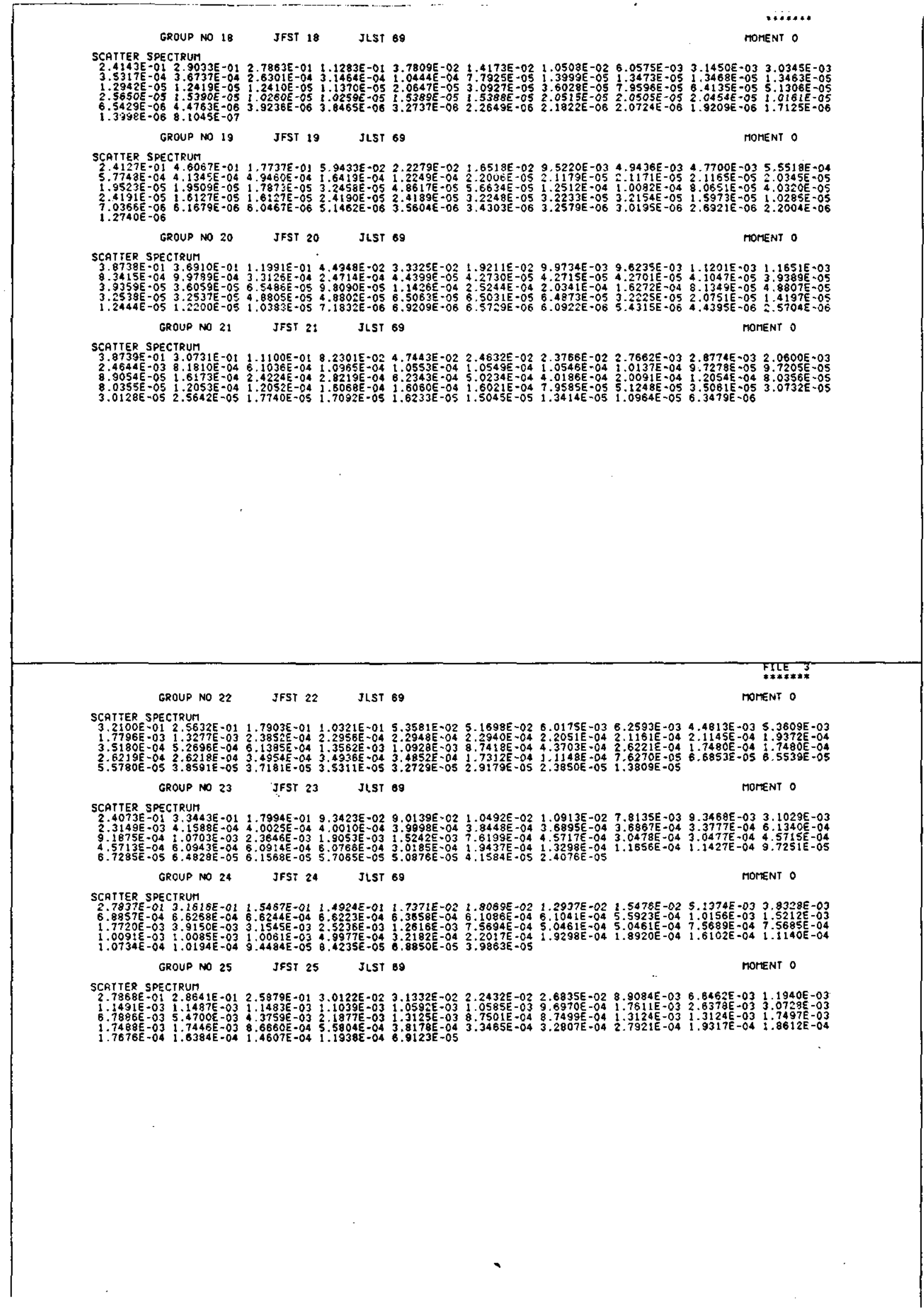

\section{B- 40}

Attachment 1 
SNF-4503, Rev. 1

WHC-SD-NR-SWD-017

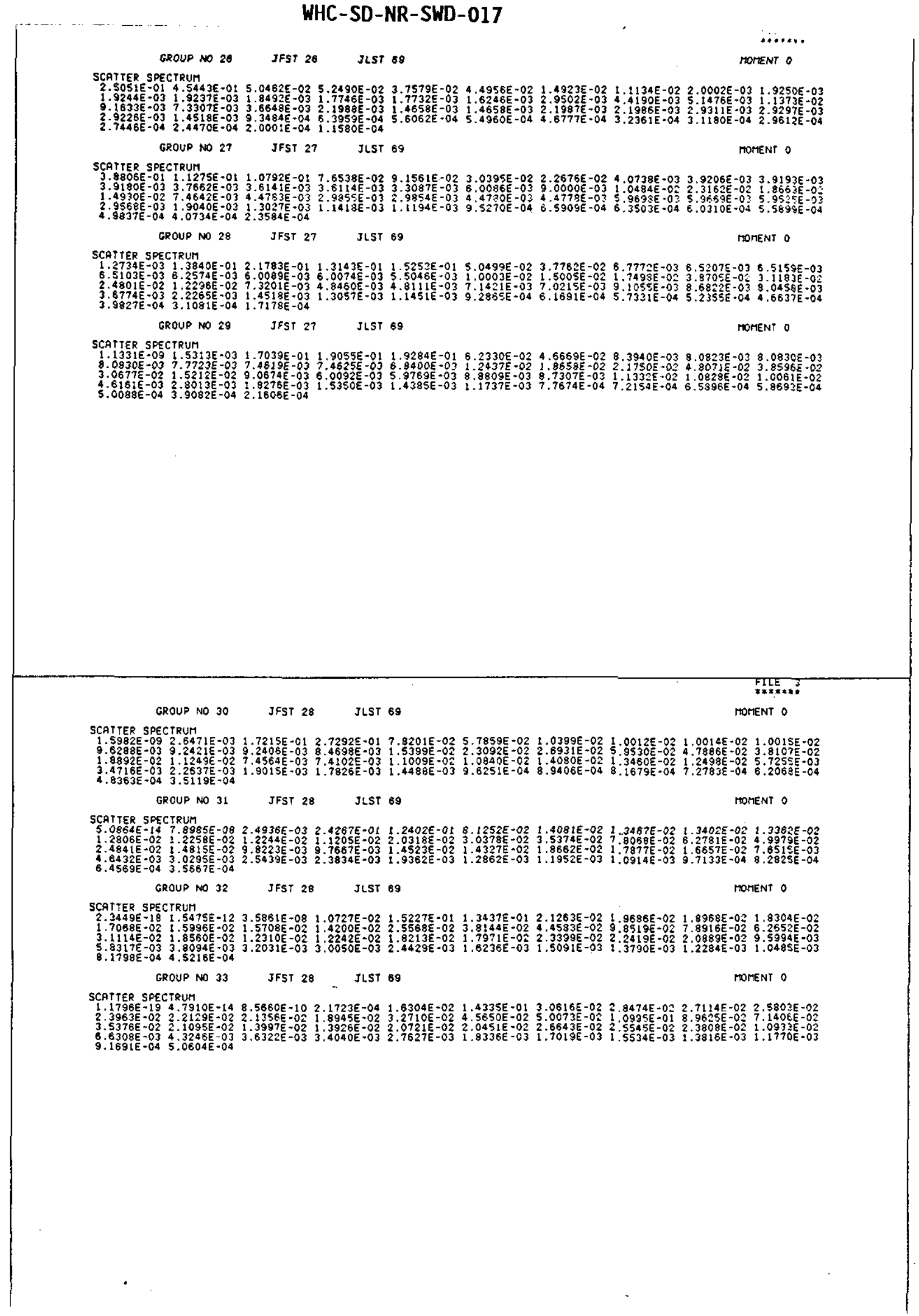

B-41

Attachment 1

$1-92$ 
SNF-4503, Rev. 1

WHC-SD-NR-SWD-017

GROUP NO $34 \quad$ JEST 28 JIST ES

MOMENT O

SCATTER SPECTRUM

B.206R SPECTRUM

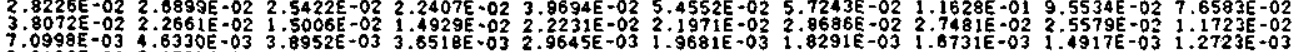
$9.9186 \mathrm{E}-04$ 5.4767E-04

GROUP NO 35 JFST 28

JLST 69

MOMENT O

SCATTER SPECTRUM

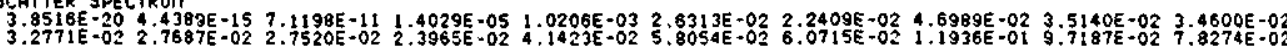

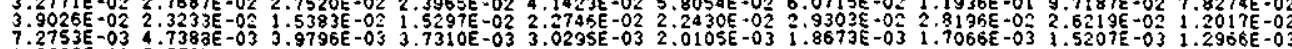
1.0099E-03 $5.5737 E-04$

GROUP NO 38 JFST 28 JLST 69

MOMENT $O$

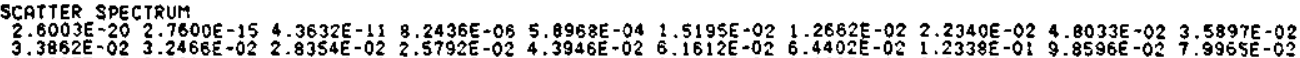

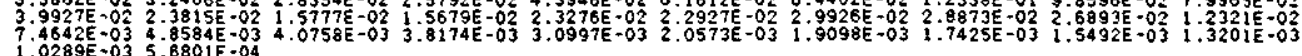

GROUP ND 37 JFST 28 JLST G9

MOMENT O

SCRTTEP SPECTQUT

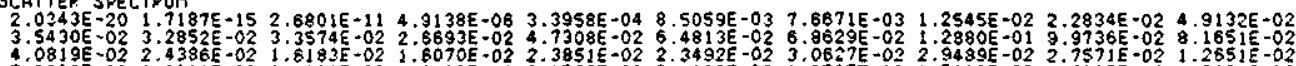

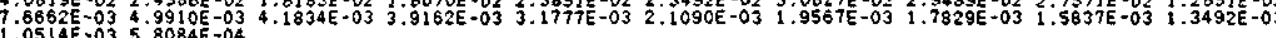

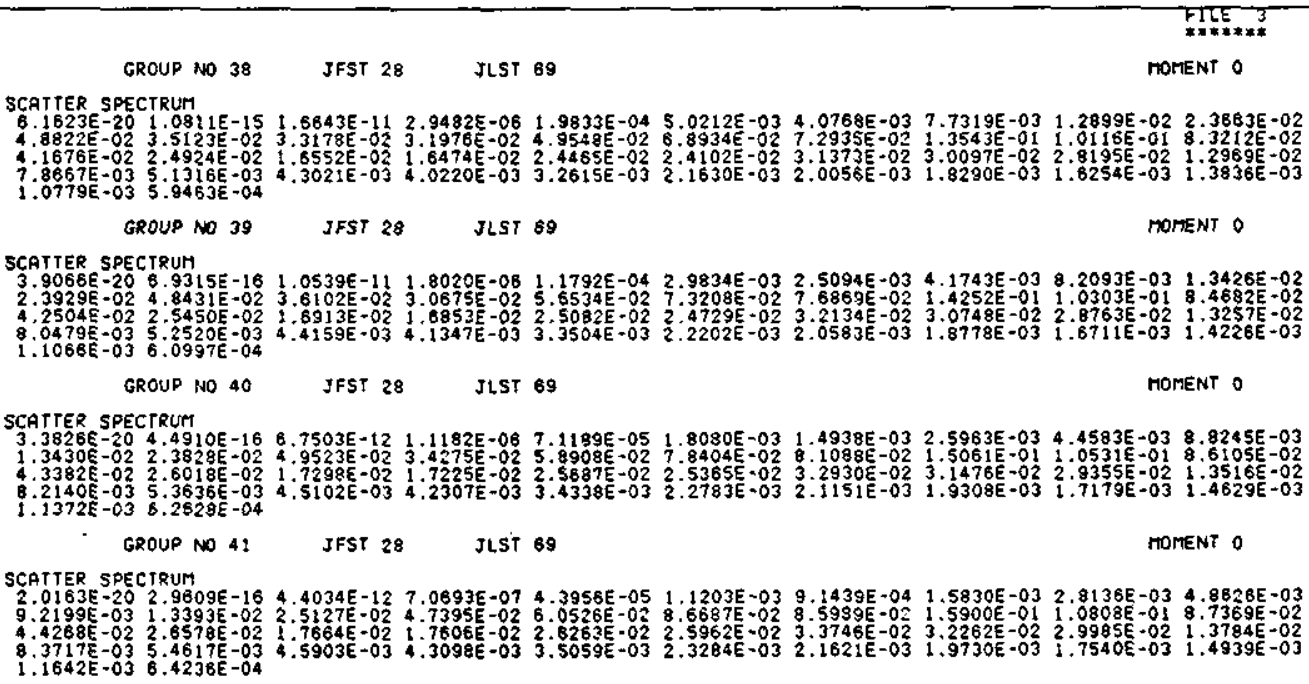


SNF-4503, Rev. 1

\section{WHC-SD-NR-SWD-017}

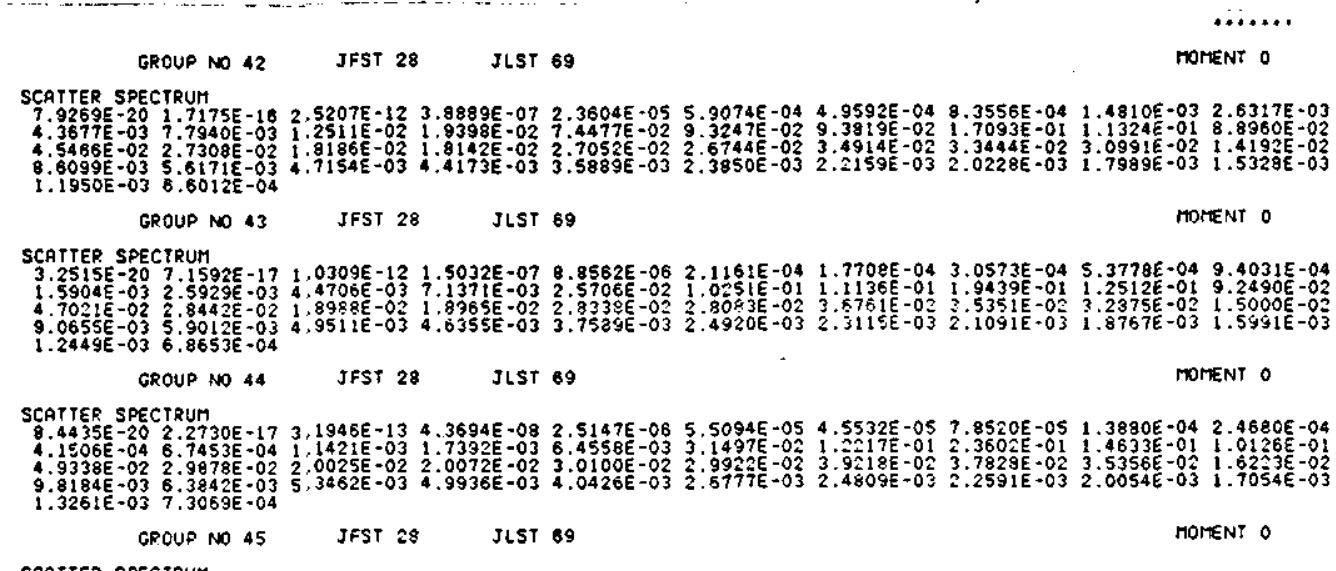

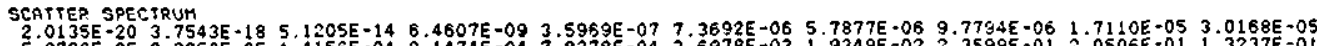

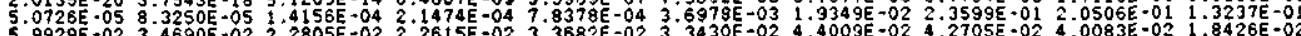

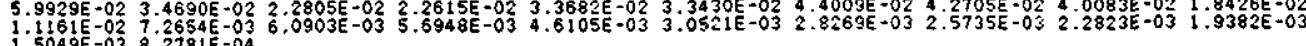

GROUP NO $46 \quad$ JFST $28 \quad$ ILST 69

SCATTER SPECTRUM

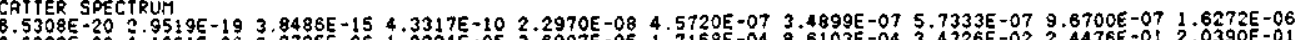

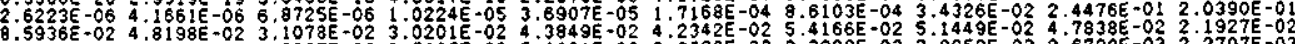
$1.3268 \varepsilon=028.6275 \varepsilon=03$

$$
\text { GROUP NO } 47 \text { JFST } 28 \text { JLST } 69
$$

MOMENT 0

SCATTER SPECTRUM

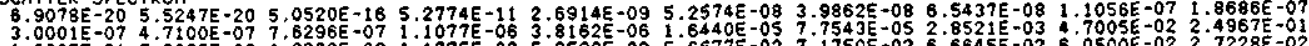

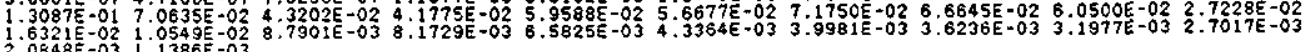
GROUP NO 48 JFST 28 JLST 69

MOMENT O

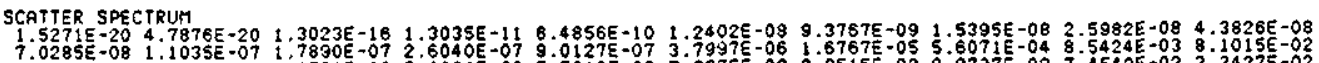

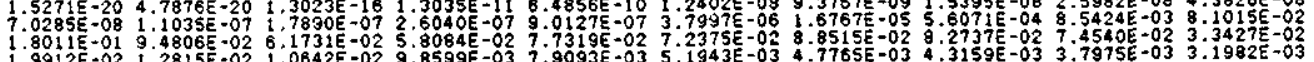
$1.9912 \mathrm{E}-02 \mathrm{1} .2815 \mathrm{E}-02$

$$
\text { GROUP NO } 49 \text { JFST } 28 \text { JLST } 69
$$

MOMENT $O$

SCATTER SPECTRUM

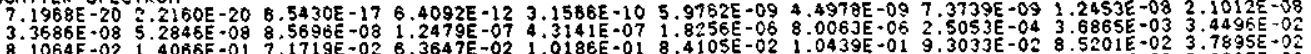

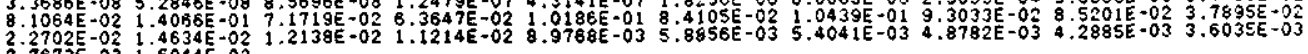


SNF-4503, Rev. 1

WHC-SD-NR-SWD-017

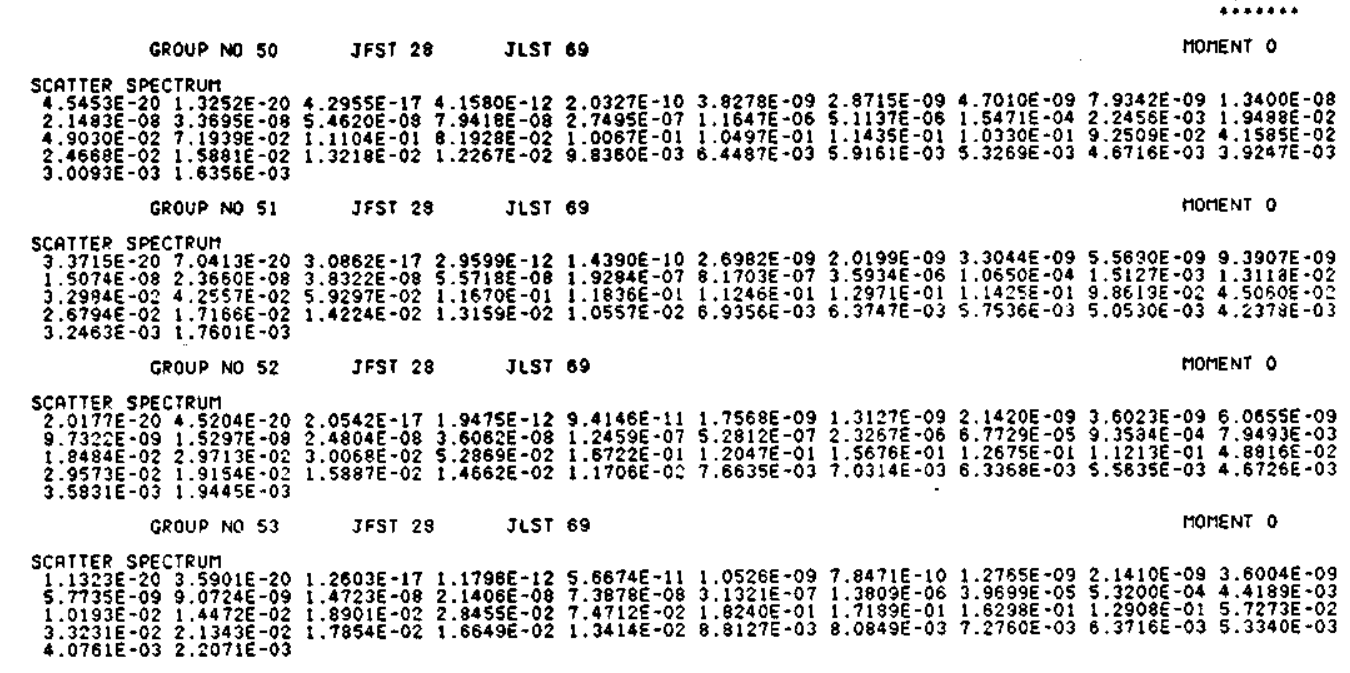

FTEE 3

GROUP NO $54 \quad$ JFST $28 \quad$ JLST 69

MOMENT 0

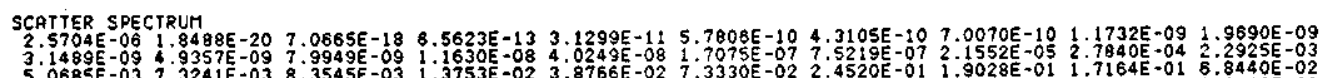

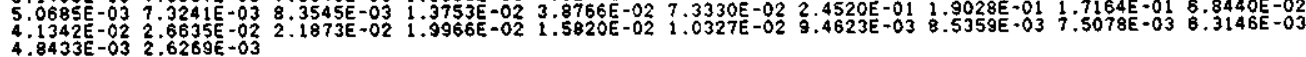
GROUP NO 55 JFST 28 JLST 69

MOMENT O

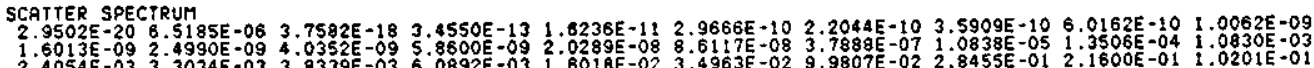

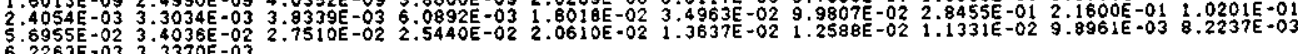
GROUP NO $56 \quad$ JFST $28 \quad$ JLST 69

MOMENT 0

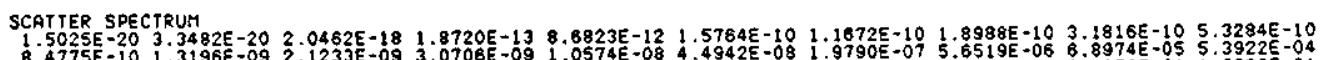

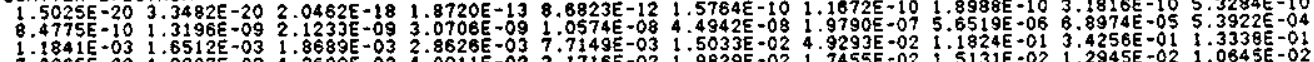
$7.0965-02 \quad 4.9807 E-024$ GROIJP NO 57 JFST 28 JLST 69

MOMENT O

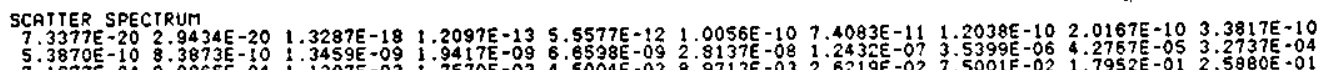

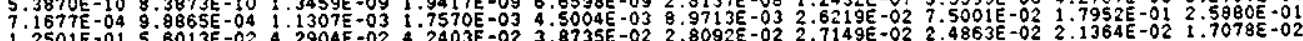
$\begin{array}{lll}1.2501 \mathrm{E}-01 & 5.8013 \mathrm{E}-02 \\ 1.2242 \mathrm{E}-02 & 8.1758 \mathrm{E}-03\end{array}$ 


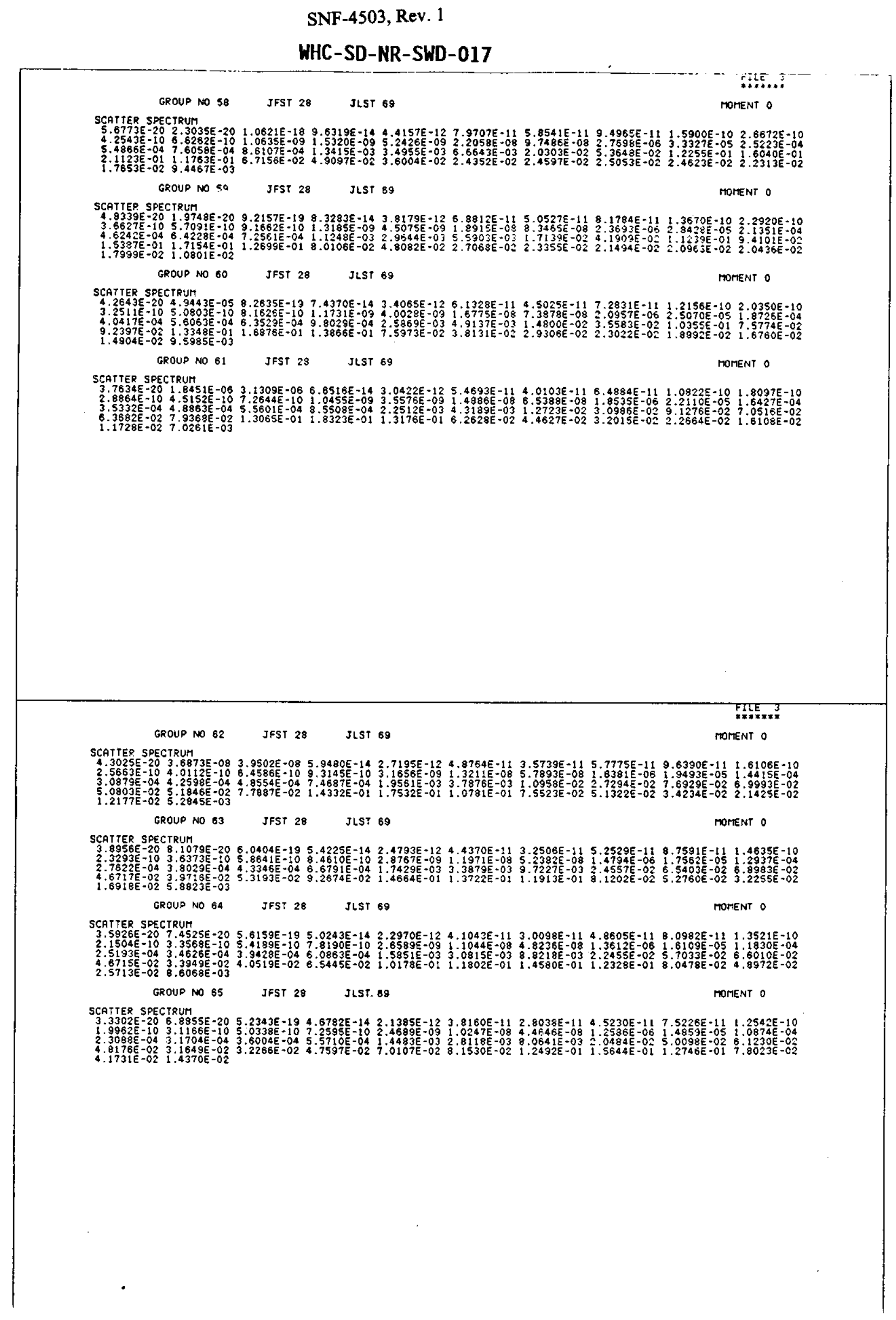

B-45

Attachment 1

1-96 
SNF-4503, Rev. 1

\section{WHC-SD-NR-SWD-017}

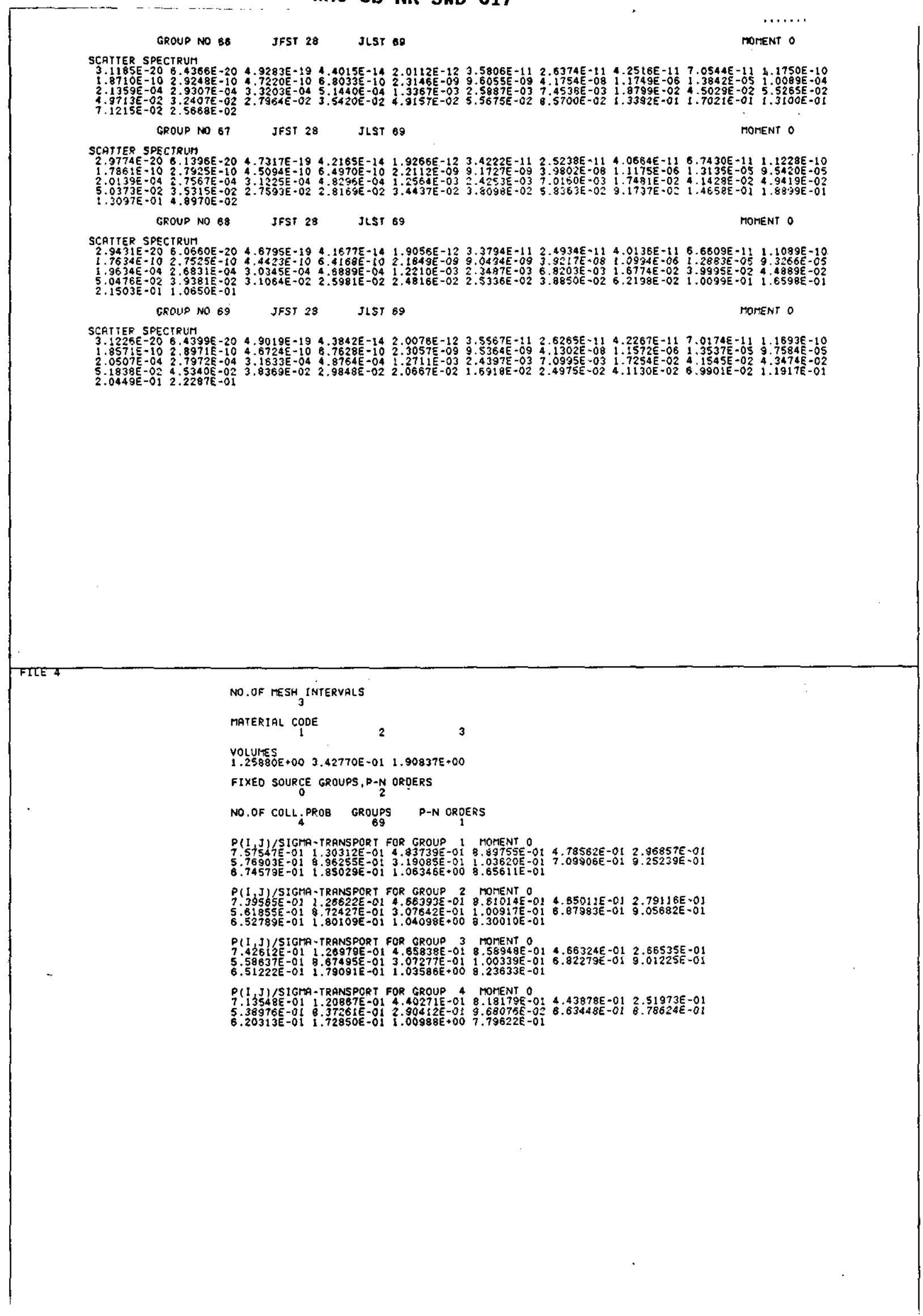




\section{WHC-SD-NR-SWD-017}

P(I, J)/SIGHA-TRANSPORT FOR GROUP 5 MOMENT O

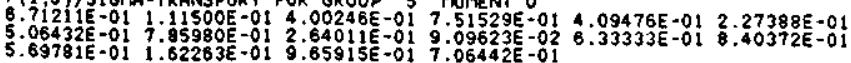

PLI J)/STCMA-TRANSPORT FOR GROUP \& MOMENT $O$

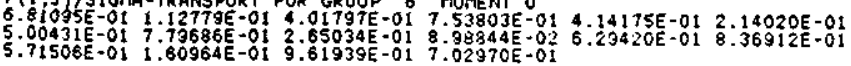

$P(I J)$ SIGMA-TRANSPORT FOR GROUP 7 MOMENT

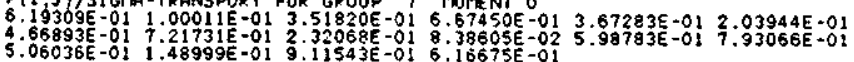

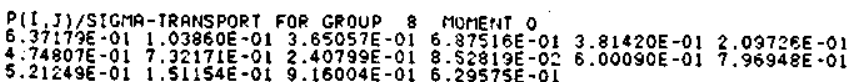

$P(1, J)$ /SIGMA-TRRNSPORT FOP GROUP 9 MOMENT O

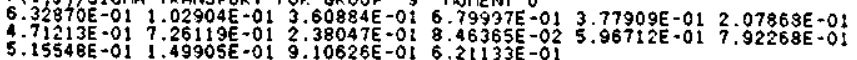

$P(I, J)$ STGMA-TRANSPORT FOR GROUP 10 MOMENT O

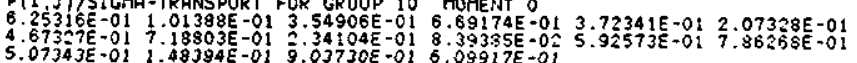

$P(1, J) / S I G M A-T R A N S P O P T$ FOR GROUP 1$\}$ MOMENT $O$

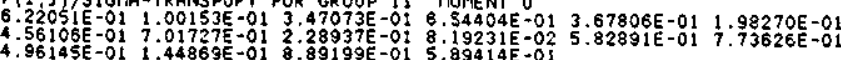

P(I J J /SIGMA-TRANSPOPT FOR GROUP 12 MOMENT O

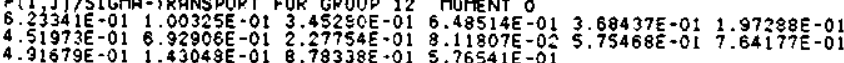

Pistic...

P(I T) SSTGMA-TRANSPORT FOR GROUP 13 TOMENT O

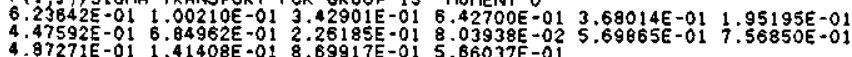

$P(I J)$ /SIGIA-TRANSPORT FOR GROUP 14 HOMENT O

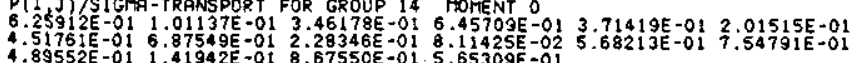

$P(I, J)$ SIGMA-TRANSPORT FOR GROUP 15 MOMENT O

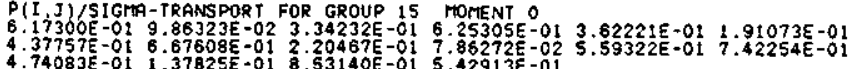

P(I J) SSTGMA-TRANSPOPT FOR GROUP 15 MOMENT O

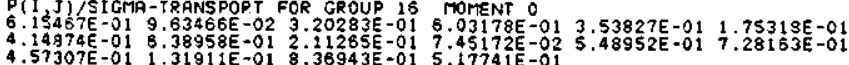

$P(I J) / S I G M A-T R A N S P O R T$ FOR GROUP 17 MOMENT $O$

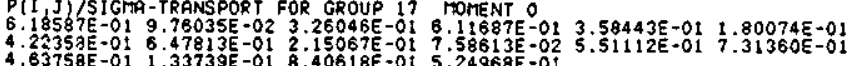

P(I J)/SIGHA-TRANSPORT FOR GROUP 18 TOMENT O

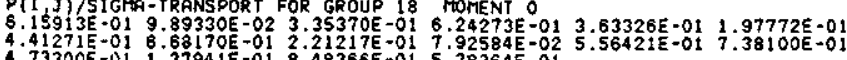

$P(I, J)$ /SIGMA-TPANSPORT FOR GROUP 19 MOMENT O

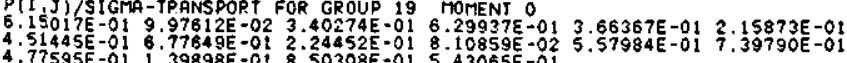

P\{I J J /SIGMA-TRANSPORT FOR GROUP 20 MOTENT O

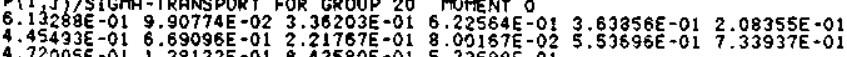

$4.72005 E-01 \quad 1.38133 \mathrm{E}-018.4358$

\section{B-47}

Attachment 1 
WHC-SD-NR-SWD-017

P(t J J SIGMA-TRANSPORT FOR GROUP 2 I MOMENT O

. $33879 E-01$ 6. $54326 E-01$ 2.26906E-01 $7.79306 E-02$ 5.59144E-01 $1.95066 E-01$ 8.34244E-01 5.19562E-01

$P(I, J)$ SIGTR-TRANSPORT FOR GROUP 22 MOMENT $O$

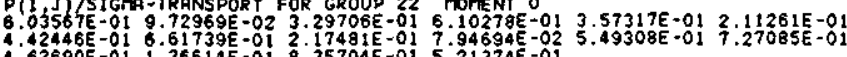

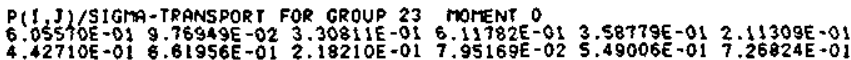

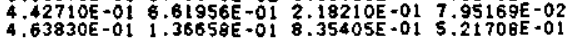

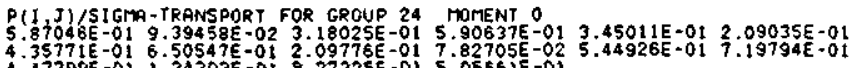
4.47799E-01 1.34303E-01 8.27325E-01 5.05661E-01

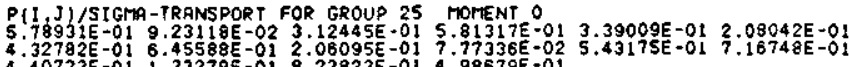
4.40733E-01 $1.33279 E-018.23823 E-014.98679 E-0$

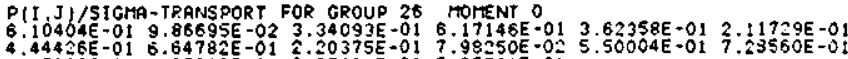

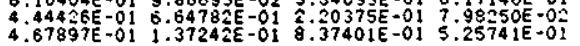

$P(1, J) / S I G H A-T R A N S P O R T$ FOP GROUP 27 MOMENT $O$

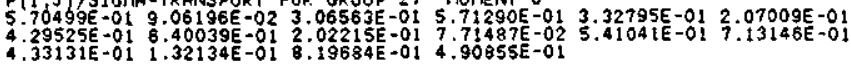

P(I J)/SIGMA-TRANSPORT FOR GROUP 28 MOMENT O

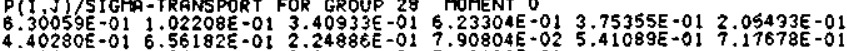
$\begin{array}{llll}4.40280 E-01 & 6.56182 E-01 & 2.2488 E E-01 & 7.90804 E-02 \\ 4.72586 E-01 & 3.35467 E-01 & 8.24892 E-01 & 5.16433 E-01\end{array}$

$P(I, J)$ SIGMA-TRANSPORT FOR GROUP 29 MOMENT $O$

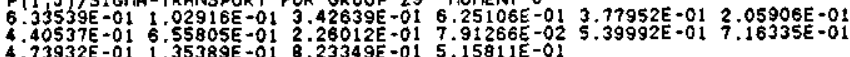

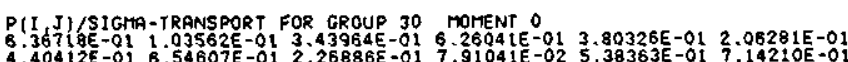

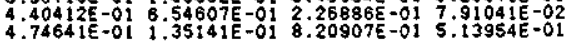

$P(1, J)$ SIGMA-TRANSPORT FOR GROUP 31 MOMENT $O$

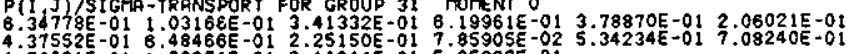
$4.70031 E-013.33874 E-018.14044 E-01$ 5.05227E-01

P I J J SSIGHA-TRANSPORT FOR GROUP 32 MOMENT 0

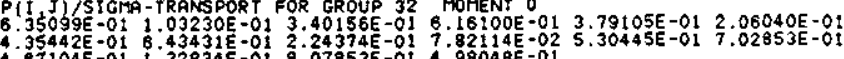

PIIJ)/SIGIG-TRANSPORT FOR GROUS 33 MOTENT O

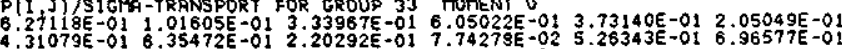
$\begin{array}{llll}4.31079 E-01 & 6.35472 E-01 & 2.20292 E-01 & 7.74273 E-02 \\ 4.58705 E-01 & 1.31191 E-01 & 8.00640 E-01 & 4.87071 E-01\end{array}$

$P$ (I J)/SIGMA-TRANSPORT FOR GROUP 34 MOMENT $O$

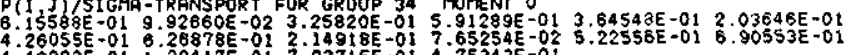

4.48293E-01 1.29417E-01 7.93715E-01 4.75343E-01

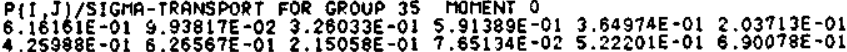

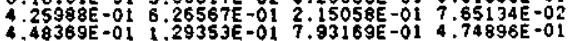

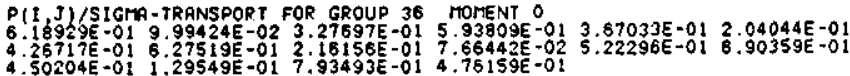

\section{B-48}

Attachment 1 
SNF-4503, Rev. 1

WHC-SD-NR-SWD-017

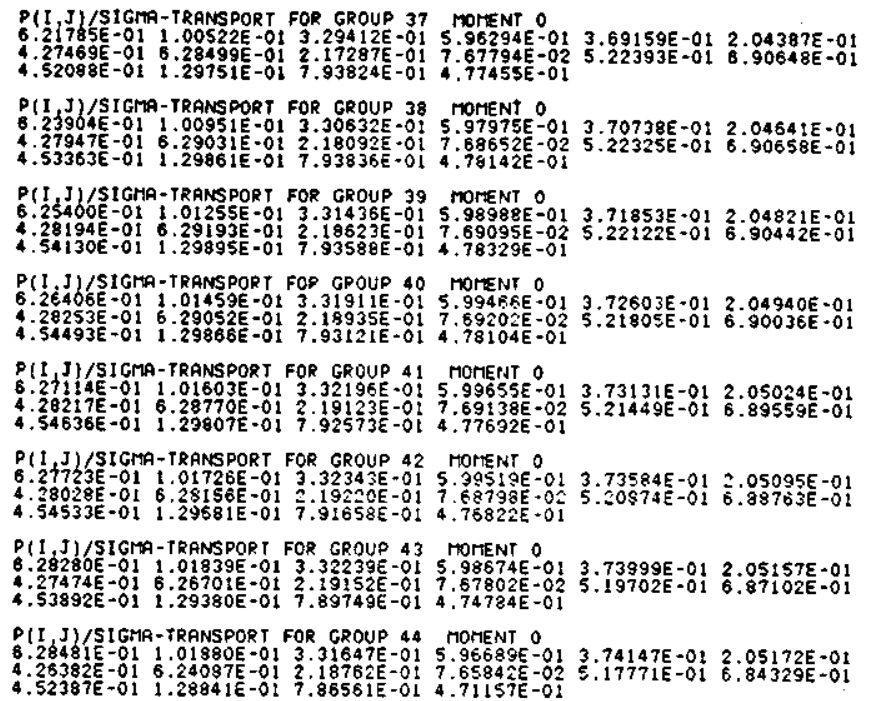

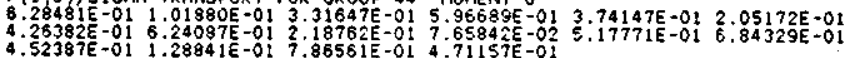

P(I J J /STGMA-TRANSPORT FOR GROUP 45 MOMENT O

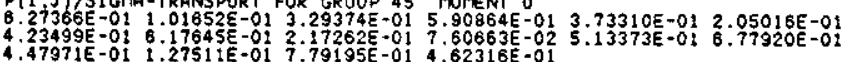

- P(I,J)/SIGMA-TRANSPORT FOR GROUP 46 MOMENT O

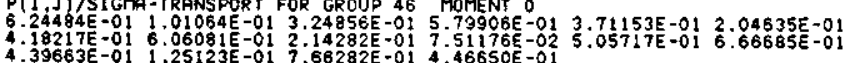

P(I J JSTGMA-TRANSPORT FOR GROUP 47 MOMENT O

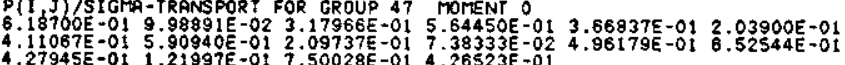

P(I,J)/SIGMA-TRANSPORT FOR GROUP 48 MOMENT O

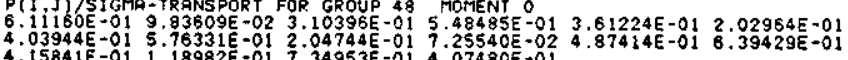

P(I,J)/SIGMA-TRANSPORT FOR GROUP 49 MOMENT 0

$\begin{array}{llllll}6.04250 E-01 & 9.69644 E-02 & 3.04241 E-01 & 5.36153 E-01 & 3.56096 E-01 & 2.02121 E-01 \\ 3.98631 E-01 & 5.85758 E-01 & 2.00684 E-01 & 7.15997 E-02 & 4.81362 E-01 & 6.30298 E-01\end{array}$

P(I,J)/SIGMA-TRANSPORT FOR GROUP 50 MOMENT 0

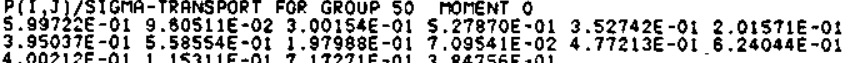

P(I J) SIGMA-TRANSPORT FOR GROUP SI MOMENT O

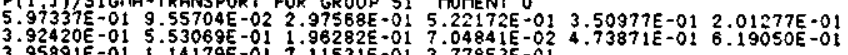

P(I.J)/SIGMA-TRANSPORT FOR GROUP 52 MOMENT O

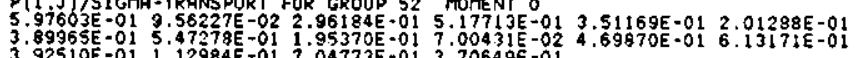


SNF-4503, Rev. 1

WHC-SD-NR-SWD-017

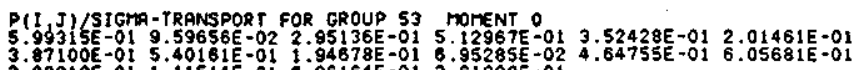

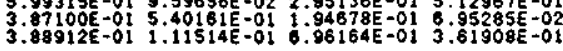

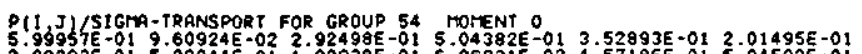

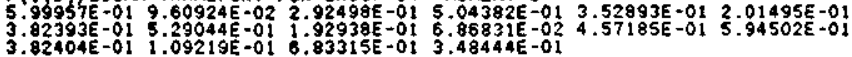
$P(1, J)$ /SIGMA-TEANSPORT FOR GROUP 55 MOMENT O $\begin{array}{llllll}5.972331 E-01 & 9.55400 E-02 & 2.86376 E-01 & 4.88284 E-01 & 3.50855 E-01 & 2.01109 E-01 \\ 3.74257 E-01 & 5.10864 E-01 & 1.88900 E-01 & 8.72218 E-02 & 4.45549 E-01 & 5.77174 E-01\end{array}$ $P(1, J) / S I G M A-T R A N S P O R T$ FOR GROUP 56 MOMENT $O$ $\begin{array}{llllll}5.901100-01 & 9.41042 E-02 & 2.76169 E-01 & 4.63717 E-01 & 3.45592 E-01 & 2.00180 E-01 \\ 3.82276 E-01 & 4.84978 E-01 & 1.82167 E-01 & 6.50698 E-02 & 4.29553 E-01 & 5.53406 E-01\end{array}$ P(I,J)/SIGTA-TRANSPORT FOR GROUP 57 MOMENT O

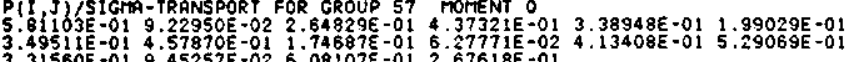
P(1 J)/SIGMA-TRANSPORT FOR GROUP 58 MOMENT O

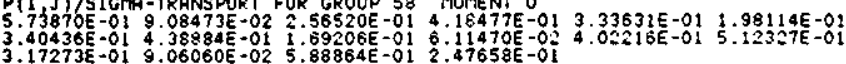
P(I J)/SIGMA-TPANSPORT FOR GROUP 59 MOMENT $O$ $\begin{array}{llllll}5.67510 E-01 & 8.95779 E-02 & 2.49796 E-01 & 4.03598 E-01 & 3.28970 E-01 & 1.97314 E-01 \\ 3.33310 E-01 & 4.24192 E-01 & 1.64764 E-01 & 5.98671 E-02 & 3.93676 E-01 & 4.99571 E-01\end{array}$

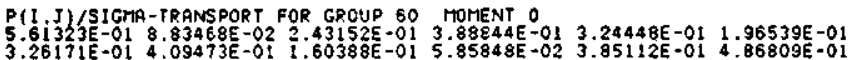
$\begin{array}{llll}3.26171 E-01 & 4.09473 E-01 & 1.60388 E-01 & 5.85848 E-02 \\ 2.94807 E-01 & 8.45343 E-02 & 5.59534 E-01 & 2.19089 E-01\end{array}$

P(I J) SIGMA-TRANSPORT FOR GROUP 81 MOMENT

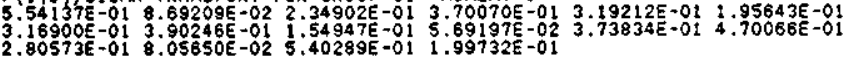

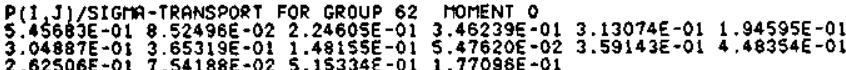
$\begin{array}{llll}3.04887 E-01 & 3.65319 E-01 & 1.48155 E-01 & 5.47620 E-02 \\ 2.62506 E-01 & 7.54188 E-02 & 5.15334 E-01 & 1.77096 E-01\end{array}$

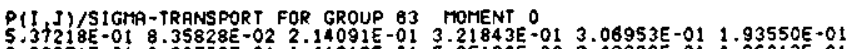
$\begin{array}{llllll}5.37218 E-01 & 8.35828 E-02 & 2.14091 E-01 & 3.21843 E-01 & 3.06953 E-01 & 1.93550 E-01 \\ 2.92371 E-01 & 3.39539 E-01 & 1.41219 E-01 & 5.25139 E-02 & 3.43936 E-01 & 4.26013 E-01\end{array}$

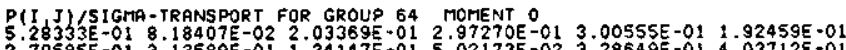

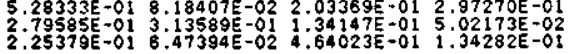

$P(I, J)$ /SIGMA-TRANSPORT FOR GROUP BS MOMENT 0 $\begin{array}{lllllll}5.17060 E-01 & 7.96416 E-02 & 1.90563 E-01 & 2.68591 E-01 & 2.92479 E-01 & 1.91082 E-01 \\ 2.64434 E-01 & 2.83495 E-01 & 1.25699 E-01 & 4.74961 E-02 & 3.10932 E-01 & 3.78094 E-0\end{array}$ $2.8434 E-01$
$2.03636 E-01$
$5.85265 E-02$

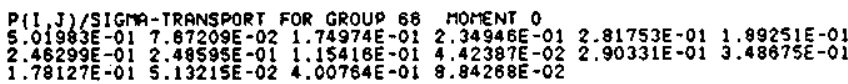

$P(I J) / S I G H A-T R A N S P O R T$ FOR GROUP 67 MOMENT O

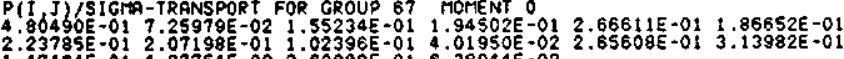
$P(I, J)$ /SIGMA-TRANSPORT FOR GROUP 68 MOMENT O

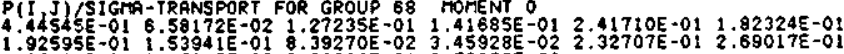
1.92421 01 . 


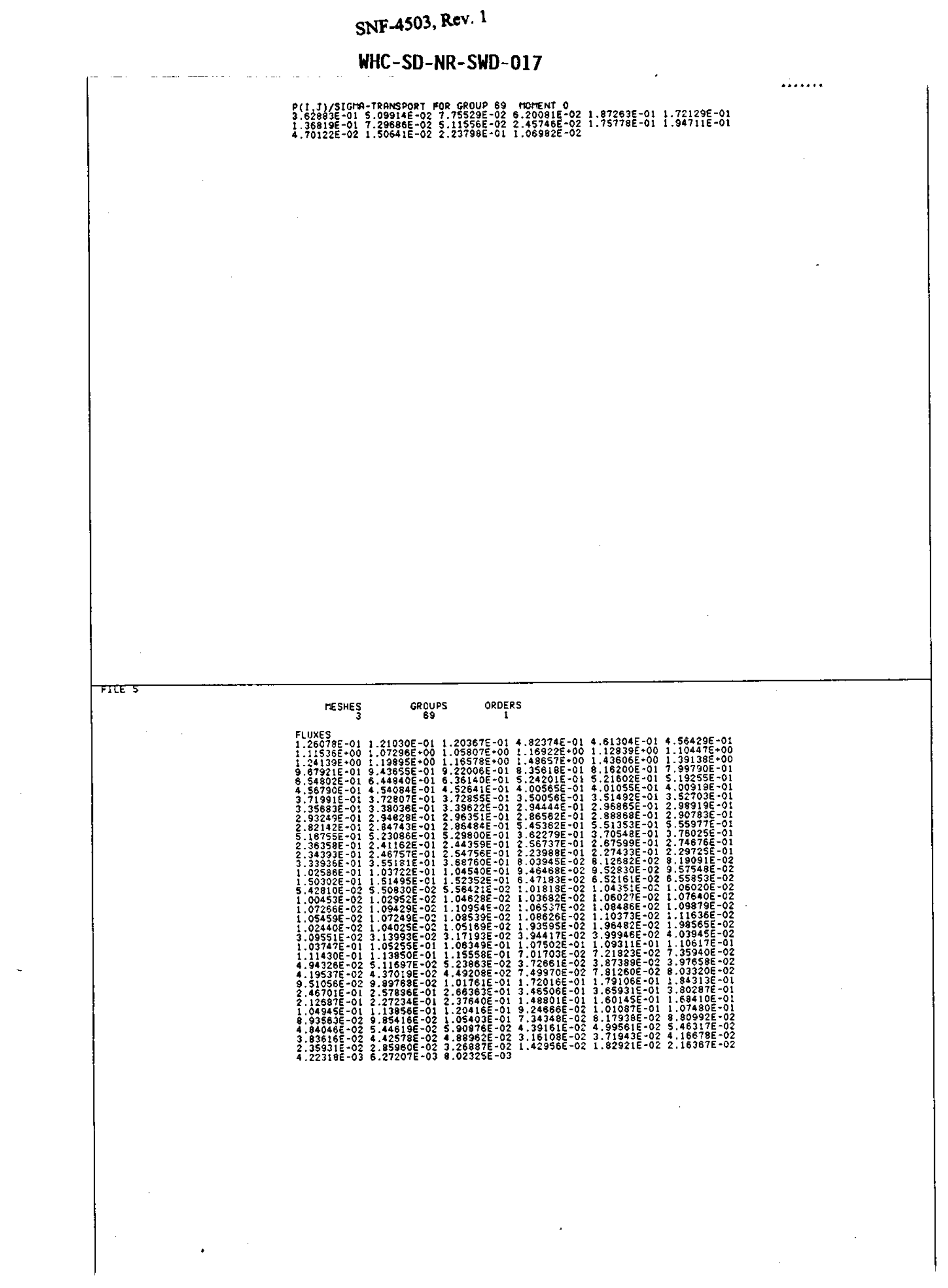

B-51

Attachment 1 
SNF-4503, Rev. 1

WHC-SD-NR-SWD-017

INTER COMPLETED

UNUSED STORAGE 297861 WOROS

TIME FROM StaRt 2.1 SECONOS. TIME IN THIS MODULE 0.2 SECONOS. UNUSED REGION THIS MOOULE $1162 \mathrm{~K}$ BYTES.

$1.20708 E+00 \quad 0.00000 E+00 \quad 0.00000 E+00 \quad 0.000000 E+00 \quad 0.000000 E+00 \quad 8.28443 E-01$

BUCXLINGS ARE CM**-2, NOT S.I. UNITS

BURNGP TIME TRRAOIATION
$0.00000 E+00$ O.00000 +00

SPARE IIEHS (I/F WRI TTEN IN OR AFTER MAY 72$)$

$0.00000 E+006.00000=00.00000 E+00 \quad 0.00000 E+000.00000 E+00 \quad 0.00000 E+00$

$0.00000 E+00 \quad 0.00000 E+000.00000 E+00 \quad 0.00000 E+00 \quad 0.00000 E+000.00000 E+00$

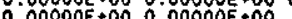

-C- WCRITIC 12

REAOS INTERFACE 1 FGRTRAN DATA SETS $11-15$ DSNAMES:

WRITES INTERFACE 2 FORTRAN DATA SETS 16-20 DSNAMES:

- $-1-$ CENT

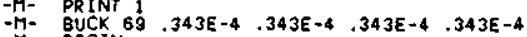

ME- BEIN

BEFF SET TO 1.000000

UNUSED STORAGE, 274109

LATDA 15 S 29.434687 TOTAL CELL ABSORPTION OF 1.0 NOT INCLUDING BUCKLING TERMS

TOTAL CELL FISSION SOURCE (NUNSIG.FISEPHI) $=1.200388$

CRITTC COMPLETED

TIME FROM START 2.4 SECONDS. TIME IN THIS MOOULE 0.2 SECONDS. UNUSEO REGion THIS MOOULE $1070 \mathrm{~K}$ BYTES. 
SNF-4503, Rev. 1

WHC-SD-NR-SWD-017

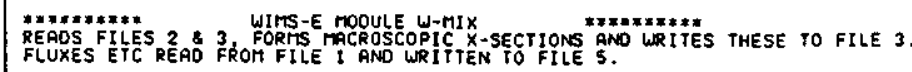

\begin{tabular}{|c|c|c|c|c|}
\hline \multirow{2}{*}{$\begin{array}{lcc}\text { LN } & 2 & \text { LT } \\
\text { CROSS-SECTIONS }\end{array}$} & 1 & & & \\
\hline & \multicolumn{4}{|c|}{ CROSS-SECTIONS } \\
\hline GROUPS & 69 & & & \\
\hline \multicolumn{5}{|c|}{ MATERIALS } \\
\hline \multicolumn{5}{|c|}{ NO. OF TATERIaLS TO BE PROCESSEO at a TINE 3} \\
\hline UNUSEO STORAGE & 230526 & I IF MATERIALS & S PROCESSED SINGLY & 2700151 \\
\hline MATERIAL 1 & & $\begin{array}{r}\text { NUCL IOE } \\
2 \\
5 \\
6\end{array}$ & $\begin{array}{r}\text { IOENTIFIER } \\
6015 \\
2235 \\
9238\end{array}$ & $\begin{array}{c}\text { NUMBEF OENSITY } \\
4.400 \% \mathrm{O}-0 \hat{1} \\
4.6787 \mathrm{E}-04 \\
2.1536 \mathrm{BE}-02\end{array}$ \\
\hline NUMBER OF & IF REACTIONS & 4 & & \\
\hline Material 2 & & NUCLIOE & $\begin{array}{l}\text { IOENTIFIER } \\
9 !\end{array}$ & $\begin{array}{c}\text { NUMBER OENSITY } \\
4.3280 \mathrm{O}-02\end{array}$ \\
\hline NUMBER OF & F REACTIONS & 3 & & \\
\hline TERIAL 3 & & NACLIDE & $\begin{array}{r}\text { IDENT IFIER } \\
3001 \\
\text { BO16 }\end{array}$ & $\begin{array}{c}\text { NUMBER OENSITY } \\
3.3439 E-02 \\
1: 6721 E-02\end{array}$ \\
\hline
\end{tabular}

NUMBER OF REACTIONS 3

WRITING FILE S

NTESH 3 NGRP BS NORDER 1

$\begin{array}{llllllllll}\text { FlUX } \\ 1.30972 E-01 & 1.25728 E-01 & 1.25039 E-01 & 5.22535 E-01 & 4.99710 E-01 & 4.94430 E-01 & 1.18980 E+00 & 1.14457 E+00 & 1.12869 E+00 & 1.271711 E+00 \\ 1.2730 E+00 & 1.20129 E+00 & 1.35238 E+00 & 1.30614 E+00 & 1.27001 E+00 & 1.58947 E+00 & 1.53546 E+00 & 1.48769 E+00 & 1.03630 E+00 & 1.01032 E+000\end{array}$

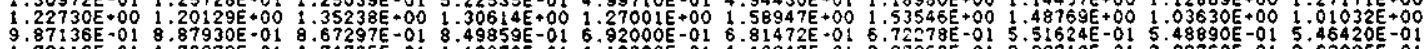

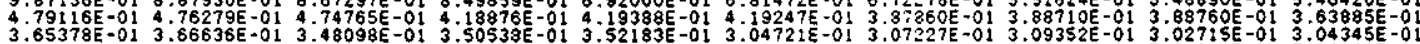

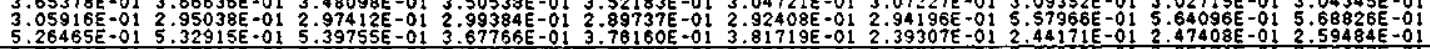

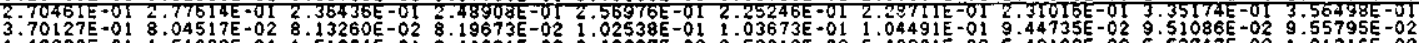

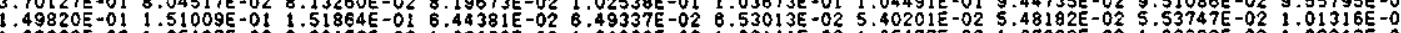

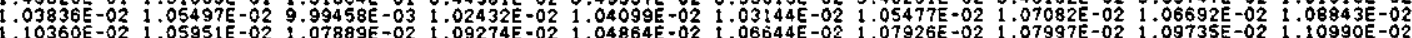

$1.01834 \mathrm{E}-02$ 1.03409E-02 $1.04547 \mathrm{E}-02$

$1.14397 \mathrm{E}=016.93633 \mathrm{E}-02$

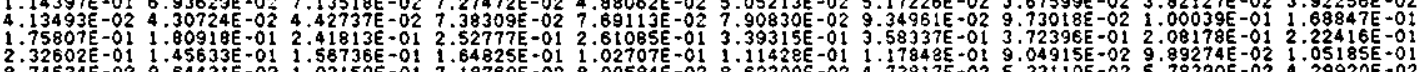

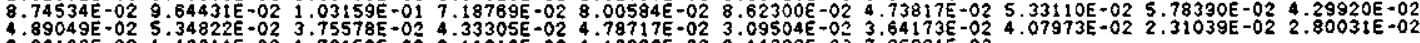

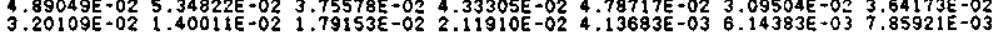

${ }_{1.0000 E}^{A K}+00^{B X} 0.0000 E+00^{B Y} \quad 0.0000 E+00^{B Z} 0.0000 E+00_{0.0000 E}^{T C} 0^{U} 2.9435 E+01$

RTIME $0.00000 E+00$ RIRRAO $0.00000 E+00$

SPARE ITETS

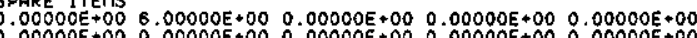

$0.00000 E+000.00000 E+000.00000 E+000.00000 E+\infty 00.00000 E++00$

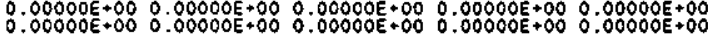

MIX COMPLETED

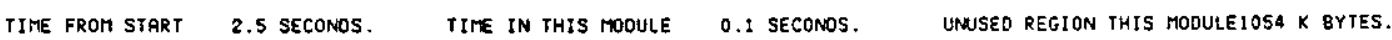




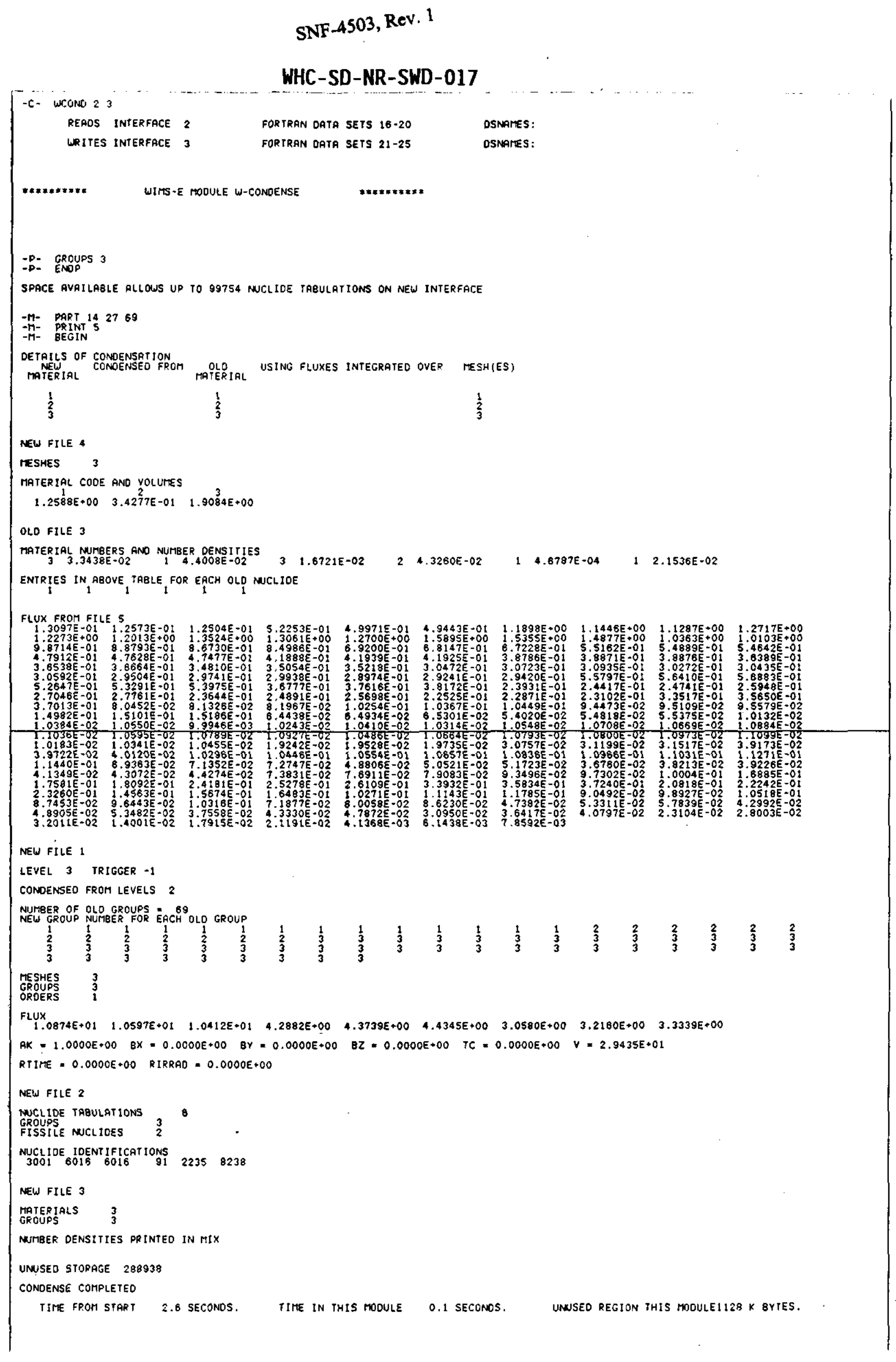

Attichiment 1 
SNF-4503, Rev. 1

WHC-SD-NR-SWD-017

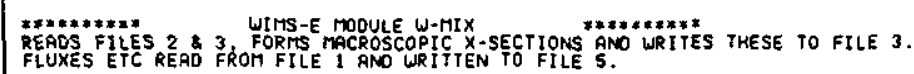

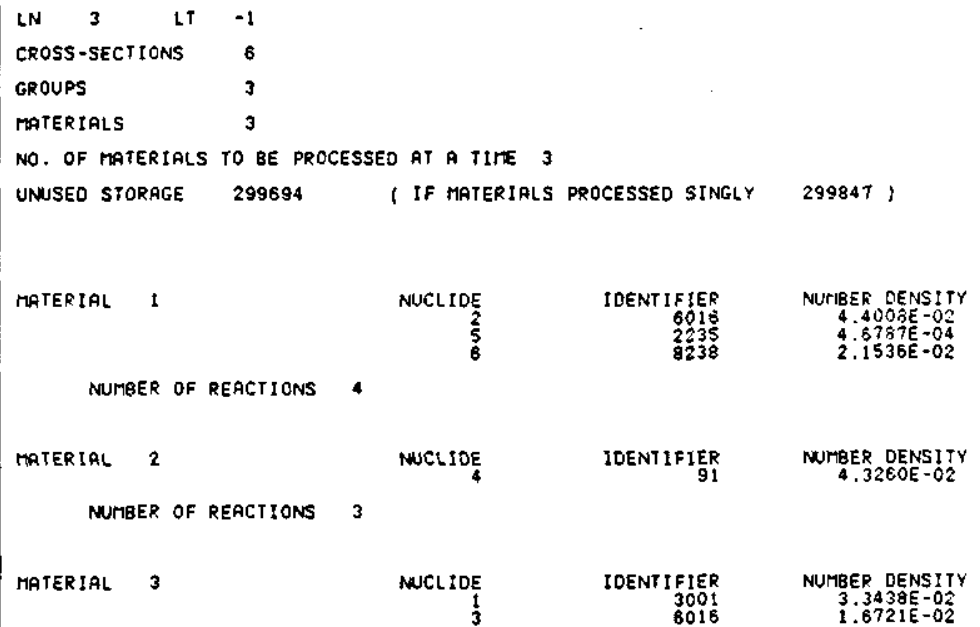


SNF-4503, Rev. 1

\section{WHC-SD-NR-SWD-017}

$-c-\operatorname{siap}$

UNUSED REGION FOR THIS RUN WASIOS4 K BYTES.

B-56

Attachment 1

1-107 
SNF-4503, Rev. 1

WHC-SD-NR-SWD-017
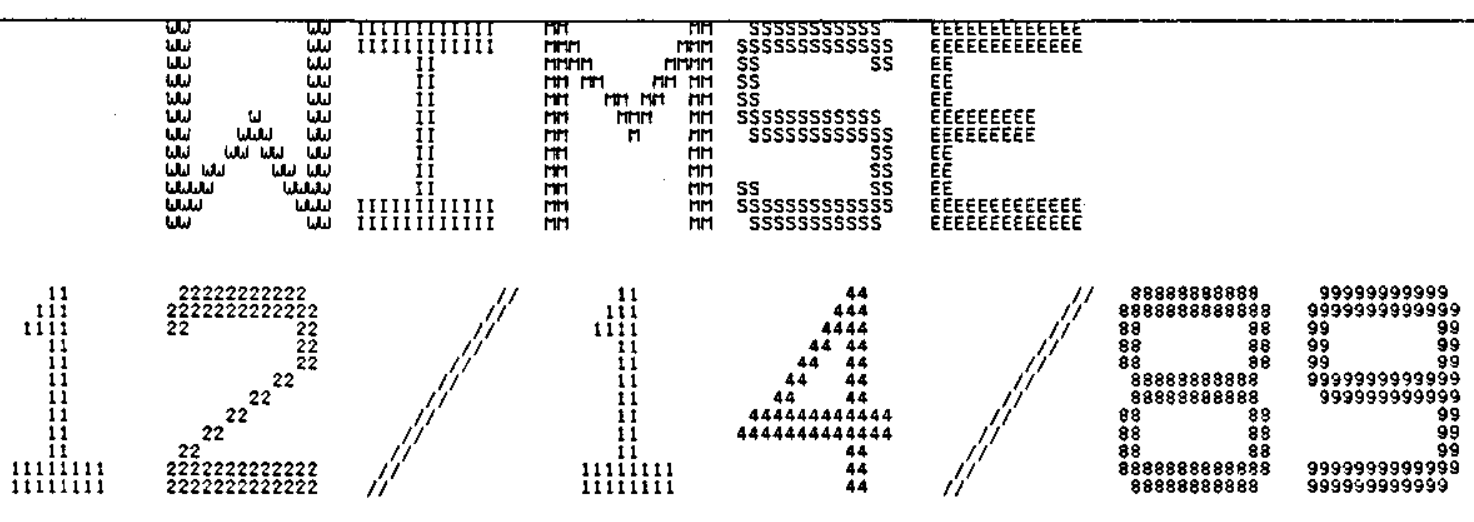

11
111
111
11
11
11
11
11
11
11
11111
1111111
11111
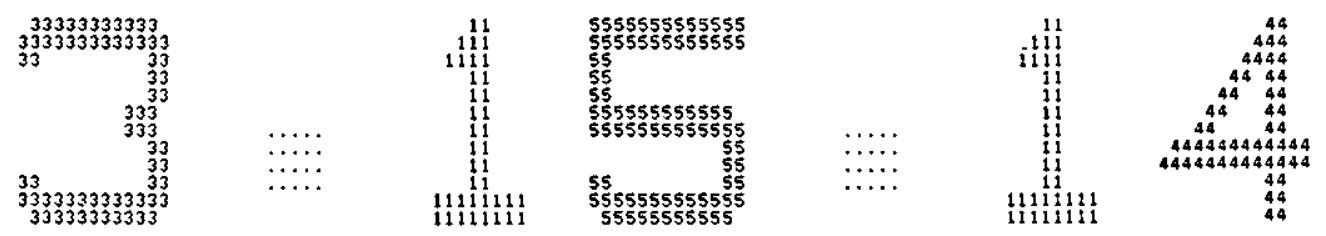
SNF-4503, Rev. 1

WHC-SD-NR-SWD-017

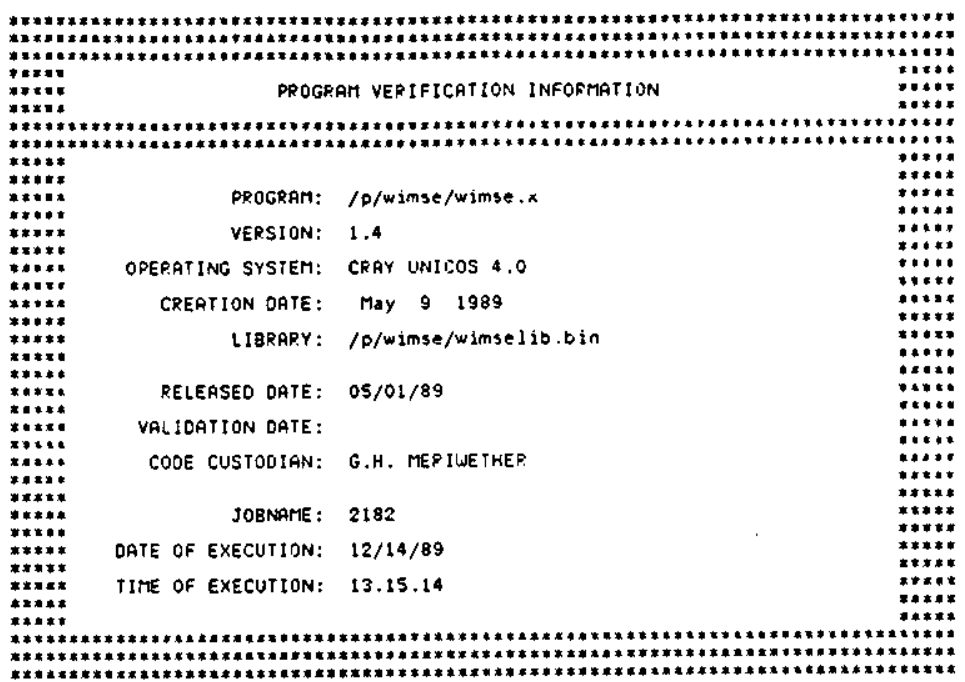

MESSAGE BOX

REPORTED PROBLEMS

1. WHEN USING CACTUS IN BURNHP CALCULATIONS. THE EXPOSURE VALUE IS NOT INTEGRATEO PPOPEPLY $(4-18-89)$ (4) 2. THE CODE CRASHES LHEN US ING WCR IT MOOULE' RIGHT AFTER THE
3. TWO MDDULES, WPRES ANO WRES, ARE NOT OPERABLE. (4-18-89) 
SNF-4503, Rev. 1

WHC-SD-NR-SWD-017

\begin{tabular}{|c|c|c|c|c|c|c|c|c|c|}
\hline MODULE & VERSION & MOOULE & VERSION & nOOULE & VERSION & MODULE & VERSION & MOOULE & VERSION \\
\hline $\begin{array}{l}\text { WBRNUP } \\
\text { WCHART } \\
\text { WTERGE } \\
\text { WFOHE } \\
\text { WSNAP }\end{array}$ & $\begin{array}{l}1988 / 11 \\
1988 / 11 \\
1988 / 11 \\
1988 / 11 \\
\text { ABSENT }\end{array}$ & $\begin{array}{l}\text { WCONO } \\
\text { WFOR } \\
\text { WFII } \\
\text { WPRES } \\
\text { WTHESEUS }\end{array}$ & $\begin{array}{l}1988 / 11 \\
1998 / 11 \\
1988 / 11 \\
1988 / 11 \\
1988 / 11\end{array}$ & $\begin{array}{l}\text { WCRITIC } \\
\text { WHEED } \\
\text { WPERSEUS } \\
\text { WPROCOL } \\
\text { WWED }\end{array}$ & $\begin{array}{l}1988 / 11 \\
1989 / 01 \\
\text { DELTED } \\
1988 / 11 \\
1988 / 11\end{array}$ & $\begin{array}{l}\text { WFLURIG } \\
\text { WINTER } \\
\text { WPIJ } \\
\text { WRES } \\
\text { WWIRE }\end{array}$ & $\begin{array}{l}1988 / 11 \\
1988 / 11 \\
1988 / 11 \\
1988 / 11 \\
1998 / 11\end{array}$ & $\begin{array}{l}\text { WCACTUS } \\
\text { WWINK } \\
\text { WPIP } \\
\text { WSMEAR }\end{array}$ & $\begin{array}{l}1989 / 11 \\
\text { ABSENT } \\
1988 / 11 \\
1988 / 11\end{array}$ \\
\hline
\end{tabular}

SUTMARY OF RECENT CHANGES

VERSION CREATED MOOULES CHANGED 112 WHEAD, WINTER, WPRES, WPES, WPIJ, WPROC, CONFROL ICYCLIC CALCULATIONS)

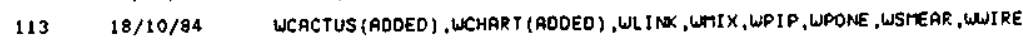

$1: 4$ O:103/87 THE FOLLOUING CHANGES HAVE BEEN MADE FOR WITS-E VERSION $114:$

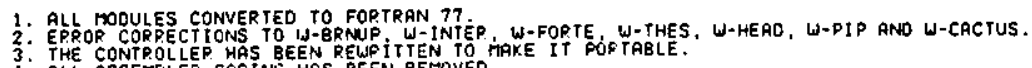

4. ALL ASSEMELEK COOIRUL HAS BEEN REMOVEO L W WE BY W-PIP SHOULO NOW BE USEO INSTERO.

6. NEW VEFSION SUPPOFTS USE OF THE 1986 WIITS NUCLEAR OATA LIERARIES.

120 08/11/88 THE FOLLOWING CHANGES HAVE BEEN HADE FOR WITS-E VERSION 120 :

1. PLL MODULES CONVERTEO ONTO THE HANFORO CPAY EXCEPT WPRES AND WRES MODULES.

3. 8 CHARACTER TO SIGNAL OATA CONTINUAT ION ON NEXT CARO MADE OPERABLE IN CACTUS MOQULE.

130 19/01/89 THE FOLLOUING CHANGES HAVE BEEN MAOE FOR WITS-E VERSION $130:$
1. ALT ARRAY IN MAINO2 ROUTINE WAS DECLAREO REAL INSTEAD OF IMPLICIT INTEGER.

140 O1/05/99 IHE FOLLOWING CHANGES HAVE BEEN MADE FOR WITS-E VERSION 140:

1. SNAP OPTION WAS AODED IN BRNUP MODULE TO SAVE THE ISOTOPICS ONTO UNIT 7.

3. OA INFORMATION PAGE WAS RODED. THIS REOUIRES Q UNICOS SHELLSCRIPT (WIMSE.EXE) TO BE EXECUTEO

TO COLLECT APPROPIATE QA INFORTATION BEFORE THE ACTUAL EXECUTION.

4. THE MESSAGE BOX WAS CHANGED TO LIST ANY REPOR YED PROBLEITS

NOTE PRINTS OF INPUT OATA (BEING READ FOR EXECUTION)

$\begin{array}{ll}\text {-C- } & \text { CONTROL ROUTINE DATA } \\ \text {-P.- } & \text { PRELUUE OATA FOR HOOULE } \\ \text {-M- } & \text { MAIN DATA FOR TODULE }\end{array}$

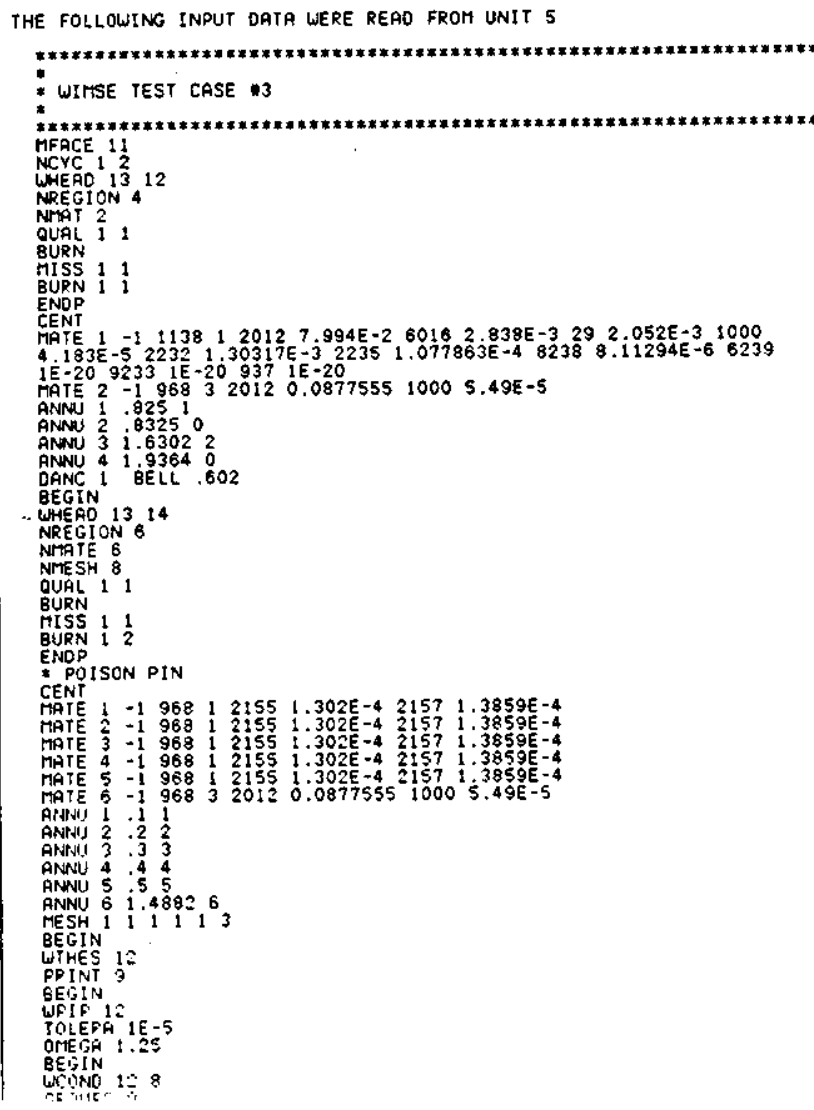




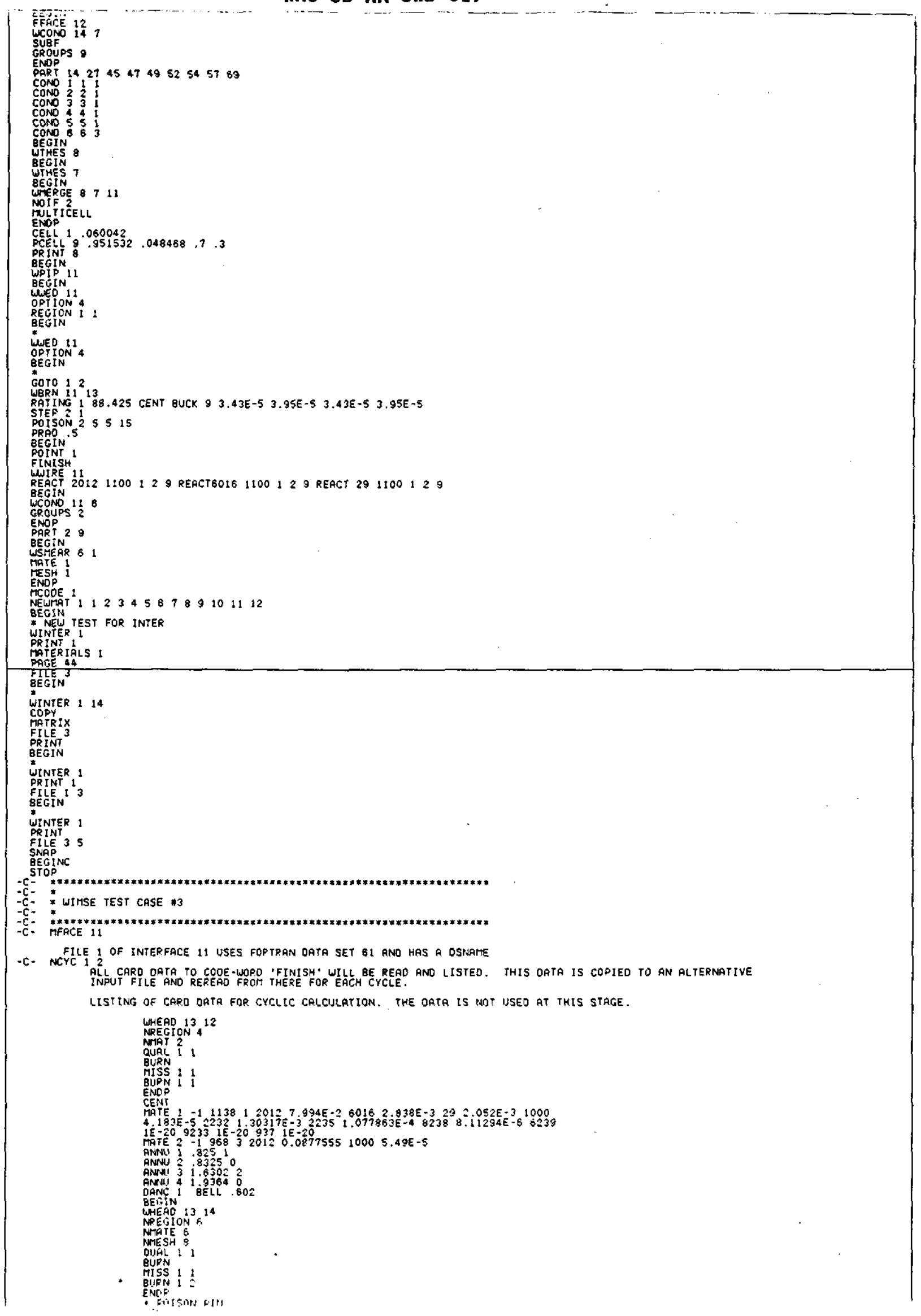


SNF-4503, Rev. 1

WHC-SD-NR-SWD-017

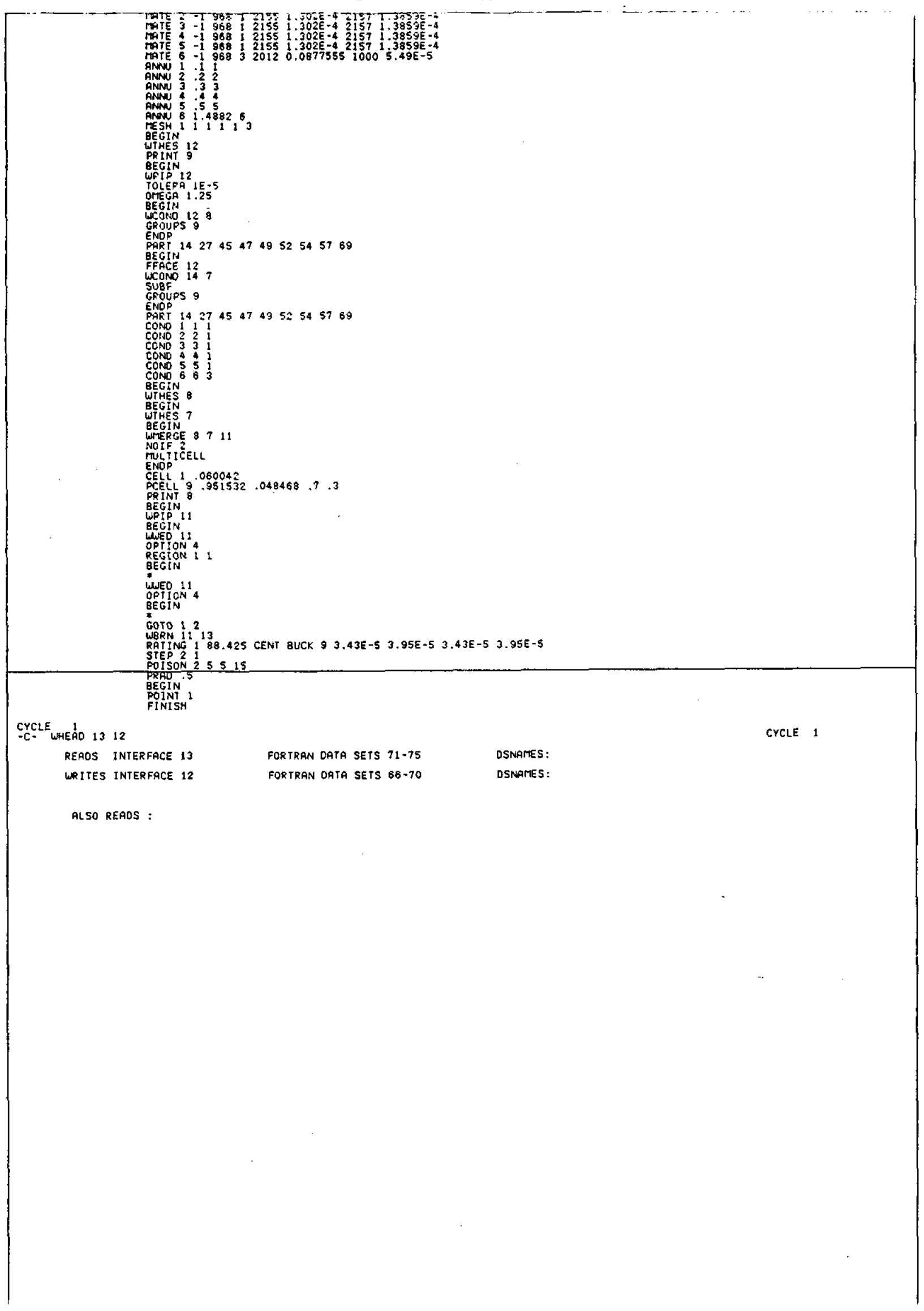


SNF-4503, Rev. 1

\section{WHC-SD-NR-SWD-017}

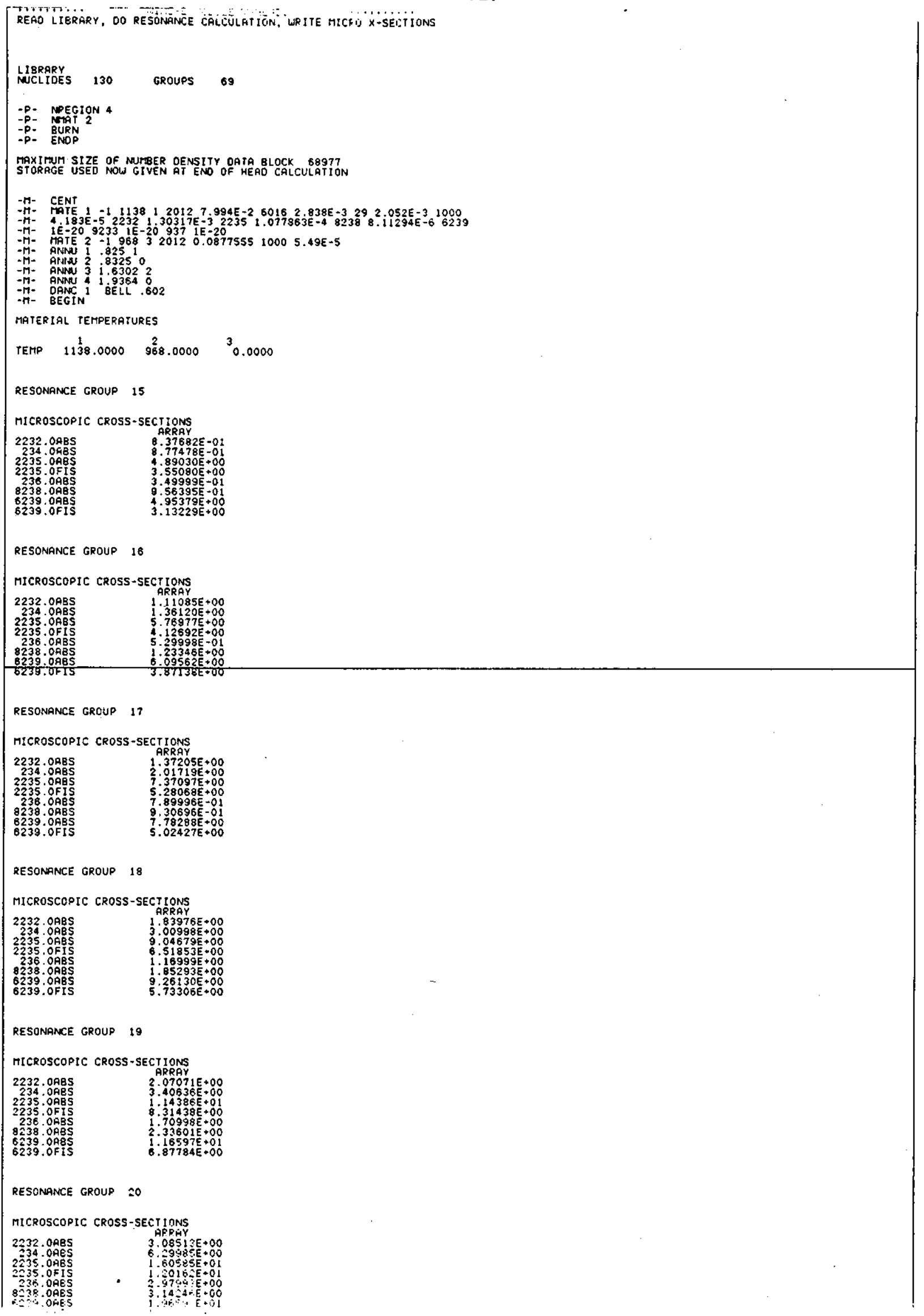




\section{SNF-4503, Rev. 1}

\section{WHC-SD-NR-SWD-017}
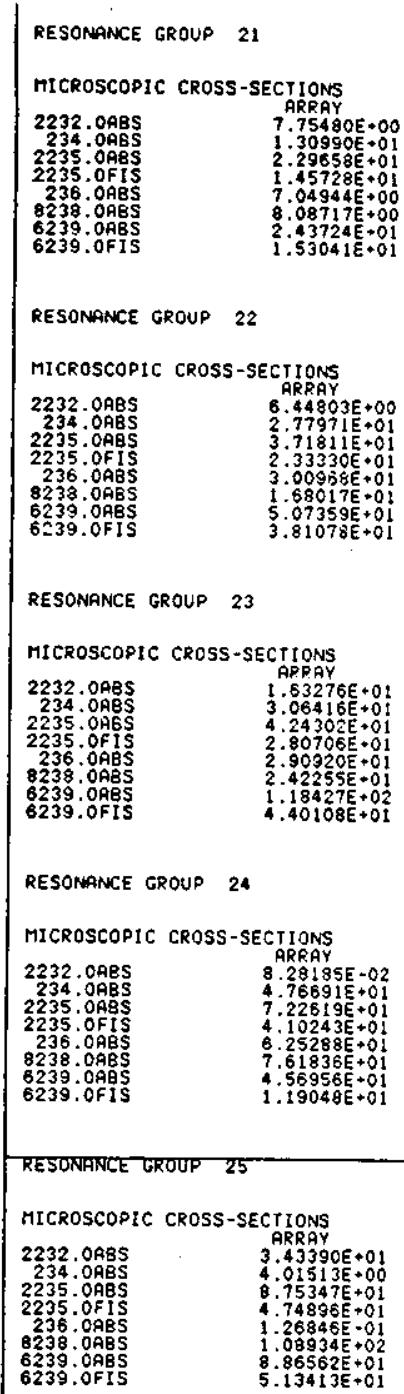

RESONANCE GROUP 26

MICROSCOPIC CROSS-SECTIONS

$\begin{array}{ll}2232 . \text { OABS } & \text { RRRAY } \\ 234 . O A B S & 5.11545 E-01 \\ 2235.0 A B S & 5.01998 E+00\end{array}$

$2235.0 A B S$
$2235.0 F 1 S$

$236.0 \mathrm{OAS}$
$3238.0 \mathrm{ABS}$

$\begin{array}{ll}6239.0 A B S & 2.73725 E+02 \\ 6239.0 F I S & 1.66 \$ 49 E+02\end{array}$

RESONANCE GROUP 27

MICROSCOPIC CROSS-SECTIONS

$2232.0 A 8 S$
$234.0 A B S$

2235 . OABS

236.0 ABS

8233.0 . ABS

6239. OABS
6239. OFIS

FILE 2

NUCLIOES 60

NUCLIOE IDENTIFICATIONS

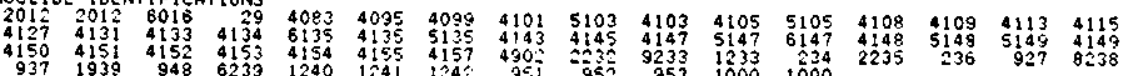

VOIOS BECOME MATERIAL 3

VOIOS EECOME MATEPIAL 3

B- 63

Attachment 1 
SNF-4503, Rev. 1

WHC-SD-NR-SWD-017

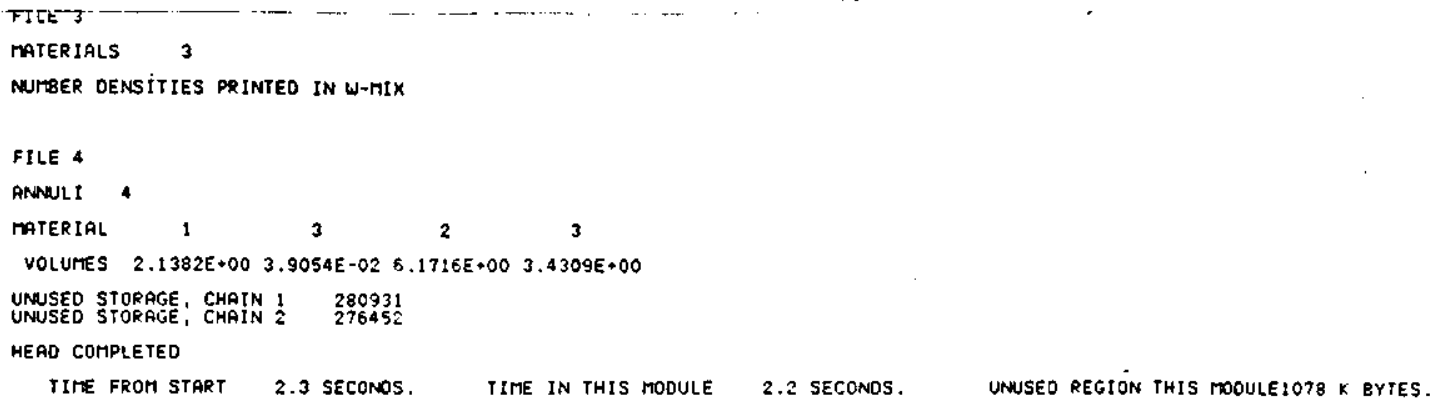


SNF-4503, Rev. 1

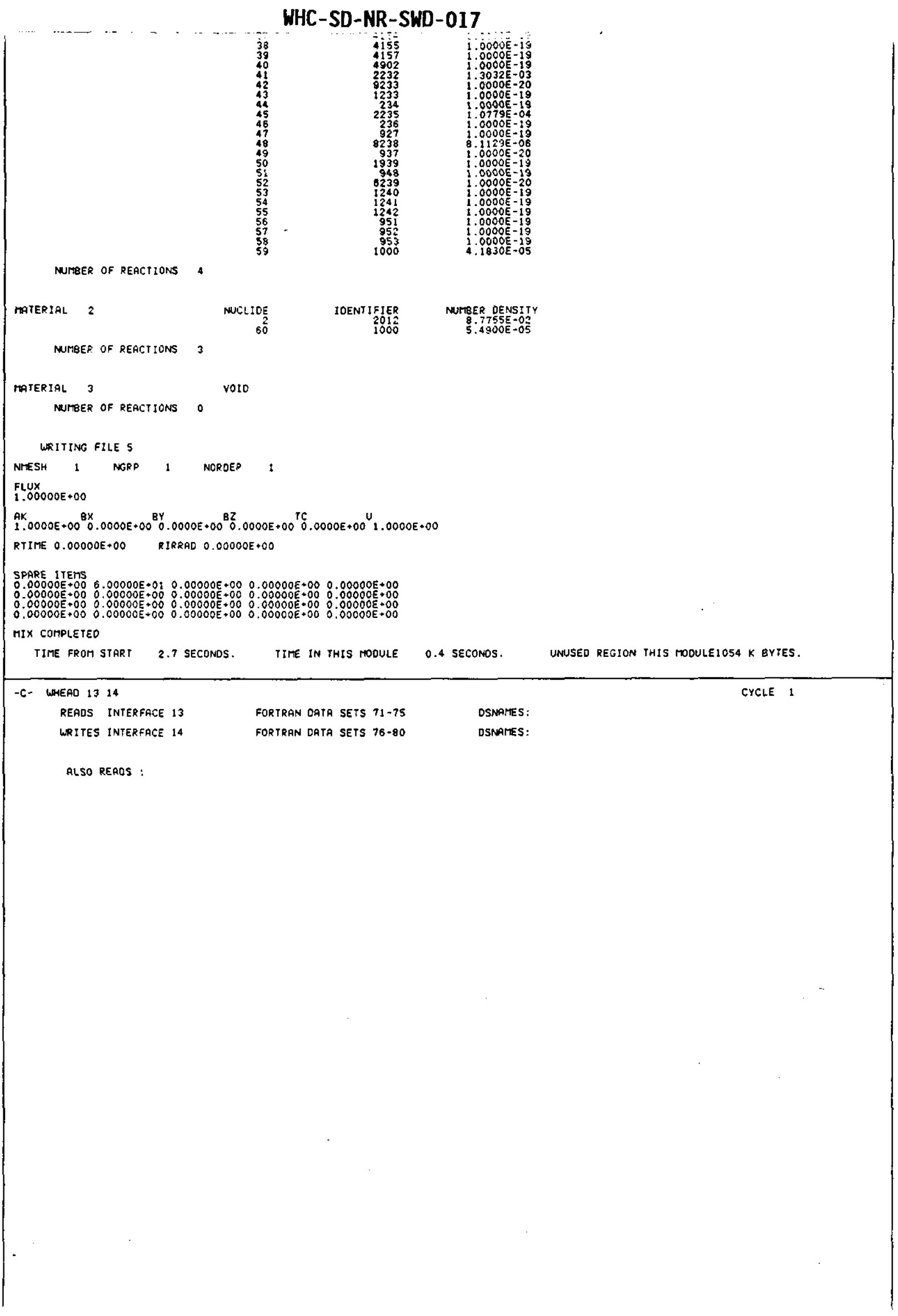

B- 65

Attachment 1

1-116 


\section{SNF-4503, Rev. 1}

\section{WHC-SD-NR-SWD-017}

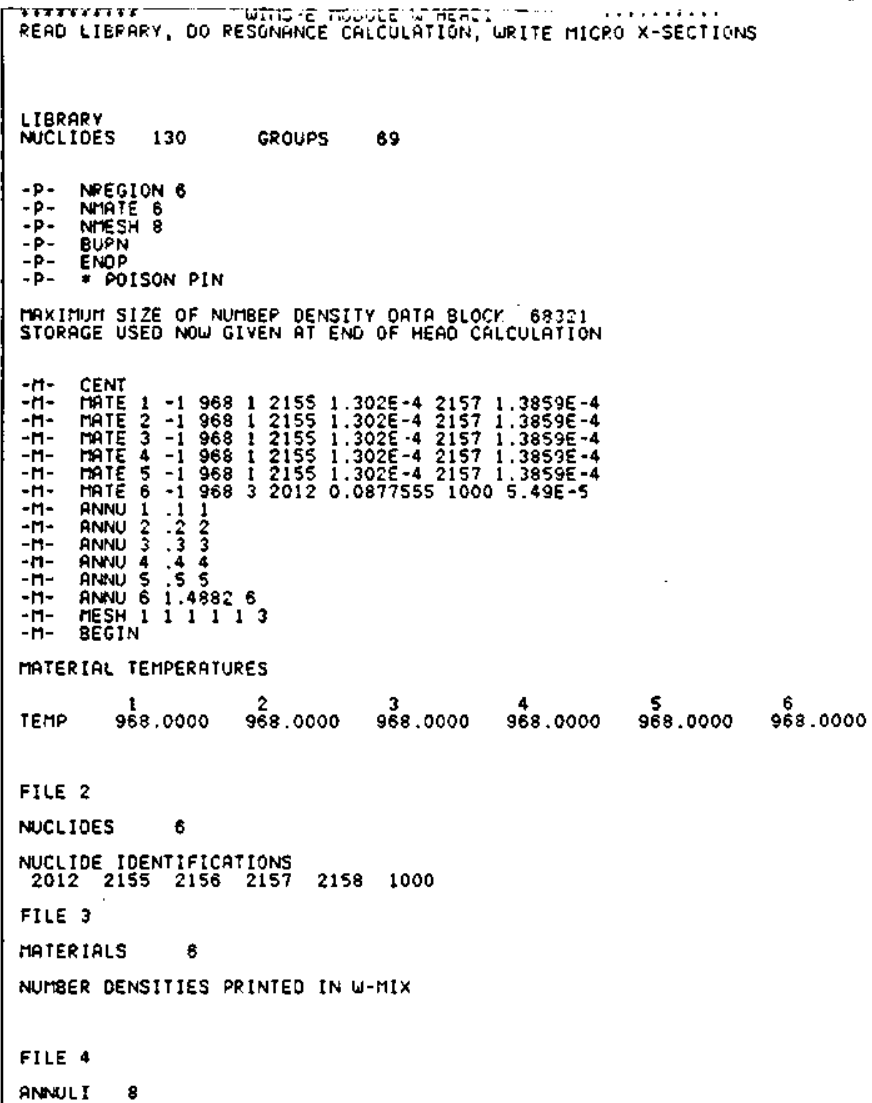


SNF-4503, Rev. 1

WHC-SD-NR-SWD-017

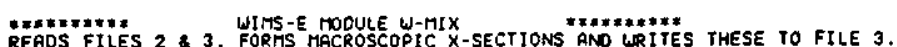
READS FILES 2 \& 3 FORMS MACROSCOPIC X-SECTIONS ANO
FLUXES ETC RERO FKOH FILE 1 AND WRITTEN TO FILE 5 .

$\begin{array}{ll}\text { LN } 1 & \text { LT } \\ \text { CROSS-SECTIONS } & 0 \\ \text { GROUPS } & 69 \\ \text { MATER IALS } & 6\end{array}$

No. OF Materials to be processed at a tIME 6

UNUSEO STORAGE 171519 (IF MATERIALS PROCESSEO SINGLY 270252)

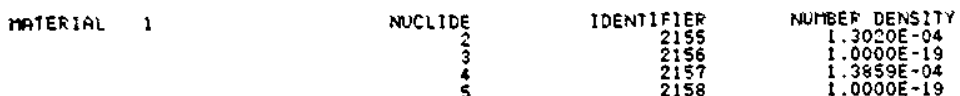

NUTBER OF REACTIONS 3

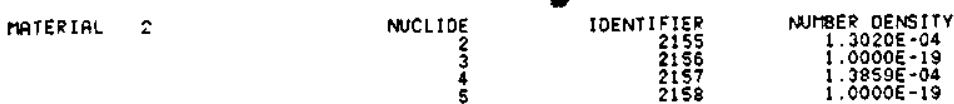

NUMBER OF REACTIONS 3

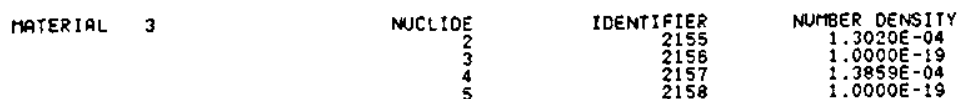

MUMEER OF REACTIONS 3

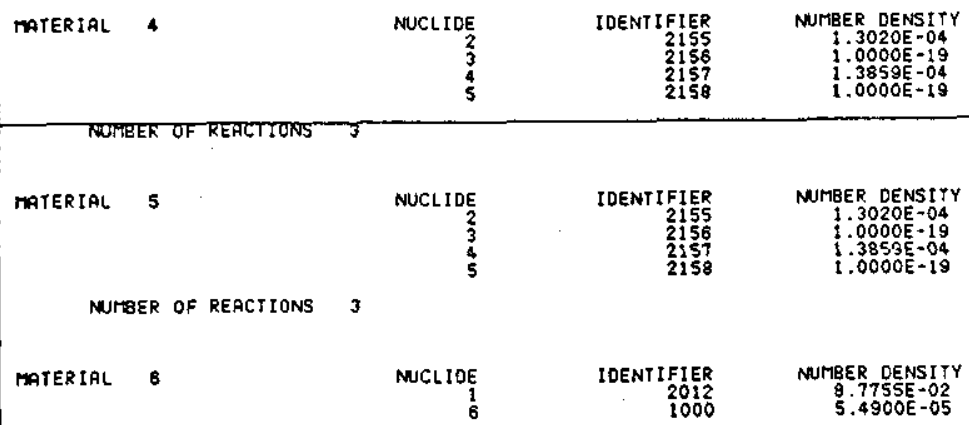

NUMBER OF REACTIONS 3

WRITING FILE 5

NTESH 1 NGRP 1 NORDER 1

FLUX $1.00000 E+00$

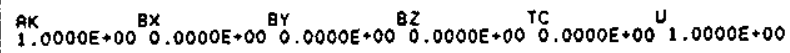

RTIME $0.00000 E+00$ RIRRAD $0.00000 E+00$

SPARE IIEMTS

$0.00000 E+002.20000 E+01 \quad 0.00000 E+00 \quad 0.00000 E+00 \quad 0.00000 E+00$

$\begin{array}{llll}0.00000 E+00 & 0.00000 E+00 \quad 0.00000 E+00 & 0.00000 E=00 & 0.000000 E+00\end{array}$

0.00000 E $+000.00000 E+00 \quad 0.00000 E+00 \quad 0.00000 E+000.00000 E+00$

MIX COMPLETED

time from start 4.1 seconos. Time in this moOvle 0.1 seconos.

UNUSEO REGION THIS HODULEIOS4 $\mathrm{X}$ BYTES. 
SNF-4503, Rev. 1

WHC-SD-NR-SWD-017

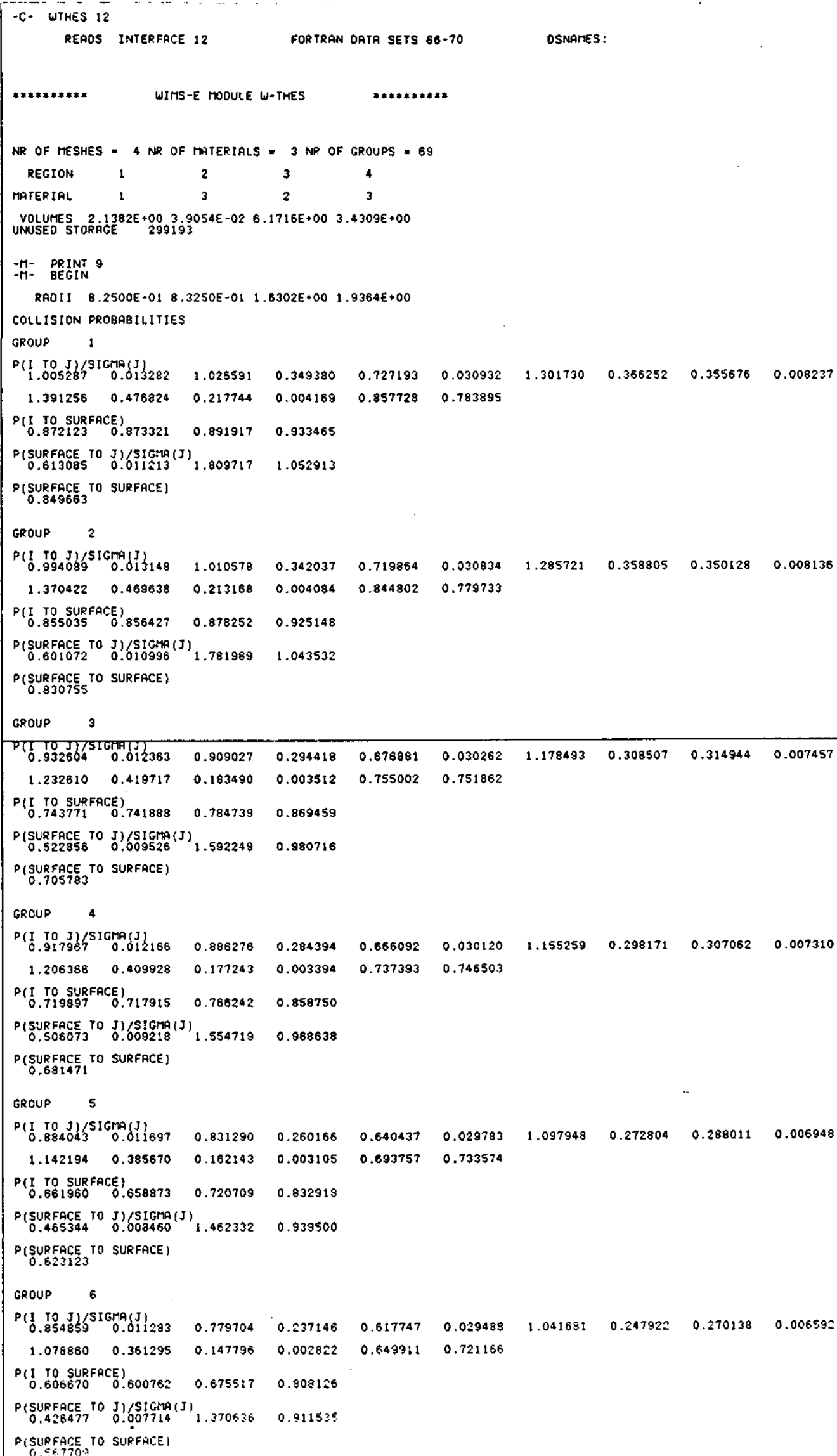

B-68

Attachment 1 
SNF-4503, Rev. 1

WHC-SD-NR-SWD-017

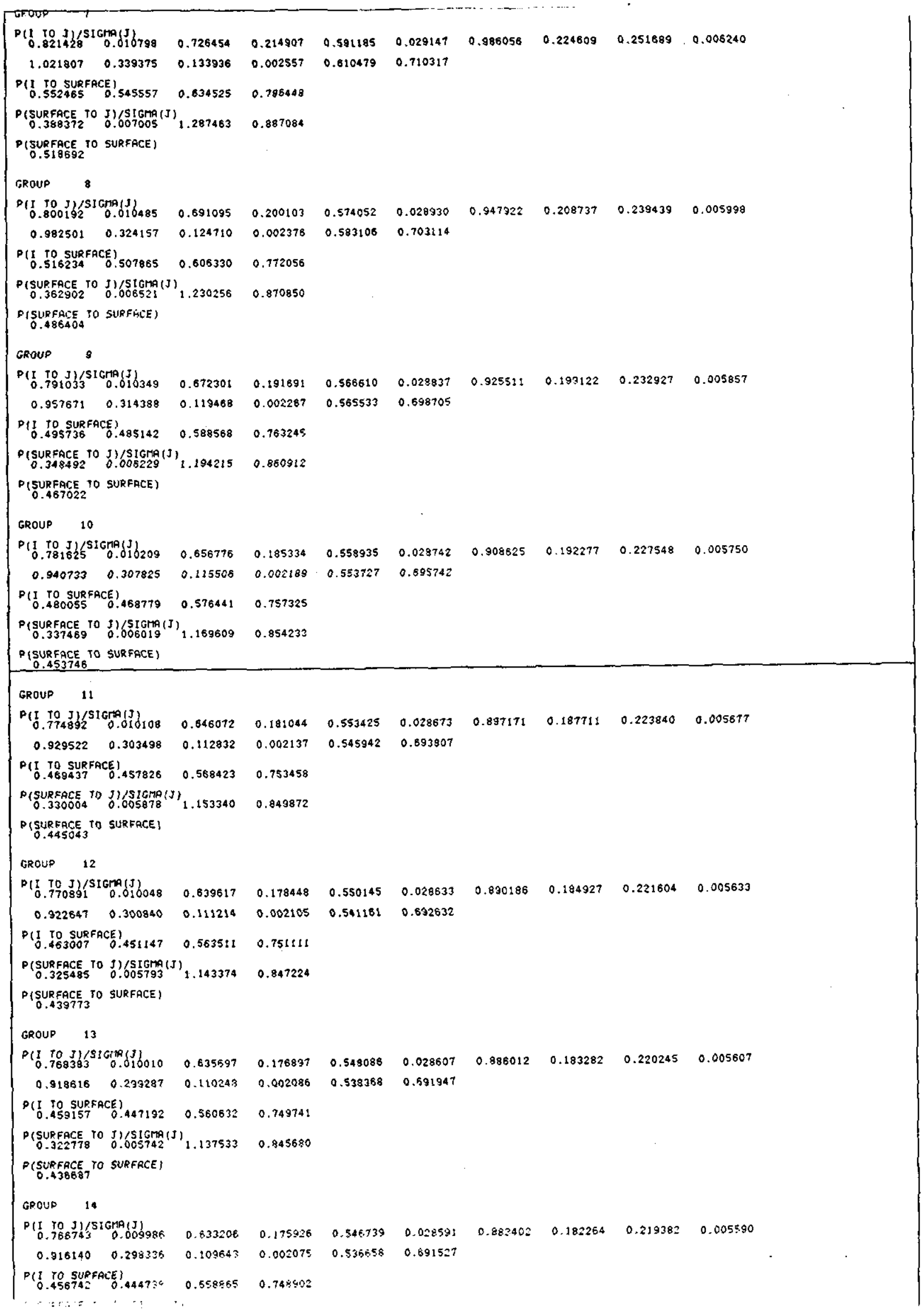

\section{B-69}

Attachment 1 
SNF-4503, Rev. 1

WHC-SD-NR-SWD-017

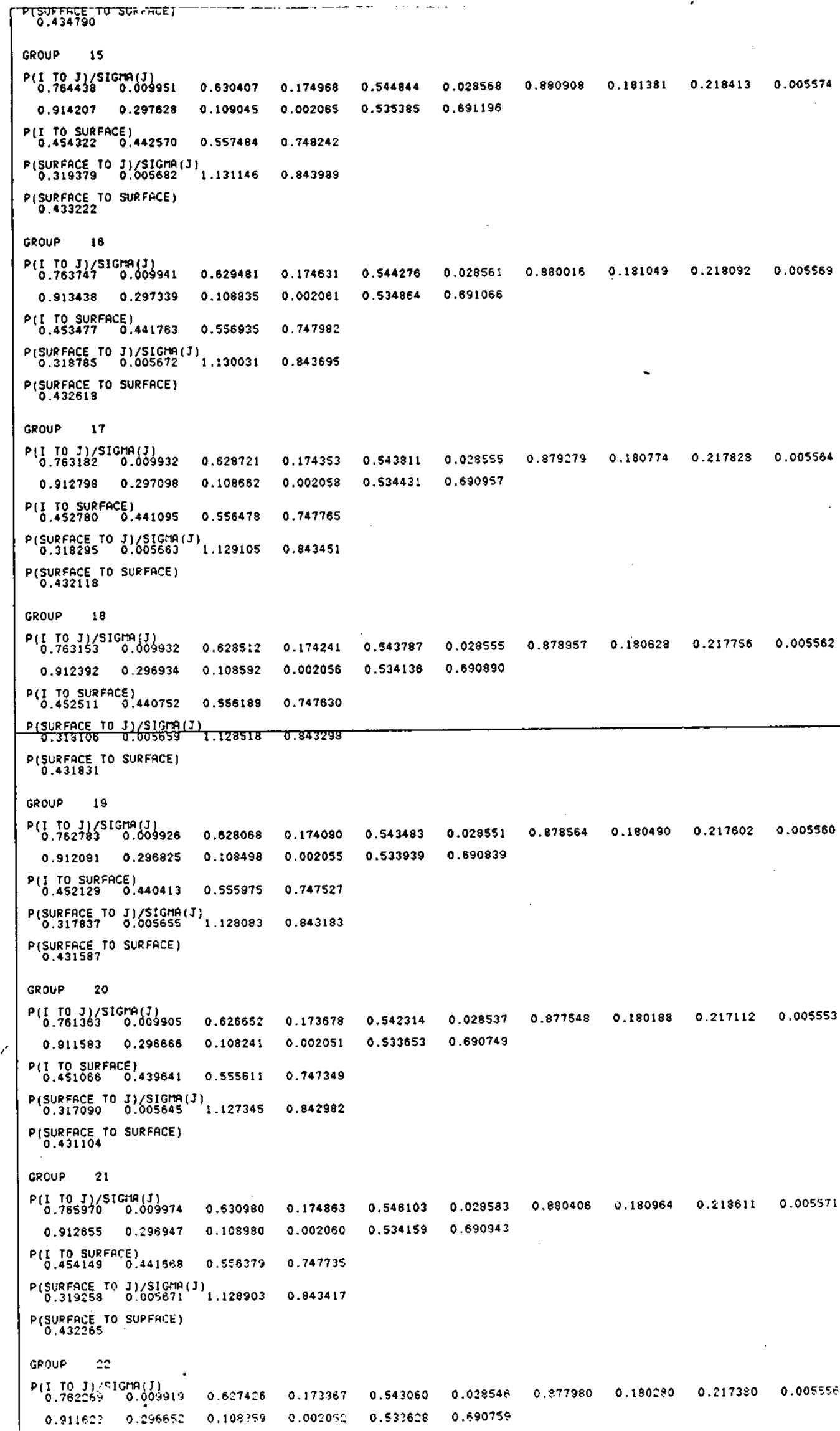

\section{Attuthinent}


SNF-4503, Rev. 1

WHC-SD-NR-SWD-017

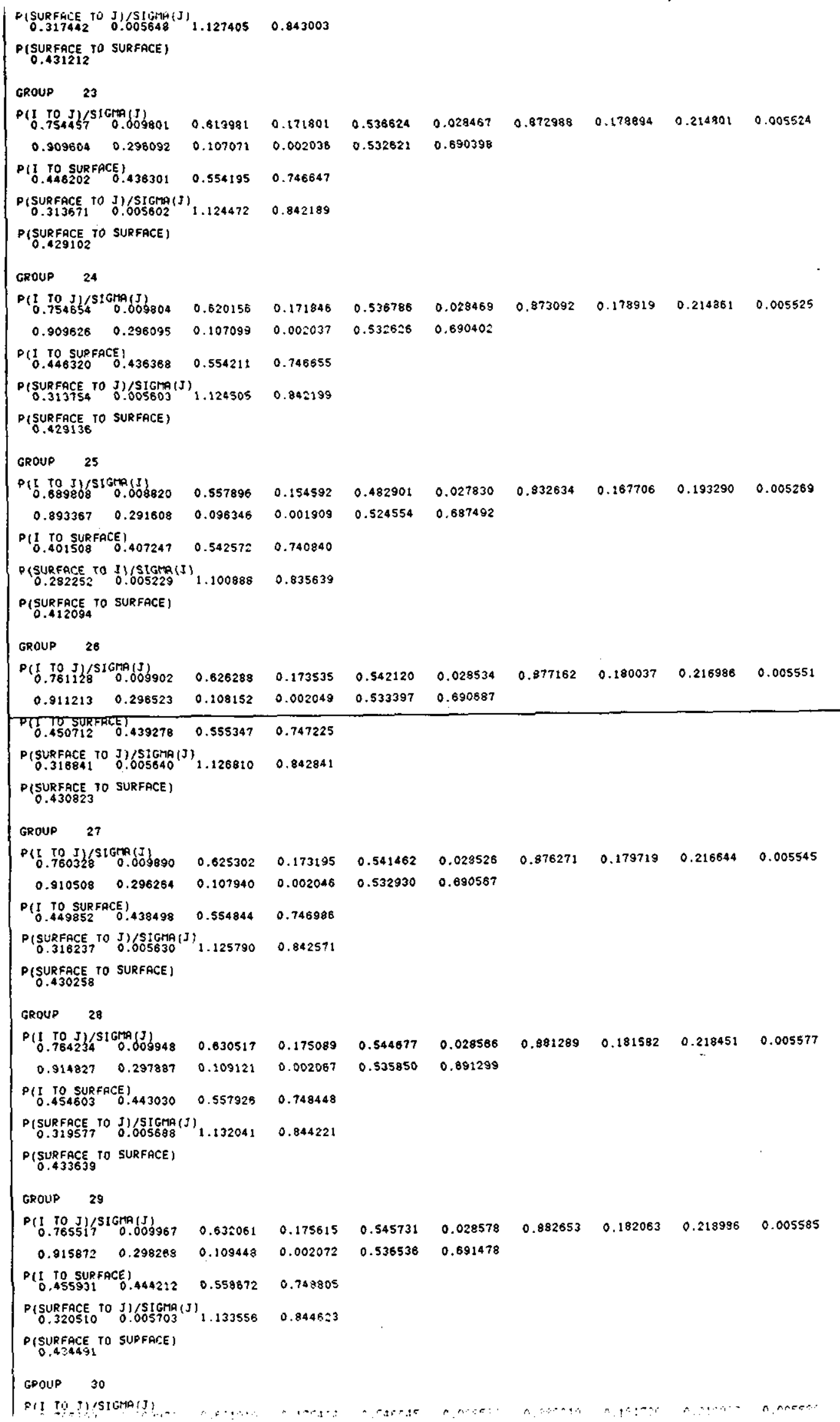

Attd ${ }^{B_{n}}$ Thent 1

1-122 


\section{SNF-4503, Rev. 1}

\section{WHC-SD-NR-SWD-017}

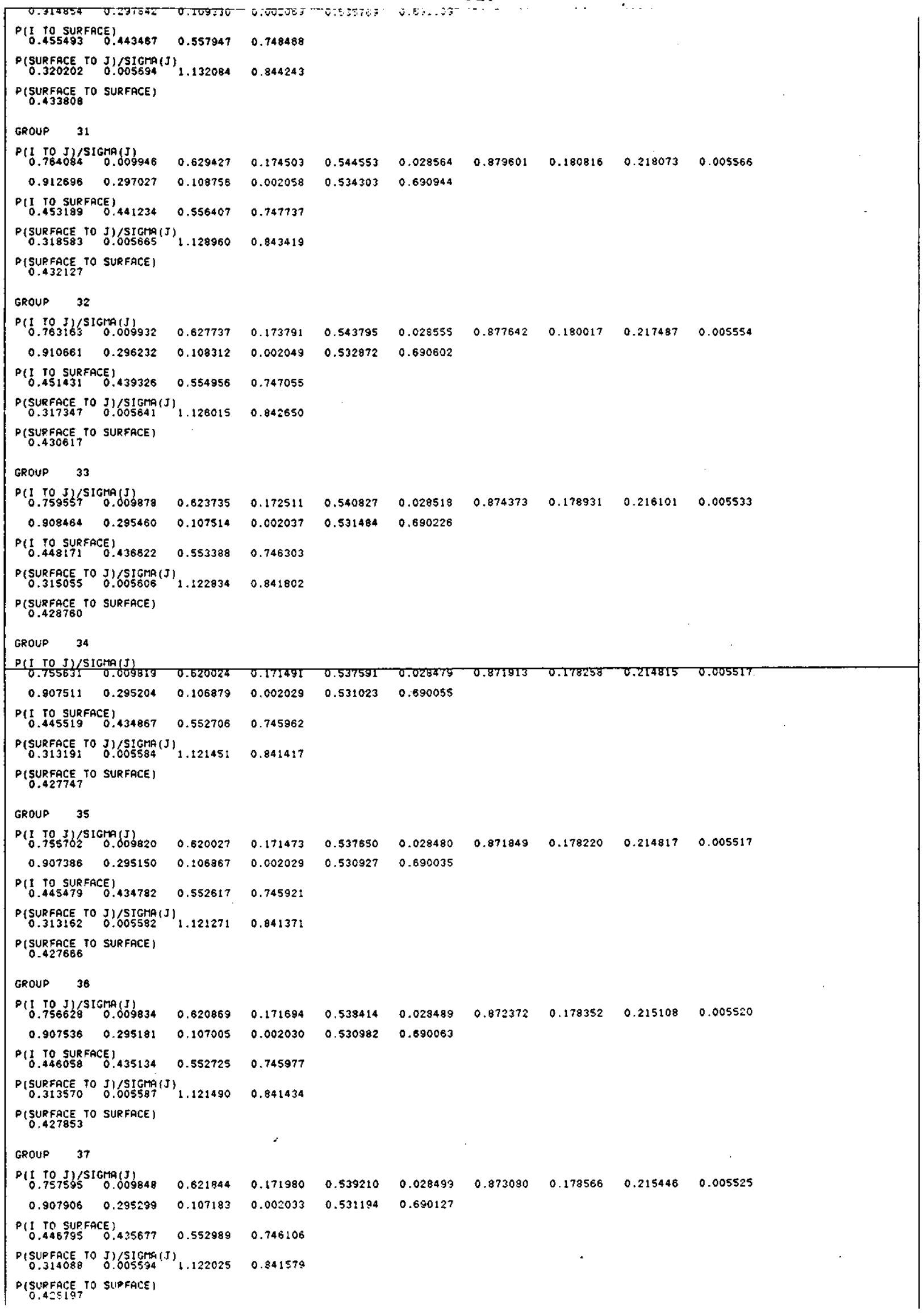


SNF-4503, Rev. 1

\section{WHC-SD-NR-SWD-017}

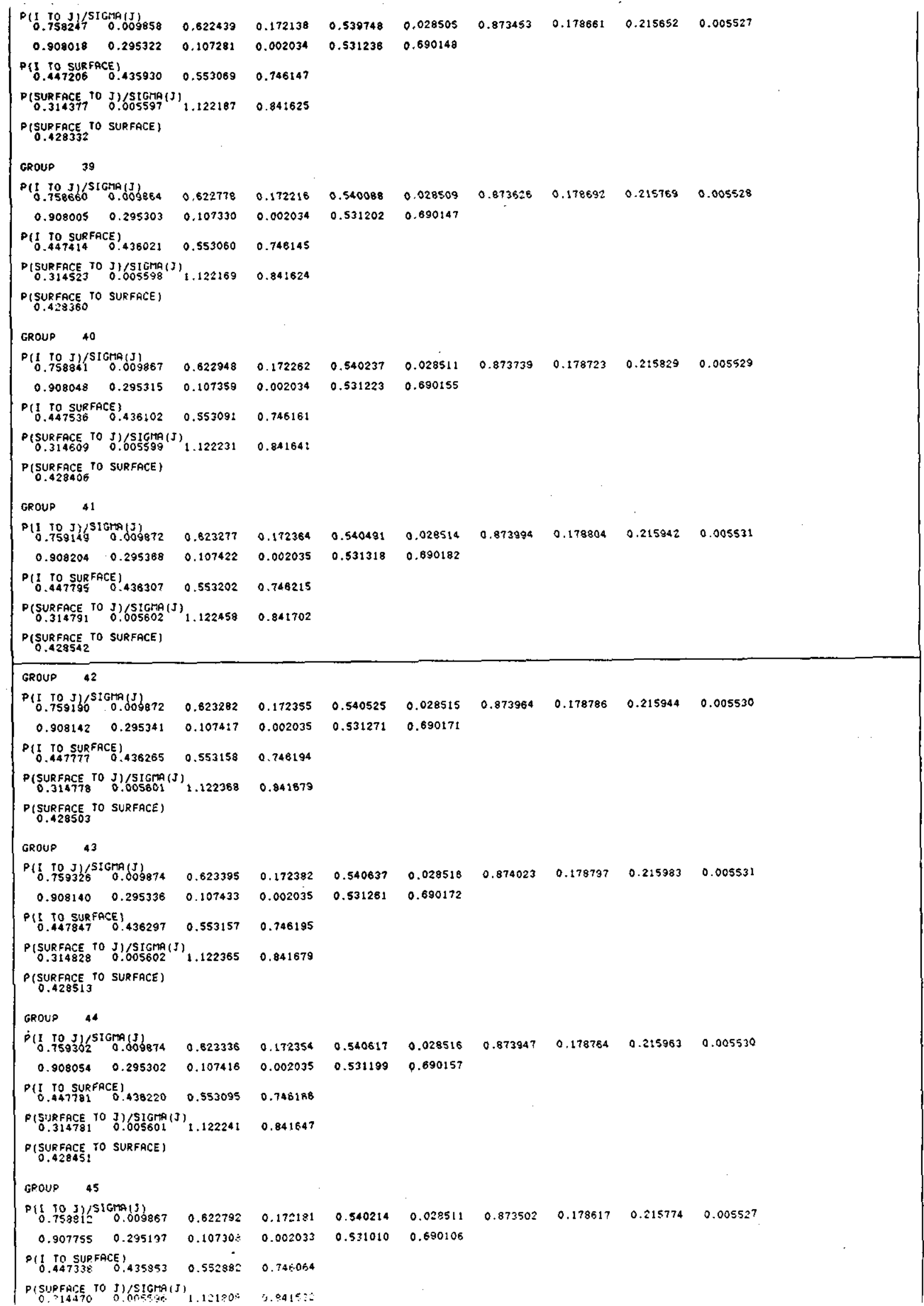


SNF-4503, Rev. 1

WHC-SD-NR-SWD-017

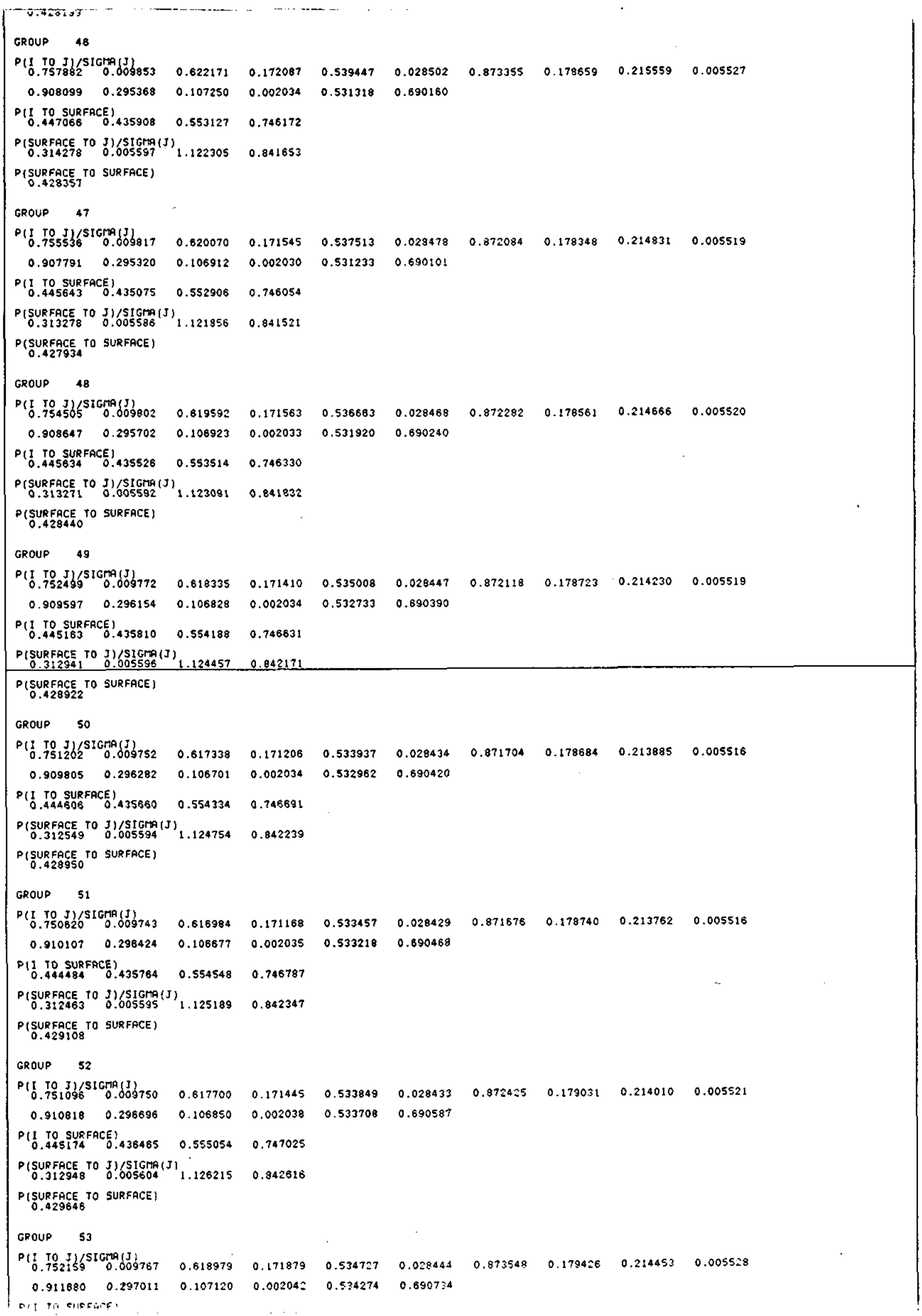

Attakinthent 1 
SNF-4503, Rev. 1

WHC-SD-NR-SWD-017

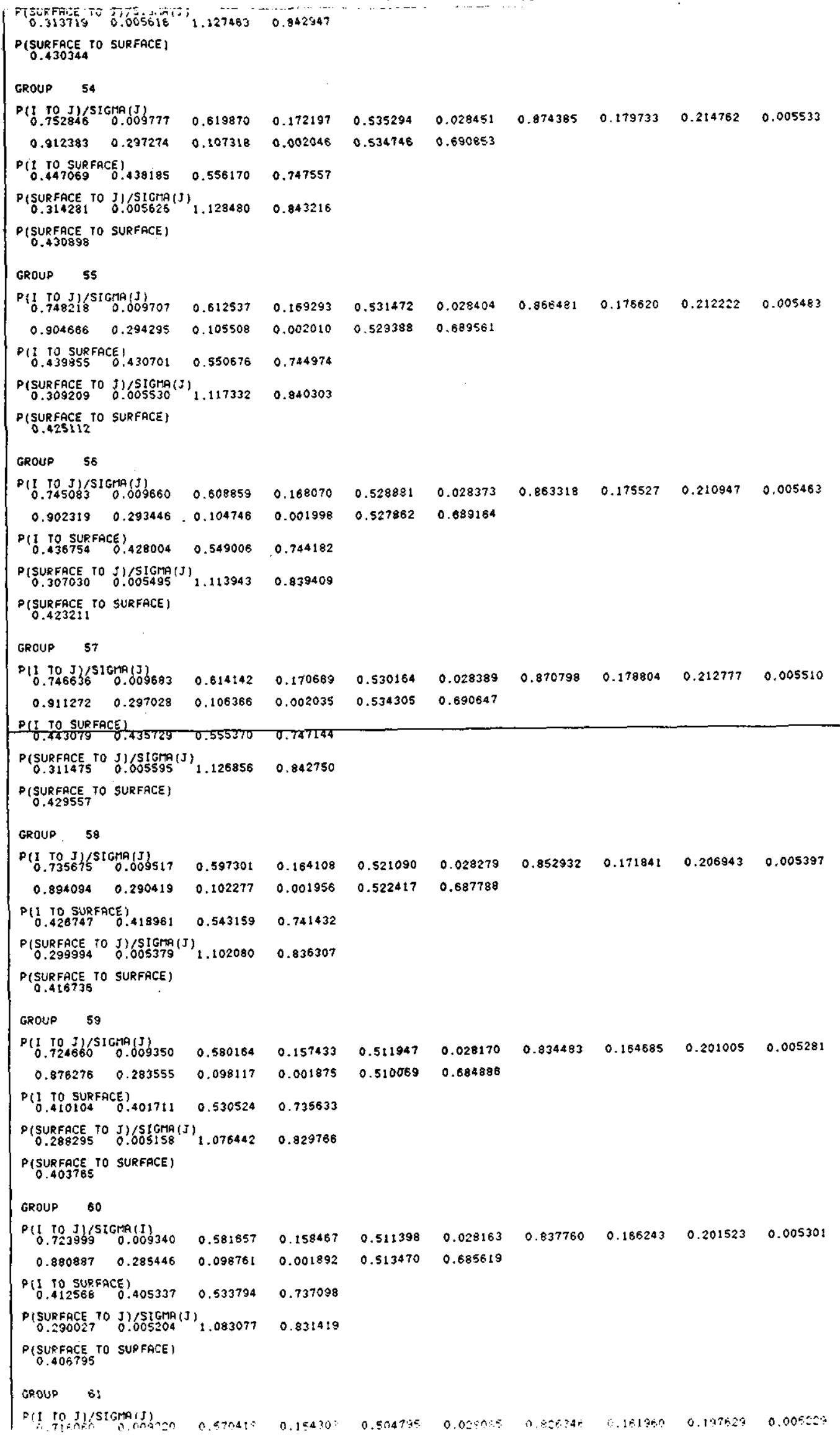

\section{Attdehtignt 1




\section{SNF-4503, Rev. 1}

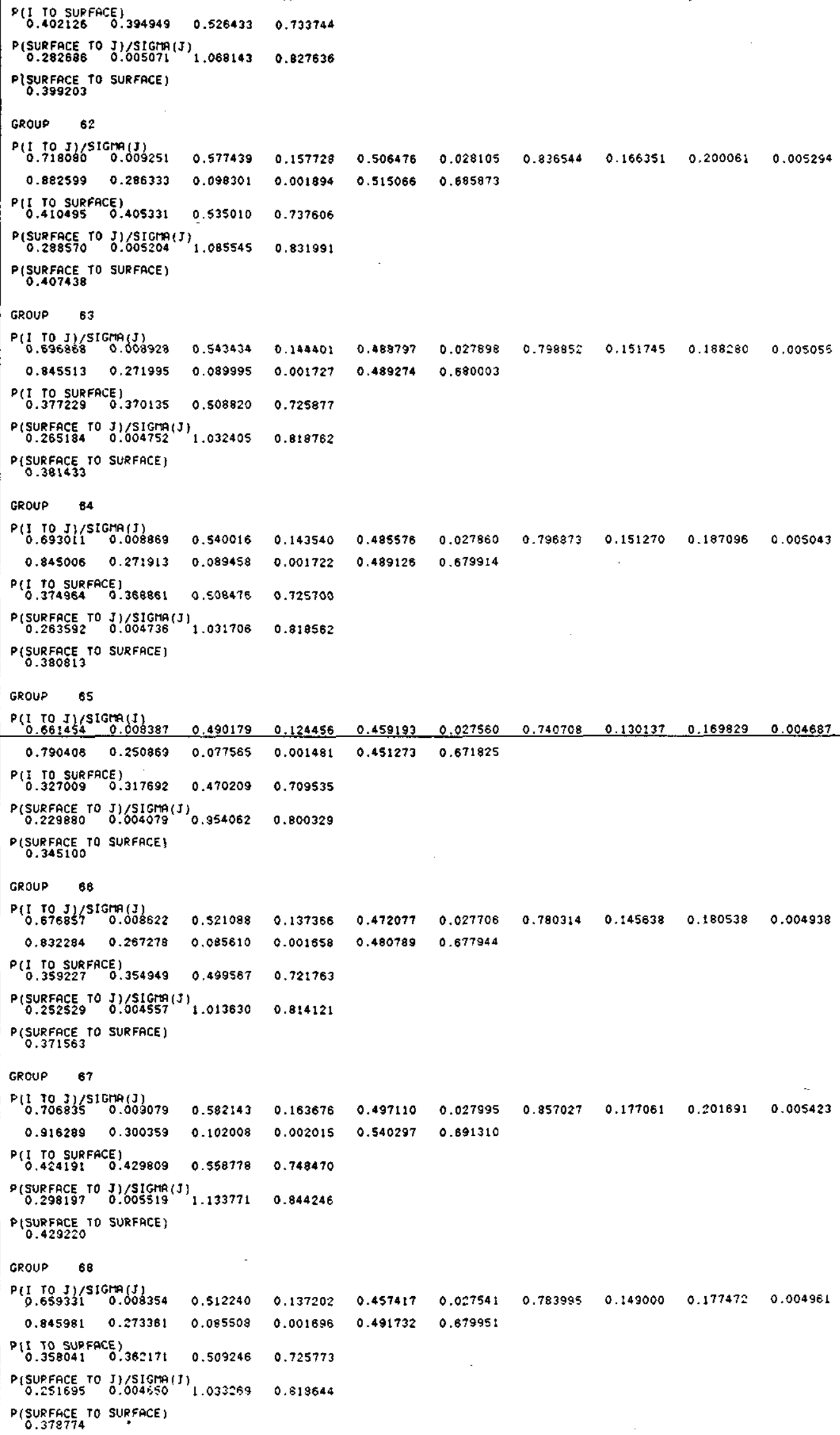

\section{WHC-SD-NR-SWD-017}


SNF-4503, Rev. 1

WHC-SD-NR-SWD-017

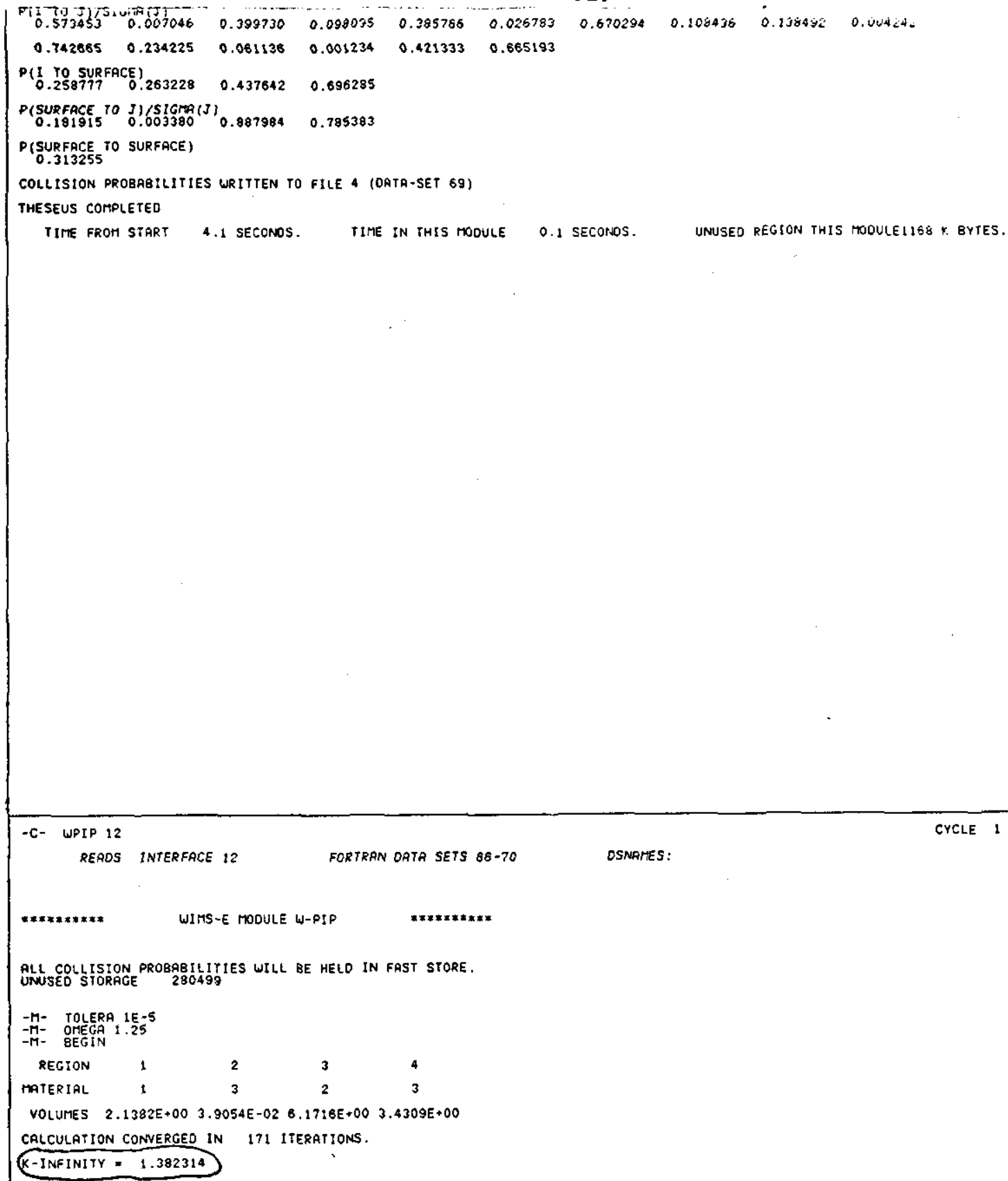




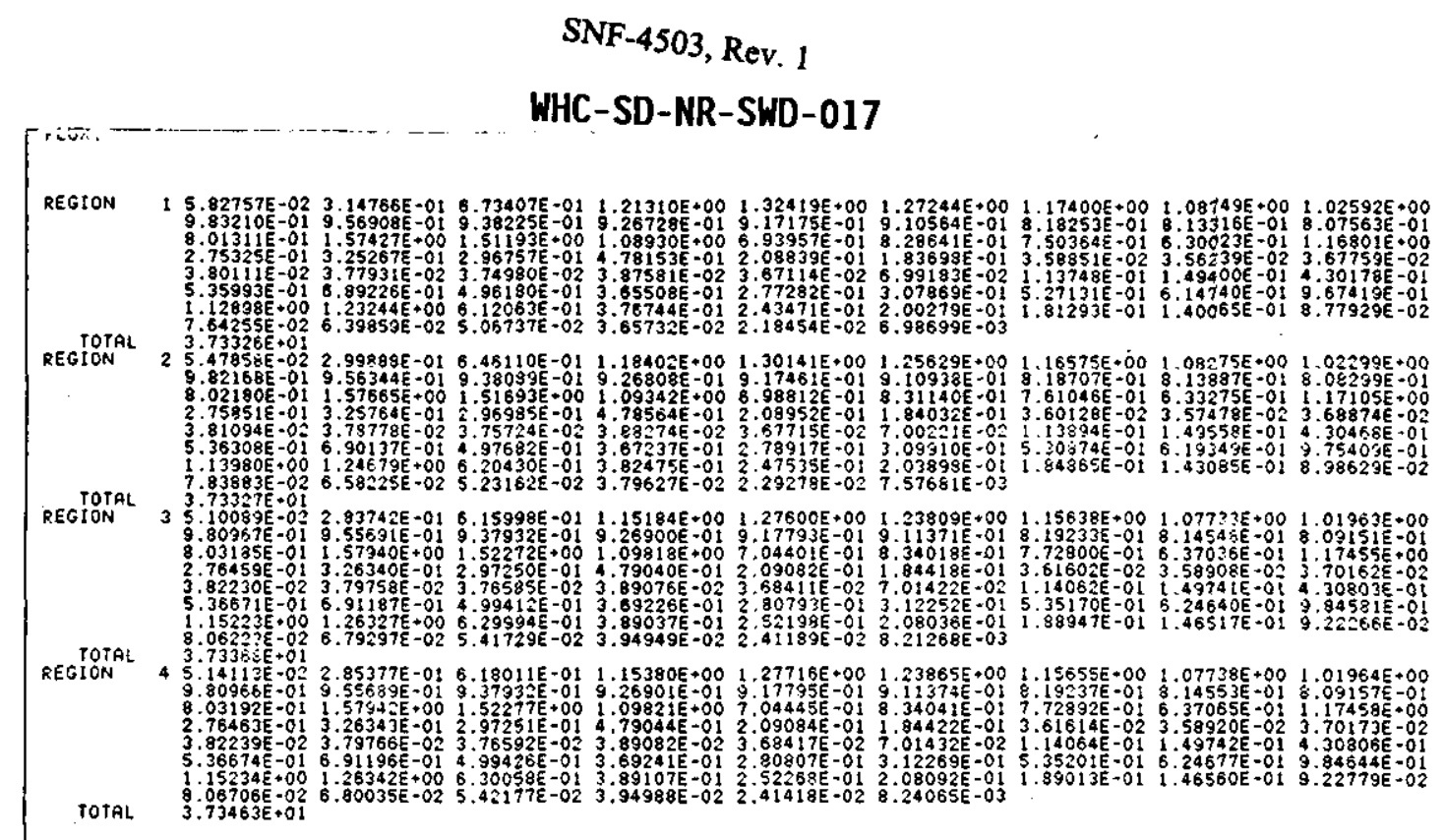

\begin{tabular}{|c|c|c|c|c|c|}
\hline GROUP & 1 & $1.24607755 E-01$ & $3.14809085 E-01$ & 1.78527327E-01 & $6.17944146 E-01$ \\
\hline GROUP & 2 & $6.73047576 E-01$ & $1.75115288 \mathrm{E}+00$ & $9.90813722 E-01$ & $3.41501416 E+00$ \\
\hline GROUP & 3 & $1.43990938 E+00$ & $3.80172030 E+00$ & $2.14557252 E+00$ & $7.38720220 E+00$ \\
\hline GROUP & 4 & $2.59389814 E+00$ & $7.10874795 E+\infty 0$ & $4.00481225 E+00$ & $1.37074583 E+01$ \\
\hline GROUP & 5 & $2.831447: 6 E+00$ & $7.87499514 E+00$ & $4.43265954 E+00$ & $1.51391018 E+01$ \\
\hline GROUP & 6 & $2.72079342 E+00$ & $7.64104832 E+00$ & $4.29877215 E+00$ & $1.466061396+01$ \\
\hline GROUP & 7 & $2.51030747 E+00$ & $7.13678354 E+00$ & $4.01355357 E+00$ & $1.36606446 E+01$ \\
\hline GROUP & 8 & $2.32531341 E+00$ & $6.84891386 E+00$ & $3.73868343 E+00$ & $1.27129107 E+0 t$ \\
\hline GROUP & 9 & $2.19387383 E \cdot 00$ & $6.29278360 \mathrm{E}+00$ & $3.53823828 E+00$ & $1.20246557 E+01$ \\
\hline GROUP & 10 & $2.10234522 E \cdot 00$ & $6.054: 8083 E+00$ & $3.40396362 E+00$ & $1.15604897 E+01$ \\
\hline GROUP & 11 & $2.04610570 E+00$ & $5.89918834 E+00$ & $3.31623279 E+00$ & $1.12605268 \varepsilon+01$ \\
\hline GROUP & 12 & $2.00615570 E+00$ & $5.78858643 E+00$ & $3.25459595 \mathrm{E}+00$ & $1.10493381 \varepsilon+01$ \\
\hline GROUP & 13 & $1.98157355 E+00$ & $5.72049966 E+00$ & $3.21630974 E+00$ & $1.09183829 E \circ 0 \mathrm{t}$ \\
\hline GROUP & 14 & $1.98114575 E+00$ & $5.66429278 E+00$ & $3.18470422 E+00$ & $1.08101428 E+01$ \\
\hline GROUP & 15 & $1.94701054 E+00$ & $5.62466000 \mathrm{E}+00$ & $3.18241992 E+00$ & $1.07340905 E+01$ \\
\hline GROUP & 16 & $1.74962590 E+00$ & $5.0560: 395 E+00$ & $2.84270157 E+00$ & $9.64834142 \varepsilon+00$ \\
\hline GROUP & 17 & $1.73906942 E+00$ & $5.02710430 E+00$ & $2.82644574 E+00$ & $9.59261945 E+00$ \\
\hline GROUP & 18 & $1.72676858 E+00$ & $4.99379208 E+00$ & $2.80771393 E+0 Q$ & $9.52827459 E+00$ \\
\hline GROUP & 19 & $1.71339984 E+00$ & $4.95637149 E+00$ & $2.78701000 E+00$ & $9.45738132 E+\infty 0$ \\
\hline GROUP & 20 & $3.36617078 E+00$ & $9.74748117 E+00$ & $5.48041887 E+00$ & $1.85940708 E+01$ \\
\hline GROUP & 21 & $3.23289531 E+00$ & $9.39771388 E+00$ & $5.28372641 E * 00$ & 1. $79143256 E+01$ \\
\hline GROUP & 22 & $2.32920155 E+00$ & $6.77755500 E+00$ & $3.81057372 E * 00$ & $1.29173303 E+01$ \\
\hline GROUP & 23 & $1.48385025 E+00$ & $4.34731498 E+00$ & $2.44417792 E+00$ & $8.27534315 E+00$ \\
\hline GROUP & 24 & $1.771838888+00$ & $5.14726570 \mathrm{E}+00$ & $2.89397864 E+00$ & $9.8130832 \hat{2} E+00$ \\
\hline GROUP & 25 & $1.80446362 E+00$ & $4.76944595 E+00$ & $2.68144425 E+\infty 0$ & $9.05535382 E+00$ \\
\hline GROUP & 26 & $1.34714357 E+00$ & $3.93155869 E+00$ & $2.21044494 E+00$ & $7.48914719 E+00$ \\
\hline GROUP & 27 & $2.4974956 E E \cdot 00$ & $7.24692623 E * 00$ & $4.07561669 E+00$ & $1.38220386 E+01$ \\
\hline -GROUP & 28 & $5.85713305 E-01$ & 1. $70620692 \mathrm{E}+00$ & $9.59293862 E-01$ & $3.25421409 E+00$ \\
\hline GRUUUP & 29 & $6.95500990 \varepsilon-01$ & $2.01405194 E+00$ & $1.13237770 E+00$ & $3.84193053 E+00$ \\
\hline GFit!lp & 30 & $0 . ? 4538995 E-01$ & $1.834518690+00$ & $1.03144155 E+00$ & $3.50049923 E+00$ \\
\hline
\end{tabular}


SNF-4503, Rev. 1

WHC-SD-NR-SWD-017

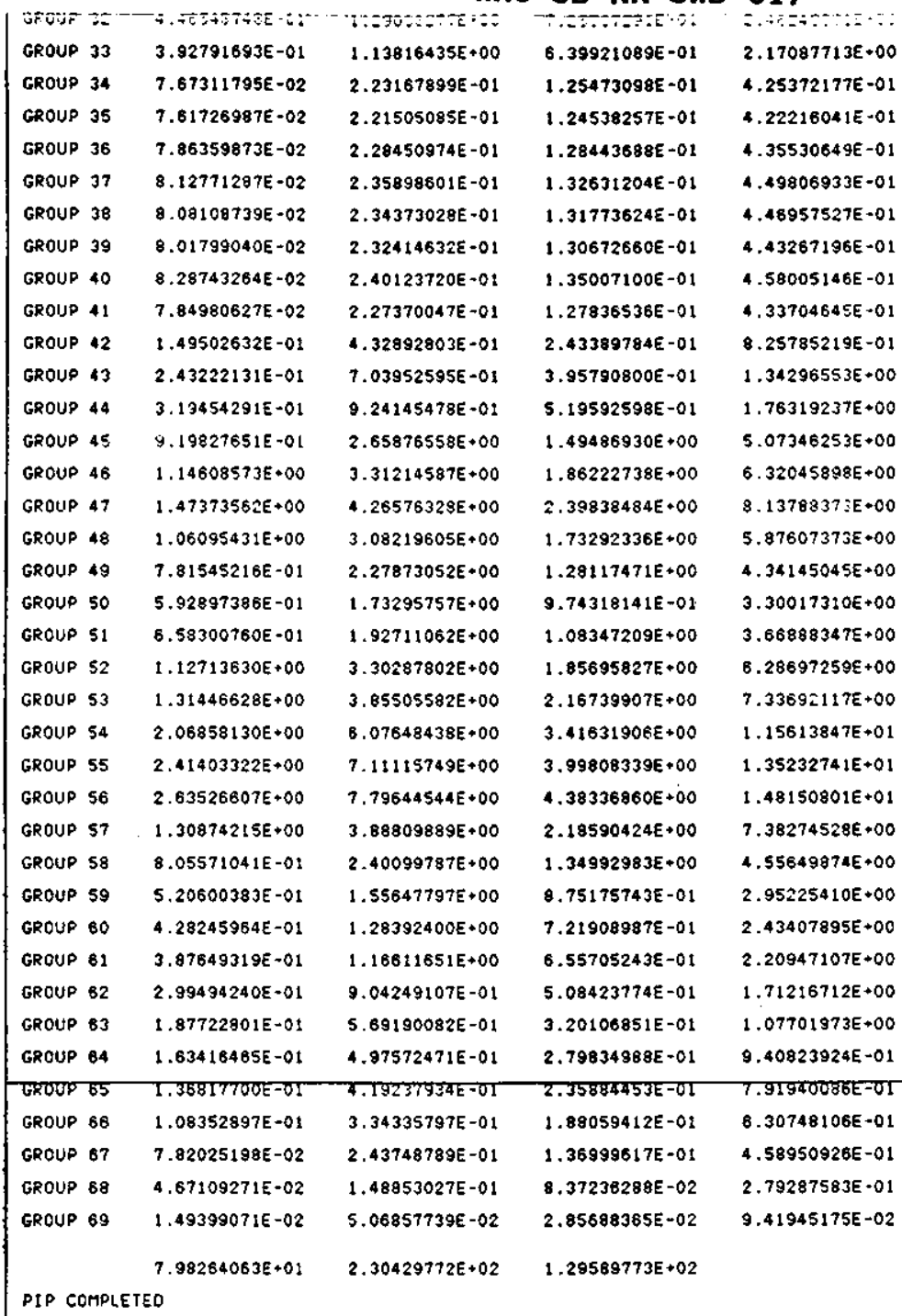

TIME FROM START 4.7 SECONOS. TIME IN THIS MOOULE 0.5 SECONOS. UNUSEO REGION THIS MODULEIOS4 K BYTES. 
SNF-4503, Rev. 1

WHC-SD-NR-SWD-017

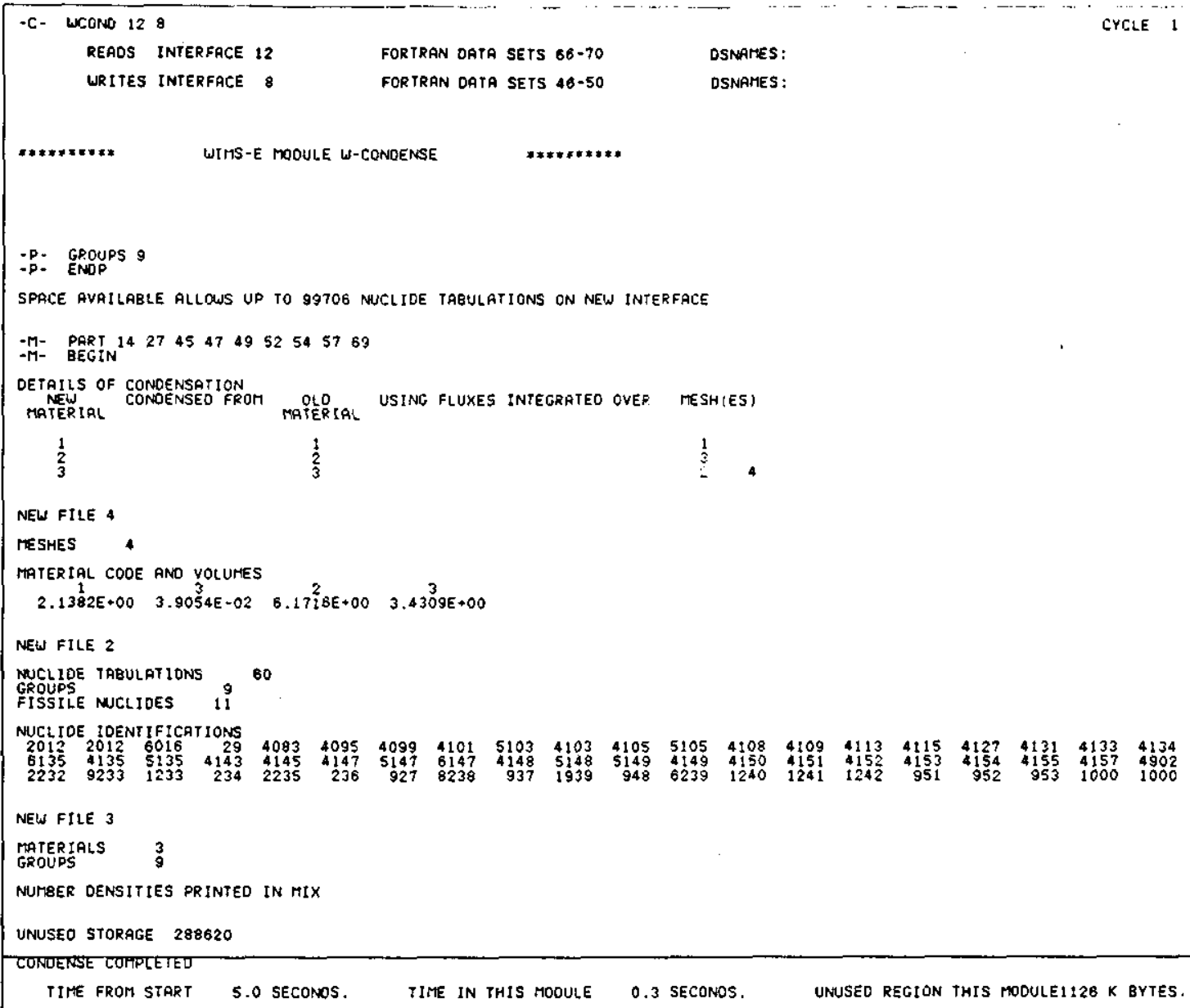


SNF-4503, Rev. 1

WHC-SD-NR-SWD-017

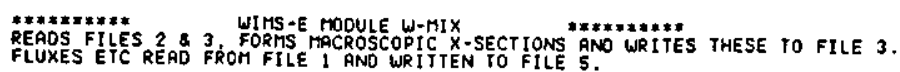

IN 2 LT

CROSS-SECTIONS 60

GROUPS

MTERIALS

9

NO. OF MATERIALS TO BE PROCESSED AT A TIME 3

UNNSEO STORAGE 238266 (IF MATERIALS PROCESSEO SINGLY 299115)

MATEEIAL,

NUCLIDE

IOE IOENTIFIEF NUMBER OENSITY

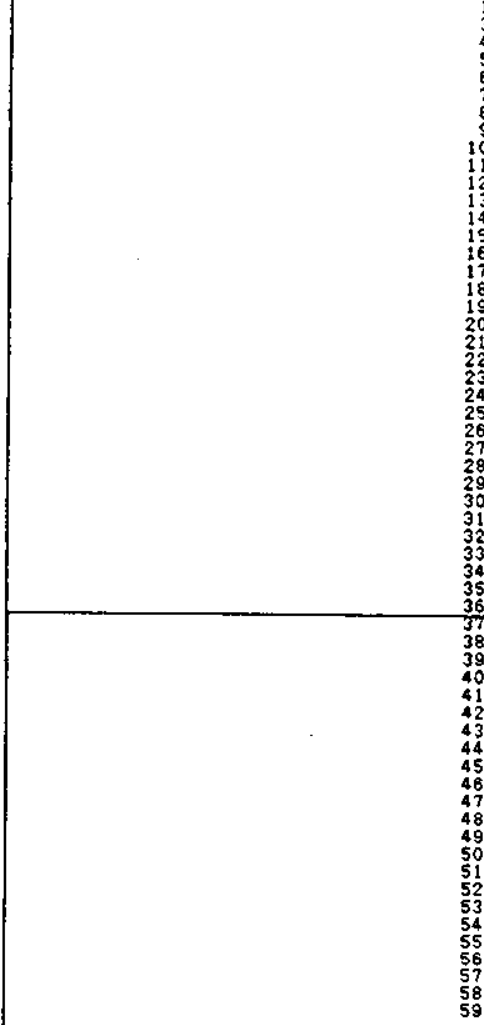

MUITERR OF REACTIONS 4

NATERIAL 2

$$
\begin{array}{r}
\text { MUCLIOE } \\
\mathbf{6 0}
\end{array}
$$

IDENTIFIER
2012
1000

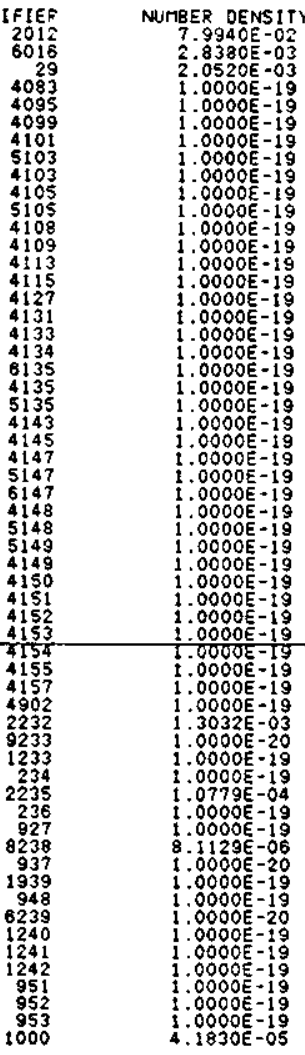

NUTBER OF REACTIONS 3

MATERIAL 3

voto

NUIBER OF REACTIONS 0

WRITING FILE \$

MTESH 4 NGRP 9 NORDER 1

FLUX

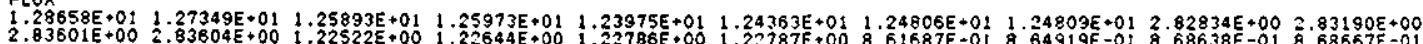

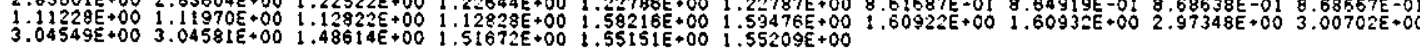

AK $1.3823 E+00^{B X} 0.0000 E+00^{B Y} 0.0000 E+00^{B Z} 0.0000 E+00^{T C} 0.0000 E+00^{U} 7.2342 E-0$.

RTIME $0.00000 E+00 \quad$ RIRRAD $0.00000 E+00$

SPARE ITEMS

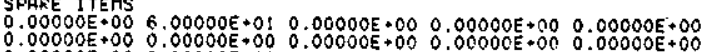

$\begin{array}{lllll}0.00000 E+00 & 0.00000 E+00 & 0.00000 E+00 & 0.00000 E+00 & 0.00000 E+00 \\ 0.00000 E+00 & 0.00000 E+00 & 0.00000 E+00 & 0.00000 E+00 & 0.00000 E+00\end{array}$ 
SNF-4503, Rev. 1

WHC-SD-NR-SWD-017

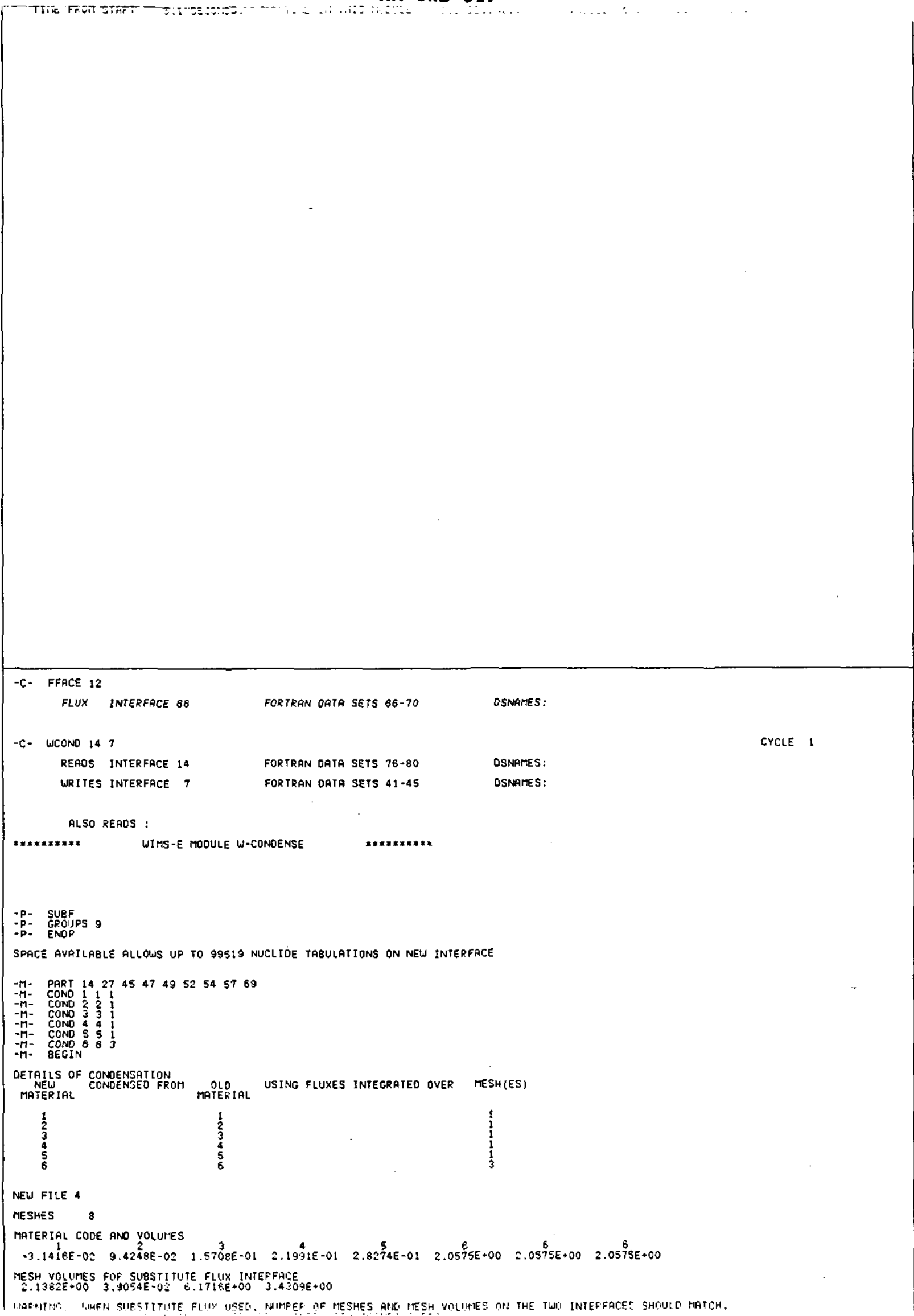

B-82

Attachment 1

1-133 
SNF-4503, Rev. 1

\section{WHC-SD-NR-SWD-017}

NELU FILE 2

NCLIOE TABULATIONS 22

GROUPS TASILE NUCLIDES 9

MCLIOE IOENTIFICATIONS

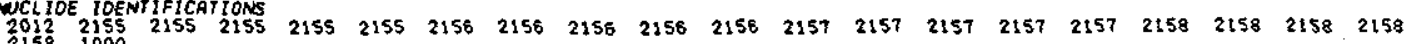

NEW FILE 3

MATERIALS 6

MUMEER DENSITIES PRINTEO IN MIX

UNUSED STORAGE 298126

CONDENSE COMPLETED

TITE FROM START 5.2 SECONOS. TIME IN THIS MODULE 0.1 SECOHOS. UNUSED REGION THIS MODULEI124 K BYTES.

REAOE FILES 2 \& 3 FORRSE MOQULE W-MIX

FLUXES ETC READ FROM FILE I AND WRITTEN TO FILE 5 .

$\begin{array}{llr}\text { LN } 2 & \text { LT } & -1 \\ \text { CROSS-SECTIONS } & 22 \\ \text { GROUPS } & 9 \\ \text { MRTERIALS } & B\end{array}$

No. OF Materials tO BE PROCESSED at a TIME 6

UNUSEO STORAGE 297024 (IF MATERIALS PROCESSED SINGLY 299357)

TATERIAL

NCLIOE
2
7
12
17

IDENIIFIER

2155
2156
2157
2158

NUMBER DENSITY

$1.3020 E-04$
$1.0000 E-19$

$3859 \mathrm{E}-04$

NUMBER OF REACTIONS 3

MATERIAL 2

NUCLIDE
3
8
13
13

IDENTIFIER
2155
2156
2157
2158

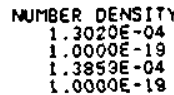

NUEER OF REACTIONS

TATERIAL 3

NUCLIDE
4
9
14
19

IDENT! FIEP
2155
2156
2157
2158

NUMEER DENSITY
$1.3020 \mathrm{E}-04$
$1.0000 \mathrm{E}-19$
$1.3859 \mathrm{E}-04$
$1.0000 \mathrm{E}-19$

NUMBEP. OF REACTIONS 3

MatePIAL : 4

NUCLISE
5
10
19

IOENTIFIEP

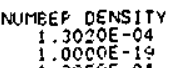

$1.3020 E-04$
$1.0000 E-19$
$3.35-04$ 


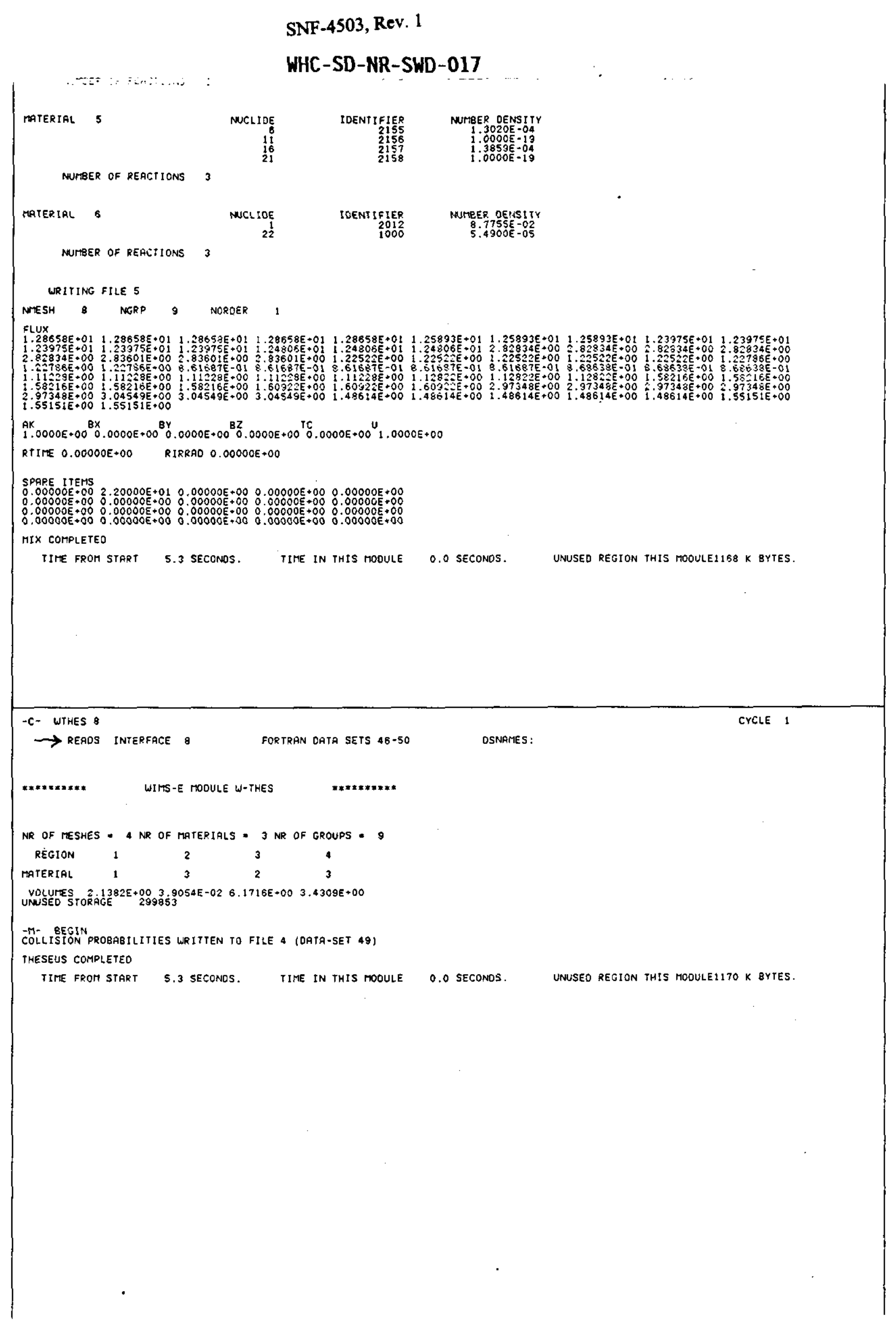


SNF-4503, Rev. 1

WHC-SD-NR-SWD-017

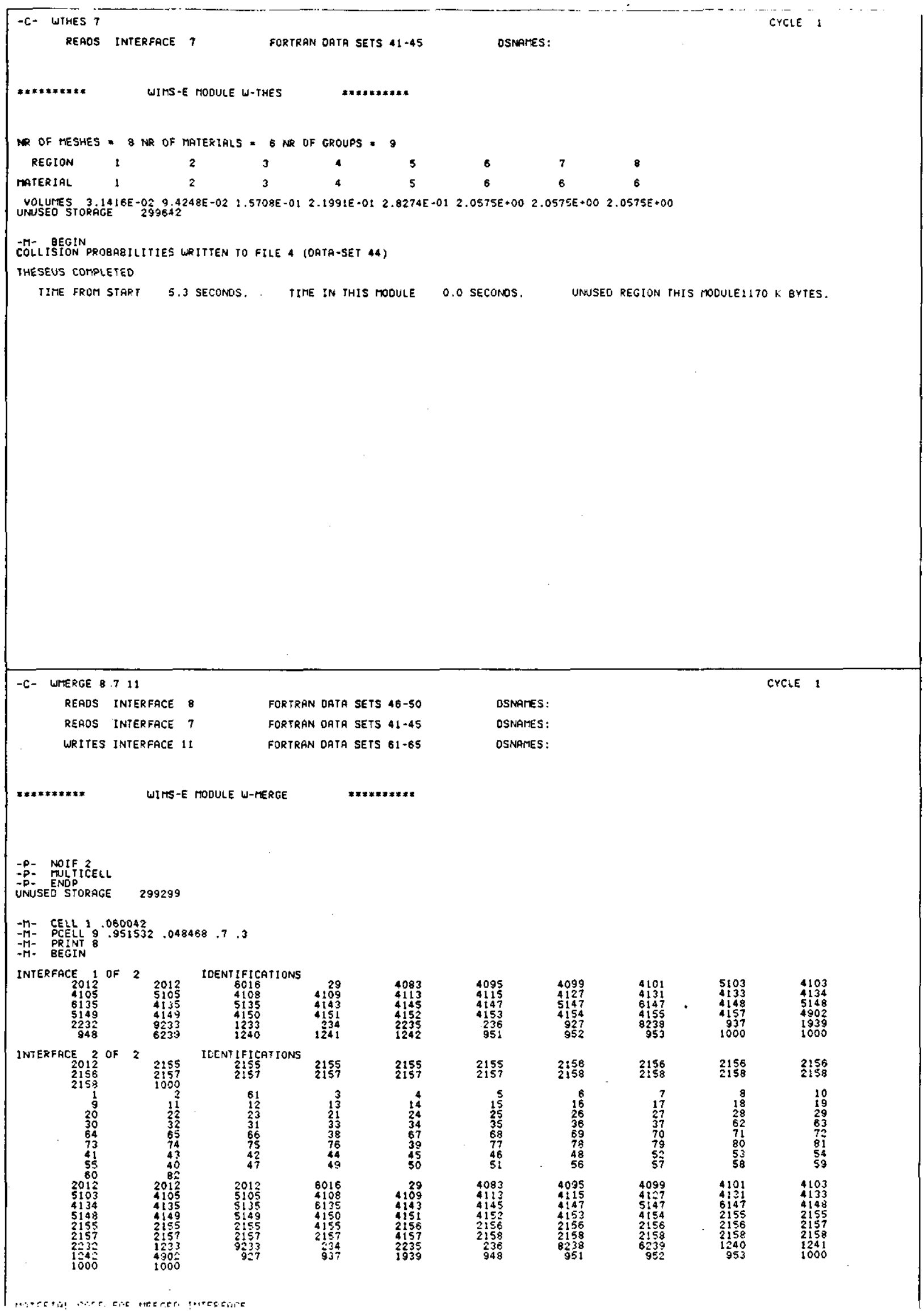


WHC-SD-NR-SWD-017

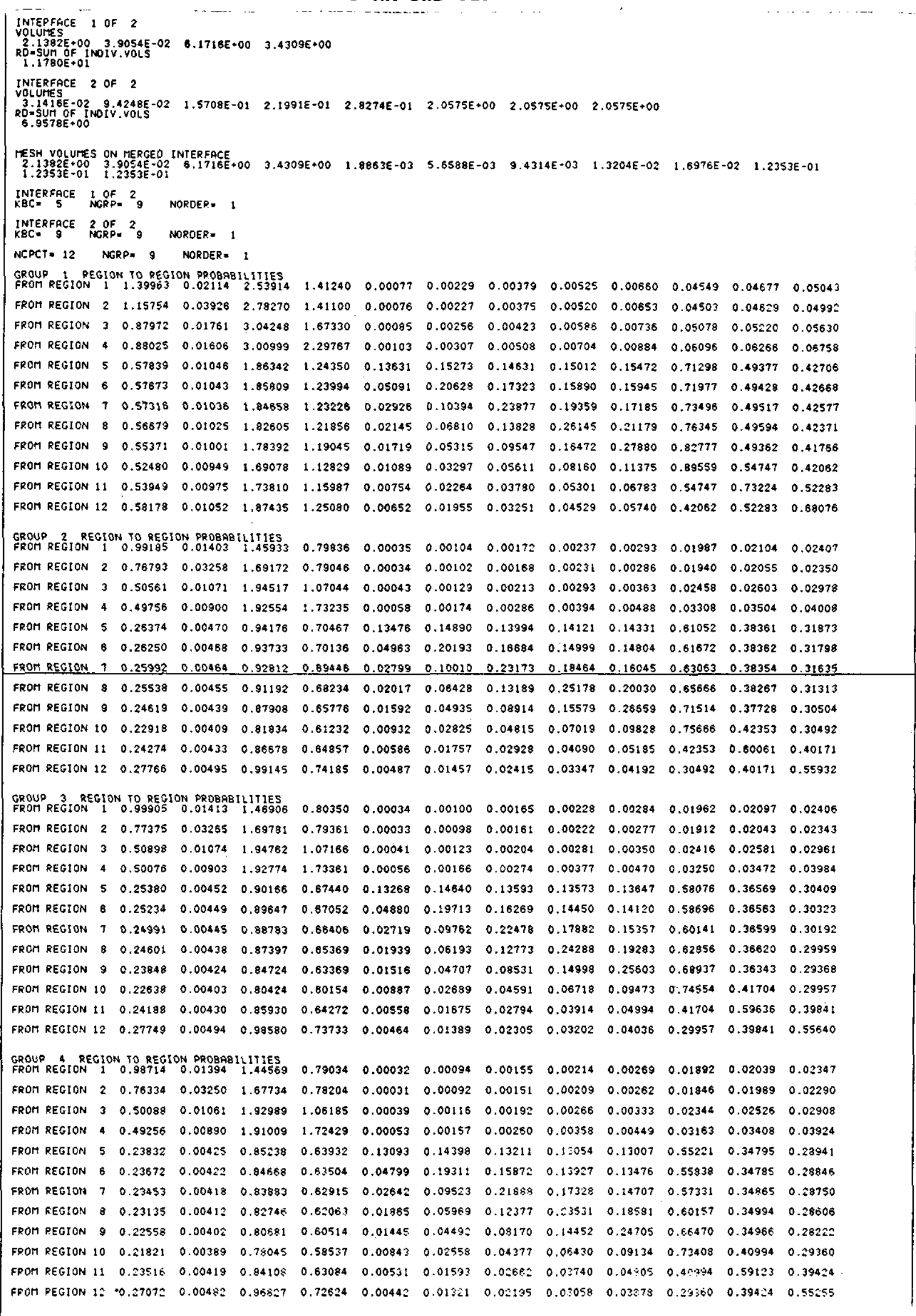




\section{WHC-SD-NR-SWD-017}

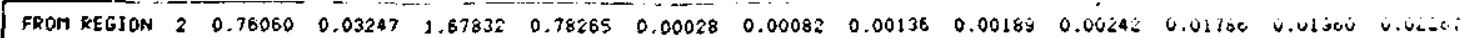
$\begin{array}{llllllllllllllll}\text { FROM REGION } 3 & 0.50004 & 0.01062 & 1.93379 & 1.06374 & 0.00035 & 0.00105 & 0.00173 & 0.00241 & 0.00307 & 0.02271 & 0.02492 & 0.02892\end{array}$ $\begin{array}{lllllllllllllllll}\text { FROM REGION } 4 & 0.49179 & 0.00891 & 1.91349 & 1.72528 & 0.00047 & 0.00141 & 0.00233 & 0.00325 & 0.00414 & 0.03060 & 0.03359 & 0.03885\end{array}$

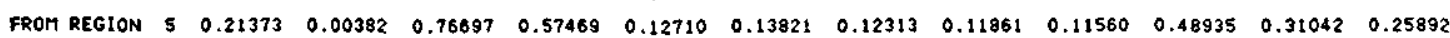
FROH REGION $6 \begin{array}{llllllllllllll} & 0.21192 & 0.00379 & 0.76046 & 0.56982 & 0.04607 & 0.18432 & 0.14937 & 0.12719 & 0.12012 & 0.49538 & 0.31032 & 0.2579 t\end{array}$ FROM REGION $7 \begin{array}{lllllllllllll}7 & 0.21039 & 0.00376 & 0.75497 & 0.56571 & 0.02463 & 0.08962 & 0.20605 & 0.16047 & 0.13223 & 0.51154 & 0.31235 & 0.25794\end{array}$ $\begin{array}{lllllllllllllll}\text { FROM REGION \& } & 0.20904 & 0.00373 & 0.75012 & 0.56207 & 0.01694 & 0.05451 & 0.11462 & 0.21896 & 0.16978 & 0.54282 & 0.31652 & 0.25890\end{array}$

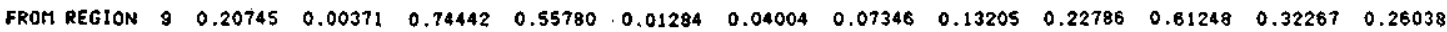
$\begin{array}{lllllllllllllll}\text { FROM REGION } 10 & 0.21067 & 0.00376 & 0.75597 & 0.58646 & 0.00747 & 0.02269 & 0.03905 & 0.05802 & 0.08417 & 0.71389 & 0.39896 & 0.28475\end{array}$

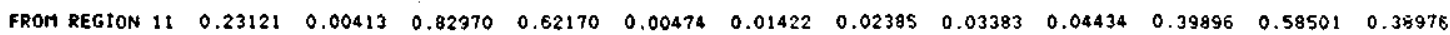

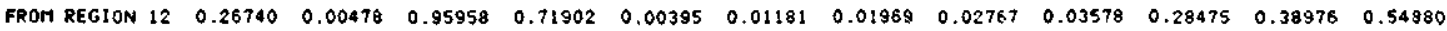

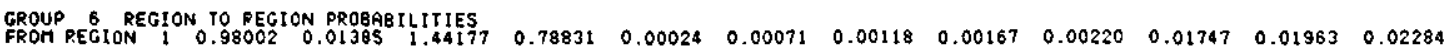
FROM REGION $2 \begin{array}{llllllllllllll}2 & 0.75828 & 0.03245 & 1.88014 & 0.78370 & 0.00023 & 0.00070 & 0.00116 & 0.00164 & 0.00216 & 0.01713 & 0.01925 & 0.02239\end{array}$ $\begin{array}{lllllllllllllll}\text { FROM REGLON } 3 & 0.49952 & 0.01063 & 1.93837 & 1.06594 & 0.00030 & 0.00099 & 0.00148 & 0.00208 & 0.00274 & 0.02179 & 0.02448 & 0.02849\end{array}$ FROM REGION $4 \begin{array}{llllllllllllll} & 0.49130 & 0.00892 & 1.91745 & 1.72644 & 0.00040 & 0.00119 & 0.00193 & 0.00281 & 0.00370 & 0.02934 & 0.03297 & 0.03835\end{array}$

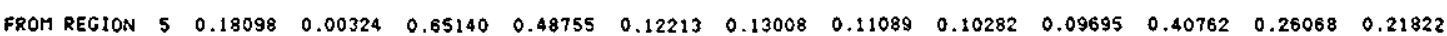
FROM REGION $6 \begin{array}{llllllllllllll}6 & 0.17917 & 0.0032 t & 0.64488 & 0.48267 & 0.04336 & 0.17304 & 0.13656 & 0.11111 & 0.10115 & 0.41341 & 0.26077 & 0.21735\end{array}$

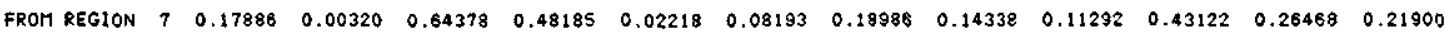
FROM REGION $B \quad \begin{array}{llllllllllllll} & 0.18034 & 0.00323 & 0.64912 & 0.48584 & 0.01469 & 0.04762 & 0.10242 & 0.19872 & 0.14900 & 0.46688 & 0.27309 & 0.22355\end{array}$

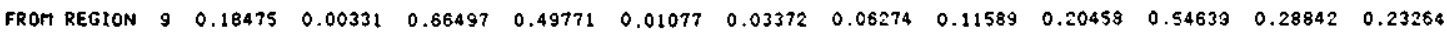
$\begin{array}{lllllllllllllll}\text { FROM REGION } & 10 & 0.20156 & 0.00361 & 0.72547 & 0.54299 & 0.00622 & 0.01894 & 0.03292 & 0.04990 & 0.07509 & 0.68915 & 0.38535 & 0.27375\end{array}$

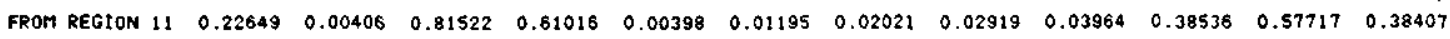

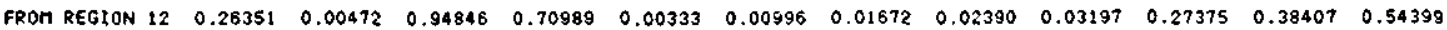

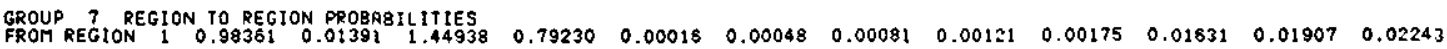
$\begin{array}{llllllllllllllll}\text { FROM REGION } & 2 & 0.76153 & 0.03250 & 1.68745 & 0.78753 & 0.00016 & 0.00047 & 0.00090 & 0.00119 & 0.00172 & 0.01599 & 0.01870 & 0.02198\end{array}$ FROM REGION $3 \begin{array}{llllllllllllll}3 & 0.50216 & 0.01068 & 1.94484 & 1.08902 & 0.00020 & 0.00059 & 0.00101 & 0.00151 & 0.00218 & 0.02030 & 0.02374 & 0.02791\end{array}$ FROM REGION $4 \begin{array}{llllllllllllll} & 0.49378 & 0.00896 & 1.92298 & 1.72849 & 0.00027 & 0.00080 & 0.00136 & 0.00202 & 0.00294 & 0.02729 & 0.03191 & 0.03752\end{array}$

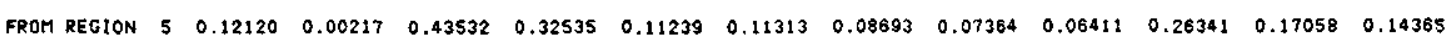
FROM REGION $6 \begin{array}{lllllllllllll} & 0.12019 & 0.00215 & 0.43172 & 0.32266 & 0.03771 & 0.15184 & 0.11134 & 0.08122 & 0.06767 & 0.26901 & 0.17155 & 0.14370\end{array}$ FROM REGION $7 \begin{array}{lllllllllllll}7 & 0.12298 & 0.00220 & 0.44172 & 0.33013 & 0.01739 & 0.06681 & 0.16046 & 0.11152 & 0.07867 & 0.28973 & 0.17936 & 0.14891\end{array}$

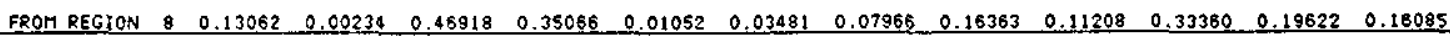
$\begin{array}{lllllllllllllll}\text { FROM REGION } & \rightarrow & 0.14727 & 0.00284 & 0.52899 & 0.39538 & 0.00712 & 0.02256 & 0.04371 & 0.08718 & 0.18587 & 0.43351 & 0.22985 & 0.18518\end{array}$

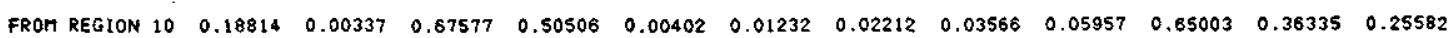

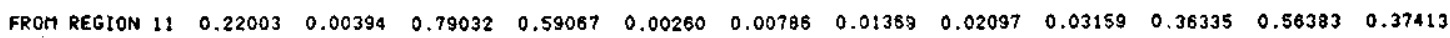

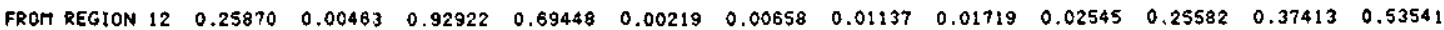

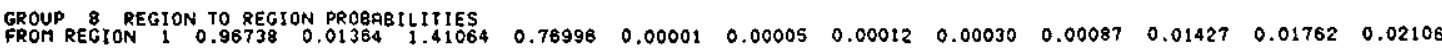
FROM REGION $2 \begin{array}{llllllllllllll}2 & 0.74658 & 0.03226 & 1.64989 & 0.76573 & 0.00001 & 0.00005 & 0.00012 & 0.00030 & 0.00085 & 0.01399 & 0.01727 & 0.02064\end{array}$ FROM REGION $3 \begin{array}{llllllllllllll}3 & 0.48874 & 0.01044 & 1.90762 & 1.04821 & 0.00002 & 0.00006 & 0.00015 & 0.00038 & 0.00109 & 0.01790 & 0.02210 & 0.02641\end{array}$ $\begin{array}{llllllllllllllll}\text { FROM REGION } & 4 & 0.47986 & 0.00872 & 1.88556 & 1.70887 & 0.00002 & 0.00008 & 0.00020 & 0.00051 & 0.00147 & 0.02420 & 0.02988 & 0.03572\end{array}$ $\begin{array}{llllllllllllllll}\text { FROM REGION } & 5 & 0.01058 & 0.00019 & 0.03855 & 0.02905 & 0.07832 & 0.05543 & 0.02397 & 0.01220 & 0.00659 & 0.02215 & 0.01467 & 0.01252\end{array}$ FROM REGION $6 \begin{array}{llllllllllllll}6 & 0.01236 & 0.00022 & 0.04474 & 0.03364 & 0.01848 & 0.08875 & 0.04286 & 0.01685 & 0.00832 & 0.02654 & 0.01730 & 0.01467\end{array}$ FROM REGION $7 \begin{array}{llllllllllllll}7 & 0.01920 & 0.00033 & 0.06590 & 0.04954 & 0.00479 & 0.02571 & 0.08757 & 0.03847 & 0.01445 & 0.04136 & 0.02619 & 0.02199\end{array}$ FROM REGION $8 \begin{array}{llllllllllllll} & 8 & 0.03251 & 0.00058 & 0.11769 & 0.08848 & 0.00174 & 0.00722 & 0.02748 & 0.08694 & 0.03691 & 0.08052 & 0.04865 & 0.04027\end{array}$ FROM REGION $9 \begin{array}{lllllllllllll} & 0.07295 & 0.00131 & 0.28412 & 0.19856 & 0.00073 & 0.00277 & 0.00803 & 0.02870 & 0.08779 & 0.21220 & 0.11635 & 0.09393\end{array}$

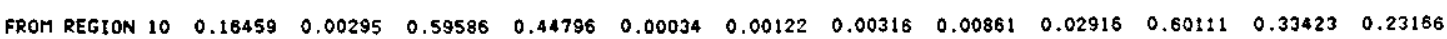

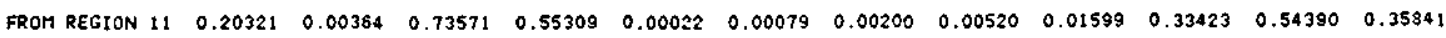

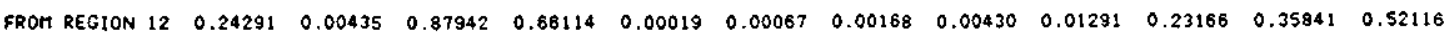

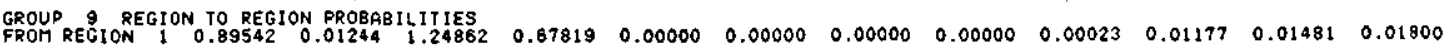
$\begin{array}{lllllllllllllllll}\text { FROM REGION } & 2 & 0.68119 & 0.03125 & 1.49431 & 0.87752 & 0.00000 & 0.00000 & 0.00000 & 0.00000 & 0.00022 & 0.01158 & 0.01457 & 0.01770\end{array}$ FROM REGION $3 \begin{array}{lllllllllllllll}3 & 0.43260 & 0.00946 & 1.75885 & 0.96710 & 0.00000 & 0.00000 & 0.00000 & 0.00000 & 0.00030 & 0.01540 & 0.01938 & 0.02355\end{array}$

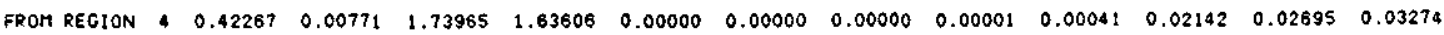
$\begin{array}{llllllllllllllllll}\text { FROM REGION } & 5 & 0.00000 & 0.00000 & 0.00000 & 0.00000 & 0.02926 & 0.00592 & 0.00016 & 0.00001 & 0.00000 & 0.000000 & 0.00000 & 0.00000\end{array}$ FR.OM REGION $6 \begin{array}{lllllllllllllll}6 & 0.00000 & 0.00000 & 0.00000 & 0.000000 & 0.00197 & 0.02930 & 0.00398 & 0.00009 & 0.00000 & 0.00000 & 0.00000 & 0.00000\end{array}$ $\begin{array}{llllllllllllllllllllll}\text { FROM REGION } & 7 & 0.00002 & 0.00000 & 0.00006 & 0.00005 & 0.00003 & 0.00239 & 0.02926 & 0.00359 & 0.00007 & 0.00004 & 0.00002 & 0.00002\end{array}$ $\begin{array}{llllllllllllllll}\text { FROM REGION } & 8 & 0.00037 & 0.00001 & 0.00141 & 0.00109 & 0.00000 & 0.00004 & 0.00256 & 0.02926 & 0.00342 & 0.00094 & 0.00059 & 0.00049\end{array}$ FROM REGION $9 \begin{array}{lllllllllllll} & 0.01308 & 0.00034 & 0.07205 & 0.05569 & 0.00000 & 0.00000 & 0.00004 & 0.00266 & 0.02938 & 0.06024 & 0.03355 & 0.02712\end{array}$

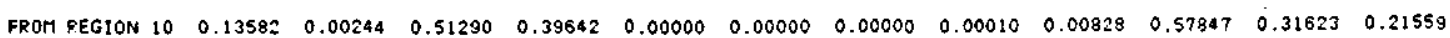

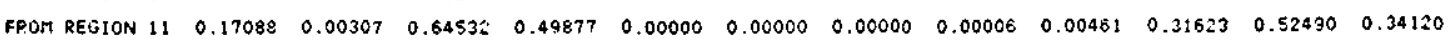

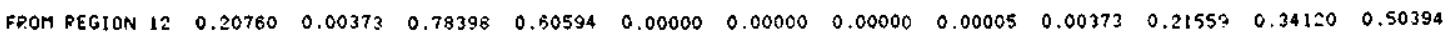


SNF-4503, Rev. 1

WHC-SD-NR-SWD-017

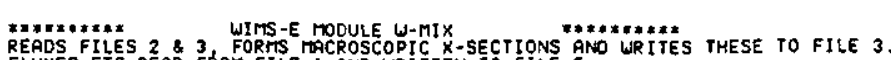

RLUXES EIC READ FROT FILE I ANO WRITTEN TO FILE 9 .

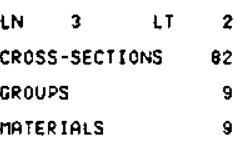

NO. OF MATERIALS TO EE PROCESSED AT A TIME 9

UNUSED STORAGE 295488 (IF MATERIALS PPOCESSEO SINGLY 298905)

MATEFIAL

NUCLIDE TOENTIFIER NUMBEF DENSITY
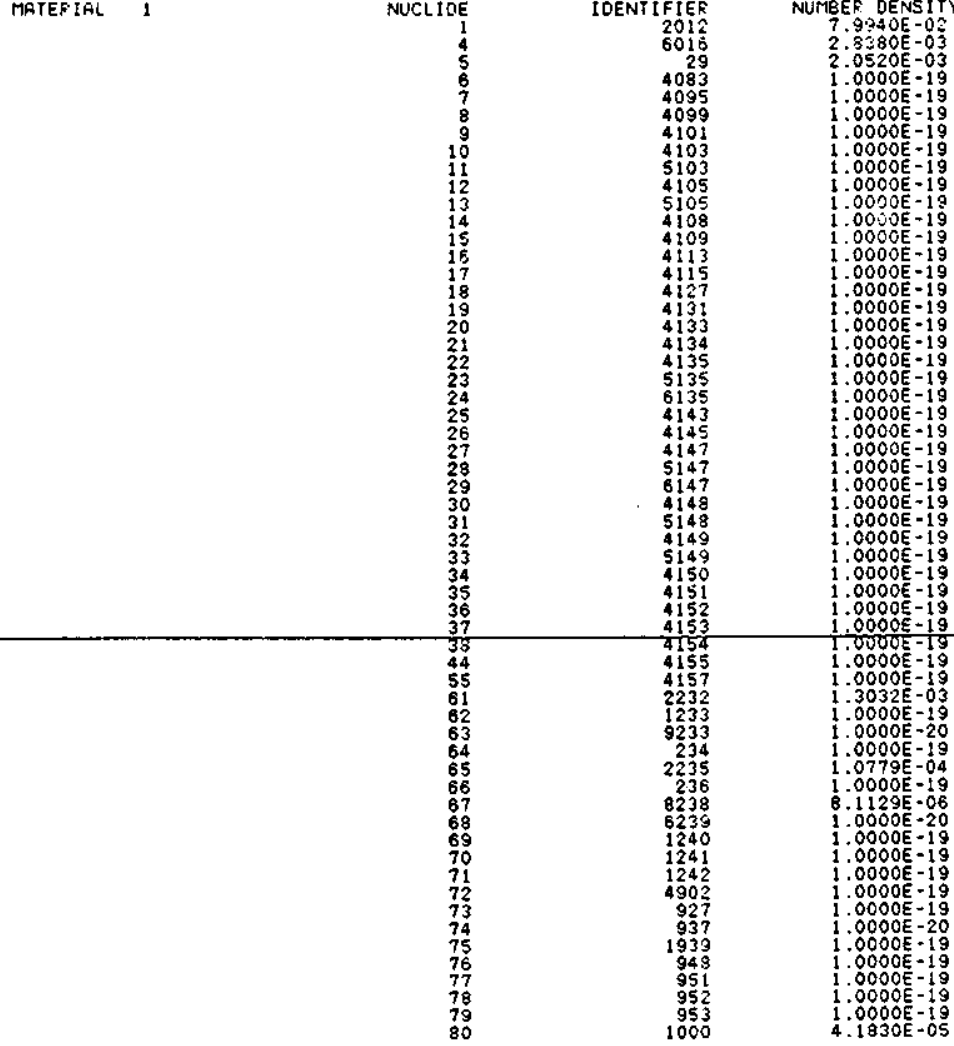

NUMBER OF REACTIONS

MATEPIAL 2

NUCLIDE

$\begin{array}{rr}2 & \text { IDENTIFIER } \\ 2 & 2012 \\ 1 & 1000\end{array}$

NUMBER OF REACTIONS 3

MATERLAL 3

voIo

NUMBER OF REACTIONS 0

MATEPIAL 4

MUCLIOE
39
45
50
56

IOENTIFIER
2155
2158
2157
2158

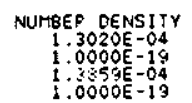

MUIBEP OF REACTIONS 3

MATEPIAL 5

NUCL TOE
40
45
51
57

IOENTIFIER
2155
2150
2157
2159

NUMBER DENSITY

1. $3020 E-04$

$1.335 .3 E=04$

NUMEEP. OF PEACTIONS

MATEPIÁL 6 NICLIGE $^{\circ}$

IUENIIFIEE NUMEE DENSITY 
SNF-4503, Rev. 1

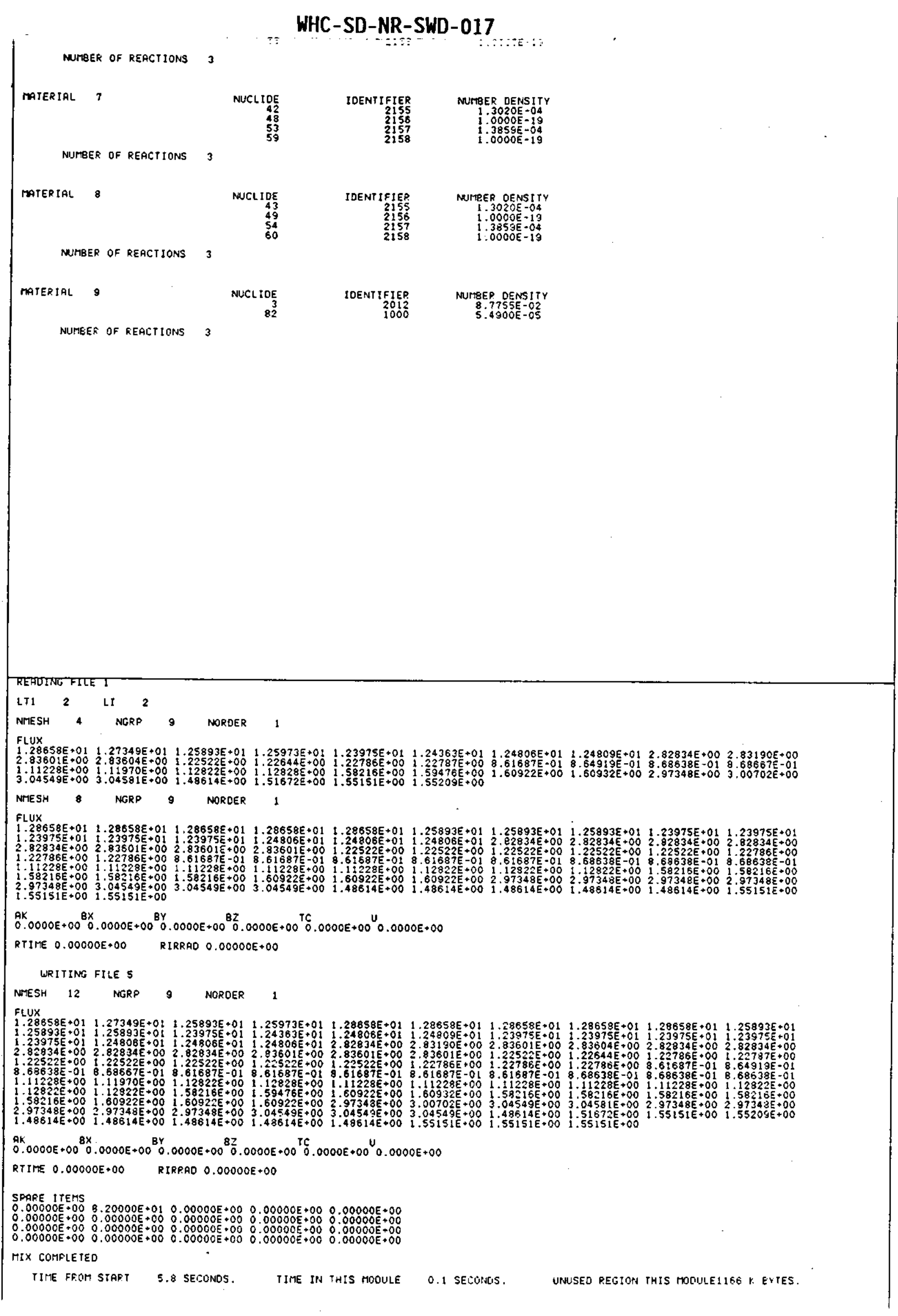

B-89

Attachment 1

$1-140$ 
SNF-4503, Rev. 1

\section{WHC-SD-NR-SWD-017}

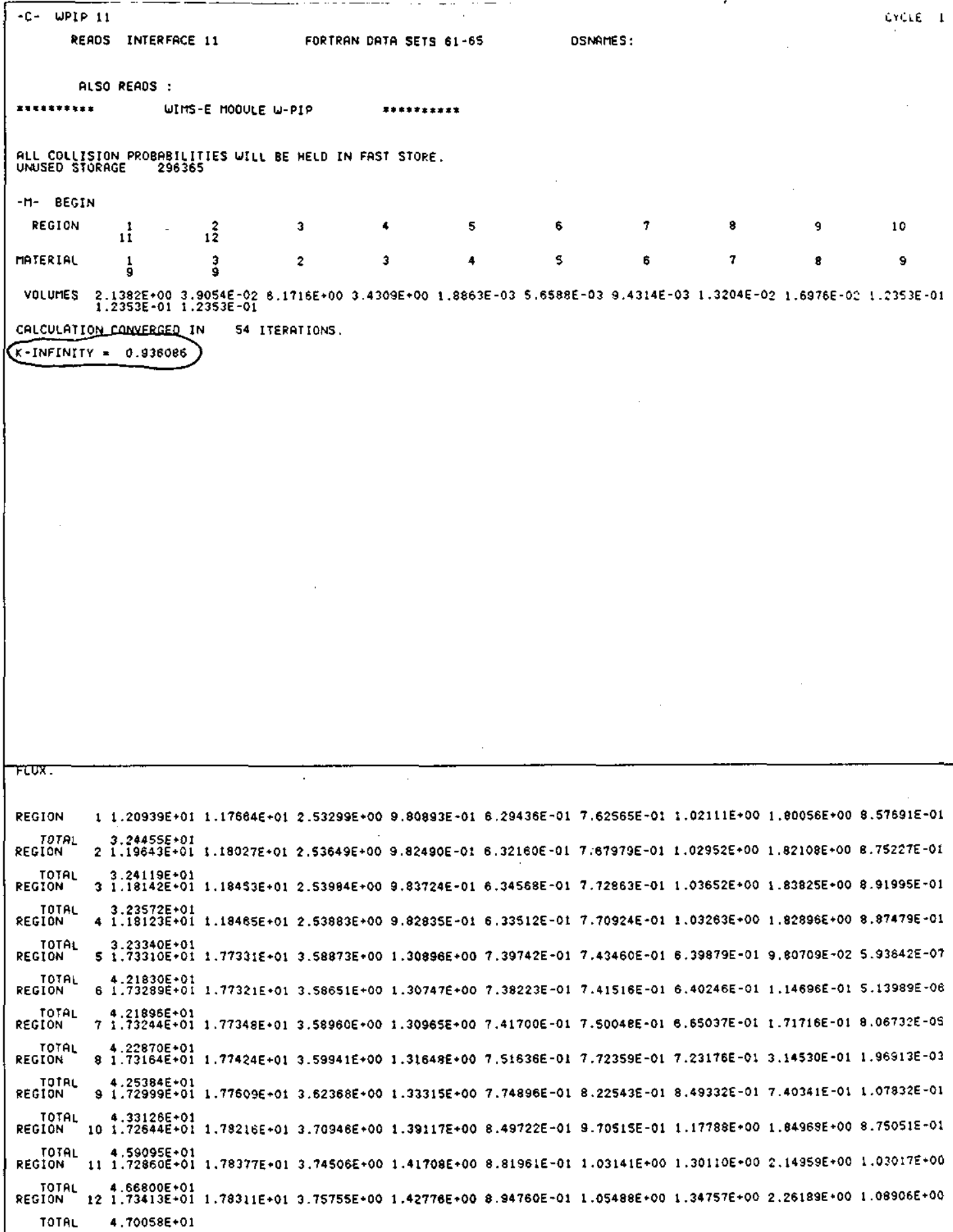


SNF-4503, Rev. 1

WHC-SD-NR-SWD-017

\begin{tabular}{|c|c|c|c|c|c|c|c|}
\hline GROUP & 1 & $\begin{array}{l}2.58597263 E+01 \\
2.28644231 E-01\end{array}$ & $\begin{array}{l}7.29129916 E+01 \\
2.93691791 E-01\end{array}$ & $\begin{array}{l}4.09942737 E+01 \\
\text { B. } \\
1041427 E+00\end{array}$ & $\begin{array}{l}3.26910669 \mathrm{E}-02 \\
1.46993887 \mathrm{0}+02\end{array}$ & $9.80612186 E-02$ & $1.63392883 E-01$ \\
\hline GrOUP & 2 & $\begin{array}{l}2.51594152 E+01 \\
2.34269735 E=01\end{array}$ & $\begin{array}{l}\text { 7.31047289E+01 } \\
3.01517009 E=01\end{array}$ & $\begin{array}{l}4.11051099 \mathrm{E}+01 \\
6.60791808 \mathrm{E}+00\end{array}$ & $\begin{array}{l}3.34495240 E-02 \\
1.46814016 E+02\end{array}$ & $1.00342617 \mathrm{E}-01$ & $1.67263673 E-01$ \\
\hline CRQUP & 3 & $\begin{array}{l}5.41514823 E+00 \\
4.75262999 E-02\end{array}$ & $\begin{array}{l}1.56749848 E+01 \\
6.15173754 E-02\end{array}$ & $\begin{array}{l}8.809558 B 8 \varepsilon+00 \\
\text { l. } 38507749 \varepsilon+00\end{array}$ & $\begin{array}{l}6.76933957 \mathrm{E}=03 \\
3.14557326 \mathrm{E}+01\end{array}$ & $2.02954531 E-02$ & $3.38548790 \mathrm{E}-02$ \\
\hline GROUP & 4 & $\begin{array}{l}2.09739118 E+00 \\
1.73926630 E-02\end{array}$ & $\begin{array}{l}6.07119789 E+00 \\
2.26321733 E-02\end{array}$ & $\begin{array}{l}3.41039125 E+00 \\
5.23293171 E-01\end{array}$ & $\begin{array}{l}2.46905206 \mathrm{E}-03 \\
1.21645079 \mathrm{0}+01\end{array}$ & $7.39876533 E-03$ & $1.23517848 E-02$ \\
\hline GROUP & $\mathbf{5}$ & $\begin{array}{l}1.34588996 E+00 \\
9.9245470 E+03\end{array}$ & $\begin{array}{l}3.91632942 E+00 \\
1.3 ! 550075 E-02\end{array}$ & $\begin{array}{l}2.19921093 E+00 \\
3.24456538 E-0 t\end{array}$ & $\begin{array}{l}1.39535640 \mathrm{E}=03 \\
7.82053453 \mathrm{0}=00\end{array}$ & $4.17747481 E-03$ & B. $99524980 E-03$ \\
\hline GROUP & 6 & $\begin{array}{l}1.63055137 E+00 \\
1.01981767 E-02\end{array}$ & $\begin{array}{l}1.7698359 ? E+00 \\
1.39638769 E-02\end{array}$ & $\begin{array}{l}2.67496439 E+00 \\
3.7762086 E E-01\end{array}$ & $\begin{array}{l}1.40 \% 37032 E \cdot 03 \\
9.48980758 E+00\end{array}$ & $4.19611080 E-03$ & $7.07398830 E-03$ \\
\hline GROUP & 7 & $\begin{array}{l}2.18339322 E+00 \\
9.54878378 E-03\end{array}$ & $\begin{array}{l}0.39703527 \mathrm{E}+00 \\
1.44186709 \mathrm{E}-02\end{array}$ & $\begin{array}{l}3.58307496 \varepsilon+00 \\
4.72711767 \varepsilon-01\end{array}$ & $\begin{array}{l}\text { 1.20598744E }=03 \\
1.26712849 E .01\end{array}$ & $3.62303990 E-03$ & $6.27221788 E-03$ \\
\hline GROUP & 8 & $\begin{array}{l}3.85005110 E+00 \\
4.15303237 \mathrm{E}-03\end{array}$ & $\begin{array}{l}1.13450185 E+01 \\
1.25683836 E-02\end{array}$ & $\begin{array}{l}6.34611912 E+00 \\
7.73469435 E-01\end{array}$ & $\begin{array}{l}1.84988779 E-04 \\
2.23338331 E+01\end{array}$ & $6,49046647 \mathrm{E}-04$ & $1.8 ! 95: 607 \mathrm{E}-03$ \\
\hline GROUP & 9 & $\begin{array}{l}1.83335548 \mathrm{E}+00 \\
2.60002285 \mathrm{E} \cdot 05\end{array}$ & $\begin{array}{l}5.50507399 \mathrm{E}+00 \\
1.8306079 \mathrm{tE}=03\end{array}$ & $\begin{array}{l}3.07904273 E+00 \\
3.69897601 E-01\end{array}$ & $\begin{array}{l}1.11977174 \mathrm{E}-09 \\
1.07898273 \mathrm{E}+01\end{array}$ & $2.90857171 E-08$ & $7.608594305-07$ \\
\hline & & $\begin{array}{l}6.93765236 E+01 \\
5.61673449 E-01\end{array}$ & $\begin{array}{l}1.99697195 E+02 \\
7.35294995 E-01\end{array}$ & $\begin{array}{l}1.12200746 E+02 \\
1.72448593 E+01\end{array}$ & 7. $95886385 E-02$ & $2.38742755 E-01$ & $3.98824353 E-01$ \\
\hline
\end{tabular}

PIP COMPLETEO

TIME FROM START 5.9 SECONOS. TIME IN THIS MODULE 0.1 SECONOS. UNUSED REGION THIS MOOULEIIS\& K 8YTES.

-C. WUEO

FORTRAN DATA SETS $81-65$

CYCLE 1

REGOS INTERFACE 11

DSNATES:

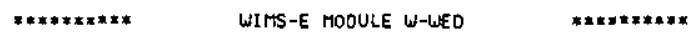

EOITEO RESULTS FROM A MAIN TRANSPORT CALCULATION

DIMENSION NUMBERS

MESHES GROUPS OROERS MATRLS XSECTS

UNUSED STORAGE 298532

$I=10$, NREGIN= 12

$-M-$
$-M-$ OPTION
$-M$
$-M-$

-M- $\underset{-M E G I N}{-M}$
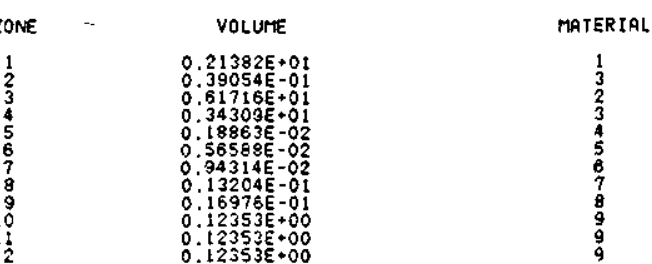

FLUX SCALE FACTOR $1.000000 E+00$

FEU-GR̃OUP REGIONAL ano CELl EDIT, INTEGPaTEd aro aVERAGed FLUXES, total EVENTS

REGION I MRTERLAL 1 VOLUTE $2.133246 E+00$

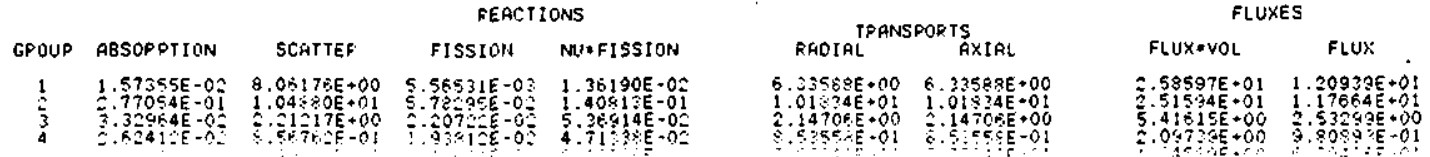

\section{A-9ustont 1}


SNF-4503, Rev. 1

\section{WHC-SD-NR-SWD-017}

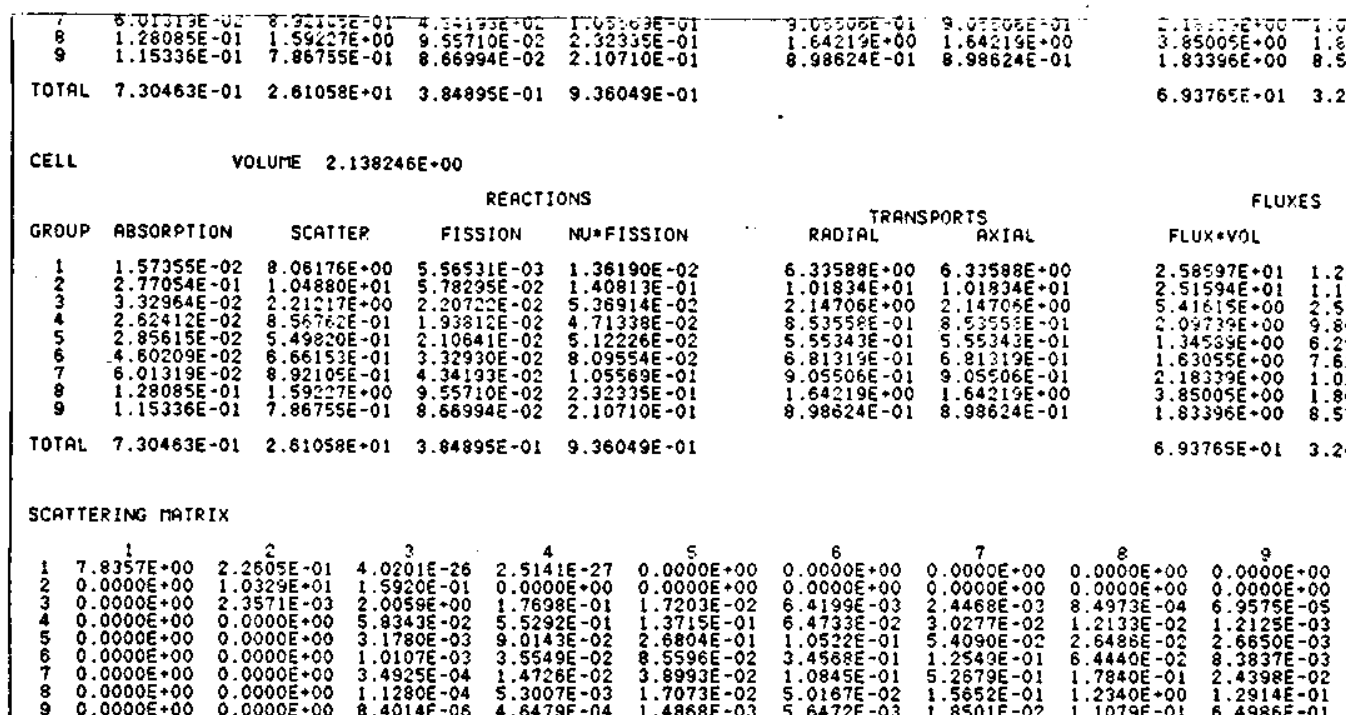

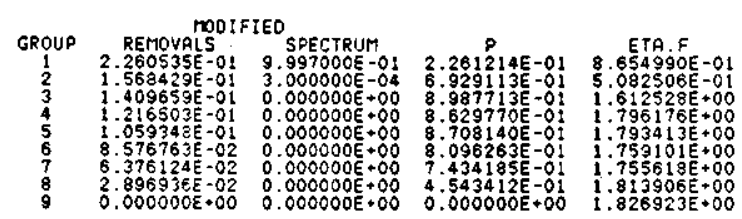

WED COMPLETEO

TIME FROM START 5.9 SECONOS. TIME IN THIS MODULE 0.0 SECONDS. UNUSED REgION THIS MODULEIIS6 K BYTES.

-C - WWED

READS INTERFACE 11

FORTRAN DATA SETS $61-65$

DSNAMES:

CYCLE 1

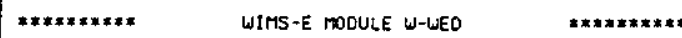

EOITED RESULTS FROM A MAIN TRANSPORT CALCULATION

DIMENS TON NUMBERS
MESHES GROUPS OROERS MATRLS XSECTS
12

UNUSED STORAGE 298532

I= 10, NREGIN= 12

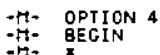

FLUX SCALE FACTOR $1.000000 E+00$
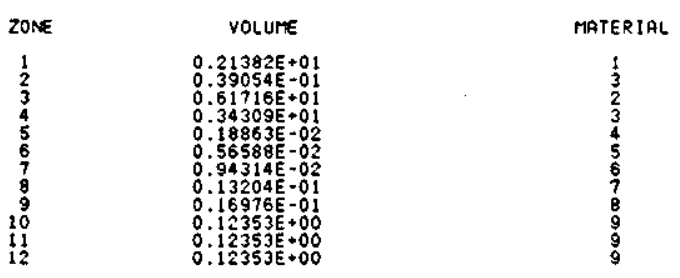

FEL-GROUP REGIONGAL ANO CELL EOIT, INTEGRATED ANO GVERAGEO FLUXES, TOTAL EVENTS

REGION 1 MATERIAL 1 VOLUTE $2.138246 E+00$

\begin{tabular}{|c|c|c|c|c|c|c|c|c|}
\hline \multirow[b]{2}{*}{ GROUP } & \multirow[b]{2}{*}{ ABSORPTION } & \multicolumn{3}{|c|}{ REACTIONS } & \multicolumn{2}{|c|}{ TEANSPOPTS } & \multicolumn{2}{|c|}{ FLUXES } \\
\hline & & SCATTER & FISSION & NU*FISSION & RACIAL & AXIAL & FLUXivOL & FLUY. \\
\hline $\begin{array}{l}1 \\
2 \\
3 \\
4 \\
2\end{array}$ & $\begin{array}{l}1.57355 E-02 \\
2.77054=01 \\
3.37904002 \\
2.64412 E-02\end{array}$ & 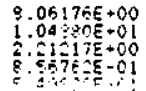 & 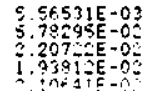 & 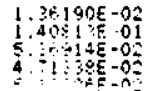 & 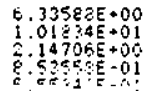 & 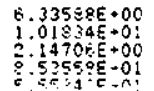 & 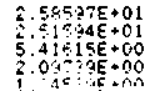 & 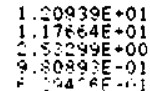 \\
\hline
\end{tabular}

B-92

Attachment 1

1-143 
WHC-SD-NR-SWD-017

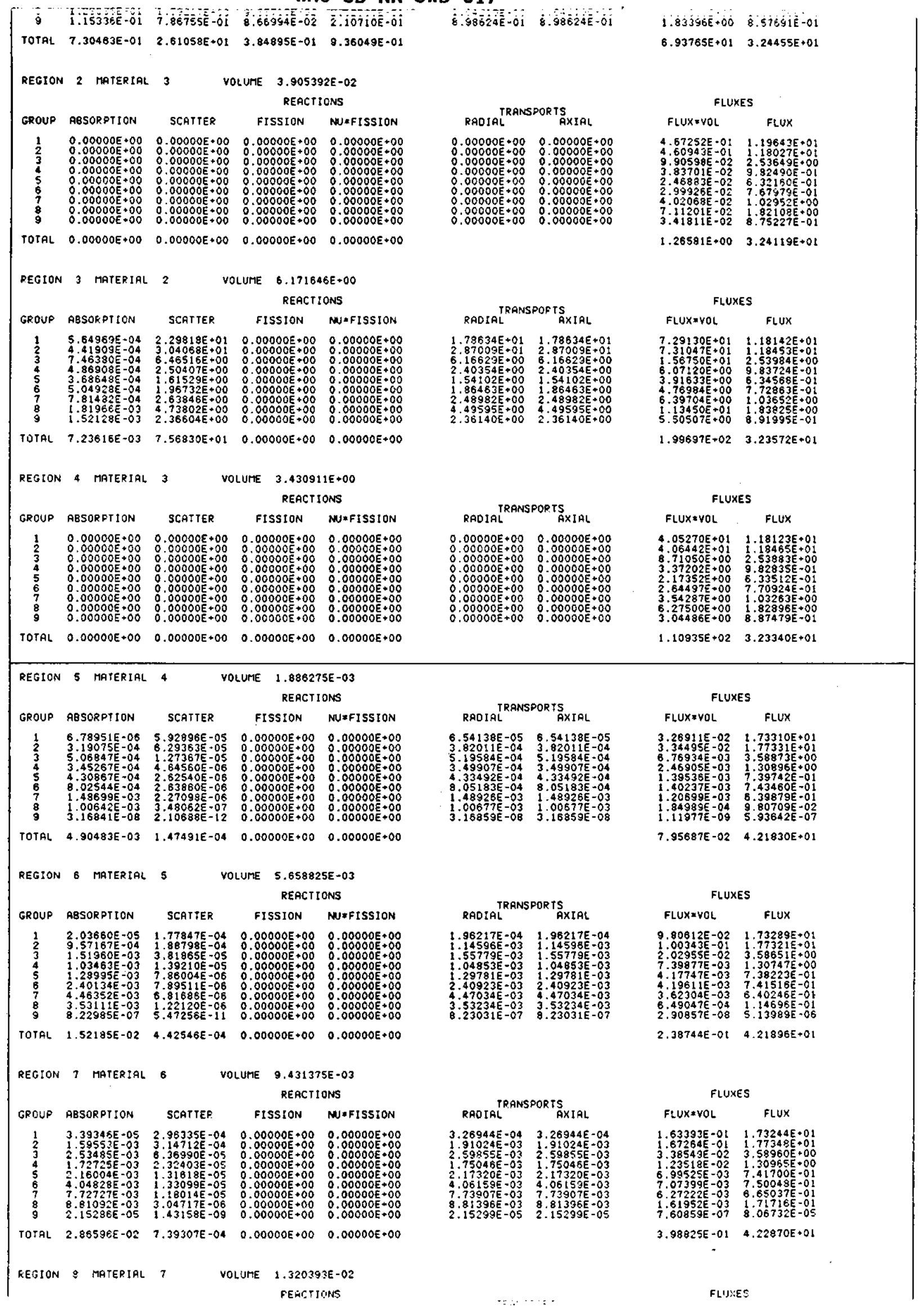




\section{WHC-SD-NR-SWD-017}

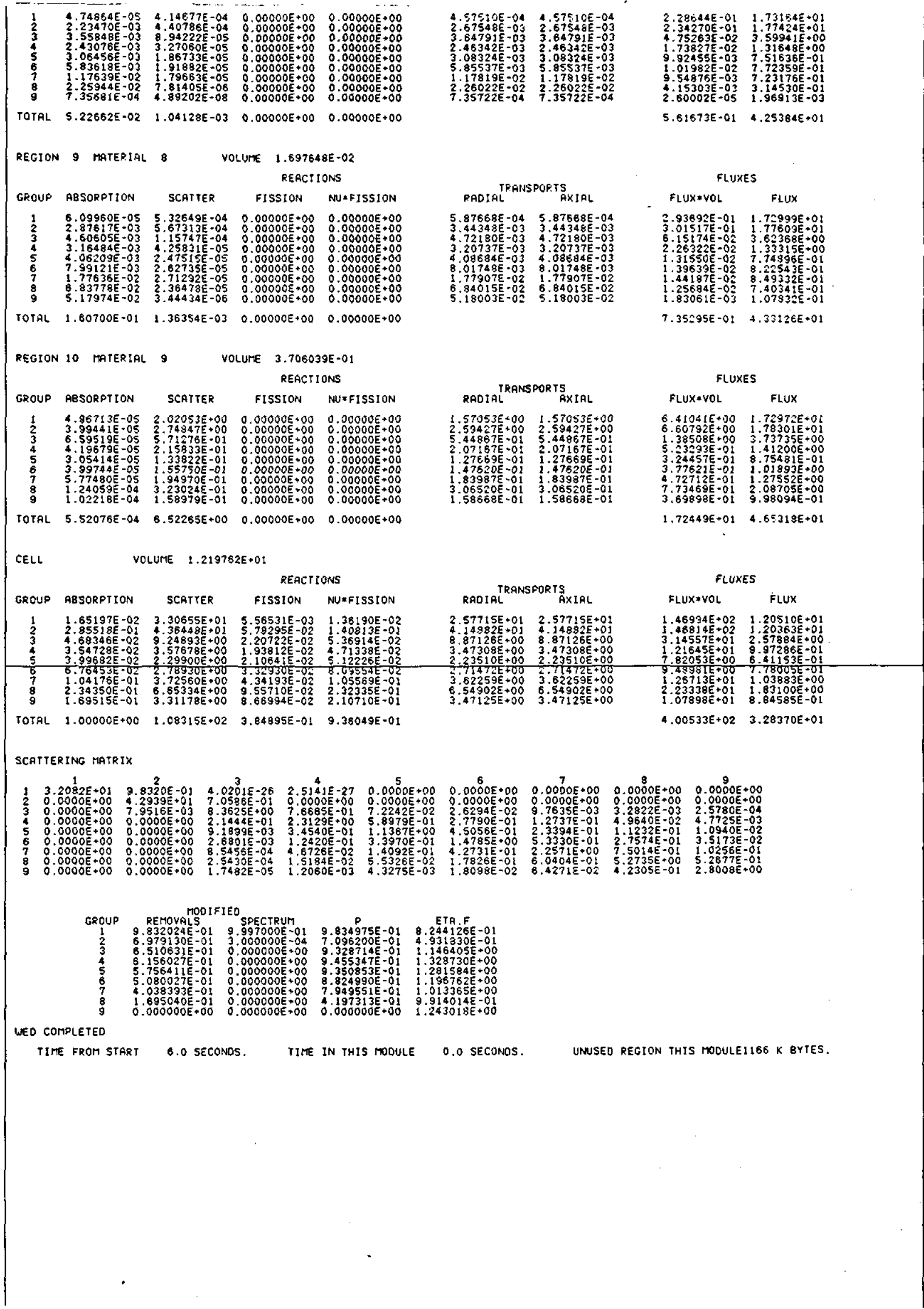




\section{WHC-SD-NR-SWD-017}

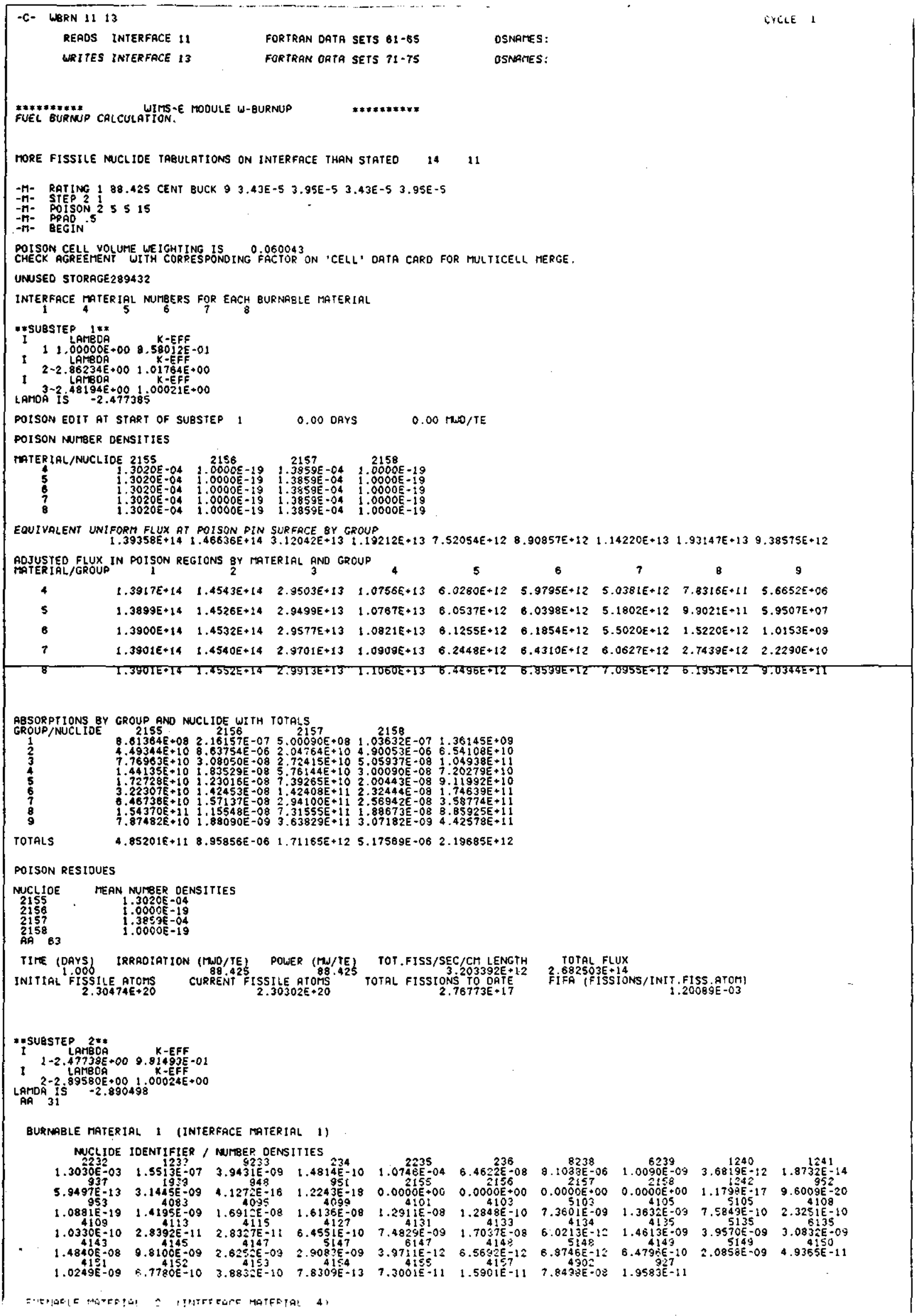


SNF-4503, Rev. 1

\section{WHC-SD-NR-SWD-017}

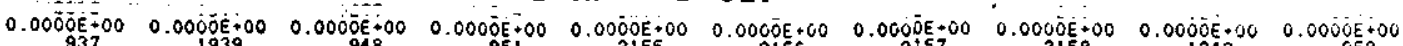

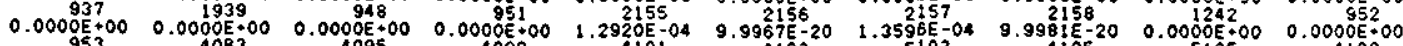
$\begin{array}{ccccccccccc}0.0000 E+00 & 0.0000 E+00 & 0.0000 E+00 & 0.0000 E+00 & 0.0000 E+00 & 0.0000 E+00 & 0.0000 E+00 & 0.0000 E+00 & 0.0000 E+00 & 0.0000 E+00\end{array}$

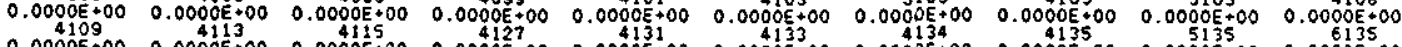
$\begin{array}{lllllllllll}0.0000 E+00 & 0.0000 E+00 & 0.0000 E+00 & 0.0000 E+00 & 0.0000 E+00 & 0.0000 E+00 & 0.0000 E+00 & 0.0000 E+00 & 0.0000 E+00 & 0.0000 E+00\end{array}$ $\begin{array}{cccccccccc}0.0000 E+00 & 0.0000 E+00 & 0.0000 E+00 & 0.0000 E+00 & 0.0000 E+00 & 0.0000 E+00 & 0.0000 E \div 00 & 0.0000 E+00 & 0.0000 E+00 & 0.0000 E+00\end{array}$ $\begin{array}{lllllllll}0.0000 E+00 & 0.0000 E+00 & 0.0000 E+00 & 0.0000 E+00 & 0.0000 E+00 & 0.0000 E+00 & 0.0000 E+00 & 0.0000 E+00\end{array}$

BURnable material 3 (INTEPFACE Material S)

NUCLIDE IDENTIFIER / NUMBER DENSITIES

$\begin{array}{cccccccccc}0.0000 E+00 & 0.0000 E+00 & 0.0000 E+00 & 0.0000 E+00 & 0.0000 E+00 & 0.0000 E+00 & 0.0000 E+00 & 0.0000 E+00 & 0.0000 E+00 & 0.0000 E+00\end{array}$ $\begin{array}{ccccccccccc}0.00037+00 & 0.00000+00 & 0.0000 E+00 & 0.0000 E+00 & 1.2916 E-04 & 9.99 E 7 E-20 & 1.3577 E-04 & 9.9981 E 8-20 & 0.0000 E+00 & 0.0000 E+00\end{array}$

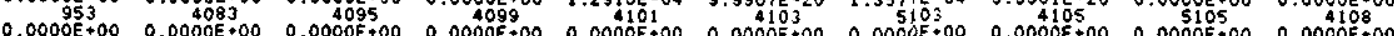

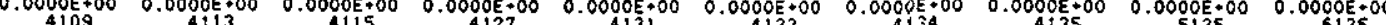
$\begin{array}{ccccccccccc}0.0000 E+00 & 0.0000 E+00 & 0.0000 E+00 & 0.0000 E * 00 & 0.0000 E+00 & 0.0000 E+00 & 0.0000 E+00 & 0.0000 E+00 & 0.0000 E+00 & 0.0000 E+00\end{array}$ $\begin{array}{cccccccccccc}0.0000 E+00 & 0.0000 E+00 & 0.0000 E+00 & 0.0000 E+00 & 0.0000 E+00 & 0.0000 E+00 & 0.0000 E+00 & 0.0000 E+00 & 0.0000 E+00 & 0.0000 E+00\end{array}$ $\begin{array}{llllllll}0.0000 E+00 & 0.0000 E * 00 & 0.0000 E+00 & 0.0000 E+00 & 0.0000 E+00 & 0.0000 E * 00 & 0.0000 E * 00 & 0.0000 E+00\end{array}$

SURNABLE MATERIRL 4 (INTERFACE MATERIAL 6)

NUCLIDE IDENTIFIER / NUTBER DENSITIES

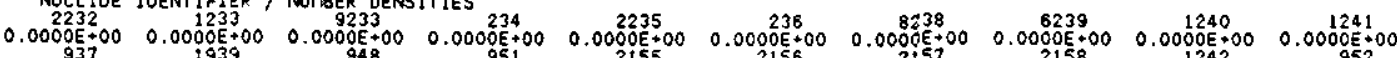
$\begin{array}{ccccccccccc}0.0000 E * 00 & 0.0000 E+00 & 0.0000 E+00 & 0.0000 E+00 & 1.2905 E-04 & 9.9967 E-20 & 1.3528 E-04 & 9.99811 E-20 & 0.0000 E+00 & 0.0000 E+00\end{array}$

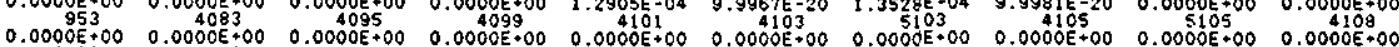

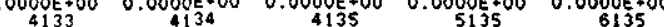
$\begin{array}{ccccccccccc}0.0000 E+00 & 0.0000 E+\infty 0 & 0.0000 E+00 & 0.0000 E+00 & 0.0000 E+00 & 0.0000 E+00 & 0.0000 E+00 & 0.0000 E+00 & 0.0000 E+00 & 0.0000 E+00\end{array}$ $\begin{array}{ccccccccccc}0.0000 E+00 & 0.0000 E+00 & 0.0000 E+00 & 0.0000 E+00 & 0.0000 E+* 00 & 0.0000 E+00 & 0.0000 E+00 & 0.00000 E+00 & 0.0000 E+00 & 0.0000 E+00\end{array}$

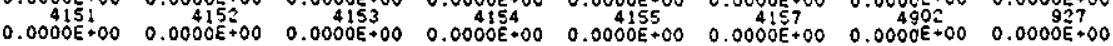

BURNABLE MATERIAL 5 (INTERFACE MATERIAL 7)

MUCL IDE IDENTIFIER / NUMBER DENSITIES

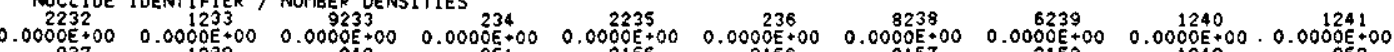

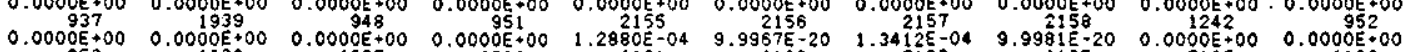
$\begin{array}{clllllllllll}0.0000 E+00 & 0.0000 E+00 & 0.0000 E+00 & 0.0000 E+00 & 0.0000 E+00 & 0.0000 E+00 & 0.0000 E+00 & 0.0000 E+00 & 0.0000 E+00 & 0.0000 E+00\end{array}$

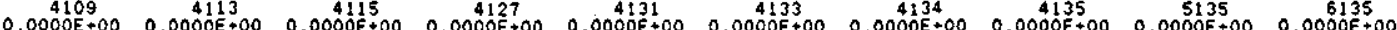
$\begin{array}{cccccccccc}0.0000 E+00 & 0.0000 E+00 & 0.0000 E+00 & 0.0000 E+00 & 0.0000 E+00 & 0.0000 E+00 & 0.0000 E+00 & 0.0000 E+00 & 0.0000 E+00 & 0.0000 E+00\end{array}$ $\begin{array}{ccccccccccc}0.0000 E+00 & 0.0000 E+00 & 0.0000 E * 00 & 0.0000 E+00 & 0.0000 E+00 & 0.0000 E * 00 & 0.0000 E+00 & 0.00000 E+00 & 0.0000 E+00 & 0.00000 E+00\end{array}$ $\begin{array}{llllllll}0.0000 \mathrm{E}+00 & 0.0000 \mathrm{E}+00 & 0.0000 \mathrm{E}+00 & 0.0000 \mathrm{4}+00 & 0.0000 \mathrm{E}+00 & 0.0000 \mathrm{E}+00 & 0.0000 \mathrm{E}+00 & 0.0000 \mathrm{E}+00\end{array}$

BURNABLE MATERIAL 6 . LINTERFACE MATERIAL 8

NUCLIOE IOENTIFTER / MUMBER DENSITIES

$\begin{array}{cccccccccc}0.0000 E+00 & 0.0000 E+00 & 0.0000 E+00 & 0.0000 E+00 & 0.0000 E+00 & 0.0000 E+00 & 0.0000 E+00 & 0.00000 E+00 & 0.0000 E+00 & 0.0000 E+00\end{array}$

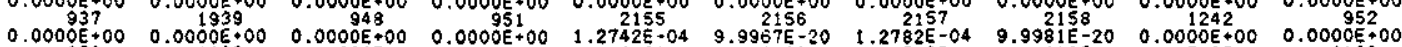
$\begin{array}{lllllllllllll}953 & 4083 & 4095 & 4099 & 4101 & 4103 & 5103 & 4105 & 0.005 & 5105 & 4108\end{array}$ $\begin{array}{lllllllllll}0.0000 E+00 & 0.0000 E * 00 & 0.0000 E+00 & 0.0000 E * 00 & 0.0000 E+00 & 0.0000 E+00 & 0.0000 E+00 & 0.0000 E+00 & 0.0000 E+00 & 0.0000 E+00\end{array}$ $\begin{array}{ccccccccccc}0.0000 E+00 & 0.0000 E+00 & 0.0000 E+00 & 0.0000 E+00 & 0.0000 E+00 & 0.0000 E+00 & 0.0000 E * 00 & 0.0000 E+00 & 0.0000 E+00 & 0.0000 E+00\end{array}$ $\begin{array}{lllllllllll}0.0000 E+00 & 0.0000 E+00 & 0.0000 E+00 & 0.0000 E+00 & 0.0000 E+00 & 0.0000 E+00 & 0.0000 E * 00 & 0.0000 E+00 & 0.0000 E+00 & 0.0000 E+00\end{array}$

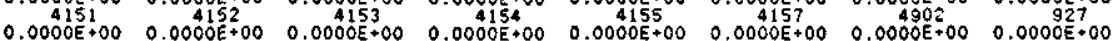


SNF-4503, Rev. 1

WHC-SD-NR-SWD-017

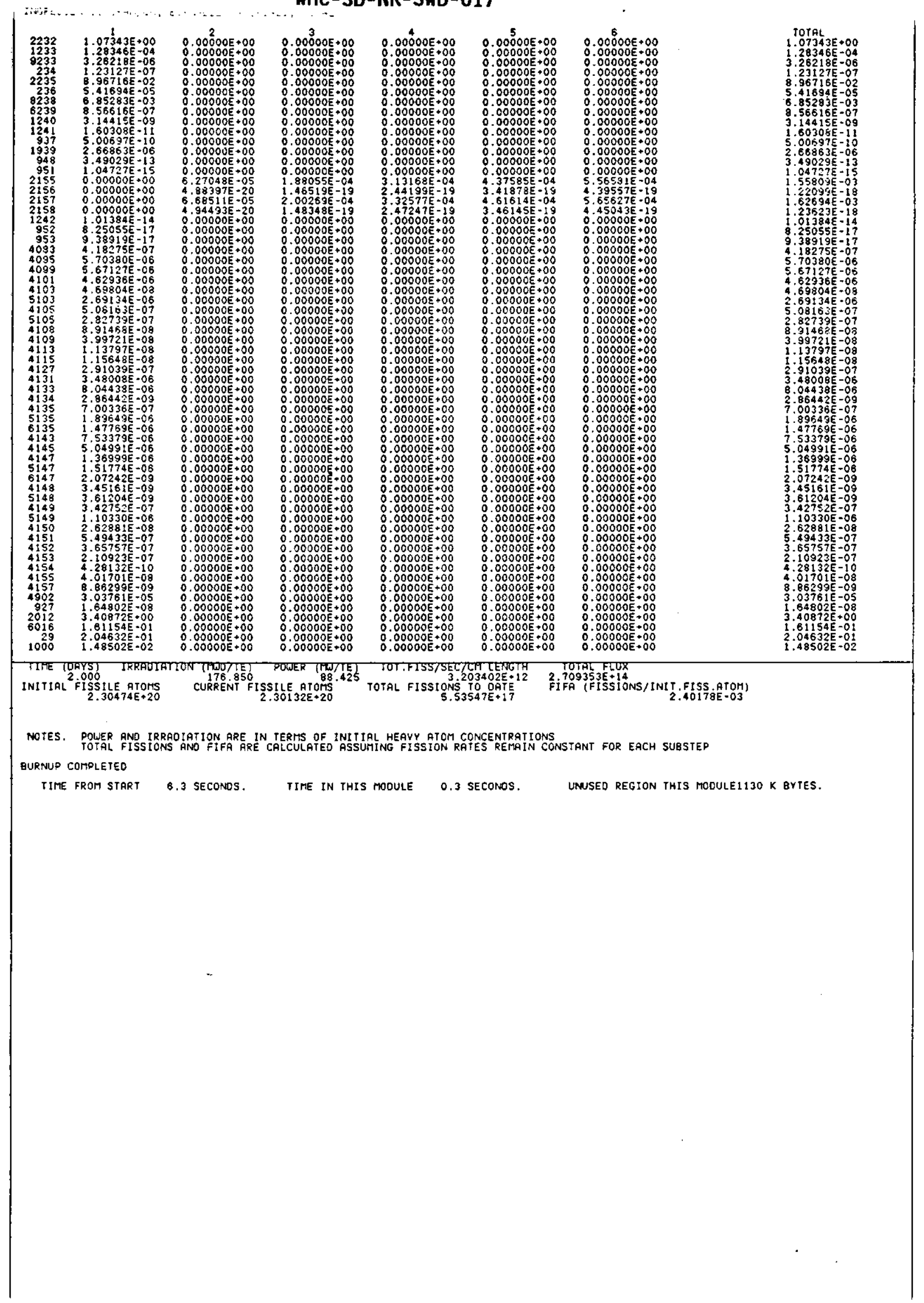

Atrachingnt 1 
SNF-4503, Rev. 1

WHC-SD-NR-SWD-017

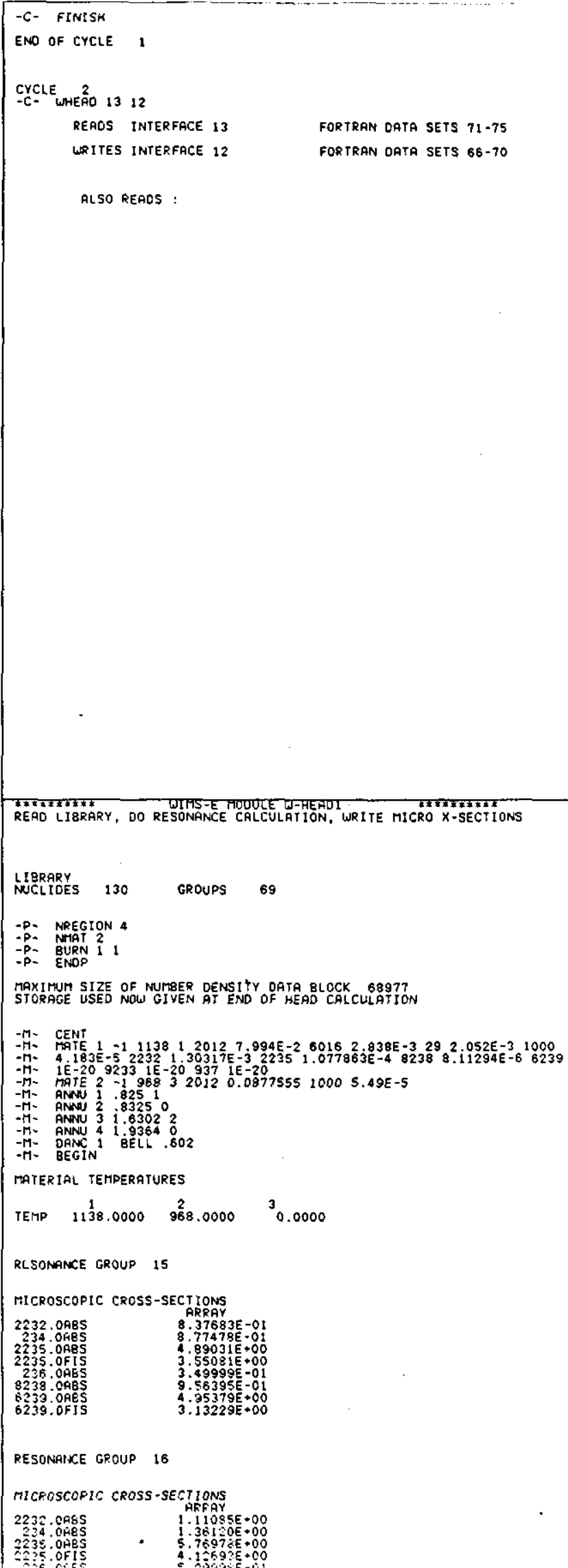


SNF-4503, Rev. 1

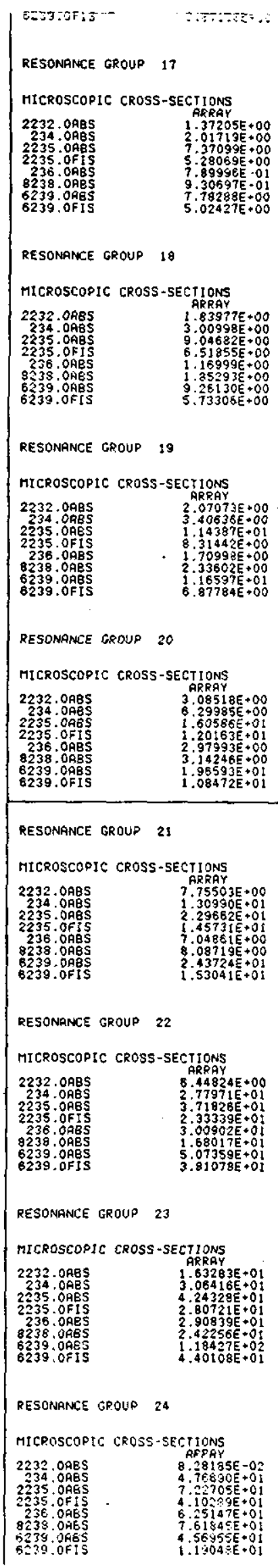

WHC-SD-NR-SWD-017 
SNF-4503, Rev. 1

WHC-SD-NR-SWD-017

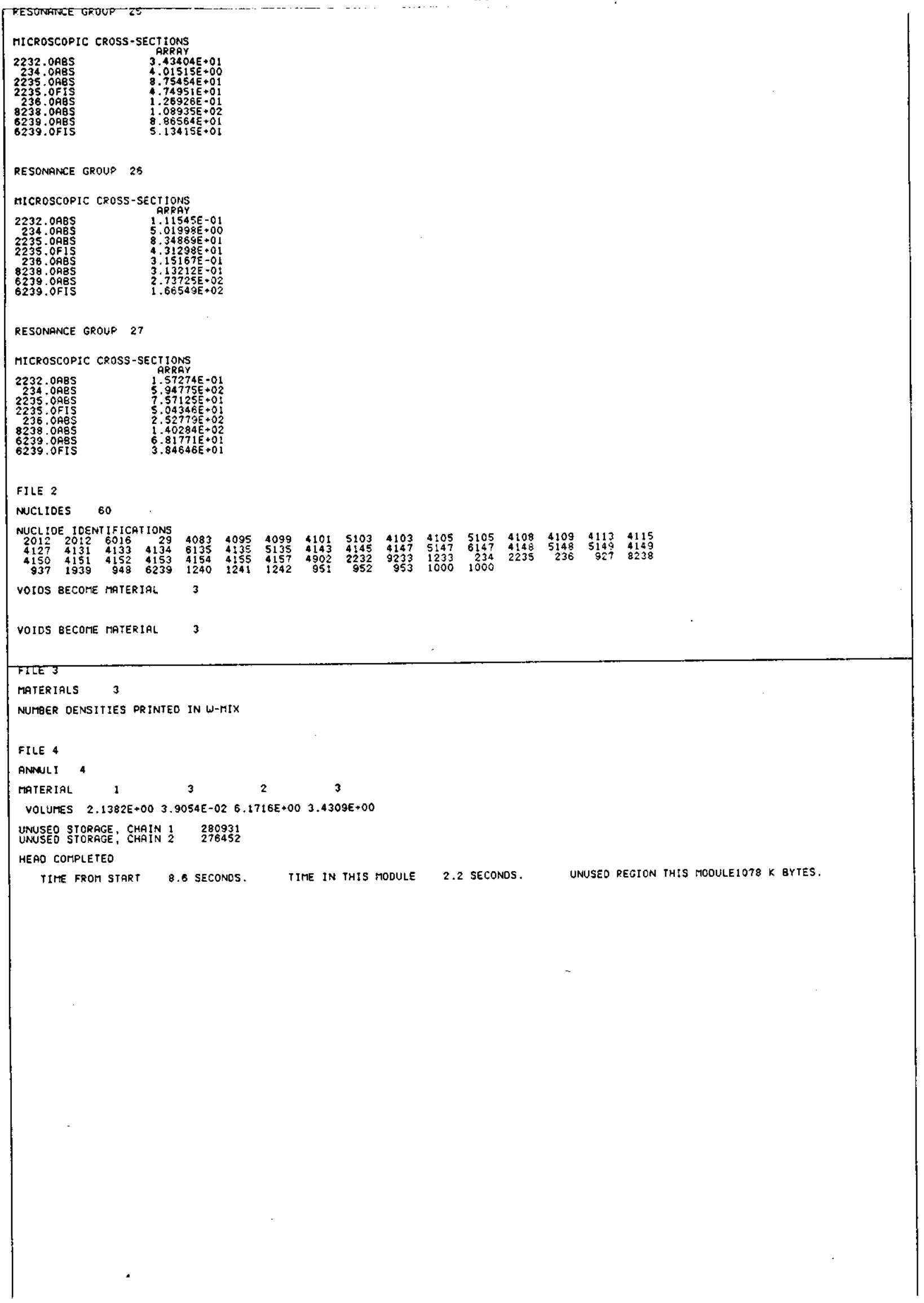

B-100

Attachment 1

1-151 
SNF-4503, Rev. 1

\section{WHC-SD-NR-SWD-017}

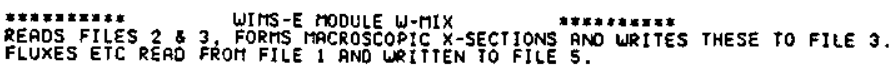

$\begin{array}{lr}\text { LNOSS-SECTIONS } & 60 \\ \text { GROUPS } & 69 \\ \text { MATERIALS } & 3\end{array}$

No. OF MATERIALS TO be PROCESSEO at a TIME 3

UNUSED STORAGE 230640 (IF MATERIALS PROCESSED SINGLY 270129)

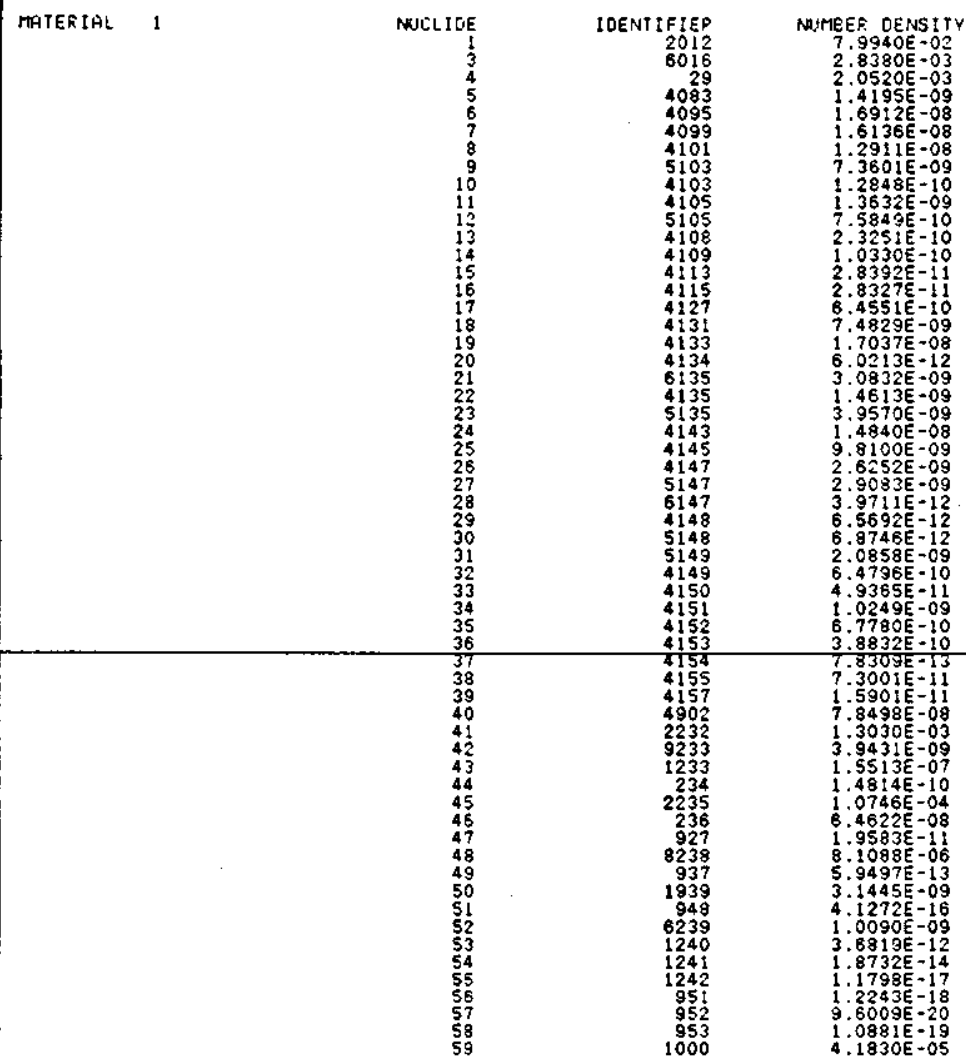

NUMBER OF REACTIONS 4

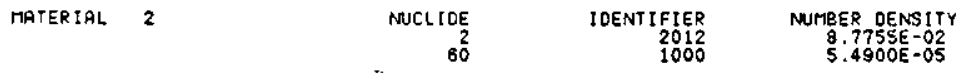

MUMBER OF REACTIONS 3

TATERIAL 3

NUTBER OF REACTIONS O

WRITING FILES

NMESH 1 NGRP 1 NORDEP 1

FLUX
$1.00000 E+00$

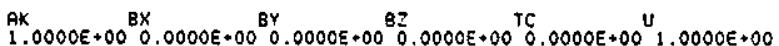

RTIME $0.20000 \mathrm{E} * 01$ RIRRAO $0.17685 E * 03$

SPAPE ITEMS

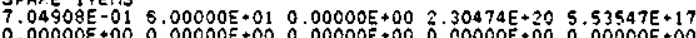

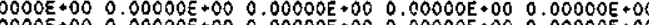

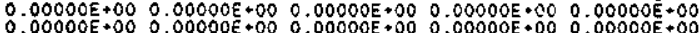

MIK COMELETEO

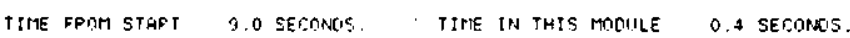

8-101

Attachment 1

$1-152$ 
WHC-SD-NR-SWD-017

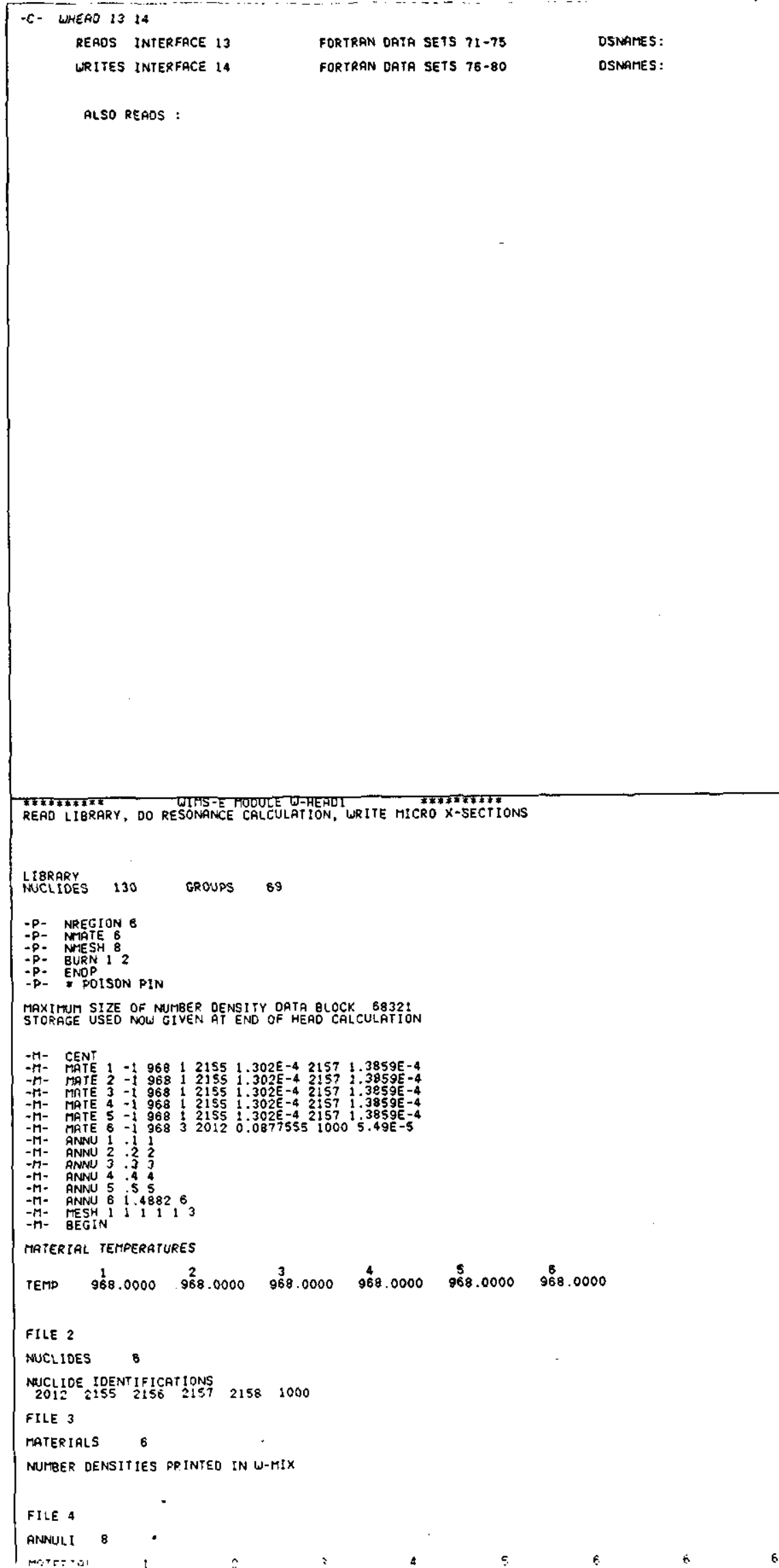

ALSO REAOS: 
SNF-4503, Rev. 1

WHC-SD-NR-SWD-017

UNWSED STOKAGE: CHAIN I 280197

HEAD COMPLETEO

TINE FROTT START 10.2 SECONOS. TIME IN THIS MOOULE 1.2 SECONOS. UNUSED REGION THIS MODULEIOE8 K BYTES.

*\#*:***** WIMS-E MOOULE U-MIX

READS FILES 2 S 3 FORMS MACROSCOPIC X-SECTTONS ANO WRITES THESE TO FILE 3
FLUXES ETC RERO FROH FILE I ANO WRITTEN TO FILE 5 .

\begin{tabular}{lr}
\multicolumn{1}{c}{1} & LT \\
CROSS-SECTIONS & 0 \\
GROUPS & 69 \\
MATERIALS & 6
\end{tabular}

NO. OF MATERIALS TO BE PROCESSEO AT A TIME 6

UNUSED STORAGE 171519

I IF MATERIALS PROCESSED SINGLY

270252 )

MATERTAL 1
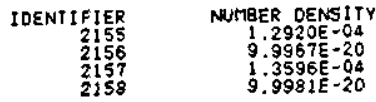

NUMBER OF REACTIONS 3

MATERIAL 2

NUCLIDE
2
3
4
5

IDENTIFI

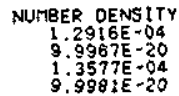

NUMBER OF REACTIONS 3

MATERIAL 3

NUCL IOE
2
3
4
5

IOENT I FIER
2155
2156
2157
2158

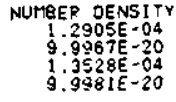

NUMBER OF REACTIONS 3

MATESIAL 4

NUCLIOE
2
3
$\vdots$

IOENTIFIEF

NUTSER DENSTTY

I.
I.
I.

B-103

Attachment 1 
SNF-4503, Rev. 1

WHC-SD-NR-SWD-017

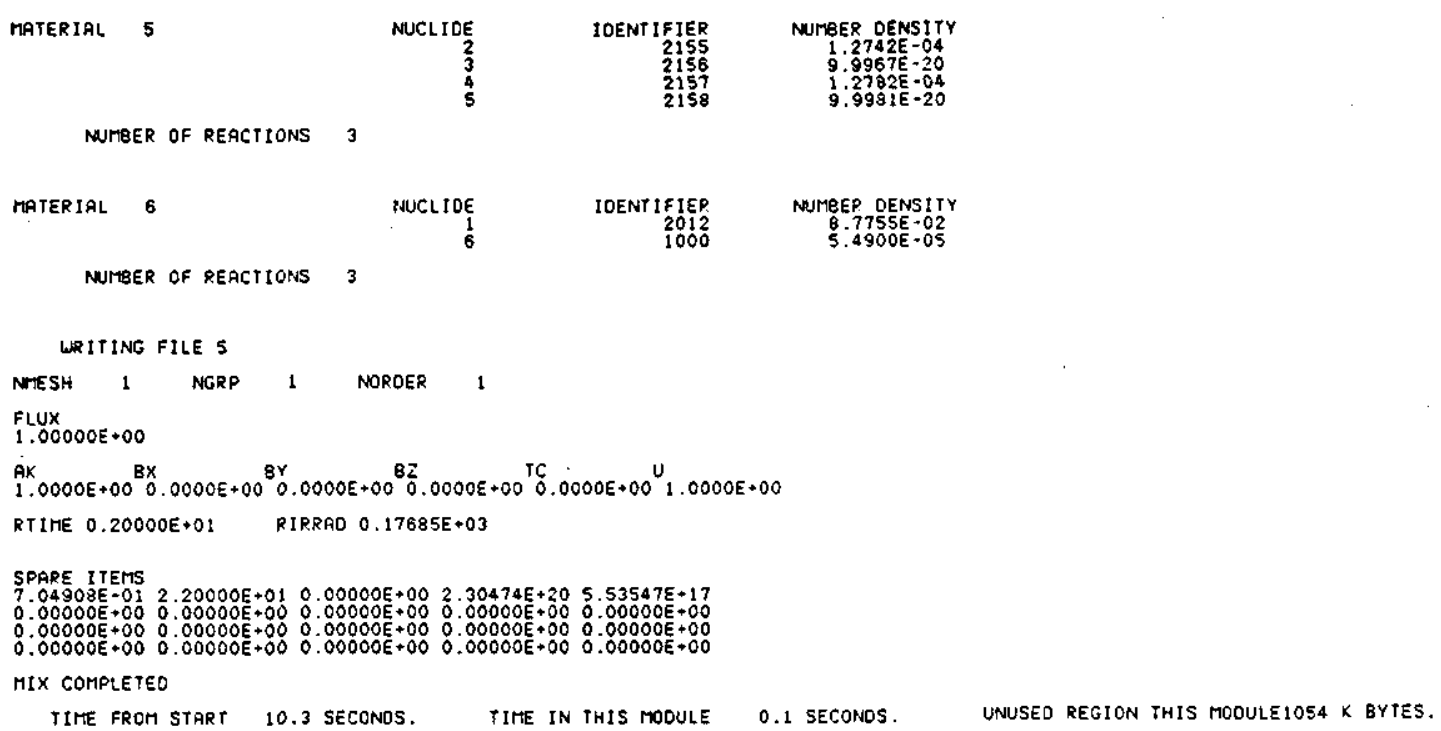

-C- WTHES 12

FORTRAN DATA SETS 66-70 DSNATES:

CYCLE 2

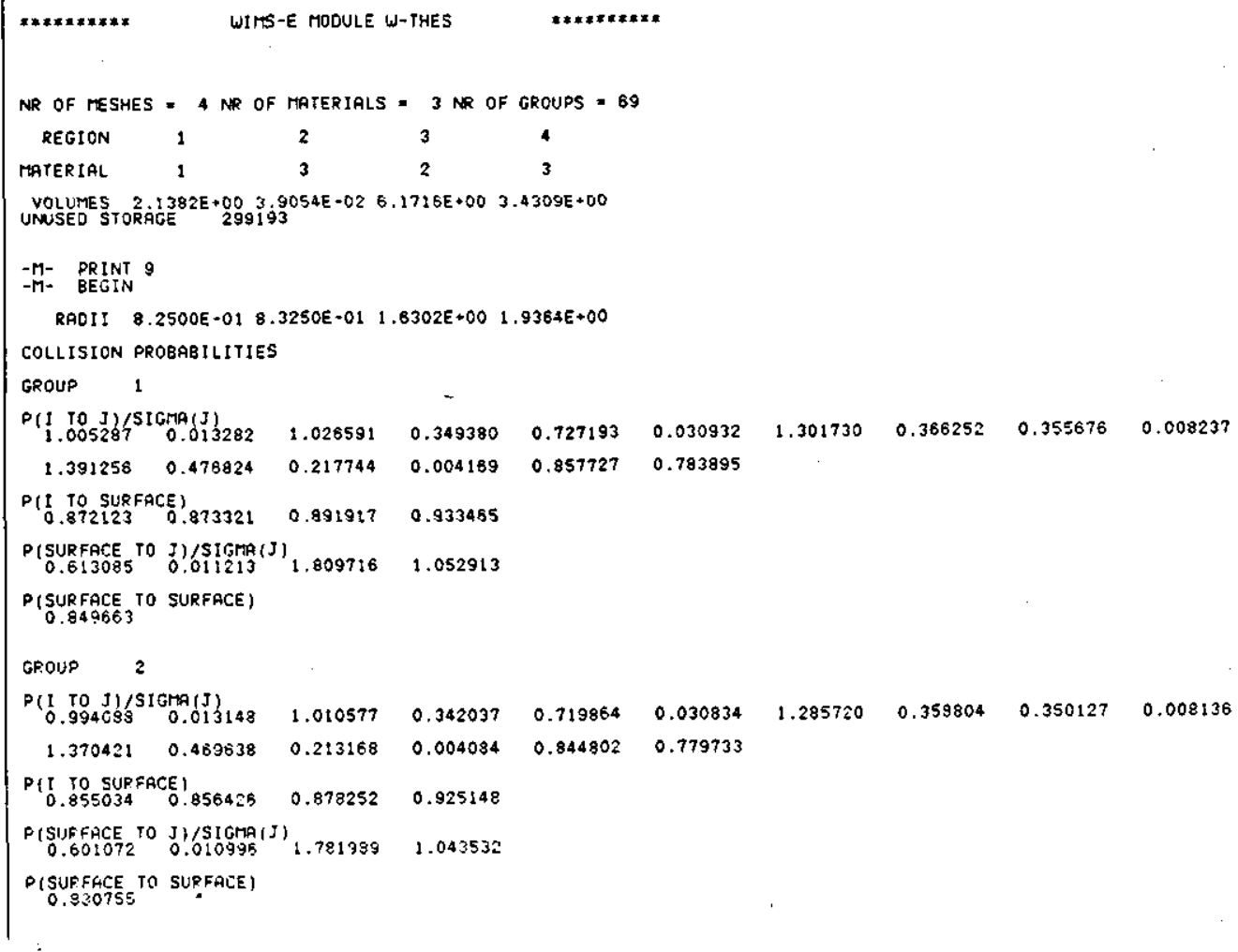


SNF-4503, Rev. 1

WHC-SD-NR-SWD-017

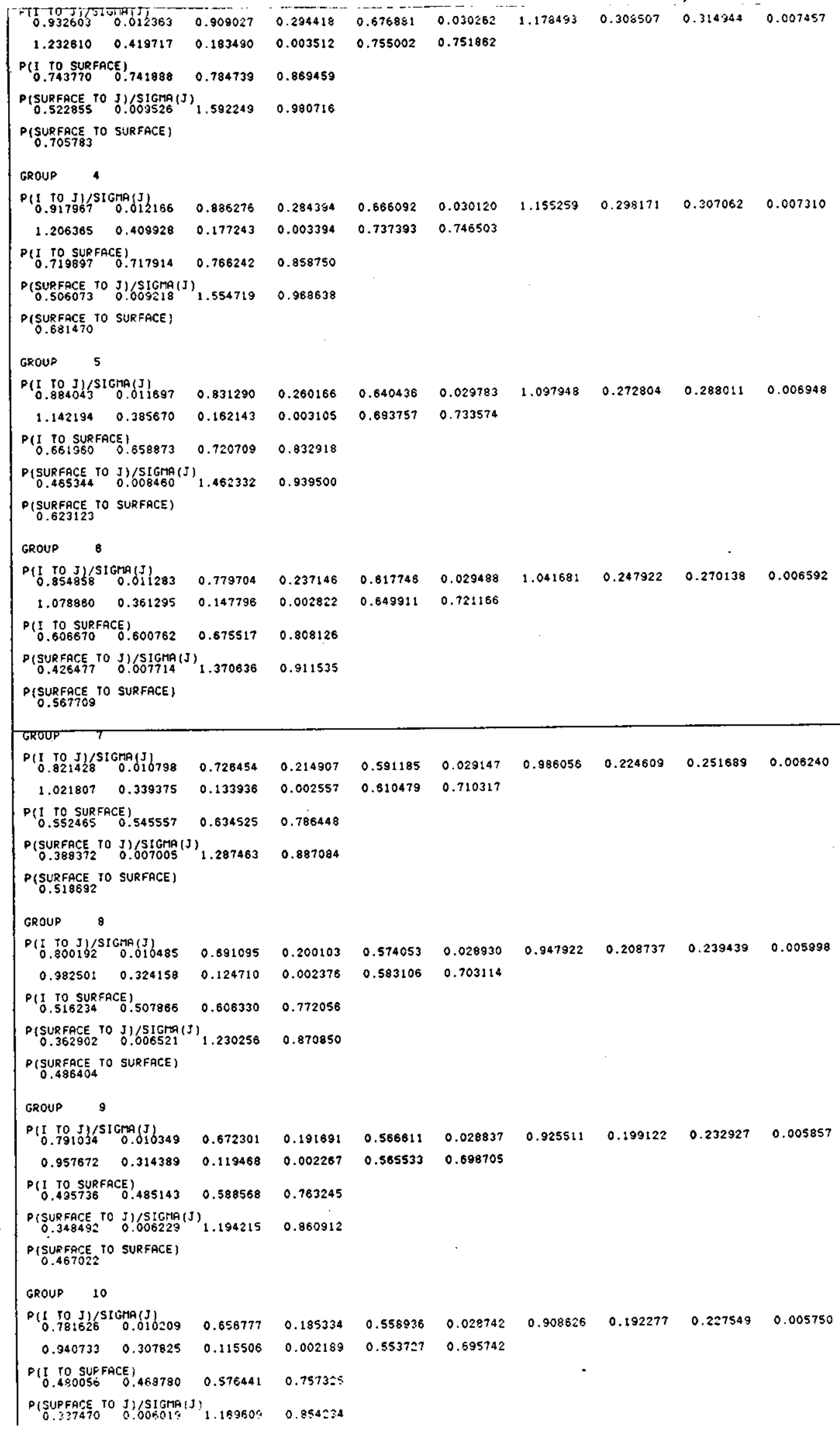


SNF-4503, Rev. 1

WHC-SD-NR-SWD-017

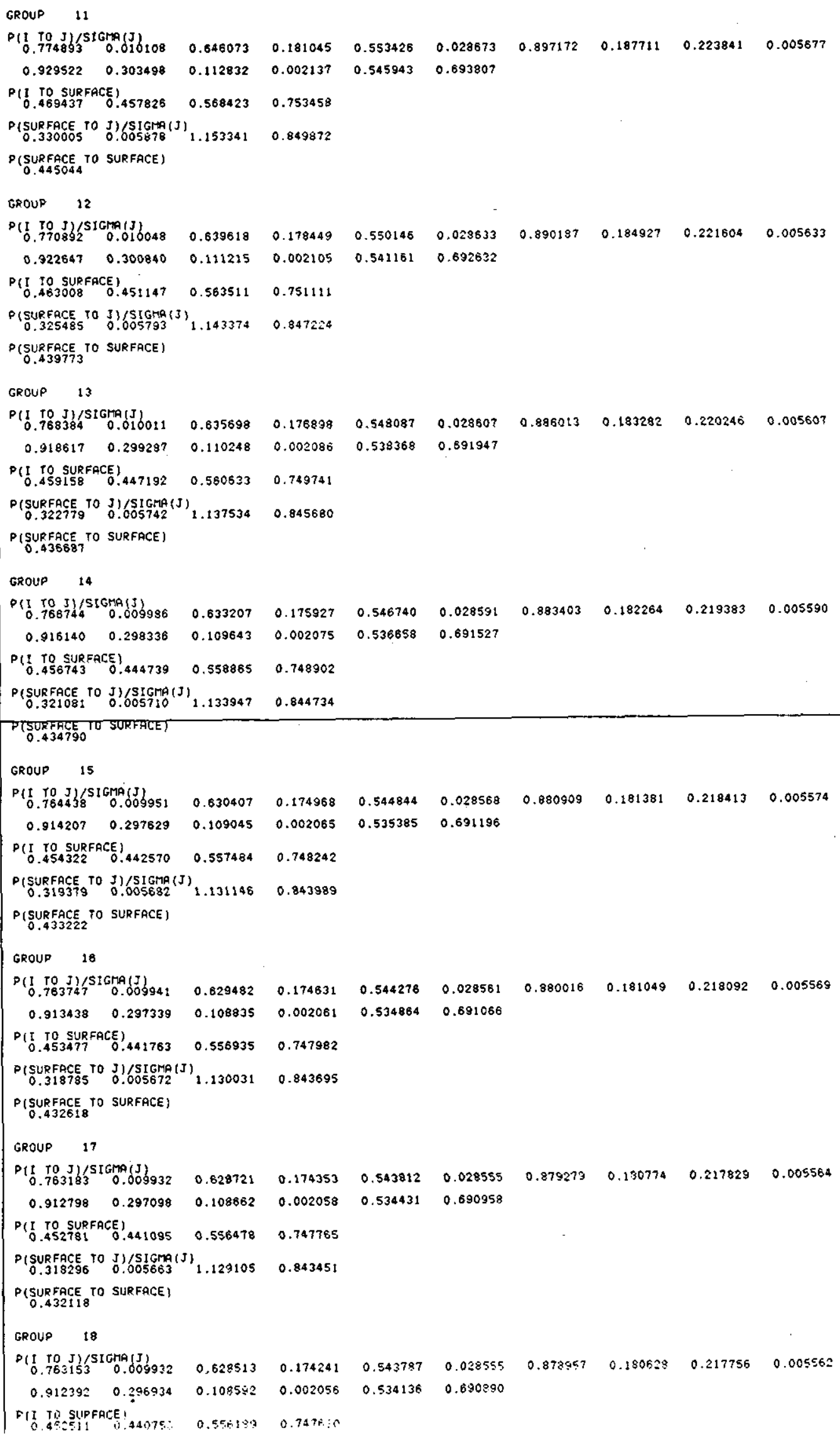


SNF-4503, Rev. 1

WHC-SD-NR-SWD-017

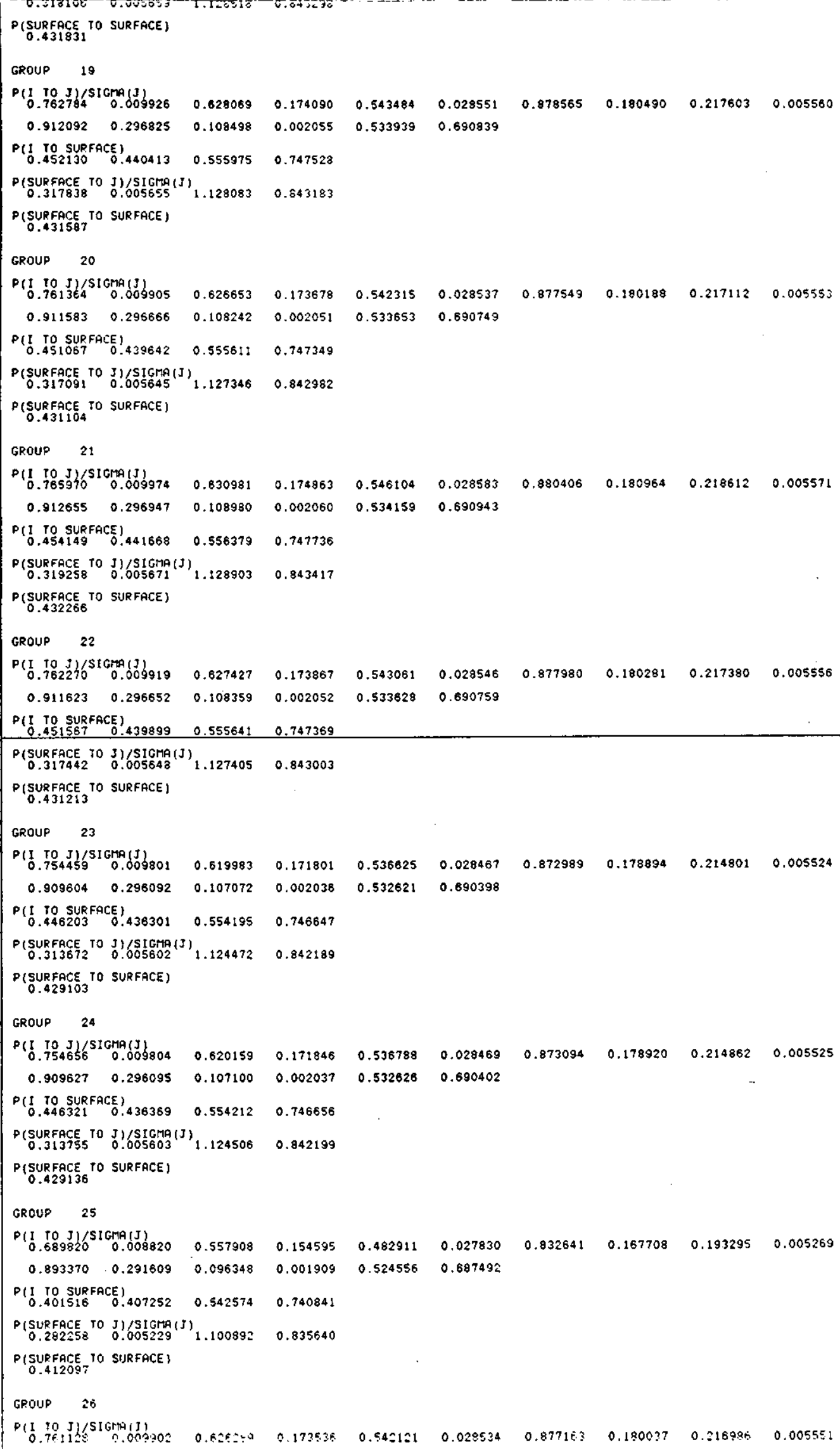


SNF-4503, Rev. 1

WHC-SD-NR-SWD-017

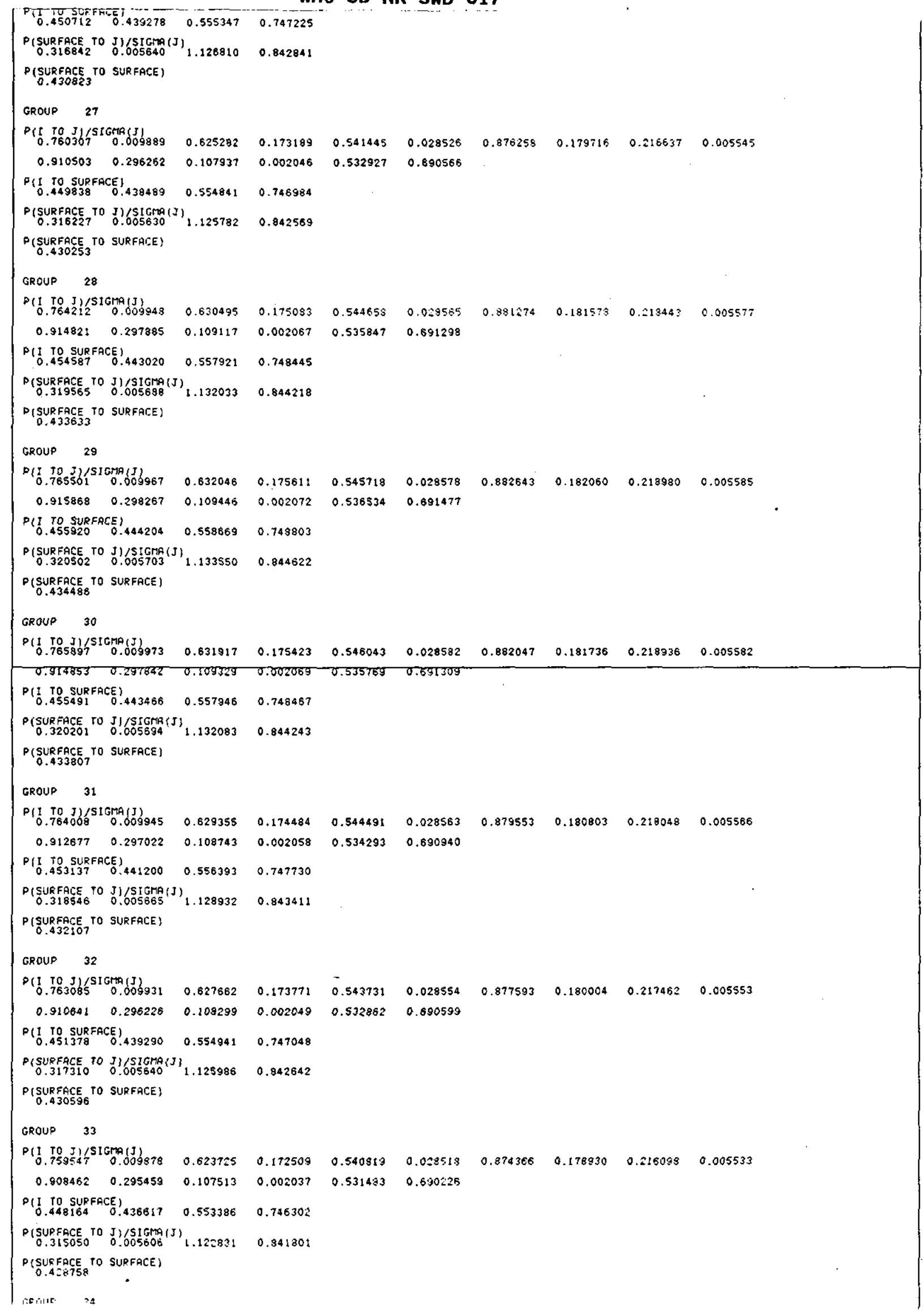


SNF-4503, Rev. 1

WHC-SD-NR-SWD-017

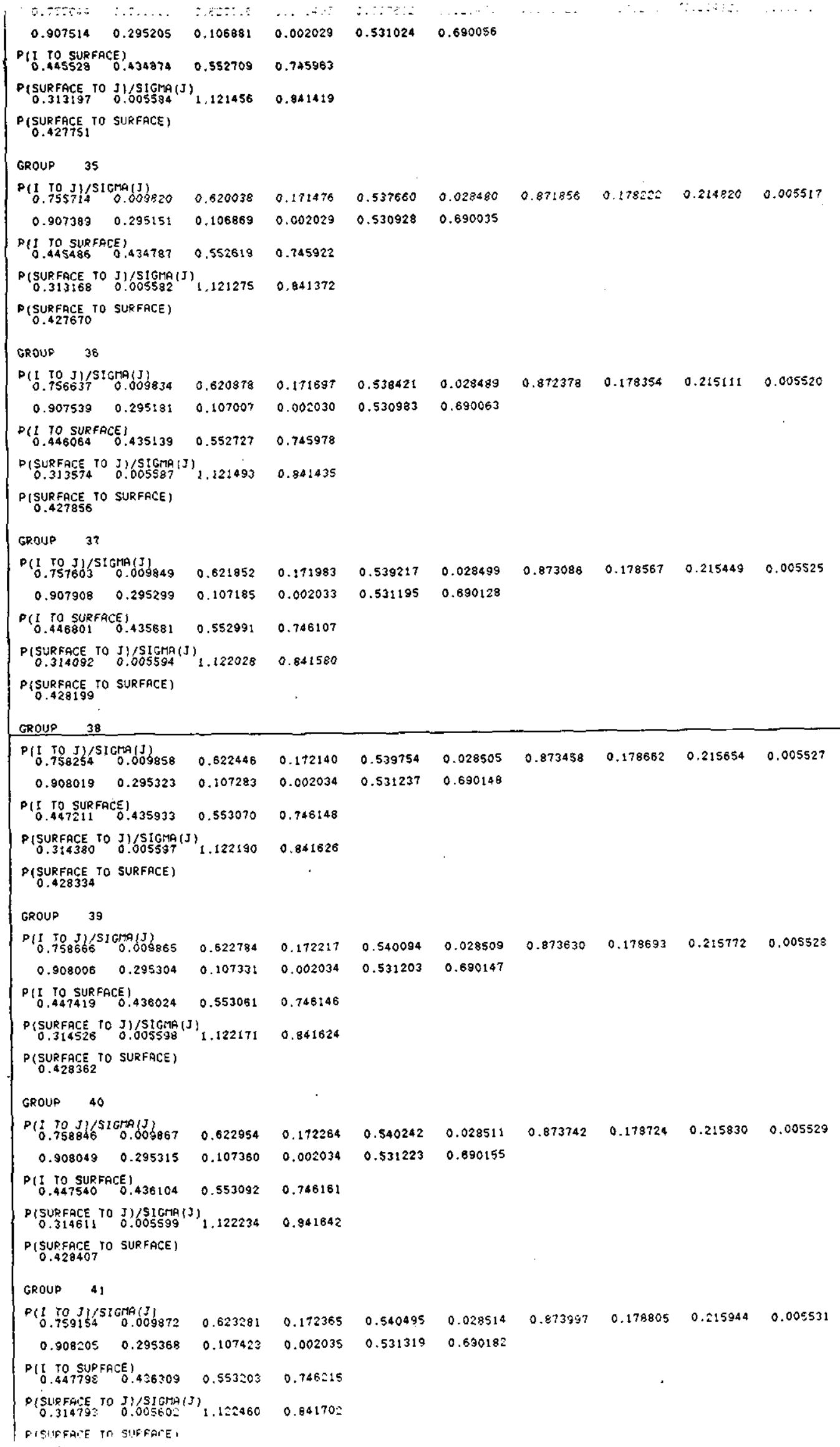


SNF-4503, Rev. 1

WHC-SD-NR-SWD-017

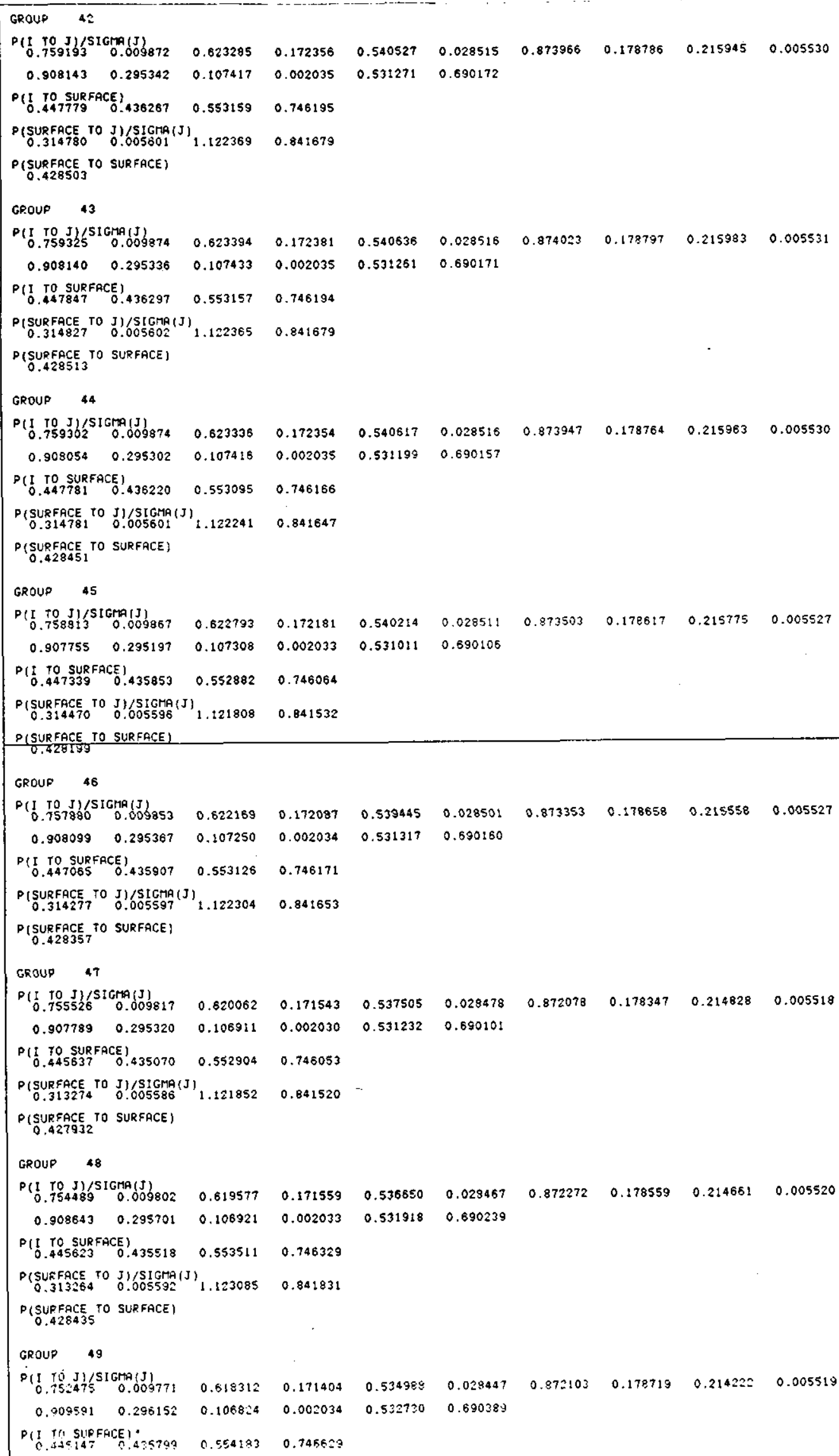


SNF-4503, Rev. 1

\section{WHC-SD-NR-SWD-017}

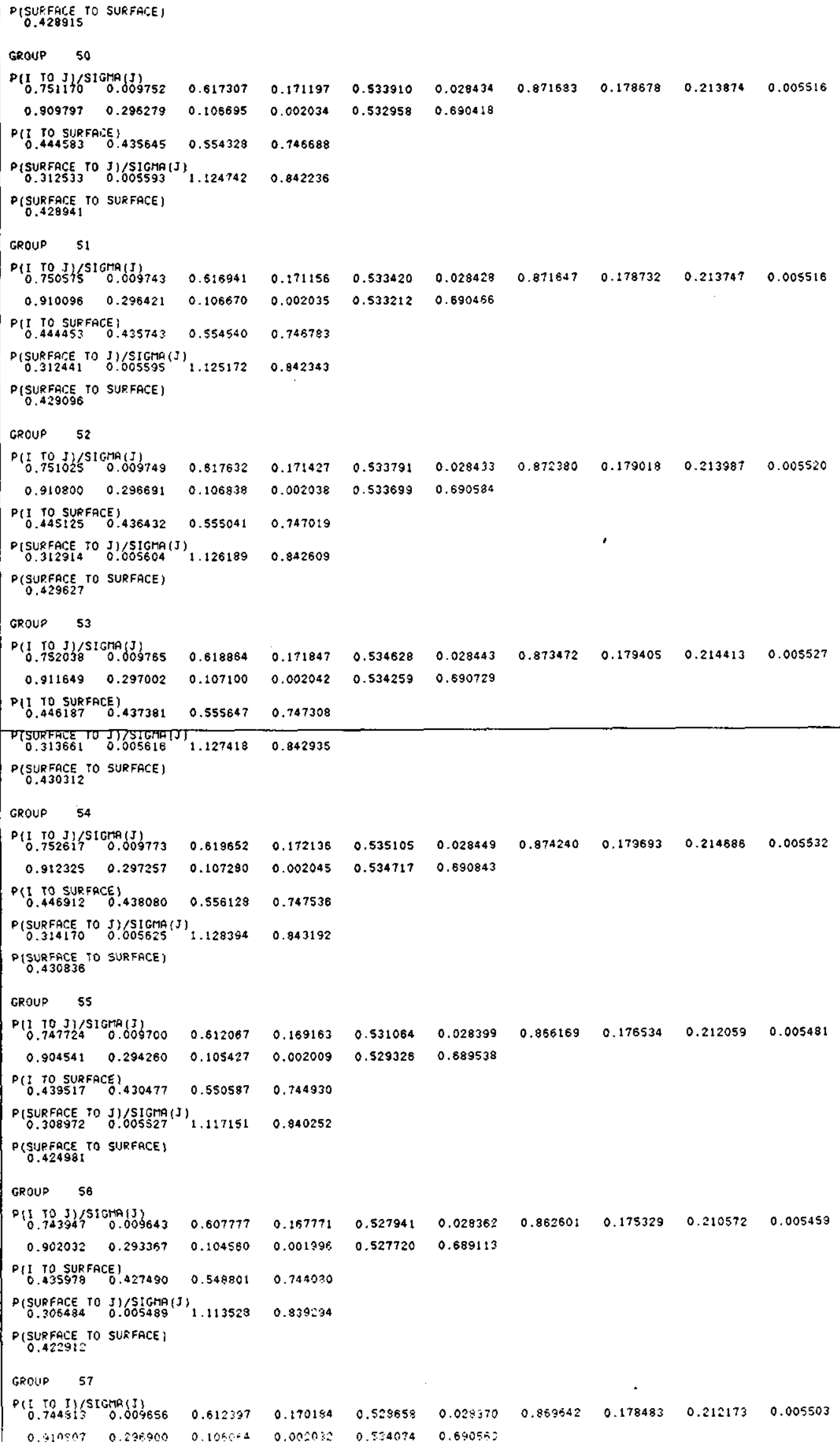


SNF-4503, Rev. 1

WHC-SD-NR-SWD-017

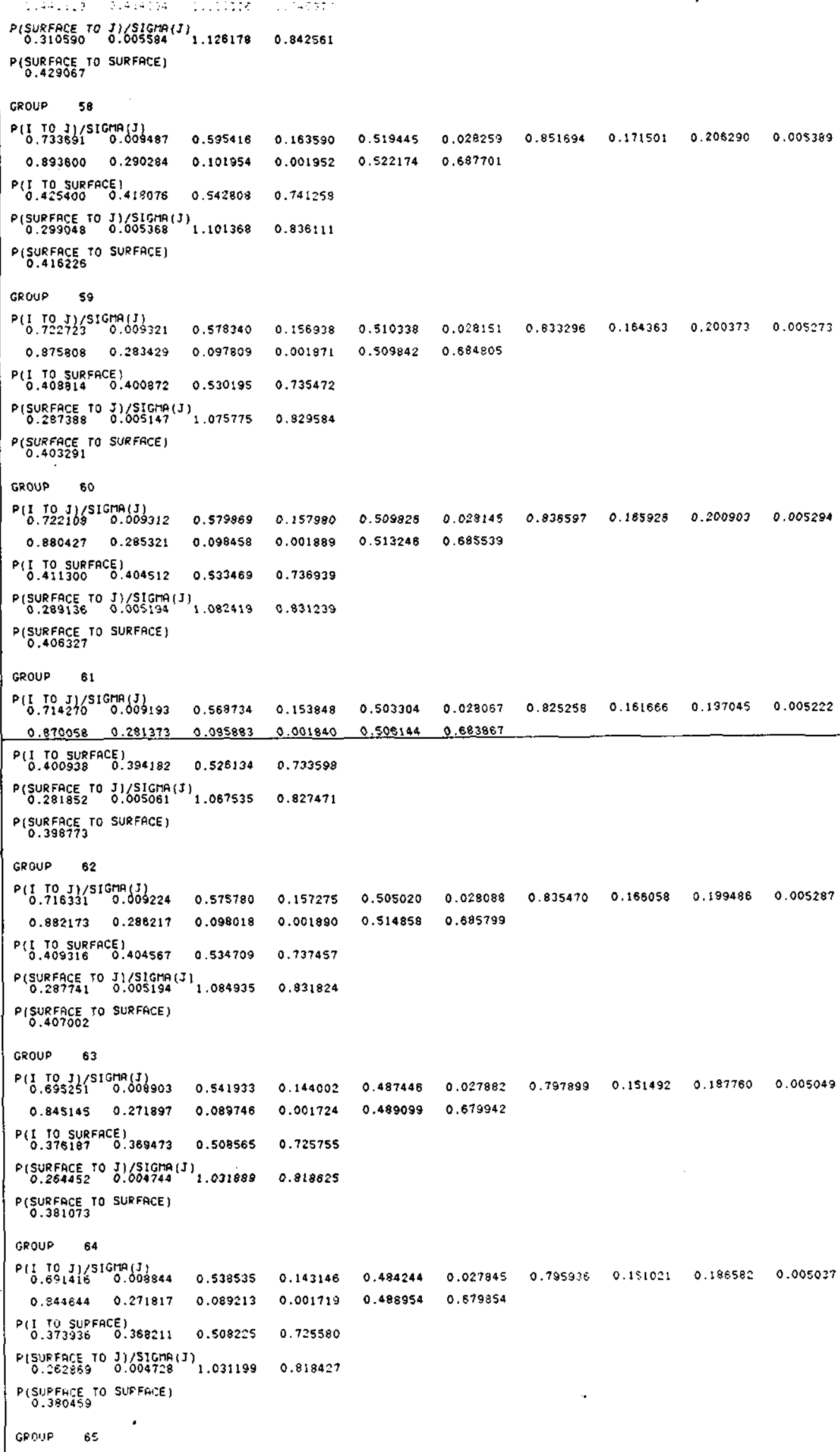


SNF-4503, Rev. 1

WHC-SD-NR-SWD-017

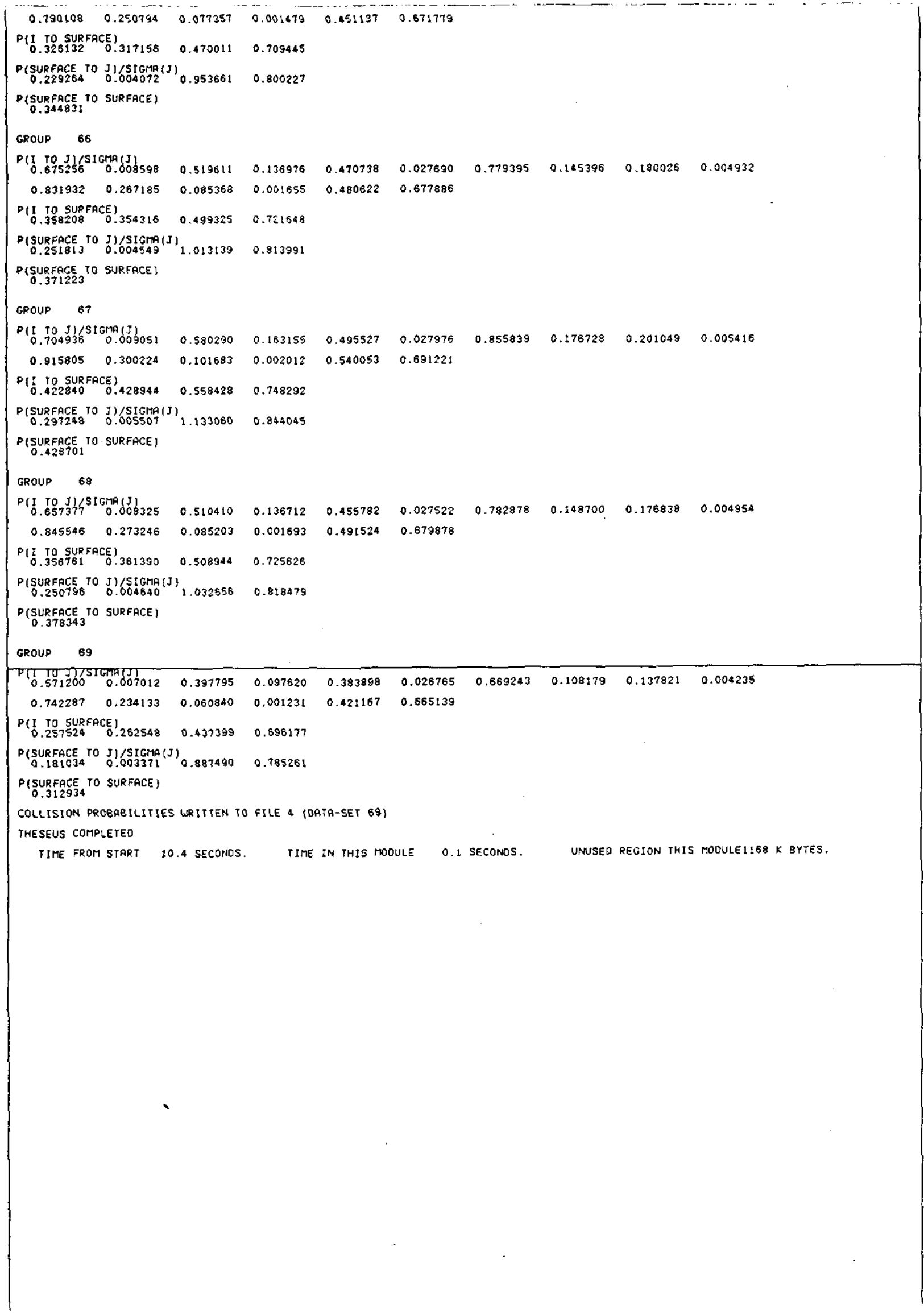

B-113

Attachment 1

1-164 
SNF-4503, Rev. 1

WHC-SD-NR-SWD-017

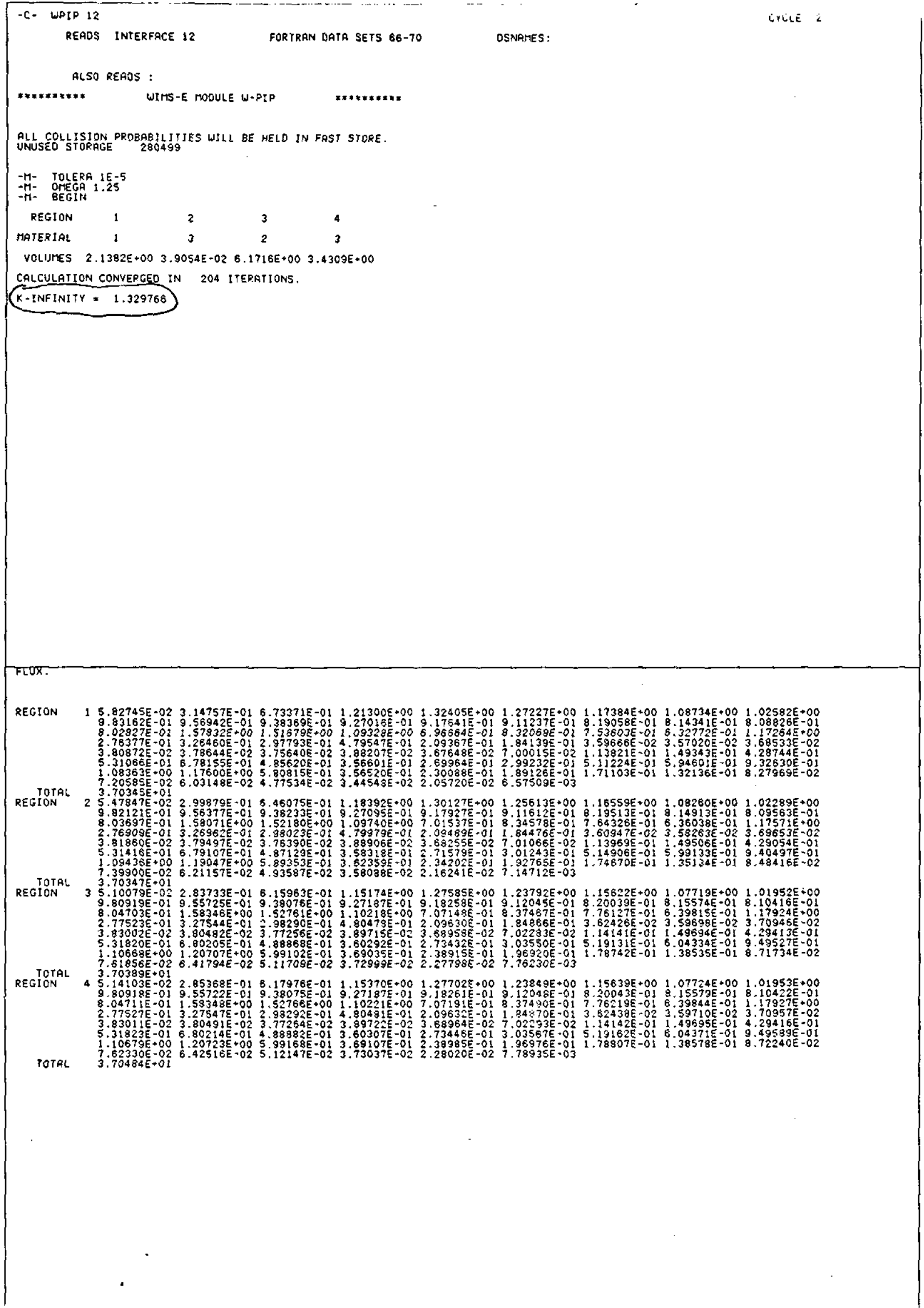

B-114

Attachment 1 
SNF-4503, Rev. 1

WHC-SD-NR-SWD-017

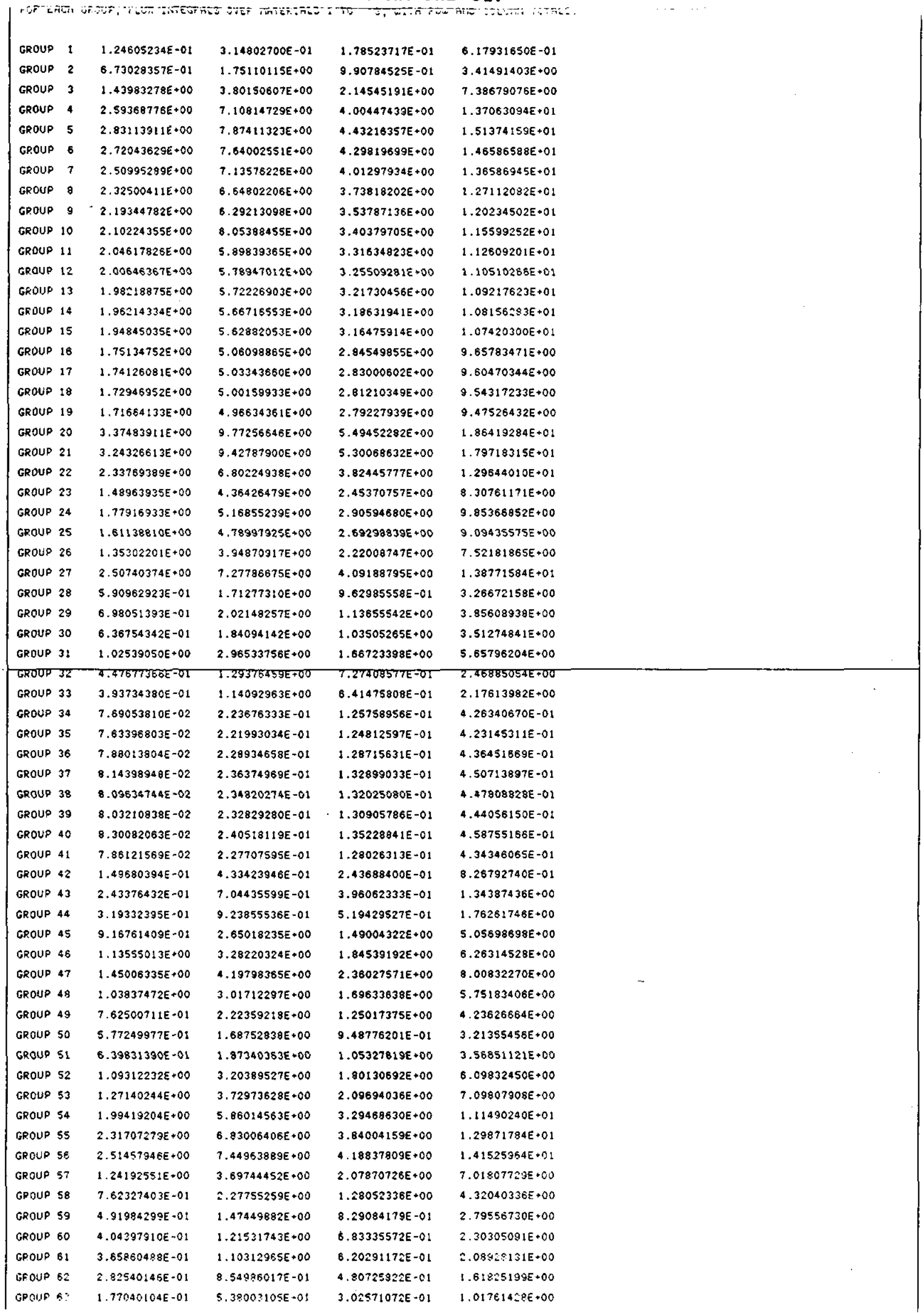


SNF-4503, Rev. 1

WHC-SD-NR-SWD-017

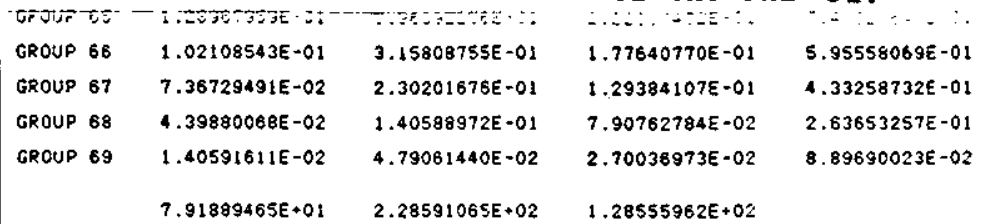
PIP COMPLETEO

TIME FROM START 11.0 SECONOS. TIME IN THIS MOOULE 0.6 SECONOS. UNUSEO REGION THIS MOOULEIO94 K OYTES.

-C- WCONO 128

READS INTERFACE 12

WRITES INTERFACE 8

FORTRAN DATA SETS $66-70$

FORTRAN DATA SETS $48-50$

ALSO READS :

$* * * * * * * * * \pi$
-P- GROUPS 9

SPACE AVAILABLE aLLOWS UP TO 99706 NUCLIDE TABULATIONS ON NEW INTERFACE

$\begin{array}{llllllll}-M- & \text { PART } 14 \quad 274547495254 \quad 5769\end{array}$

OETAILS OF CONDENSATION MATERIAL

$\frac{1}{2}$

WTMS-E MODULE W-CONOENSE

************

NEW FILE 4

MESHES 4

MATERIAL COOE ANO VOLUMES

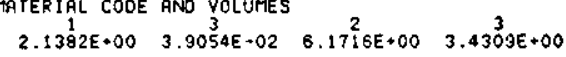

NEW FILE 2

NUCLIOE TRBULATIONS, 60

CROLISS NUCLIOES 11

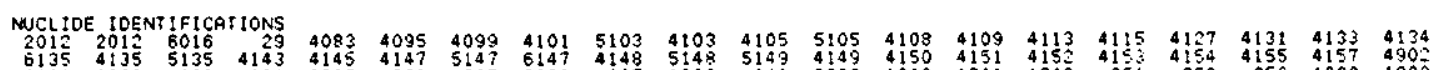

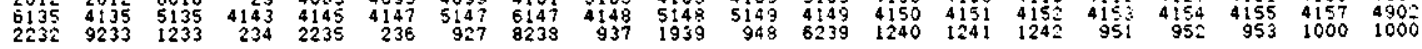

NEW FILE 3

MATERTALS
GFDUPS

NIMBEP DENSITIES PPINTEO IN MIX

\section{B-116}

Attachment 1 
SNF-4503, Rev. 1

WHC-SD-NR-SWD-017

CONGENSE COMFLETED

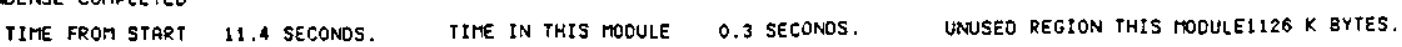

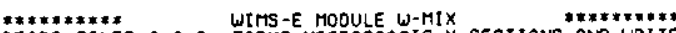

THESE TO FILE 3.

FLUXES ETC REOO FROM FILE I ANO WRITIEN TO FILE 5 .

\begin{tabular}{|c|c|c|c|c|}
\hline LN & -1 & & & \\
\hline CROSS-SECTIONS & 60 & & & \\
\hline GROUPS & 9 & & & \\
\hline MATERIRLS & 3 & & & \\
\hline NO. OF MATERIALS & TO BE P & ED AT A TIME 3 & & \\
\hline UNUSEO STORAGE & 298266 & ( IF MRTERIALS & PROCESSED SINGLY & 2991151 \\
\hline MATERIAL 1 & & $\begin{array}{r}\text { NUCLIDE } \\
1 \\
3 \\
3 \\
4 \\
5 \\
6 \\
7 \\
7 \\
8 \\
9 \\
10 \\
11 \\
12 \\
13 \\
14 \\
15 \\
16 \\
17 \\
18 \\
19 \\
20 \\
21 \\
21 \\
23 \\
24 \\
25 \\
2 \epsilon \\
27 \\
23 \\
23 \\
30 \\
31 \\
3 \hat{3} \\
30 \\
31\end{array}$ & $\begin{array}{r}\text { IOENT IFIER } \\
2012 \\
6015 \\
29 \\
4083 \\
4095 \\
4099 \\
4101 \\
5103 \\
4103 \\
4105 \\
5105 \\
4108 \\
4109 \\
4113 \\
4115 \\
4127 \\
4131 \\
4133 \\
4134 \\
6135 \\
4135 \\
5135 \\
4143 \\
4145 \\
4147 \\
5147 \\
6147 \\
4148 \\
5148 \\
5149 \\
4149 \\
4150 \\
4101\end{array}$ & 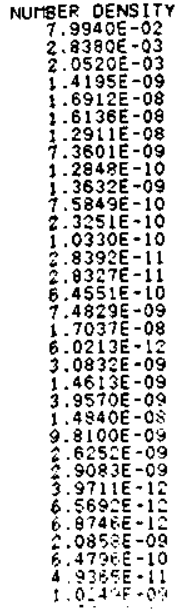 \\
\hline
\end{tabular}

B-117

Attachment 1

$1-168$ 


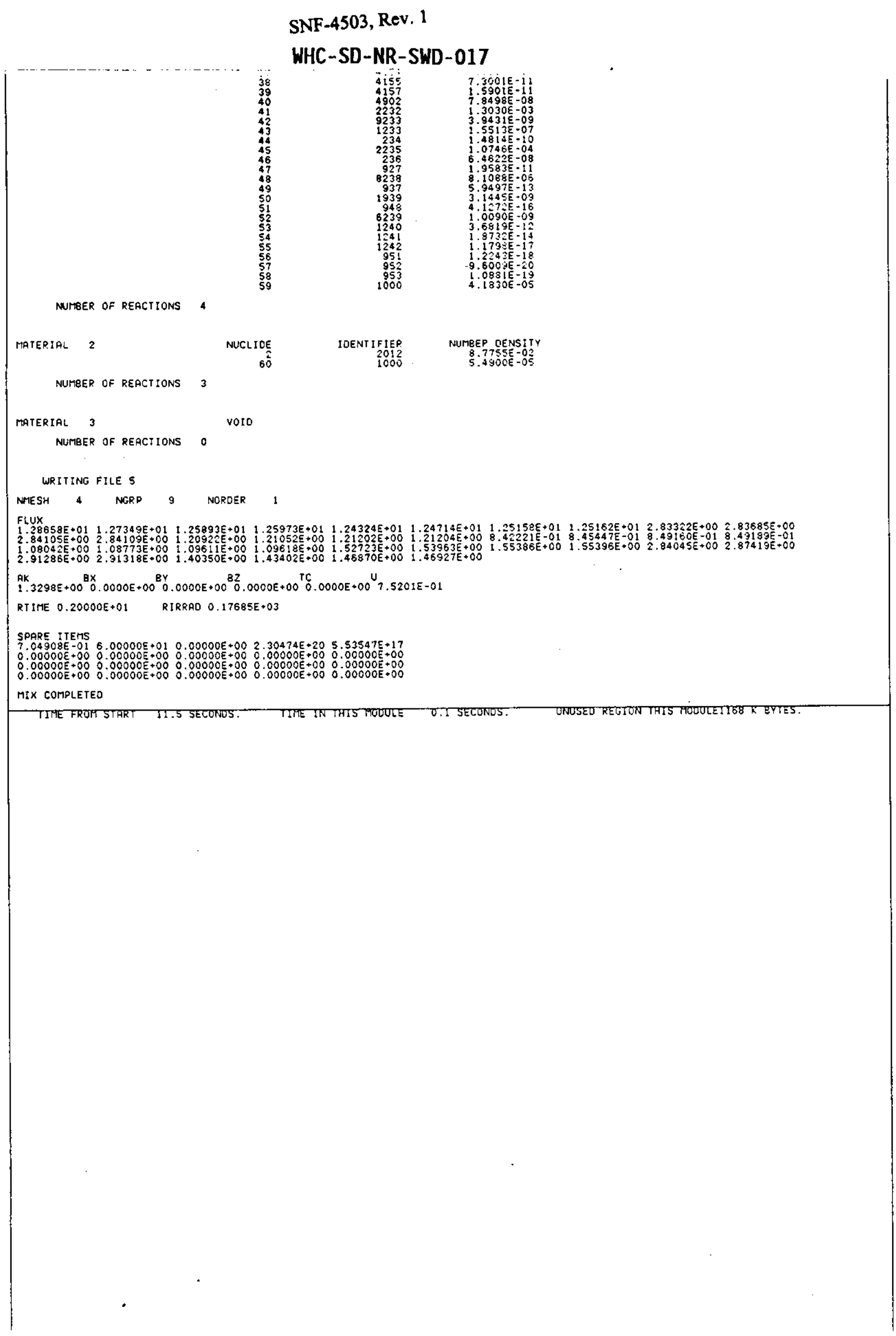

B-118

Attachment 1 
SNF-4503, Rev. 1

WHC-SD-NR-SWD-017

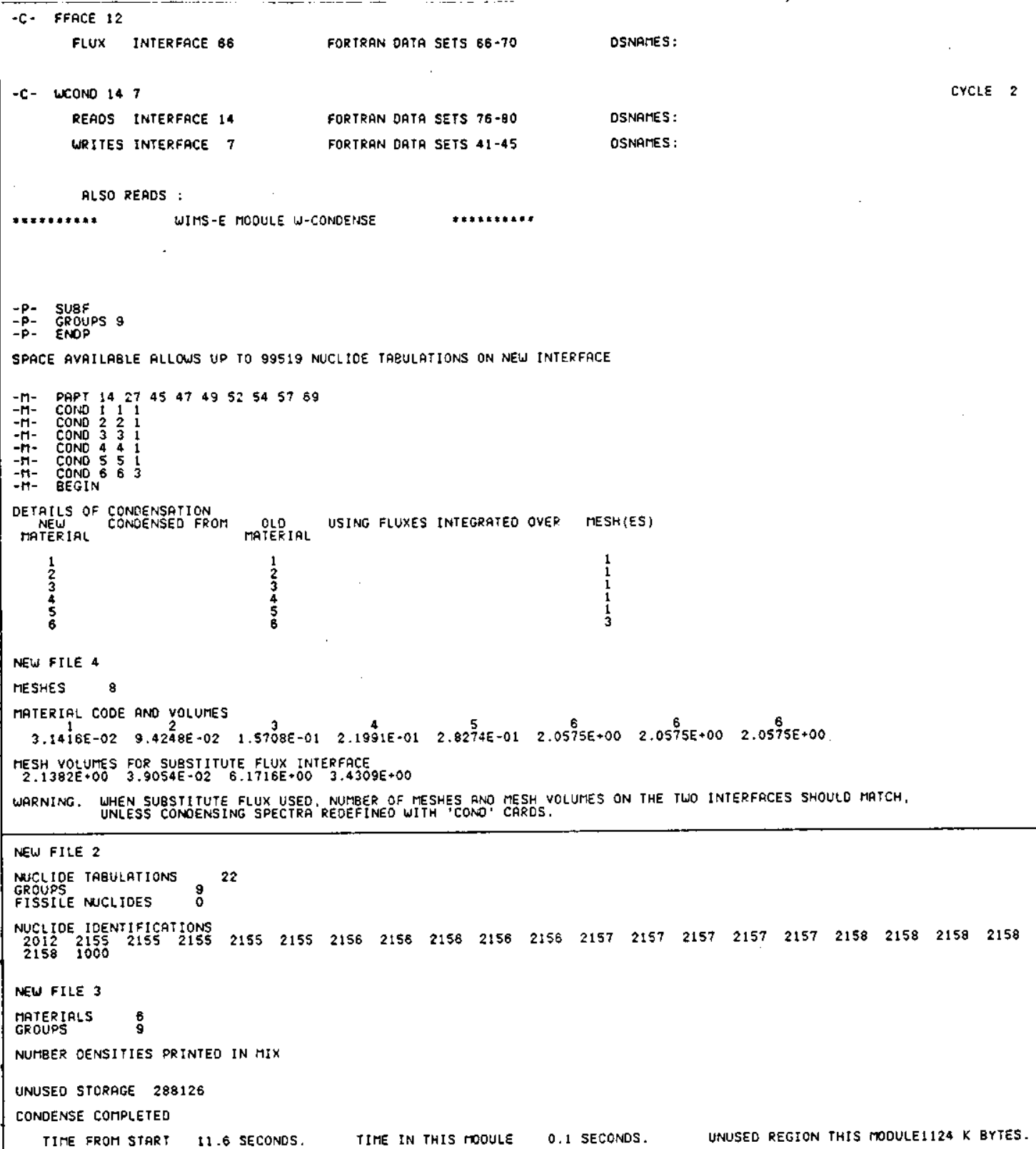


SNF-4503, Rev. 1

WHC-SD-NR-SWD-017

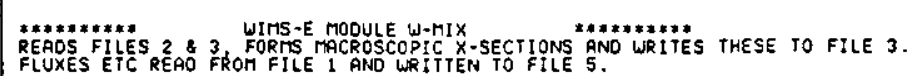

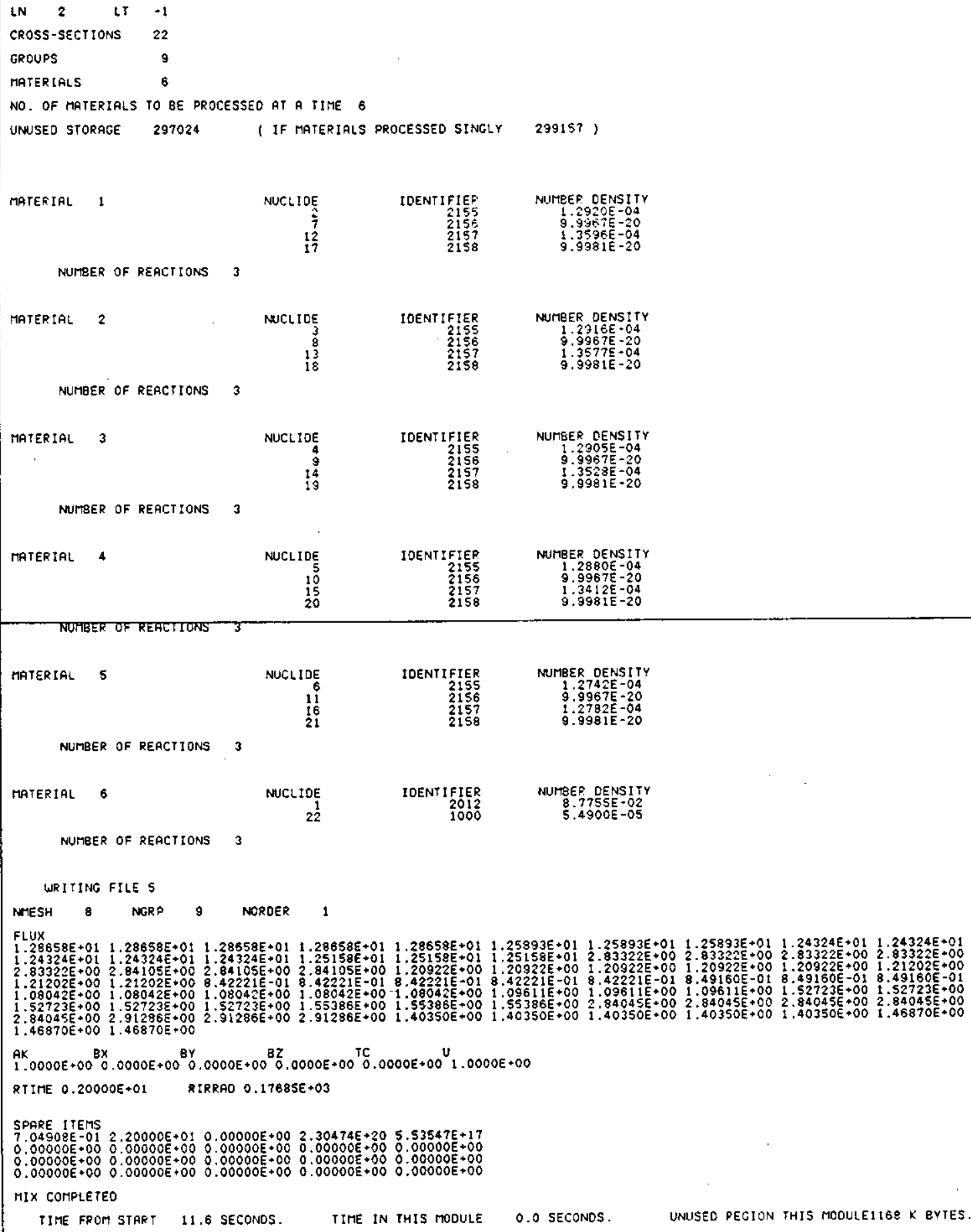


SNF-4503, Rev. 1

WHC-SD-NR-SWD-017

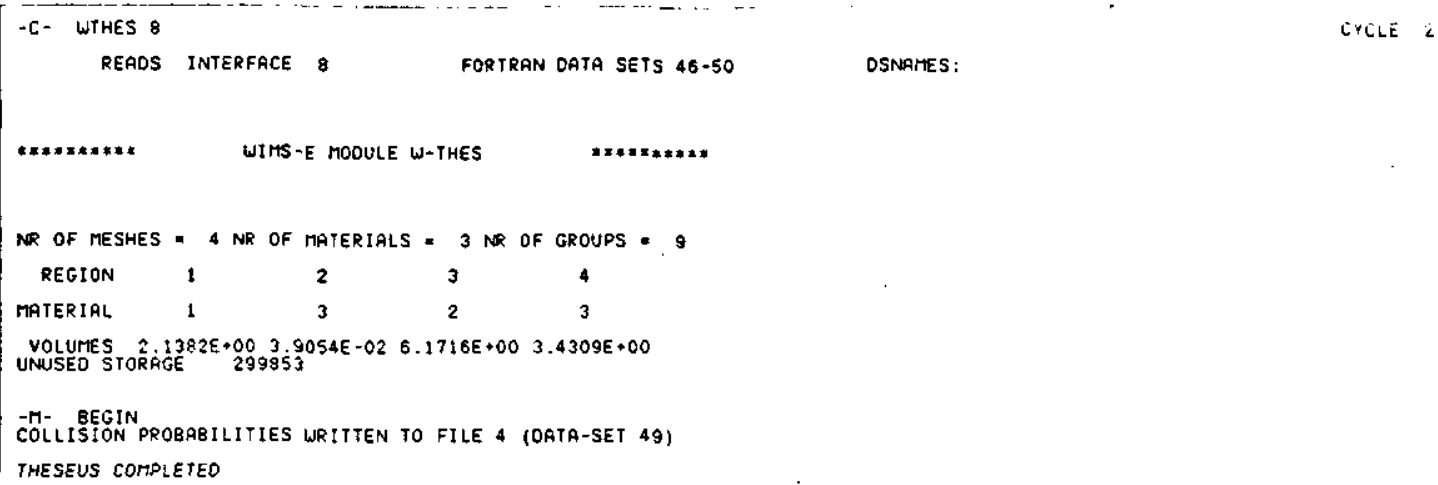


SNF-4503, Rev. 1

WHC-SD-NR-SWD-017

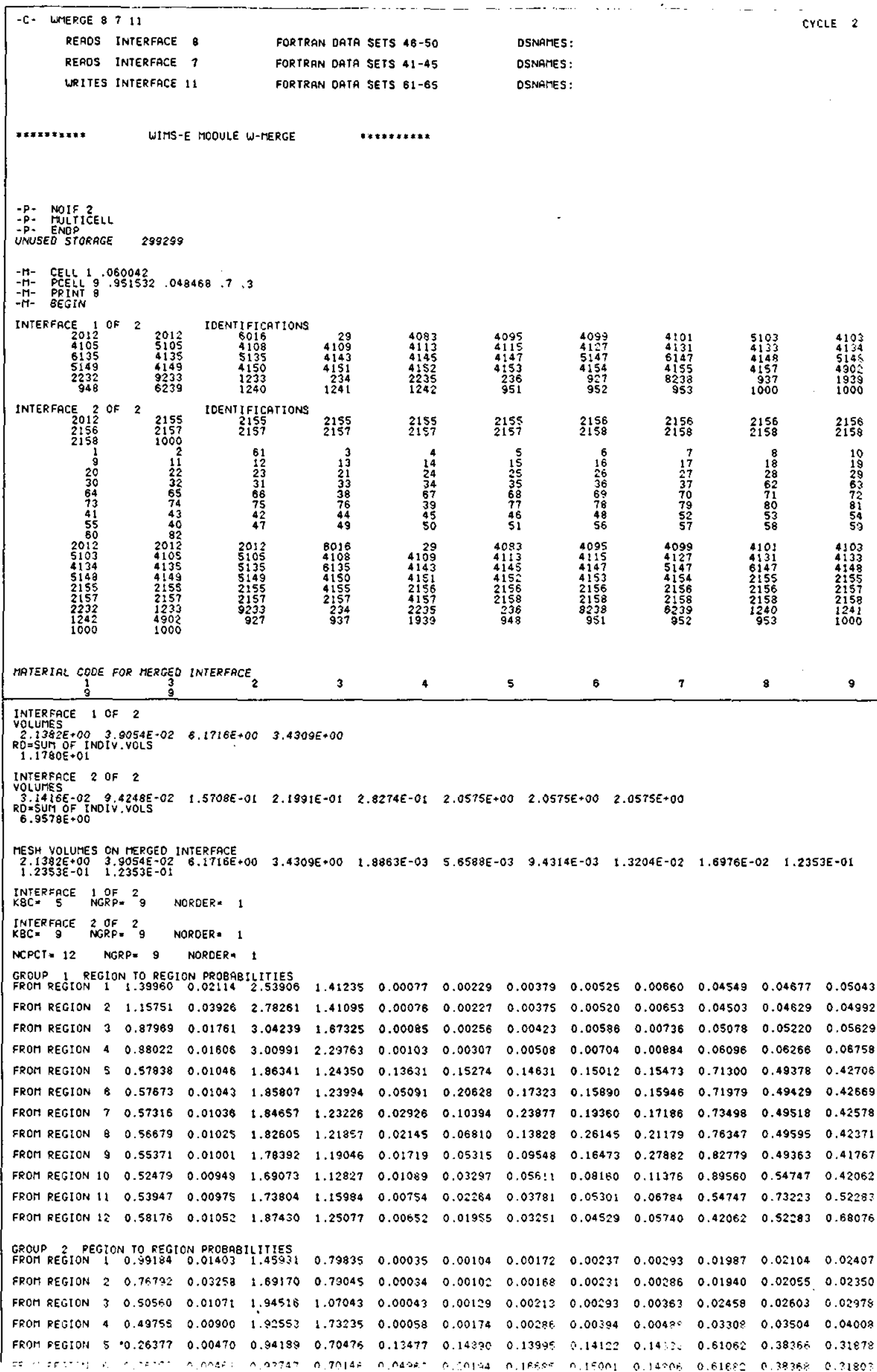

B-122

Attachment 1 
WHC-SD-NR-SWD-017

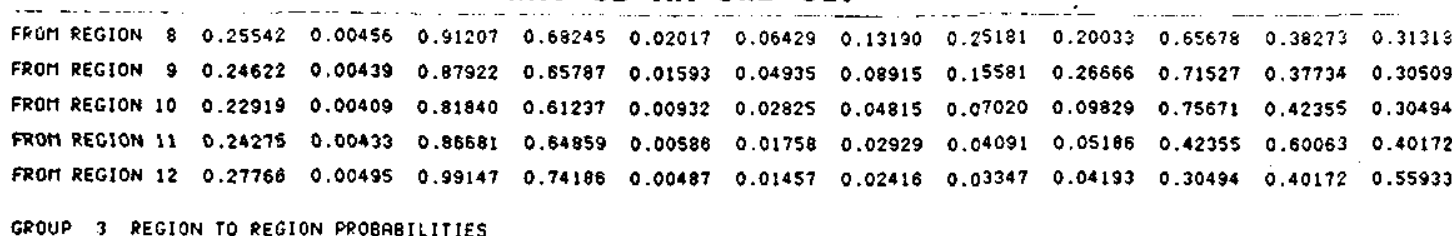
GROUP 3 REGION TO REGION PROBABILITIES

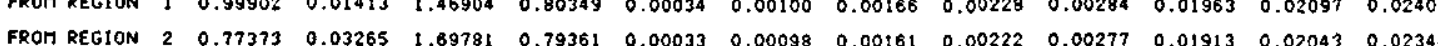
$\begin{array}{llllllllllllllll}\text { FROM REGION } 3 & 3 & 0.50897 & 0.01074 & 1.94764 & 1.07167 & 0.00041 & 0.00123 & 0.00204 & 0.00281 & 0.00350 & 0.02417 & 0.02581 & 0.02951\end{array}$ $\begin{array}{llllllllllllllll}\text { FROH REGION } & 4 & 0.50076 & 0.00903 & 1.92776 & 1.73382 & 0.00056 & 0.00168 & 0.00274 & 0.00378 & 0.00471 & 0.03251 & 0.03473 & 0.03384\end{array}$

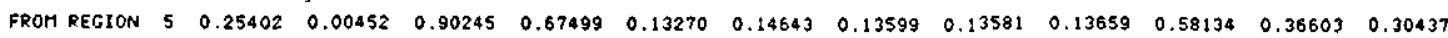
FROM REGION $6 \begin{array}{llllllllllllll} & 0.25257 & 0.00449 & 0.89728 & 0.67113 & 0.04881 & 0.19719 & 0.16275 & 0.14458 & 0.14133 & 0.58755 & 0.36598 & 0.30351\end{array}$

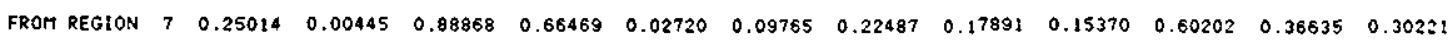
FROM PEGION $8 \begin{array}{llllllllllllll} & 0.24626 & 0.00438 & 0.87487 & 0.65436 & 0.01940 & 0.06196 & 0.12779 & 0.24302 & 0.19300 & 0.62923 & 0.36658 & 0.29990\end{array}$

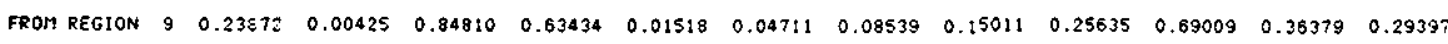

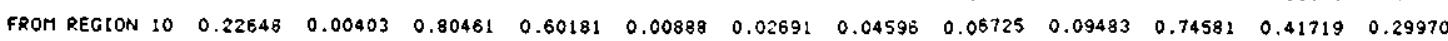

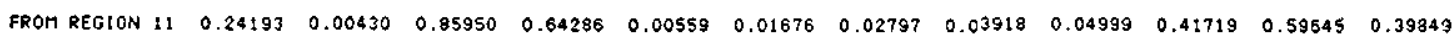
$\begin{array}{llllllllllllll}\text { FROH REGION } 12 & 0.27753 & 0.00494 & 0.98536 & 0.73745 & 0.00465 & 0.01390 & 0.02307 & 0.03206 & 0.04040 & 0.29970 & 0.39849 & 0.55646\end{array}$

GROUP 4 REGION TO REGION PROBABILITIES

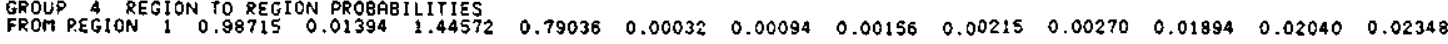

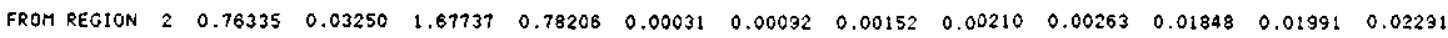
$\begin{array}{llllllllllllllll}\text { FROM REGION } 3 & 0.50089 & 0.01061 & 1.92992 & 1.06188 & 0.00039 & 0.00117 & 0.00193 & 0.00267 & 0.00334 & 0.02347 & 0.02528 & 0.02910\end{array}$ FROM REGION $4 \begin{array}{lllllllllllllll} & 0.49258 & 0.00890 & 1.91014 & 1.72433 & 0.00053 & 0.00158 & 0.00260 & 0.00360 & 0.00451 & 0.03167 & 0.03411 & 0.03926\end{array}$

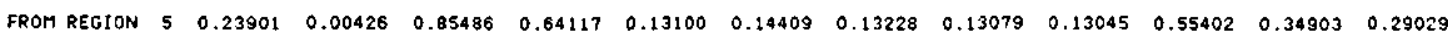
FROM REGION $6 \begin{array}{llllllllllllll} & 0 & 0.23744 & 0.00423 & 0.84923 & 0.63635 & 0.04803 & 0.19328 & 0.15890 & 0.13953 & 0.13516 & 0.56024 & 0.34896 & 0.28936\end{array}$ FROII REGION $\quad 7 \quad \begin{array}{llllllllllllll} & 0.23527 & 0.00419 & 0.84148 & 0.63114 & 0.02646 & 0.09534 & 0.21915 & 0.17357 & 0.14749 & 0.57526 & 0.34979 & 0.28842\end{array}$ FROM REGION $8 \begin{array}{llllllllllllll} & 0.23213 & 0.00414 & 0.83027 & 0.62273 & 0.01868 & 0.05980 & 0.12398 & 0.23574 & 0.18632 & 0.60369 & 0.35114 & 0.28704\end{array}$ FROM REGION $9 \begin{array}{llllllllllllll} & 0.22633 & 0.00403 & 0.80951 & 0.60716 & 0.01449 & 0.04505 & 0.08194 & 0.14492 & 0.24801 & 0.66699 & 0.35080 & 0.28314\end{array}$

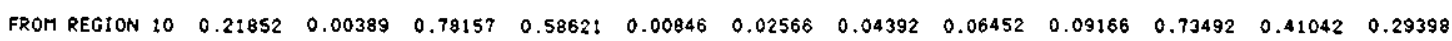

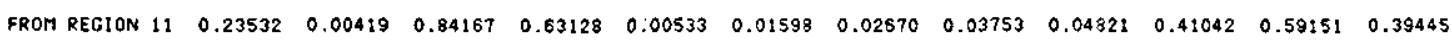

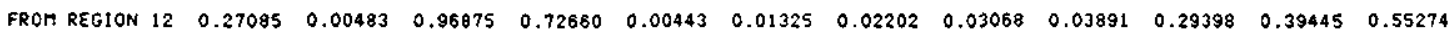

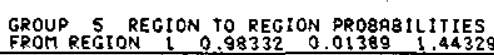

FROM REOION $2 \quad 0.760590 .03247 \quad 1.67834$ $\begin{array}{lllllllllllllllll}\text { FROM REGION } & 3 & 0.50005 & 0.01062 & 1.93384 & 1.06378 & 0.00035 & 0.00105 & 0.00174 & 0.00243 & 0.00309 & 0.02277 & 0.02495 & 0.02885\end{array}$ $\begin{array}{lllllllllllllll}\text { FROM REGION } & 4 & 0.49180 & 0.00891 & 1.91356 & 1.72533 & 0.00048 & 0.00142 & 0.00235 & 0.00327 & 0.00417 & 0.03069 & 0.03363 & 0.03988\end{array}$

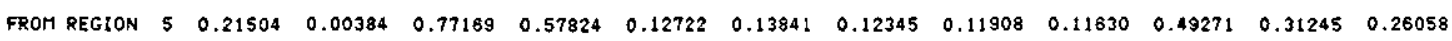

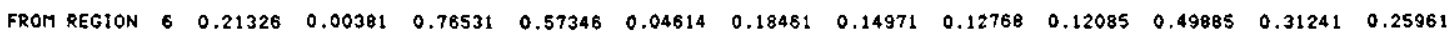
FROM REGION $7 \begin{array}{llllllllllllll}7 & 0.21178 & 0.00378 & 0.75999 & 0.56947 & 0.02489 & 0.08983 & 0.20653 & 0.16100 & 0.13302 & 0.51521 & 0.31451 & 0.25970\end{array}$

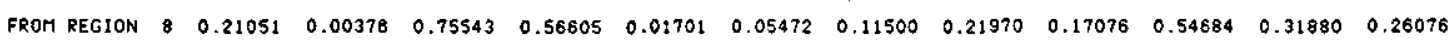
FROM REGTON $9 \begin{array}{llllllllllllll} & 0.20884 & 0.00373 & 0.74944 & 0.56158 & 0.01292 & 0.04028 & 0.07390 & 0.13281 & 0.22951 & 0.61875 & 0.32480 & 0.26210\end{array}$

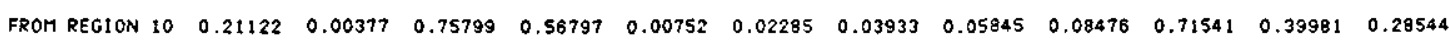

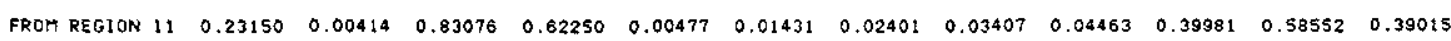

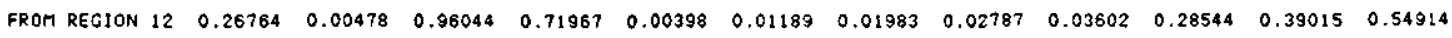

GROUP BR REGION TO REGION PROBABILITIES

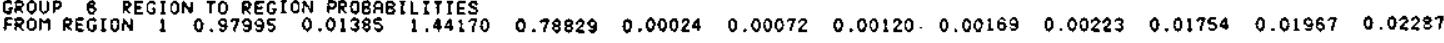
$\begin{array}{llllllllllllllll}\text { FROM REGION } & 2 & 0.75822 & 0.03245 & 1.68011 & 0.78370 & 0.00024 & 0.00071 & 0.00117 & 0.00186 & 0.00218 & 0.01719 & 0.01928 & 0.02242\end{array}$

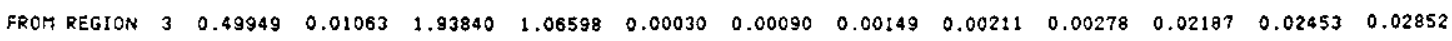
FROM REGION $4 \begin{array}{lllllllllllll}4 & 0.49129 & 0.00892 & 1.91753 & 1.72851 & 0.00041 & 0.00121 & 0.00201 & 0.00284 & 0.00374 & 0.02945 & 0.03303 & 0.03840\end{array}$

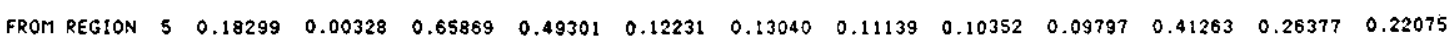
FROM REGION $B \begin{array}{lllllllllllll} & 0.18122 & 0.00324 & 0.65231 & 0.48824 & 0.04347 & 0.17347 & 0.13710 & 0.11185 & 0.10223 & 0.41861 & 0.26393 & 0.21994\end{array}$ FROM REGION $7 \begin{array}{llllllllllllll}7 & 0.18098 & 0.00324 & 0.65146 & 0.48760 & 0.02228 & 0.08226 & 0.19055 & 0.14421 & 0.11411 & 0.43676 & 0.28796 & 0.22168\end{array}$

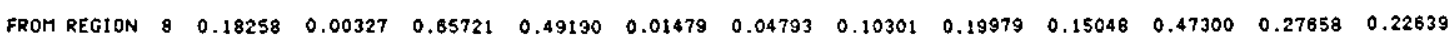

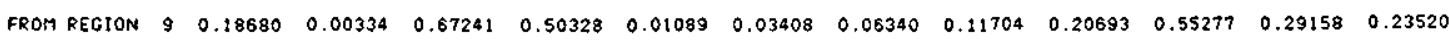

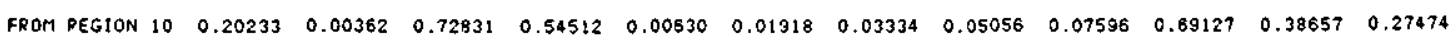

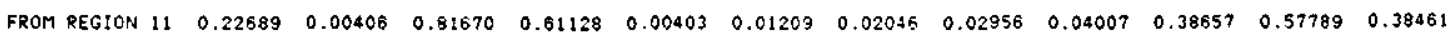

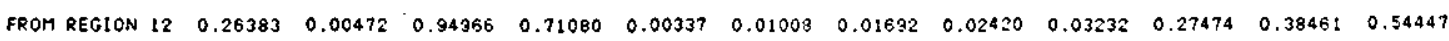

GROUP 7 REGION TO PEGION PROBABILITIES
FROM REGION 1 T $0.983300 .01390 \quad 1.44894$ FROM REGION $2 \begin{array}{lllllllllllll}2 & 0.36127 & 0.03250 & 1.68715 & 0.78739 & 0.00016 & 0.00048 & 0.00082 & 0.00121 & 0.00175 & 0.01606 & 0.01873 & 0.02201\end{array}$ FROM REGION $3 \begin{array}{lllllllllllllll}3 & 0.50201 & 0.01068 & 1.94470 & 1.06897 & 0.00020 & 0.00051 & 0.00104 & 0.00154 & 0.00222 & 0.02039 & 0.02379 & 0.02795\end{array}$ $\begin{array}{lllllllllllllllll}\text { FROM PEGLON } 4 & 0.49365 & 0.00896 & 1.92289 & 1.72847 & 0.00027 & 0.0005 & 0.00139 & 0.00207 & 0.00299 & 0.02742 & 0.03198 & 0.03757\end{array}$

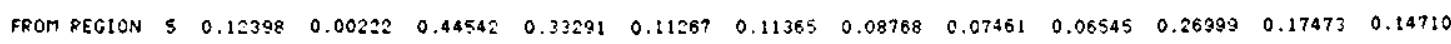

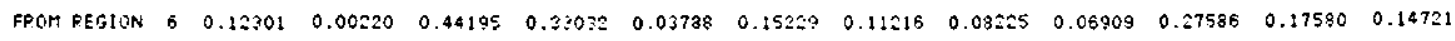

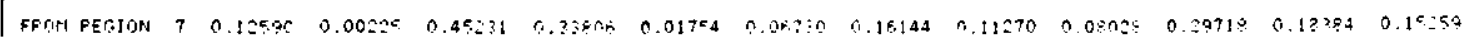


SNF-4503, Rev. 1

WHC-SD-NR-SWD-017

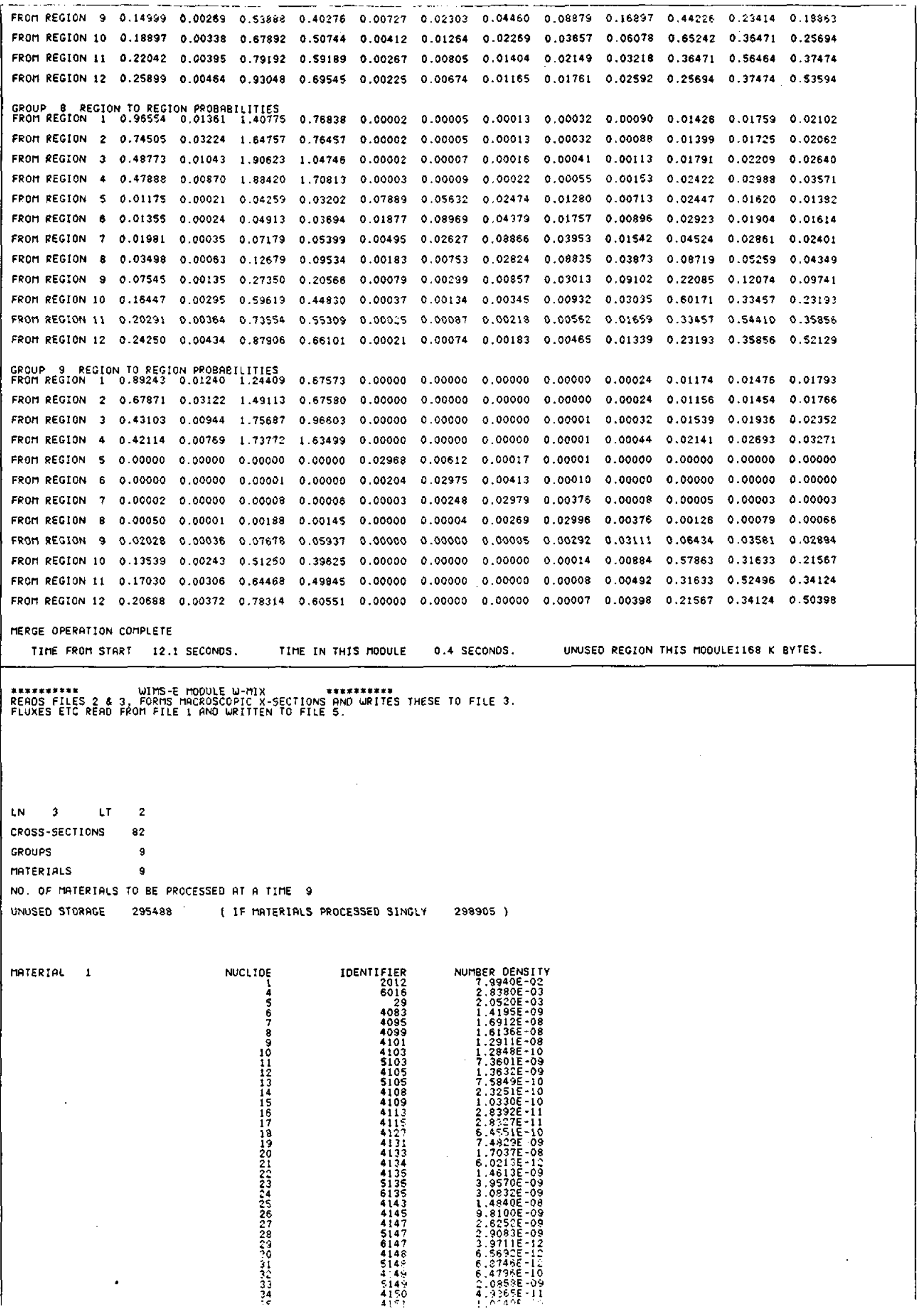

B-124

Attachment 1

1-175 
SNF-4503, Rev. 1

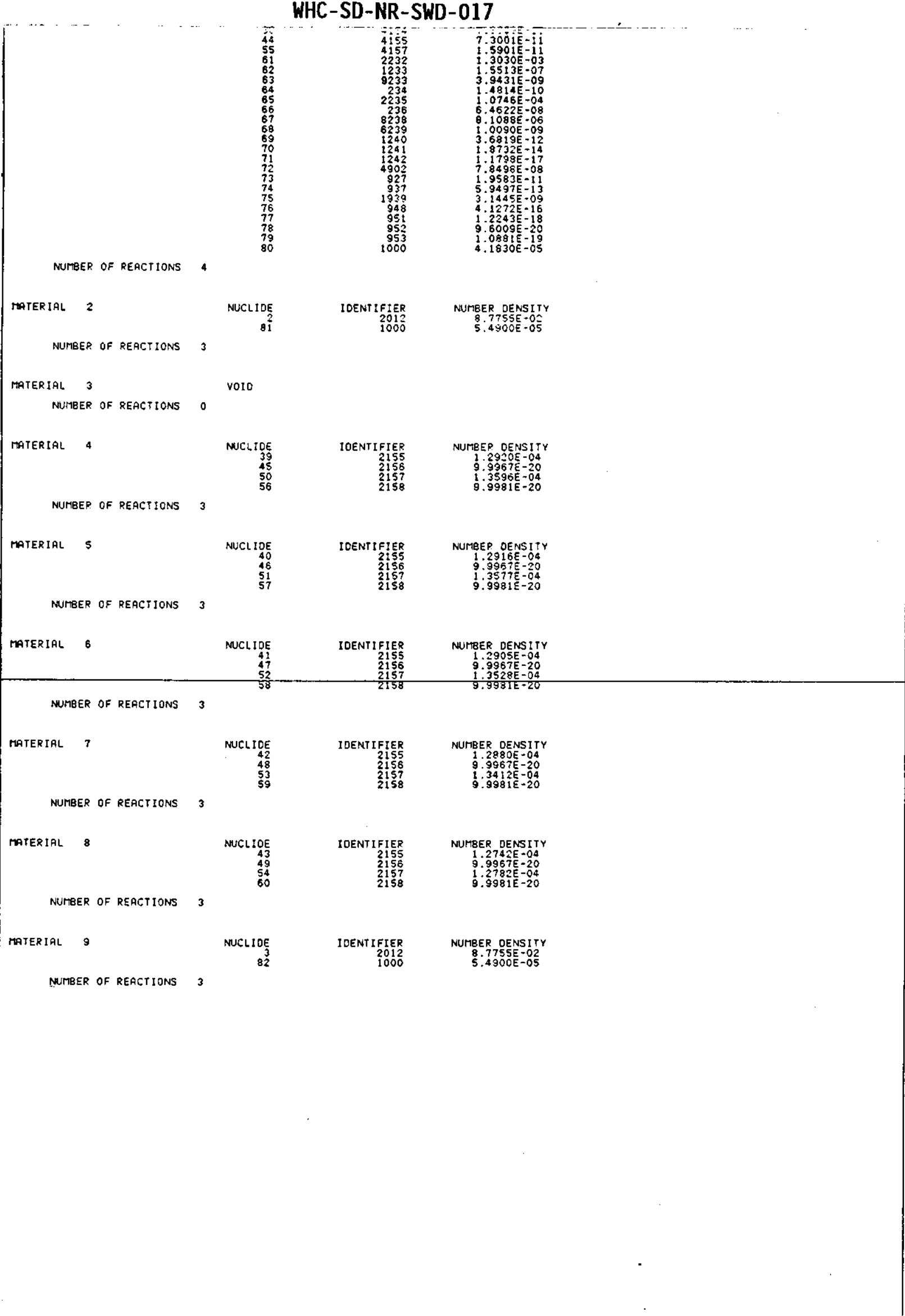

\section{B-125}

Attachment I 
SNF-4503, Rev. 1

WHC-SD-NR-SWD-017

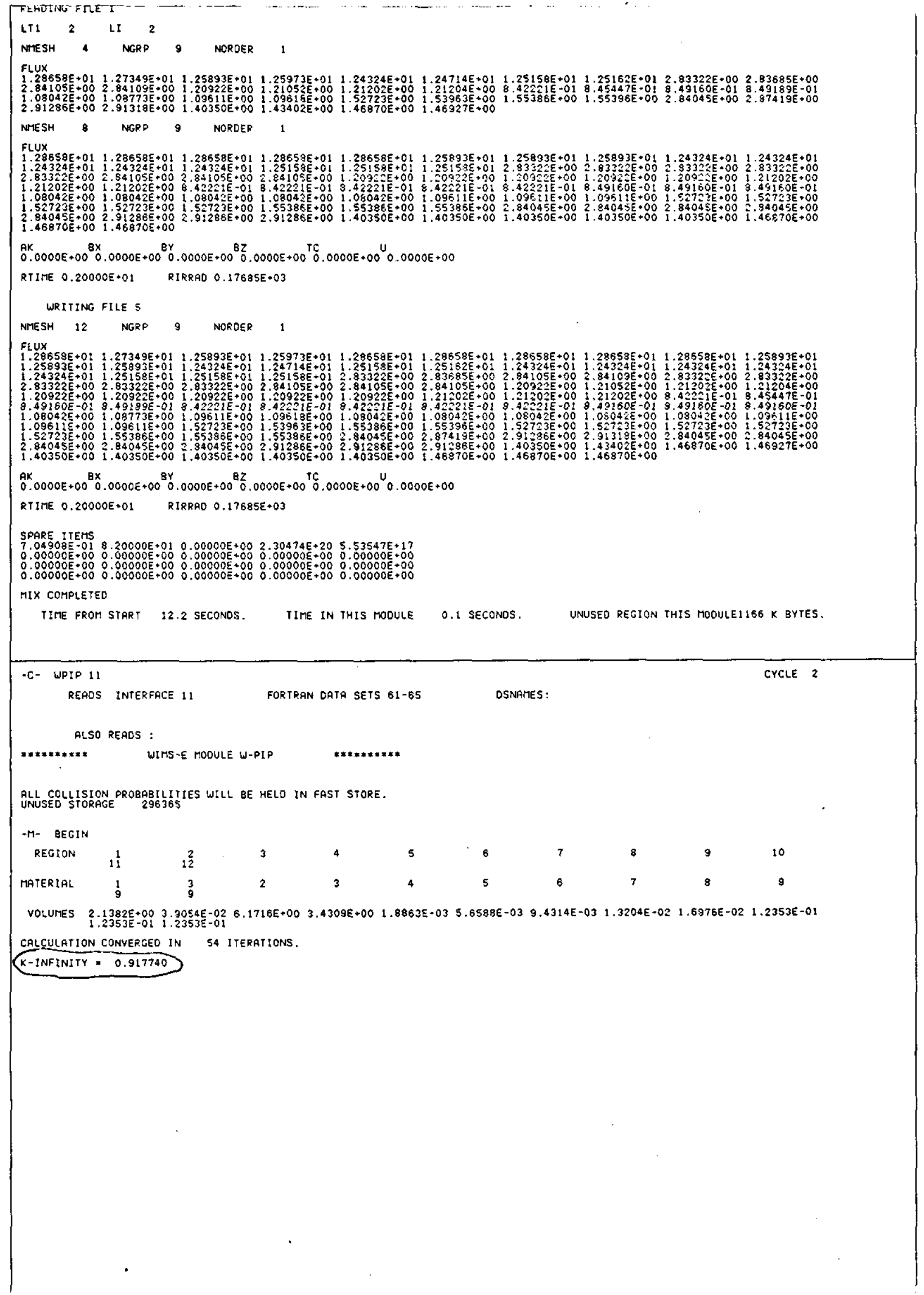

\section{B-126}

Attachment 1 


\section{WHC-SD-NR-SWD-017}

REGION $11.20882 E+01 \quad 1.17558 E+01 \quad 2.54220 E+00 \quad 9.78010 E-01 \quad 6.24762 E-01 \quad 7.54353 E-01 \quad 1.00530 E+001.75797 E+00 \quad 8.28719 E-01$

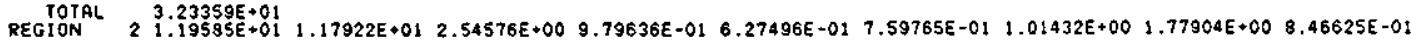
$\begin{array}{lllllllll}\text { TOTAL } & 3.23034 E+01 & 1.18347 E+01 & 2.54918 E+00 & 9.80930 E-01 & 8.29948 E-01 & 7.64699 E-01 & 1.02144 E+00 & 1.79705 E+00 \quad 8.63919 E-01\end{array}$

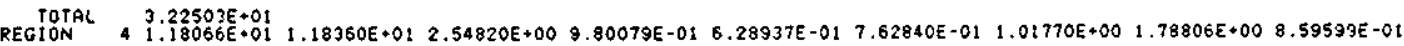

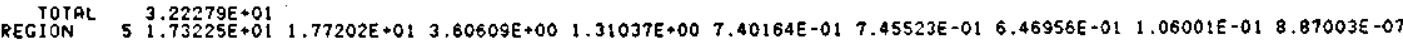

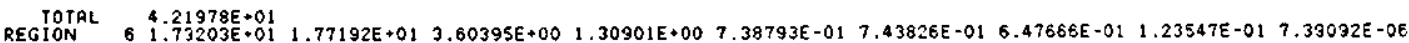

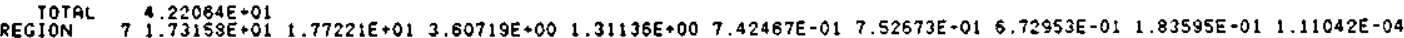

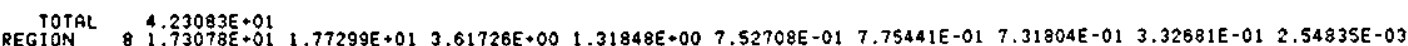

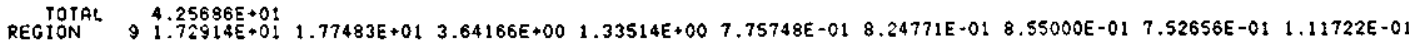

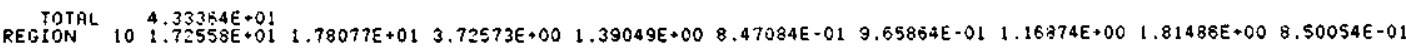

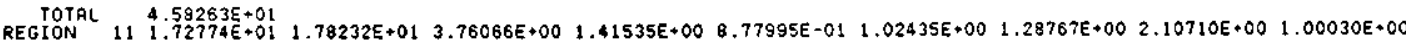

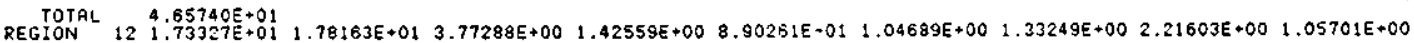
TOTAL $\quad 4.68901 E+01$

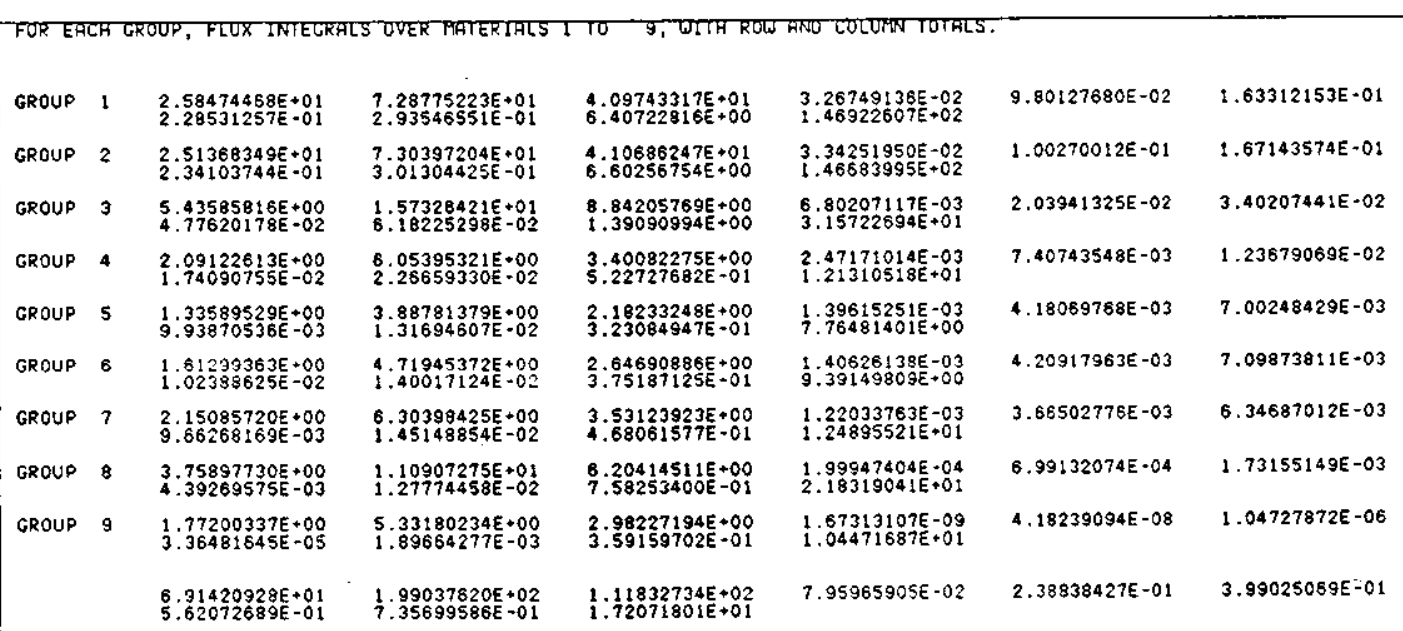

PIP COMPLETEO TIME FROM START 12.3 SECONDS. TIME IN THIS MOOULE 0.1 SECONOS. UNUSED REGION THIS MODULEIIS8 K BYTES. 
SNF-4503, Rev. 1

WHC-SD-NR-SWD-017

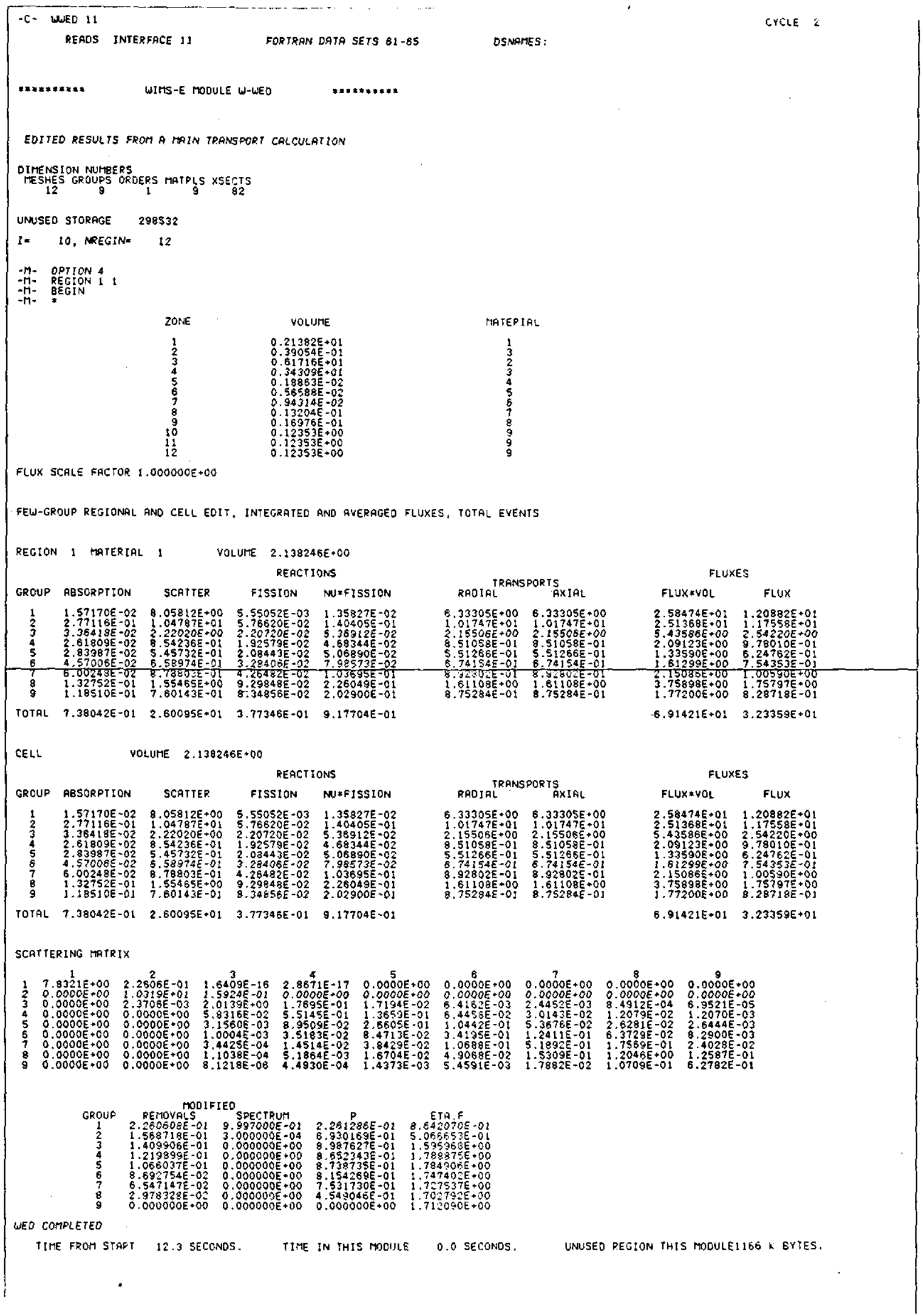


SNF-4503, Rev. 1

WHC-SD-NR-SWD-017

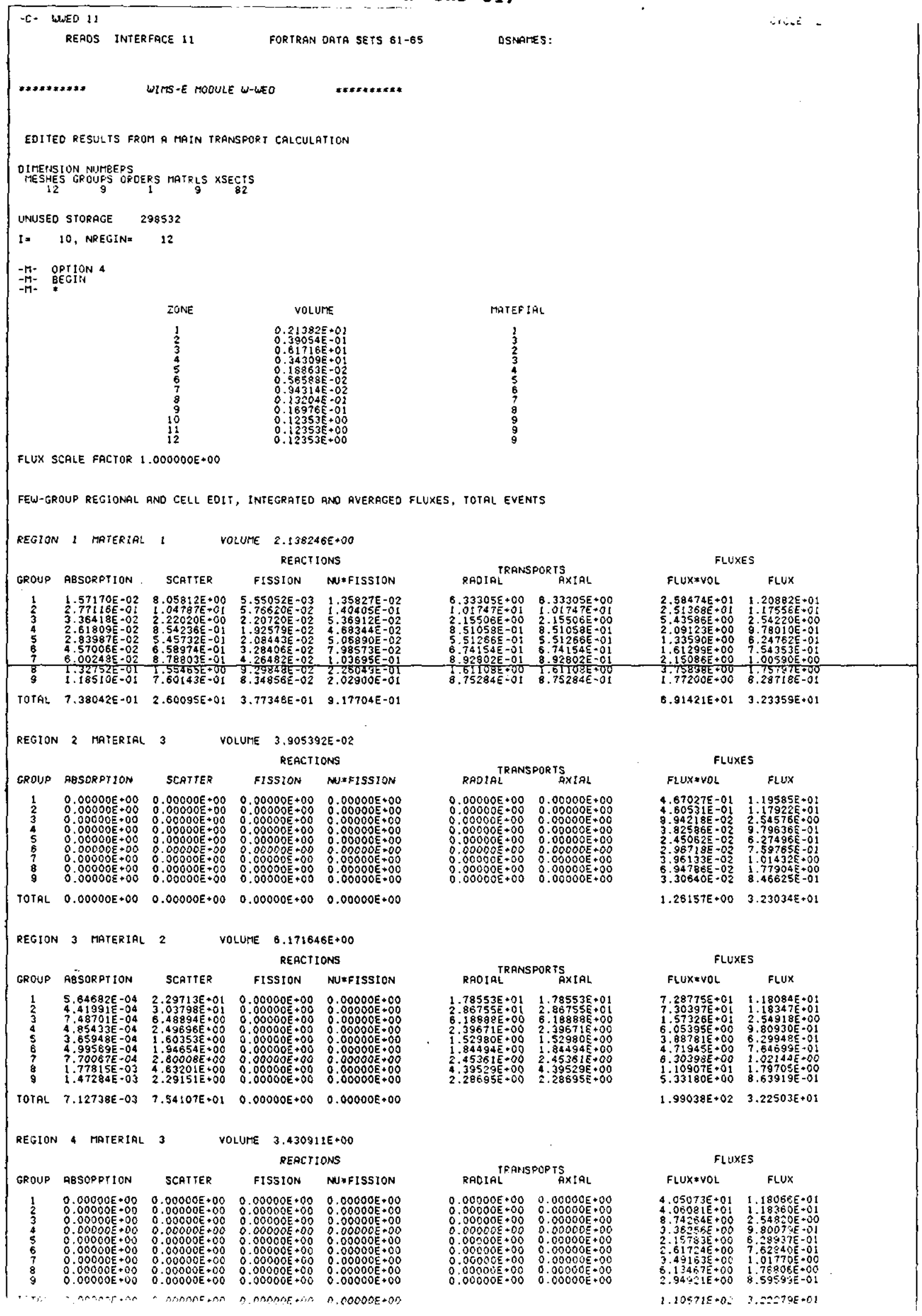


SNF-4503, Rev. 1

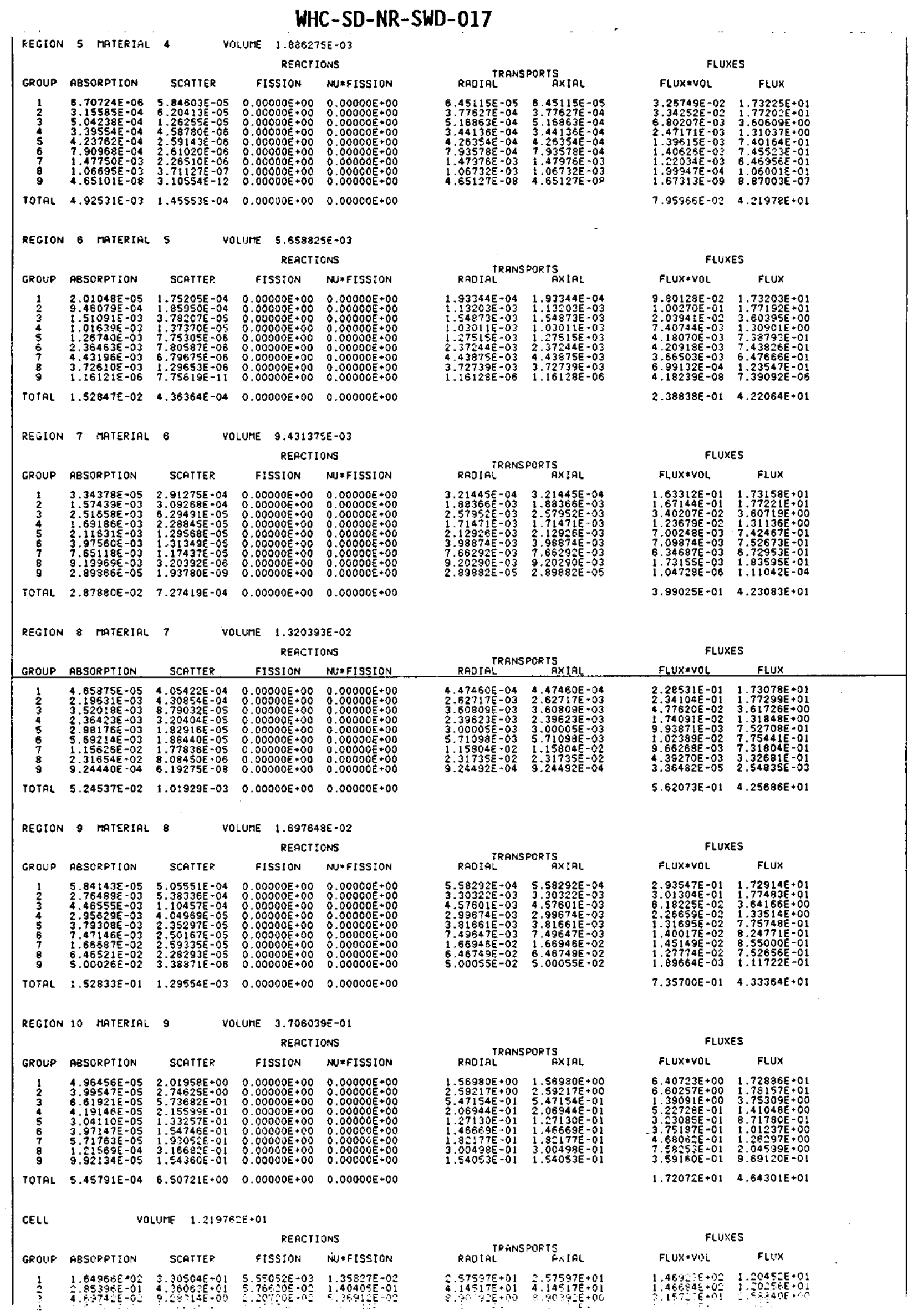


SNF-4503, Rev. 1

WHC-SD-NR-SWD-017

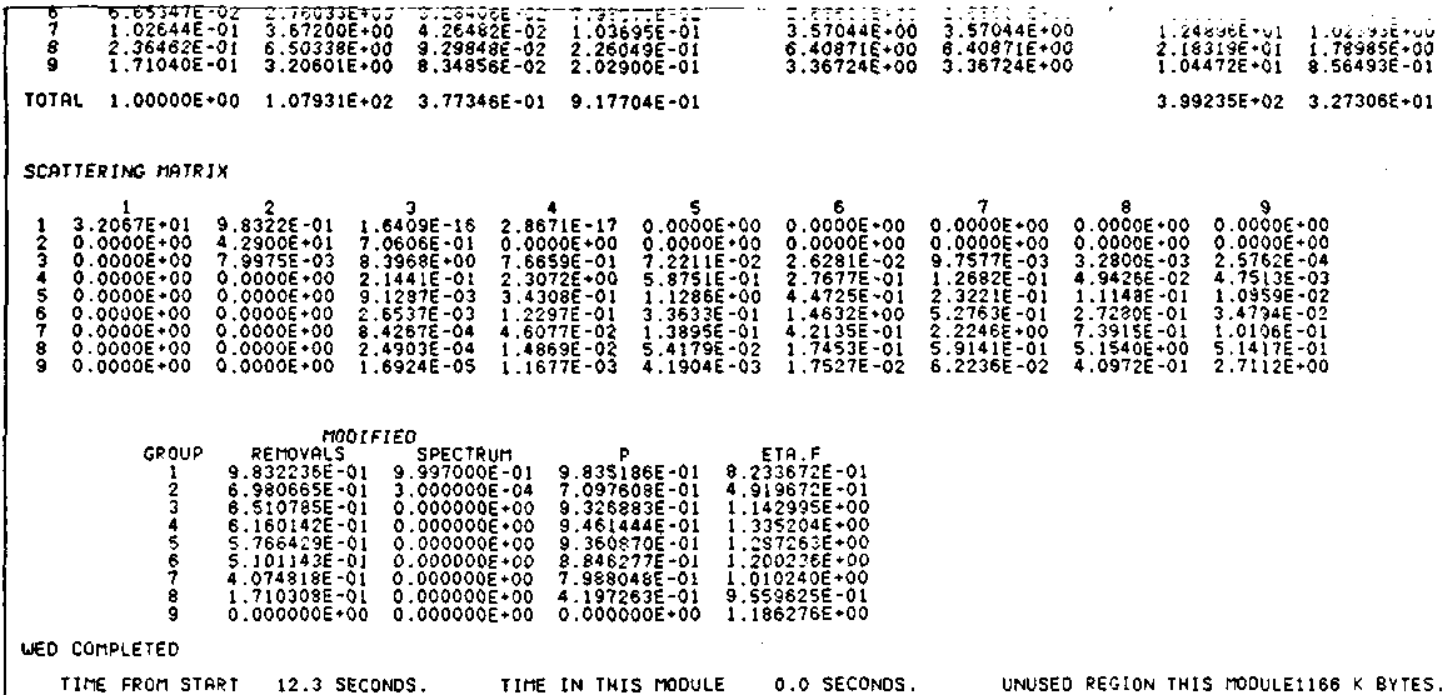

-C- FINISH

ENO OF CYCLE 2

-C- WhIRE 11

READS INTERFACE 11 FORTRAN OATA SETS 61 -65 OSNAMES:

B-131

Attachment 1 
SNF-4503, Rev. 1

WHC-SD-NR-SWD-017

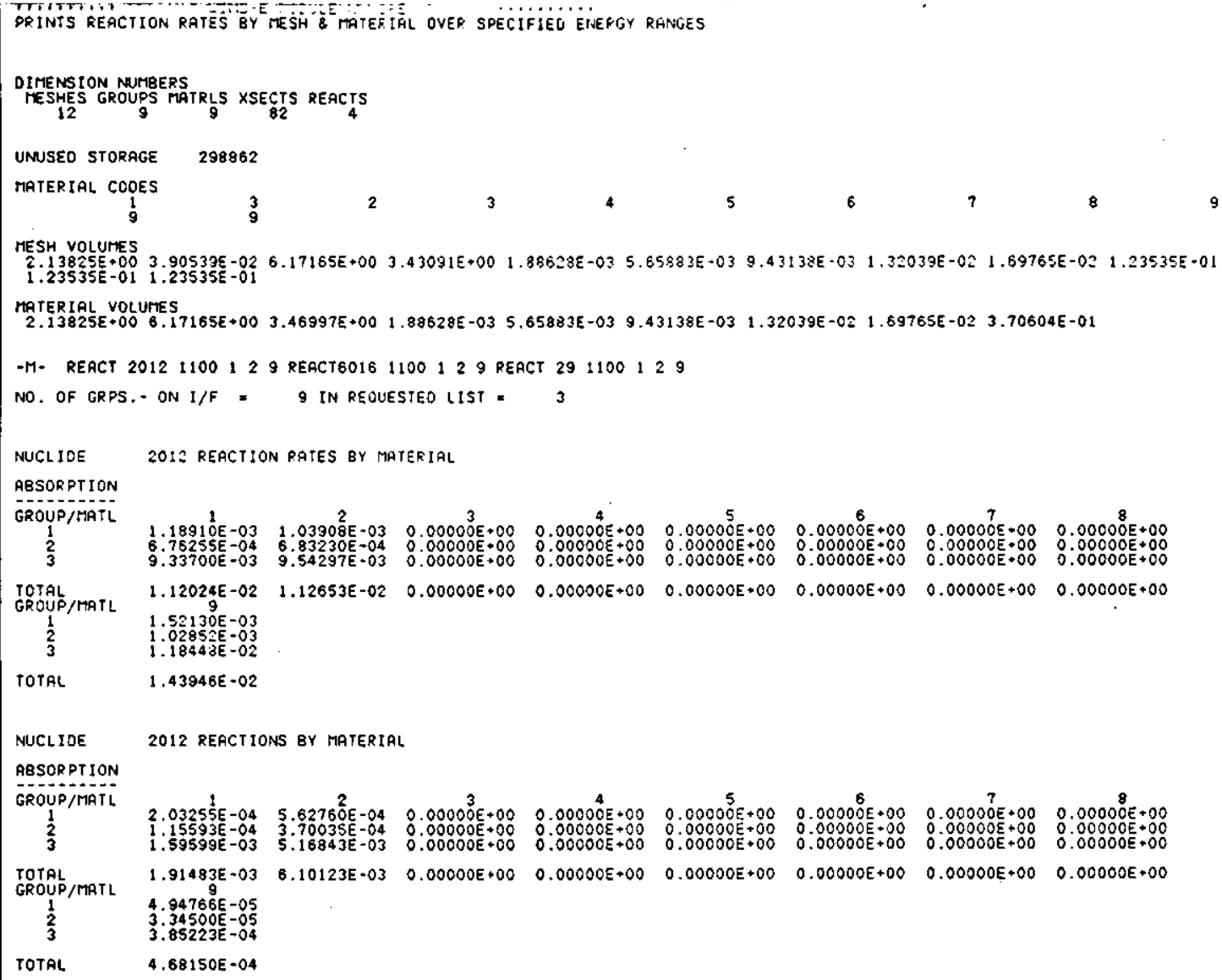


SNF-4503, Rev. 1

WHC-SD-NR-SWD-017

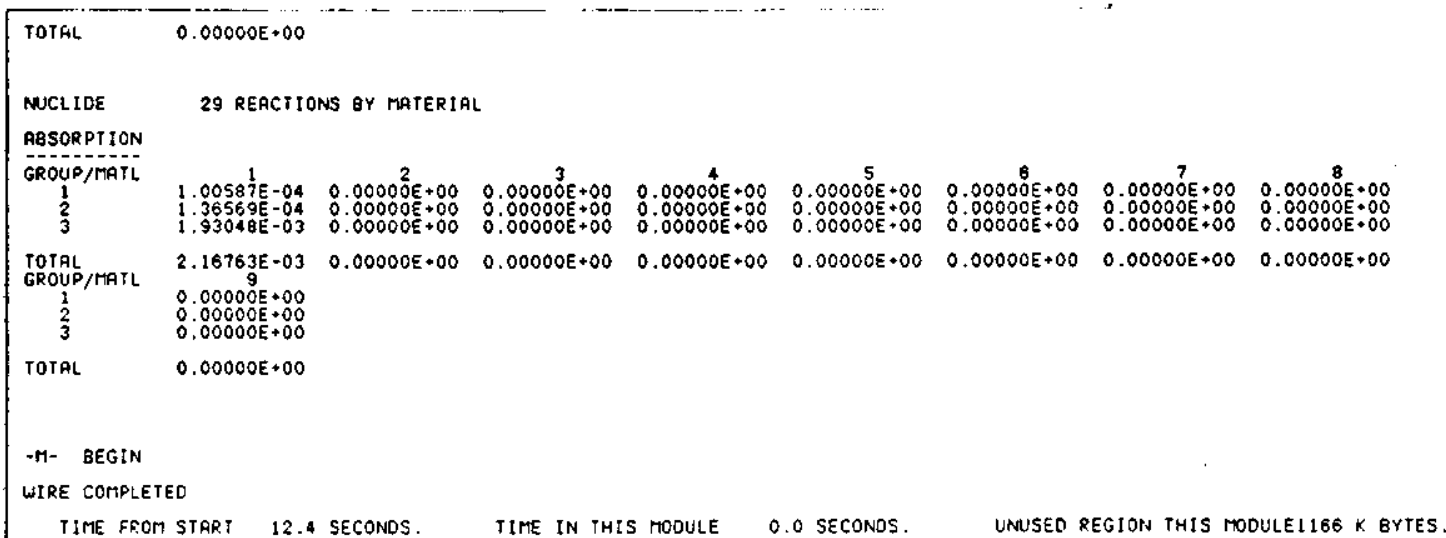

TIME FROM STRRT 12.4 SECONDS. TIME IN THIS MODULE 0.0 SECONOS. UNUSEO REGION THIS MODULELI66 K BYTES.

-C- WCONO 116

READS INTERFACE 1: FORTRAN OATA SETS $61-65$ DSNAMES:

WRITES INTERFACE 6 FORTRAN DATA SETS 36.40 OSNAMES:

ALSO READS:

*********) WIMS-E MODULE W-CONOENSE $\quad * * * * * * * * *$

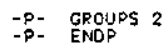

SPACE AVAILABLE ALLOWS UP TO 99807 NUCLIDE TABULATIONS ON NEW INTERFACE

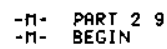

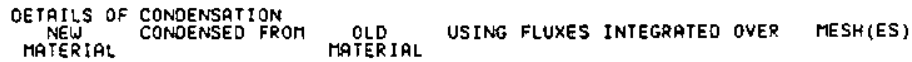

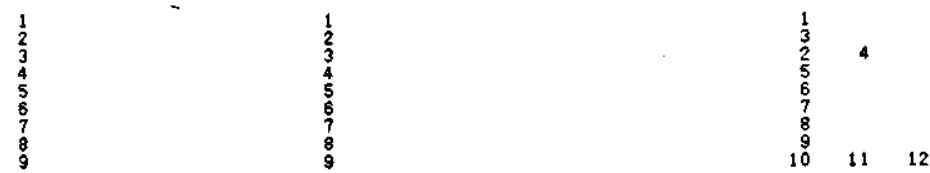

NEU FILE 4

MESHES 12

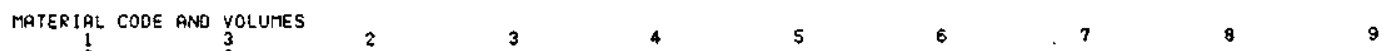

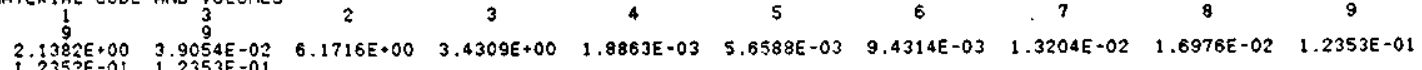
NEW FILE 2

NUCLLIOE TRBULATIONS, 82

FISSILE NJTLLIOES $\quad$ :?

RUCLIOE IDENTIFILATIONS

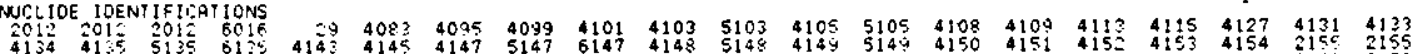

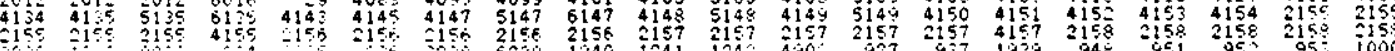

B-133

Attachment 1 
SNF-4503, Rev. 1

WHC-SD-NR-SWD-017

NEW FILE 3

MRTERIALS $\quad \mathbf{9}$

NUTBER DENSITIES PRINTED IN MIX

UNUSEO STORAGE 299043

CONDENSE COMPLETEO

TIME FROM START 12.6 SECONOS. TIME IN THIS MODULE 0.2 SECONOS. UNUSEO REGION THIS MOOULEIIG8 K BYTES.

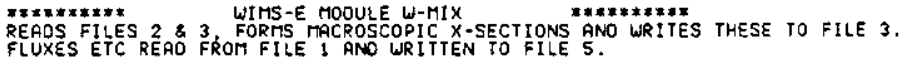

LN 4 LT -1

CROSS-SECIIONS 82

GROUPS 2

MATERIALS 9

No. OF MATERIALS TO BE PROCESSEO AT A TIME 9

UNUSED STORAGE 299240 (IF MATERIALS PROCESSEO SINGLY 299633)

MATERIAL

\begin{tabular}{|c|c|c|}
\hline $\begin{aligned} \text { NUCLIOE } \\
1 \\
4 \\
5 \\
6 \\
6 \\
7 \\
8 \\
9 \\
10 \\
11 \\
12 \\
13 \\
13 \\
14 \\
15 \\
16 \\
17 \\
18 \\
19 \\
20 \\
21 \\
21 \\
23 \\
24 \\
24 \\
25 \\
26 \\
27 \\
28 \\
20 \\
30 \\
30 \\
31 \\
32 \\
33 \\
34 \\
30\end{aligned}$ & $\begin{array}{r}\text { IDENTI FIER } \\
2012 \\
8016 \\
209 \\
4083 \\
4095 \\
4099 \\
4101 \\
4103 \\
5103 \\
4105 \\
5105 \\
4108 \\
4109 \\
4113 \\
4115 \\
4127 \\
4131 \\
4133 \\
4134 \\
4135 \\
5135 \\
6135 \\
4143 \\
4145 \\
4147 \\
5147 \\
6147 \\
4148 \\
514 \\
414 \\
5141 \\
4150 \\
4151\end{array}$ & 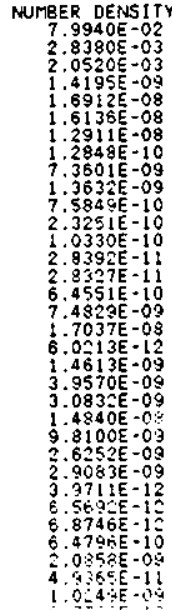 \\
\hline
\end{tabular}

B-134

Attuchment 1

1-185 
SNF-4503, Rev. 1

WHC-SD-NR-SWD-017

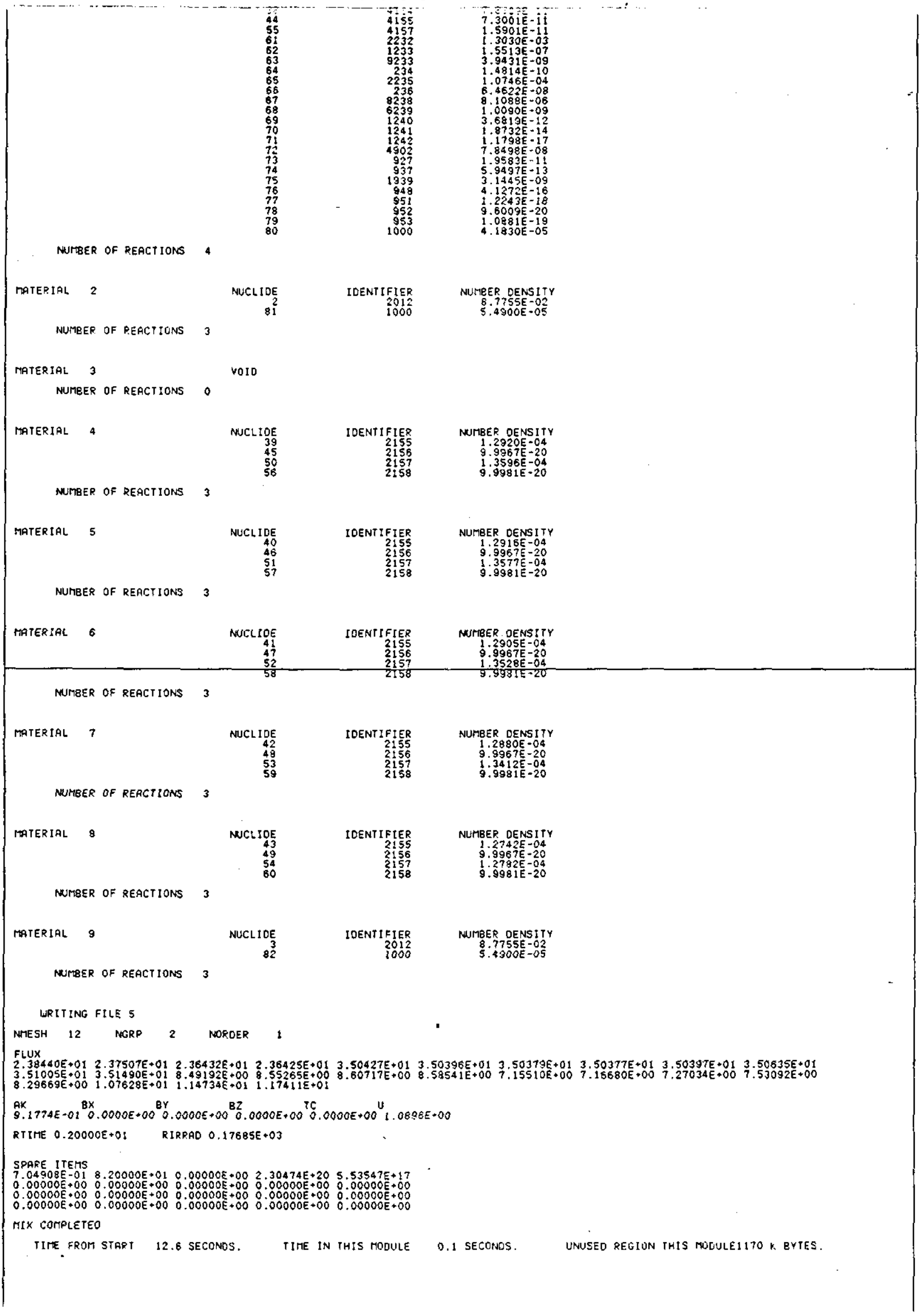

B-135

Attachment 1 
SNF-4503, Rev. 1

WHC-SD-NR-SWD-017

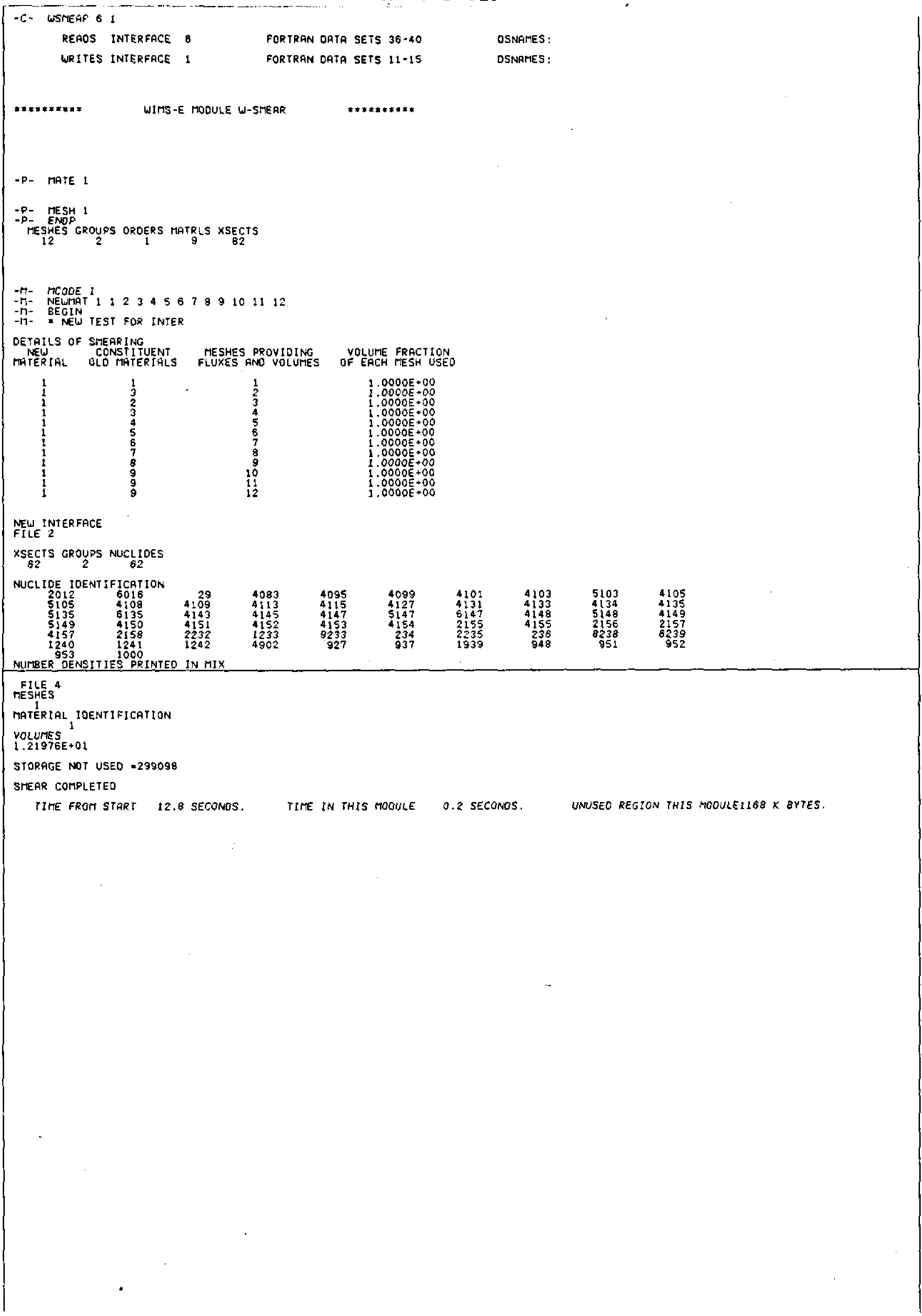


SNF-4503, Rev. 1

WHC-SD-NR-SWD-017

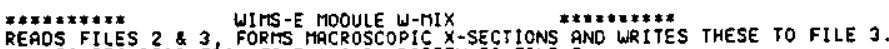
READS FILES 2 \& 3 FORTS MACROSCOPIC X-SECTIONS AND
FLUXES ETC READ FROM FILE I ANO WRITTEN TO FILE 5 .

$\begin{array}{lrr}\text { LN } \quad 5 & \text { LT } & 1 \\ \text { CROSS-SECTIONS } & 62 \\ \text { GROUPS } & 2 \\ \text { MAIEPIALS } & 1 \\ \text { NO. OF MRTERIALS TO BE PROCESSEO AT A TIME }\end{array}$

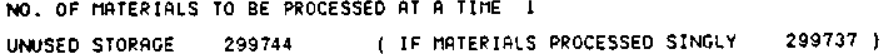

MATERIAL 1

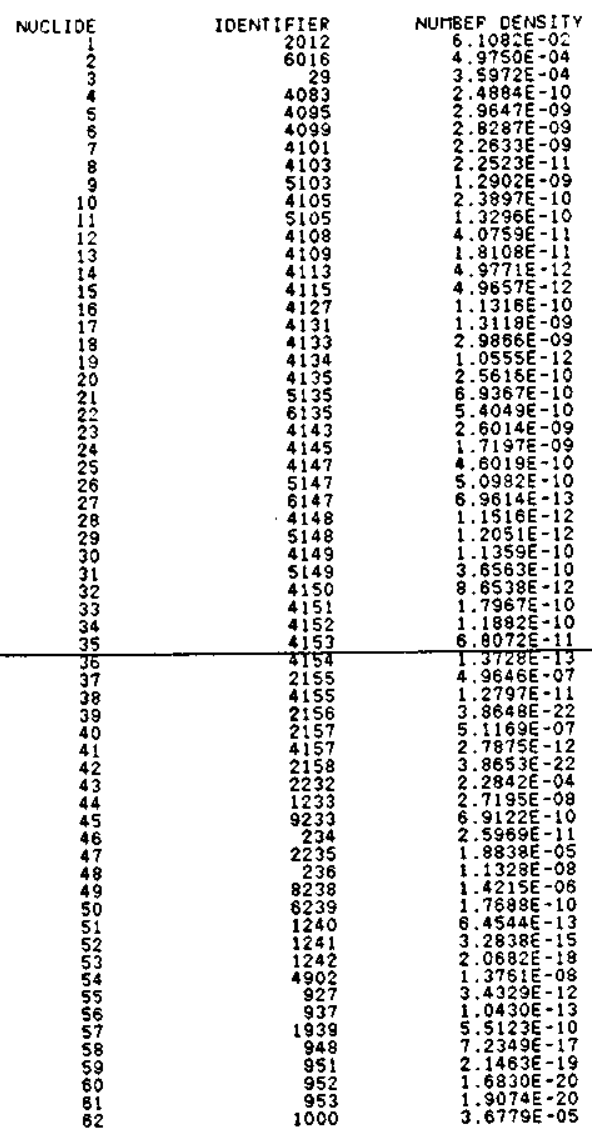

NUMBER OF REACTIONS 4

WRITING FILE 5

NMESH 1 NGRP 2 NOROER

FLUX
$2.40708 E+01 \quad 8.65974 E+00$

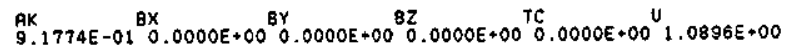

RTIME $0.20000 E+0$ I RIRRAO $0.17685 E+03$

$7.04308 E-016.20000 E+010.00000 E+00 \quad 2.39474 E+20 \quad 5.53547 E+17$

0.00000 E

$0.00000 E+00 \quad 0.00000 E+00 \quad 0.00000 E+00 \quad 0.0000 E+000.0000 E+00$

MIX COMPLETED

TIME FROM START 12.9 SECONOS. TIME IN THIS MODULE

0.1 SECONOS.

UNUSED REGION FHIS NOOULE1170 K BYTES. 
SNF-4503, Rev. 1

WHC-SD-NR-SWD-017

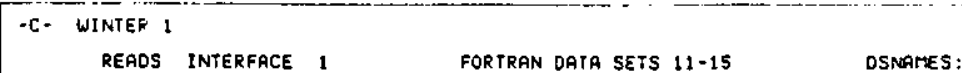

**********) WITS-E ROOULE W-INTER **********

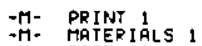

-M- PAGE 44

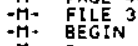

$-M \cdot=$

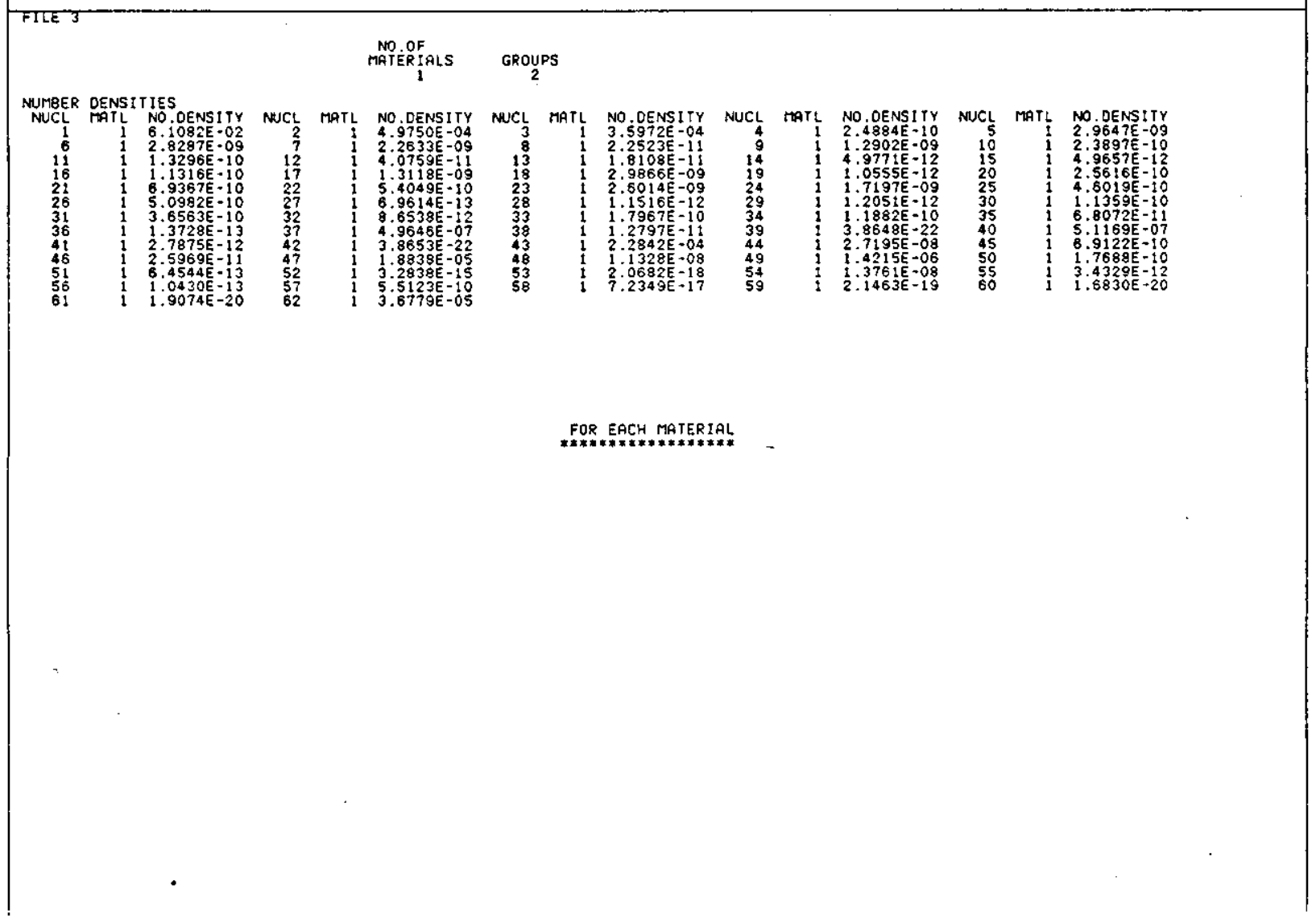

B-138

Attachment 1 


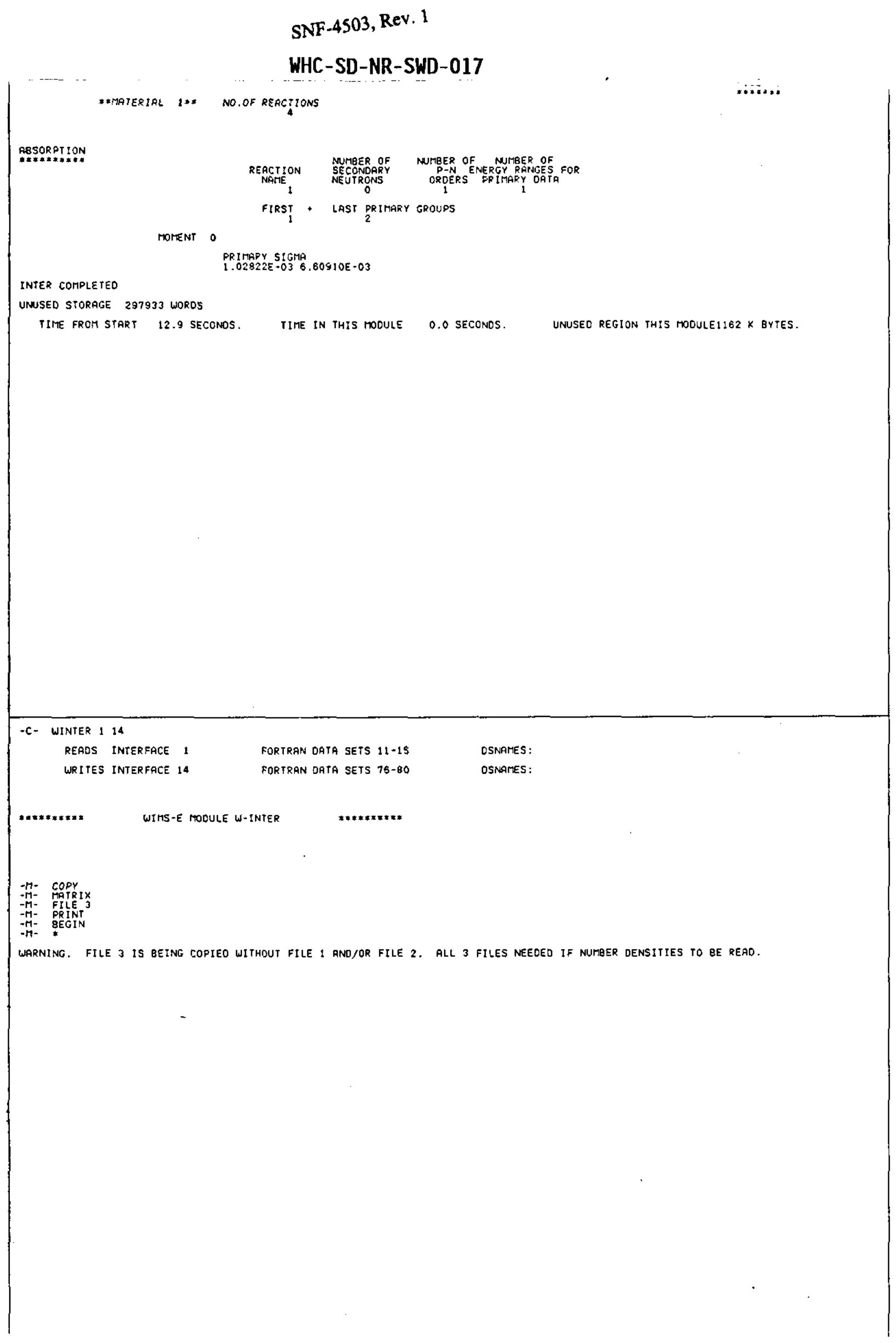

8-139

Attachment 1

$1-190$ 


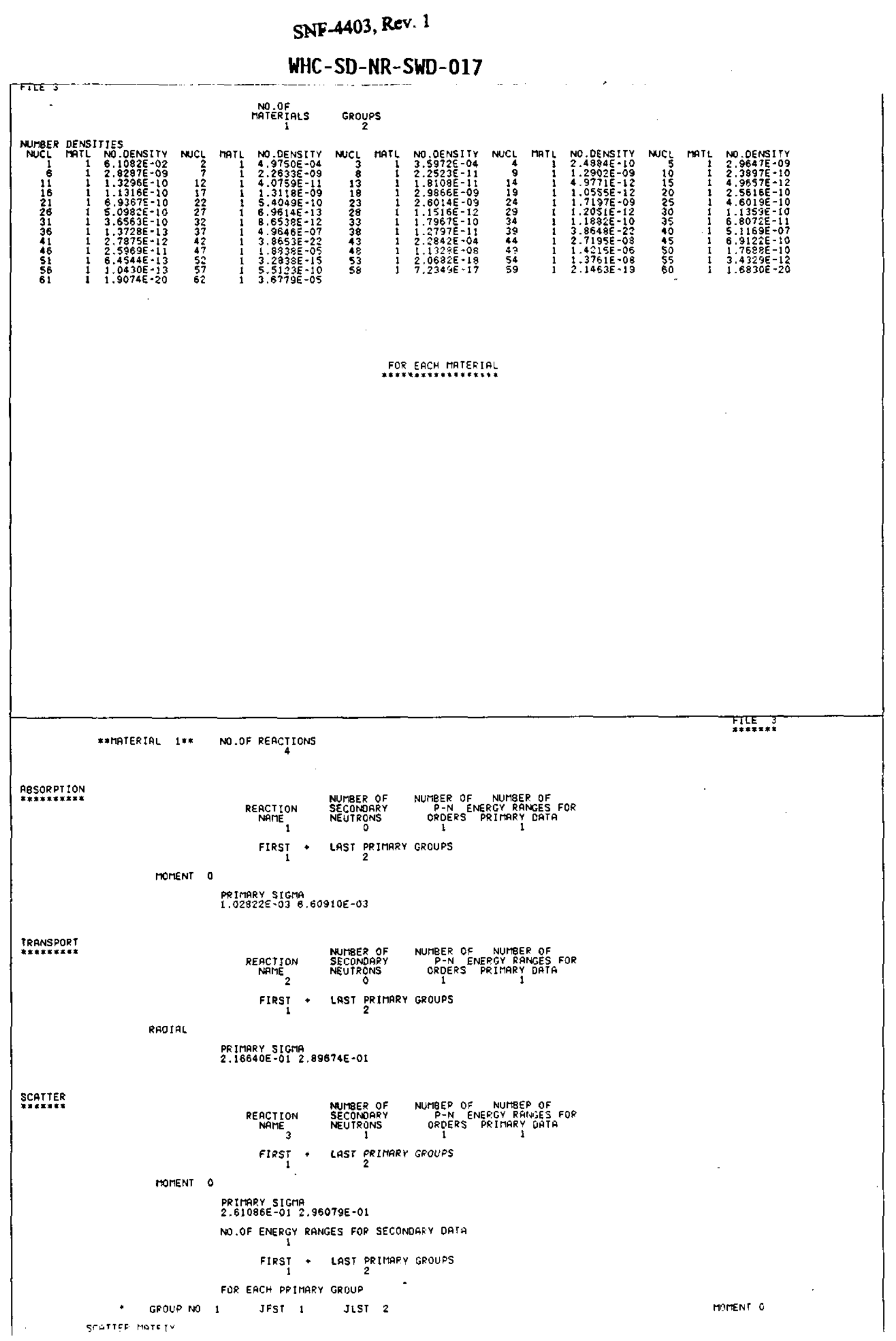

B- 140

Attachment 1 
SNF-4503, Rev. 1

WHC-SD-NR-SWD-017

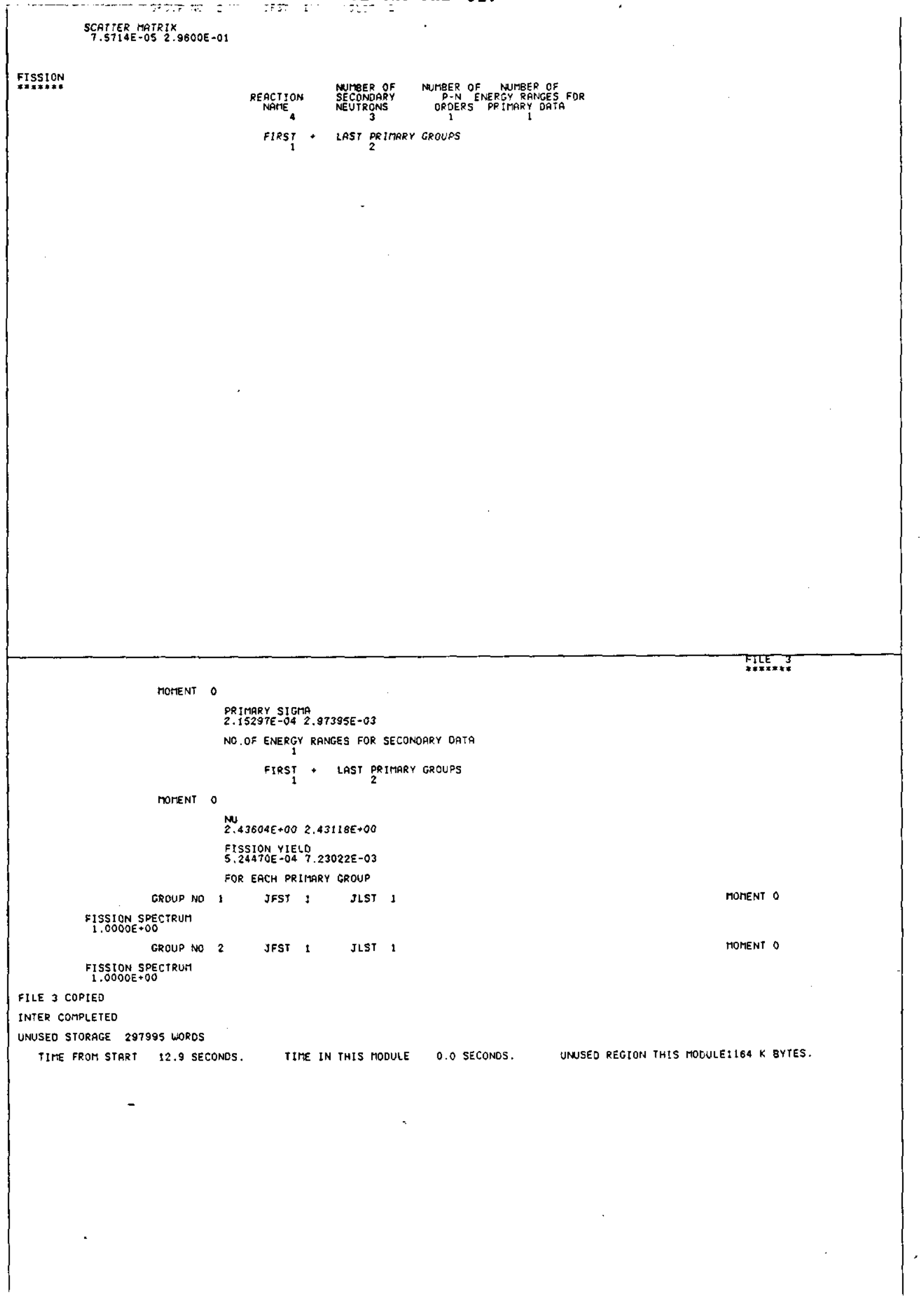

B-141

Attachment 1 
SNF-4503, Rev. 1

WHC-SD-NR-SWD-017

-C- WINTER 1
READS INTERFACE 1 FORTRGN DATA SETS $11-15$

*Ax****** WITS-E MOOULE W-INTER \#*********

$\begin{array}{ll}-M- & \text { PRINT } 1 \\ -M- & \text { FIIE } 13 \\ -M- & \text { BEGIN } \\ -M- & \end{array}$

LEVEL 5 NO.OF PREVIOUS LEVELS

PREVIOUS LEVELS

FOR EACH OLD LEVEL

LEVEL NO. 1

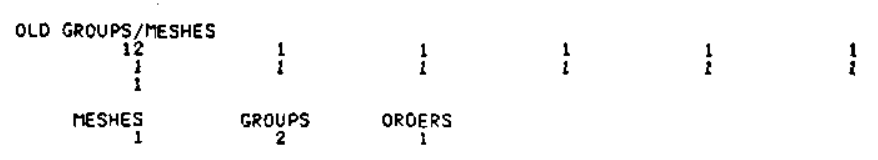

FLUXES
$2.40708 E+01 \quad 8.65974 E+00$

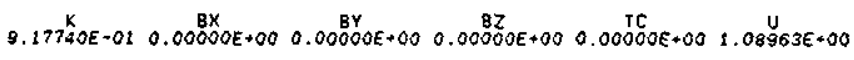
BUCKLINGS ARE CM**-2, NOT S.I. UNITS

BURNUP TIME IRRAOIATION
$2.00000 E+00$ 1.76850E+02

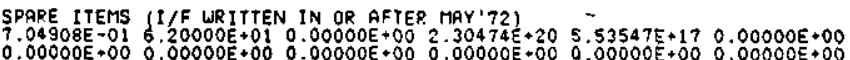

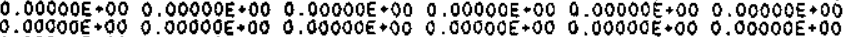

$0.00000 \mathrm{E}+00 \quad 0.00000 \mathrm{E}+00$ 


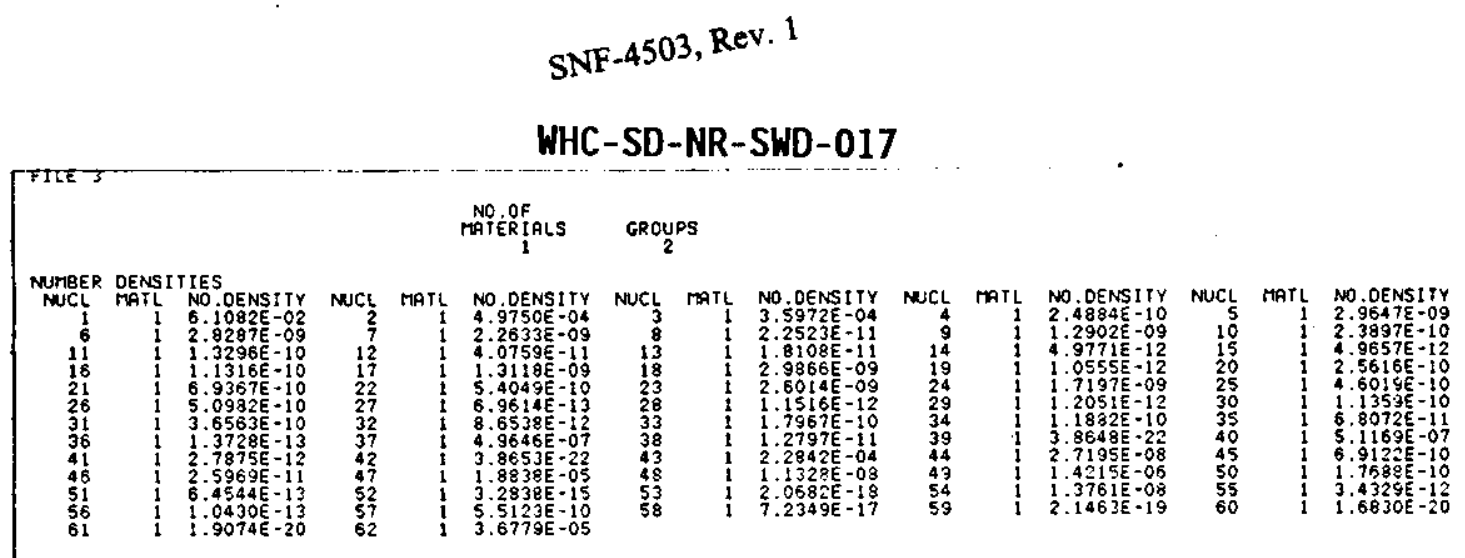

FOR EACH MATERIAL

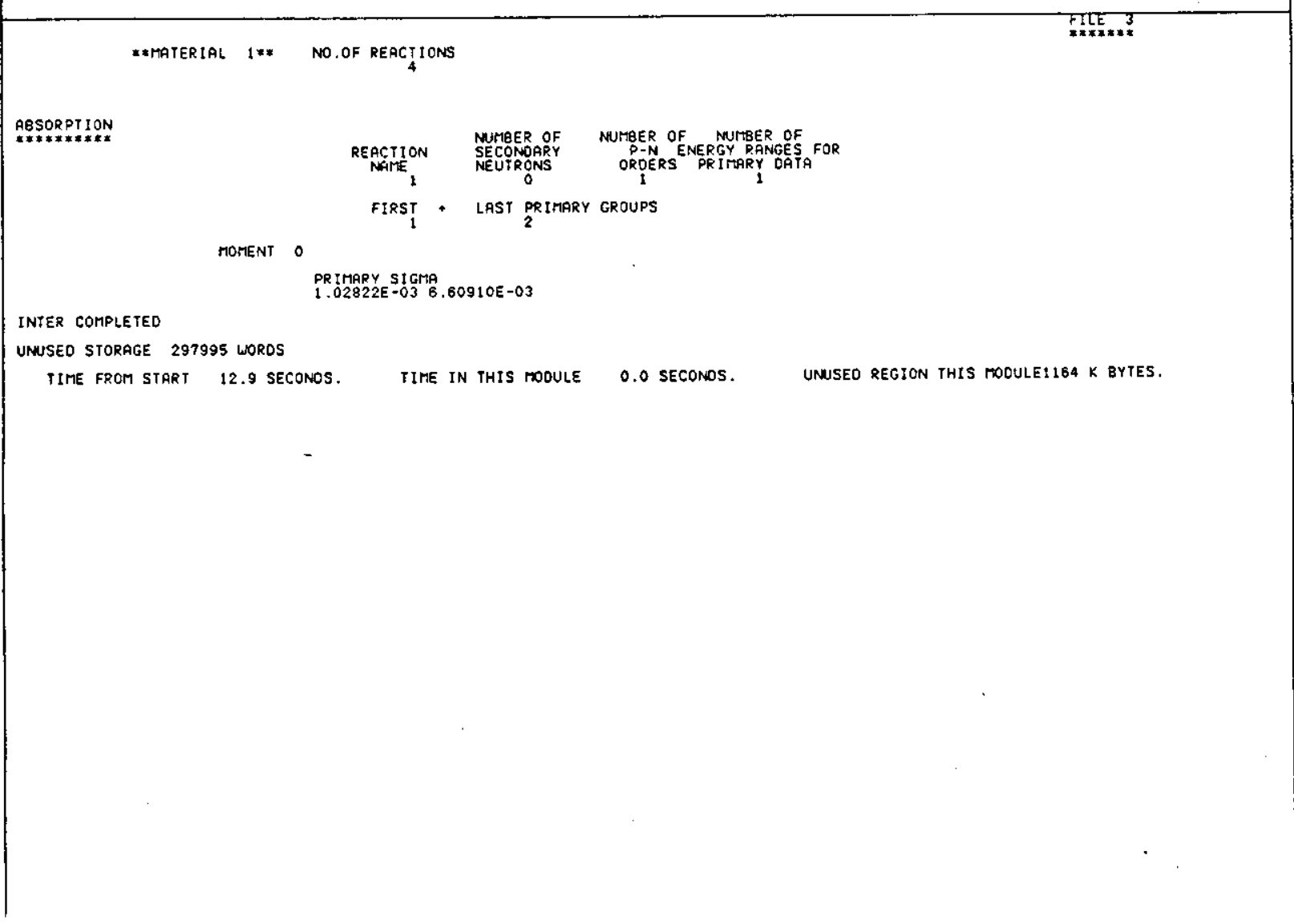




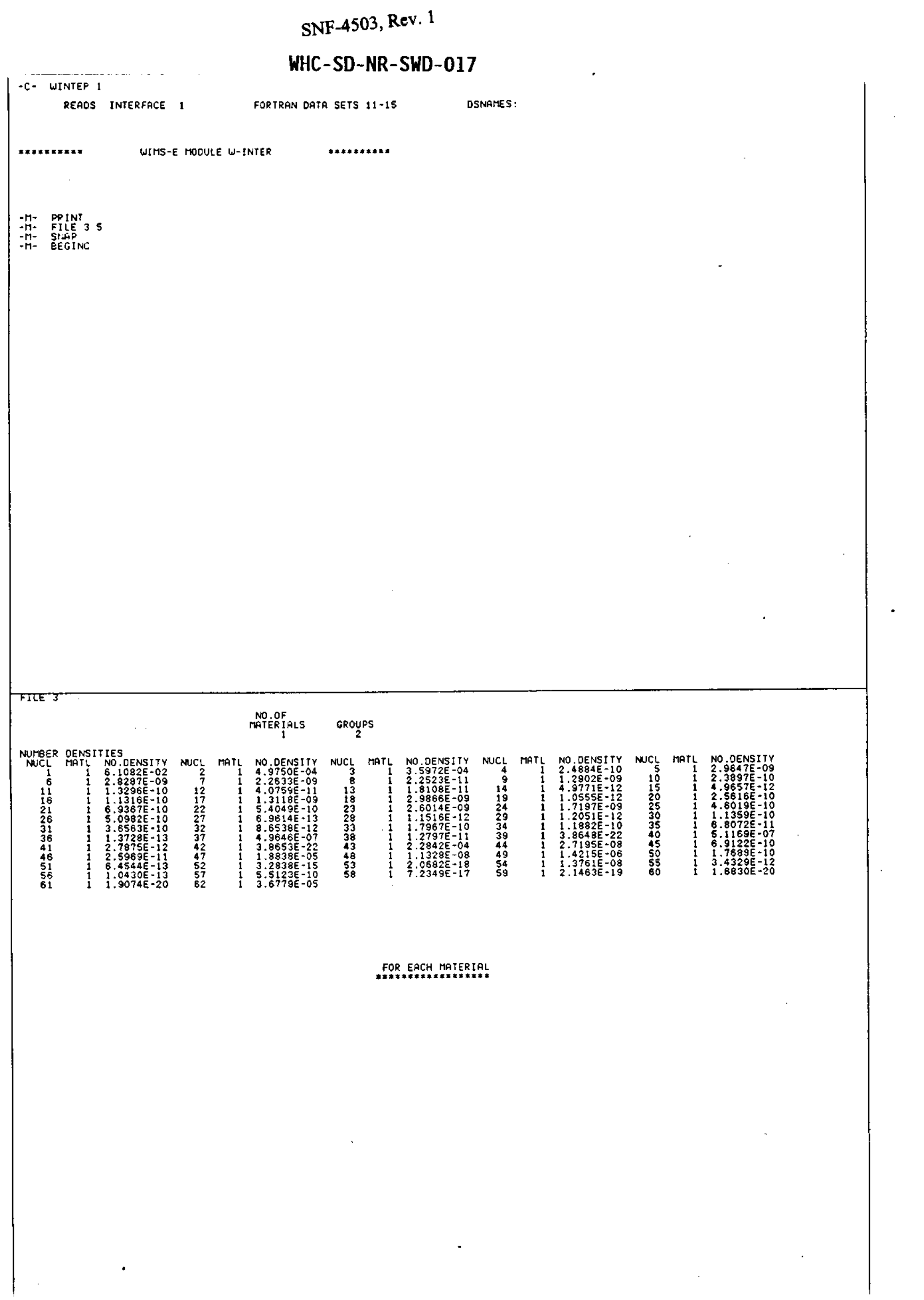

B-144

Attachment 1 
SNF-4503, Rev. 1

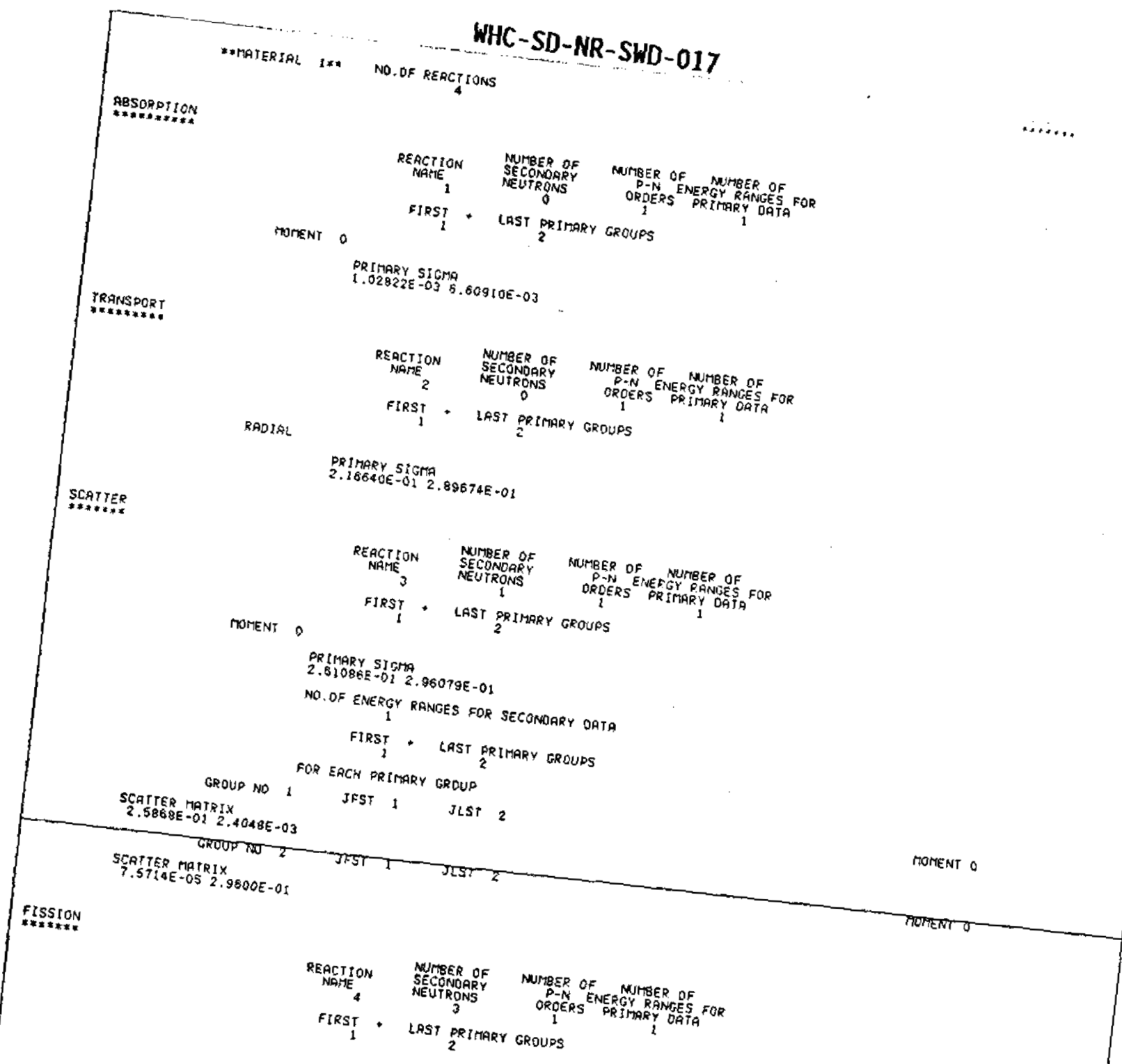


SNF-4503, Rev. 1

WHC-SD-NR-SWD-017

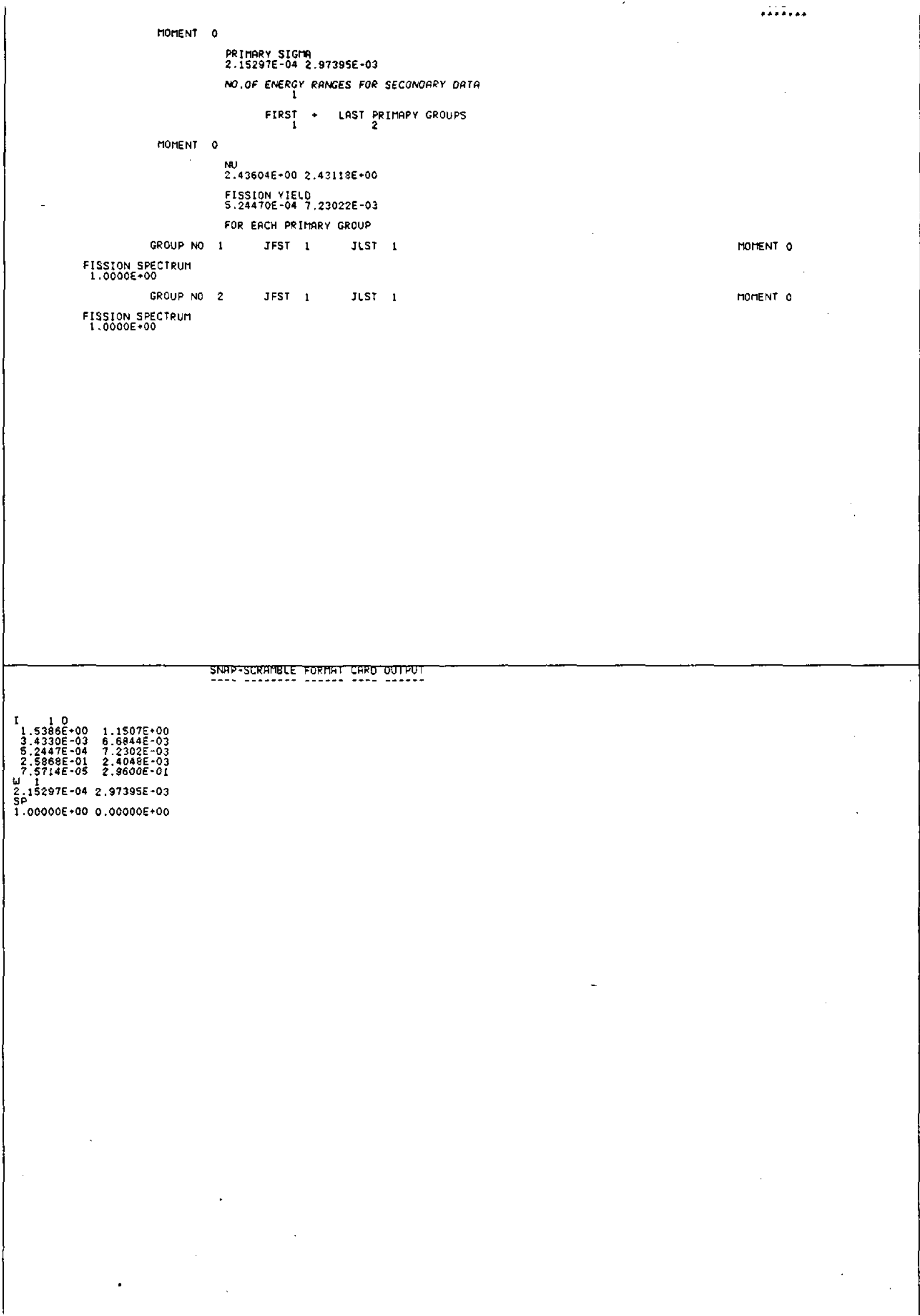

B- 146

Attachment 1

1-197 
SNF-4503, Rev. 1

WHC-SD-NR-SWD-017

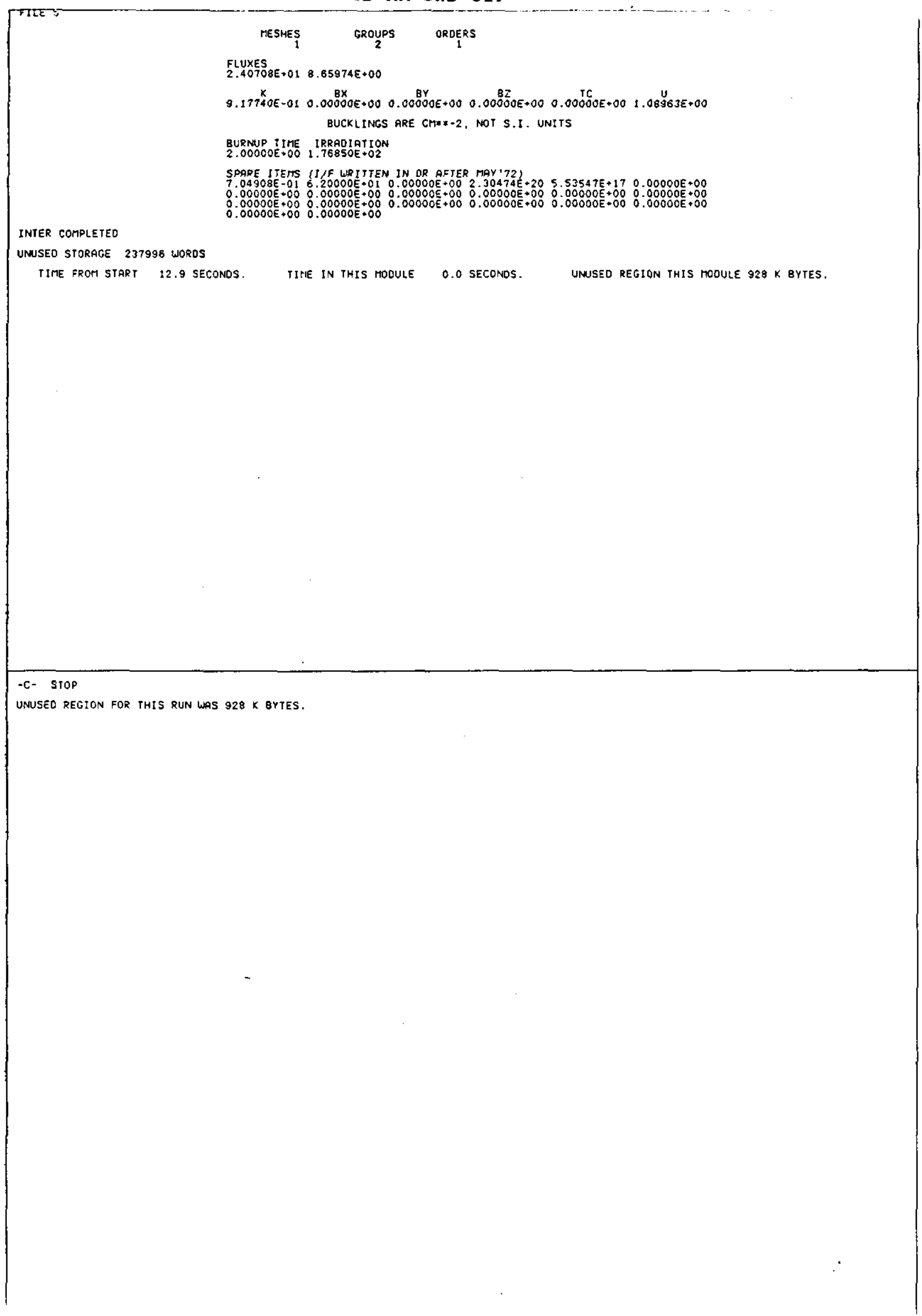


SNF-4503, Rev. 1

WHC-SD-NR-SWD-017

\section{Appendix C}

WIMS-E Validation and Benchmarking Document

This appendix contains a summary of some of the work performed to validate and benchmark the WIMS-E code for Hanford Site applications. The analysis results generated by the WIMS-E code were compared with results produced by other applicable codes. 


\subsection{INTRODUCTION}

The WIMS-E computer code is a state-of-the-art lattice physics neutron transport system capable of modeling nuclear systems with complex geometries, using a choice of numerical method options, and in up to 69-energy groups. WIMS-E was developed in England at the Atomic Energy Establishment Winfrith (AEEW) and was obtained by the Hanford Site under special license agreement.

When this code was received from Winfrith, a set of four test problems was included for code verification. Output from two of these test problems was included in the WIMS-E software quality assurance documentation (Appendix B). Excellent agreement was obtained between results from these sample problems executed on the Hanford CRAY X/MP-18, and with the documented British results.

Earlier versions of the WIMS code have been extensively validated against measured data (Askew 1969, Mallen et al. 1979, Robinson 1989, Schwinkendorf 1989, and others). This report serves to document the benchmarking of the WIMS-E code system against other computer codes, for both reactivity predictions and isotopic depletion calculations for Light Water Reactor (LWR) systems.

\subsection{SUMMARY}

This document contains the results of WIMS-E code benchmarking against reactivity predictions from both WIMS-D and the LEOPARD computer code, for a single fuel pin cell from a standard Westinghouse LWR design, for both zero exposure, and as a function of exposure.

\subsection{COMPUTER CODES AND INPUT}

\subsection{PCODE}

The PCODE computer code is a simple program written at WHC, which performs pin cell thermalhydraulics and heat transfer analysis in order to evaluate the temperature distribution within a nuclear fuel element. A one thermal group lattice physics calculation, involving diffusion theory "lattice functions", is al so employed. This physics routine provides the thermal neutron diffusion length, which allows for an analytic diffusion theory estimate of the radial pin power distribution, which then feeds into the calculation of radial temperature within the fuel region.

PCODE performs a self-consistent calculation of thermally expanded dimensions, based on region averaged temperatures, and reduced densities. This code has been used by WHC for the calculation of hot operating conditions for LWR analysis by the WIMS-E code. 
SNF-4503, Rev. 1

WHC-SD-NR-SWD-017

\subsection{WIMS-D}

WIMS-D was used to perform a 69 group neutron thermalization calculation, using the SPECTROX routine, and a spatial neutron transport calculation in 18 energy groups, using the one dimensional collision probability option PERSEUS, for the benchmark problem. A set of hot operating conditions, consisting of temperatures, thermally expanded dimensions and reduced densities, was provided by the PCODE computer code.

\subsection{LEOPARD}

The LEOPARD code (Barry 1964) was originally developed for use on an IBM 7094 mainframe comuter, and performs pin cell burnup calculations for an LWR lattice. The resonance integral calculations are performed using the MUFT scheme.

The LEOPARD code, associated cross section library, and pre-processing code, SPOTS, was acquired from Oregon State University.

\subsection{WIMS-E}

The WIMS-E code was employed to calculate the reactivities under green and exposed conditions, for the benchmark problem. Both the neutron thermalization and spatial transport calculations were performed in the full 69-energy groups, although the burnup equations were evaluated in the same 18 group structure as employed in the WIMS-D calculations.

\subsection{BENCHMARK PROBLEM}

A standard Westinghouse LWR fuel design (Duderstadt, et. a1.) consists of a core operating at 3411 MWth, using 193 assemblies containing a rectangular array of $17 \times 17$ pins, of which 264 are fuel elements. The active core height is equal to $366 \mathrm{~cm}$. The following is a summary table of other pertinent operating data.

This table consists of sufficient input data for PCODE, which produced hot operating conditions for a single fuel element, which were then input into the WIMS-D, LEOPARD, and WIMS-E computer codes.

\subsection{RESULTS}

The above three computer codes were executed on the benchmark problem. Table 4.1 contains the results of the zero exposure calculations. All of these calculations were performed on the Hanford RLVAX1 computer, a DEC VAX 11/780, except for the WIMS-E calculation, which was performed on the Hanford CRAY $X / M P-18$. The WIMS-D calculation used the 1235.4 and 3238.5 resonance tabulations for the uranium isotopes, which produce the highest k-infinity of any other combination, and which have been identified earlier for use in LWR reactor spectra, in conjunction with New Production Reactor (NPR) studies. 
SNF-4503, Rev. 1

WHC-SD-NR-SWD-017

Table 3.1. Standard Westinghouse LWR Design and Operating Data

Design Parameters

Lattice Pitch

Fuel pellet diameter

Fuel/clad gap

Clad thickness

Enrichment (this calc)

System pressure

Primary flow

Inlet temperature

Fuel:

Helium Fill gas
Values

$$
\begin{array}{ll}
1.25 & \mathrm{~cm} \\
0.819 & \mathrm{~cm} \\
0.0041 \mathrm{~cm} & 0.0572 \mathrm{~cm}
\end{array}
$$

$3.1 \mathrm{wt} \%$

2250 psia

$62 \mathrm{e} 6 \mathrm{~kg} / \mathrm{hr}$

$300{ }^{\circ} \mathrm{C}$

95\% TD

$2 \%$ porosity

$2.5 \%$ dishing fraction

$10.133 \mathrm{~g} / \mathrm{cc}$ effective density

400 psia

Table 4.1. Zero Exposure Benchmark Results

Computer Code

PCODE

LEOPARD

WIMS-D

WIMS-E
k-Infinity

1.319658

1.31215

1.30521

1.311807 
The PCODE program does not have burnup capability, so WIMS-E exposuredependent reactivity predictions were compared to WIMS-D and LEOPARD results. Table 4.2 contains the results of these calculations, all of which were performed on the Hanford CRAY (except for the LEOPARD calculations which were performed on the VAX 11/780). One reason why WIMS-E predicts a smaller value for xenon worth (compared to WIMS-D) is that WIMS-E builds in Xe-135 explicitly in time, and two days was assumed to build in this isotope to "nearly" its assymptotic value. WIMS-D builds in the full limiting concentration of $\mathrm{Xe}-135$ instantaneously. The exposure times were all on the same basis.

Table 4.2. Exposure-Dependent Benchmark Results $\underline{\text { Exposure }} \quad \underline{k-I n f(W I M S-D)} \quad \underline{k-I n f(W I M S-E)} \quad \underline{k-I n f(L E O P A R D)}$

$\begin{array}{llll}\text { Green } & 1.30521 & 1.311807 & 1.31215 \\ \text { +Xenon } & 1.25584 & 1.265821 & 1.27008 \\ 32 \text { days } & 1.23852 & 1.244110 & 1.24394 \\ 62 \text { days } & 1.22361 & 1.228966 & 1.22726 \\ 92 \text { days } & 1.20791 & 1.213257 & 1.21022 \\ 122 \text { days } & 1.19230 & 1.197615 & 1.19331 \\ 152 \text { days } & 1.17720 & 1.182487 & 1.17692 \\ 182 \text { days } & 1.16283 & 1.168114 & 1.16117 \\ 212 \text { days } & 1.14917 & 1.154498 & 1.14611 \\ \begin{array}{c}\text { Xenon Worth } \\ \text { Reactivity } \\ \text { change }\end{array} & 38.6 \mathrm{mk} & 35.7 \mathrm{mk} & 32.6 \mathrm{mk} \\ & 88.8 \mathrm{mk} & 92.1 \mathrm{mk} & 102.7 \mathrm{mk}\end{array}$

\subsection{CONCLUSIONS}

WIMS-E has been benchmarked against other computer codes (WIMS-D and LEOPARD) for applications for which this code as been utilized for at the Hanford Site. Acceptable agreement has been shown.

\section{APPENDIX}

At present, WIMS-E at the Hanford Site has only been used for LWR calculations. N Reactor modeling has not been possible, since the 69-group cross section library was generated assuming a light water neutron spectrum, and because the resonance integral calculations were not capable of correcting for the heterogeneous effects of tube-in-tube geometry. WIMS-D also has this problem, but since there are a number of different resonance integral tabulations in the WIMS-D data library, it was possible to evaluate many combinations of these tabulations to establish (empirically) which combinations resulted in the optimum agreement with Physical Constants Test Reactor (PCTR) measurements. 


\section{WHC-SD-NR-SWD-017}

However, the complete WIMS-E system does have the capability to model these tube-in-tube systems explicitiy, performing heterogeneous resonance integral calculations using first principles. The ability to execute those modules which perform these calculations depends upon the presence of one particular routine which has only recently arrived from Winfrith. Utilizing this new capability, and using 69-group cross sections which were generated assuming a graphite spectrum, should allow for the accurate modeling of $N$ Reactor with WIMS-E. The construction of a graphite spectrum 69-group library for WIMS-E would entail executing the NJOY cross section processing code system. Once this is accomplished, meaningful benchmarking of WIMS-E against WIMS-D N Reactor models and DCODE predictions of reactivity changes during an exposure cycle would be possible.

\section{References:}

WCAP-6058, "LEOPARD - A Spectrum-Dependent Non-spatial Depletion Code for the IBM-7094," USAEC, 1964.

"Nuclear Reactor Analysis," J. J. Duderstadt and L. J. Hamilton, John Wiley \& Sons, Inc., New York, Appendix H, p. 634, 1975. 
SNF-4503, Rev. 1

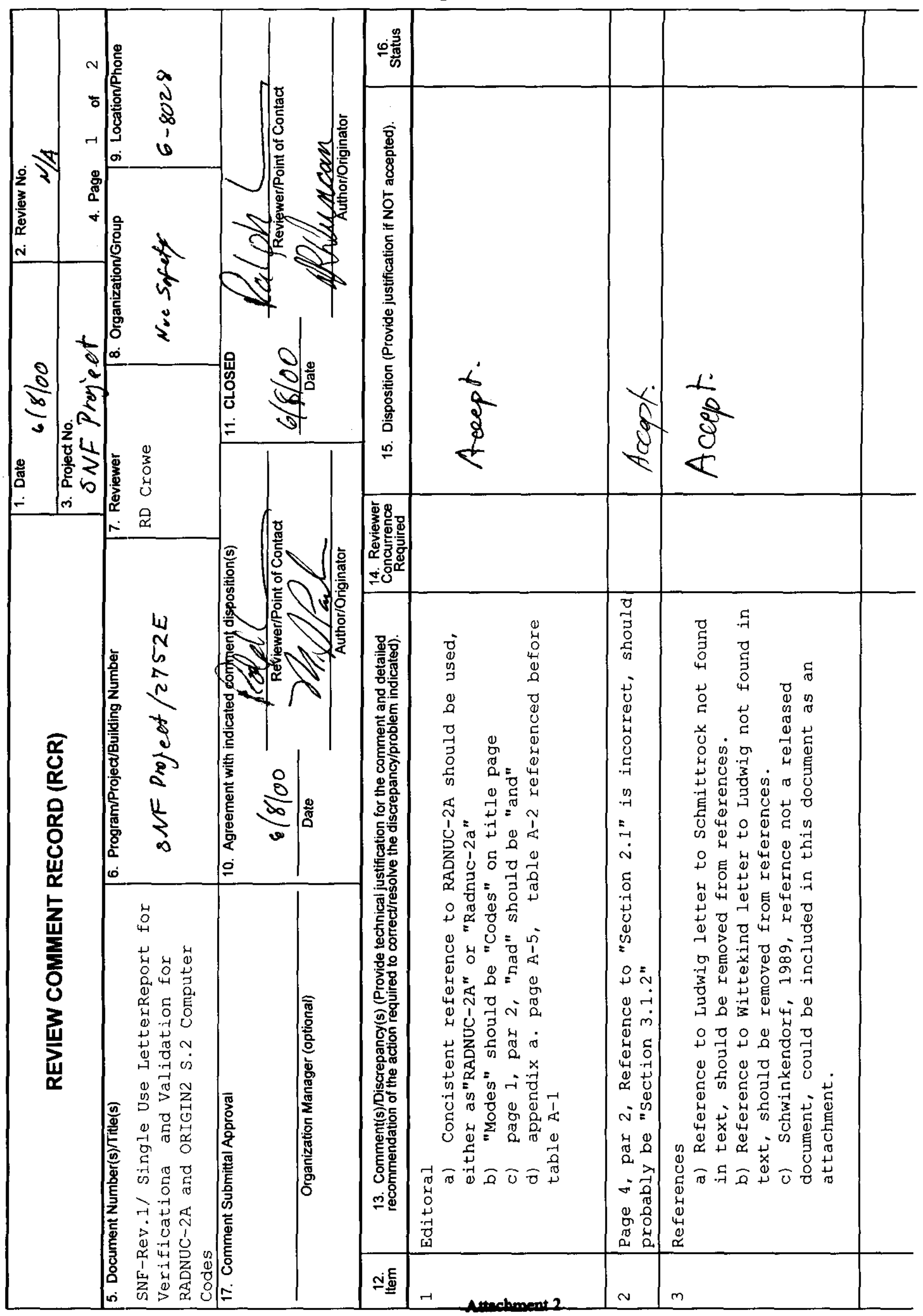


Attachment to Review

In order to SNF-4503, Rev. 1 to assess adequacy of its RADNUC-2a verification and validation for a single use application according to HNF-PRO-309 Rev. 0, the information presented in SNF-4503 was compared to procedural steps, as defined in HNF-PRO-309, Rev. 0, required for the software System/Owner Owner Organization. Those steps applicable to a single use application were matched to corresponding section of SNF-4503. The SNF project is not the owner/system owner organization of this software. However, comparing as appropriate, these procedural steps to the information in SNF-4503, provides an assurance that the single use of these computer codes is consistent with the practice and requirements of software development and usage.

Steps in Procedure for System Owner/System Owner Organization from Computer Software Quality Assurance Requirements, HNF-PRO-309, Rev. 0

1 Determine need to acquire a new software 1 1. Addressed in Section 1.0 Summary product or to have it developed.

2 Determine the extent and rigor of project review and acceptance testing, based on the

2. Test cases and acceptance logic addressed in importance of the software and justified in Section 2.0 Test Cases and Approach. project planning documents.

3 Initiate a procurement document in accordance with HNF-PRO-268, Control of Purchased Items and Services.

4 Develop project planning document (Section 2.2).

5 Identify required documentation (Section 2.5).

3. NA

4. NA

5. This document, SNF-4503, is the documentation for single use verification and validation of RADNUC-2A.

\begin{tabular}{ll|ll}
6 & Review project activities throughout a & 6. & NA
\end{tabular} software life cycle (Section 2.3).

7 Ensure software development, user documentation, and traceability of documentation are complete.

8 Ensure software is ready to be formally tested against the current software requirements.

9 Perform software verification and document results.

7. Addressed in Section 1.0 Summary

8. Addressed in Sections; 1.0 Summary Section

9. Addressed in Appendices: App. A - V\&V of RADNUC-2A App. C - V\&V of Origin2-S.2.

10 Establish and maintain a software configuration management system (Section 2.6).

10. Hardware configuration in following sections:

5.1 RADNUC-2A

5.2 ORIGEN2

Software configuration as program source listing included in appendices: App. B - Source listing for RADNUC-2A App. C - Source listing for Origin2-S.2.

11 Prepare software validation (test) plan (Section 2.4.3).

12 Evaluate as-built software, and verify required reviews.

11. Addressed in Section 4.0.

12. Addressed in following sections and appendices:

5.0, Results for Single-Use Test problems App. A, Section 3 RADNUC-2A 
SNF-4503, Rev. 1

\begin{tabular}{|c|c|}
\hline & App. C, Section 4 ORIGENs S.2 \\
\hline $\begin{array}{l}13 \text { Verify completion and adequacy of support } \\
\text { documentation to satisfy the requirements } \\
\text { (Section 2.4.3). }\end{array}$ & $\begin{array}{l}\text { 13. This document, SNF-4503, provides } \\
\text { documentation for single use verification } \\
\text { and validation of RADNUC-2A. }\end{array}$ \\
\hline $\begin{array}{l}14 \text { Perform software validation per approved } \\
\text { plan and document results (Section 2.4.3). }\end{array}$ & $\begin{array}{l}\text { 14. Testing documented in following } \\
\text { appendices: } \\
\text { App. A, Section } 3 \text { RADNUC-2A } \\
\text { App. C, Section } 4 \text { ORIGENs S. } 2\end{array}$ \\
\hline $\begin{array}{l}15 \text { Assure that software and required } \\
\text { documentation are received and approved } \\
\text { prior to the distribution and operation of the } \\
\text { software. }\end{array}$ & 15. NA \\
\hline $\begin{array}{l}16 \text { Distribute software per the requirements of } \\
\text { the configuration control document. }\end{array}$ & 16. NA \\
\hline
\end{tabular}


SNF-4503, Rev. 1

\section{REVIEW CHECKLIST}

iment Reviewed:

:-4503 Rev 1., Single Use Letter Report for Verification and Validation of RADNUC-2A and

IIGIN2 S.2 Computer Codes, Packer, M. J.

\section{Scope of Review:}

Reviewed SNF-4503, Rev. 1 to assess adaquancy of its RADNUC-2a verification and validation for a single use application according to HNF-PRO-309 Rev. 0. Validation and verifcation of ORIGINS S.2 for single use application to provide input to RADNUC-2A was also reviewed.

\section{Yes No NA}

$\bigotimes \square \square$

$\otimes$

$\square \square \quad \square$

$\otimes$

$\otimes$

$凶$

\section{$凶$}

$\square \quad \square \quad \square$

$\otimes$

$\square \square \quad \otimes$

$\otimes$

$\otimes$

$\square \square \quad \otimes$

$\square \quad \square \quad \otimes$

$\otimes$

$\otimes \square \square$

$\square \square \otimes$

$\nabla$

$\otimes$

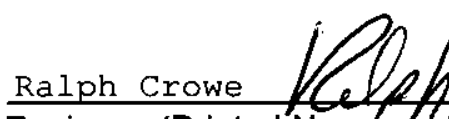

Reviewer (Printed Name and Signature)

\section{Document approved.}

- Previous reviews complete and cover analysis, up to scope of this review, with no gaps.

Problem completely defined.

Accident scenarios developed in a clear and logical manner.

Necessary assumptions explicitly stated and supported.

Computer codes and data files documented.

Data used in calculations explicitly stated in document.

Data checked for consistency with original source information as applicable.

Mathematical derivation checked including dimensional consistency of results.

Models appropriate and used within range of validity or use outside range of established validity justified.

Hand calculations checked for errors. Spreadsheet results should be treated exactly the same as hand calculations.

Software input correct and consistent with document reviewed.

Software output consistent with input and with results reported in document reviewed.

Limits/criteria/guidelines applied to analysis results are appropriate and referenced.

Limits/criteria/guidelines checked against references.

Safety margins consistent with good engineering practices.

Conclusions consistent with analytical results and applicable limits.

Results and conclusions address all points required in the problem statement.

Format consistent with appropriate NRC Regulatory Guide or other standards.

* Review calculations, comments, and/or notes are attached.

*Any calculations, comments, or notes generated as part of this review should be signed, dated and attached to this checklist. Such material should be labeled and recorded in such a manner as to be intelligible to a technically qualified third party. 